1978

\title{
REACTIVITY OF LIME AND RELATED MATERIALS WITH SULPHUR DIOXIDE
}

\section{O'NEILL, PETER}

http://hdl.handle.net/10026.1/2065

http://dx.doi.org/10.24382/1344

University of Plymouth

All content in PEARL is protected by copyright law. Author manuscripts are made available in accordance with publisher policies. Please cite only the published version using the details provided on the item record or document. In the absence of an open licence (e.g. Creative Commons), permissions for further reuse of content should be sought from the publisher or author. 


\title{
REACTIVITY OF LIME AND RELATED MATERIALS
}

WITH SULPHUR DIOXIDE

Peter O'NEILL

A thesis presented for the Research Degree of

\author{
DOCTOR OF PHILOSOPHY \\ of the
}

COUNCIL FOR NATIONAL ACADEMIC AWARDS

LONDON

John Graymore Chemistry Laboratories

School of Enviromental Sciences

Plymouth Polytechnic

P1ymouth PL4 8AA

Devon

September 1978 


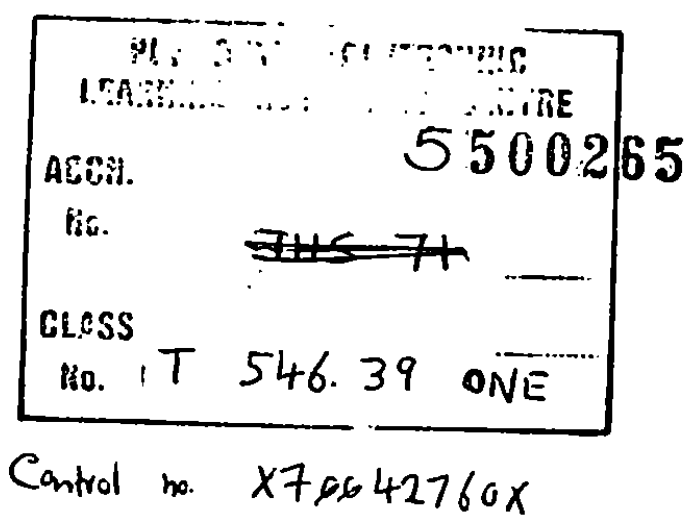




\section{ABSTRACT}

A study has been made of reactions between some alkaline earth metal compounds and sulphur dioxide. The compounds studied included naturally-occurring forms, limestone and dolomite, and industrial products, Limbux and quick-lime. Particular attention was paid to reactions which could have proved useful in the desulphurisation of industrial flue gases.

All the substances used reacted to some extent with sulphur dioxide, but often slowly. The greatest reactivity was shown by calcium-based compounds as the carbonate or hydroxide decomposed to form fresh, highly active calcium oxide. Reaction rates, below $400^{\circ} \mathrm{C}$, were only appreciable for calcium oxide. The reaction products, depending upon conditions, included sulphites, sulphates, sulphides and oxides. At lower temperatures, sulphite was formed and the thermal stabilities of the alkaline earth metal sulphites were studied in greater detail.

$X$-ray diffraction examination indicated that the structures of anhydrous calcium, strontium and barium sulphites were similar and closely related to the structure of calcium sulphite hemihydrate. Differences in orthorhombic unit cell dimensions were in agreement with changes in the cationic radii.

The thermal stabilities of the alkaline earth metal sulphites varied with changes in the gaseous atmosphere surrounding the samples. In non-oxidising atmospheres there was competition between (a) reactions leading to oxide formation and (b) disproportionation reactions, leading to the formation of a mixture of sulphate and sulphide. The relative importance of the disproportionation reaction increased as the atomic number of the cation increased. A proposed mechanism suggested how the various phases found in different reactions 
could be formed. In oxidising atmospheres there was extensive formation of sulphate from both sulphite and sulphide.

The use of dry absorbents, based on alkaline earth metal compounds, for the desulphurisation of flue gases appeared to be an expensive process. 


\section{Acknowledgements}

The author wishes to express his very sincere thanks to Dr. D.R. Glasson for his helpful advice and guidance during the course of this work.

He is grateful to Dr. G. H.W. Milburn for his introduction to single-crystal X-ray studies, to Mr. B. Lakey for discussions concerning the electron microscope, and to Mr. L.C. Anderson for his many useful comments.

He would like to thank the Polytechnic for providing the research facilities and Imperial Chemical Industries Ltd. (Mond Division) for providing some of the materials used in these studies. He would also like to thank Mrs. G. Lane for her special care in typing the manuscript. 
CHAPTER ONE

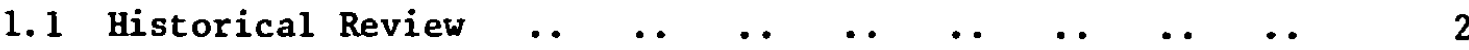

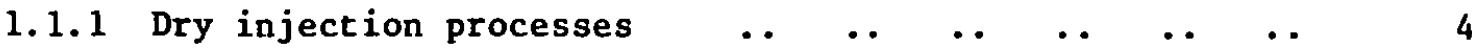

1.1.2 Comparison of natural limestone and magnesite absorbents with their calcined and hydrated products ... $\quad . . \quad \ldots \quad 5$

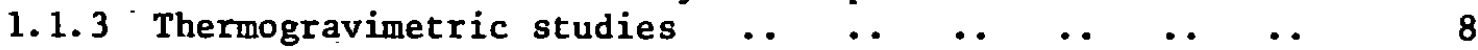

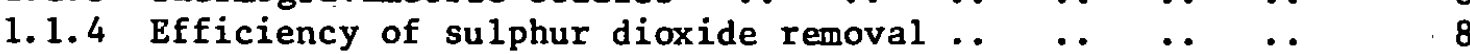

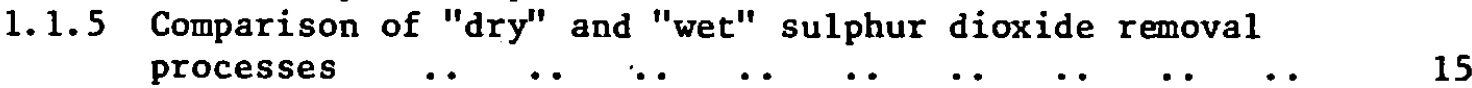

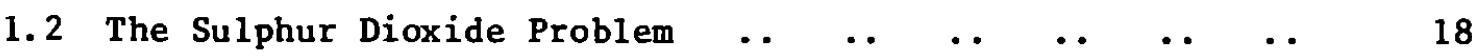

CHAPTER TWO

EXPERIMENTAL TECHNIQUES

$\begin{array}{llllllllllll}2.1 & \text { Introduction } & \ldots & \ldots & \ldots & \ldots & \ldots & \ldots & \ldots & \ldots & \ldots & 20\end{array}$

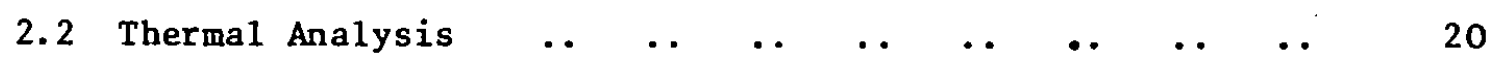

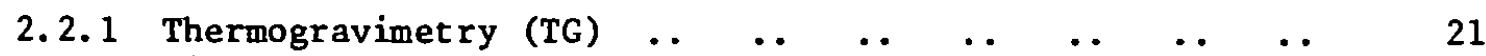

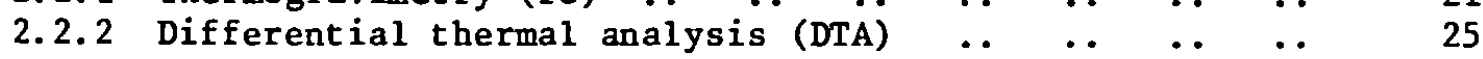

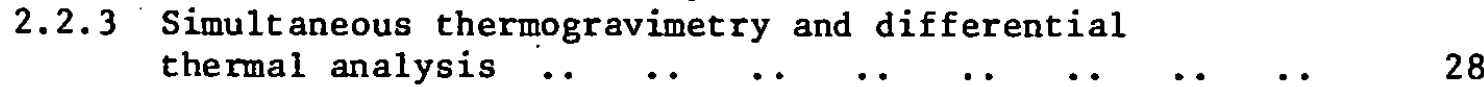

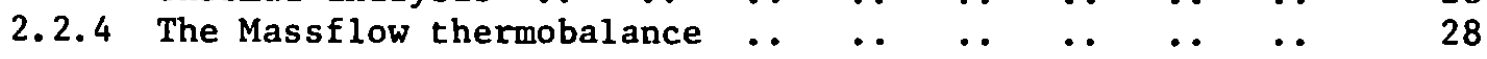

2. 3 Surface Area, Porosity and Particle Size $\ldots \quad \ldots \quad \ldots \quad 32$

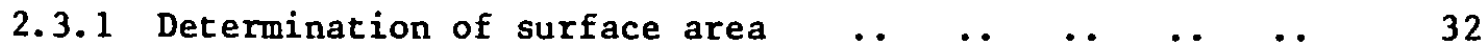

2.3.2 The sorption balance $\ldots \begin{array}{llllllll} & \ldots & \ldots & \ldots & \ldots & \ldots & \ldots & 35 \\ \end{array}$

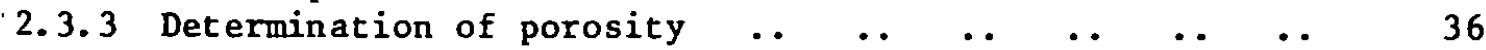

$\begin{array}{llllllll}2.3 .4 & \text { Estimation of particle size. . } & \ldots & \ldots & \ldots & \ldots & \ldots & 38\end{array}$

2.4 Electron Microscopy $\ldots \begin{array}{lllllllll} & \ldots & \ldots & \ldots & \ldots & \ldots & \ldots & \ldots & 40\end{array}$

2.4.1 The electron microscope $\quad \ldots \quad$.

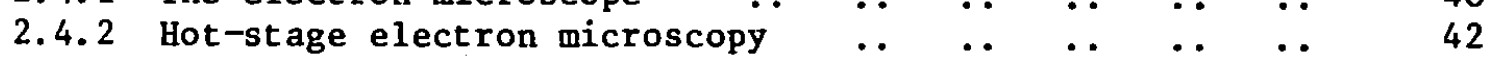

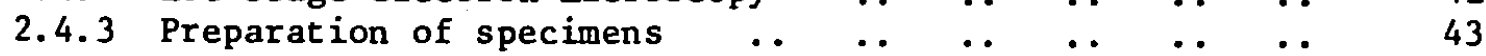

$\begin{array}{llllllllllll}2.5 & \text { Optical Microscopy } & \ldots & \ldots & \ldots & \ldots & \ldots & \ldots & \ldots & \ldots & & 44\end{array}$

$\begin{array}{lllllllllll}2.6 & \text { X-ray Diffraction } & \ldots & \ldots & \ldots & \ldots & \ldots & \ldots & \ldots & \ldots & 44\end{array}$

$\begin{array}{lllllllllll}2.6 .1 & \text { General theory } & \ldots & \ldots & \ldots & \ldots & \ldots & \ldots & \ldots & \ldots & 44\end{array}$

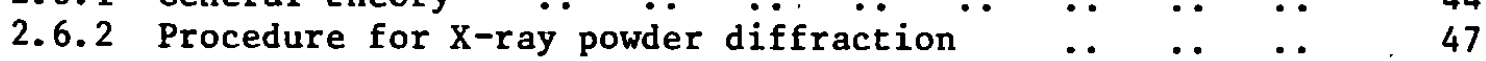

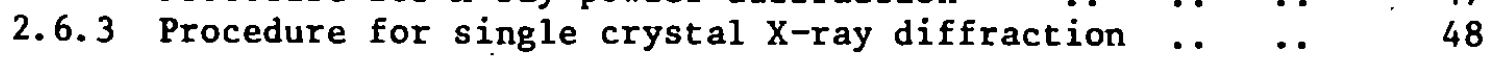

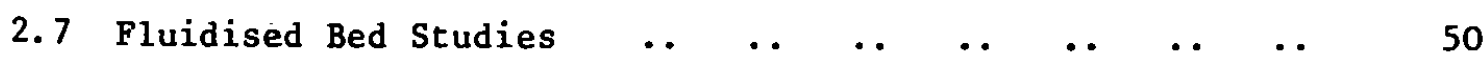

$\begin{array}{llllllllllll}2.8 & \text { Chemical Analysis } & \ldots & \ldots & \ldots & \ldots & \ldots & \ldots & \ldots & \ldots & & 54\end{array}$ 


\section{CBAPTER THREE}

THE PREPARATION AND DETERMINATION OF SOME CRYSTALLOGRAPHIC

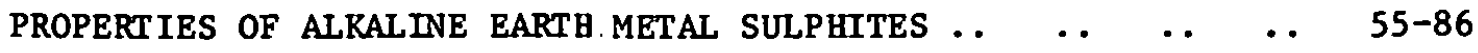

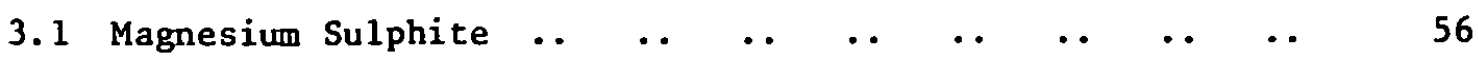

3.1.1 Preparation of magnesium sulphite hexahydrate .. $\quad . . \quad 56$

3.1.2 Structure of magnesium sulphite hexahydrate $\ldots$.. $\quad 57$

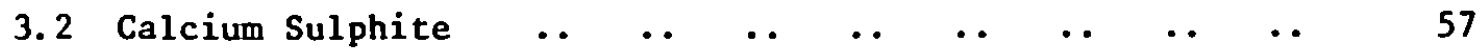

3.2.1 Preparation of calcium sulphite hemihydrate .. $\quad . . \quad 57$

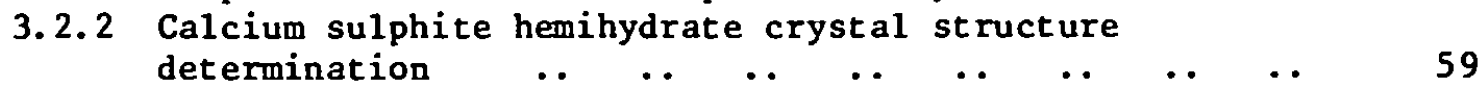

3.2.3 Powder diffraction patterns of hydrated and anhydrous

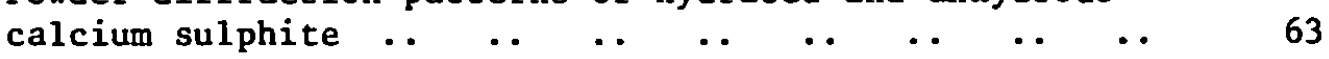

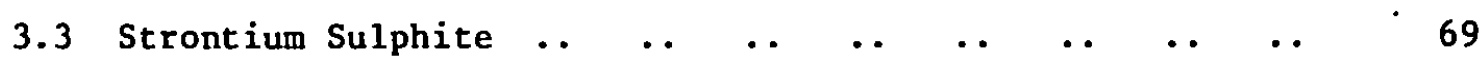

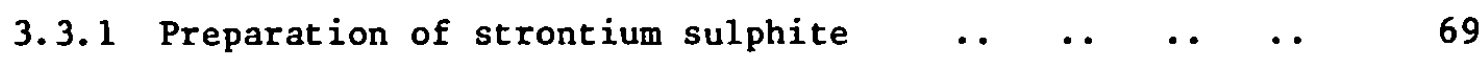

3.3.2 X-ray studies $\quad \ldots \quad$.

$\begin{array}{llllllllllll}3.4 & \text { Barium Sulphite } & \ldots & \ldots & \ldots & \ldots & \ldots & \ldots & \ldots & \ldots & & 77\end{array}$

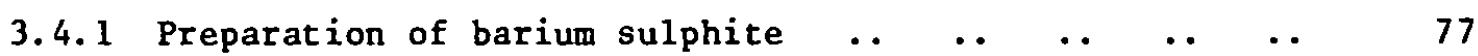

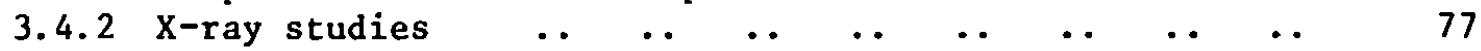

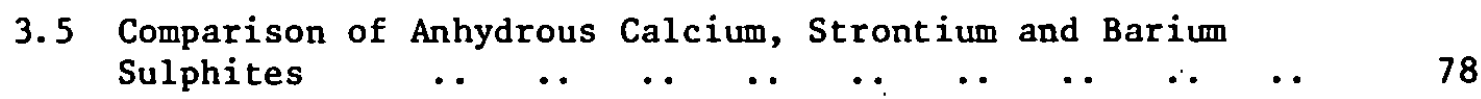
CHAPTER FOUR

THERMAL STABILITY OF ALKALINE EARTH METAL SULPHITES $\ldots$.. $87-191$

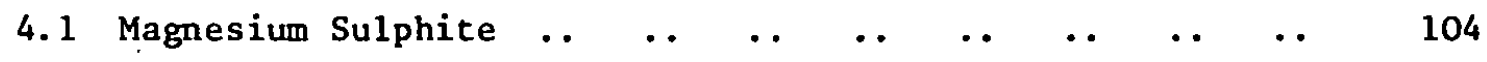

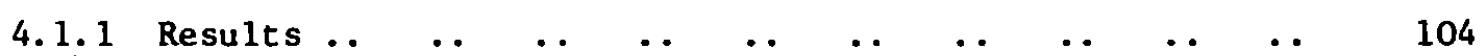

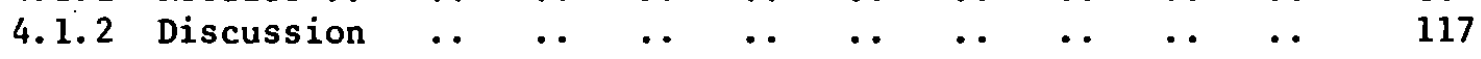

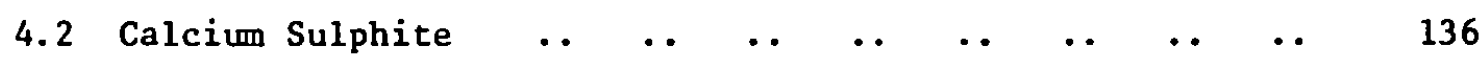

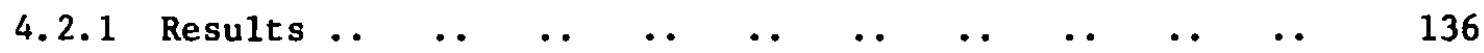

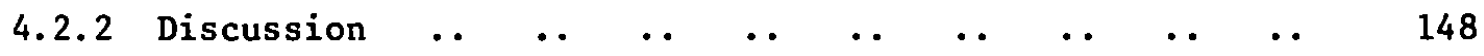

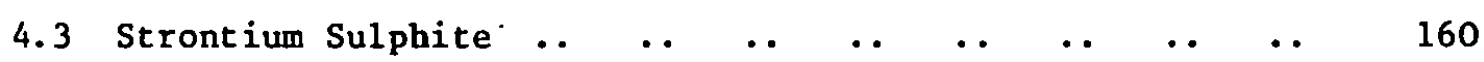

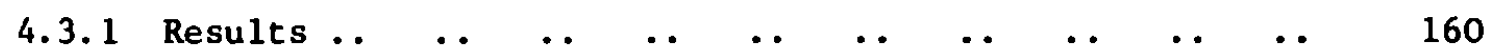

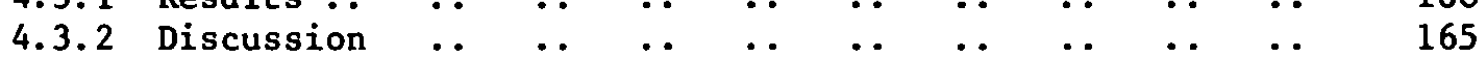

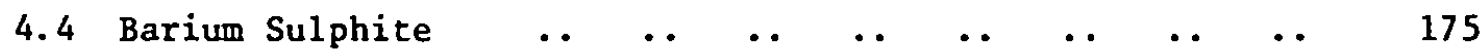

4.4 .1 Results ..

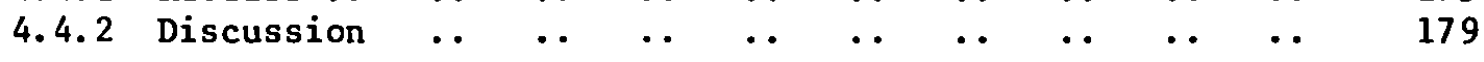

$\begin{array}{lllllllllll}4.5 & \text { General Discussion } & \ldots & \ldots & \ldots & \ldots & \ldots & \ldots & \ldots & \ldots & \end{array}$ 
CHAPTER FIVE

REACTIVITY OF SOME ALKALINE EARTH METAL COMPOUNDS WITH

SULPHUR DIOXIDE

$192-235$

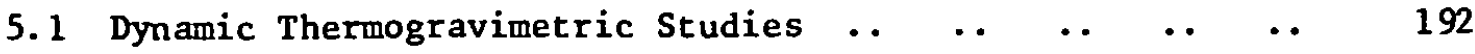

$\begin{array}{llllllll}5.1 .1 & \text { Efficiency of solid absorbents } & \ldots & \ldots & \ldots & \ldots & \ldots & 210\end{array}$

$\begin{array}{lllllllll}5.1 .2 & \text { Industrial applicability } & \ldots & \ldots & \ldots & \ldots & \ldots & \ldots & 217\end{array}$

$\begin{array}{lllllll}5.2 & \text { Porosity Changes in Calcined Limbux } & \ldots & \ldots & \ldots & \ldots & 219\end{array}$

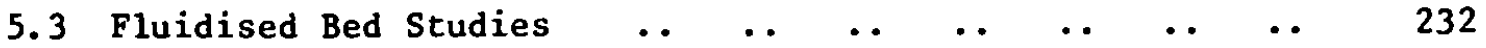

$\begin{array}{lllllllllll}5.3 .1 & \text { Int roduction } . . & \ldots & \ldots & \ldots & \ldots & \ldots & \ldots & \ldots & \ldots & 232\end{array}$

$\begin{array}{lllllllll}5.3 .2 & \text { Results and discussion .. } & \ldots & \ldots & \ldots & \ldots & \ldots & \ldots & 233\end{array}$

CHAPTER SIX

THE USE OF ALRALINE EARTH METAL COMPOUNDS FOR INDUSTRIAL FLUE

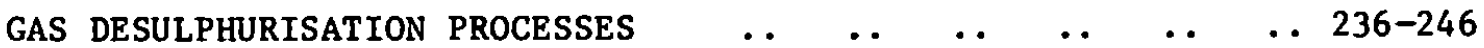

6. 1 Recent Trends in Flue Gas Desulphurisation .. $\ldots$.. 236

6.2 "Dry" Flue Gas Desulphurisation Systems .. $\quad \ldots \quad \ldots \quad$.. $\quad 237$

6. 3 "Wet". Flue Gas Desulphurisation Systems .. $\quad \ldots \quad \ldots \quad \ldots \quad 239$

6.4 Economics of Flue Gas Desulphurisation Systems .. $\quad$. $\quad 243$

CHAPTER SEVEN

$\begin{array}{lllllllllllll}\text { CONCLUSIONS } & \ldots & \ldots & \ldots & \ldots & \ldots & \ldots & \ldots & \ldots & \ldots & \ldots & 247-250\end{array}$

REFERENCES

APPENDICES

Appendix 1

Computer program for Philiips spot shape correction

Appendix 2

List of $F_{\text {(obs) }}$ and $F_{\text {(calc) }}$ values for calcium sulphite

hemihydrate

Appendix 3

Powder diffraction data for strontium hydroxide

Appendix 4

Publications based on work in this Thesis

(a) Thermogravimetric studies of alkaline earth metal sulphites, First European Symp. Thermal Anal. 1976, Salford. 
(b) Hot-stage microscopy of alkaline earth metal sulphites, 2nd Anglo-French Symp. Thermal Anal. 1977, P1ymouth.

(c) Porosity of absorbents for desulphurisation of industrial flue gases, Symp. on the Characterisation of Porous Solids 1978, Neuchatel.

Appendix 5

Private communication, 1978.

Anderson L.C., Glasson D.R., Porosity of quicklimes and hydrated 1 imes. 


\section{CHAPTER ONE}

\section{INTRODUCTION}

The work described in this thesis commenced in 1970 when a number of countries, particularly the U.S.A. and Japan, were introducing much stricter controls over the emission of sulphur dioxide from stationary sources, i.e. electricity generating stations and other industrial plant. At this time few desulphurisation methods were in operation for plants emitting gases containing less than $1 \%$ sulphur dioxide, and relatively little data had been published on the chemical reactions which seemed most likely to be readily applicable to the problems of flue gas desulphurisation.

of the many methods of achieving a reduction in sulphur dioxide emissions, it was decided to study some of the reactions and reactants associated with the use of alkaline earth metal compounds. This was a natural continuation of the extensive work already carried out in these laboratories by Glasson ${ }^{1,2}$ and the more limited studies carried out by the present author 2,3 .

Dry processes of flue gas desulphurisation have the advantage that it should be possible to treat the flue gas without causing a large reduction in temperature, as occurs with wet scrubbing methods; the problems associated with lack of plume buoyancy, which occur when the gas temperature becomes too low, would be avoided. Calcium carbonate, oxide and hydroxide and the similar derivatives of dolomite are relatively abundant and low-cost materials; thus, their usage was likely to be favoured.

The investigation was to examine:

(a) The thermal stabilities of the likely products of the desulphurisation process in order to assess the possibilities of re-cycling the 
alkaline earth metal compounds and using the captured sulphur as a source of sulphur compounds. Particular attention was to be directed to the sulphites which were likely to be major products at flue gas temperatures ${ }^{4}$.

(b) The applicability of utilizing a fluidised bed system. Published work ${ }^{5}$ had indicated that the reaction of sulphur dioxide with particles of -calcium carbonate, etc. occurred on the surface of the particles and that a surface layer of product was formed which prevented further reaction between the unreacted core of the particles and more sulphur dioxide. Fluidised beds, as well as increasing the particle/gas contact time ${ }^{6}$, of ten lead to abrasion ${ }^{7}$ between the fluidised particles and it was thought that this might help to remove the reacted surface layer from the particles.

(c) The relative reaction rates of yarious alkaline earth :metal compounds with sulphur dioxide. Though. thermodynamic data $8,9,10$ for many of the reactions was available, this did not indicate which reactions actually took. place at a worthwile rate.

(d). The crystal structure of calcium sulphite hemihydrate, a major product in scrubbing processes involving calcium compounds. At this time, none of the structures of the alkaline earth metal sulphites were known. In fact, there were still references to the hydrated form of calcium sulphite as a dihydrate ${ }^{11}$.

(e) The general economics of the implementation of a dry flue gas desulphurisation process.

\subsection{Historical Review}

The use of alkaline earth metal compounds for the removal of sulphur dioxide from boiler and furnace exhaust gases has an extensive history ${ }^{12}$, but the major impetus to research in this area came in the late 1960's. During this latter period, there was concern in several 
countries about the large quantities of sulphur dioxide being emitted by stationary fossil fuel burning installations and legislation was enacted for implementation in the $1970^{\prime} \mathrm{s}^{13,14}$. It would seem to be useful to consider the position, as published, of the processes and types of reactions used in the period up to 1970.

A recent article $e^{12}$ traces the history of the development of the various types of flue gas desulphurisation systems since 1850 , and indicates that nine types of process had major studies carried out on them in the 1850 - 1950 period. The processes considered were
(1) Water scrubbing;
(2) Metal ion solutions;
(3) Catalytic oxidation;
(4) Dry adsorption;
(5) Wet lime scrubbing;
(6) Wet limestone scrubbing;
(7) Double alkali process;
(8) Amonia scrubbing;
(9) Processes

based on sulphur dioxide reduction. Of these nine areas, five involved the use of alkaline earth metal compounds. These were:

(a). Dry adsorption - using lime and first developed in $1915^{15}$, when dry lime was injected directly into the bed of the furnace. This process, using also limestone, dolomite and hydrated compounds, was implemented on a large scale. in the $1960^{\prime} \mathrm{s}^{16}$.

(b). Wet lime scrubbing - in which lime slurries were used to absorb sulphur dioxide. First patented in $1909^{17}$ and installed in the Swansea Power Station in $1935^{18}$.

(c) Wet limestone scrubbing - in which a slurry of limestone, rather than lime, was used to absorb the sulphur dioxide. Though used in the chemical industry to produce sulphite acid cooking liquor, there was little development work done until the late 1960's.

(d) Double alkali process - first patented in $1918^{19}$. The sulphur dioxide was absorbed by a solution of a highly soluble alkali, usually sodium hydroxide, which was then treated with a lime slurry to 
precipitate sulphur compounds for disposal and allow regeneration and recycling of the more expensive soluble alkali.

(e) Reduction of sulphur dioxide - this type of reaction has been mainly applied to situations where there were relatively high. concentrations of sulphur dioxide, as in smelter gases. The thiogen process ${ }^{20}$ involved the use of calcium sulphide or calcium sulphate, or barium sulphide. Up to 19.70, the removal of sulphur dioxide from the gaseous emissions of large scale units appears to have been operated only on relatively concentrated sources of sulphur dioxide, such as smelters, apart from the three units installed in the United Kingdom in the 1930's, at Battersea, Swansea and Fulham power stations. However, in the 1960's an increasing amount of interest was developing and various processes were being investigated, so that by 1972 a summary of processes 16 included 21 being actively worked on, some by several different companies.

\subsubsection{Dry Injection Processes}

Wickert ${ }^{21}$ carried out tests on both laboratory scale and commercial units of dry injection methods to prevent high- and lowtemperature corrosion in oil- and coal-fired equipment. Carbonates or hydroxides of calcium and magnesium, or their dolomitic equivalents, injected into the burner zone of a furnace (at $1300^{\circ}-1400^{\circ} \mathrm{C}$ ) would all be converted to their respective oxides. Laboratory tests on the degree of reaction, with sulphur dioxide, of the various oxides at temperatures from $400^{\circ}$ to $1400^{\circ} \mathrm{C}$ were performed and indicated that the maximum degree of desulphurisation occurred at about $900^{\circ} \mathrm{C}$ with a rapid decrease in efficiency above $1000^{\circ} \mathrm{C}$ for $\mathrm{MgO} . \mathrm{CaO}$ and above $1200^{\circ} \mathrm{C}$ for $\mathrm{CaO}$. In the laboratory studies, a retention time of 0.5 seconds was required for almost complete desulphurisation of a gas containing 1 vol \% $\mathrm{SO}_{2}$, but times of 1 second or more would be needed in operational burners. Tests were also carried out on commercial furnaces using hydrated dolime, 
$\mathrm{Ca}(\mathrm{OH})_{2} \cdot \mathrm{Mg}(\mathrm{OH})_{2}$, which achieved up to $91 \%$ sulphur dioxide removal. The retention times quoted were approximately 7 seconds, which were higher than other workers ${ }^{4,22}$ suggest as likely in large furnaces. Further work $^{23}$ in Germany showed that the removal of sulphur dioxide from coalfired burners was lower than from oil-fired burners and that in both cases there was some build-up of deposits on boiler surfaces. As well as slagging problems on heat exchanger surfaces, another problem became apparent $24,25,26$. The removal of 1 ton of sulphur dioxide yields over 2 tons of solid product, plus the excess unreacted adsorbent, plus the normal fly ash to give a much increased dust load to be removed by the dust collection system. Electrostatic precipitators depend upon sulphur trioxide to provide a large portion of the gas conductivity that gives this system its high efficiency ${ }^{27}$. Limestone-type additives react preferentially with the sulphur trioxide in the flue gas, even though its concentration is only $1 \%$ or $2 \%$ of that of the sulphur dioxide. As a result the efficiency of the electrostatic precipitators was reduced by as much as $30 \%$.

\subsubsection{Comparison of natural limestone and magnesite absorbents with}

\section{their calcined and hydrated products}

Various studies $11,22,28,29$ were made on calcium and magnesium carbonate rocks to determine the differences in the sulphur dioxide absorption characteristics of these materials and of their calcined and hydrated products. The aim was to identify the physical and chemical properties responsible for the differences in the rate and quantity of sulphur dioxide absorption shown by different samples. The results obtained by Potter ${ }^{28}$ suggested the following variability: (a) There was little difference between the reactivity of the raw stone and pre-calcined samples at $980^{\circ} \mathrm{C}$, but there were very large differences between carbonate rocks from different localities. 
(b) The differences in reactivity with sulphur dioxide could be correlated with the total mercury pore volume, but there was no significant correlation with the B.E.T. nitrogen specific surface. The number of pores larger than $0.3 \mu \mathrm{m}$ appeared particularly significant. (c) The utilisation of calcium oxide in a fixed-bed reactor varied from $1 \%$ up to $90 \%$ with an average of $45 \%$.

(d) At $430^{\circ} \mathrm{C}$, the absorption capacities were hydrated $>$ calcined $>$ uncalcined stones. At $705^{\circ} \mathrm{C}$, the same relationship was found, but the capacities had almost doubled. At $980^{\circ} \mathrm{C}$, the capacities of the hydrated and calcined samples had fallen, whilst the uncalcined stones had . increased in capacity to the same level as the calcined samples.

In contrast, Coutant et a1 22 , using a simulated flue gas containing 3000 ppm sulphur dioxide and a dispersed phase reactur at temperatures between $815^{\circ} \mathrm{C}$ and $1150^{\circ} \mathrm{C}$, found that limestone reactivity was raw stone $>$ hydroxide $>$ lime, while for dolomite the reactivity was greater and the order was fully hydrated dolime > raw stone > monohydrated dolime, and that these relationships held for all temperatures. This work also indicated that as the residence time of a particle in the reactor increased, the amount of sulphur dioxide absorbed increased to a maximum and then decreased. The author's conclusions were that "the overall reaction between $\mathrm{raw}$ stones and $\mathrm{SO}_{2}$ in the reactor follows a complex path, the nature of which is due in part to the slow heat-up of stone particles as a result of the thermal requirements for calcining of the stone. Sulphite formation is the primary mode of sulphur pick-up during the early stages of the process, during which time the stone is still relatively cool. In later stages of the process, as the stone heats up to temperatures above the thermodynamic limit for sulphite existence (about $1400^{\circ} \mathrm{F}$ ) $\left[760^{\circ} \mathrm{C}\right]$, the sulphite can calcine, and sulphur dioxide is lost from the particles. Concurrent with these steps, the sulphite can be oxidised and/or disproportionate to form sulphate. The 
net result is a maximum in sulphur pick-up during the first second of exposure in the reactor. The time required for attainment of this maximum and the magnitude of the maximum pickup are likely to depend on factors which influence the heat-up time and the rate of oxidation or disproportionation, e.g. particle size, injection temperature, oxygen concentration, duration of exposure at a given temperature and the details of the physical state of the lime formed during the calcination step."

The rates of reaction found by Coutant were much higher than those found in isothermal studies by Borgwardt ${ }^{30}$ using pre-calcined limestones and dolomites. These studies of isothermal kinetics of sulphur dioxide absorption appear to indicate that the removal of significant quantities of sulphur dioxide would not occur during the short residence times, 0.5 - 4 seconds, available during passage of the gases through a boiler. However, in boilers, non-isothermal conditions exist with respect to the solid particles immediately after injection into the gas stream, thus favouring Coutant's results. Attempts to improve the effectiveness of sulphur dioxide removal in boiler tests by calcining the stone under controlled conditions prior to injection into the furnace have given results which were not as good as the injection of raw stone ${ }^{31}$. Likewise, lime recovered after injection tests and then re-injected has proved to be relatively unreactive compared to fresh limestone ${ }^{11}$. These results contradict the generally accepted mechanism whereby $\mathrm{SO}_{2}$ is absorbed by $\mathrm{CaO}$ after the loss of $\mathrm{CO}_{2}$, but are entirely consistent with the mechanism postulated (by Coutant) where the reaction occurs during heat-up and calcination. The low reactivity of pre-calcined limestone compared to raw stione would follow as a natural consequence of the more extreme non-isothermal conditions existing in the latter case, where considerably more heat is absorbed during the process of chemical dissociation of the carbonate $\mathrm{e}^{31}$. 


\subsubsection{Thermogravimetric Studies}

Using thermogravimetric methods, Chan et al ${ }^{11}$ studied the action of a $5 \% \mathrm{SO}_{2}$ : $95 \% \mathrm{~N}_{2}$ gas mixture on samples of limestone and dolomite precalcined at $745^{\circ} \mathrm{C}$. The results were interpreted as showing (i) rapid initial chemisorption at room temperature to form a $\mathrm{SO}_{2}$ monolayer; (ii) an intermediate absorption region between $200^{\circ}-400^{\circ} \mathrm{C}$ to give 8 layers of sulphite on the calcined limestone and 4 layers on the calcined dolomite; (iii) a fast absorption region starting between $500^{\circ}$ and $600^{\circ}$ and becoming slower at $750^{\circ} \mathrm{C}$. The authors suggested that the disproportionation of calcium sulphite

$$
4 \mathrm{CaSO}_{3} \longrightarrow 3 \mathrm{CaSO}_{4}+\mathrm{CaS}
$$

which occurs at about $600^{\circ} \mathrm{C}$ would break up the surface layers of calcium sulphite, thus exposing fresh oxide layers for reaction with sulphur dioxide. Above $750^{\circ} \mathrm{C}$ the calcium sulphite begins to dissociate

$$
\mathrm{CaSO}_{3} \longrightarrow \mathrm{CaO}+\mathrm{SO}_{2}
$$

and a number of other reactions become important, namely

$$
\begin{aligned}
& 6 \mathrm{SO}_{2} \longrightarrow 4 \mathrm{SO}_{3}+\mathrm{S}_{2} \\
& \mathrm{CaS}+2 \mathrm{SO}_{2} \longrightarrow \mathrm{CaSO}_{4}+\mathrm{S}_{2} \\
& \mathrm{SO}_{3}+\mathrm{CaO} \longrightarrow \mathrm{CaSO}_{4}
\end{aligned}
$$

The final utilisation of the limestone was $86 \%$ of the stoichiometric amount, and for the dolomite it was $74 \%$.

\subsubsection{Efficiency of sulphur dioxide removal}

In most studies carried out up to 1970 , the efficiency of sulphur dioxide removal compared to the quantities of calcareous materials used was not impressive ${ }^{32}$, as is illustrated by Fig. 1.1. The relatively simple process of addition of dry calcareous compounds is in fact quite complex ${ }^{4,32}$. If the particles are injected directly into the flame zone, their temperatures will rise rapidly to a maximum of $1650^{\circ} \mathrm{C}$ and then fall to about $150^{\circ} \mathrm{C}$ within approximately 4 seconds. The average sulphur dioxide 
concentration for a $2.7 \%$ s-containing fuel will be $2200 \mathrm{ppm}$, but will vary widely in the combustion zone, as will the concentrations of oxygen, carbon dioxide and water. As a result of these variables and, thus, the large number of possible competing reactions, the rates of reaction must be determined experimentally. However, conventional thermodynamic calculations can be used to predict whether a reaction is likely to occur and to what extent it would occur if equilibrium was reached. Extensive data on the reactions of calcium and magnesium compounds with sulphur compounds have been published ${ }^{8}$, although. a number of important reactions, particularly disproportionation reactions, are not included. Table 1.1 lists reactions which can occur when dry desulphurisation methods are used with calcium and magnesium compounds. Calculation of free energy changes, $\Delta G$, shows that sulphur dioxide will react with calcium and magnesium carbonates, oxides and hydroxides in the temperature range found in furnaces and the associated flue gases. The equilibrium constant, $K$, for a reaction is related to the change in free energy as shown in equation $1.1^{33}$

$$
\begin{aligned}
& \log _{10^{K}} \mathrm{~K} \frac{-\Delta \mathrm{G}^{\circ}}{2.303 \mathrm{RT}} \\
& \text { where } \mathrm{K}=\text { equilibrium constant } \\
& \begin{aligned}
\Delta \mathrm{G}^{\circ} & =\text { standard Gibbs free energy change } \\
& \text { in } \mathrm{J} \cdot \mathrm{mol}^{-1} \\
\mathrm{~T} & =\text { temperature in degrees Kelvin } \\
\mathrm{R} & =\text { universal gas constant }
\end{aligned}
\end{aligned}
$$

For the reaction between calcium oxide and sulphur dioxide the equilibrium constant is related also to the partial pressure of sulphur dioxide. 
Table 1.1 Possible reactions involving calcium, magnesium and sulphur compounds under dry flue gas desulphurisation conditions

In each case the symbol $M$ represents an alkaline earth metal.

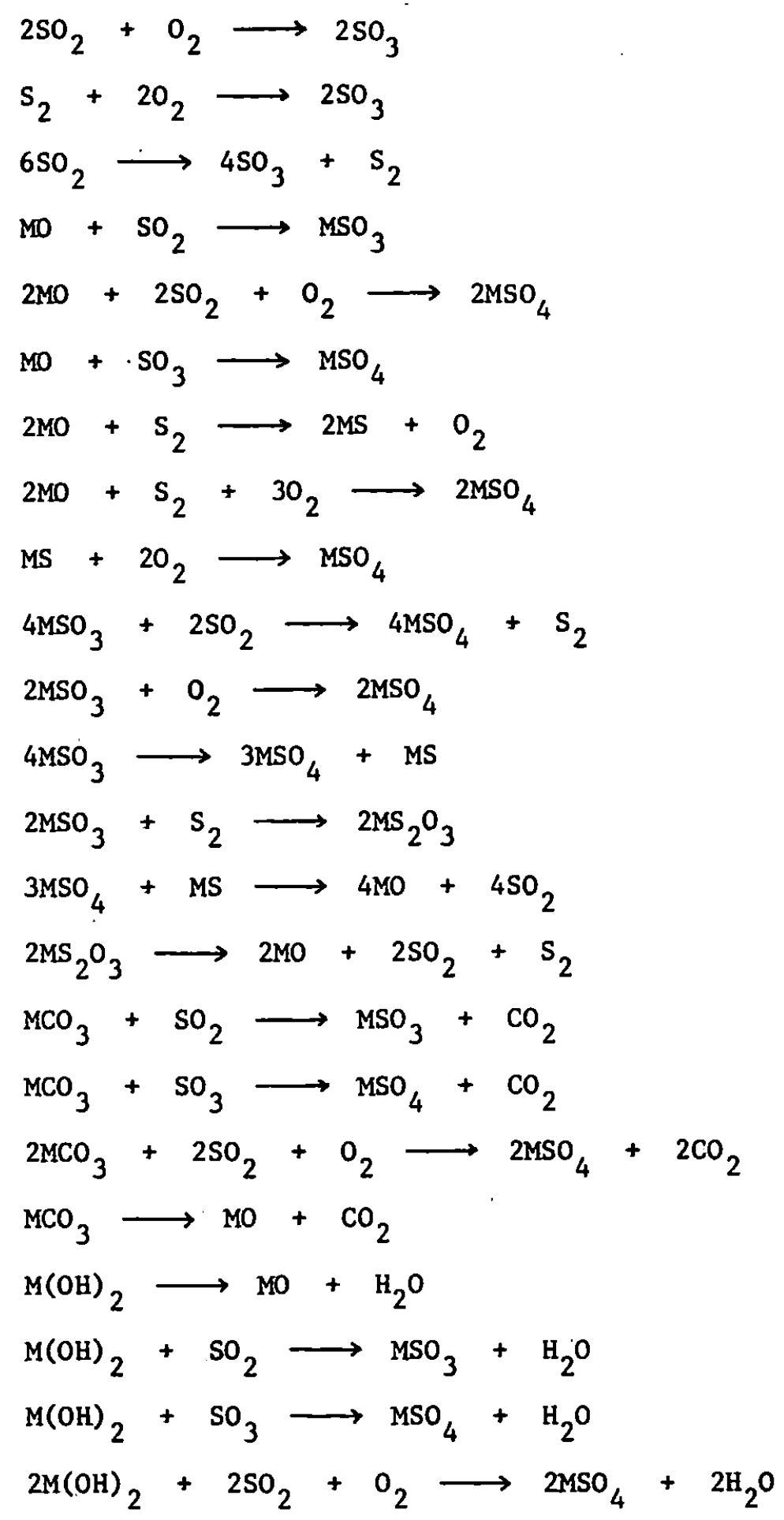


$\mathrm{CaO}(\mathrm{c})+\mathrm{SO}_{2(\mathrm{~g})} \longrightarrow \mathrm{CaSO}_{3(\mathrm{c})}$

Therefore $\mathrm{K}=\frac{{ }^{\mathrm{a}} \mathrm{CaSO}_{3}}{{ }^{\mathrm{a}} \mathrm{CaO}{ }^{\mathrm{a}} \mathrm{SO}_{2}}$

where ${ }^{\mathrm{a}} \mathrm{CaSO}_{3}=$ activity of $\mathrm{CaSO}_{3}$ (assumed to be 1 as solid)

${ }^{\mathrm{a}} \mathrm{CaO}=$ activity of $\mathrm{CaO}$ (assumed to be $\mathrm{l}$ as solid)

${ }^{\mathrm{a}} \mathrm{SO}_{2}=$ activity of $\mathrm{SO}_{2}$ (assumed to be equal to the partial pressure of $\mathrm{SO}_{2}, \mathrm{P}_{\mathrm{SO}_{2}}{ }_{2}$ )

therefore $\mathrm{K}=\frac{1}{\mathrm{P}_{\mathrm{SO}_{2}}}$

1.4

therefore for reaction $1.2, \log \mathrm{K}=-\log \mathrm{p}_{\mathrm{SO}_{2}}$

Table 1.2 lists the equilibrium constants and equilibrium levels of sulphur dioxide, at different temperatures, as calculated for reaction 1.2. Table 1.3 shows the effect of the presence of oxygen, based on reaction 1.6 , and equation 1.7 , which was derived in a similar manner to equation 1.5 .

$\mathrm{CaO}(\mathrm{c})+\mathrm{SO}_{2(\mathrm{~g})}+\mathrm{fO}_{2(\mathrm{~g})} \longrightarrow \mathrm{CaSO}_{4(\mathrm{c})}$

$\log \mathrm{K}=-\log \left(\mathrm{p}_{\mathrm{SO}_{2}} \cdot \mathrm{P}_{\mathrm{O}_{2}}{ }^{\frac{1}{2}}\right)$

where $\mathrm{p}_{2}=$ partial pressure of oxygen

As the concentration of sulphur dioxide in flue gas is of the order of $2500 \mathrm{ppm}$, the upper temperature at which calcium oxide will be effective in removing sulphur dioxide will be about $750^{\circ} \mathrm{C}$ for reaction 1.2 and between $1200^{\circ} \mathrm{C}$ and $1300^{\circ} \mathrm{C}$, depending upon the concentration of oxygen, for reaction 1.6. With decreasing temperature, the quantity of sulphur dioxide in equilibrium with the calcium oxide decreases for both reactions, so that the efficiency of removal theoretically increases. However, because the rate of reaction also decreases with. a reduction in temperature, equilibrium may not be reached, particularly for short 
Table 1.2 Equilibrium concentration of sulphur dioxide in contact with calcium oxide for the reaction

$$
\mathrm{CaO}_{(\mathrm{c})}+\mathrm{SO}_{2(\mathrm{~g})} \longrightarrow \mathrm{CaSO}_{3(\mathrm{c})}
$$

\begin{tabular}{|c|c|c|}
\hline $\begin{array}{c}\text { Temperature } \\
\text { oC }\end{array}$ & Equilibrium constant, $K$ & $\begin{array}{c}\text { Equilibrium concentration of } \\
\text { sulphur dioxide in p.p.m. }\end{array}$ \\
\hline 250 & $3.2 \times 10^{14}$ & $3 \times 10^{-9}$ \\
500 & $3.9 \times 10^{6}$ & $3 \times 10^{-1}$ \\
750 & $3.6 \times 10^{2}$ & $3 \times 10^{3}$ \\
1000 & 1.9 & $5 \times 10^{5}(0.5 \mathrm{~atm})$ \\
1035 & 1.0 & $1 \times 10^{6}(1 \mathrm{~atm})$ \\
1250 & $5.5 \times 10^{-2}$ & $2 \times 10^{7}$ \\
\hline
\end{tabular}

Table 1.3 Effect. of oxygen on the equilibrium levels of sulphur dioxide in contact with calcium oxide, based on the reaction

$$
\mathrm{CaO}_{(\mathrm{c})}+\mathrm{SO}_{2(\mathrm{~g})}+{ }_{2}^{1} \mathrm{O}_{2}(\mathrm{~g}) \longrightarrow \mathrm{CaSO}_{4}(\mathrm{~g})
$$

\begin{tabular}{|c|c|c|c|c|}
\hline \multirow{2}{*}{$\begin{array}{c}\text { Temperature } \\
{ }^{\circ} \mathrm{C}\end{array}$} & $\begin{array}{c}\text { Equilibrium } \\
\text { Constant, } \mathrm{K}\end{array}$ & \multicolumn{4}{|c|}{ Equilibrium concentration of $\mathrm{SO}_{2}$ in p.p.m. } \\
\cline { 3 - 6 } & 1 vol-\% $0_{2}$ & 2.5 vol-\% $0_{2}$ & 5 vol-\% $0_{2}$ \\
\hline 800 & $8.2 \times 10^{9}$ & $1 \times 10^{-3}$ & $7 \times 10^{-4}$ & $5 \times 10^{-4}$ \\
1000 & $1.9 \times 10^{6}$ & 5 & 3 & 2 \\
1200 & $7.6 \times 10^{3}$ & $1 \times 10^{3}$ & $8 \times 10^{2}$ & $6 \times 10^{2}$ \\
1400 & 47 & $2 \times 10^{5}$ & $1 \times 10^{5}$ & $9 \times 10^{4}$ \\
\hline
\end{tabular}


contact times between the calcium oxide and gas, which are likely in a practical flue gas desulphurisation system. For these reasons it has been suggested ${ }^{4}$ that the working temperature for desulphurisation using calcium oxide would be about $960^{\circ} \mathrm{C}$ to $1230^{\circ} \mathrm{C}$ and if magnesium oxide was used the working range would be $650^{\circ} \mathrm{C}$ to $850^{\circ} \mathrm{C}$. Table 1.3 shows that the likely changes in oxygen concentration in a furnace system would have a relatively small effect on the sulphur dioxide equilibrium concentration, but of course the complete absence of oxygen makes a big difference.

Calcium carbonate can react with sulphur dioxide in a similar manner to calcium oxide, equations 1.8 and 1.9 :

$$
\begin{aligned}
& \mathrm{CaCO}_{3(\mathrm{c})}+\mathrm{SO}_{2(\mathrm{~g})} \longrightarrow \mathrm{CaSO}_{3(\mathrm{c})}+\mathrm{CO}_{2(\mathrm{~g})} \quad 1.8
\end{aligned}
$$

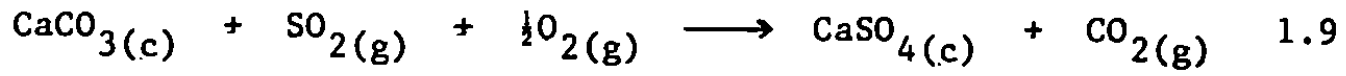

Tables 1.4 and 1.5 indicate the relative equilibrium concentration of sulphur dioxide at different temperatures.

On the basis of the four reactions considered, calcium carbonate appears to be a better absorbent for sulphur dioxide than calcium oxide at higher temperatures, but the calcium carbonate would dissociate in the burner zone at these temperatures to form calcium oxide. Similarly calcium hydroxide would also decompose to form calcium oxide when injected into a furnace: Nevertheless calcium carbonate would still be an effective desulphuriser below its decomposition temperature. The formation of sulphur trioxide, from the sulphur dioxide, would increase the tendency for the calcium compounds to act as desulphurising agents because the equilibrium constants for these reactions are much higher than for the corresponding reactions with sulphur dioxide.

The thermodynamic data for magnesium compounds ${ }^{8}$ indicates that these compounds would not be so effective as the corresponding calcium 
Table 1.4 Equilibrium concentration of sulphur dioxide in contact with calcium carbonate, in the presence of 14 vol-\% $\mathrm{CO}$, for the reaction

$$
\mathrm{CaCO}_{3(\mathrm{c})}+\mathrm{SO}_{2(\mathrm{~g})} \longrightarrow \mathrm{CaSO}_{3(\mathrm{c})}+\mathrm{CO}_{2(\mathrm{~g})}
$$

\begin{tabular}{|c|c|c|}
\hline $\begin{array}{c}\text { Temperature } \\
\text { OC }^{\prime}\end{array}$ & Equilibrium constant, $\mathrm{K}$ & $\begin{array}{c}\text { Equilibrium concentration of } \\
\text { sulphur dioxide in p.p.m. }\end{array}$ \\
\hline 250 & $9.6 \times 10^{4}$ & 1 \\
500 & $5.5 \times 10^{2}$ & $3 \times 10^{2}$ \\
700 & 52 & $3 \times 10^{3}$ \\
800 & 23 & $6 \times 10^{3}$ \\
$* 900$ & 16 & $9 \times 10^{3}$ \\
\hline
\end{tabular}

Table 1.5 Equilibrium concentration of sulphur dioxide in contact with calcium carbonate, in the presence of 14 vol- $\%$ CO 2 and 2.5 vol $-\% 0_{2}$, for the reaction

$$
\mathrm{CaCO}_{3(\mathrm{c})}+\mathrm{SO}_{2(\mathrm{~g})}+\frac{1}{2} \mathrm{O}_{2} \longrightarrow \mathrm{CaSO}_{4(\mathrm{c})}+\mathrm{CO}_{2(\mathrm{~g})}
$$

\begin{tabular}{|c|c|c|}
\hline $\begin{array}{c}\text { Temperature } \\
{ }^{\circ} \mathrm{C}\end{array}$ & Equilibrium constant, $K$ & $\begin{array}{c}\text { Equilibrium concentration of } \\
\text { sulphur dioxide in p.p.m. }\end{array}$ \\
\hline 250 & $7.7 \times 10^{25}$ & $1 \times 10^{-20}$ \\
500 & $2.4 \times 10^{15}$ & $4 \times 10^{-10}$ \\
700 & $7.1 \times 10^{10}$ & $1 \times 10^{-5}$ \\
800 & $2.1 \times 10^{9}$ & $4 \times 10^{-4}$ \\
$* 900$ & $9.8 \times 10^{7}$ & $9 \times 10^{-3}$ \\
\hline
\end{tabular}

*Calcium carbonate thermodynamically unstable. 
compounds at the same temperature. For example, the equilibrium concentration of sulphur dioxide, in the presence of 2.5 vol-\% $\mathrm{O}_{2}$ at $700^{\circ} \mathrm{C}$, for reaction 1.10 is $13 \mathrm{p} \cdot \mathrm{p} . \mathrm{m}$. compared to $3 \times 10^{-6} \mathrm{p} \cdot \mathrm{p} \cdot \mathrm{m}$. when calcium oxide is used under the same conditions.

$\mathrm{MgO}_{(\mathrm{c})}+\mathrm{SO}_{2(\mathrm{~g})}+\mathrm{H}_{2(\mathrm{~g})} \longrightarrow \mathrm{MgSO}_{4(\mathrm{c})}$

The sulphated magnesium compounds also have lower decomposition temperatures than the corresponding calcium compounds so the working temperature range will be lower for the magnesium compounds.

The results illustrated in Fig. 1.1 which are better than normal were obtained either under laboratory conditions or in relatively smal1scale plants. Zielke et $a 1^{34}$ used a fluidised bed combustion process, in which dolomite was added with the coal, to give much better sulphur oxide removal properties. They also demonstrated the possibility of regeneration of the sulphated dolomite using carbon monoxide at $1065^{\circ} \mathrm{C}$ $\mathrm{CaSO}_{4}+\mathrm{CO} \longrightarrow \mathrm{CaO}+\mathrm{SO}_{2}+\mathrm{CO}_{2}$ The concentration of sulphur dioxide in the gases from the regeneration process was about $6 \%$ which enables these to be used to produce sulphur or other sulphur compounds by standard methods such as the Claus process ${ }^{35}$.

\subsubsection{Comparison of "dry" and "wet" sulphur dioxide removal processes}

Consideration of the rather poor efficiencies of the dry desulphurisation systems makes it clear that to achieve a reasonable degree of desulphurisation something of the order of twice the stoichiometric quantity of additive must be used. As a result, the combined total weight of (a) sulphated product, (b) excess additive and (c) fly ash will be about twice that of fly ash alone. If a wet scrubbing process based on calcareous materials was used, the efficiency of both the removal of sulphur dioxide (80-90\%) and the use of additive (approximately stoichiometric) would be much better ${ }^{36}$. Because of the large amount of water trapped in the sludge, the disposal of 2.5 to 3 times the weight of wet sludge, compared with coal ash alone would 
Figure 1.1 Sulphur dioxide removal efficiencies obtained in a number of investigations

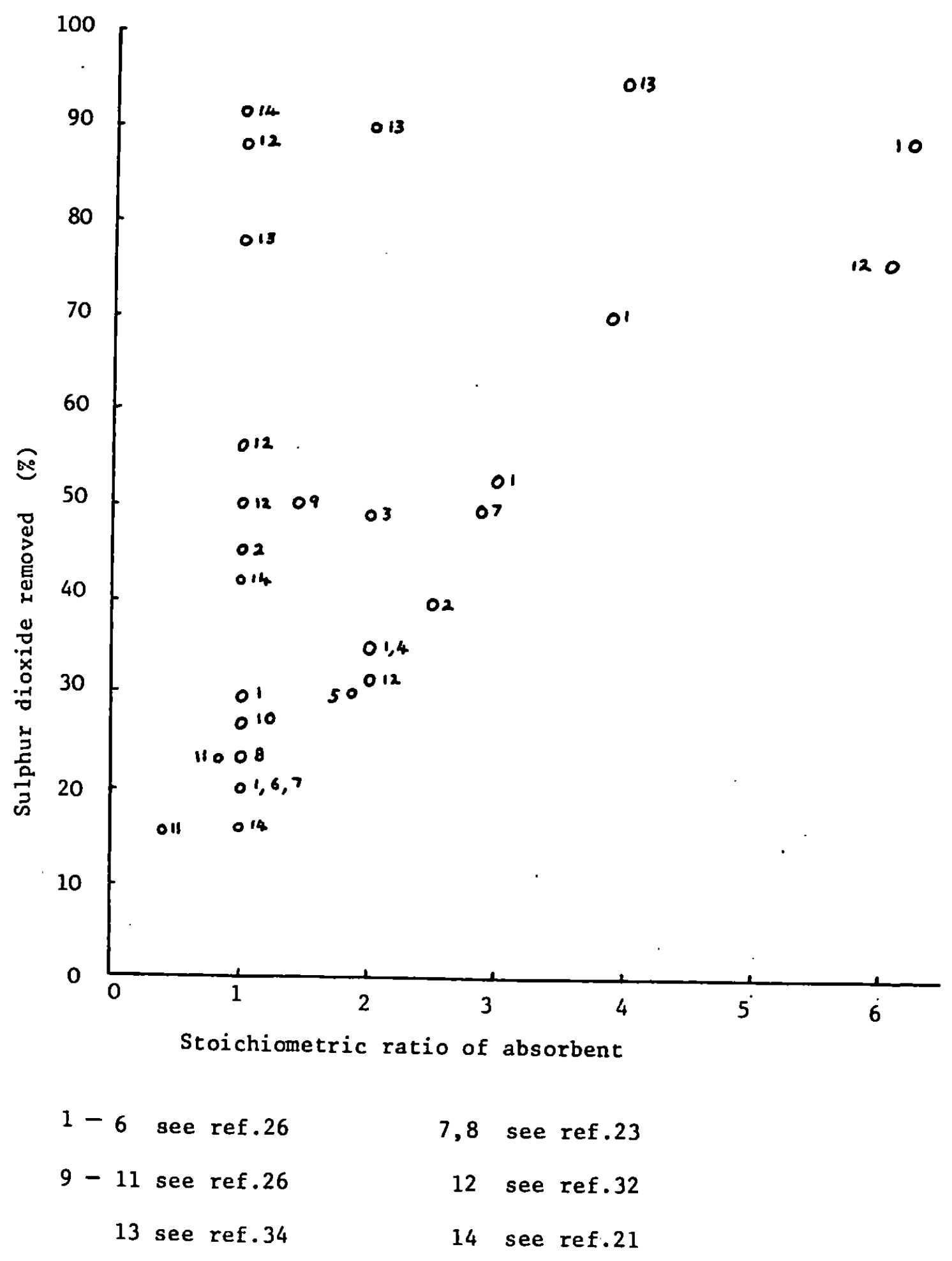


be required ${ }^{37}$. These disposal problems of throwaway systems seem to make necessary the development of processes in which the desulphurising agent is regenerated. The alkaline earth metal compounds are used for flue gas desulphurisation because they are relatively cheap and available in large quantities. It appeared that an investigation in some detail of the thermal stabilities of the products of the desulphurisation process was required. In particular, the sulphites were chosen for study because the evidence was that they were the first-formed compounds in many of the desulphurisation reactions and their relative lack. of stability at higher temperatures suggested that regeneration might be possible by thermal methods alone, as well as by the use of reducing agents.

A search of the literature showed that relatively few papers had been published concerning the thermal stabilities of the alkaline earth metal sulphites. Foerster and Kube $1^{38}$ heated samples of calcium sulphite hemihydrate and dehydrated magnesium sulphite trihydrate for, usually, two hour periods in nitrogen at temperatures between $300^{\circ} \mathrm{C}$ and $1100^{\circ} \mathrm{C}$. Analysis of the samples showed that calcium sulphite underwent disproportionation to form calcium sulphate and calcium sulphide at temperatures above $600^{\circ} \mathrm{C}$, but magnesium sulphite decomposed to form magnesium oxide at this temperature, with no evidence of it having undergone a similar disproportionation reaction at a lower temperature. In 1948 X-ray powder diffraction data for calcium sulphite hemihydrate 39 was published and the various statements $40,41,42$ that there was a dihydrate were refuted. Differential thermal analytical studies, in air, of magnesium sulphite hexahydrate, together with X-ray diffraction and infra-red examination of the products were carried out by Okabe and Hori ${ }^{43}$, who showed that dehydration was followed by oxidation, and then dissociation. Strontium and barium sulphites 
heated for one hour periods ${ }^{44}$, in nitrogen, between $400^{\circ} \mathrm{C}$ and $800^{\circ} \mathrm{C}$ both underwent disproportionation reactions with very little dissociation. However, Pechkovskii and Ketov ${ }^{45}$, reported rather more extensive dissociation of barium sulphite when they heated it in argon.

\subsection{The Sulphur Dioxide Problem}

"Sulphur dioxide is now generally considered to be a serious and damaging air pollutant when associated with smoke and when present in high concentrations at ground level." 46 The extent to which it should be regarded as harmful at low concentrations, in the absence of smoke, or when dispersed at high levels in the atmosphere is more controversial.

Most of the sulphur dioxide emitted in the United Kingdom originates from the combustion of fossil fuels, among which bituminous coal and heavy fuel oil are those mainly responsible. However, more localised sources of higher concentration may be provided by the gases emitted from various smelting operations, though these all now have desulphurising methods applied to them.

The Clean Air Act, 1956, together with the move to the more convenient heating qualities of electricity and gas, has brought about a reduction in the sulphur dioxide. emissions from domestic sources. The annual mean concentration of sulphur dioxide at U.K.

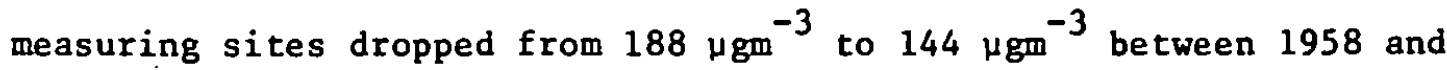
$1970^{46}$. Against the relatively small reduction in domestic-emitted sulphur dioxide must be put the larger increase in emissions from electricity power stations (approx. $1 \times 10^{6}$ tonnes $\mathrm{SO}_{2}$ in $1952^{46}$ to approx. $2.7 \times 10^{6}$ tonnes $\mathrm{SO}_{2}$ in $1976 / 7^{47}$ ). These figures would appear to indicate that the "tall stack" method of dispersal has been, at least, partially successful. 
On a world-wide scale, present estimates are that about seventy million tonnes of sulphur per year ${ }^{48}$ enter the atmosphere from manmade emissions and this compares with a total input to the atmosphere from all sources of $200-220$ million tonnes of sulphur per year ${ }^{49,50}$. As the majority of industrial sources are concentrated in the Northern Hemisphere it seems probable that man-made emissions now outweigh natural emissions in this hemisphere.

The fate of sulphur dioxide in the atmosphere is not known in detail, but the general pathways are now beginning to be understood. The sulphur dioxide may be washed out or rained out. In moderate rainfall $\left(1 \mathrm{~mm}^{-1}\right)$ all the sulphur would be removed in $50-100 \mathrm{~km}$, whereas in dry conditions the sulphur compounds may be carried several hundred kilometres ${ }^{48}$. The sulphur dioxide in the atmosphere undergoes gradual oxidation, becoming converted mainly to sulphate aerosols, containing species such as ammonium sulphate, ammonium hydrogen sulphate and sulphuric acid. The acid components lower the $\mathrm{pH}$ of the rain and thus cause problems in the corrosion of buildings 51 , effects on plant and $\mathrm{fish}$ life $\mathrm{e}^{52,53}$ etc. Sulphates are now being considered as a major factor in the adverse effects of sulphur dioxide on health, particularly with respect to bronchitis and other respiratory diseases 54,55 .

The levels of sulphur dioxide, or its products, which are acceptable have not been clearly determined ${ }^{46,54}$. Thus, it is impossible to relate the costs of desulphurisation processes, which can be calculated, with the savings, which cannot be calculated at present. 


\section{CHAPTER TWO}

\section{EXPERIMENTAL TECHNIQUES}

\subsection{Introduction}

Prepared specimens of the alkaline earth metal sulphites were studied using thermal analytical methods. The phase composition and crystallinity of the products of these studies was examined with the aid of an X-ray diffractometer. Optical and electron microscopes were used also in the examination of samples, particularly in conjunction with hot-stage attachments for both instruments. The specific surfaces of some of the products were calculated by the B.E.T.procedure from physisorption isotherms of nitrogen, at $77 \mathrm{~K}$, determined gravimetrically on a sorption balance. Standard chemical methods were used to quantitatively analyse samples.

The crystal structure of calcium sulphite hemihydrate was determined using single crystal X-ray diffraction methods based on intensity data collected on a Weissenberg camera with copper $K_{\alpha}$ radiation.

The reactivity of various materials with sulphur dioxide was studied using a thermoanalytical balance. Phase compositions were determined using $X$-ray diffraction methods and chemical analysis. Specific surfaces of some reactants and products, together with porosity values, were calculated from gravimetrically determined nitrogen sorption isotherms.

\subsection{Thermal Analysis}

Thermal analysis may be defined as "those techniques in which some physical parameter of the system is determined as a function of temperature". 56 The principal techniques of thermal analysis are thermogravimetry (TG) and differential thermal analysis (DTA) and these were the two techniques used in this study. 


\subsubsection{Thermogravimetry (TG)}

This is a technique in which the change in mass of a sample is recorded as a function of temperature or time. It provides quantitative information on processes taking place with a change in weight and enables the stoichiometry of such a process to be followed directly.

Thermogravimetry may be performed in one of three modes, namely (a) isothermal, or static, where the sample mass is recorded as a function of time at a constant temperature; (b) quasi-static, where the sample is heated to a constant mass at each of a series of temperatures; (c) dynamic, where the sample is heated at a linear rate. The resulting mass change versus temperature, or time, curve can provide information concerning the thermal stability of a compound, e.g. dehydration, decomposition or reactivity with gaseous reactants in suitably prepared atmospheres.

Reactions of the type

$$
\mathrm{A}_{\text {(solid) }} \longrightarrow{ }^{\mathrm{B}_{(\text {solid })}}+\mathrm{C}_{\text {(gas) }}
$$

would give a dynamic TG mass loss curve of the type shown in Fig. 2.1. $\mathrm{T}_{i}$ is the "initial temperature", or procedural decomposition temperature, when the cumulative mass-change reaches a magnitude that the thermobalance can detect. It is neither a transition temperature, in the phase-rule sense, nor a true decomposition temperature below which the reaction rate suddenly becomes zero. $T_{f}$ is the "final temperature", at which the cumulative mass-change first reaches its maximum value, corresponding to complete reaction. At a linear heating rate $T_{f}$ must be greater than $T_{i}$ and $\left(T_{f}-T_{i}\right)$ is called the reaction interval. The values of both $T_{i}$ and $T_{f}$ are affected by factors such as heating rate, mass of sample, atmospheric composition. 
Figure 2.1 Characteristics of a single-stage reaction TG curve

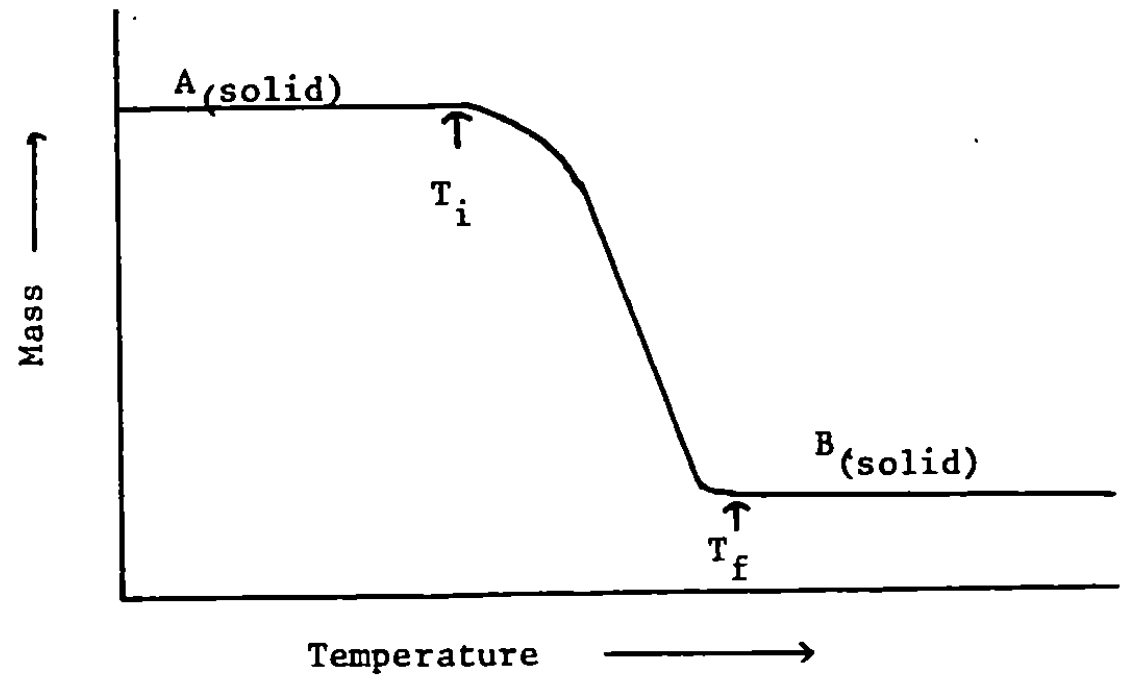

Figure 2.2 Characteristics of an exothermic reaction DTA curve

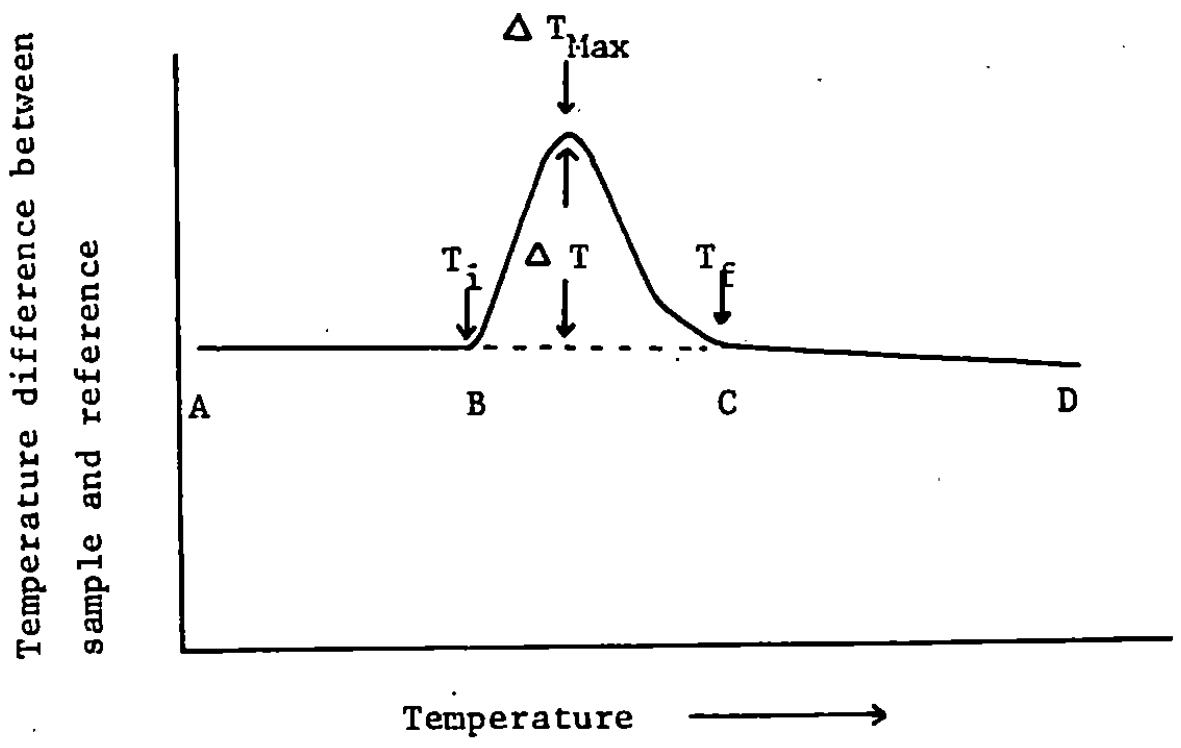


Isothermal thermogravimetry has been widely used to study the kinetics of thermal decomposition. The basis for the calculation of kinetic data from isothermal curves is the general equation 572.1

$$
\begin{aligned}
&-\frac{\mathrm{dX}}{\mathrm{dt}}=\mathrm{k}_{1} \mathrm{x}^{\mathrm{n}} \\
& \text { where } \mathrm{x}=\text { sample mass } \\
& \mathrm{n}=\text { order of reaction } \\
& \mathrm{t}=\text { time } \\
& \mathrm{k}_{1}=\text { rate constant }
\end{aligned}
$$

The temperature dependence of the specific rate constant, $k$, is expressed by the Arrhenius equation ${ }^{58}, 2.2$

$$
\begin{aligned}
\mathrm{k}=\mathrm{Ae} & -\mathrm{E} / \mathrm{RT} \\
\text { where } \mathrm{A} & =\text { pre-exponential factor } \\
\mathrm{E} & =\text { activation energy } \\
\mathrm{R} & =\text { Universal gas constant } \\
\mathrm{T} & =\text { temperature, in } \mathrm{R}
\end{aligned}
$$

The process of collecting the necessary data to determine the kinetics of a reaction and its activation energy, by isothermal methods, is very time consuming. Dynamic thermogravimetry has the capability of providing, in one mass-change curve, an amount of information equivalent to that provided by a large number of isothermal mass-change curves $^{59}$. However, dynamic TG data are only narrowly definitive and, in consequence, it is often only possible to determine empirical kinetic parameters. The reaction mechanism usually cannot be determined and as a result the meanings of the activation energy, order of reaction and frequency factor are uncertain. A large number of methods of determining kinetic parameters nonisothermally have been proposed and a review of these is given by Wendlandt 56 , but no one method has outstanding advantages over the others. Various comparisons 57,60 showed that many 
of the methods gave very similar results. Several of the methods also depend upon knowing the order of reaction before they can be fully utilised.

There are a large number of factors which affect the nature, precision and accuracy of results obtained by dynamic thermogravimetry. of particular importance are the following: (a) Furnace heating rate increasing the heating rate increases both $T_{i}$ and $T_{f}$, the relative amounts depending upon whether the reaction is exothermic or endothermic. (b) Furnace atmosphere - only rates of reaction involving gaseous reactants or products will be affected. In flowing inert gas atmospheres the gaseous products will be removed, so increasing the rate of reaction, by preventing a build-up in the concentration of the gaseous decomposition product. In a static atmosphere there would tend to be a build-up of gaseous decomposition products, but due to convection currents in the furnace gas atmosphere, the gas concentration around the sample would be changing continuously, and irregularly, giving irreproducible results. The presence of a gaseous-reactant or product in the furnace atmosphere would affect the reaction in a manner predictable from Le Chatelier's principle. The composition of the furnace atmosphere will also introduce a buoyancy effect which must be taken into account when measuring mass changes. This can be achieved by comparing the mass-change curve for the system being studied with that obtained with an inert substance in the place of the solid reactant. (c) Sample holder - the geometry of the sample holder can affect the rate of loss or admission of gaseous products or reactants and so change the rate of mass change. The material from which the sample holder is constructed may react with one of the products or reactants, or catalyse a change in one of these. (d) Sample mass the TG curve can be affected in three ways: (i) the larger the mass 
the greater the deviation of the sample temperature, during exothermic or endothermic reactions, from the linear temperature change.

(ii) The larger the mass the slower will be the rate of diffusion of gaseous products, or reactants, through the void space surrounding the solid particles. (iii) The larger the mass, the greater will be the thermal gradient throughout the sample, particularly for materials of low thermal conductivity. (e) Sample packing - may affect the partial pressure gradient throughout the mass of the sample. The more loosely and thinly the sample is packed, the smaller this effect will be.

\subsubsection{Differential Thermal Analysis (DTA)}

This is a "technique in which the temperature of a sample, compared with the temperature of a thermally inert material, is recorded as a function of the sample, the inert material, or furnace temperature as the sample is heated or cooled at a uniform rate" ${ }^{16}$. The temperature changes result from exothermic or endothermic enthalpic transitions or reactions, e.g. phase changes, decomposition reactions, oxidation or reduction reactions. Any temperature difference between the sample and reference material is monitored by two thermocouples, one close to the sample and one close to the reference material, differentially coupled. The output trace (the DTA curve) is a record of temperature difference between sample and reference against, usually, the temperature of the reference. A typical DTA curve showing an exothermic change is illustrated in Fig. 2.2. $A B$ is the pre-transition baseline and $C D$ is the posttransition baseline, the latter showing some base-line drift. The procedural initial deviation temperature is $T_{i}$ and the final deviation temperature of the curve is $T_{f}$. The peak maximum temperature is $\Delta \mathrm{T}_{\max }$ and the peak height is $\Delta \mathrm{T}$, i.e. the maximum temperature 
difference between the sample and reference. In practice $\Delta T$ values are recorded in $\mu \mathrm{V}$ i.e. the thermocouple output, and a correlation curve, Fig. 2.3, must be used to convert these to temperature differences because the thermocouple output is not linear with temperature.

The number, shape and position of the various endothermic and exothermic peaks with reference to the temperature may be used as a means of qualitative identification of the substance under investigation. The area under the peak is proportional to the heat change involved and may be used for the quantitative determination of heats of reaction, after suitable calibration. The heat of transition (or reaction) can be determined from equation $2.3^{56}$

$$
\begin{aligned}
\Delta \mathrm{H} . \mathrm{m}=\mathrm{KA} & \\
\text { where } \Delta \mathrm{H} & =\text { heat of transition (or reaction) } \\
\mathrm{m} & =\text { mass of sample } \\
\mathrm{K} & =\text { calibration coefficient } \\
\mathrm{A} & =\text { curve peak area }
\end{aligned}
$$

However, determination of the calibration coefficient to a precision of $\pm 1 \%$ at a $95 \%$ confidence level has been calculated to require 30 samples for the calibration 61 .

As with thermogravimetry, differential thermal analysis results are affected by a wide variety of variables. Amongst the more important are the following: (a) Heating rate increases will

(i) increase the $\mathrm{Ti}, \Delta \mathrm{T}_{\max }$ (or $\Delta \mathrm{T}_{\min }$ ) and $\mathrm{T}_{\mathrm{f}}$ temperatures

(ii) decrease peak resolution (iii) increase sensitivity, in that small transitions may be detected. (b) Furnace atmosphere. The peak temperature and shape of the peak for a reaction involving a gaseous component will be affected by pressure changes, flow rates, 


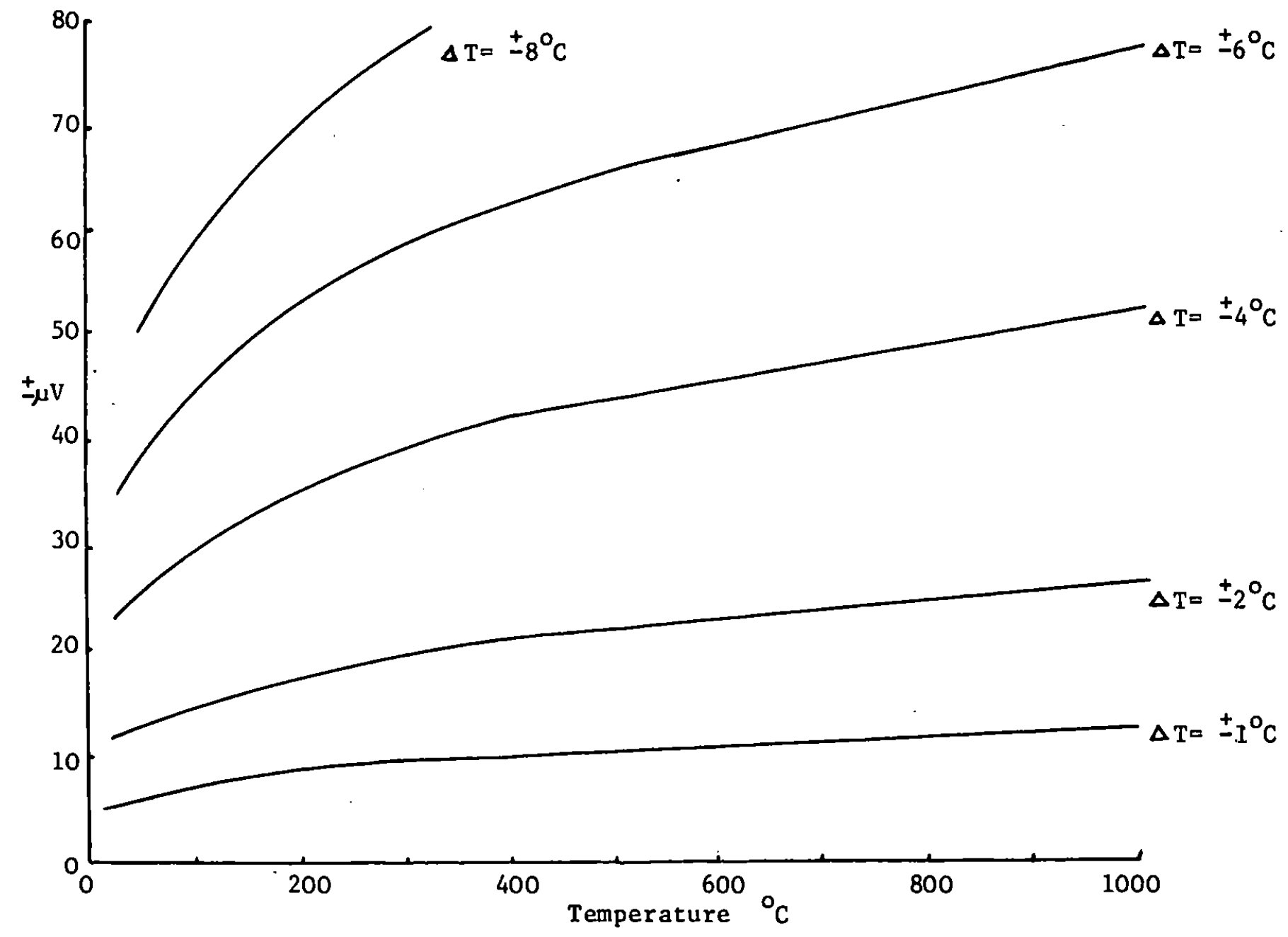


presence of the gaseous component or some other interacting gas.

(c) Sample holders influence the rate of transfer of heat out of or into the sample and so affect the shape of the DTA curve. In general, metal sample holders tend to give smaller peaks at higher temperatures for endothermic reactions. The relative advantages and disadvantages of block or isolated sample holders have been reviewed by Wendlandt 56 . (d) The positioning and size of the thermocouples can make considerable differences to the DTA curves, as during enthalpic changes the temperature of the sample is not uniform throughout ${ }^{62}$. The two thermocouples should be as close as possible to the centre of their respective samples. The thickness of the thermocouple wire must be such that the thermal conductance is not too large and the electrical conductance is not too small. (e) The packing of the sample affects its thermal conductivity and hence the DTA peak area.

\subsubsection{Simultaneous thermogravimetry and differential thermal analysis}

To reduce the effects of variations in experimental conditions when correlating TG and DTA data on the same substance, it is advantageous to carry out both measurements simultaneously on the same instrument. However, as the sample for DTA measurements should be packed around the thermocouple, this is not always satisfactory for TG studies of reactions involving gases, where a thin layer is preferable to reduce diffusion effects. The use of simultaneous TG-DTA measurements cannot be used always to replace TG and DTA performed separately.

\subsubsection{The Massflow thermobalance}

The equipment employed to study the thermal stabilities of the alkaline earth metal sulphites and the reactivity of a number of alkaline earth metal compounds with sulphur dioxide was a StantonRedcroft Massflow Thermobalance Model MF-H5 Fig. 2.4. 
Figure 2.4. Diagram of Stanton-Redcroft Massflow balance MF-H5

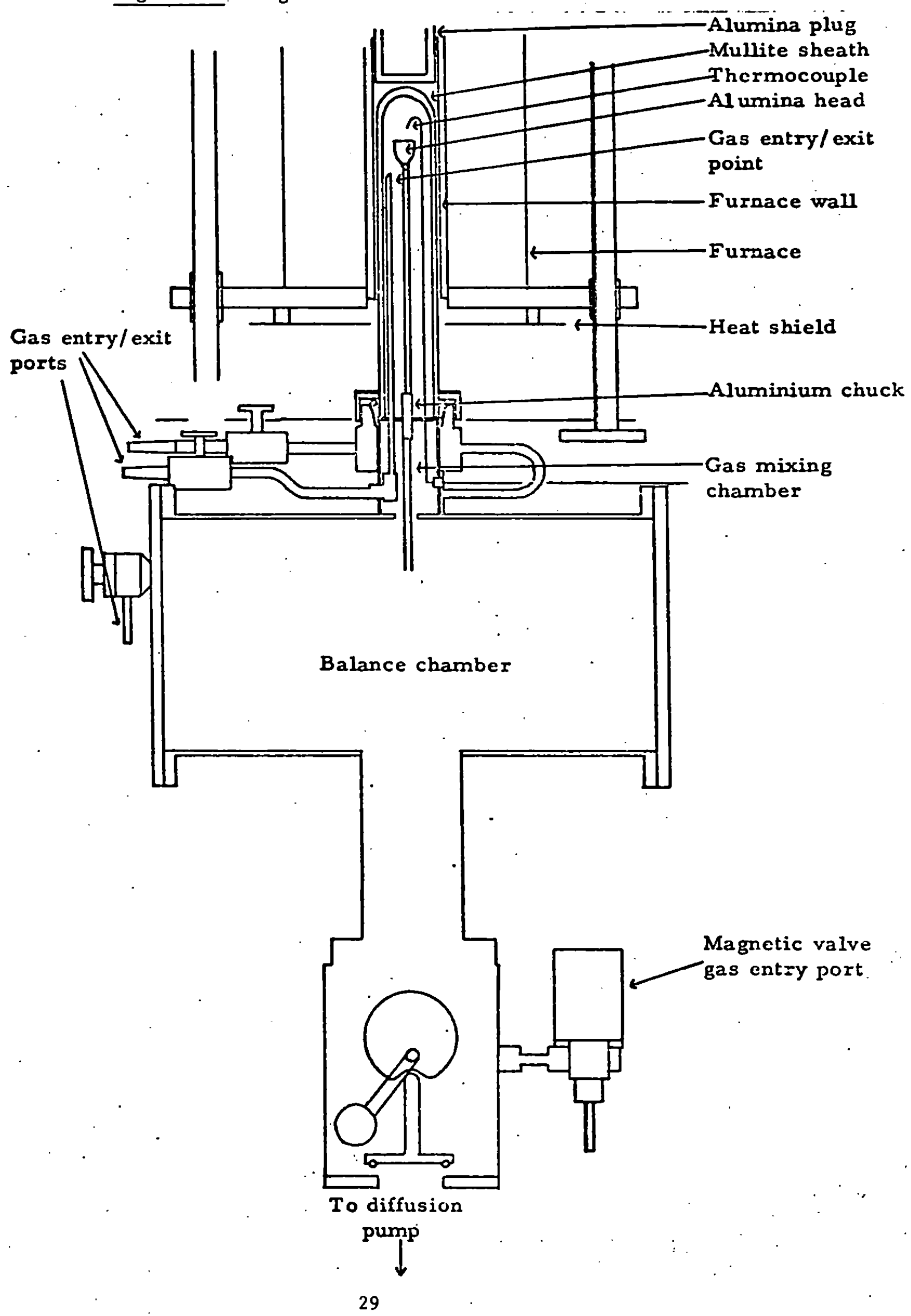


The balance chamber was a 10-gauge copper tube with $10 \mathrm{~mm}$ thick doors sealed with "0" rings. A water-cooled silicone "0" ring seals the mullite reaction sheath to the chamber. There are four gas entry or exit ports, two to the reaction sheath and two to the main balance chamber; all are fitted with valves.

The thermobalance design incorporates two beams, one inside the chamber and the other outside, the two being coupled by a magnetic link. Changes in weight occurring on the inner beam are transferred to the outer beam, detected electronically and indicated by an arm with a full beam deflection of $20 \mathrm{mg}$ and sensitivity of $0.2 \mathrm{mg}$.

Automatic electric weight loading increases the range of the instrument to the equivalent of ten full beam deflections of gain or loss, without a decrease in sensitivity. This enables weight gains or losses of up to $200 \mathrm{mg}$ to be followed.

During operation, the balance automatically arrests and releases itself every five minutes to check that it is not sticking and to improve the sensitivity with very small weight changes.

When the thermobalance is used with the DTA attachment, the sample holder consists of an aluminium block $20 \mathrm{~mm}$ diameter and $13 \mathrm{~mm}$ in depth with two wells each $6.5 \mathrm{~mm}$ diameter and $10 \mathrm{~mm}$ in depth to take the crucibles. The aluminium head is. coupled to the internal balance by alumina and silica rods joined by an aluminium chuck. Two Pt/13\% Rh.Pt thermocouples are employed to detect the temperature difference between sample and reference ( $\alpha$-alumina). $0.025 \mathrm{~mm}$ compensated platinum wires pass from the thermocouples down the inside of the alumina and silica rods to the outside of the balance chamber. Further compensated leads are used to connect the thermocouples leads with a DC amplifier and a constant-reference-temperature ice-bath. 
The DC amplifier has seven pre-set ranges from $20-1000 \mu \mathrm{V}$; the $100 \mu \mathrm{V}$ setting was used for most measurements. A single channel Leeds-Northrup Speedomax-W chart recorder is used with a switching unit, enabling the differential output to be recorded for $4 \min 55 \mathrm{~s}$ and then the temperature recorded for $5 \mathrm{~s}$.

Two matched $(0.8 \mathrm{~g})$ platinum crucibles with dimples were used to contain the sample and reference material. The crucibles were placed in the $6.5 \mathrm{~mm}$ wells of the alumina head with the thermocouples sitting in the dimples, so that they were effectively surrounded by the sample. Alumina crucibles were also employed for reactions in atmospheres containing sulphur dioxide and air, to prevent the catalytic oxidation of sulphur dioxide to sulphur trioxide by platinum.

With the four gas entry and exit ports it was possible to keep a nitrogen, or air, atmosphere in the balance chamber and add the sulphur dioxide to the reaction chamber. By means of the vacuum pumps, the system could be flushed out and then known atmospheres introduced. The gases used were all obtained from pressurised cylinders fitted with flow regulators. The gas flow was monitored by rotameters and adjusted as necessary. In addition, the sulphur dioxide flow rates were periodically monitored on the out let side by means of a Leco sulphur determinator (see section 2.7 ).

The vacuum equipment consisted of a single-stage rotary and diffusion pump with Pirani and Penning gauges. The rotary pump enabled the pressure to be reduced to 10-1 $\mathrm{Pa}$ and with the diffusion pump to about $0.01 \mathrm{~Pa}$.

The platinum-rhodium bifilar wound furnace had a $50 \mathrm{~mm}$ bore and was closed at the top with a 100 mon deep alumina plug filled with a-alumina powder. The maximum temperature the furnace was rated for 
was $1350^{\circ} \mathrm{C}$. The temperature was controlled by a Stanton-Redcroft Eurotherm temperature controller with a sensing $\mathrm{Pt} / 13 \% \mathrm{Rh} . \mathrm{Pt}$ thermocouple trapped between the mullite reaction sheath and the furnace wall. The controller enabled the heating rate to be continuously varied from $1^{\circ}$ to $20^{\circ} \mathrm{Cmin}^{-1}$ with the maximum temperature pre-selected and subsequently held constant.

Initially, a set of calibration curves were recorded to determine the buoyancy corrections for the thermogravimetric work. This was done by using the standard reference material in both the sample and reference crucibles and a heating rate of $5^{\circ} \mathrm{C}$ min ${ }^{-1}$. This procedure was repeated with the appropriate gas atmospheres and flow rates. These correction curves were then applied to the experimental results.

\subsection{Surface area, porosity and particle size'}

\subsubsection{Determination of surface area}

Surface areas of samples were estimated from the adsorption isotherms using the Brunauer, Emmett and Teller ${ }^{63}$ (BET) approach. The adsorption isotherms, which show the relationship between the amount of nitrogen adsorbed, at a fixed temperature (77K), and a known pressure, were constructed for each sample from gravimetric measurements made on an electrical sorption balance.

As the nitrogen was below its critical temperature the equation expressing the isotherm was of the type 64

$$
\begin{aligned}
x=f\left(p / p_{0}\right) & T, \text { gas, solid } \\
\text { where } x & =\text { weight of nitrogen adsorbed } \\
p & =\text { equilibrium pressure } \\
P_{0} & =\text { saturated vapour pressure } \\
T & =\text { temperature }
\end{aligned}
$$


The BET method is an extension of the work of Langmuir ${ }^{65}$, who regarded the surface of a solid as an array of adsorption sites of equal energy, each site being capable of adsorbing one molecule. The BET theory extended the mechanism to second and higher layers and, in common with the Langmuir theory, the rates of condensation and evaporation were assumed to be equal when equilibrium was reached. Making the following assumptions led to the BET equation. (i) The heat of adsorption in all layers above the first was equal to the latent heat of condensation. (ii) The evaporation-condensation constants in all layers above the first were identical. (iii) When the equilibrium pressure, $P$, became equal to the saturated vapour pressure, $P_{0}$, the adsorbate vapour condensed as an ordinary liquid on to the adsorbed film, so that the number of molecular layers became infinite on the surface.

The BET equation may be expressed as

$$
\frac{\mathrm{P}}{\chi\left(\mathrm{P}_{\mathrm{o}}-\mathrm{P}\right)}=\frac{1}{\mathrm{C} \chi_{\mathrm{m}}}+\frac{\mathrm{C}-1}{\mathrm{C} \chi_{\mathrm{m}}} \cdot \frac{\mathrm{P}}{\mathrm{P}_{\mathrm{o}}}
$$

$$
\begin{aligned}
\text { where } x_{m}= & g \text { of adsorbate per } g \text { of solid, when there } \\
& \text { is a complete monolayer of adsorbate on the } \\
& \text { surface of the solid. } \\
x= & g \text { of adsorbate per } g \text { of solid } \\
C \quad= & \text { a constant, which may be equated to the } \\
& \text { relative life times of molecules in the first } \\
& \text { and higher layers, and is related to the net } \\
& \text { heat of adsorption. }
\end{aligned}
$$

If equation 2.5 is plotted in the form $x / x_{m}$ against $P / P_{0}$, the physisorption isotherm produced can be classified as belonging to one of six types, Fig. 2.5 (five are members of the Brunauer, Deming, Deming, Teller ${ }^{66}$, [BDDT] classification plus the stepwise isotherm identified more recent $l y^{67}$ ). The isotherms determined in the present work were either of Type II or Type IV. The monolayer capacity, $x_{m}$, for both 
Figure 2.5 Types of physisorption isotherms

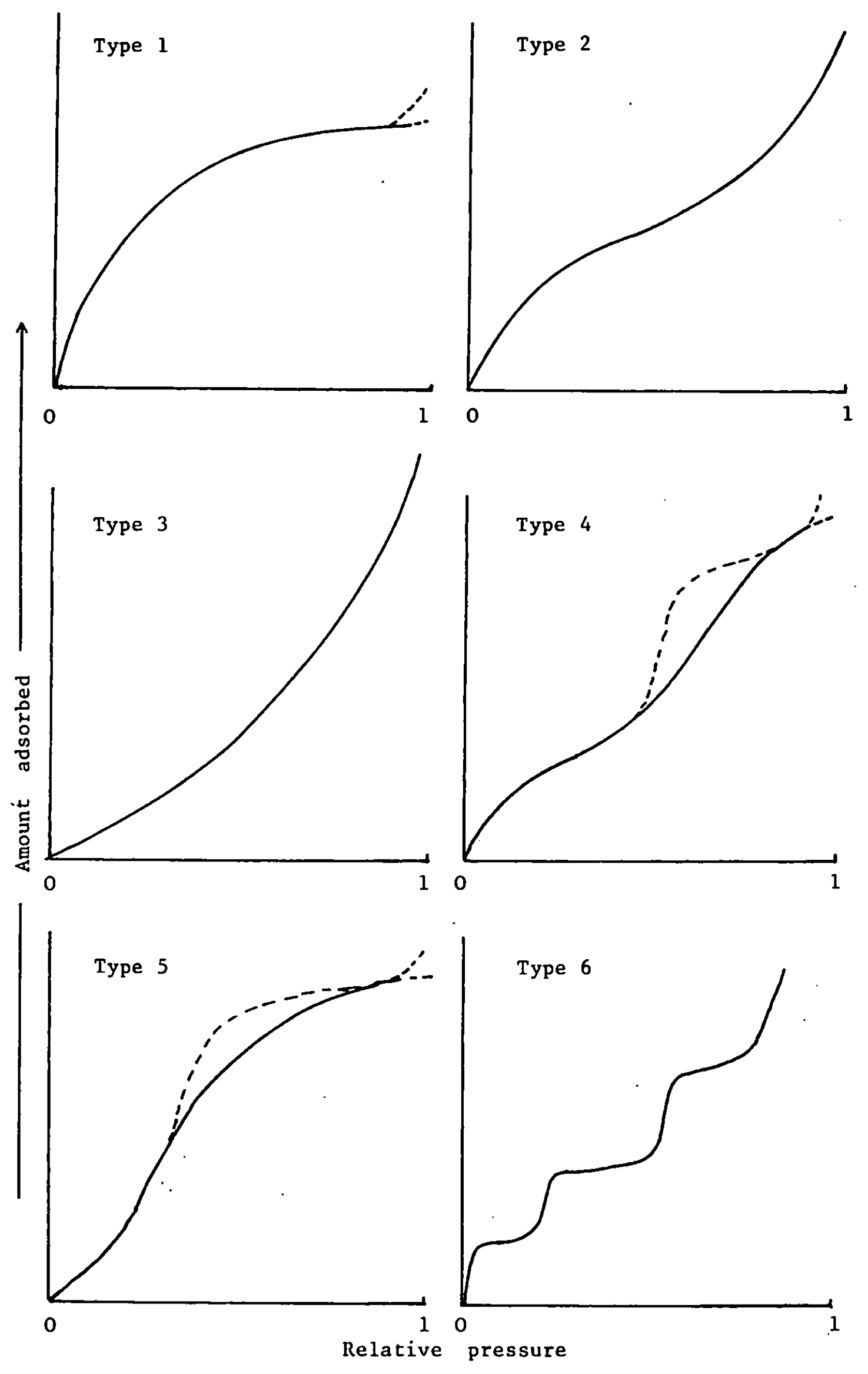


these types may be found by plotting $\frac{P}{\Sigma\left(P_{0}-P\right)}$ against $P / P_{0}$ and determining the slope and intercept for values of $P / P_{0}$ below about 0.3 .

From the value of the monolayer capacity, $x_{m}$, it was possible to find the specific surface, $S$, of the solid, being defined as the surface area in square metres of one gram of solid. The relationship used was

$$
\begin{array}{rl}
\mathrm{S}=\frac{\mathrm{x}_{\mathrm{m}}}{\mathrm{M}} \cdot \mathrm{N} \cdot \mathrm{Am} & 2.6 \\
\text { where } \mathrm{M}= & \text { molecular weight of adsorbate } \\
\mathrm{N}= & \text { Avogadros number } \\
\mathrm{Am}= & \text { area occupied by one molecule of adsorbate in } \\
& \text { the completed monolayer. A value of } 0.162 \mathrm{~nm}^{2} \\
& \text { at } 77 \mathrm{~K} \text { was taken for nitrogen } 67
\end{array}
$$

A discussion of the theoretical significance of the BET method has been given by Gregg and Sing $64,67,68$.

\subsubsection{The sorption balance}

The sorption balance was designed and constructed for the determination of surface areas within the range $0.2 \mathrm{~m}^{2} \mathrm{~g}^{-1}$ to $1000 \mathrm{~m}^{2} \mathrm{~g}^{-1}$ using samples of $0.25 \mathrm{~g}$. The balance head used was a "CI microforce balance Mark $2 B^{\prime \prime}$ with five weight ranges, 0-25 $\mu \mathrm{g}$ to 0-100 $\mathrm{mg}$ with sensitivities of $1 \times 10^{-7} \mathrm{~g}$ and $5 \times 10^{-4} \mathrm{~g}$ respectively. In practice there was too much vibration in the building for the lowest weight range to be operated satisfactorily.

The sample was placed in an aluminium foil bucket suspended from the balance with a fine pyrex fibre $(27 \mathrm{~cm}$ long). This enabled the sample to be at least $15 \mathrm{~cm}$ below the level of the liquid nitrogen, keeping the temperature to within $\pm 0.1 \mathrm{~K}$ as previously determined by Glasson $^{69}$. A perspex counterweight was suspended from the other arm of the balance. The balance head was coupled by taps and glass tubing 
to a two-stage rotary pump (enabling the pressure to be reduced to $0.1 \mathrm{~Pa}$ ), and to a nitrogen reservoir and gauges, the nitrogen pressure being measured by a mercury manometer.

After the sample had been mounted on the balance, the system was evacuated and the sample outgassed at $150^{\circ} \mathrm{C}$ for $20 \mathrm{~min}$ (except for magnesium sulphite hexahydrate samples which were held at room temperature to reduce the rate of dehydration). After cooling to room temperature, the balance limb containing the sample was immersed in liquid nitrogen and allowed to reach equilibrium. Nitrogen was admitted to the system in amounts which gave pressure increases of the order of $5000 \mathrm{~Pa}(40 \mathrm{~mm} \mathrm{Hg})$ and in each case the weight change was recorded when equilibrium had been reached. Readings were taken up to pressures of $3 \times 10^{4} \mathrm{~Pa}$ or $9.5 \times 10^{4} \mathrm{~Pa}$ depending on whether specific surface or porosity determinations were to be made. Readings were corrected for buoyancy effects.

For some of the studies carried out in this thesis, the balance constructed by Glasson and described in previous work ${ }^{3}$ was used in thermal stability and surface area determinations.

\subsubsection{Determination of porosity}

The hysteresis loop of the Type IV isotherm is associated with capillary condensation in mesopores (Table 2.1) and this part of the isotherm was used for porosity measurements.

Table 2.1 IUPAC classification of pores according to their width 70

\begin{tabular}{|l|l|}
\hline Pore. Type & Pore Width \\
\hline Micropores & Less than approx. $2 \mathrm{~nm}$ \\
Mesopores & Between approx. $2 \mathrm{~nm}$ and approx,50 nm \\
Macropores & Above approx. 50 nm \\
\hline
\end{tabular}


Comprehensive reviews of the theory of physical adsorption of gases by porous solids have been published by Gregg and Sing $64,67,68$.

If the pores were all cylindrical, the Kelvin equation ${ }^{71}, 2.7$, applies

$$
\begin{aligned}
& \ln \left(\mathrm{P} / \mathrm{P}_{0}\right)=-\frac{2 V_{Y}}{\mathrm{rRT}} \cdot \cos \phi \\
& \text { where } \mathrm{P}_{0}=\text { saturated vapour pressure of adsorbate at } \\
& \text { temperature } \mathrm{T} \mathrm{K} \text { of the system } \\
& \mathrm{P}=\text { vapour pressure in the capillary } \\
& \mathrm{V}=\text { molar volume of liquid adsorbate } \\
& \gamma=\text { surface tension of liquid adsorbate } \\
& \phi \quad=\text { angle of contact between liquid and capillary } \\
& \mathrm{R}=\text { universal gas constant } \\
& \mathrm{r}=\text { radius of cylindrical pore }
\end{aligned}
$$

Equation 2.7 is the limiting case of the more general expression, 2.8.

$$
\begin{aligned}
\frac{d v}{d s}=-\frac{V y}{R T \ln \left(P / P_{0}\right)} \cdot \cos \phi & 2.8 \\
\text { where } v= & \text { volume of capillaries } \\
s= & \text { surface area of capillary walls per g solid } \\
& {[\text { i.e. the specific (internal) surface] }}
\end{aligned}
$$

The pore will have a layer of adsorbate already present before capillary condensation occurs, and a layer left after evaporation of the liquid, therefore the "Kelvin radius", $r$, must be corrected.

$$
\begin{aligned}
r_{p}=r+t & \\
\text { where } r_{p} & =\text { true pore radius } \\
t & =\text { thickness of adsorbed layer }
\end{aligned}
$$

The value of $t$ may be obtained from the $t$ curve of Lippens and de Boer ${ }^{72}$ or.by calculation from equation $2.10^{64}$

$$
t=3.5\left[\frac{5}{2.303 \log \left(\mathrm{P}_{0} / \mathrm{P}\right)}\right]^{1 / 3}
$$




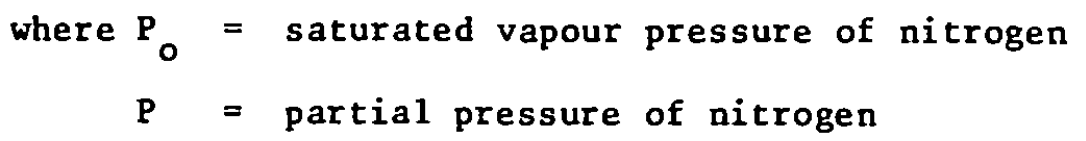

The method of calculation of pore size distribution followed that detailed by Gregg and $\operatorname{Sing}^{64}$ (p 162-172).

\subsubsection{Estimation of particle size}

A. From specific surface measurements

The assumption was made that the samples were non-porous solids though this was not true for the specimens giving Type IV isotherms, hysteresis being a sign of porosity. The specific surface of a nonporous solid must be directly related to the particle size and shape. It would therefore be relatively easy to calculate the mean particle size if the particles were all of the same known shape. Assuming all the particles to be spherical then

$$
\begin{aligned}
& s=\frac{4 \pi(0.5 d)^{2} n}{\sqrt{4 / 3 \pi(0.5 d)^{3} p n}} \\
& d=\frac{6}{p s}
\end{aligned}
$$

where $d=$ mean diameter of spherical particles

$$
\begin{aligned}
& \mathbf{P}=\text { density of solid } \\
& \mathbf{s}=\text { specific surface of solid } \\
& \mathbf{n}=\text { number of particles }
\end{aligned}
$$

Relationship 2.12 also holds for cubic particles when $d$ becomes the edge length of the cube. Other relationships may be derived for other particles of known shape. In practice, the wide variety of sizes and shapes found in a sample means that the expression of size on the basis of a single dimension inevitably leads to results which differ from the "true" values. However as interest was only directed to general trends in particle size changes, between similar types of particles, simplifications were acceptable. The use of specificsurface coefficients ${ }^{67}$ to take account of particle shape variation has 
been suggested as these can lead to closer agreement between sizes derived from specific surface measurements and from microscopic observations. For trend analysis this is of no advantage unless different factors are introduced for different samples.

B. From $\mathrm{X}$-ray line broadening

The diffraction peak obtained from a powder sample (section 2.6) always shows line broadening due to instrumental factors ${ }^{73}$ such as beam divergence, slit widths, specimen size. In addition, if the crystallite size is smaller than about $200 \mathrm{~nm}$ further broadening may be produced. Larger crystals, which do not have lattice defects, contain numerous parallel planes, with constant interatomic distances, giving a sharp diffraction maximum. With smaller crystallites the number of atomic planes per crystallite is less and there is incomplete reinforcement of the waves scattered by successive planes which leads to line broadening.

Line broadening due to cubic crystallites may be expressed by equation 2.13

$$
\begin{aligned}
B_{t}=\frac{C \lambda}{d \cos \theta} & \\
\text { where } B_{t} & =\text { broadening } \\
C & =\text { constant (approximately } 1 \text { ) } \\
\lambda & =\text { X-ray wavelength } \\
d & =\text { edge length of crystallite } \\
\theta & =\text { Bragg angle }
\end{aligned}
$$

Thus line broadening is negligible if $\mathrm{d}>10^{-6} \mathrm{~m}$.

The instrumental broadening was determined using a single calcite crystal. The Jones ${ }^{74}$ method was employed to calculate the average crystallite size. 
Copper $\mathrm{K}_{\alpha}$ radiation was used. This was composed of a doublet with a finite breadth, $z$, which was calculated from equation 2.14.

$$
z=c \tan \theta \quad 2.14
$$

where $\theta=$ angle of calcite diffraction peak used

$$
c=\text { constant ( } 0.285 \text { for copper } \mathrm{K}_{\alpha} \text { radiation) }
$$

Using the Jones correction curve, Fig. 2.6, of $b / B_{0}$ against $z / B_{0}$, a corrected line breadth, $b$, was obtained $~ B_{0}$ was the measured half-peak breadth of the calcite peak). A further correction for instrumental broadening was applied by the curve $B_{t} / B$ against b/B, Fig. 2.7, where $B_{t}$ was the true diffraction breadth, $b$ was the corrected breadth for calcite and $B$ was the measured half-peak breadth for the specimer. The mean crystallite size could then be calculated from equation 2.13. C. From examination using optical and electron microscopes.

Both these methods allowed direct observation of the particles or aggregates, so that the size and shape characteristics could be determined. However, this sort of analysis is very time-consuming and the return of information obtained was not thought worthwhile in the present study. Therefore, only general observations of size and shape variations were made.

In the case of optical microscopy, the small size of many of the particles made observation difficult.

The method of preparation of the samples for the electron microscope (section 2.4.3) meant that the larger particles were not present on the grids, thus biasing the observations towards the smaller particle sizes.

\subsection{Electron Microscopy}

\subsubsection{The electron microscope}

Samples were examined by transmission in a Philips EM 300 electron microscope. This had a vertical tube, with the electron gun at the top 
Figure 2.6 Correction of observed line breadth for fact it is formed by a $K_{\alpha}$ doublet

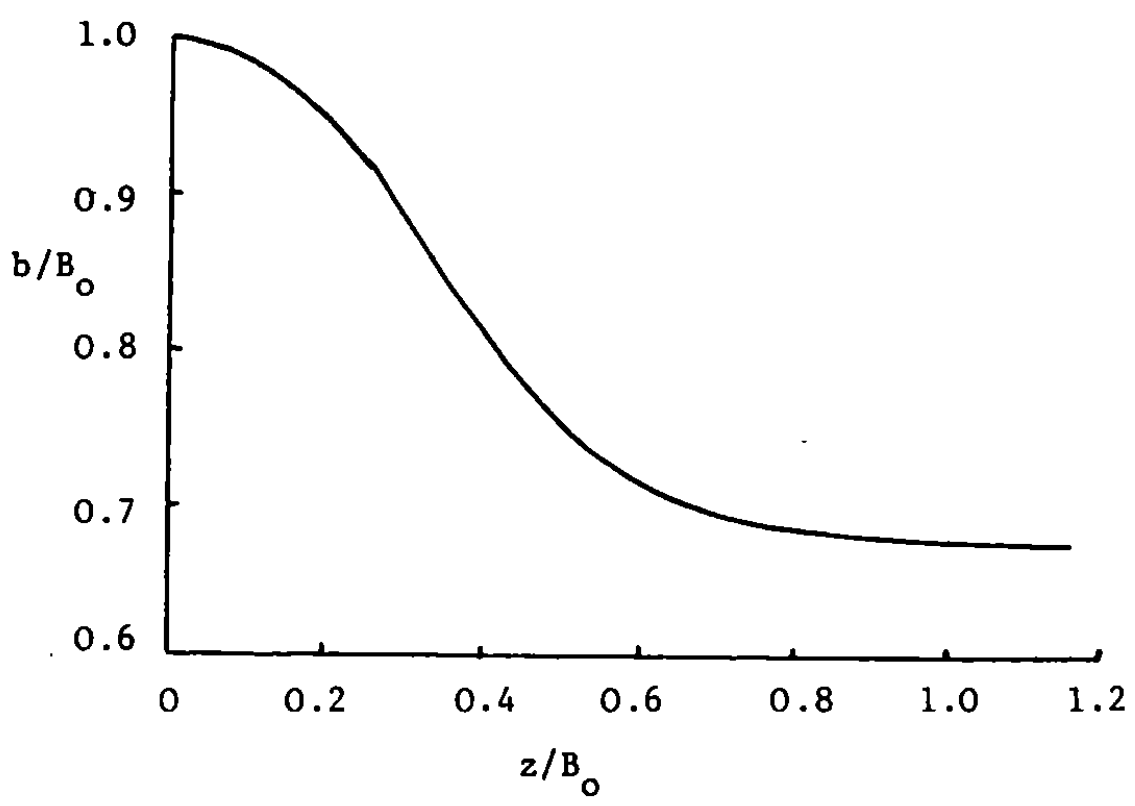

Figure 2.7 Correction of line breadth for effect of instrumental broadening

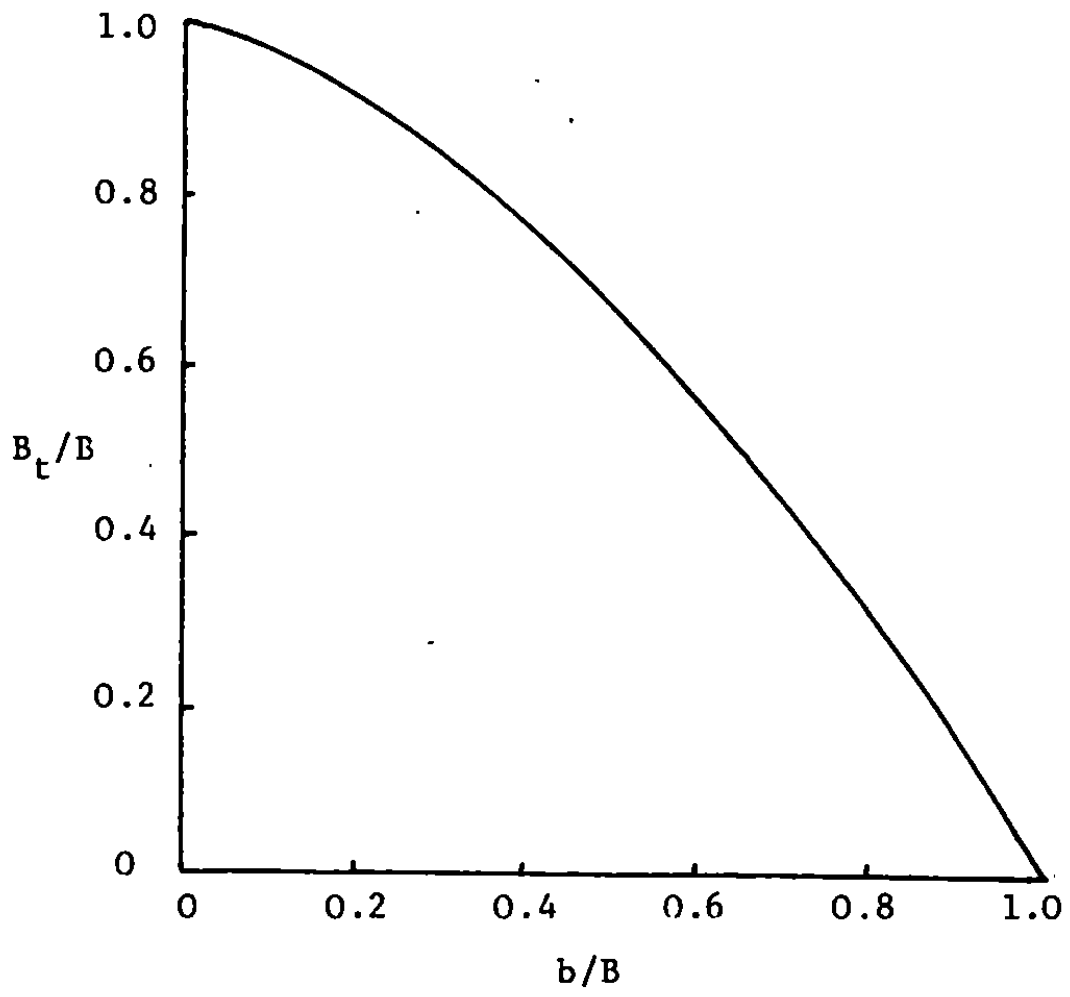


and a fluorescent screen at the bottom to allow viewing of the sample images. An accelerating voltage of $80 \mathrm{kV}$ was used and the appropriate magnification factor was selected for the specimen under observation. The specimens were prepared as detailed in section 2.4.3.

The microscope could be used either in transmission mode, which allowed the normal transmission image to be studied, or in the diffraction mode, which produced an electron diffraction image of the crystallites under observation. Electron diffraction studies were unsatisfactory with many samples because they were too thick (>30 $\mathrm{nm})$ to give diffraction patterns. The focussed images were photographed as necessary, using either $35 \mathrm{~mm}$ film or $31 / 3^{\prime \prime}$ by $4^{\prime \prime}$ plates (or cut film). The $35 \mathrm{~mm}$ camera was quicker to operate (an advantage for observations made when the hot-stage was being used) than the plate camera, but the quality of the photomicrographs was not so high as with the larger plates.

\subsubsection{Hot-stage electron microscopy}

The electron microscope was mainly used in conjunction with the Philips PW 6550 heating holder which allowed the sample to be studied as it was heated inside the electron microscope. In the heating holder the specimen grid was clamped to a small furnace element. A thermocouple was welded to the furnace and was used to monitor the temperature. The temperature control unit contained the current supply for the heater and the circuitry necessary to measure the voltage generated by the thermocouple. Nickel specimen grids, with a carbon film, were mounted in the holder between platinum conduction rings and these were held in position by a spring clip. The conduction rings were used primarily to prevent welding of the grid to the furnace element.

The temperature was raised by increasing the applied voltage with the current held at a constant value. The maximum temperature attainable was $1000^{\circ} \mathrm{C}$. 
A number of problems were found in the use of this equipment. (a) The temperature of the specimen was not necessarily the same as the temperature of the grid. This was particularly the case for crystals directly under the electron beam which were, therefore, absorbing energy from the beam. At high magnifications the beam was focussed over a very small area and the more electron-opaque materials absorbed a relatively large amount of energy. As a result, it was not always possible to use the higher magnifications to study the lower temperature reactions. (b) During and after temperature changes, the position of the specimen relative to the beam changed, i.e. there was specimen drift. This meant that though it was possible to observe the particles, and any changes occurring, on the fluorescent screen, it was very difficult to obtain good quality photomicrographs. During the time it took to operate the camera, the particles would have moved slightly and no longer be in sharp focus. This was an acute problem at high magnifications where focussing was a very sensitive operation. Observations over a wide temperature range required long periods at each temperature, to wait for the drift to be reduced to acceptable proportions. In general, the smaller the increase in temperature, the shorter the wait. The photographic recording of changes as they actually happened posed great problems.

The information provided by the use of the heating holder could only be considered as qualitative as far as relating observed changes to temperature was concerned.

\subsubsection{Preparation of specimens}

Samples were dispersed in dry acetone, to prevent hydration and solution effects. The sample was added to a stoppered tube containing acetone and then dispersed by immersing the tube in an ultra-sonic bath. A drop of the suspension was transferred, by means of a freshly 
drawn micropipette, to a carbon film which was supported on a nickel grid. The acetone evaporated rapidly leaving the sample particles scattered over the carbon film.

For specimens being studied on the hot-stage nickel grids, $3.1 \mathrm{~mm}$ diameter, with 50 micron perforations were used, but for non-heating observations standard copper grids of the same dimensions were used (copper grids would fuse at the upper temperature range of the hotstage).

This method of preparation meant that the coarser particles and aggregates were not transferred to the grids. The size distribution observed with the electron microscope was, therefore, weighted towards the smaller size range.

\subsection{Optical Microscopy}

The thermal stabilities of the alkaline. earth. metal sulphites were studied, in air, at temperatures up to $350^{\circ} \mathrm{C}$ on a Reichert hotstage microscope. This was a low power polarising microscope with an electrically heated hot-stage. A control unit adjusted the applied voltage so that the temperature could be increased at varying rates. The temperature was read from specially constructed thermometers which fitted into the hot-stage and the instrument was calibrated with pure organic compounds of known melting points.

\subsection{X-Ray Diffraction}

\subsubsection{General theory}

Comprehensive surveys of the theory and practice of $\mathrm{X}$-ray diffraction as applied to single crystals and powder samples have been given by Stout and Jensen ${ }^{75}$, and Lipson and Steeple ${ }^{73}$.

Crystals consist of regular three-dimensional arrays of atoms 
in space. Points which have identical surroundings within a structure are known as lattice points. A collection of lattice points forms a crystal lattice. When adjacent lattice points are joined together a unit cell is obtained; this is the smallest convenient repeating unit of the structure. In general, the unit cell is a parallelepiped, but it may have a more regular shape.

The size and shape of a unit cell can be described by the lengths of $i$ ts three edges $(a, b, c)$ and the angles between them $(a, \beta, \gamma)$, i.e. the angle between $a$ and $b$ is $\gamma$. Crystals can be classified into seven crystal systems, Table 2.2 , according to the symmetry of their unit cells. When the actual atoms or molecules which are associated with each lattice point are taken into consideration further symmetry operations become possible to give a total of 230 space groups.

Table 2.2 Crystal systems

\begin{tabular}{|c|c|c|}
\hline Crystal system & $\begin{array}{l}\text { Conditions limiting } \\
\text { cell dimensions }\end{array}$ & $\begin{array}{l}\text { Characteristic } \\
\text { symmetry }\end{array}$ \\
\hline Cubic & $a=b=c \quad \alpha=\beta=\gamma=90^{\circ}$ & Four three-fold axes \\
\hline Tetragonal & $a=b \neq c \quad \alpha=\beta=\gamma=90^{\circ}$ & One four-fold axis \\
\hline Orthorhombic & $\alpha=\beta=\gamma=90^{\circ}$ & $\begin{array}{l}\text { Two perpendicular } \\
\text { two-fold axes or two } \\
\text { perpendicular planes } \\
\text { of symmetry }\end{array}$ \\
\hline Trigonal & $a=b=c \quad \begin{array}{l}\alpha=\beta=\gamma<120^{\circ} \\
\neq 90^{\circ}\end{array}$ & One three-fold axis \\
\hline Hexagonal & $\begin{array}{ll}a=b \neq c \quad & \alpha=\beta=90^{\circ}, \\
& \gamma=120^{\circ}\end{array}$ & One six-fold axis \\
\hline Monoclinic & $\begin{array}{ll}a \neq b \neq c \quad & \alpha=\beta=90^{\circ}, \\
\gamma \neq 90^{\circ}\end{array}$ & One two-fold axis \\
\hline Triclinic & $a \neq b \neq c \quad \alpha \neq \beta \neq \gamma \neq 90^{\circ}$ & One-fold only. \\
\hline
\end{tabular}


Various sets of parallel planes may be drawn through the lattice points. Each set of planes can be completely described by three integers, $h, k$ and $l$, known as the Miller indices, where the intercepts made by the plane with the unit cell edges are $a / h, b / k$, and $c / 1$ respectively. The plane, therefore, is described as the (hk1) plane and would produce the hkl X-ray reflection.

As the dimensions of a crystal lattice are of the same order of magnitude as the X-ray wavelength employed, the lattice behaves as a three-dimensional diffraction grating. A diffraction maximum is formed when the rays scattered from each plane of a set are in phase. The conditions for this maximum are given by Bragg's equation 76

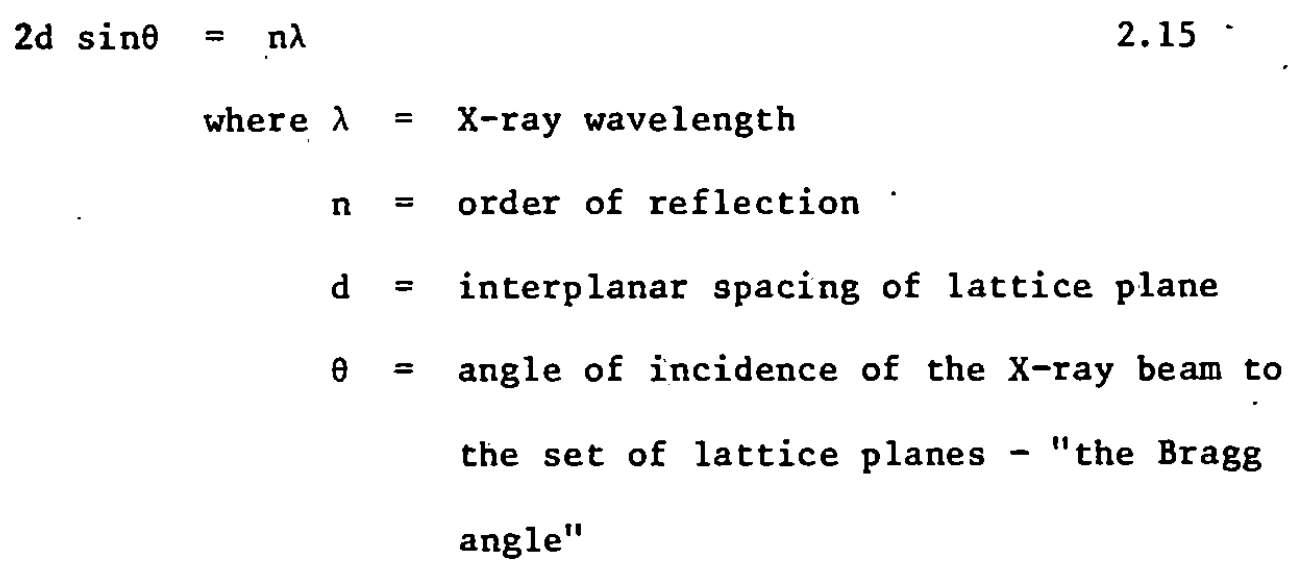

The intensity and distribution of the diffracted beam with respect to the Bragg angle, $\theta$, is characteristic of a particular structure. For single crystals, the diffraction caused by a set of lattice planes is a single beam. For a powder, which can be considered to be a mass of randomly orientated crystals, the resulting diffraction will produce a cone of X-rays, with its apex at the specimen and its axis in the direction of the incident $X$-ray beam. Therefore, on a photographic plate the single crystal produces individual spots and the powder gives circles (or curved lines). The larger the crystals in the powder, the more "spotty" is the line.

Powder diffraction patterns of many crystalline materials are listed in the ASTM tables ${ }^{77}$, thus enabling phases to be identified. 
As shown in section 2.3 .4 , broadening of the diffraction peaks may be used to estimate the size of the crystallites in the powder.

\subsubsection{Procedure for $X$-ray powder diffraction}

The Hilger and Watts $\mathrm{X}$-ray. generator was fitted with a Philips $\mathrm{X}$-ray tube and copper target. Voltage and current settings of $40 \mathrm{kV}$ and $20 \mathrm{~mA}$ respectively were used. The X-rays generated were filtered with nickel foil to reduce the $K_{B}$ component, passed through a collimator and slits before striking the specimen mounted vertically at the centre of a $50 \mathrm{~cm}$ Berthold diffraction table. The diffracted rays were detected by a gas-filled proportional counter connected to a discriminator/ratemeter and a Honeywell chart recorder.

The table was aligned and calibrated with a single calcite crystal.

Specimens were prepared by mixing the powdered material with acetone and pouring the suspension on to a microscope cover slip. The acetone evaporated, leaving the sample adhering to the slip. (Occasionally a drop of the adhesive "Durofix" was added to the acetone/powder mixture to make the sample adhere to the slip.)

For phase composition analysis, the table was rotated at one degree per minute and the chart paper at thirty inches per hour; this gave a trace of the intensity of the diffracted radiation against Bragg angle, in degrees, with a spacing of 0.5 in per degree. The integrating time constant was 3 seconds.

For line broadening measurements the slits were reduced to a minimum to reduce the effect of instrumental broadening. The table was rotated at 0.1 degree per minute and the selected peak scanned. Chart speed was thirty inches per hour and integrating time constant 3 seconds. 


\subsubsection{Procedure for single crystal X-ray diffraction}

For single crystals, the directions of the emergent beams are sufficient to determine the unit cell dimensions; the systematic absences of reflections from certain planes provide information about the symmetry elements present in the crystal; whilst, a knowledge of the intensities of the individual diffracted rays is necessary for the determination of the atomic parameters of the structure. The directions and intensities of the diffracted beams may be recorded using photographic film or by the use of a diffractometer.

Oscillation photographs were taken by oscillating the crystal, mounted on a glass fibre, about one of its axial directions in a cylindrical camera. The diffraction maxima were arranged in layers and the spacing, $h$, between the layers was related to the cell dimension, $q$, along the crystal axis under consideration.

$$
\begin{aligned}
q= & \frac{n \lambda}{\sin \left(\tan ^{-1} \mathrm{~h} / \mathrm{r}\right)} \\
\text { where } \lambda & =\mathrm{x} \text {-ray wavelength } \\
\mathrm{r} & =\text { radius of camera } \\
\mathrm{n} & =\text { integer ("layer number") }
\end{aligned}
$$

More precise cell dimensions were later obtained from Weissenberg photographs calibrated with gold wire.

Weissenberg photographs of the individual layers shown on the oscillation photographs were taken by screening all other layers and photographing the required one, while the film was moved in conjunction with the rotation of the crystal. An Enraf-Nonius Weissenberg camera was used in conjunction with copper $\mathrm{Ka}$ radiation. The zero and first layer Weissenberg photographs taken about two separate axes were used to determine the space group from the systematic absences. 
The density of the crystals was measured by the flotation method. From a knowledge of the cell dimensions, molecular weight and density it was possible to determine the number of molecules per unit cell.

$$
\begin{aligned}
z=\frac{\rho V N}{M} & \\
\text { where } z & =\text { number of molecules per unit cell } \\
\rho & =\text { density of crystal } \\
V & =\text { volume of unit cell } \\
N & =\text { Avogadros Number } \\
M & =\text { molecular weight }
\end{aligned}
$$

Intensities were collected with the Weissenberg camera, using a four-film pack to extend the range of intensities collected at one time. The more intense reflections had their intensities attenuated by each successive film until they were reduced to measurable values. The crystal was mounted about each axis in turn and intensity data collected from a number of layers. The intensities were measured by comparison with the intensities of a calibrated set of spots. The calibrated spots were produced by exposing different portions of a film to the X-rays diffracted by a single set of planes for a series of known exposure times.

The measured values were corrected for a number of effects. (i) The unpolarised incident $\mathrm{X}$-ray beam is partially polarised on diffraction by a crystal. This causes a diminuition of the intensity which increases with the angle of reflection. The phenomenon is called the polarisation effect. (ii) The Lorentz effect is caused by the relative time any crystal plane spends within the narrow angular range over which reflection occurs and the value depends upon the position of the plane and the intensity collecting device used. The Lorentz and polarisation factors are normally applied together when the corrections are made. A prepared computer program for these corrections was used. (iii) The spots on the higher layer Weissenberg 
photographs are extended on one half of the film and compacted on the other half. The extended spots were measured and the Philips spot shape correction was applied. A program was written to carry out this correction. (iv) Absorption and extinction effects were not corrected.

The intensities from different layers were put on a common scale by recalculating the corrected values so that reflections common to more than one layer had the same values. These scaled and corrected values were used to compute a three-dimensional Patterson map. This enabled the positions of the calcium atoms to be determined. A series of Fourier synthesis were computed and from the electron density maps produced, the positions of the sulphur and oxygen atoms were eventually determined.

The details for solving the structure of calcium sulphite hemihydrate are provided in Chapter Three.

\subsection{Fluidised Bed Studies}

A fluidised bed system which could operate at temperatures up to $400^{\circ} \mathrm{C}$ was constructed to study the absorption of sulphur dioxide by limestone and related commercial materials. A schematic diagram of the apparatus is given in Fig. 2.8.

The fluidised bed, $F$, was contained in a glass tube 400 m long, $35 \mathrm{~mm}$ diameter, above a porosity 2 sintered glass disc, which acted as a gas distributor. The reaction tube was surrounded by two 750 watt electrical tube heaters, A, with adjustable heat outputs. The upper portion of the reaction tube was insulated with removable glass fibre tubing. Above the reaction tube there was an expansion chamber, E, to reduce the carry-over of fines by the gas stream. The temperature of the fluidised bed was measured by a chromel-alumel thermocouple, $T$, in a glass sheath to protect it from the action of the bed contents. The. gases were supplied from pressurised containers fitted with flow:valves 
KEY FOR Figure 2.8

A Tube heaters

B Pre-heater

C Water-cooled condenser

D $\mathrm{SO}_{2}$ absorbing solution $\left(6 \% \mathrm{H}_{2} \mathrm{O}_{2}\right)$

E Expansion chamber

F Fluidised bed

L Leco sulphur determinator

T Thermocouple

W Water bath 
Figure 2.8 Apparatus used in fluidised-bed studies

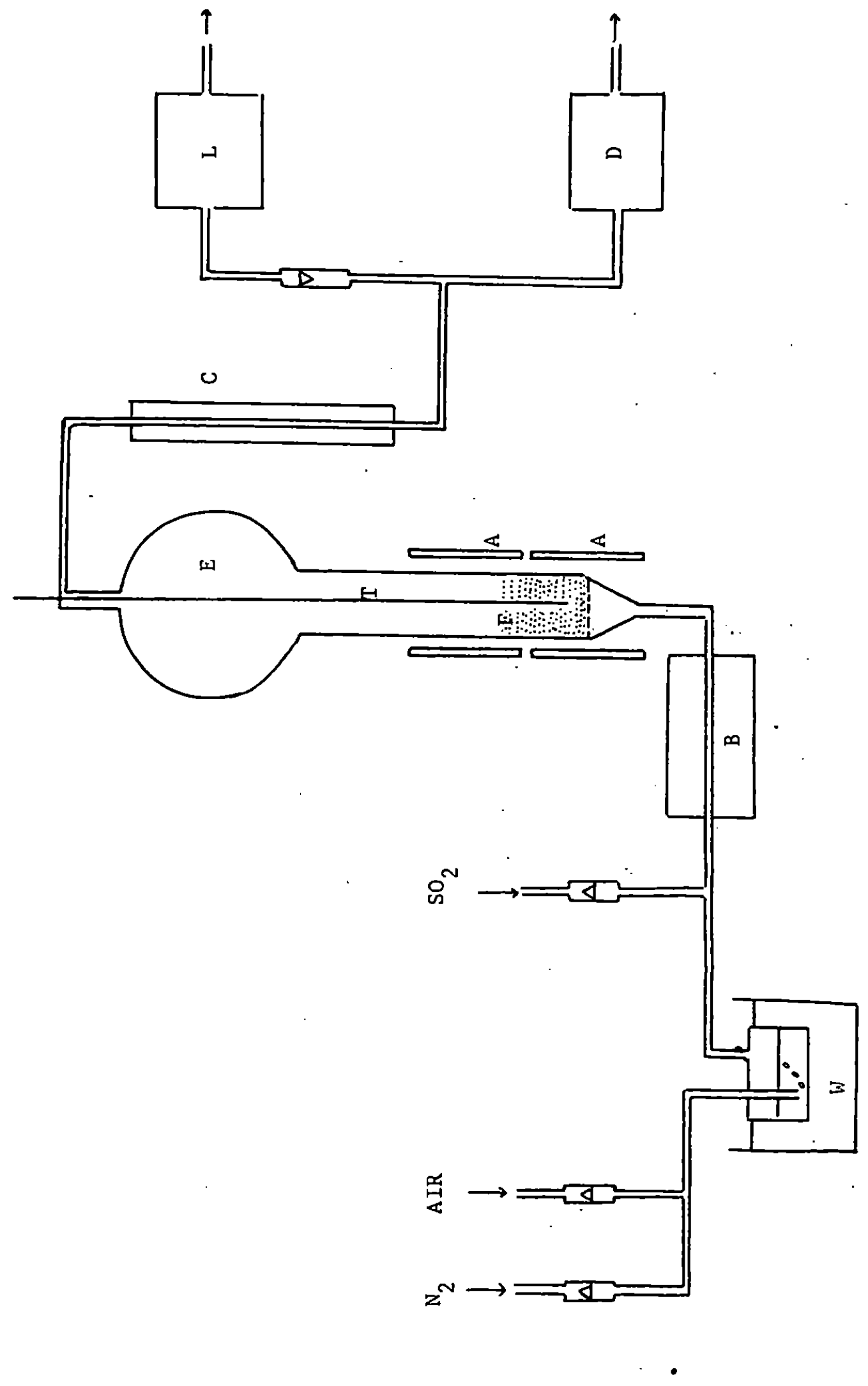


and the flow rates were monitored with rotameters and manometers. Water vapour was: added to the gases by bubbling the air and nitrogen supplies through water held at $65^{\circ} \mathrm{C}$ in a constant-temperature water bath, W. Heating tape was used to prevent condensation before the moist gas entered the pre-heater, B. The sulphur dioxide was added to the gas stream just before the pre-heater, which consisted of a tube, containing alumina granules, in a tube furnace. The furnace was switched on and brought to temperature several hours before a run was made, to allow the heat-exchanging granules to come to a steady temperature.

The exit gases from the fluidised bed, after leaving the expansion chamber, passed through a water cooled condenser, $C$, before either being bubbled through $6 \%$ hydrogen peroxide solution, $D$, or the Leco sulphur determinator (L). The hydrogen peroxide solution absorbed all the sulphur dioxide, and titration of the contents of the three gas absorption vessels with standard $0.1 \mathrm{M} \mathrm{NaOH}$ enabled the quantity of sulphur dioxide absorbed to be determined.

$$
\mathrm{H}_{2} \mathrm{O}_{2}+\mathrm{SO}_{2} \longrightarrow \mathrm{H}_{2} \mathrm{SO}_{4}
$$

The concentration of sulphur dioxide in the exhaust gases was determined by the use of the Leco sulphur determinator.

The Leco sulphur determinator consisted of a cell containing potassium iodate, excess potassium iodide, hydrochloric acid and starch as indicator. The iodine released gave the solution a blue colour and the intensity of this colour was measured by a lamp, filter, and photocell with a current meter. Sulphur dioxide in the gases passing through the cell reacted with the iodine and reduced the intensity of the blue colour.

$$
\mathrm{KIO}_{3}+5 \mathrm{KI}+6 \mathrm{HCl} \longrightarrow 6 \mathrm{KCl}+3 \mathrm{H}_{2} \mathrm{O}+3 \mathrm{I}_{2}
$$




$$
\mathrm{SO}_{2}+\mathrm{I}_{2}+2 \mathrm{H}_{2} \mathrm{O} \longrightarrow \mathrm{H}_{2} \mathrm{SO}_{4}+2 \mathrm{HI}
$$

Standardised potassium iodate solution was in the burette and potassium iodide solution, dilute hydrochloric acid and starch were added to the reaction cell. A small aliquot of potassium iodate solution was added from the burette to give a small constant reading on the meter. This reading was taken as the "zero" reading. Another aliquot of potassium iodate solution was added and its volume recorded. The sulphur dioxide containing gases were bubbled through the cell until the meter returned to the "zero value". The time and rate of flow of the gas was noted. The concentration of the sulphur dioxide in the gas could then be calculated. The sensitivity of detection of sulphur dioxide could be varied by changing the concentration of potassium iodate and the size of aliquot added.

120 g.samples of dry absorbent were added to the reaction tube to form a bed about $100 \mathrm{~mm}$ deep. The tube heaters, A, were switched on and the bed and its contents allowed to heat up. Short bursts of dry nitrogen were passed through the bed to give some degree of mixing during the pre-heating period. When equilibrium had been reached, the required gas mixture was passed through the bed, at a rate sufficient to give fluidisation, for measured periods of time. The pressure build-up in the apparatus was about $670 \mathrm{~Pa}(5 \mathrm{~cm} \mathrm{Hg})$. The amount of sulphur dioxide absorbed by the. fluidised bed was determined from the difference between the quantity of sulphur dioxide added to the gas stream and the quantity found in the exit gases. After the reaction, the solid sample was analysed for sulphur uptake and sieved to determine the increase in "fines" during fluidisation. 


\subsection{Chemical Analysis}

Standard methods. ${ }^{78,79}$ of chemical analysi's were used to determine the composition of samples. The mixtures of sulphide, sulphite and sulphate were analysed by the method given by Mocek. and Erdos ${ }^{80}$. Briefly, this was addition of carbon dioxide to a boiling suspension of the specimen, in water, and absorption of the released hydrogen sulphide by cadmium acetate solution, followed by the addition of dilute hydrochloric acid to the suspension and absorption of any remaining hydrogen sulphide, plus the sulphur dioxide released, in a mixture of cadmium acetate and potassium hydroxide solutions. The cadmium sulphide precipitates and the potassium sulphite solution were each added to iodine solution and the excess iodine determined by titration with standard sodium thiosulphate solution. The sulphate was determined gravimetrically by the addition of barium chloride solution to the acidified specimen solution. 
THE PREPARATION AND DETERMINATION OF SOME CRYSTALLOGRAPHIC PROPERTIES

OF ALKALINE EARTH METAL SULPHITES

The alkaline earth metal sulphites used for the thermal stability studies detailed in chapter 4 were prepared by the methods indicated below.

At the commencement of the work presented in this thesis the crystal structures of the alkaline earth metal sulphites were not known. The solubilities of strontium and barium sulphites were such that only very small crystals were produced and these were too small for single crystal $\mathrm{X}$-ray diffraction methods. Calcium sulphite hemihydrate crystals were somewhat larger and it was thought that crystals of a suitable size might be grown. Magnesium sulphite hexahydrate produced much larger crystals, but the relative lightness of the magnesium atom made this structure less attractive for an initial determination by photographic methods with the equipment available. Initial powder diffraction studies confirmed the results of Matthews and McIntosh ${ }^{39}$ that the patterns of hydrated and anhydrous calcium sulphite were very similar thus indicating little difference between their structures. The structure of calcium sulphite hemihydrate might, therefore, provide a good approximation for the structure of anhydrous calcium sulphite which might, in turn, be used as a model to cover the structures of the other anhydrous alkaline earth metal sulphites.

The major features of the structure of calcium sulphite hemihydrate had been determined when a full structural analysis, based. on diffractometer measurements, was published by Schropper ${ }^{81}$. As the major features of the two determinations agreed and as the data obtained by a diffractometer is of higher quality than that determined by 
photographic methods, further refinement of the present author's data, which would have involved a redetermination of the intensity data, was not carried out.

The structure of magnesium sulphite hexahydrate was published ${ }^{82}$ during this period as well.

The powder diffraction patterns of strontium and barium sulphite were indexed and the cell parameters determined.

\subsection{Magnesium Sulphite}

\subsubsection{Preparation of magnesium sulphite hexahydrate}

Crystals of magnesium sulphite hexahydrate were prepared by adding $250 \mathrm{~cm}^{3} 3 \mathrm{M}$ sodium sulphite solution to $250 \mathrm{~cm}^{3} 4 \mathrm{M}$ magnesium sulphate solution and allowing to stand overnight under an atmosphere of nitrogen

$$
\mathrm{Na}_{2} \mathrm{SO}_{3}+\mathrm{MgSO}_{4}+6 \mathrm{H}_{2} \mathrm{O} \longrightarrow \mathrm{MgSO}_{3} \cdot 6 \mathrm{H}_{2} \mathrm{O}+\mathrm{Na}_{2} \mathrm{SO}_{4}
$$

The colourless crystalline product was filtered under reduced pressure, washed with cold de-oxygenated water, and then with acetone. The crystals were dried and stored in a desiccator over silica gel. Chemical analysis indicated the product was $99.6 \%$ pure, Table 3.1.1. Table 3.1.1 Composition of prepared magnesium sulphite hexahydrate

\begin{tabular}{|l|c|c|}
\hline \multirow{2}{*}{ Component } & \multicolumn{2}{|c|}{ Percentage Composition } \\
\cline { 2 - 3 } & Actual & Theoretical \\
\hline Magnesium & 11.5 & 11.45 \\
Sulphite & 37.6 & 37.7 \\
Water & 50.6 & 50.85 \\
Sulphate & 0.3 & - \\
\hline
\end{tabular}

The water used in all stages of the above preparation was de-oxygenated by boiling distilled water vigorously for five minutes 
and bubbling nitrogen through continuously during the latter stages of boiling and as the water cooled to room temperature. Analar BDH sodium sulphite heptahydrate and magnesium sulphate heptahydrate were used for the appropriate solutions. A number of batches of magnesium sulphite hexahydrate were prepared and the purest batch used in subsequent experiments.

\subsubsection{Structure of magnesium sulphite hexahydrate}

Flack ${ }^{82}$ found that $\mathrm{MgSO}_{3} \cdot 6 \mathrm{H}_{2} \mathrm{O}$ crystallised in the space group R3 with $a=8.830 \AA, c=9.075 \AA$ (hexagonal axes) and $z=3$. The structure consisted of a slightly distorted CsCl arrangement of octahedral $\mathrm{Mg}_{2}\left(\mathrm{H}_{2}\right)_{6}{ }^{2+}$ and pyramidal $\mathrm{SO}_{3}{ }^{2-}$ ions with $0-\mathrm{S}-\mathrm{O}$ angles of $103.9^{\circ}$.

Koehler and Burns ${ }^{83}$ reported that $\mathrm{MgSO}_{3} \cdot 3 \mathrm{H}_{2} \mathrm{O}$ was orthorhombic of space group $\mathrm{Pb}_{\mathrm{n}}{ }^{1} 1$, containing 4 molecules per unit cell, with $a=9.36 \AA ; b=9.45 \AA ; c=5.51 \AA$. A clear powder Aiffraction pattern for anhydrous magnesium sulphite was not obtained due to the dehydration products being so fine that excessive line broadening occurred. This same phenomenon was reported by Okabe and Hori ${ }^{43}$.

\subsection{Calcium Sulphite}

\subsubsection{Preparation of calcium sulphite hemihydrate}

A. For thermal stability studies.

The water used in the preparation of the solutions was de-oxygenated by the method described in 3.1.1. The crystals of calcium sulphite hemihydrate were precipitated by mixing $250 \mathrm{~cm}^{3}$ 1M sodium sulphite solution with $250 \mathrm{~cm}^{3} 1 \mathrm{M}$ calcium chloride solution. The precipitate was filtered off using reduced pressure and washed with cold de-oxygenated water and then with acetone. The crystals were dried at $105^{\circ} \mathrm{C}$ in an oven and kept in a desiccator 
over silica gel. Chemical analysis indicated that the product was 99.2\% pure, see Table 3.2.1.

Table 3.2.1 Composition of prepared calcium sulphite hemihydrate

\begin{tabular}{|l|c|c|}
\hline \multirow{2}{*}{ Component } & \multicolumn{2}{|c|}{ Percentage Composition } \\
\cline { 2 - 3 } & Actual & Theoretical \\
\hline Calcium & 30.9 & 31.04 \\
Sulphite & 61.5 & 61.99 \\
Water & 7.3 & 6.97 \\
Sulphate & 0.45 & - \\
\hline
\end{tabular}

Three samples of calcium sulphite hemihydrate were prepared by the above method with purities of $98.9 \%, 99.1 \%$ and $99.2 \%$ respectively and the purest sample was used in subsequent experiments. B. For single crystal $\mathrm{X}$-ray diffraction studies

The method of growing calcium sulphite hemihydrate crystals was that outlined by Matthews and McIntosh ${ }^{39}$ in which solutions of sodium sulphite and calcium chloride were allowed to slowly diffuse into each other. $0.5 \mathrm{~g}$ sodium sulphite was placed in a $50 \mathrm{~cm}^{3}$ filtration tube and $0.5 \mathrm{~g}$ calcium chloride placed in a similar tube. The two side arms were joined by a short length of rubber tubing. The two tubes were each carefully filled with de-oxygenated water upto the cross-arms. Further water was added to completely fill both tubes and rubber stoppers fitted. These displaced the excess water so that no air was trapped in the tubes. The apparatus was left for two or three days to enable some crystals to grow. Longer periods of time produced intergrown masses of crystals. The excess liquid was poured off. The crystals were washed out on to a filter paper with acetone and air dried. 
The dry crystals were examined through a polarising microscope. It was found that the larger crystals were not single crystals but aggregates. Several batches of crystals had to be grown before one of a suitable size $(0.08 \mathrm{~mm} \times 0.08 \mathrm{~mm} \times 0.04 \mathrm{~mm})$ for single-crystal $X$-ray diffraction was obtained.

\subsubsection{Calcium sulphite hemihydrate crystal structure determination}

\section{A. Data Collection}

A small tabular crystal of calcium sulphite hemihydrate was mounted on a glass fibre, under a polarising microscope, to give as close alignment as possible with the extinction direction. The glass fibre was attached to the goniometer head. Oscillation photographs were taken about this axis and the crystal lined up so that its axis was coincident with the axis of rotation of the camera.

A zero-layer Weissenberg photograph was taken and this was calibrated by replacing the crystal with gold wire and superimposing the powder pattern of the gold at the two ends of the film. A firstlayer Weissenberg photograph was also taken. The crystal was then mounted about another axis and another zero-layer, gold calibrated, Weissenberg photograph was taken, followed by a first-layer photograph.

The systematic absences were of the types:

$0 \mathrm{k} 1$

$k=2 n+1$

h01

$1=2 n+1$

hko

$h+k=2 n+1$

hoo

$h=2 n+1$

OkO

$k=2 n+1$

001

$$
1=-2 n \pm-1
$$

These indicated that the space group was $\mathrm{Pbcn}$, though using the alternative setting based on increasing length of the $a, b$ and $c$ axis the space group symbol becomes Pbna. 
The unit cell dimensions were determined to be

$$
\begin{aligned}
& a=6.486 \pm 0.005 \AA \\
& b=9.810 \pm 0.005 \AA \\
& c=10.664 \pm 0.005 \AA
\end{aligned}
$$

hence the unit cell volume was $678.5 \AA$. The unit cell dimensions reported by Schropper ${ }^{81}$ were

$$
\begin{aligned}
& a=6.4844 \pm 0.0005 \AA \\
& b=9.8123 \pm 0.0005 \AA \\
& c=10.6629 \pm 0.001 \AA
\end{aligned}
$$

The density of calcium sulphite hemihydrate was measured by the flotation method using a mixture of acetone and tribromomethane. and was found to be $2.5463 \mathrm{gcm}^{-3}$. Therefore for the molecular formula $\mathrm{CaSO}_{3} \mathrm{O} .5 \mathrm{H}_{2} \mathrm{O}$, molecular weight $=129.15$, the number of molecules per unit cell $=8$. The calculated density was $2.528 \mathrm{~cm}^{-3}$.

Intensities were collected from the crystal rotated about its c axis using copper $k_{\alpha}$ radiation and an Enraf Nonius Weissenberg camera. A four-film pack was used and the layers hkn $(\mathfrak{n}=0=52$ were studied. The crystal was then mounted about its $b$ axis and layers hnk $(n=0-5)$ studied. Because the crystal was tabular mounting about the a axis was not convenient, though the zero-layer intensities were collected.

The intensities were measured by comparison with a calibrated spot scale with a $\sqrt{2}$ difference in intensities between spots. Layers were scaled by hand using reflections common to more than one layer. B. Structure Determination

The. reflections were corrected for Lorentz and polarisation effects, but not for absorption. The. Phillips spot shape correction was applied to non-zero layer reflections, to compensate for the extension of the measured spots in these layers. The Durban ${ }^{84}$ package 
of X-ray programmes for the IBMI 130 computer, together with the addition of a program for the Phillips spot shape correction, Appendix 1, were used for these calculations and in subsequent steps of the structure determination.

A three dimensional Patterson map was computed. Space group Pbna would give rise to heavy atom peaks in the vector positions given in Table 3.2.2 and the peaks of height greater than 250 which were found in the asymmetric unit of the Patterson map have been listed in Table 3.2.3. The co-ordinates of the calcium ion were determined to be $x=0.01 ; y=0.13 ; z=0.355$

The position of the calcium ion was used in a structure factor calculation for which the reliability index, $R$, was 0.46 . Using the phases provided for this atom a three dimensional electron density map was computed. Peaks in this map suggested the position of the sulphur atom fairly clearly and possible positions for the oxygen atoms. Incorporation of these atoms and the compilation of a series of maps allowed the positions of all the oxygens to be found eventually and the positions of all the atoms (calcium, sulphur and oxygen, but not hydrogen) to be adjusted to give a reliability index value of 0.154 . The positions of the atoms found agreed, within the limits of the data available, with the structure determination of Schropper 81 . It was, however, clear that further refinement of the structure would entail a checking of the measured intensities and inter-film scale factors. The purpose of the structure determination was to find the relative positions of the atoms in calcium sulphite hemihydrate in order to possibly provide some insight into the mechanism of thermal stability changes. The extra effort required to improve the data was not thought worthwhile as a structure based on diffractometer data, which are inherently more precise than photographic 
Table 3.2.2 General equivalent positions in Patterson map for space group $\mathrm{P}_{\mathrm{bcn}}$

$$
\begin{aligned}
& \frac{1}{2}-2 x ; \quad \frac{1}{2}-2 y ; \quad \frac{1}{2} \\
& \frac{1}{2}-2 \mathrm{x} ; \quad \frac{1}{2} \quad ; \quad 0 \\
& 0 \quad ; \quad 2 \mathrm{y} \quad ; \quad \frac{1}{2} \\
& 2 \mathrm{x} \quad ; \quad 0 \quad ; \quad \frac{1}{2}-22 \\
& \frac{1}{2} \quad ; \quad \frac{1}{2}-2 \mathrm{y} ; 2 \mathrm{z} \\
& \frac{1}{2} ; \frac{1}{2} ; \frac{1}{2}-2 z \\
& 2 \mathrm{x} \quad ; \quad 2 \mathrm{y} \quad ; \quad 2 z
\end{aligned}
$$

Table 3.2.3 Peaks corresponding to general equivalent positions in Patterson map.

\begin{tabular}{|l|l|l|c|}
\hline$x$ & $y$ & $z$ & Peak height \\
\hline 0.24 & 0.21 & 0.48 & 306 \\
0.24 & 0.50 & 0 & 504 \\
0 & 0.21 & 0.5 & 413 \\
0.26 & 0.01 & 0.49 & 453 \\
0.5 & 0.29 & 0.01 & 443 \\
0.5 & 0.5 & 0.5 & 886 \\
0.26 & 0.29 & 0 & 276 \\
\hline
\end{tabular}


data, had been published.

The positional parameters and inter-atomic distances have been listed in Table 3.2.4 and Table 3.2.5 respectively. Fig. 3.2.1 3.2.3 illustrated the positions of the atoms as projected on the $a b$, bc and ac planes respectively. The lists of $F_{h k 1 \text { (obs) and }}$ $F_{\text {hkl (calc) have been given in Appendix } 2 .}$

The calcium ions in calcium sulphite hemihydrate were surrounded by seven oxygen atoms situated at the corners of an irregular polyhedron. Six of these oxygen atoms were also bound to sulphur atoms. Each sulphur atom was at the apex of a trigonal pyramid with oxygen atoms occupying the base corners. The seventh oxygen atom in the Ca-O polyhedron was derived from the water molecule and, as there were only four water molecules per unit cell, this oxygen was linked to two calcium ions. The hydrogen atoms were too light to detect by photographic methods, but Schropper ${ }^{81}$ indicated their probable positions.

The distances between the oxygen atoms, Table 3.2 .5 , in the Ca-O polyhedron differed depending upon whether adjacent oxygen atoms were attached to the same sulphur atom or not. Adjacent Ca-0 polyhedra had some common edges resulting in the calcium atoms being aligned along the $c$ axis.

\subsubsection{Powder diffraction patterns of hydrated and anhydrous calcium}

\section{sulphite}

Comparison of the powder diffraction patterns of air-dried and vacuumdried samples of precipitated calcium sulphite hemihydrate indicated that there were small differences in their crystallographic parameters, Table 3.2.6, which also differed slightly from those determined from single crystals. The parameters of a sample calcined in vacuo for two hours at $400^{\circ} \mathrm{C}$ to produce anhydrous calcium sulphite gave unit 
Table 3.2.4 Positional parameters for atoms in $\mathrm{CaSO}_{3} \cdot 0.5 \mathrm{H}_{2} \mathrm{O}$

\begin{tabular}{|l|c|c|c|c|}
\hline Atom & $\mathrm{x}$ & $\mathrm{y}$ & $\mathrm{z}$ & $\begin{array}{c}\text { Isotropic temperature } \\
\text { factor }\end{array}$ \\
\hline $\mathrm{Ca}$ & 0.014 & 0.133 & 0.356 & 1 \\
$\mathrm{~S}$ & 0.169 & 0.384 & 0.127 & 1 \\
$\mathrm{O}_{1}$ & 0.362 & 0.404 & 0.053 & 2 \\
$0_{2}$ & 0.204 & 0.260 & 0.206 & 2 \\
$0_{3}$ & 0.177 & 0.507 & 0.211 & 2 \\
$0_{\mathrm{w}}$ & 0.253 & 0.250 & 0.500 & 2 \\
\hline
\end{tabular}

Table 3:2.5 Inter-atomic distances $(\AA)$ and angles $\left(^{\circ}\right)$

Calcium-oxygen polyhedron

$\begin{array}{llll}\mathrm{Ca}_{2}-\mathrm{O}_{17} & 2.58 & \mathrm{Ca}_{2}-\mathrm{O}_{43} & 2.34 \\ \mathrm{Ca}_{2}-0_{19} & 2.46 & \mathrm{Ca}_{2}-\mathrm{O}_{45} & 2.99 \\ \mathrm{Ca}_{2}-0_{22} & 2.37 & \mathrm{Ca}_{2}-\mathrm{O}_{46} & 2.45 \\ \mathrm{Ca}_{2}-\mathrm{O}_{24(w)} & 2.46 & \text { Mean } & 2.52\end{array}$

Sulphite pyramid

$\begin{array}{llll}\mathrm{s}_{9}-0_{17} & 1.49 & 0_{17}-\mathrm{s}_{9}-0_{18} & 106.0 \\ \mathrm{~s}_{9}-0_{18} & 1.50 & 0_{17}-\mathrm{s}_{9}-0_{19} & 100.6 \\ \mathrm{~s}_{9}-0_{19} & 1.50 & 0_{18}-\mathrm{s}_{9}-0_{19} & 108.2 \\ \text { Mean } & 1.50 & \text { Mean } & 104.9\end{array}$


Figure 3.2.1 Projection of part of $\mathrm{CaSO}_{3} \cdot 0.5 \mathrm{H}_{2} \mathrm{O}$ unit cell on to the ab plane

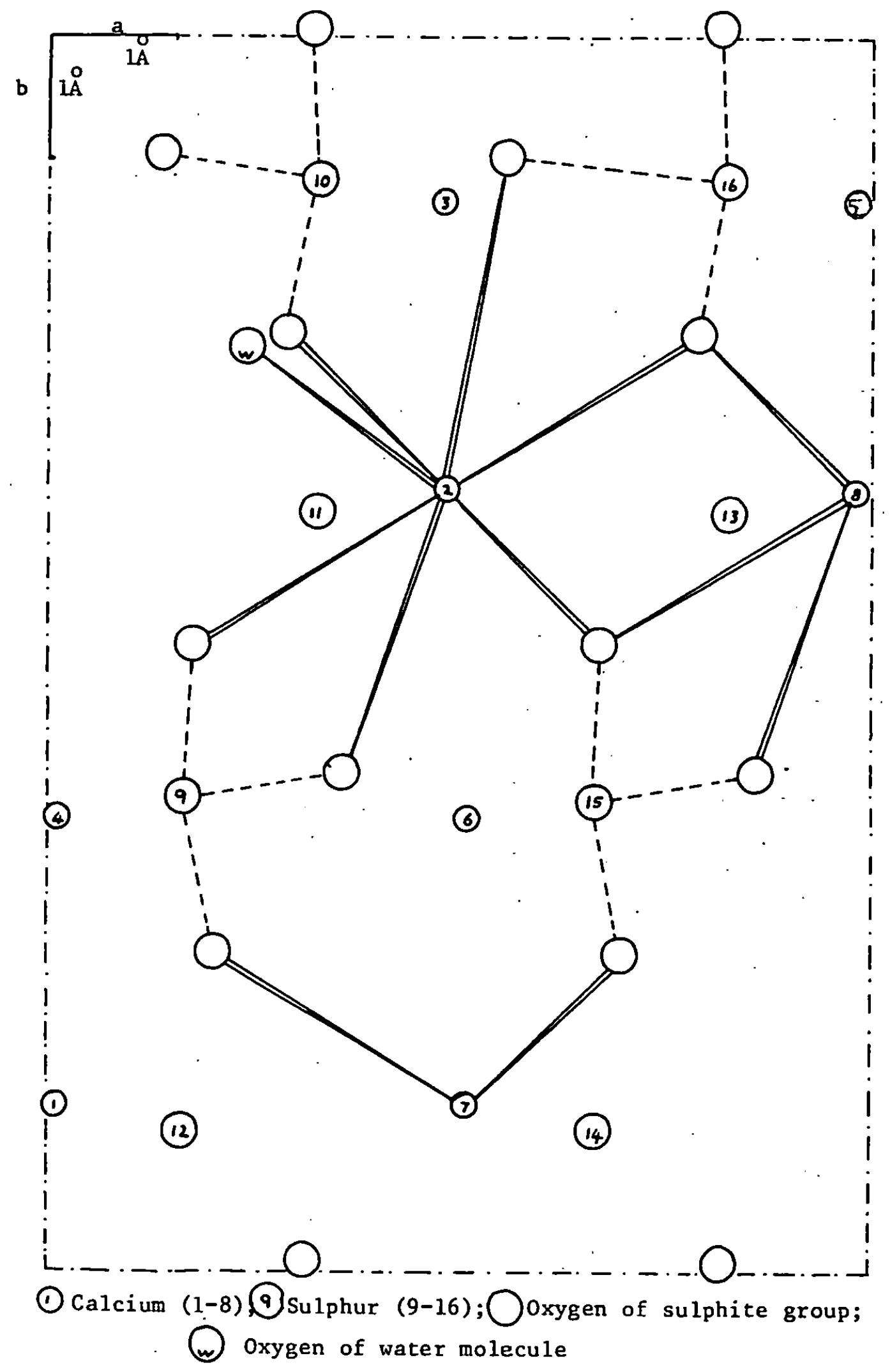


Figure 3.2.2 Projection of part of $\mathrm{CaSO}_{3} \cdot 0.5 \mathrm{H}_{2} \mathrm{O}$ unit cell on to the bc plane

$1 \mathrm{o}]^{c}{ }^{1} \AA_{b}$

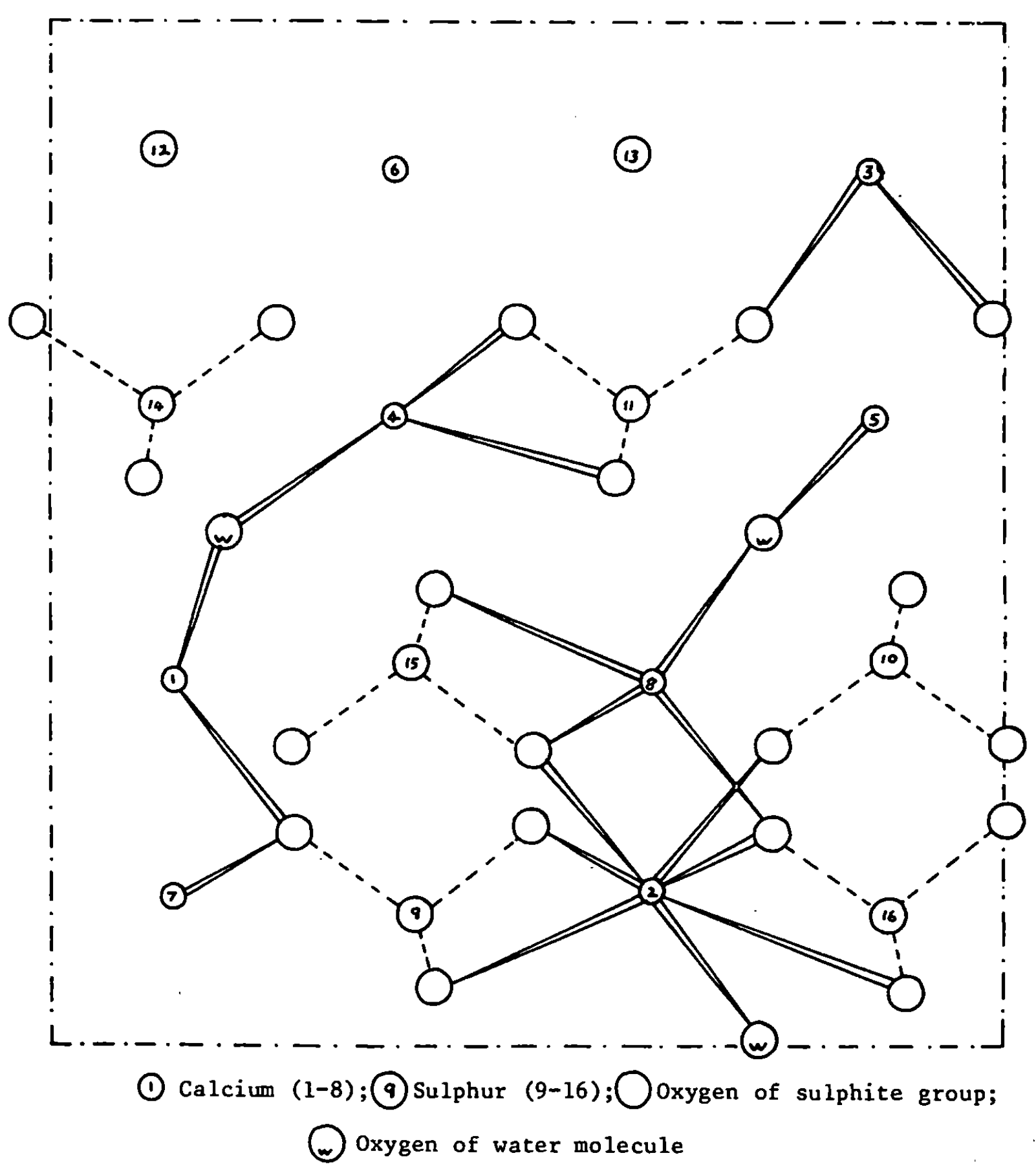


Figure 3.2.3 Projection of part of $\mathrm{CaSO}_{3} \cdot 0.5 \mathrm{H}_{2} \mathrm{O}$ unit cell onto the ac plane

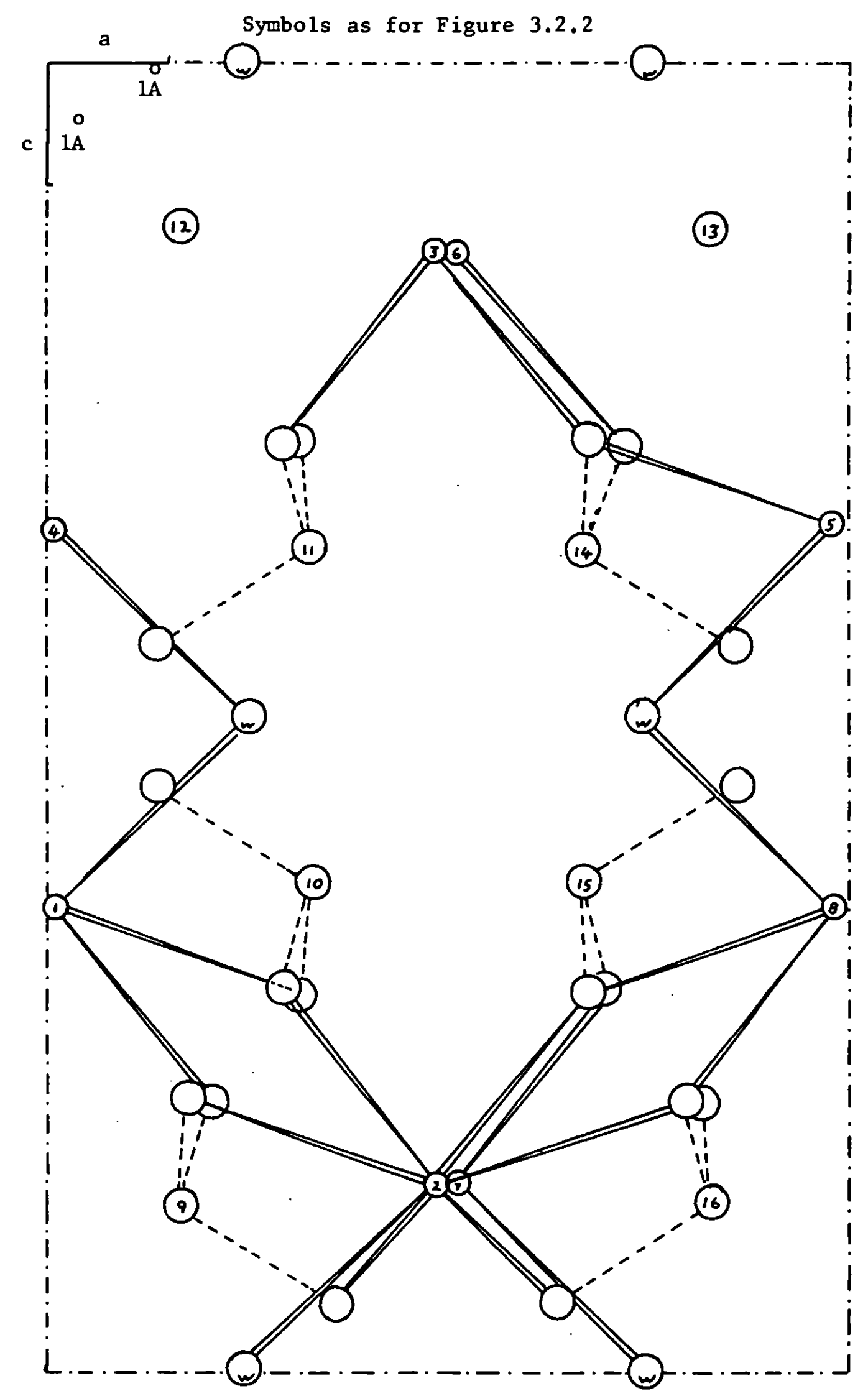


Table 3.2.6 Comparison of crystal parameters of hydrated and anhydrous calcium sulphite

\begin{tabular}{|c|c|c|}
\hline Sample & $\begin{array}{l}\text { Orthorhombic } \\
\text { parameters }\end{array}$ & $\begin{array}{l}\text { Unit cell edge } \\
\text { length (\&) }\end{array}$ \\
\hline $\begin{array}{l}\mathrm{CaSO}_{3} \cdot 0.5 \mathrm{H}_{2} \mathrm{O} \\
\text { "Air dried" }\end{array}$ & $\begin{array}{l}\text { A } 0.01425 \\
\text { B } 0.00622 \\
\text { C } 0.00523\end{array}$ & $\begin{array}{l}\text { a } \quad 6.46 \\
\text { b } \quad 9.78 \\
\text { c } \quad 10.66\end{array}$ \\
\hline $\begin{array}{l}\mathrm{CaSO}_{3} \cdot 0.5 \mathrm{H}_{2} \mathrm{O} \\
\text { "Vacuum dried" }\end{array}$ & $\begin{array}{l}\text { A } 0.0143 \\
\text { B } 0.00627 \\
\text { C } 0.00526\end{array}$ & $\begin{array}{l}\text { a } \quad 6.45 \\
\text { b } \quad 9.74 \\
\text { c } \quad 10.63\end{array}$ \\
\hline $\begin{array}{l}\mathrm{CaSO}_{3} \cdot 0.5 \mathrm{H}_{2} \mathrm{O} \\
\text { Single crystal, present work }\end{array}$ & $\begin{array}{l}\text { A } 0.01413 \\
\text { B } 0.00618 \\
\text { C } 0.00522\end{array}$ & $\begin{array}{lr}\text { a } & 6.486 \\
\text { b } & 9.810 \\
\text { c } & 10.664\end{array}$ \\
\hline $\begin{array}{l}\mathrm{CaSO}_{3} \cdot 0.5 \mathrm{H}_{2} \mathrm{O} \\
\text { Single crystal, Schropper } \\
81\end{array}$ & $\begin{array}{l}\text { A } 0.014144 \\
\text { B } 0.006177 \\
\text { C } 0.005230\end{array}$ & $\begin{array}{l}\text { a } \quad 6.4844 \\
\text { b } 9.8123 \\
\text { c. } 10.6629\end{array}$ \\
\hline $\mathrm{CaSO}_{3}$ & $\begin{array}{l}\text { A } 0.0143 \\
\text { B } 0.00630 \\
\text { C } 0.00530\end{array}$ & $\begin{array}{lr}\text { a } & 6.45 \\
\text { b } & 9.72 \\
\text { c } & 10.60\end{array}$ \\
\hline
\end{tabular}


cell dimensions only slightly smaller than those of the hydrated samples. This small difference in unit cell dimensions between the anhydrous and hydrated forms of calcium sulphite indicated that the loss of water probably caused little change in the relative positions of the calcium and sulphite ions. The calcium would become octahedrally surrounded by oxygen atoms due to the loss of the water oxygen, which occupied the seventh co-ordination position in the hemihydrate, and was itself co-ordinated to two calcium ions.

\subsection{Strontium Sulphite}

\subsubsection{Preparation of strontium sulphite}

A. For thermal stability studies

Samples of strontium sulphite were prepared by mixing $250 \mathrm{~cm}^{3}$ $M$ sodium sulphite solution with $250 \mathrm{~cm}^{3} \mathrm{M}$ strontium nitrate solution while nitrogen was bubbled through the solutions. The precipitated strontium sulphite was filtered under reduced pressure and the precipitate washed with cold water, followed by acetone. The samples were dried in an oven at $105^{\circ} \mathrm{C}$ and stored in a desiccator over silica gel. The water used in the preparation of solutions, and for washing, was de-oxygenated as described previously in section 3.1 .1

Table 3.3.1 Composition of prepared strontium sulphite

\begin{tabular}{|l|c|c|}
\hline \multirow{2}{*}{ Species } & \multicolumn{2}{|c|}{ Percentage Composition } \\
\cline { 2 - 3 } & Actual & Theoretical \\
\hline Strontium & 52.0 & 52.26 \\
Sulphite & 47.3 & 47.74 \\
Sulphate & 0.21 & - \\
Water & 0.56 & - \\
\hline
\end{tabular}




\section{B. Using sulphur dioxide}

A sample of strontium sulphite was prepared by passing sulphur dioxide into $100 \mathrm{~cm}^{3} \mathrm{M}$ strontium nitrate solution. The precipitated strontium sulphite was filtered under reduced pressure, washed, dried and stored as above.

\subsubsection{X-ray studies}

The powder diffraction pattern of strontium sulphite was not recorded in the ASTM tables ${ }^{77}$. The X-ray powder diffraction traces obtained from samples prepared as in 3.3.1 A and B were recorded and subsequently indexed. It was assumed that the unit cell of strontium sulphite would be similar to that of anhydrous calcium sulphite, but slightly larger due to the increased radius of the $\mathrm{Sr}^{2+}$ ion 108 (octahedral radius $1.16 \AA$ ) compared to the $\mathrm{Ca}^{2+}$ ion ${ }^{108}$ (octahedral radius $1.00 \AA)$. The results obtained from the diffraction traces, together with the suggested indices and cell parameters have been listed in Tables 3.3.2 and 3.3.3. Lutz and E1 Suradi ${ }^{86}$ published intensity data and $\mathrm{d}$ values for strontium sulphite which contained many more peaks than those found by the present author. The strontium sulphite had been prepared by the action of sulphur dioxide on strontium hydroxide. Comparison with the d values of strontium hydroxide, containing a little strontium carbonate, as prepared and indexed (Appendix 3) by Glasson, in accordance with earlier work ${ }^{107}$, indicated that strontium hydroxide was not the source of these extra peaks. Closer study showed that the extra peaks had d values close to those of celestite, the mineral form of strontium sulphate. Assuming that freshly precipitated strontium sulphate had lattice constants increased by 1 - $3 \%$ compared to celestite, gave a set of $d$ values which could be satisfactorily indexed and which corresponded to the majority of the extra peaks found by Lutz and 
Table 3.3.2 X-ray powder diffraction data for strontium sulphite prepared from solutions of strontium nitrate and sodium sulphite

Orthorhombic parameters: $A=0.0140 ; \quad B=0.0060 ; C=0.0052$ Lattice constants: $\quad a=6.52 \AA ; \quad b=9.96 \AA ; c=10.70 \AA$

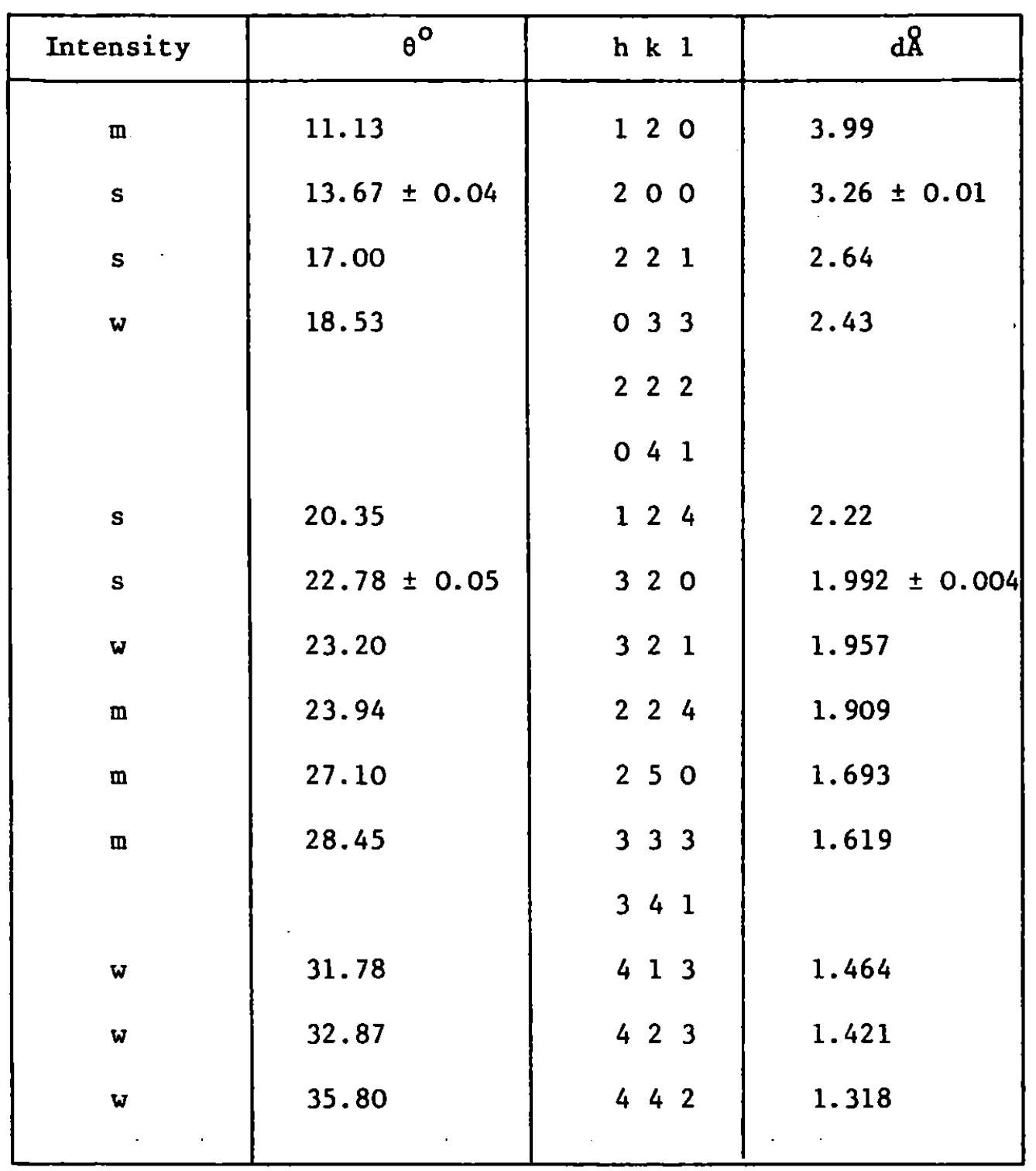

$s=$ strong; $m=$ medium; $w=$ weak 
Table 3.3.3 X-ray powder diffraction data for strontium sulphite prepared by passing sulphur dioxide into strontium nitrate solution

Orthorhombic parameters: $A=0.01405 ; B=0.00605 ; C=0.0052$ Lattice constants: $\quad a=6.51 \AA ; \quad b=9.92 \AA ; \quad c=10.70 \AA$

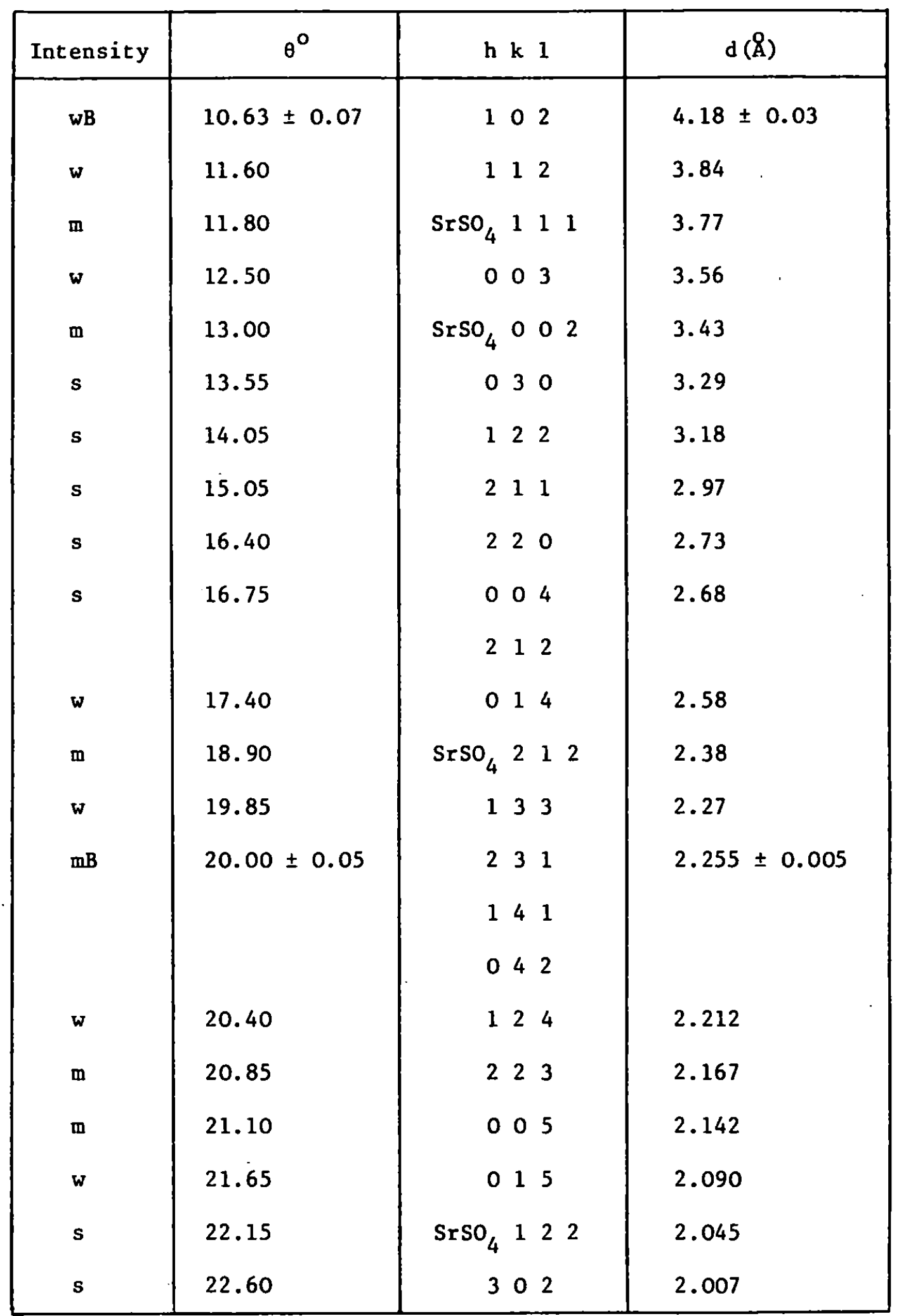




\begin{tabular}{|c|c|c|c|}
\hline Intensity & $\theta^{0}$ & h k 1 & $\mathrm{~d}(\AA)$ \\
\hline m & 23.30 & $\begin{array}{lll}3 & 2 & 1\end{array}$ & 1.950 \\
\hline & & 051 & \\
\hline$w$ & 23.45 & 143 & 1.938 \\
\hline w & 24.45 & 322 & 1.863 \\
\hline w & 25.10 & 044 & 1.818 \\
\hline w & $25: 25$ & 330 & 1.808 \\
\hline $\mathbf{s}$ & 25.85 & $\mathrm{SrSO}_{4} 303$ & 1.769 \\
\hline w & 26.20 & 144 & 1.747 \\
\hline wB & $26.50 \pm 0.05$ & $\mathrm{SrSO}_{4} 031$ & $1.728 \pm 0.003$ \\
\hline wB & $26.70 \pm 0.05$ & 332 & $1.716 \pm 0.003$ \\
\hline w & 27.15 & $\mathrm{SrSO}_{4} 412 / 131$ & 1.690 \\
\hline $\mathrm{m}$ & 27.30 & 304 & 1.681 \\
\hline $\mathrm{m}$ & 28.00 & $\mathrm{SrSO}_{4} 230$ & 1.643 \\
\hline$w$ & 28.30 & 400 & 1.627 \\
\hline m & 28.75 & 410 & 1.603 \\
\hline m & 28.90 & 324 & 1.596 \\
\hline w & 29.40 & $\mathrm{SrSO}_{4} 231$ & 1.571 \\
\hline m & 29.70 & 402 & 1.556 \\
\hline w & 31.00 & 334 & 1.497 \\
\hline$w$ & 31.30 & 422 & 1.484 \\
\hline & & $34-3$ & \\
\hline $\mathbf{m}$ & 31.45 & 403 & 1.478 \\
\hline $\mathbf{w}$ & 31.75 & 413 & 1.466 \\
\hline $\mathbf{m}$ & 32.15 & 431 & 1.449 \\
\hline m & 32.70 & $\mathrm{SrSO}_{4} 124$ & 1.428 \\
\hline $\mathbf{w}$ & 32.90 & 423 & 1.420 \\
\hline w & 33.10 & $\mathrm{SrSO}_{4} 314$ & 1.412 \\
\hline
\end{tabular}




\begin{tabular}{|c|c|c|c|}
\hline Intensity & $\theta^{\circ}$ & h $k 1$ & $d(\AA)$ \\
\hline w & 33.25 & 432 & 1.407 \\
\hline w & 33.60 & 344 & 1.394 \\
\hline m & 33.70 & 404 & 1.390 \\
\hline wB & $34.10 \pm 0.05$ & 414 & 1.376 \\
\hline$w$ & 34.55 & 440 & 1.360 \\
\hline w & 34.85 & 441 & 1.350 \\
\hline & & 433 & \\
\hline m * & 35.15 & 424 & 1.340 \\
\hline w & 35.80 & 442 & 1.318 \\
\hline w & 37.00 & 434 & 1.281. \\
\hline m & 37.40 & 443 & 1.270 \\
\hline wB & $39.50 \pm 0.10$ & 444 & 1.216 \\
\hline
\end{tabular}

*Reinforced by 040 reflection of $\mathrm{SrSO}_{4}, \mathrm{~d}=1.338 \AA$ $\mathrm{s}=$ strong; $\mathrm{m}=$ medium; $\mathrm{w}=$ weak $; \mathrm{B}=$ broadened 
Table 3.3.4 X-ray powder diffraction data for strontium sulphite recorded by Lutz and EI Suradi ${ }^{86}$.

Orthorhombic parameters: $A=0.01411 ; \quad B=0.00602 ; \quad C=0.00522$ Lattice constants: $\quad a=6.49 \AA ; \quad b=9.94 \AA ; \quad c=10.68 \AA$

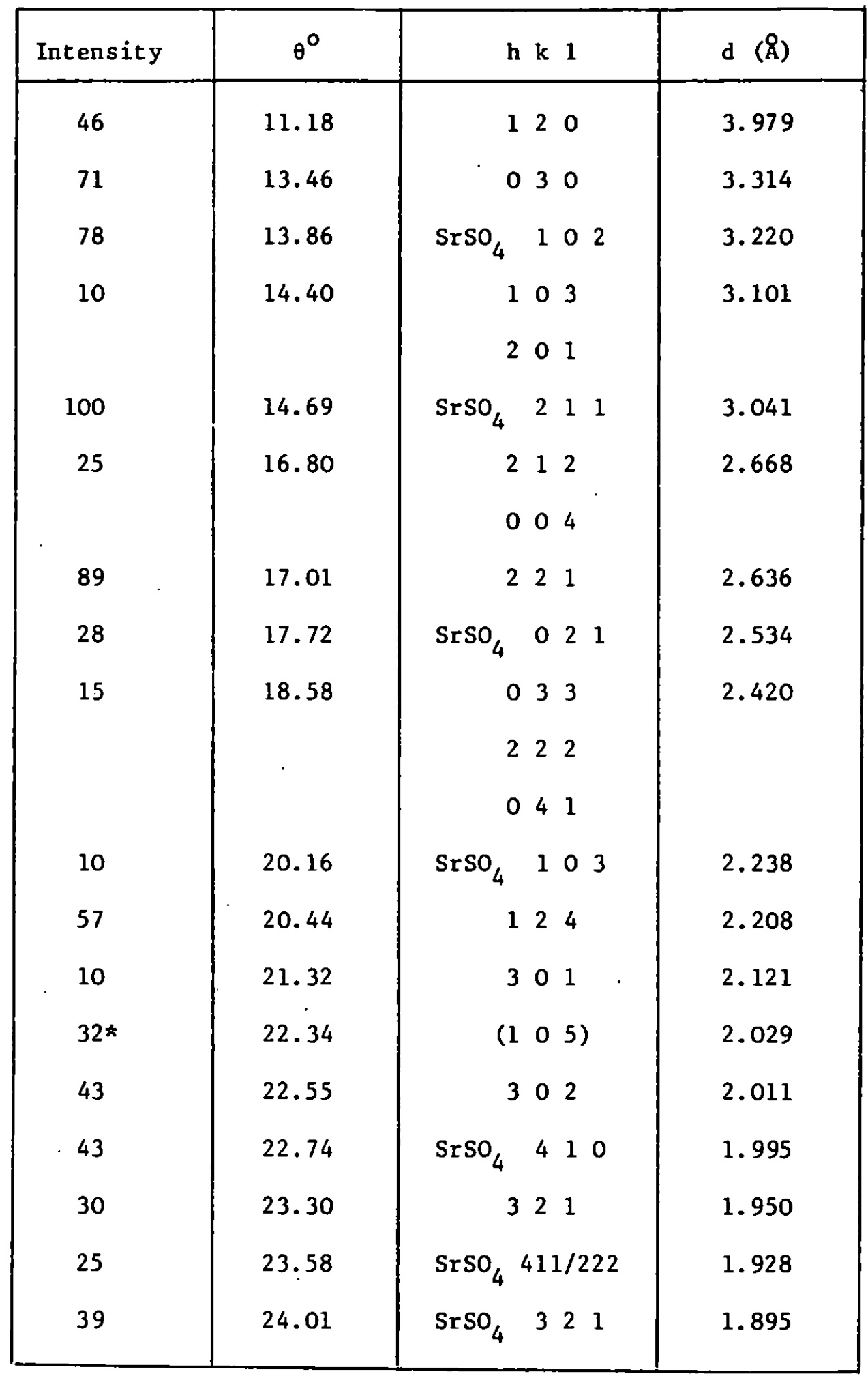




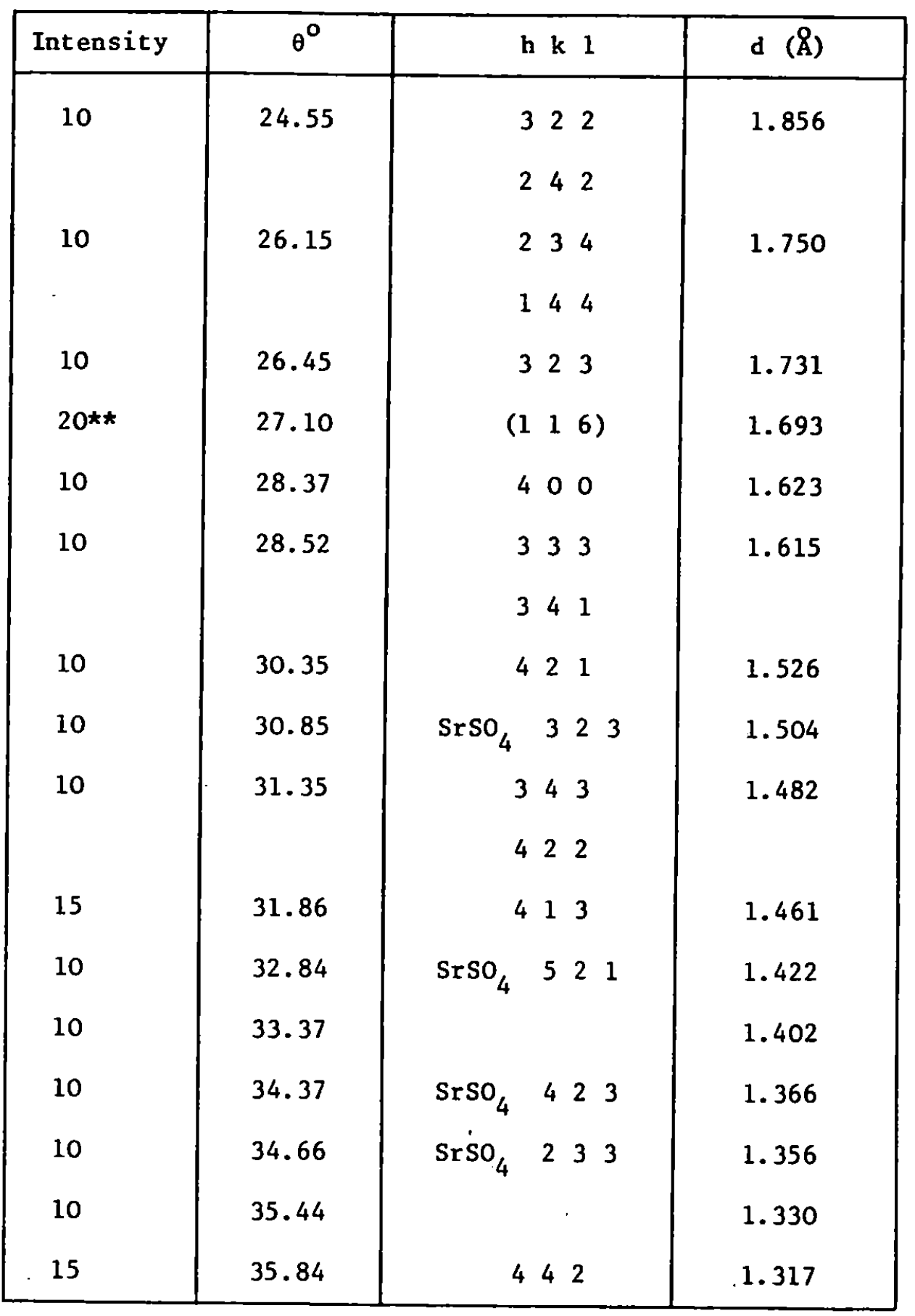

*Reinforced by 203 reflection of $\mathrm{SrSO}_{4}$ **Reinforced by 420 reflection of $\mathrm{SrSO}_{4}$ 
E1 Suradi, Table 3.3.4. It would therefore appear that their strontium sulphite sample contained significant amounts of strontium sulphate. The present author found that the preparation of strontium sulphite samples low in sulphate required a lot of care in excluding atmospheric oxygen.

\subsection{Barium Sulphite}

\subsubsection{Preparation of barium sulphite}

Batches of barium sulphite were prepared by mixing $250 \mathrm{~cm}^{3}$ $M$ sodium sulphite solution with $250 \mathrm{~cm}^{3}$ M barium .chloride solution while nitrogen was bubbled through the solutions. The precipitated barium sulphite was filtered under reduced pressure and the precipitate washed with cold water, followed by acetone. The samples were dried in an oven at $105^{\circ} \mathrm{C}$ and stored in a desiccator over silica gel. The water used in the preparation of the solutions, and for washing, was de-oxygenated as described in section 3.1.1.

Table'3.4.1 Composition of prepared barium sulphite

\begin{tabular}{|l|c|c|}
\hline \multirow{2}{*}{ Species } & \multicolumn{2}{|c|}{ Percentage Composition } \\
\cline { 2 - 3 } & Actual & Theoretical \\
\hline Barium & 63.0 & 63.18 \\
Sulphite & 36.5 & 36.82 \\
Sulphate & 0.25 & - \\
Water & 0.27 & - \\
\hline
\end{tabular}

\subsubsection{X-ray studies}

Samples prepared as in section 3.4 .1 produced $X$-ray powder diffraction traces similar to the un-indexed data recorded in: the ASTM tables 77 . Again, on the assumption that the unit cell of 
barium sulphite would be slightly larger than the unit cells of calcium and strontium sulphites (octahedral radius ${ }^{108} \mathrm{Ba}^{2+}=1.36 \AA$ ), possible cell. parameters were proposed which resulted in the indexing of the peaks as listed in Table 3.4.2 and 3.4.3. Data for barium sulphite prepared by the action of sulphur dioxide on barium hydroxide were published by Lutz and E1 Suradi ${ }^{86}$ and this has also been indexed and the cell parameters determined, Table 3.4.4. The published dat $a^{86,77}$ showed the 004 and 220 reflections as being coincident, whereas in the present work the peak at this position was broadened, indicating a tendency for the two peaks to be separated. A strong peak at 200 was found, which was not recorded in other work 87,77 and this confirmed the lower value determined for the A parameter.

A sample of barium sulphite which had been heated up to $500^{\circ} \mathrm{C}$, in vacuo, as part of the thermal stability studies (chapter 4) gave an $X$-ray pattern whose peaks were recorded in Table 3.4.5. The cell parameters required to index this pattern indicated that the value of the B parameter must be lower than in the previously discussed examples. This lower value was confirmed by the 220 and 004 reflections being separated in this sample and the peaks at higher angles were correspondingly displaced towards lower angles. A small quantity of barium sulphate was also present in the vacuum heated sample which indicated that disproportionation may have commenced, see chapter 4 .

\subsection{Comparison of Anhydrous Calcium, Strontium and Barium Sulphites}

The lattice constants for calcium sulphite, strontium sulphite and barium sulphite as determined from the $X$-ray powder diffraction data have been listed in Table 3.5.1. The increases in size of the 
Table 3.4.2 $\mathrm{X}$-ray powder diffraction data for barium sulphite prepared from solutions of barium chloride and sodium sulphite

Orthorhombic parameters: $A=0.0137 ; \quad B=0.00581 ; \quad C=0.00492$

Lattice constants:

$a=6.59 \AA ; b=10.12 \AA ; c=11.00 \AA$

\begin{tabular}{|c|c|c|c|}
\hline Intensity & $\theta^{\circ}$ & h $k 1$ & d (\&) \\
\hline $\mathbf{s}$ & 10.62 & 102 & 4.18 \\
\hline $\mathbf{s}$ & 13.00 & 013 & 3.43 \\
\hline $\mathbf{s}$ & 13.55 & 200 & 3.29 \\
\hline wB & $15.9 \pm 0.1$ & 202 & $2.81 \pm 0.02$ \\
\hline \multirow[t]{2}{*}{ sB } & $16.25 \pm 0.05$ & 220 & $2.75 \pm 0.01$ \\
\hline & & 004 & \\
\hline wB & $16.7 \pm 0.1$ & 221 & $2.68 \pm 0.02$ \\
\hline $\mathbf{s}$ & 19.40 & 133 & 2.32 \\
\hline $\mathrm{mB}$ & $21.3 \pm 0.1$ & 034 & $2.12 \pm 0.01$ \\
\hline \multirow[t]{2}{*}{ sB } & $21.72 \pm 0.05$ & 043 & $2.08 \pm 0.005$ \\
\hline & & 105 & \\
\hline $\mathrm{mB}$ & $22.78 \pm 0.005$ & 312 & $1.99 \pm 0.005$ \\
\hline . & & 051 & \\
\hline \multirow[t]{4}{*}{$\mathrm{mB}$} & $25.85 \pm 0.05$ & 053 & $1.77 \pm 0.005$ \\
\hline & & 106 & \\
\hline & & 323 & \\
\hline & & 243 & • \\
\hline w & 26.90 & 251 & 1.70 \\
\hline m & 27.17 & 314 & 1.69 \\
\hline & & 060 & \\
\hline $\mathbf{w}$ & 29.00 & 342 & 1.59 \\
\hline
\end{tabular}




\begin{tabular}{|l|l|l|l|}
\hline Intensity & $\theta^{0}$ & h k 1 & $d(\AA)$ \\
\hline w & 30.13 & 315 & 1.54 \\
WB & $31.1 \pm 0.1$ & 403 & $1.49 \pm 0.01$ \\
& & 055 & \\
\hline
\end{tabular}

$\mathrm{s}=$ strong; $\mathrm{m}=$ medium; $\mathrm{w}=$ weak $; \mathrm{B}=$ broadened 
Table 3.4.3 X-ray powder diffraction data for barium sulphite recorded in ASTM tables $1-0604^{77}$

Orthorhombic parameters: $A=0.01385 ; \quad B=0.00581 ; \quad C=0.00492$ Lattice constants: $\quad a=6.55 \AA ; \quad b=10.12 \AA ; \quad c=11.00 \AA$

\begin{tabular}{|c|c|c|c|}
\hline Intensity & $\theta^{\circ}$ & h k 1 & d (\&) \\
\hline 63 & 10.58 & 102 & 4.20 \\
\hline 100 & 12.95 & 130 & 3.44 \\
\hline 75 & 13.95 & 031 & 3.20 \\
\hline 63 & 16.29 & $\begin{array}{lll}0 & 0 & 4 \\
2 & 2 & 0\end{array}$ & 2.75 \\
\hline 35 & 19.41 & 133 & 2.32 \\
\hline 45 & 21.76 & $\begin{array}{l}043 \\
105\end{array}$ & 2.08 \\
\hline 10 & 22.80 & $\begin{array}{lll}3 & 1 & 2 \\
0 & 5 & 1\end{array}$ & 1.99 \\
\hline 10 & 25.83 & $\begin{array}{lll}0 & 53 \\
1 & 0 & 6\end{array}$ & 1.77 \\
\hline 10 & 27.17 & $\begin{array}{lll}3 & 1 & 4 \\
0 & 6 & 0\end{array}$ & 1.69 \\
\hline 5 & 29.00 & 342 & 1.59 \\
\hline 5 & 31.17 & $\begin{array}{l}403 \\
055\end{array}$ & 1.49 \\
\hline 5 & 33.98 & $\begin{array}{l}008 \\
440\end{array}$ & 1.38 \\
\hline 5 & 35.75 & 361 & 1.32 \\
\hline 5 & 37.74 & $\begin{array}{lll}5 & 2 & 1\end{array}$ & 1.26 \\
\hline 5 & 40.81 & 504 & 1.18 \\
\hline
\end{tabular}


Table 3.4.4 X-ray powder diffraction data for barium sulphite recorded by Lutz and E1 Suradi 86

Orthorhombic parameters: $A=0.1385 ; \quad B=0.00581 ; \quad C=0.00491$

Lattice constants: $\quad a=6.55 \AA ; \quad b=10.12 \AA ; \quad c=11.01 \AA$

\begin{tabular}{|c|c|c|c|}
\hline Intensity & $\theta^{0}$ & h k 1 & d $(\AA)$ \\
\hline 57 & 10.67 & 102 & 4.163 \\
\hline 35 & 12.88 & 0113 & 3.458 \\
\hline 28 & 13.24 & 030 & 3.368 \\
\hline 100 & 13.97 & 103 & 3.195 \\
\hline \multirow[t]{2}{*}{28} & 16.28 & 220 & 2.751 \\
\hline & & 004 & \\
\hline 18 & 16.94 & 014 & 2.647 \\
\hline 35 & 19.43 & 133 & 2.318 \\
\hline 18 & 21.50 & 204 & 2.104 \\
\hline \multirow[t]{2}{*}{18} & 21.72 & 043 & 2.084 \\
\hline & & 105 & \\
\hline \multirow[t]{2}{*}{28} & 22.81 & 312 & 1.989 \\
\hline & & 051 & \\
\hline
\end{tabular}


Table 3.4.5 $\mathrm{X}$-ray powder diffraction data for barium sulphite sample heated for $2 \mathrm{~h}$, in vacuo, at $500^{\circ} \mathrm{C}$

Orthorhombic parameters: $A=0.0137 ; \quad B=0.00575 ; \quad C=0.00492$ Lattice constants: $a=6.59 \AA ; \quad b=10.17 \AA ; c=11.00 \AA$

\begin{tabular}{|c|c|c|c|}
\hline Intensity & $\theta^{\circ}$ & h k 1 & $d(\AA)$ \\
\hline $\mathrm{mB}$ & $10.10 \pm 0.05$ & $\mathrm{BaSO}_{4}$ & $4.39 \pm 0.03$ \\
\hline $\mathbf{s}$ & 10.60 & 102 & 4.19 \\
\hline w & 11.40 & 112 & 3.90 \\
\hline $\mathbf{s}$ & 12.95 & 013 & 3.44 \\
\hline WB & $13.55 \pm 0.05$ & 200 & $3.29 \pm 0.01$ \\
\hline $\mathbf{s}$ & 13.85 & 031 & 3.22 \\
\hline & & 103 & \\
\hline w & 14.4 & $\mathrm{BaSO}_{4}$ & 3.10 \\
\hline w & 15.75 & 202 & 2.84 \\
\hline $\mathbf{s}$ & 16.15 & 220 & 2.77 \\
\hline $\mathbf{s}$ & 16.30 & 004 & 2.75 \\
\hline w & 16.70 & 221 & 2.68 \\
\hline $\mathbf{s}$ & 19.30 & 133 & 2.33 \\
\hline w & 21.17 & 034 & 2.13 \\
\hline wB & $21.40 \pm 0.1$ & 304 & $2.11 \pm 0.01$ \\
\hline \multirow[t]{2}{*}{$s$} & 21.70 & 043 & 2.09 \\
\hline & & 105 & \\
\hline \multirow[t]{2}{*}{$\mathbf{s}$} & 22.70 & 312 & 2.00 \\
\hline & & 051 & \\
\hline m & 25.70 & 053 & 1.78 \\
\hline \multirow[t]{3}{*}{ m } & 25.95 & 106 & 1.76 \\
\hline & & 323 & \\
\hline & & 243 & \\
\hline
\end{tabular}




\begin{tabular}{|c|c|c|c|}
\hline Intensity & $\theta^{\circ}$ & h k 1 & $\mathrm{~d}(\AA)$ \\
\hline $\mathrm{mB}$ & $26.9 \pm 0.1$ & 251 & $1.705 \pm 0.005$ \\
$\mathrm{~m}$ & 27.10 & 060 & 1.693 \\
& & 314 & \\
$\mathrm{w}$ & $28.0 \pm 0.1$ & 400 & $1.643 \pm 0.005$ \\
$\mathrm{w}$ & 28.7 & 411 & 1.606 \\
$\mathrm{mB}$ & $29.0 \pm 0.1$ & 342 & $1.591 \pm 0.005$ \\
$\mathrm{mB}$ & $30.05 \pm 0.05$ & 315 & $1.540 \pm 0.002$ \\
\hline
\end{tabular}

$\mathrm{s}=$ strong; $\mathrm{m}=$ medium; $\mathrm{w}=$ weak $; \mathrm{B}=$ broadened 
Table 3.5.1 Lattice constants of anhydrous calcium, strontium and barium sulphites

\begin{tabular}{|c|c|c|c|}
\hline Compound & a $(\AA)$ & b (\&) & c (\&) \\
\hline $\mathrm{CaSO}_{3}$ & 6.45 & 9.72 & 10.60 \\
\hline $\begin{array}{r}\mathrm{SrSO}_{3} \text { (i) see Table } 3.3 .2 \\
\text { (ii) see Table } 3.3 .3 \\
\text { (iii) see Table } 3.3 .4\end{array}$ & $\begin{array}{l}6.52 \\
6.51 \\
6.49\end{array}$ & $\begin{array}{l}9.96 \\
9.92 \\
9.94\end{array}$ & $\begin{array}{l}10.70 \\
10.70 \\
10.68\end{array}$ \\
\hline $\begin{array}{r}\mathrm{BaSO}_{3} \text { (i) see Table } 3.4 .2 \\
\text { (ii) see Table } 3.4 .3 \\
\text { (iii) see Table } 3.4 .4 \\
\text { (iv) see Table } 3.4 .5\end{array}$ & $\begin{array}{l}6.59 \\
6.55 \\
6.55 \\
6.59\end{array}$ & $\begin{array}{l}10.12 \\
10.12 \\
10.12 \\
10.17\end{array}$ & $\begin{array}{l}11.00 \\
11.00 \\
11.01 \\
11.00\end{array}$ \\
\hline
\end{tabular}

Table·3.5.2 Comparison of sizes of unit cells and cations

\begin{tabular}{|c|c|c|c|c|c|c|}
\hline \multirow[t]{2}{*}{ Compound } & \multirow{2}{*}{$\begin{array}{c}\text { Cation } \\
\text { radius } \\
8^{3}\end{array}$} & \multirow{2}{*}{$\begin{array}{c}\text { Unit } \\
\text { cell } \\
\text { volume } \\
\AA^{3^{-}}\end{array}$} & \multirow{2}{*}{$\begin{array}{c}\text { Volume } \\
\text { per } \\
\text { molecule } \\
\AA^{3}\end{array}$} & \multirow{2}{*}{$\begin{array}{c}\text { Volume } \\
\text { occupied } \\
\text { by cation } \\
\AA^{3}\end{array}$} & \multicolumn{2}{|c|}{$\begin{array}{l}\text { Volume available } \\
\text { for sulphite ion }\end{array}$} \\
\hline & & & & & $8^{3}$ & $\%$ \\
\hline $\mathrm{CaSO}_{3}$ & 1.00 & 664.5 & 83.1 & 4.2 & 78.9 & 94.7 \\
\hline $\mathrm{SrSO}_{3}$ & 1.16 & 691.3 & 86.4 & 6.5 & 79.9 & 92.5 \\
\hline $\mathrm{BaSO}_{3}$ & 1.36 & 733.6 & 91.7 & 10.5 & 81.2 & 88.5 \\
\hline
\end{tabular}


unit cell with the increase in atomic number of the cation appeared to be due to the increased size of the cation as the volume of the unit cell available for occupation by the sulphite ion only increased slightly, Table 3.5 .2 and the proportion actually decreased.

The crystal structures of the anhydrous sulphites appeared to be closely related to each other, being based on an orthorhombic unit cell, and similar to the structure of calcium sulphite hemihydrate. These relationships were supported by the assignment of reasonably small indices to the recorded $\mathrm{X}$-ray powder diffraction peaks based on the assumed cell parameters. 


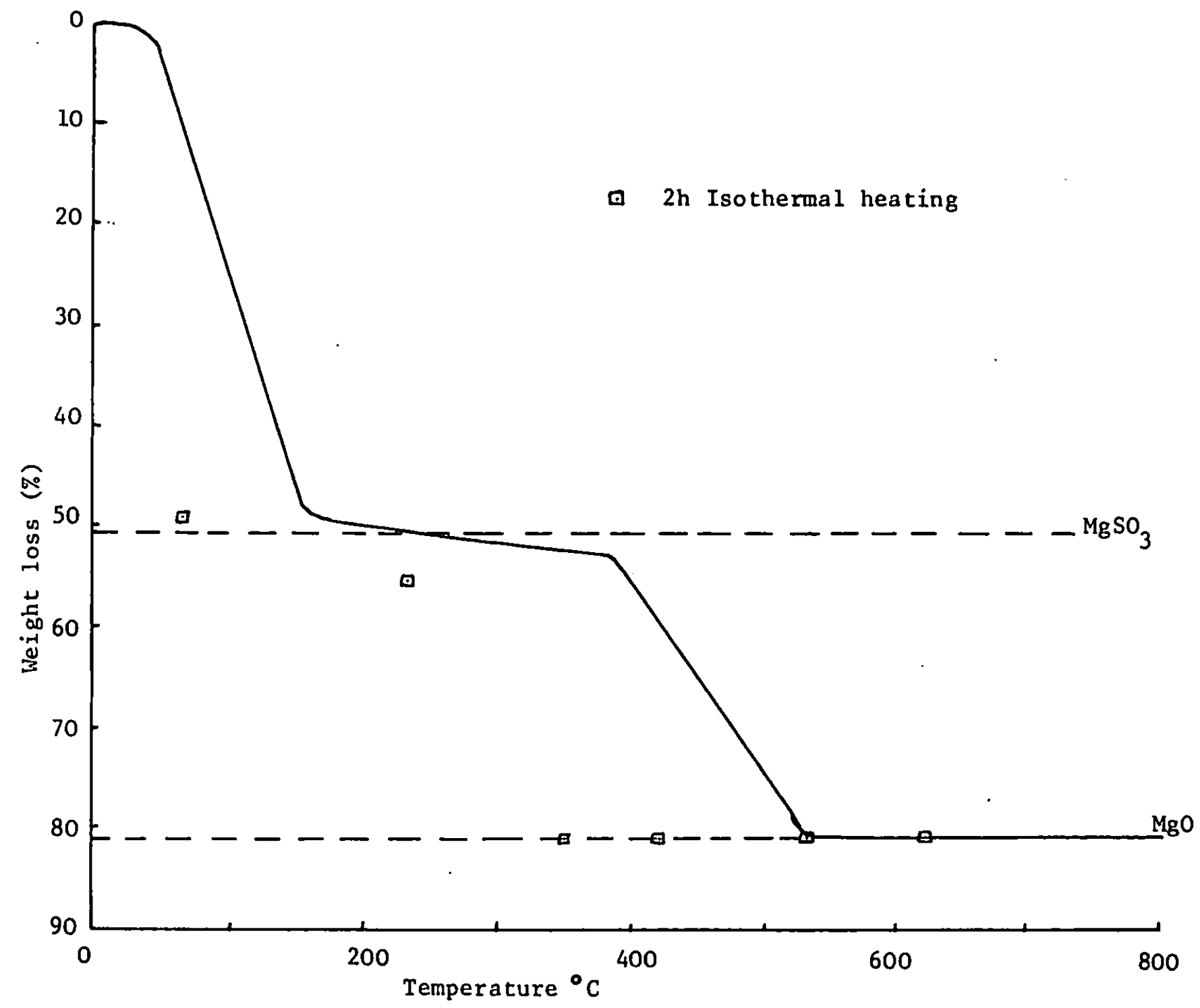




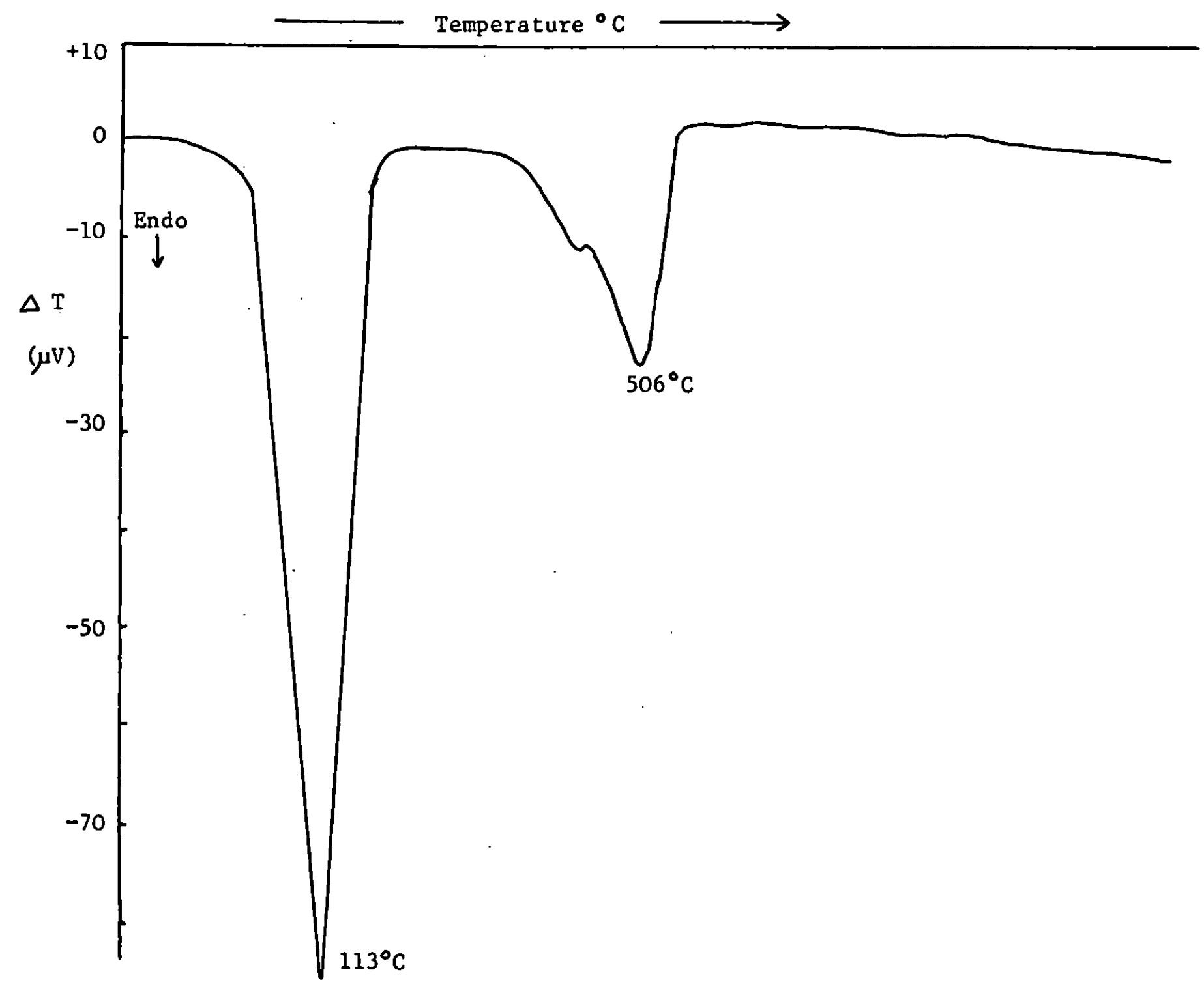




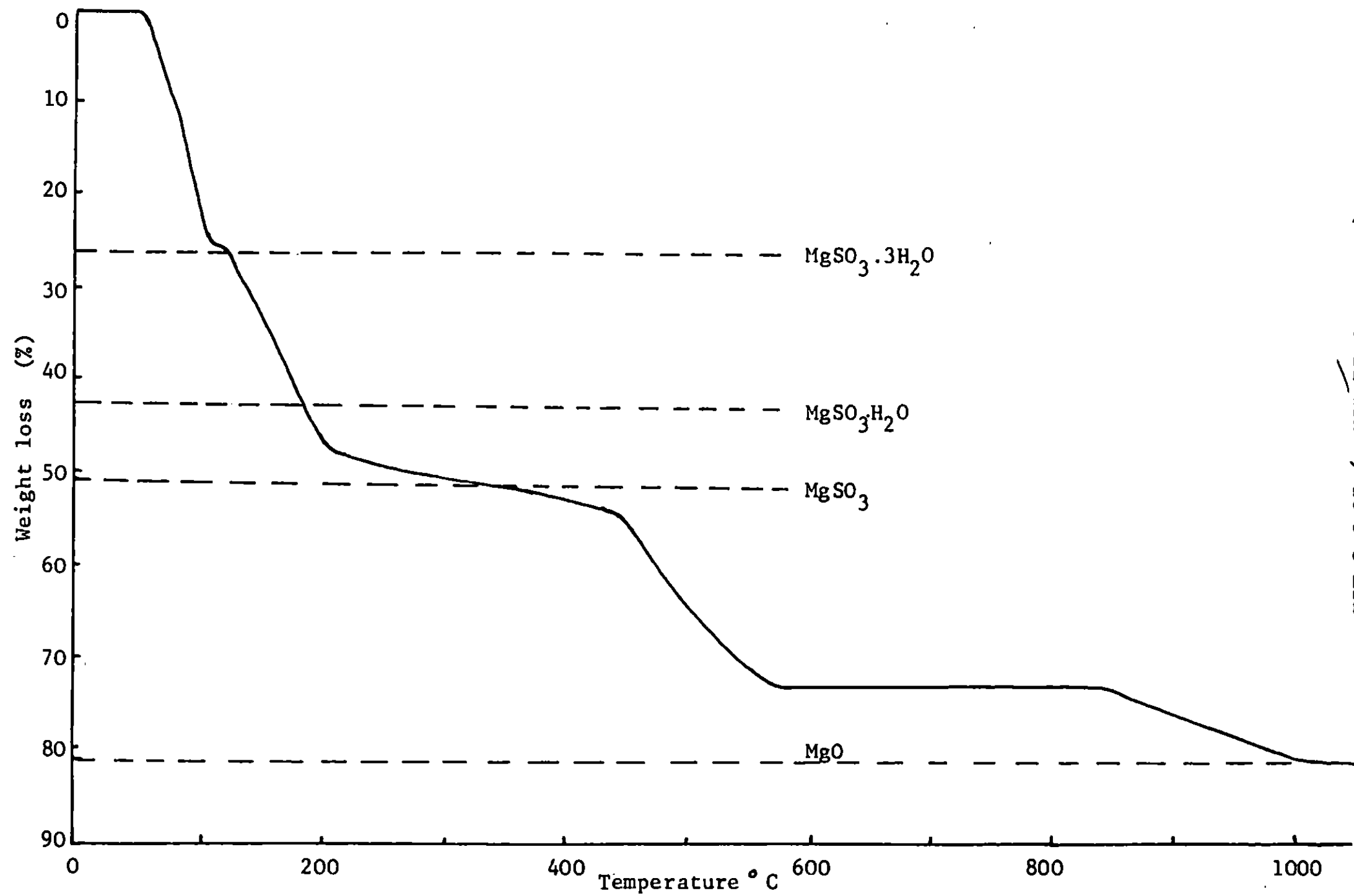




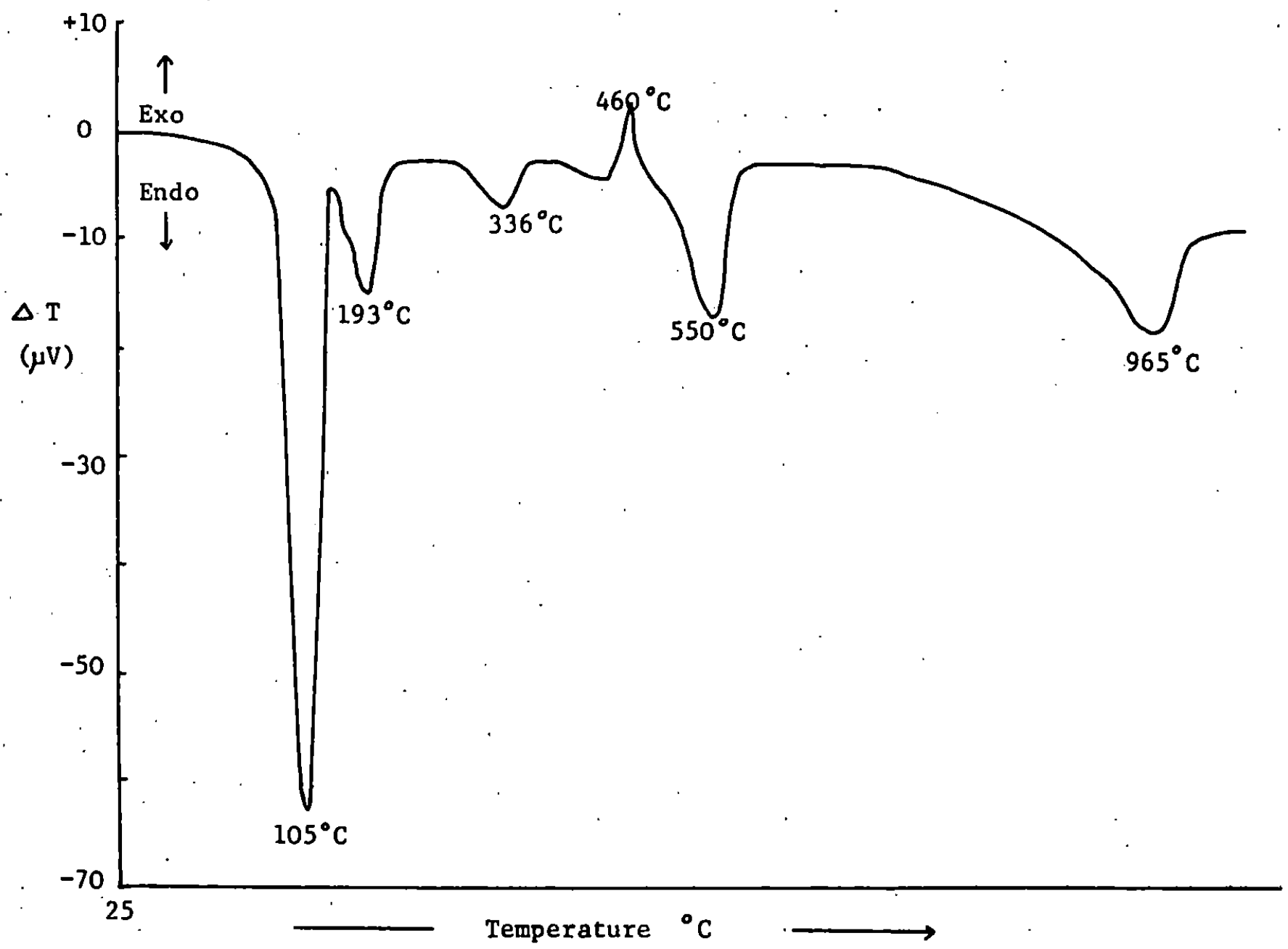




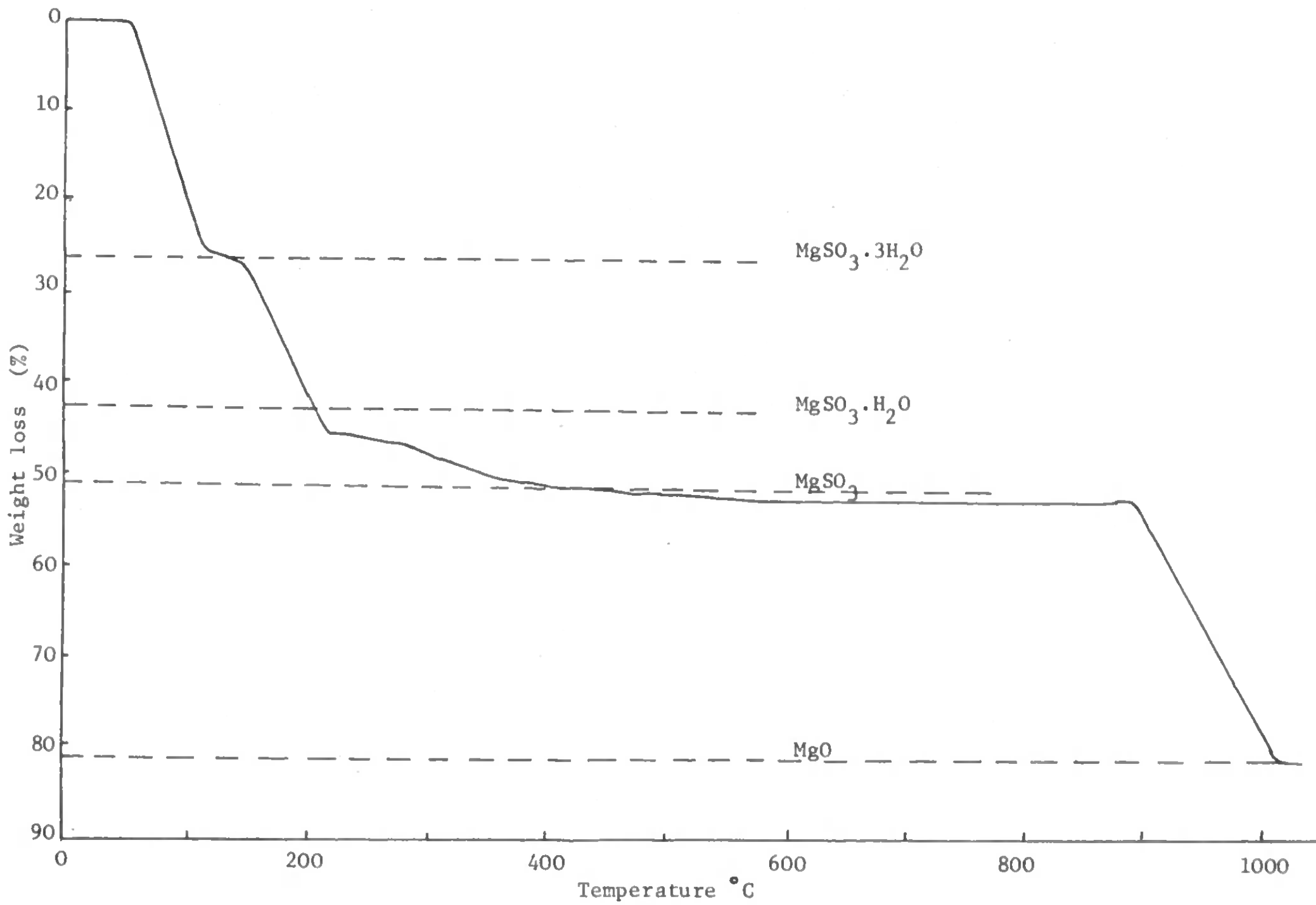




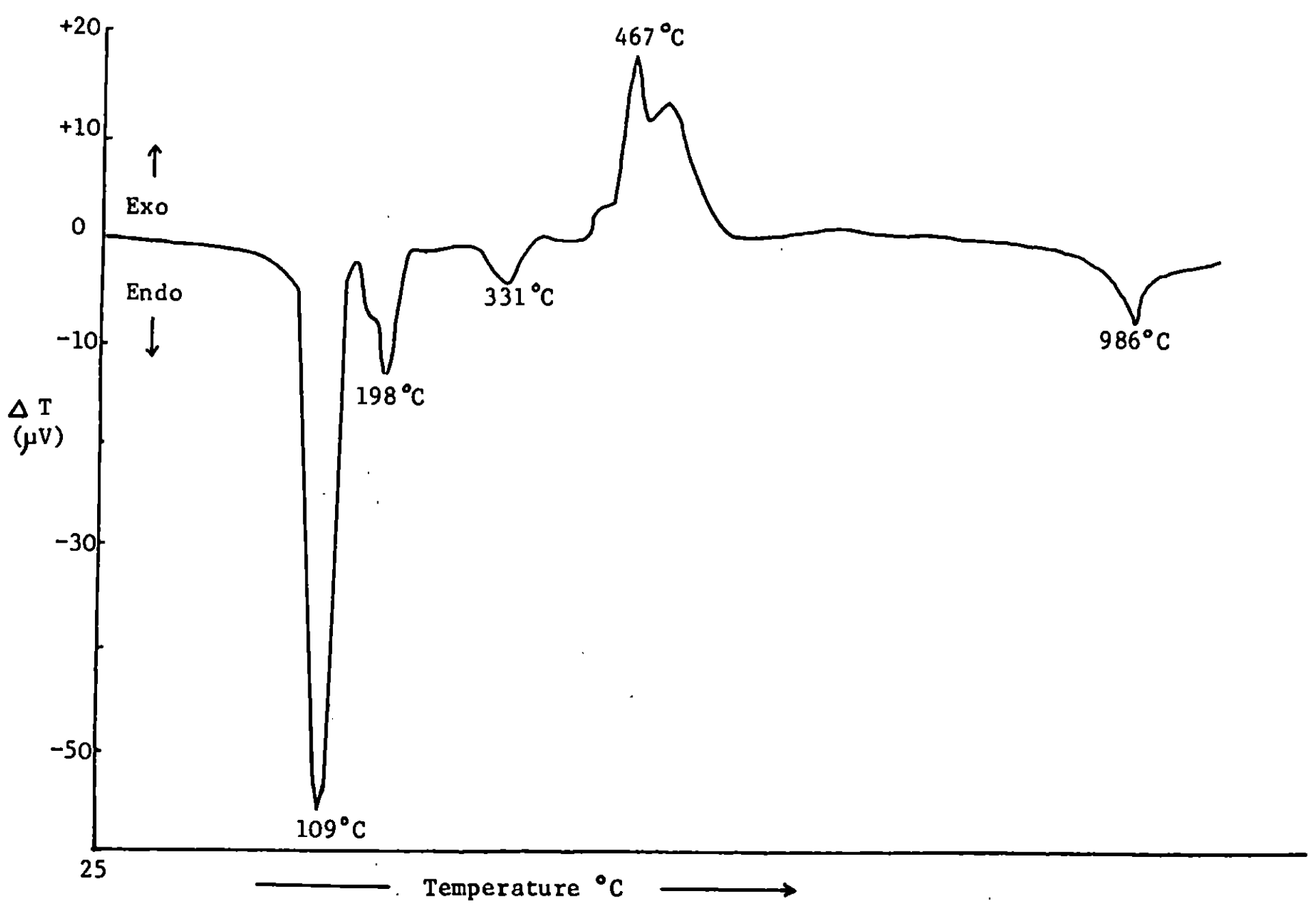




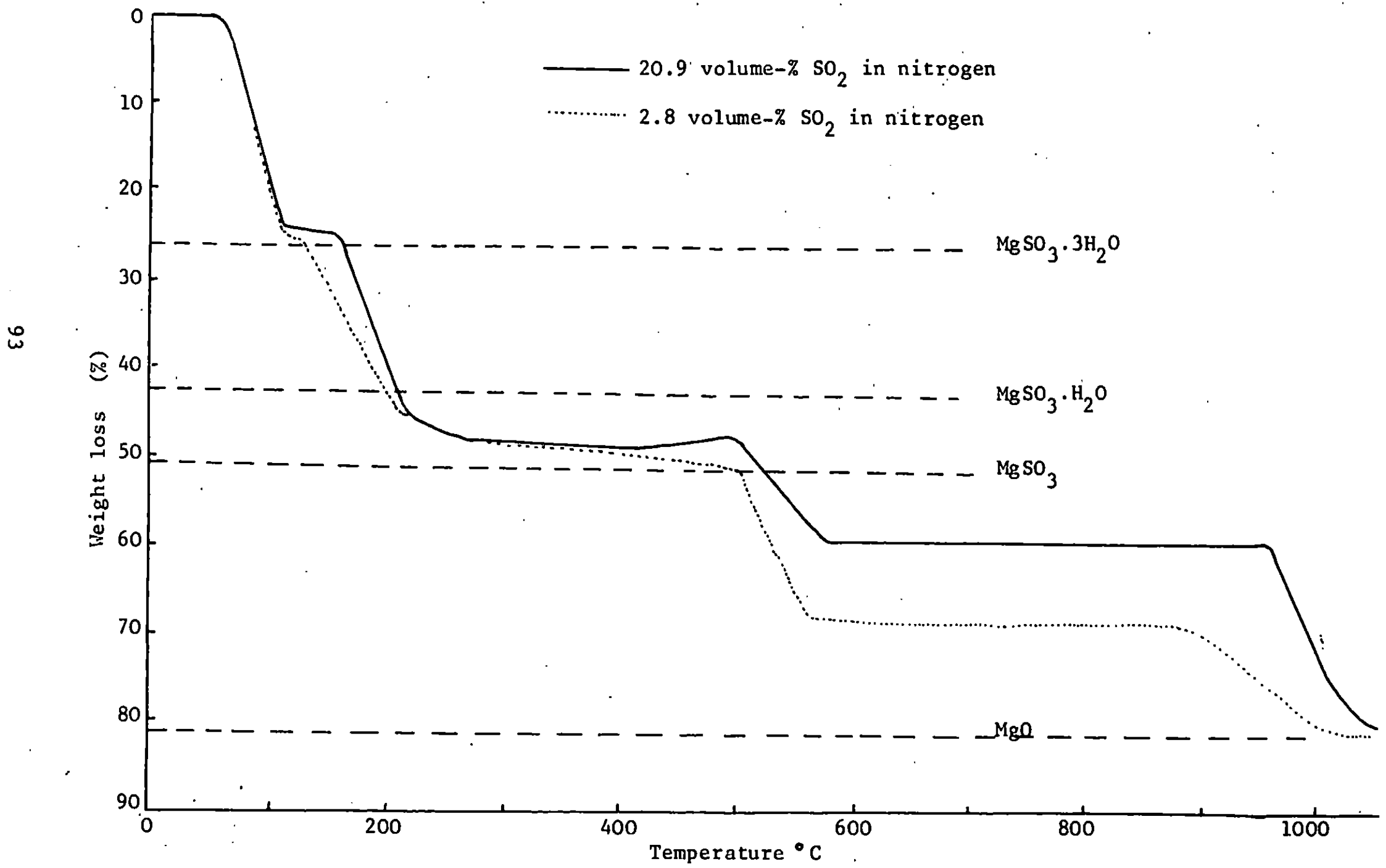




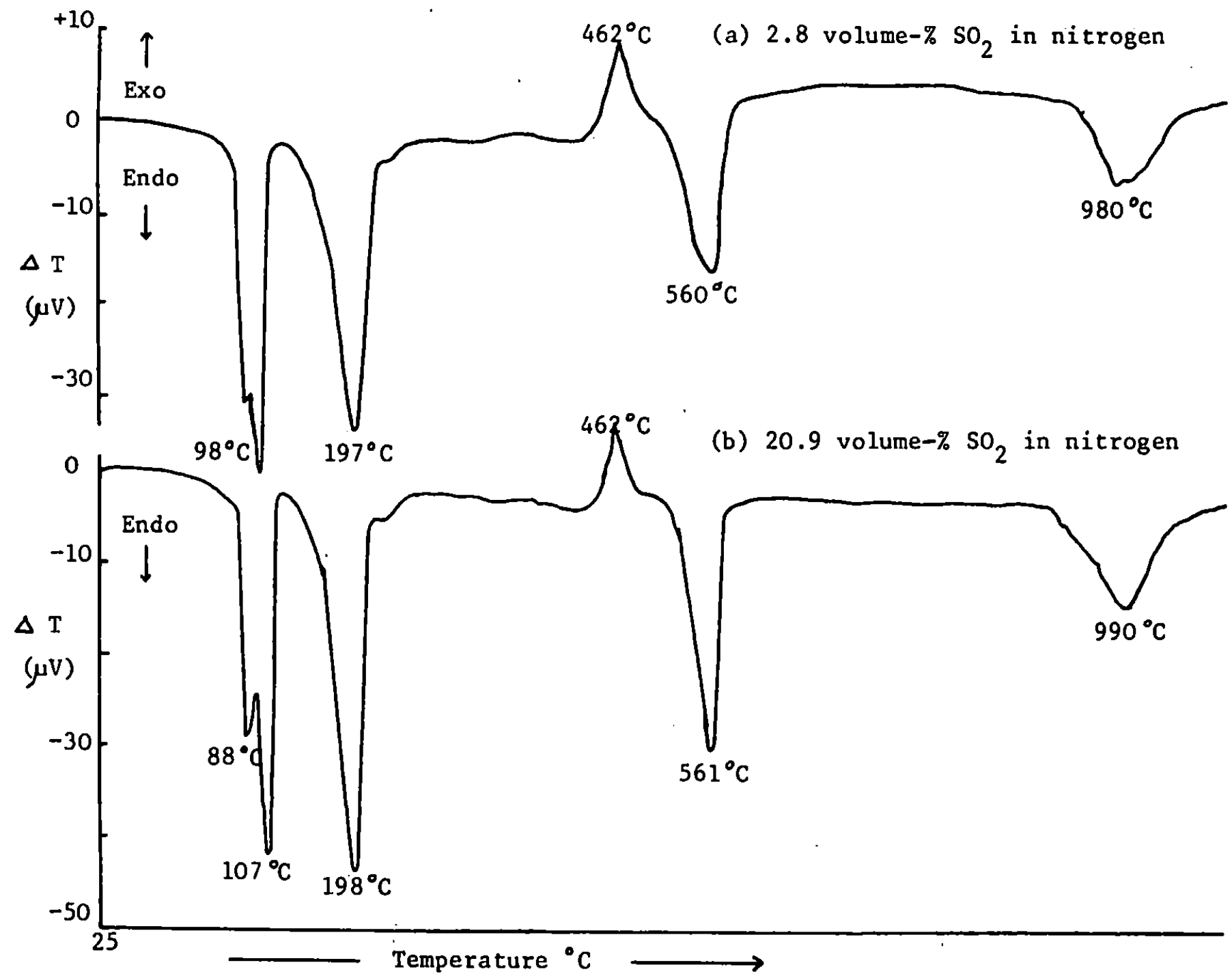


Figure 4.1.9 $\mathrm{MgSO}_{3} \cdot 6 \mathrm{H}_{2} \mathrm{O}$ heated on electron microscope hot-stage
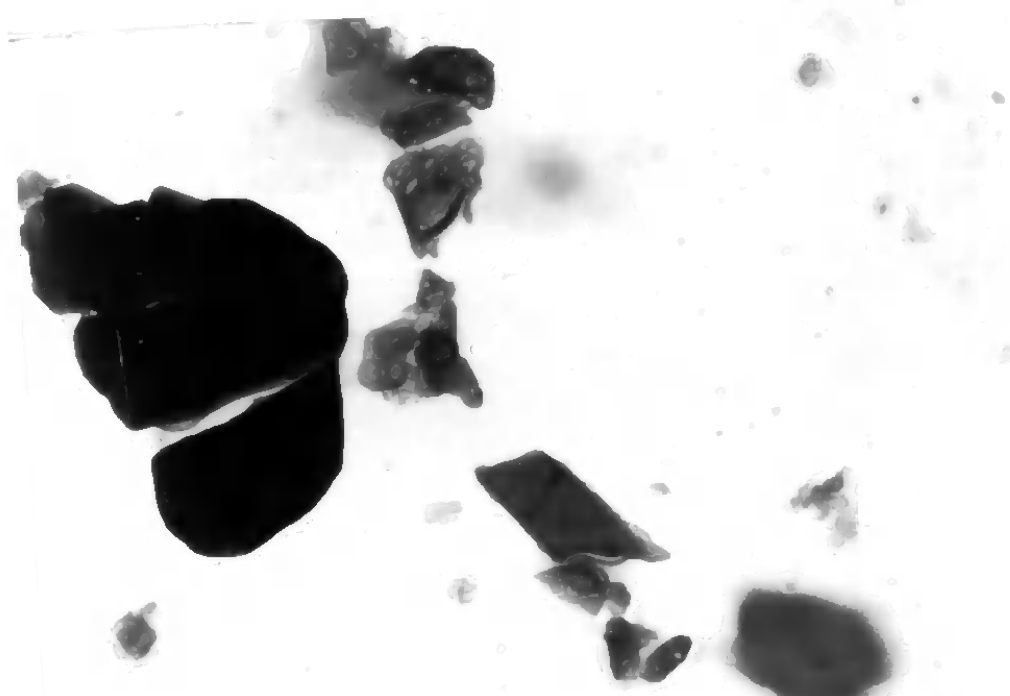

(a) At $25^{\circ} \mathrm{C}$
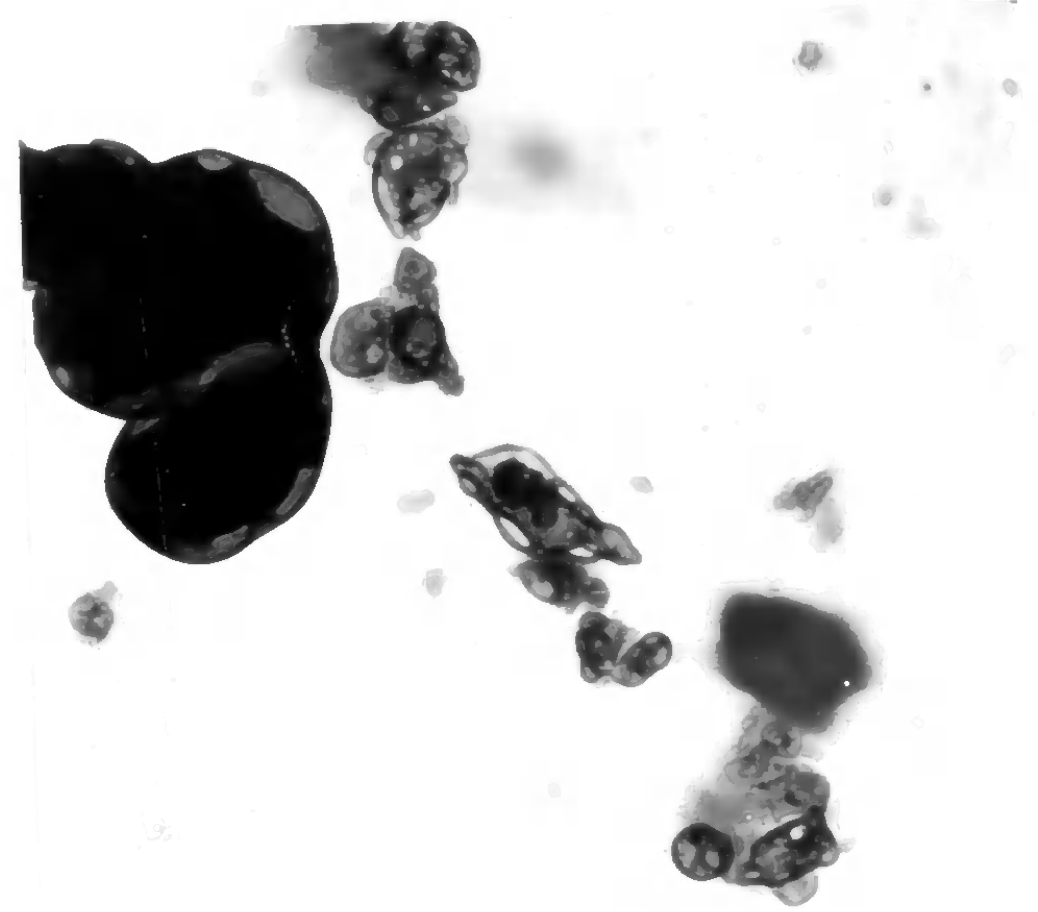

(b) At $100^{\circ} \mathrm{C}$ 
Figure 4.1 .9
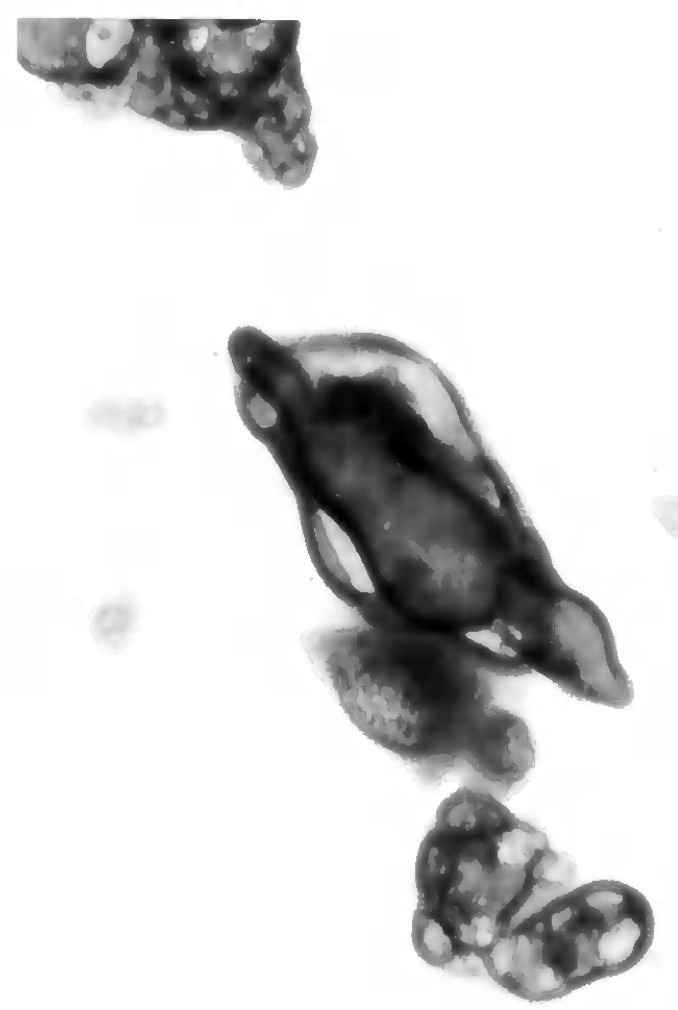

(c) At $150^{\circ} \mathrm{C}$
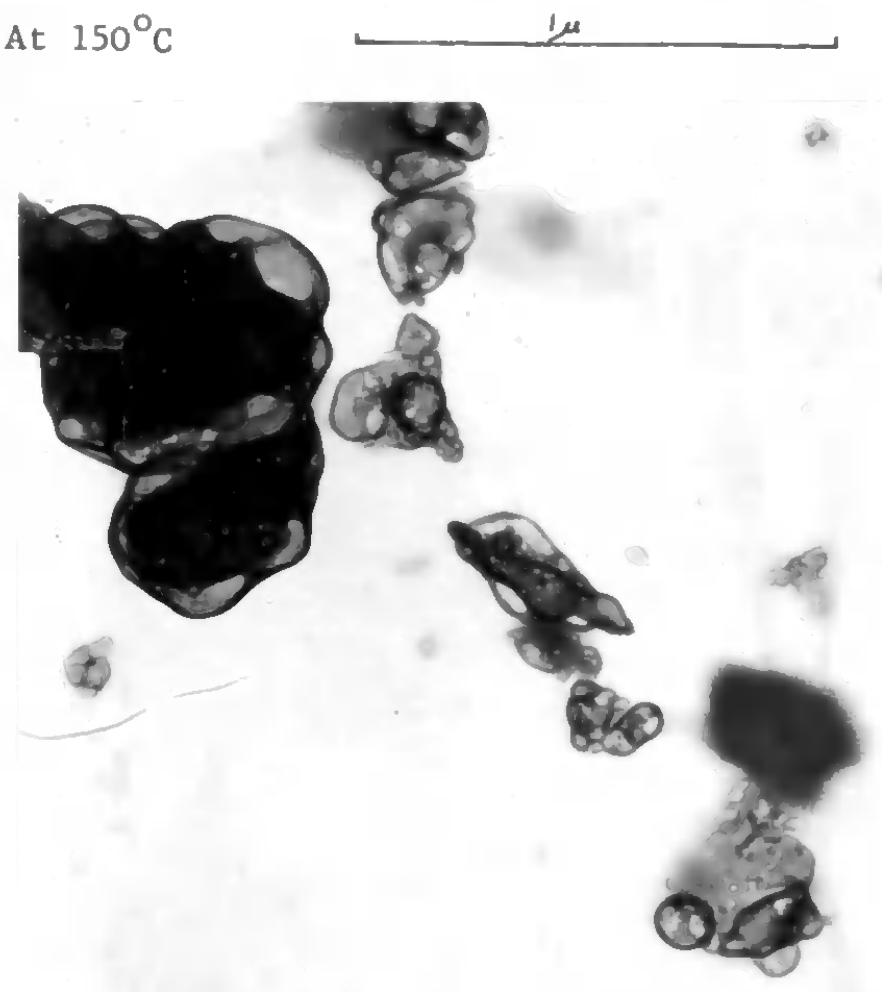

(d) At $310^{\circ} \mathrm{C}$

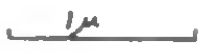


Figure 4.1.9
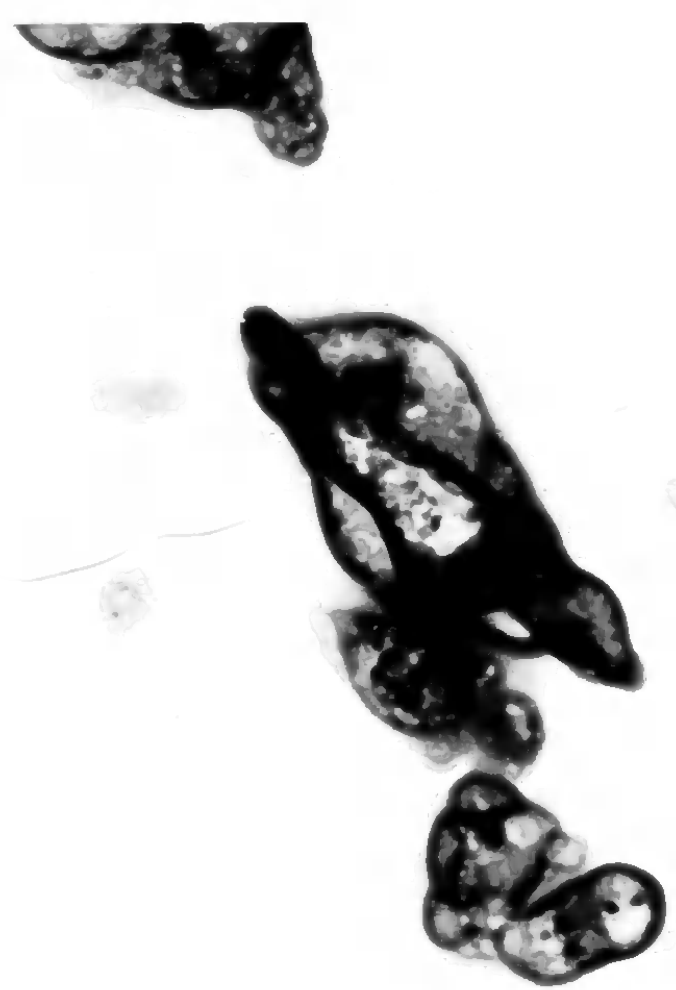

(e) At $310^{\circ} \mathrm{C}, 4$ minutes after (d)
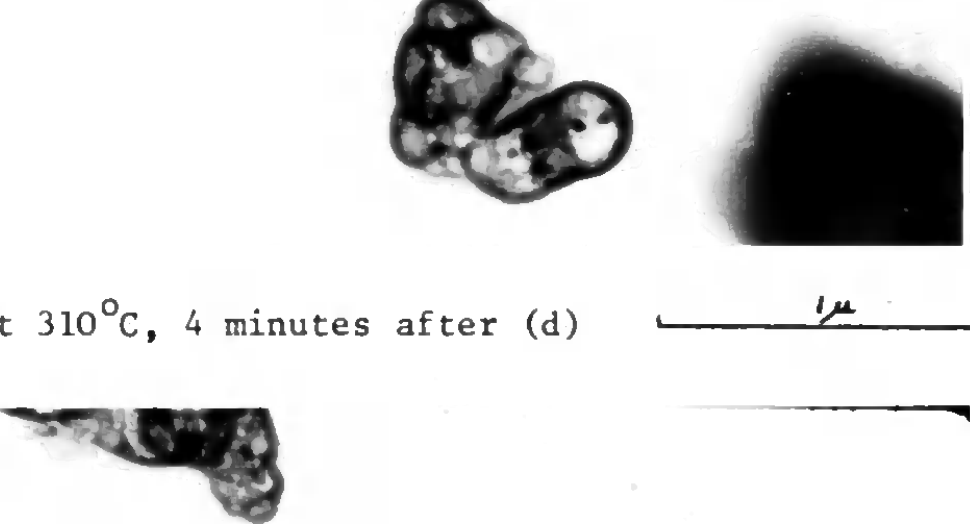

$1 \mu$

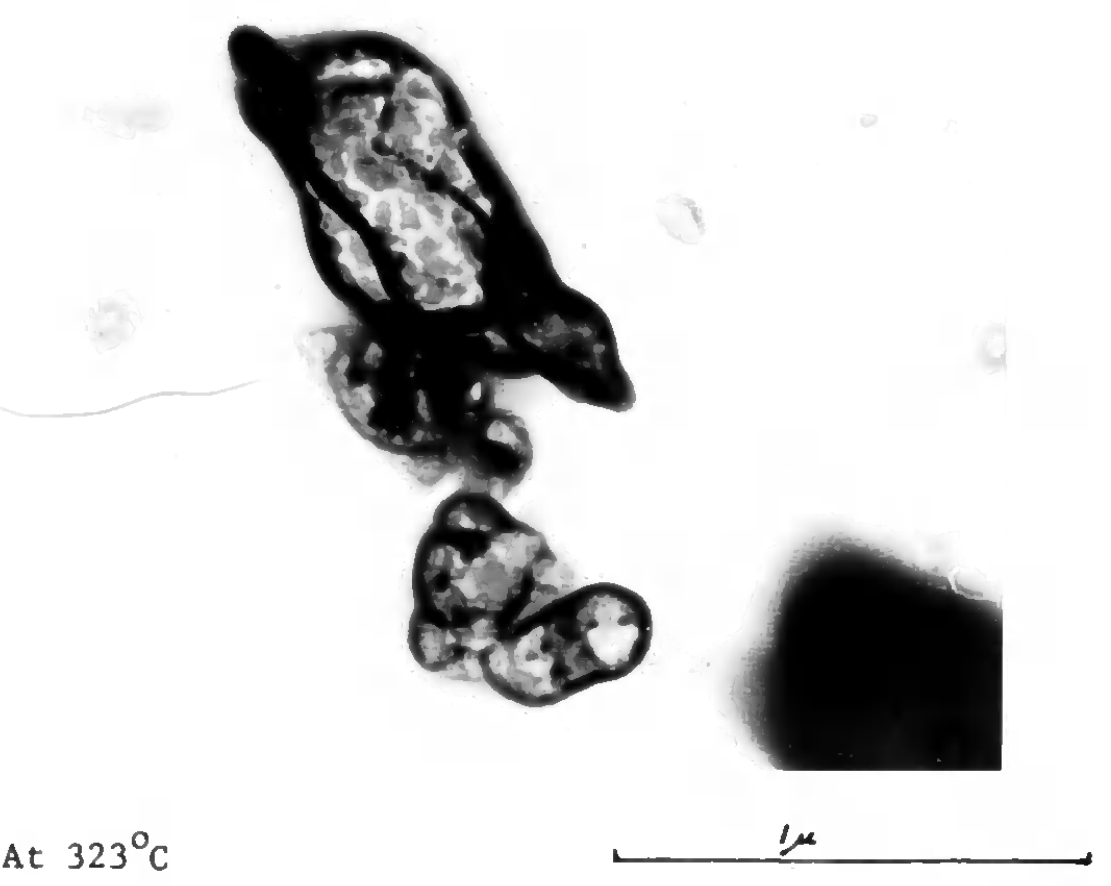

(f) At $323^{\circ} \mathrm{C}$ 
Figure 4.1.9

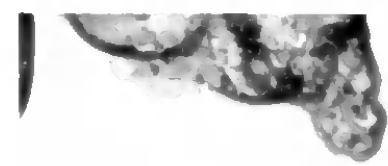

(g) At $467^{\circ} \mathrm{C}$
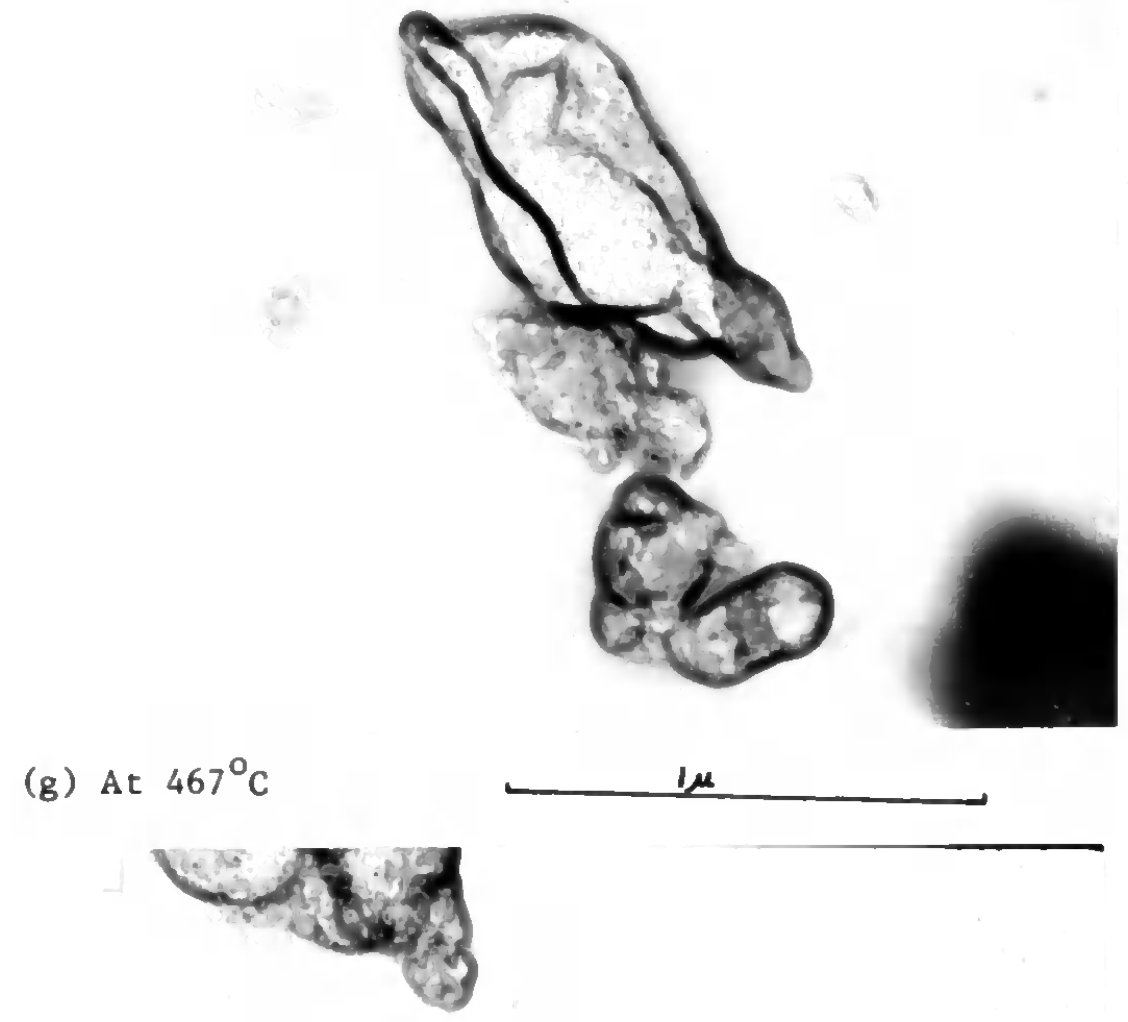

(h) At $594^{\circ} \mathrm{C}$
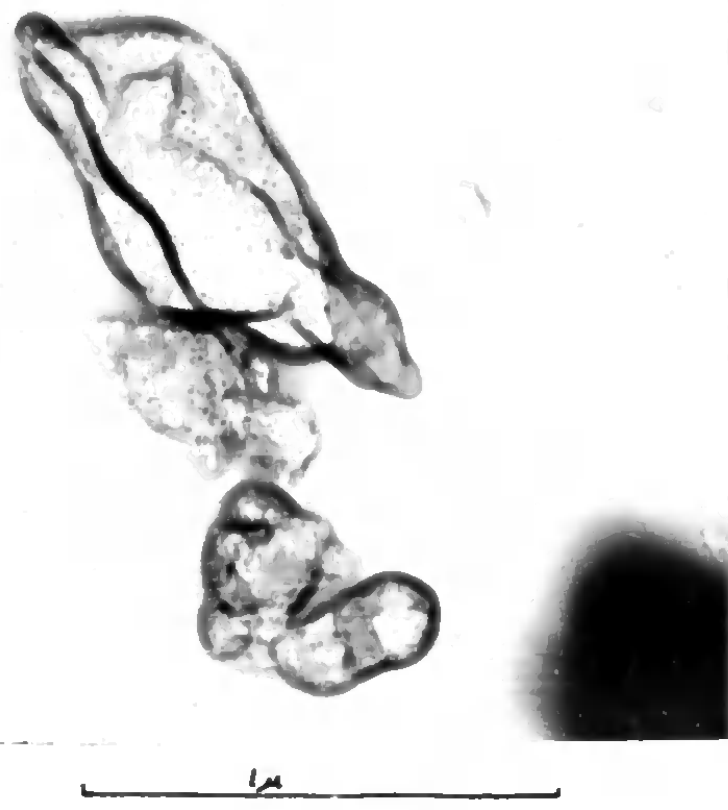
Figure 4.1.10 Specific surfaces of $\mathrm{MgSO}_{3} \cdot 6 \mathrm{H}_{2} \mathrm{O}$ samples calcined for $2 \mathrm{~h}$ in vacuo

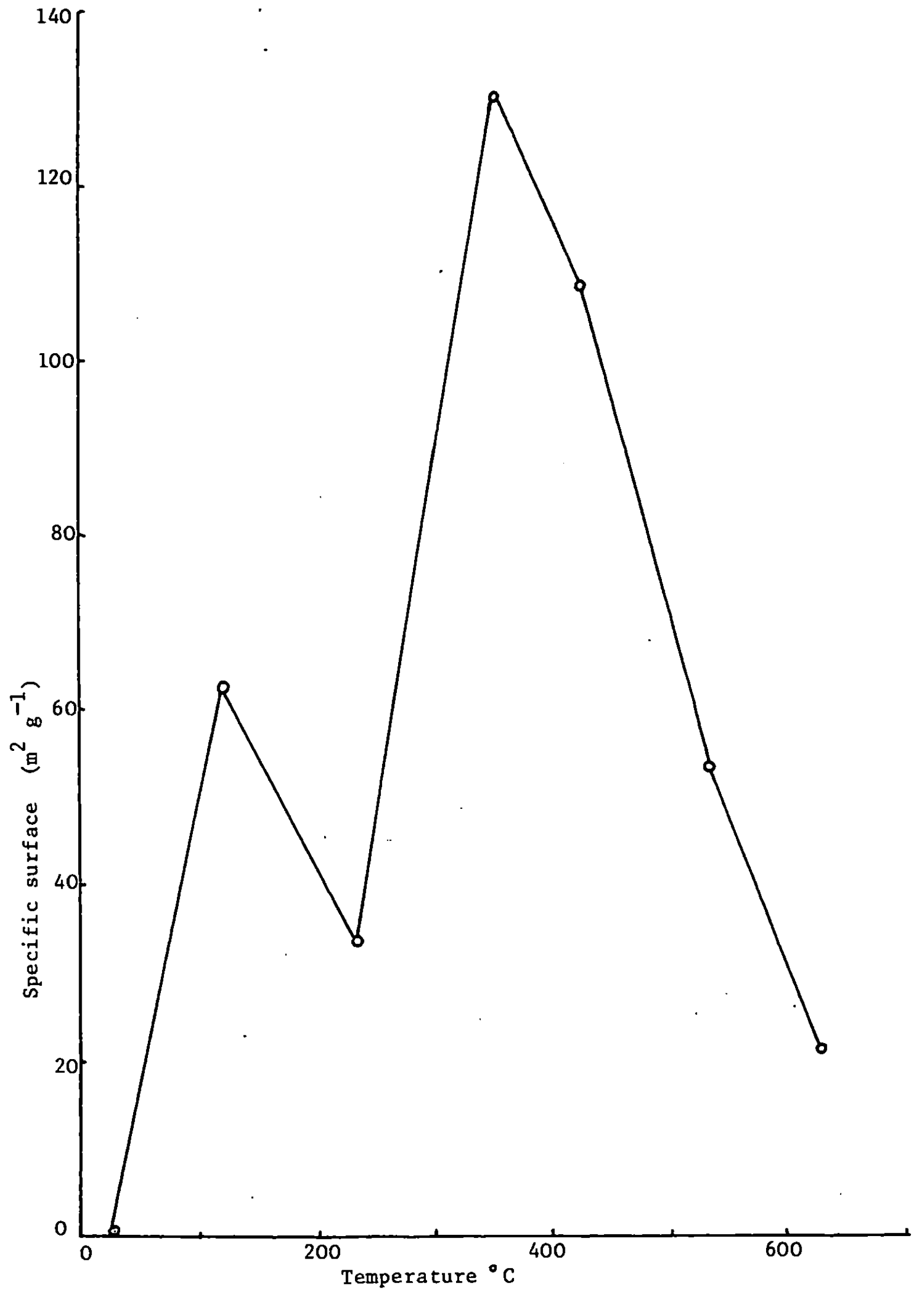


Figure 4.1.11 X-ray powder diffraction patterns of $\mathrm{MgSO}_{3} \cdot 6 \mathrm{H}_{2} \mathrm{O}$ samples calcined for $2 \mathrm{~h}$ in vacuo

(d) $425^{\circ} \mathrm{C}$
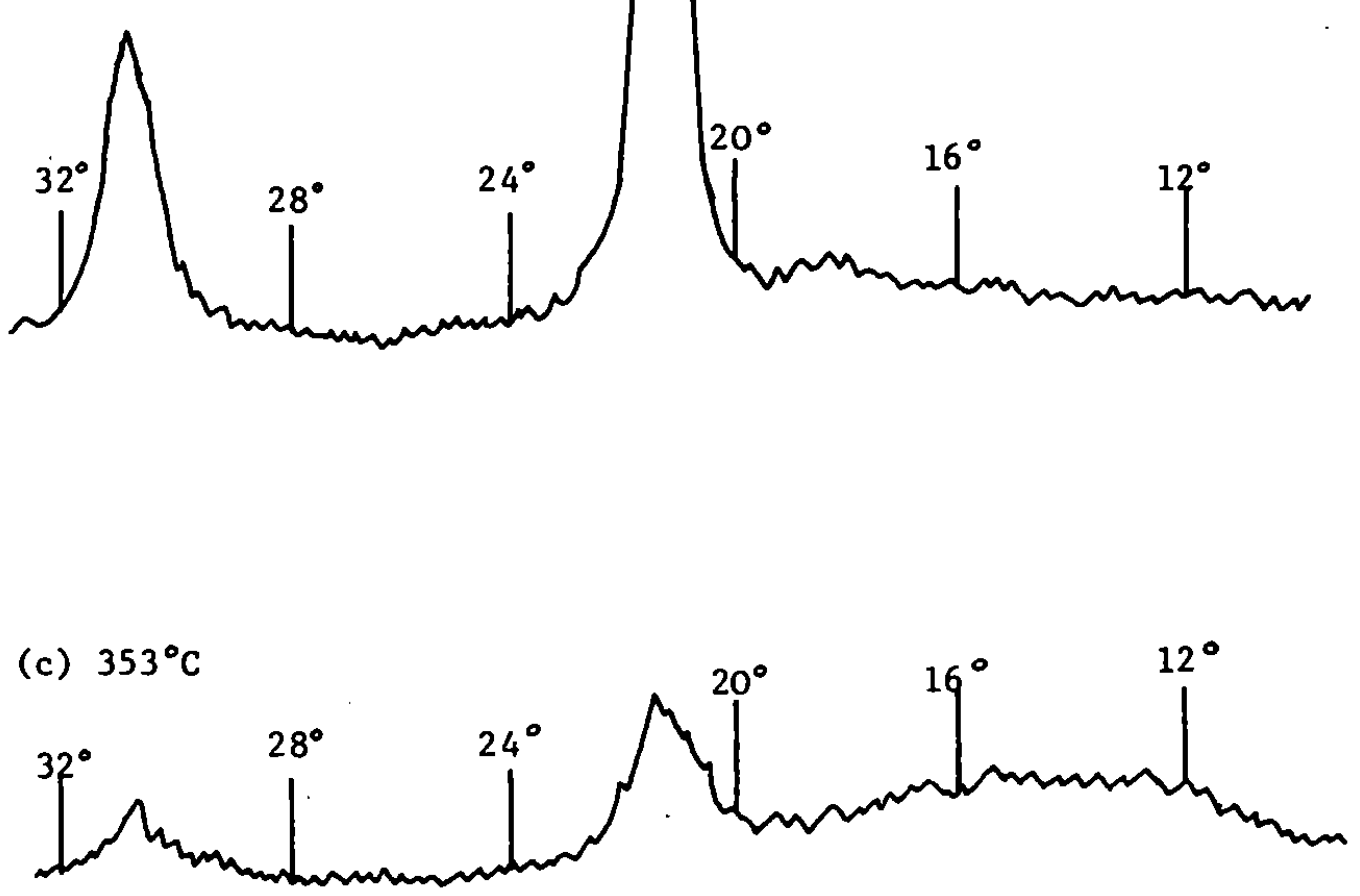

(b) $235^{\circ} \mathrm{C}$
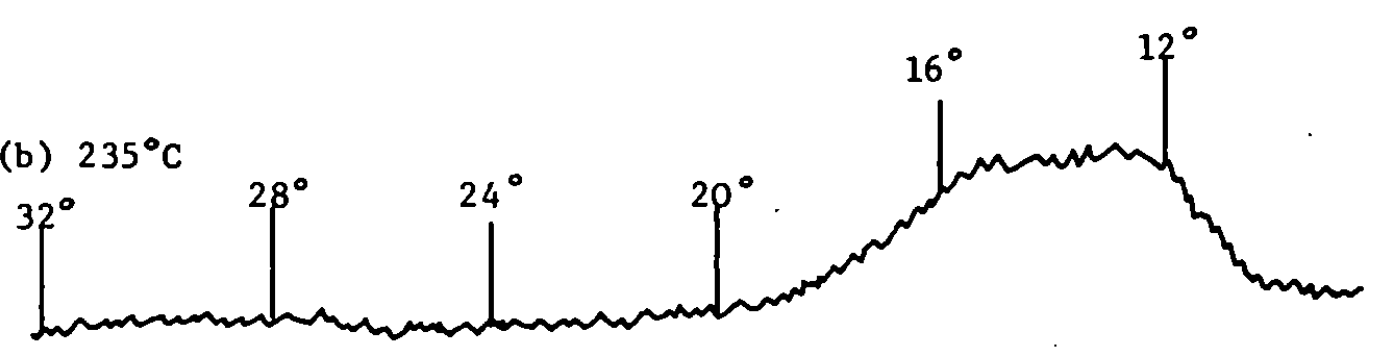

(a) $120^{\circ} \mathrm{C}$

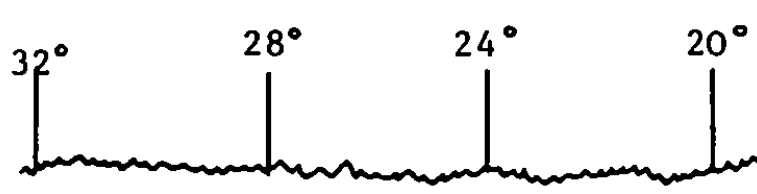


Figure 4.1.11

(f) $628^{\circ} \mathrm{C}$
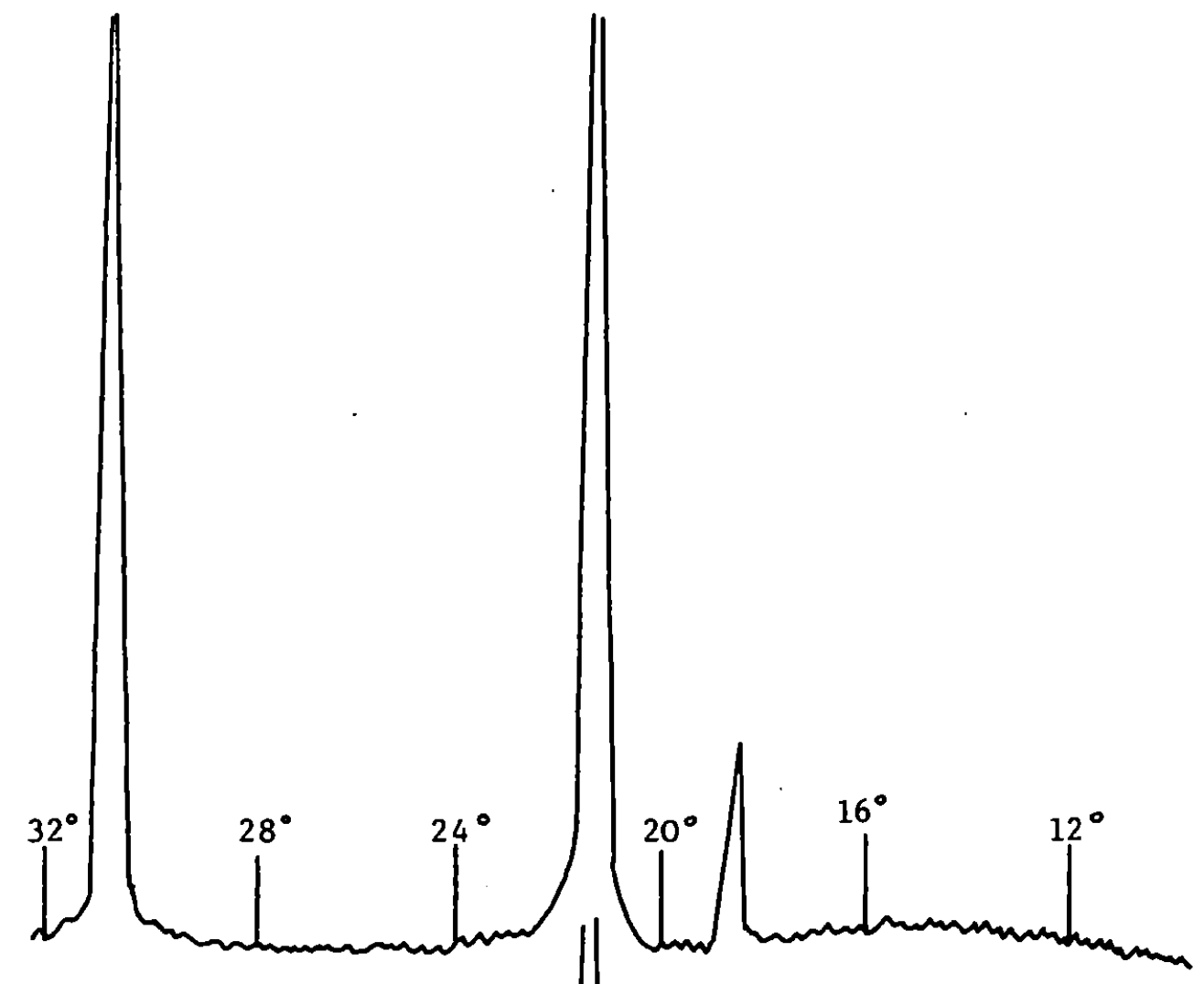

(e) $535^{\circ} \mathrm{C}$
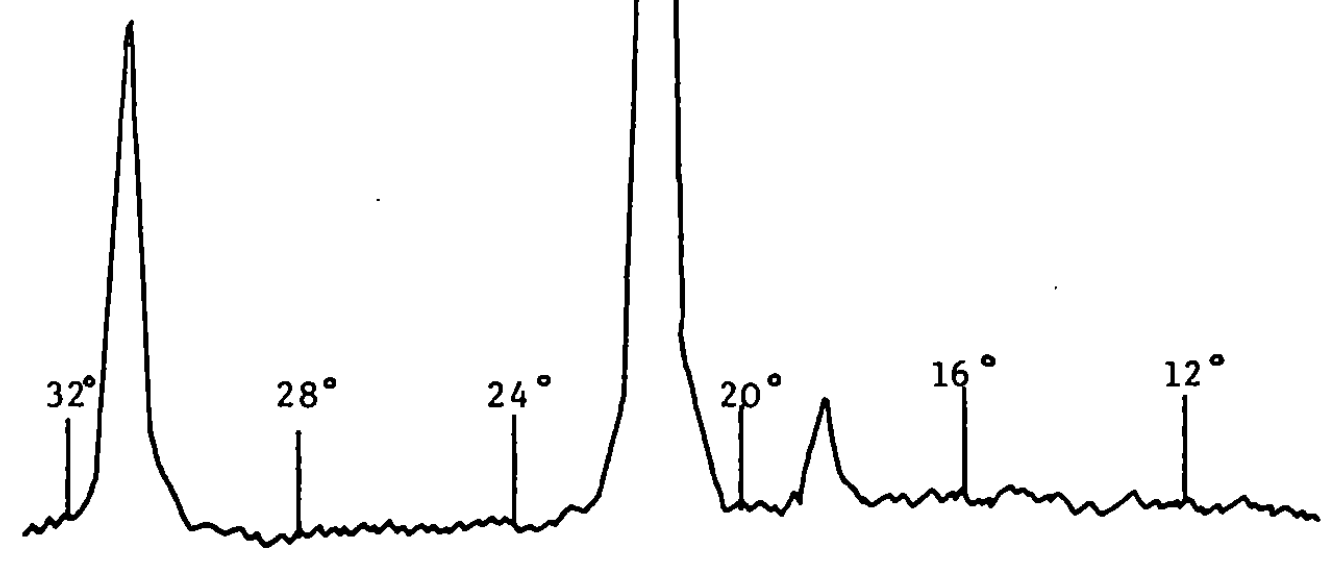
Figure 4.1.12 Parts of TG curves for $\mathrm{MgSO}_{3} \cdot 6 \mathrm{H}_{2} \mathrm{O}$ samples heated in air at $5^{\circ} \mathrm{C} \min ^{-1}$

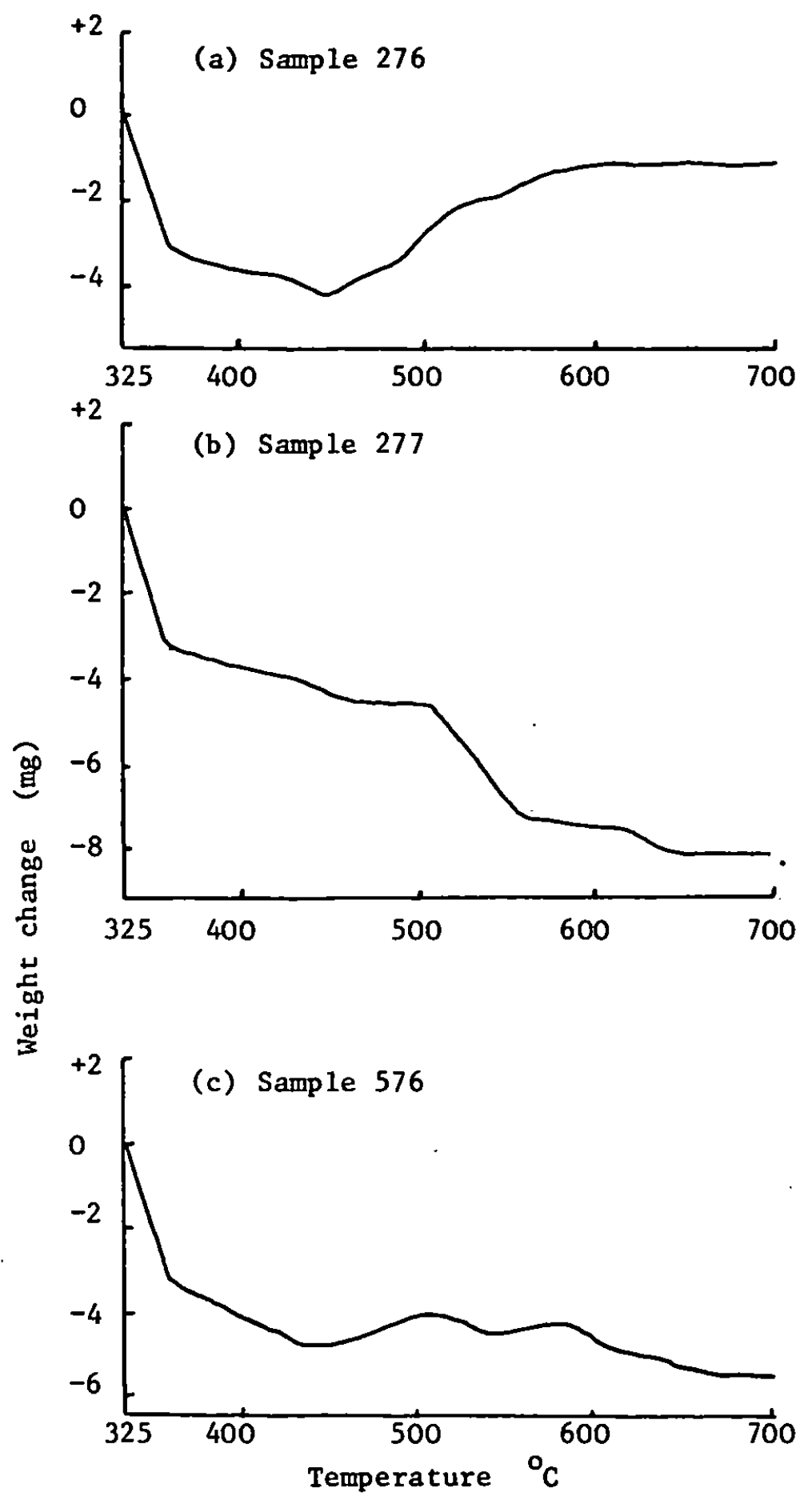


Figure 4.1.13 Exothermic peaks in DTA curves shown by $\mathrm{MgSO}_{3} \cdot 6 \mathrm{H}_{2} \mathrm{O}$ samples heated in air at $5^{\circ} \mathrm{C} \min ^{-1}$

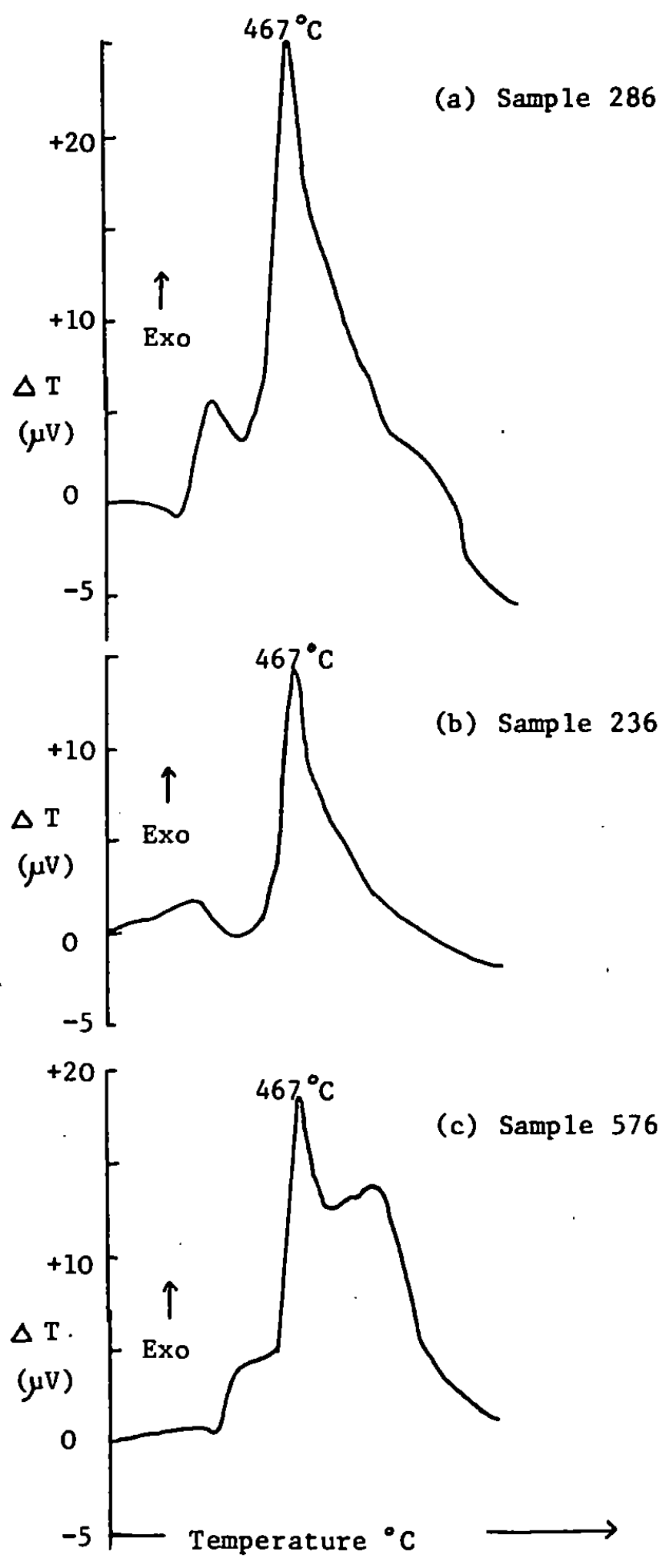




\section{CHAPTER FOUR}

\section{THERMAL STABILITY OF ALKALINE EARTH METAL SULPHITES}

Magnesium, calcium, strontium and barium sulphites have been prepared, as detailed in Chapter 3, and the various reactions they undergo on heating (a) in vacuo, (b) in nitrogen, (c) in air, (d) in sulphur dioxide and nitrogen, have been studied.

The results obtained for each alkaline earth metal compound will be discussed individually and the types of reaction will be compared for the sulphites of all four elements.

\subsection{Magnesium sulphite}

\section{1 .1 Results}

Dynamic thermogravimetry (TG) carried out under various atmospheric conditions, at a heating rate of $5^{\circ} \mathrm{C}$ per minute, gave the weight changes shown in figures $4.1 .1,4.1 .3,4.1 .5,4.1 .7$ and the simultaneous differential thermal analysis (DTA) curves are reproduced in figures $4.1 .2,4.1 .4,4.1 .6,4.1 .8$.

In all cases, the initial reaction was dehydration and the final product was magnesium oxide, but sometimes different intermediate reactions were found.

\section{(a) "In vacuo"}

The dehydration commenced at room temperature under a reduced pressure of $1.3 \mathrm{~Pa}\left(10^{-2}\right.$ torr $)$ and became very rapid between $42^{\circ} \mathrm{C}$ and $160^{\circ} \mathrm{C}$, fig. 4.1.1. This stage of the reaction was so violent that, in the first runs carried out under these conditions, the sample spurted out of the holder. To overcome this problem, silica wool was placed in the crucible above the sample to trap the solid particles but allow rapid escape of the gaseous products. In atmospheres of nitrogen and of air, where there was only occasional spurting, the presence or absence of the silica wool made no apparent difference to the TG and DTA results obtained and it was assumed that the "in 
vacuo" results were similarly unaffected.

The loss of water produced a single large endothermic peak at $113^{\circ} \mathrm{C}$, which terminated at $198^{\circ} \mathrm{C}$, fig. 4.1.2. Though the loss of water appeared to occur in one step, the last remnants (4.4\%) were not completely removed until the temperature reached $230^{\circ} \mathrm{C}$.

The final stages of the dehydration and the commencement of breakdown of the magnesium sulphite overlap, so that there was a steady weight loss as the temperature rose to $387^{\circ} \mathrm{C}$. At this temperature, $6 \%$ of the magnesium sulphite had been converted to magnesium oxide.

$$
\mathrm{MgSO}_{3} \longrightarrow \mathrm{MgO}+\mathrm{SO}_{2} 4.1
$$

Above this temperature the decomposition became rapid and desulphurisation was completed at $531^{\circ} \mathrm{C}$. This decomposition produced an endothermic peak at $506^{\circ} \mathrm{C}$ on the DTA curve.

The photomicrographs fig. 4.1 .9 (a) - (h) illustrate the effects, caused by the various stages of the reaction, on the morphology of crystals which were heated, on the hot-stage attachment, in the electron microscope (pressure $10^{-2} \mathrm{~Pa}$ ). Even with a nominal temperature of $25^{\circ} \mathrm{C}$, fig. 4.1.9.(a), dehydration had commenced, though, as discussed in chapter 2 , the actual temperature of the crystals may have been somewhat higher than the registered temperature due to the heating effect of the electron beam. The increase in temperature to $100^{\circ} \mathrm{C}$, fig. 4.1 .9 (b) caused the break-up of the original hexahydrate crystals. In particular, the crystal in the centre of the field of view became grossly distorted. An interesting feature of the changes was the "bubbling effect" which a number of the crystals showed as a result of dehydration. Other workers ${ }^{87}$ using hot-stage optical microscopy have observed similar effects during the dehydration of other hydrated compounds, but the structures have 
collapsed too rapidly for photographs to be obtained. The optical hot-stage microscope available for the work described in this thesis could not be operated with the sample in vacuo. Because of the small magnification and the large difference in refractive index between the crystals and their surroundings, it would have been unlikely that the phenomena would have been observed. The "bubbled" surfaces shown on the electron photomicrographs were preserved by the supporting section of the carbon film on the "blown out" fragments of magnesium sulphite. The dehydrated magnesium sulphite underwent some rearrangement of the crystallites as the temperature rose, Fig. $4.1 .9(\mathrm{c})$, to $150^{\circ} \mathrm{C}$, and higher magnifications could be used without causing further changes in structure. When the temperature reached $310^{\circ} \mathrm{C}, \mathrm{Fig}, 4.1 .9(\mathrm{~d})$ and (e), desulphurisation had commenced and the crystallites can be seen to have changed with time as (e) was taken four minutes after (d). Fig. 4.1.9(F), taken fourteen minutes after (e), with the temperature at $323^{\circ} \mathrm{C}$, showed that the rearrangement, due to loss of sulphur dioxide, was just about complete. The final two photomicrographs, (g) and (h) show the gradual reorganisation of the magnesium oxide crystallites as the temperature was increased further. Comparison with the low temperature photomicrographs indicated that the electron transmissivity of the magnesium oxide crystallites, despite their higher density, was much higher than that of the magnesium sulphite hexahydrate crystals. This was due to the thinning which had occurred on the loss of water and sulphur dioxide. On the basis that the crystals were tabular, and that only the thickness was reduced by the loss of mass $(81.02 \%)$, the magnesium oxide crystals would be less than one tenth the thickness of the original magnesium 
sulphite hexahydrate. The photomicrographs indicated that the reduction in thickness was probably greater than this as the area covered by the magnesium oxide crystals was about $20 \% 1$ arger than the area of the original crystals.

Samples of the hexahydrate were isothermally heated for two hour periods, in vacuo. The variation in specific surface of the product with temperature, Fig. 4.1.10, showed that the dehydration process produced a larye increase in surface area, followed by a decrease, as the freshly produced anhydrous magnesium sulphite crystallites became more ordered. The initial decomposition of the magnesium sulphite formed magnesium oxide with a high specific surface, as shown by the $353^{\circ} \mathrm{C}$ sample. Samples calcined at the higher temperatures of $425^{\circ} \mathrm{C}, 535^{\circ} \mathrm{C}$ and $628^{\circ} \mathrm{C}$ had specific surfaces which decreased as the temperature increased. Though the rapid rise to the isothermal caicination temperature would be expected to produce very high surface area products, due to extremely rapid dehydration and desulphurisation causing massive disruption of the crystal lattices, this effect would be superseded by the reorganisation of the final product as the crystal lattices became more ordered and the larger crystallites grew at the expense of the smaller ones. This latter process, which in the case of magnesium oxide involved only solid diffusion reactions, occurred more readily as the temperacure increased ${ }^{88}$. As a result, those samples in which the final products were held at the highest temperatures for the longest periods had the smallest specific surfaces .

The $\mathrm{x}$-ray diffraction traces of the products of isothermal heating showed, Fig. 4.1.11, that the initially crystalline magnesium sulphite hexahydrate formed essentially X-ray amorphous 
dehydrated products and, then, as the magnesium oxide crystallites became larger and more ordered the peaks due to the 200 and 220 reflections appeared and became sharper. Average crystallite sizes, Table 4.1.1 determined from (a) specific surfaces measurements and (b) peak broadening of the X-ray traces, both showed the same trend in increase in crystallite size with increasing temperature.

Table 4.1.1 Crystallite sizes of the products of the isothermal, in vacuo, calcination of $\mathrm{MgSO}_{3} \cdot 6 \mathrm{H}_{2} \mathrm{O}$.

\begin{tabular}{|c|c|c|}
\hline $\begin{array}{c}\text { Isothermal } \\
\text { calcination } \\
\text { temperature } \\
{ }^{\circ} \mathrm{C}\end{array}$ & $\begin{array}{c}\text { Apparent crystallite } \\
\text { size, based on X-ray } \\
\text { 1ine-broadening } \\
\text { nm }\end{array}$ & $\begin{array}{c}\text { Equivalent spherical } \\
\text { diameters, based } \\
\text { on specific surfaces } \\
\text { sm }\end{array}$ \\
\hline Initial sample. & - & 4900 \\
120 & - & 40 \\
235 & - & 75 \\
353 & 5 & 13 \\
425 & 7 & 15 \\
535 & 21 & 32 \\
628 & 47 & 77 \\
\hline
\end{tabular}

Chemical analyses of the isothermally decomposed samples showed that the $120^{\circ} \mathrm{C}$ sample was $96.5 \%$ dehydrated. The $235^{\circ} \mathrm{C}$ sample was completely dehydrated and $15 \%$ of the magnesium sulphite had been converted to magnesium oxide. The remaining samples were completely converted to magnesium oxide.

\section{(b) In nitrogen}

Both the dynamic thermogravimetric curve, Fig. 4.1.3, and the DTA curve, Fig. 4.1.4, for the calcinations carried out in an atmosphere of nitrogen, flowing at a rate of $11 \mathrm{~min}^{-1}$, showed 
differences from the corresponding "in vacuo" curves. The increased pressure due to the atmosphere of nitrogen (approx. $1 \times 10^{5} \mathrm{~Pa}$ ) increased the temperature, at which dehydration produced a noticeable weight change, to $54^{\circ} \mathrm{C}$ compared to $20^{\circ} \mathrm{C}$ at $1.3 \mathrm{~Pa}$. However, the DTA curve showed that the first endotherm associated with the dehydration reaction had an initial deviation temperature of $42^{\circ} \mathrm{C}$ indicating that the initial stages in the dehydration had produced a rearrangement of the crystal structure before a weight loss was recorded. The dehydration occurred rapidly as the temperature rose to $114^{\circ} \mathrm{C}, \cdot$ by which time the equivalent of three molecules of water had been lost. The rate of weight loss was reduced for about $5^{\circ} \mathrm{C}$ rise and then increased again as approximately another two and a half molecules of water were lost as the temperature rose to $215^{\circ} \mathrm{C}$. By $350^{\circ} \mathrm{C}$ the final $6.8 \%$ of the water (equivalent to $0.4 \mathrm{H}_{2}$ ) was removed. This three step process was also indicated in the DTA curve where there were three endotherms with peak temperatures of $105^{\circ} \mathrm{C}, 193^{\circ} \mathrm{C}$ and $336^{\circ} \mathrm{C}$.

The weight loss gradually increased as the temperature rose above. $400^{\circ} \mathrm{C}$, as a result of the decomposition of the magnesium sulphite, but, unlike the decomposition in vacuo, this desulphurisation stage came to an end at $576^{\circ} \mathrm{C}$ before there was complete conversion to magnesium oxide. A sample which had been heated to $639^{\circ} \mathrm{C}$ and analysed after rapid cooling was found to contain $46.1 \% \mathrm{MgSO}_{4}, 53.8 \% \mathrm{MgO}$ and $0.2 \% \mathrm{MgS}$.

A number of competing reactions can be considered to take place: (1) Decomposition of magnesium sulphite to form magnesium oxide

$$
\mathrm{MgSO}_{3} \longrightarrow \mathrm{MgO}+\mathrm{SO}_{2} 4.1
$$

This became the dominant reaction above $440^{\circ} \mathrm{C}$, but occurred to a lesser extent at lower temperatures. 
(2) Formation of magnesium thiosulphate

$$
\begin{array}{ll}
\mathrm{MgSO}_{3} \longrightarrow \mathrm{MgO}+\mathrm{SO}_{2} & 4.1 \\
4 \mathrm{MgSO}_{3}+2 \mathrm{SO}_{2} \longrightarrow \mathrm{MgSO}_{4}+\mathrm{S}_{2} & 4.2 \\
2 \mathrm{MgSO}_{3}+\mathrm{S}_{2} \longrightarrow \mathrm{MgS}_{2} \mathrm{O}_{3} & 4.3
\end{array}
$$

This series of reactions occurred to a small extent at temperatures above $300^{\circ} \mathrm{C}$, with $1.4 \% \mathrm{Mg}_{2} \mathrm{~S}_{2} \mathrm{O}_{3}$ being found in a sample which had been heated to $370^{\circ} \mathrm{C}$ and then cooled rapidly. As the temperature increased, two factors would tend to reduce the quantities of magnesium thiosulphate produced, namely the increase in vapour pressure of any sulphur formed would reduce the chances of it reacting with magnesium sulphite and the rate of dissociation of the magnesium thiosulphate would increase.

$$
\begin{array}{ll}
2 \mathrm{MgS}_{2} \mathrm{O}_{3} \longrightarrow 2 \mathrm{MgO}+2 \mathrm{SO}_{2}+\mathrm{S}_{2} & 4.4 \\
2 \mathrm{MgS}_{2} \mathrm{O}_{3} \longrightarrow 2 \mathrm{MgSO}_{3}+\mathrm{S}_{2} & 4.5
\end{array}
$$

(3) Formation of sulphur

No direct evidence of the formation of sulphur was found in samples heated on the Mass-Flow balance, but other workers 38,89 have described the formation of sulphur in small quantities. A $1 \mathrm{~g}$ sample of magnesium sulphite hexahydrate was heated in nitrogen (flow rate $1 \mathrm{~min}^{-1}$ ) at $320^{\circ} \mathrm{C}$ for one hour, with the exit gases passing over a cold finger. A total of $1.8 \%$ sulphur was found, together with $3.8 \%$ $\mathrm{MgS}_{2} \mathrm{O}_{3}$. The most probable method for the formation of sulphur would be by reactions 4.1 and 4.2 .

(4) Formation of magnesium sulphate

Reactions 4.1 and 4.2 as well as playing a part in the production of sulphur and magnesium thiosulphate also yield magnesium sulphate. Disproportionation of magnesium sulphite would be another reaction by which magnesium sulphate could be formed

$$
4 \mathrm{MgSO}_{3} \longrightarrow 3 \mathrm{MgSO}_{4}+\mathrm{MgS} \quad 4.6
$$


Disproportionation did not appear to be a major reaction pathway as only traces of magnesium sulphide were found in the $639^{\circ} \mathrm{C}$ sample and even this magnesium sulphide could have been formed by reaction of magnesium oxide and sulphur

$$
2 \mathrm{MgO}+\mathrm{S}_{2} \longrightarrow 2 \mathrm{MgS}+\mathrm{O}_{2} \quad 4.7
$$

Schwitzgebel and Lowe $11^{90}$ have reported that "no $\mathrm{MgS}$ is found in the decomposition products", however, earlier in the same article they state "In contrast to the findings from most of the other sulfites few or no sulfides were found in magnesium sulfite decomposition products." Certainly the small amount of published work on magnesium sulphite does not specifically mention the formation of magnesium sulphide.

The TG curve indicated the presence of magnesium sulphate, which was stable until the temperature reached $819^{\circ} \mathrm{C}$ when gradual conversion to magnesium oxide occurred. The decomposition being completed at $1002{ }^{\circ} \mathrm{C}$. The conversion of $22.3 \%$ of the original magnesium sulphite to magnesium sulphate provided this step in the TG curve, which was not found in vacuo. The higher pressure of about $1 \times 10^{5} \mathrm{~Pa}$ (760 torr), compared to $1.3 \mathrm{~Pa}\left(10^{-2}\right.$ torr) in vacuo, under which the reactions occurred, in the runs carried out in nitrogen, reduced the rate of evolution of sulphur dioxide, thus more time was allowed for the interaction between sulphur dioxide and the undecomposed magnesium sulphite, required to produce magnesium sulphate (reaction 4.2). The higher temperature at which the main decomposition of the magnesium sulphite occurred in nitrogen $\left(437^{\circ}-\right.$ $576^{\circ} \mathrm{C}$ compared to $387^{\circ}-531^{\circ} \mathrm{C}$, in vacuo) (a) gave more time for the secondary reactions to occur, and (b) as the secondary reactions were occurring at higher temperatures their rates of reaction would be increased. The higher temperature reactions would favour the 
production of magnesium sulphate and sulphur since magnesium thiosulphate, which had a similar stability range as magnesium sulphite, would be unstable above $500^{\circ} \mathrm{C}^{89}$. The volatility of sulphur, boiling point $444.6^{\circ} \mathrm{C}$, would also be much greater at these higher temperatures, which would markedly reduce the tendency for the magnesium thiosulphate reaction (4.3) to occur.

The various peaks in the DTA curve may be explained as follows. At $385^{\circ} \mathrm{C}$ an endotherm, due to initial decomposition of magnesium sulphite, commenced, but this was soon converted into an exotherm, as magnesium sulphate was formed, to give a peak at $460^{\circ} \mathrm{C}$. The large scale decomposition of the magnesium sulphite then became the major reaction and the endotherm peaking at $550^{\circ} \mathrm{C}$ was produced. The final decomposition of the magnesium sulphate was shown by the broad endotherm peaking at $960^{\circ}-970^{\circ} \mathrm{C}$.

\section{(c) In air}

The TG, Fig. 4.1.5, and DTA, Fig. 4.1.6, curves were initially similar to those given in nitrogen. Dehydration occurred in three steps, with initial loss of three molecules of water between $57^{\circ} \mathrm{C}$ and $115^{\circ} \mathrm{C}$, followed by the loss of approximately two and a half molecules of water by $220^{\circ} \mathrm{C}$ and the remaining water by $340^{\circ} \mathrm{C}$. The presence of oxygen introduced the possibility of oxidation of the magnesium sulphite to magnesium sulphate occurring, 4.8, in addition to the various reactions 4.1 to 4.7 discussed above.

$$
2 \mathrm{MgSO}_{3}+\mathrm{O}_{2} \longrightarrow \mathrm{2MgSO}_{4} \quad 4.8
$$

The major reactions occurring in air were the oxidation reaction 4.8 and decomposition reaction 4.1 and the small weight changes which were recorded between $340^{\circ} \mathrm{C}$ and $600^{\circ} \mathrm{C}$ indicated that the overall effects of these two reactions just about cancelled each other out. In practice it was found that different samples 
produced slightly different results and the TG curve, Fig. 4.1.5, was a record of the mean of the weight changes observed. In Fig. 4.1.12 other actual traces of a number of TG curves, as recorded, have been reproduced to indicate the variation actually observed and in Table 4.1.2 the percentage conversion of magnesium sulphite to magnesium sulphate and magnesium oxide has been presented.

Table 4.1.2 Proportional oxidation and desulphurisation of $\mathrm{MgSO}_{3}$ in air

\begin{tabular}{|c|c|c|}
\hline $\begin{array}{c}\text { Calcination temperature } \\
{ }^{\circ} \mathrm{C}\end{array}$ & \multicolumn{2}{|c|}{$\begin{array}{r}\text { Percentage of } \mathrm{MgSO}_{3} \text { converted to } \\
\text { (a) } \mathrm{MgSO}_{4}\end{array}$} \\
\hline & \multicolumn{3}{|c|}{ (b) $\mathrm{Mg0}$} \\
\hline 400 & 25.3 & 5.4 \\
450 & 50.5 & 13.0 \\
500 & 66.3 & 19.4 \\
550 & 73.8 & 22.6 \\
600 & 76.1 & 23.9 \\
\hline
\end{tabular}

The oxidation reaction produced an exotherm in the DTA curve with usually one or two shoulders, presumably as a result of the competing endothermic dissociation reaction, though the oxidation process itself may have been complex with the individual steps in the process producing a series of exothermic reactions. As with the TG curves, the details of the DTA curves varied between runs as illustrated in Fig. 4.1.13, but in every case the maximum exothermic deflection occurred at $467^{\circ} \mathrm{C}$.

Comparison of the TG curves obtained in nitrogen and in air (Fig. 4.1.3 and 4.1.5) and of the corresponding DTA curves (Fig. 4.1.4 and 4.1 .6 ) showed clearly that, in the $400^{\circ}-600^{\circ} \mathrm{C}$ temperature range, in nitrogen the decomposition of magnesium sulphite to form 
magnesium oxide was the dominant reaction, which produced a large weight loss and endothermic deflection, whereas, in air, the loss in weight was very much less and an exothermic deflection was produced due to the dominance of the magnesium sulphate forming reaction.

The magnesium sulphate was more stable in air than in nitrogen and began to decompose at $883^{\circ} \mathrm{C}\left(\mathrm{cf} .819^{\circ} \mathrm{C}\right.$ in $\left.\mathrm{N}_{2}\right)$. The decomposition to magnesium oxide was completed with the temperature at $1022^{\circ} \mathrm{C}$, and an endotherm peaking at $986^{\circ} \mathrm{C}$ was recorded in the D.T.A. curve. (d) In mixtures of sulphur dioxide and nitrogen

Figs. 4.1 .7 and 4.1 .8 record the results which were obtained when magnesium sulphite hexahydrate was thermally decomposed in the presence of (a) 2.8 vol $\% \mathrm{SO}_{2}$ in $\mathrm{N}_{2}$ and (b) 20.9 vol \% $\mathrm{SO}_{2}$ in $\mathrm{N}_{2}$. The results obtained, particularly with the higher concentration of sulphur dioxide, indicated that magnesium sulphite was more readily oxidised by oxygen (air contains 20.95 vol $\% 0_{2}^{91}$ ) than by sulphur dioxide.

The presence of 2.8 vol $\% \mathrm{SO}_{2}$ in $\mathrm{N}_{2}$ made little apparent difference to the TG curve, for the dehydration of the hexahydrate, compared to the use of nitrogen alone. However in the DTA curve what was a single endotherm, in nitrogen, corresponding to the loss of three molecules of water appeared as a composite of two over lapping peaks with maxima at $88^{\circ} \mathrm{C}$ and $98^{\circ} \mathrm{C}$. With a higher concentration of sulphur dioxide, 20.9 vol $\%$, the resolution into two endothermic peaks was even clearer. This double initial endotherm, coinciding with the loss of the first three molecules of water, had been reported by Okabe and Hor $i^{43}$ for DTA runs carried out in air at heating rates of $3^{\circ} \mathrm{C}$ and $5^{\circ} \mathrm{C}$ per minute. They used relatively large samples, $0.5 \mathrm{~g}$ compared to the $0.1 \mathrm{~g}$ samples used in the present work and this would explain the absence of two peaks 
for the runs in air, and presumably nitrogen. The greater density of sulphur dioxide, compared to nitrogen and oxygen, meant that the pressure in the reaction vessel was raised and this would increase the resolution of the DTA peaks 56 . The TG curve gave no indication of a two stage loss of water in this temperature range. $\mathrm{MgSO}_{3} \cdot 6 \mathrm{H}_{2} \mathrm{O}$ has a rhombohedral structure with three molecules in the unit cel1 81 whereas $\mathrm{MgSO}_{3} \cdot 3 \mathrm{H}_{2} \mathrm{O}$ has an orthorhombic structure with four molecules in the unit cel1 82 . The two peaks could be due to the combined effects of (a) loss of water and (b) rearrangement of the crystal lattice. That the $\mathrm{MgSO}_{3} \cdot 3 \mathrm{H}_{2} \mathrm{O}$ lattice was stabilised by the presence of sulphur dioxide (or the higher pressure associated with its presence) was shown by the relatively long interval $\left(114^{\circ} \mathrm{C}-157^{\circ} \mathrm{C}\right.$ in 20.9 vol \% $\mathrm{SO}_{2}$ ) before the $\mathrm{MgSO}_{3} \cdot 3 \mathrm{H}_{2} \mathrm{O}$ began to decompose rapidly and a further two and a half molecules of water were lost.

The final stages of dehydration were accompanied by the onset of oxidation, with the higher concentration of sulphur dioxide producing a greater degree of oxidation.

$$
2 \mathrm{MgSO}_{3}+\mathrm{SO}_{2} \longrightarrow 2 \mathrm{MgSO}_{4}+\mathrm{S}
$$

The concentrations of the various products, Table 4.1.3, and the weight changes observed, Fig. 4.1.7, indicated that the presence of sulphur dioxide reduced the initial rate of decomposition of magnesium sulphite, but the degree of oxidation of the remaining sulphite was not as great as in air. The breakdown, to magnesium oxide, of both the magnesium sulphite and the small quantity of magnesium thiosulphate which had been formed, became the dominant reaction above $502^{\circ} \mathrm{C}$. 
Table 4.1.3 Composition of magnesium sulphite samples heated in $\mathrm{SO}_{2}$ and $\mathrm{N}_{2}$ at $5^{\circ} \mathrm{C} \min ^{-1}$.

\begin{tabular}{|c|c|c|c|c|c|c|}
\hline \multirow{2}{*}{$\begin{array}{l}\text { Volume } \% \\
\mathrm{SO}_{2} \text { in } \mathrm{N}_{2}\end{array}$} & \multirow{2}{*}{$\begin{array}{c}\text { Temperature } \\
{ }^{\circ} \mathrm{C}\end{array}$} & \multirow{2}{*}{$\begin{array}{r}\text { Wt loss \% } \\
\left(\mathrm{MgSO}_{3} \cdot 6 \mathrm{H}_{2} \mathrm{O}\right) \\
\end{array}$} & \multicolumn{4}{|c|}{ Composition \% } \\
\hline & & & $\mathrm{MgSO}_{3}$ & $\mathrm{MgS}_{2} \mathrm{O}_{3}$ & $\mathrm{MgSO}_{4}$ & $\mathrm{MgO}$ \\
\hline 2.76 & 421 & 50.1 & 84.5 & 0.8 & 14.4 & 0.3 \\
\hline 2.76 & $615-890$ & 68.2 & - & - & 60.8 & 39.2 \\
\hline 20.9 & 496 & 47.8 & 53.8 & 2.2 & 43.7 & 0.3 \\
\hline 20.9 & $590-960$ & 63.3 & - & - & 72.7 & 27.3 \\
\hline
\end{tabular}

The formation of magnesium thiosulphate depended upon the reaction sequence $4.1,4.2,4.3$. The increased concentration of sulphur dioxide would reduce the rate of reaction 4.1 , but the rate of reaction 4.2 would be increased, and hence the total amount of magnesium thiosulphate formed should be increased compared to the reactions in nitrogen alone. However, when the magnesium sulphate and sulphur were formed by the action of the sulphur dioxide in the surrounding gas atmosphere the conversion would take place from the outside of the particle inwards. The sulphur so produced, unless it reacted rapidly with magnesium sulphite would be isolated from further reaction as the $\mathrm{SO}_{2} / \mathrm{MgSO}_{3}$ reaction zone moved inwards leaving the sulphur surrounded by magnesium sulphate. The sulphur would tend to migrate outwards, due to its high vapour pressure at these temperatures, and only come in contact with magnesium sulphate, or more sulphur, as it did so. In contrast the production of magnesium sulphate and sulphur by the thermal decomposition of magnesium sulphite would be more evenly spread through the particle and the sulphur which migrated towards the exterior could come in contact with magnesium sulphite to allow reaction 4.3 to occur. 
The stability range of magnesium sulphate was increased to higher temperatures by the presence of sulphur dioxide. The onset of decomposition was at $890^{\circ} \mathrm{C}$ in $2.8 \mathrm{vol} \% \mathrm{SO}_{2}$ and $965^{\circ} \mathrm{C}$ in 20.9 vol $\% \mathrm{SO}_{2}$ compared to $819^{\circ} \mathrm{C}$ in nitrogen and $883^{\circ} \mathrm{C}$ in air. These changes were qualitatively as predicted by reaction 4.10 with the partial pressure of sulphur dioxide having a greater effect than the partial pressure of oxygen on the equilibrium constant.

$$
2 \mathrm{MgSO}_{4} \longrightarrow 2 \mathrm{MgO}+2 \mathrm{SO}_{2}+\mathrm{O}_{2} \quad 4.10
$$

The DTA curve, Fig. 4.1.8, showed that the initial exothermic oxidation reaction almost completely masked the final endothermic loss of water. The main oxidation produced the exothermic peak between $420^{\circ}$ and $487^{\circ} \mathrm{C}$ followed by the large endotherm related to the formation of magnesium oxide between $500^{\circ}$ and $600^{\circ} \mathrm{C}$. This. endotherm commenced at $483^{\circ} \mathrm{C}$ in $2.8 \mathrm{vol} \% \mathrm{SO}_{2}$ and $511^{\circ} \mathrm{C}$ in $20.9 \mathrm{vol}$ $\%_{\mathrm{SO}}{ }_{2}$. The final decomposition of the magnesium sulphate was marked by the endotherms peaking between $980^{\circ}$ and $990^{\circ} \mathrm{C}$.

\subsubsection{Discussion}

The dehydration of magnesium sulphite hexahydrate clearly involved the production of magnesium sulphite trihydrate as an intermediate, except "in vacuo" where the reaction was too rapid to distinguish this step. The crystal structure of the hexahydrate was rhombohedral with three molecules in the unit cell whereas the trihydrate was orthorhombic with four molecules in its unit cell. The water molecules in the hexahydrate were arranged octahedrally. around the magnesium ion with two axial waters having slightly. longer $\mathrm{Mg}-\mathrm{O}$ bond lengths than the four square planar molecules 81 . The twoustep dehydration process indicated by DTA measurements in $\mathrm{SO}_{2}$ and in air ${ }^{43}$ could possibly be due to the initial loss of two molecules of water followed by the loss of the third molecule in 
association with the rearrangement of the crystal structure.

The question of the formation of a hemihydrate was not satisfactorily resolved. Long periods of dehydration at temperatures below $200^{\circ} \mathrm{C}$ led to the removal of more than five and a half molecules of water. Nevertheless the last few percent of water was very difficult to remove, as the TG curves also indicate. Other workers ${ }^{82}$ have heated both the hexahydrate and trihydrate for 94 hour periods, at $160^{\circ} \mathrm{C}$, and obtained a product of composition $\mathrm{MgSO}_{3} \cdot 0.5 \mathrm{H}_{2} \mathrm{O}$.

After dehydration the subsequent reaction sequence appeared simple "in vacuo", with rapid decomposition to magnesium oxide, whereas, in nitrogen, a number of side reactions occurred leading to the formation of magnesium sulphate together with some magnesium thiosulphate and magnesium sulphide. In air and sulphur dioxide the formation of magnesium sulphate was mainly by direct oxidation reactions with the introduced atmosphere resulting in a greater degree of conversion to sulphate. The final reaction was the decomposition of the sulphate to magnesium oxide.

A recent study ${ }^{92}$ of $\mathrm{MgSO}_{3} \cdot 6 \mathrm{H}_{2} \mathrm{O}$, using DTA at $10^{\circ} \mathrm{Cmin}^{-1}$ and TG and DTG (derivative thermogravimetry) at $2^{\circ} \mathrm{C} \min ^{-1}$, both in argon, produced results essentially similar to those obtained in nitrogen, in the present work; variations were of the type expected from the different heating rates and equipment. No explanation of the results was offered, apart from the dehydration occurring in two steps with $\mathrm{MgSO}_{3} \cdot 3 \mathrm{H}_{2} \mathrm{O}$ as an intermediate. 


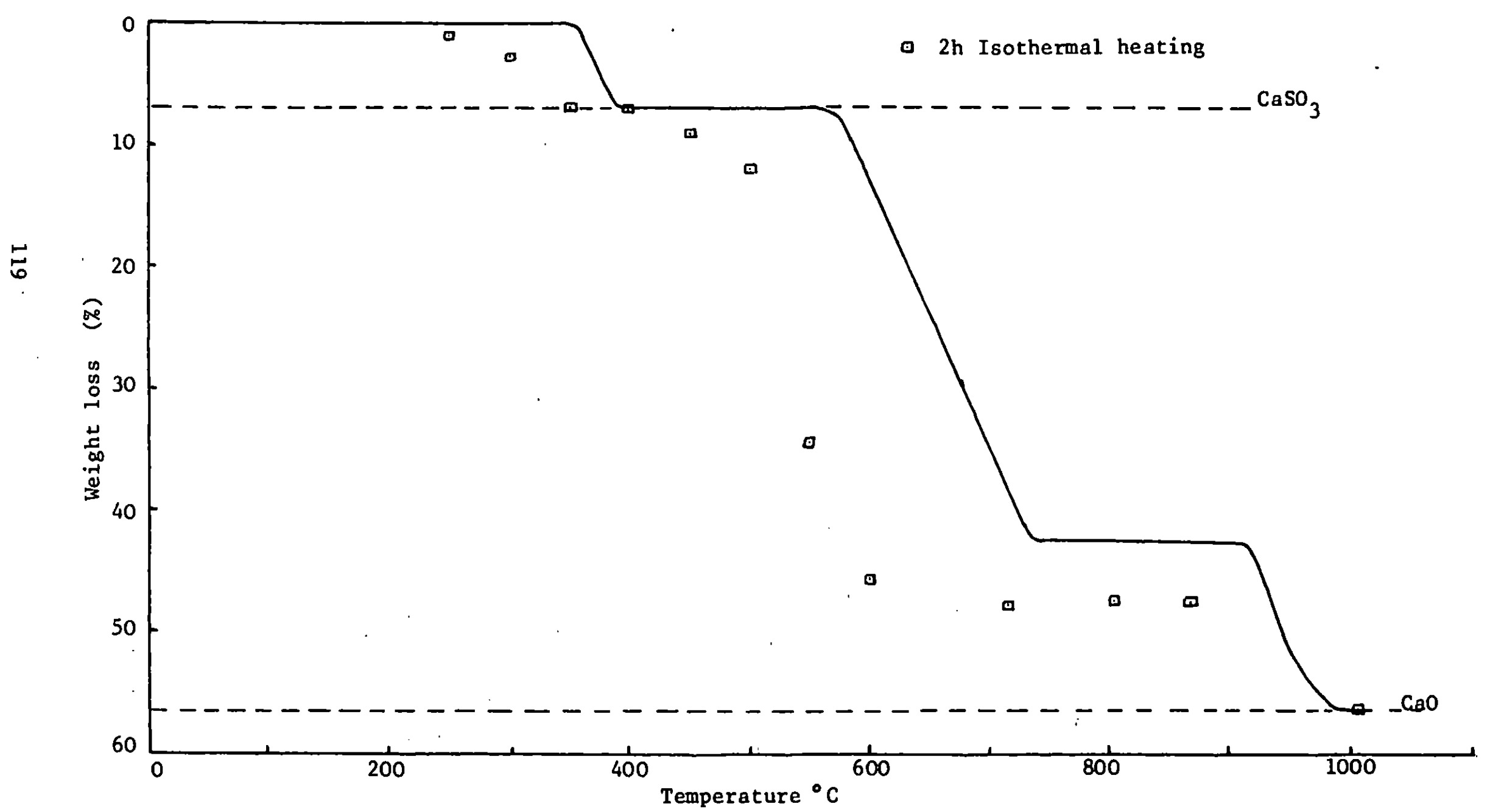




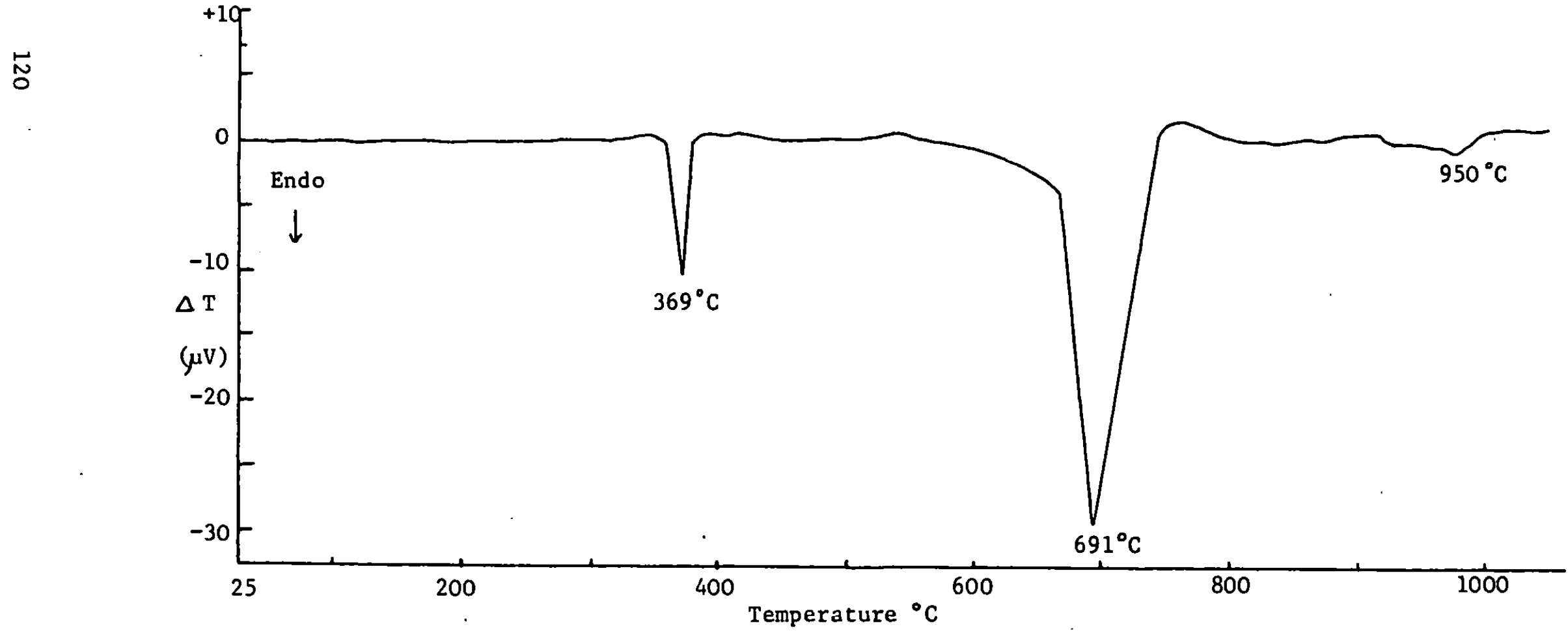

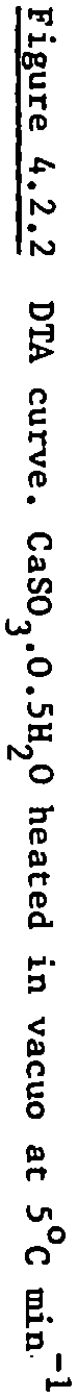


Figure 4.2 .3 TG curve. $\mathrm{CaSO}_{3} \cdot 0.5 \mathrm{H}_{2} \mathrm{O}$ heated in nitrogen (flow rate $18 \mathrm{~min}^{-1}$ ) at $5^{\circ} \mathrm{Cmin}^{-1}$

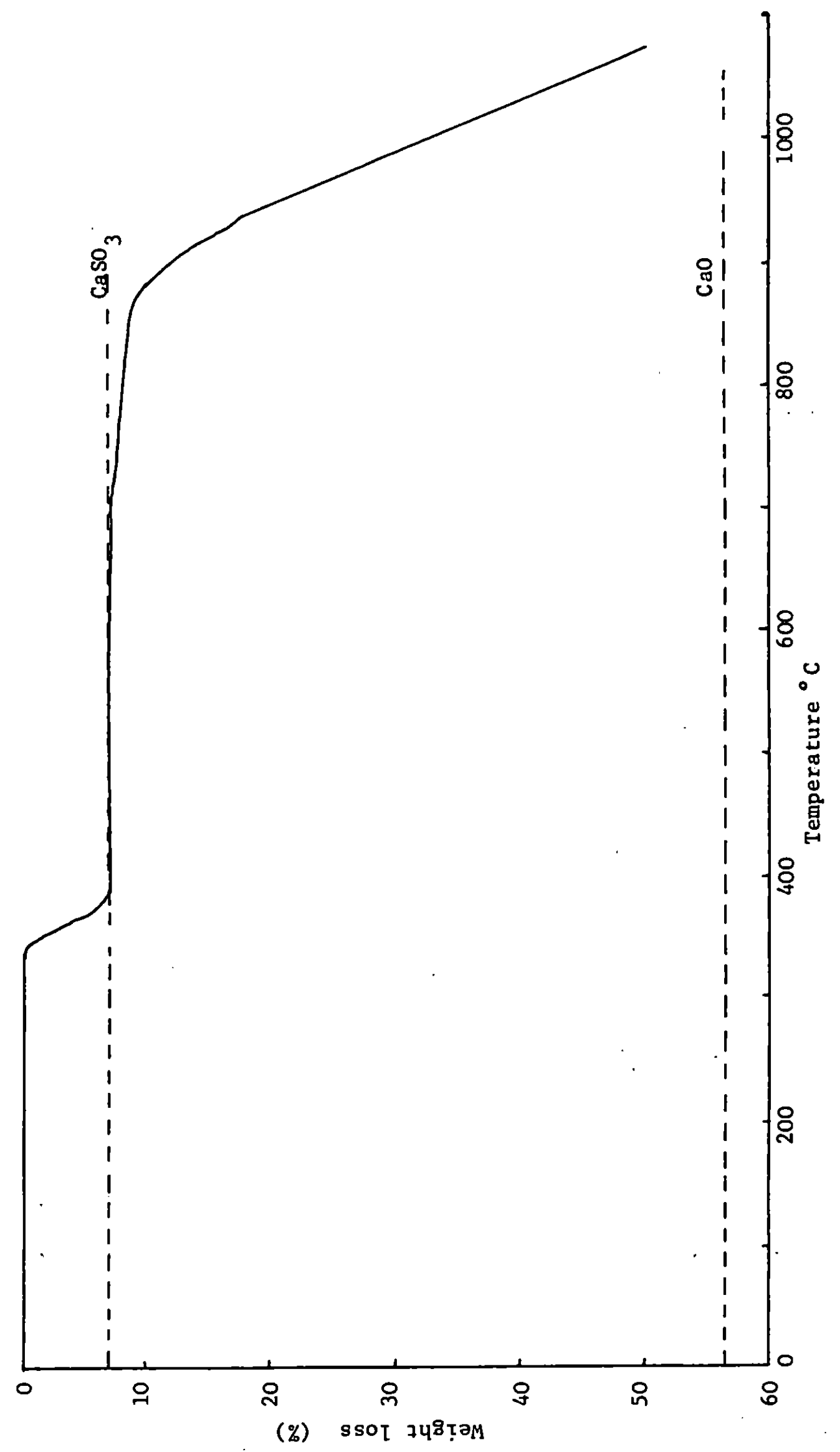


Figure 4.2.4 DTA curve. $\mathrm{CaSO}_{3} \cdot 0.5 \mathrm{H}_{2} \mathrm{O}$ heated in nitrogen (flow rate $18 \mathrm{~min}^{-1}$ ) at $5^{\circ} \mathrm{C} \min ^{-1}$

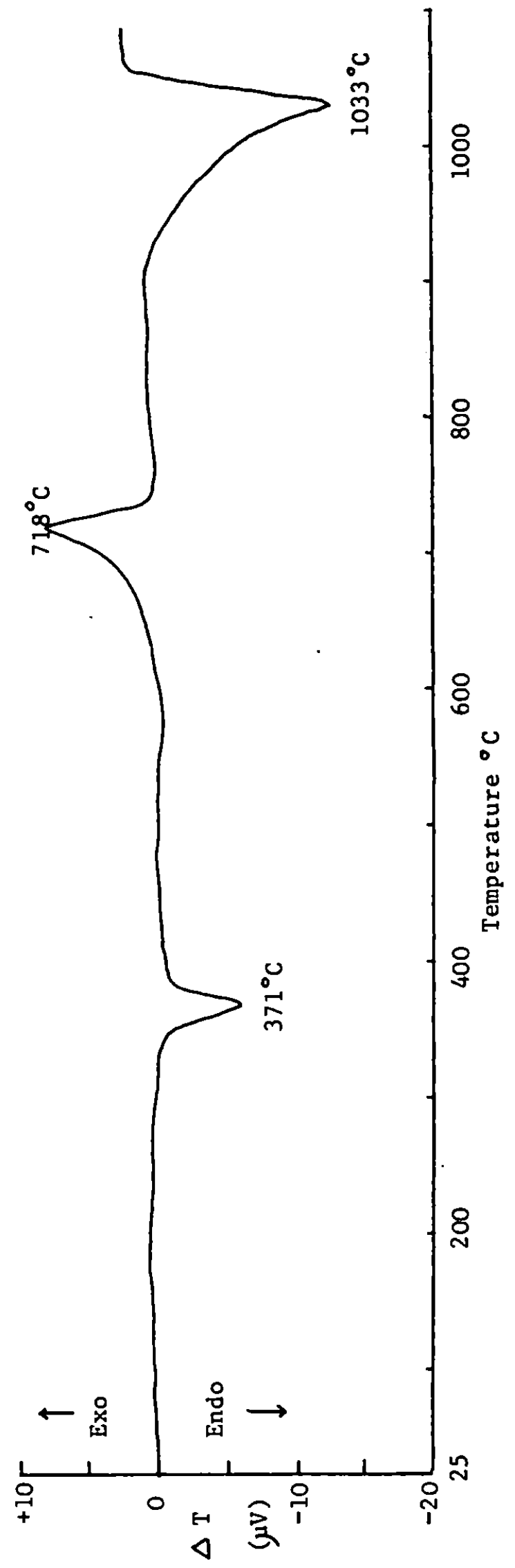


Figure 4.2.5 TG curve. $\mathrm{CaSO}_{3} \cdot 0.5 \mathrm{H}_{2} \mathrm{O}$ heated in air (flow rate $10 \mathrm{~min}^{-1}$ ) at $5^{\circ} \mathrm{Cmin}^{-1}$

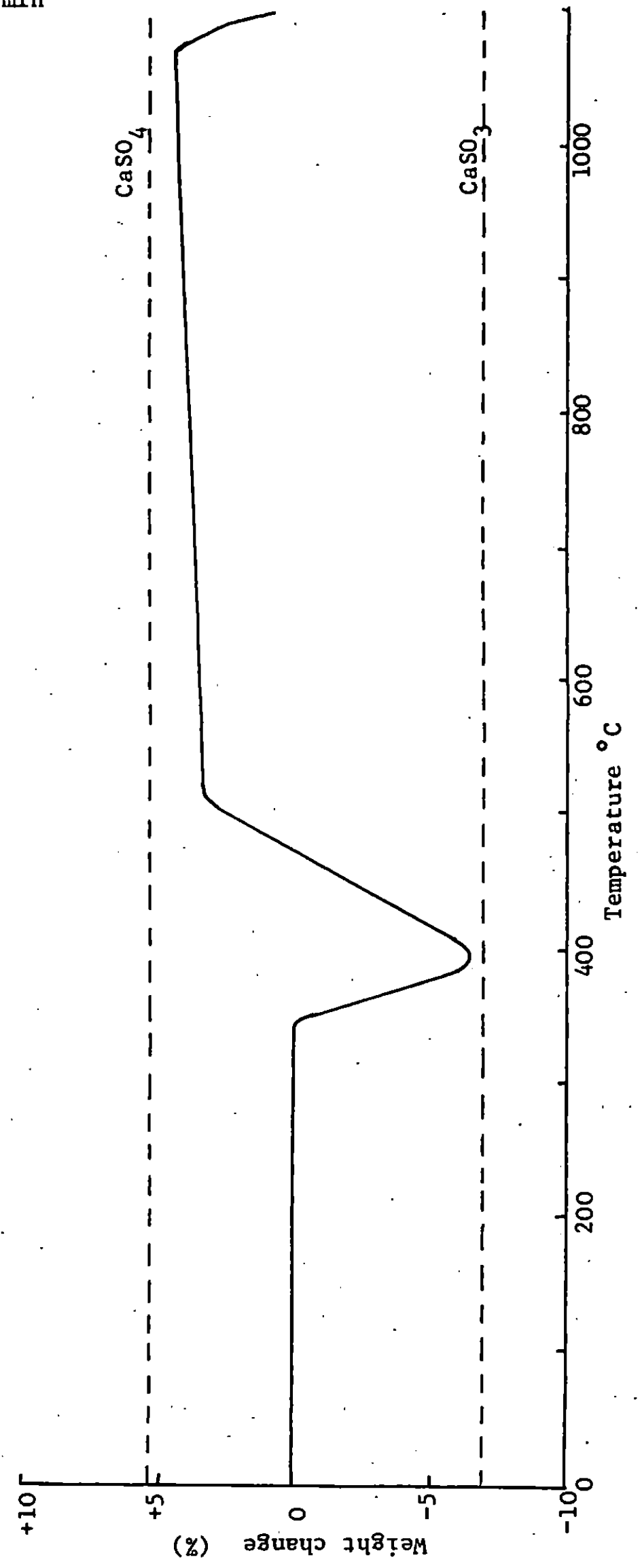




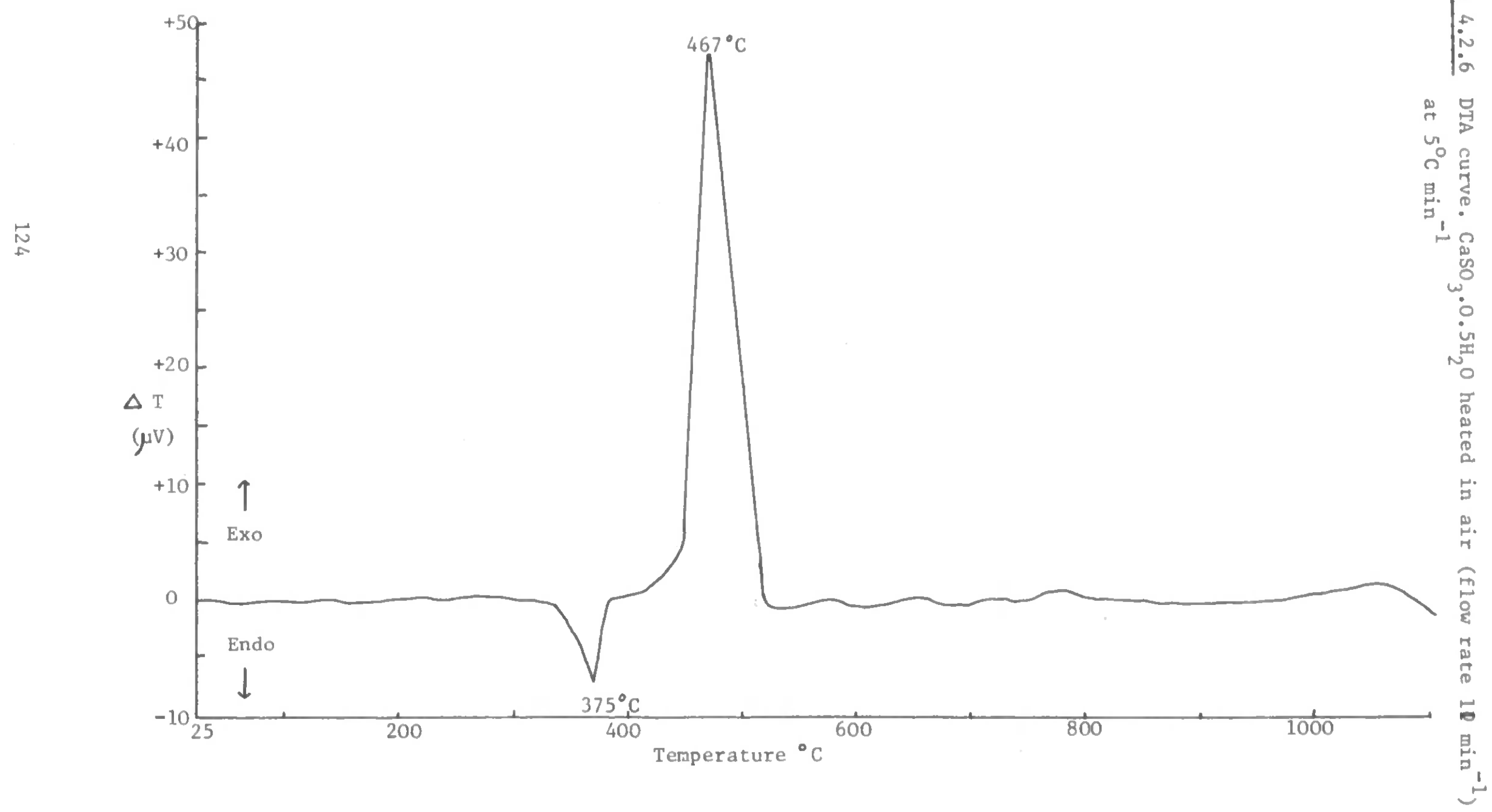


Figure 4.2.7 TG curve. $\mathrm{CaSO}_{3} \cdot 0.5 \mathrm{H}_{2} \mathrm{O}$ heated in $\mathrm{N}_{2} / \mathrm{SO}_{2}$ mixtures (flow rate $12 \min ^{-1}$ ) at $5^{\circ} \mathrm{C} \min ^{-1}$

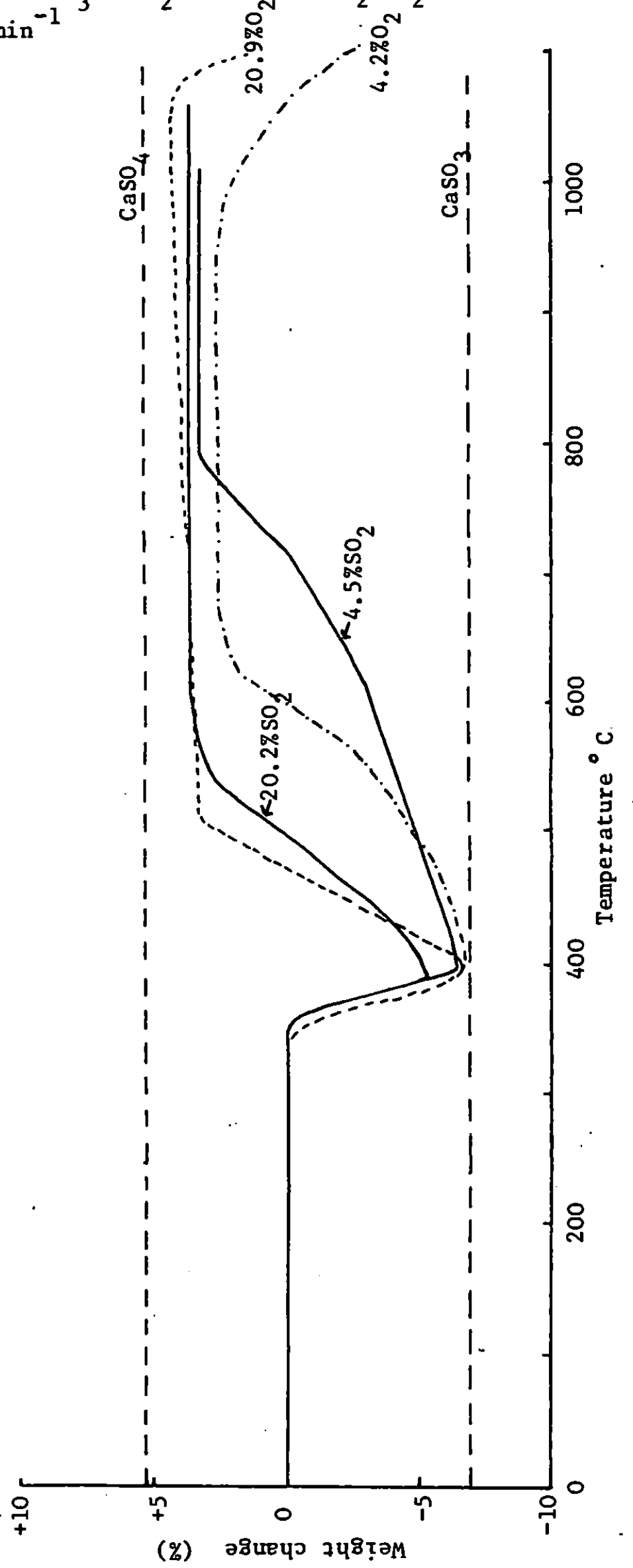


N
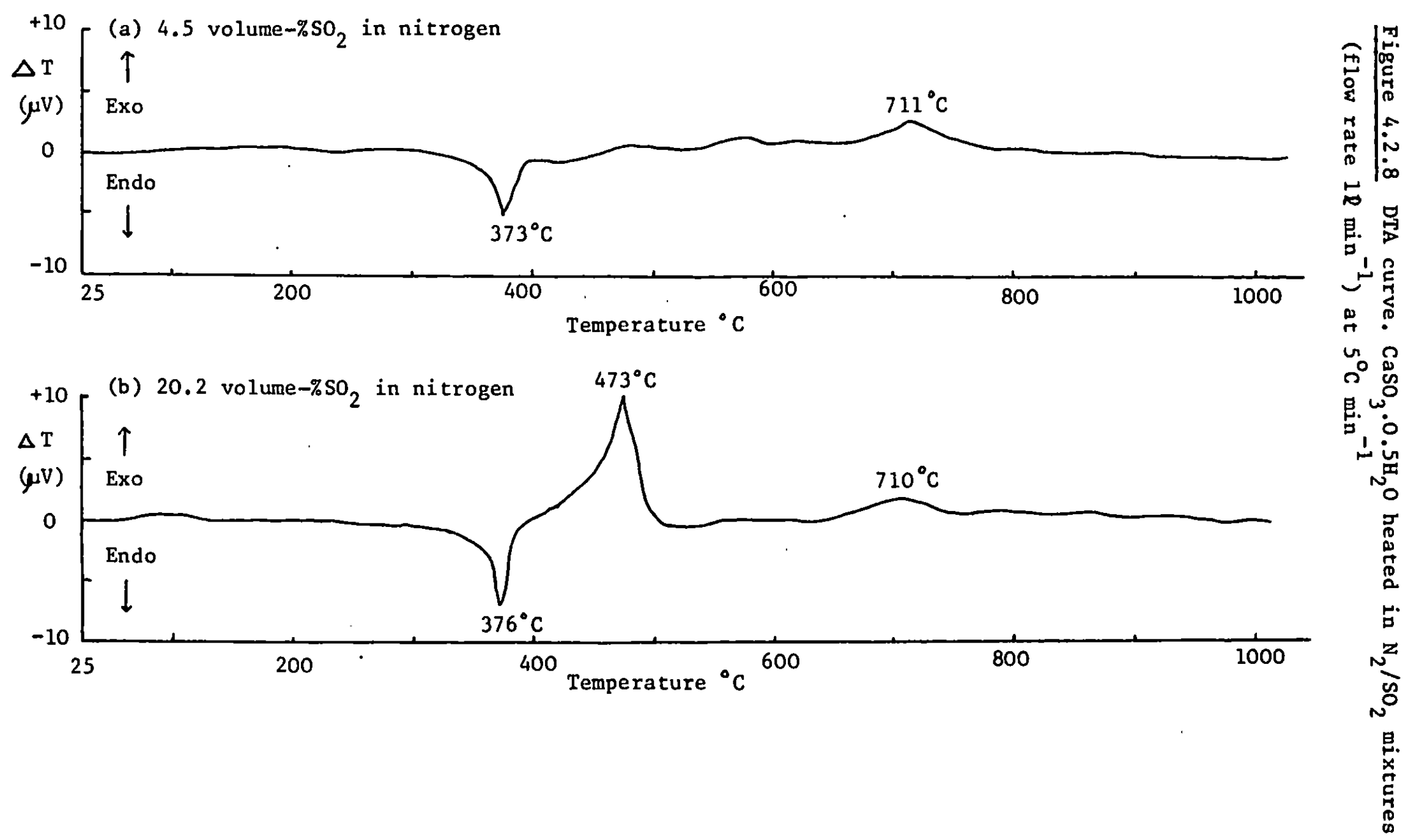
Figure 4.2.9 Free energy changes for some reactions involving calcium sulphite 8,93

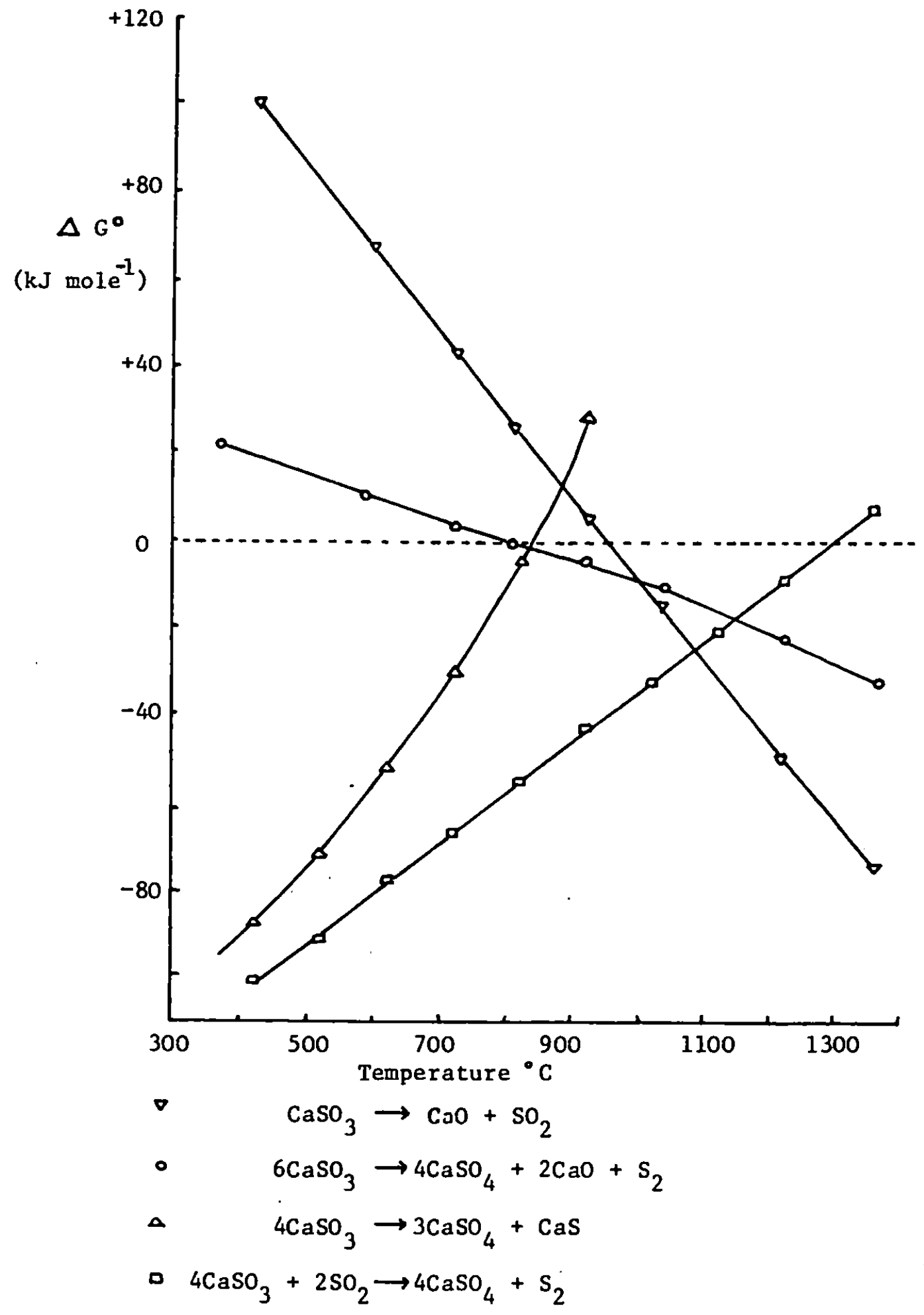


Figure 4.2.10 $\mathrm{CaSO}_{3} \cdot 0.5 \mathrm{H}_{2} \mathrm{O}$ calcined in vacuo for $2 \mathrm{~h}$ periods
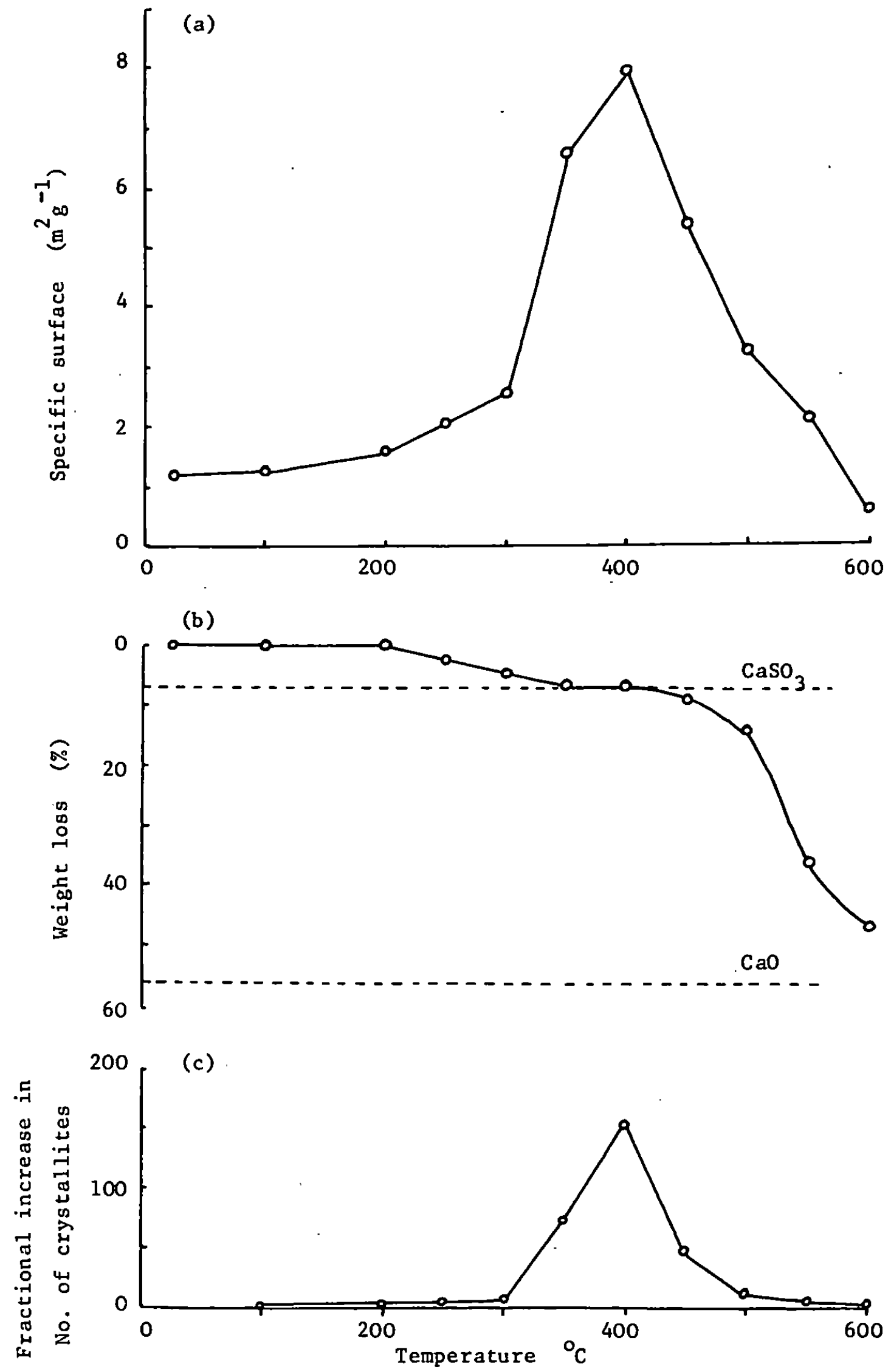
Figure $4.2 .11 \mathrm{CaSO}_{3} \cdot 0.5 \mathrm{H}_{2} \mathrm{O}$ heated on electron microscope hot-stage

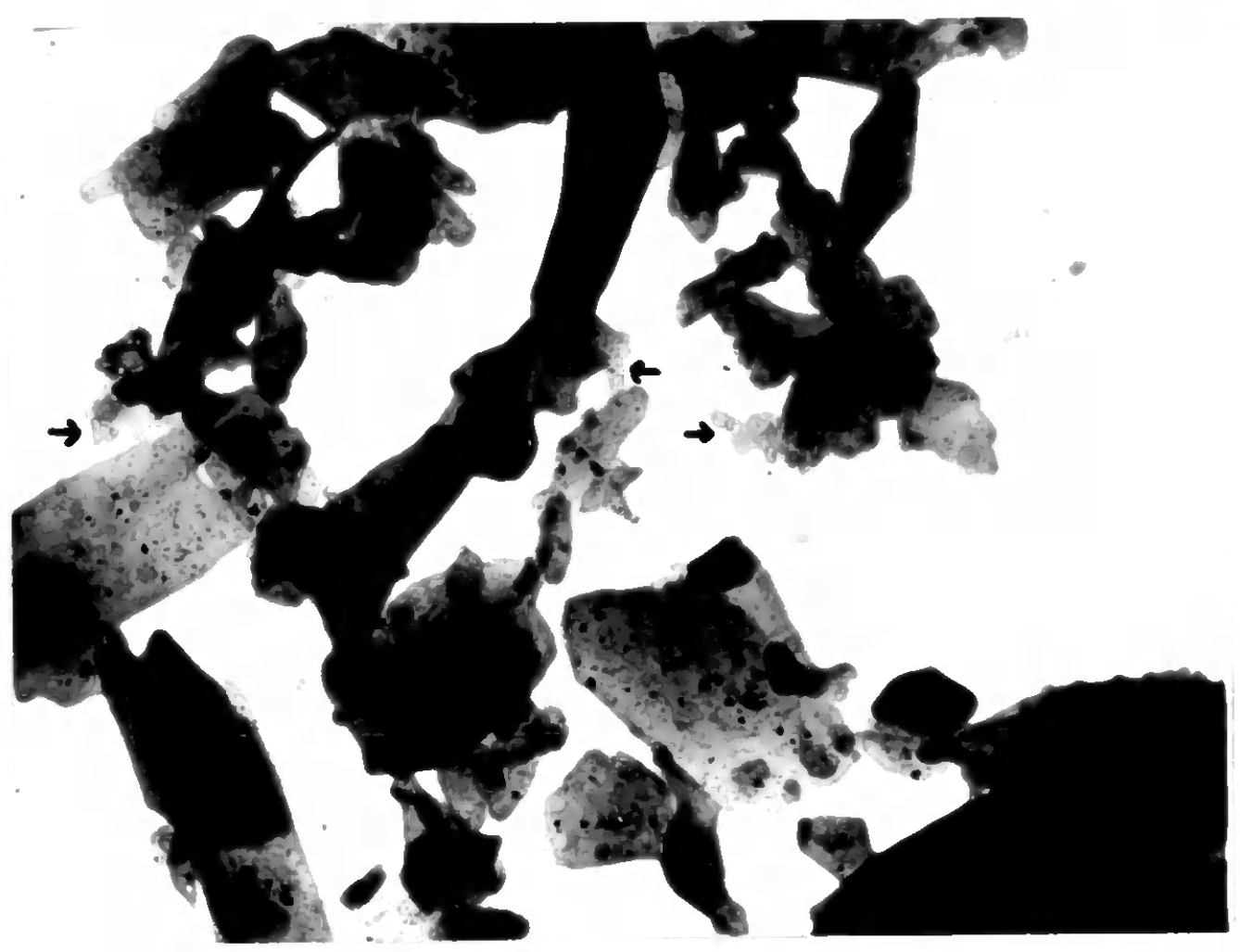

(a) At $327^{\circ} \mathrm{C}$

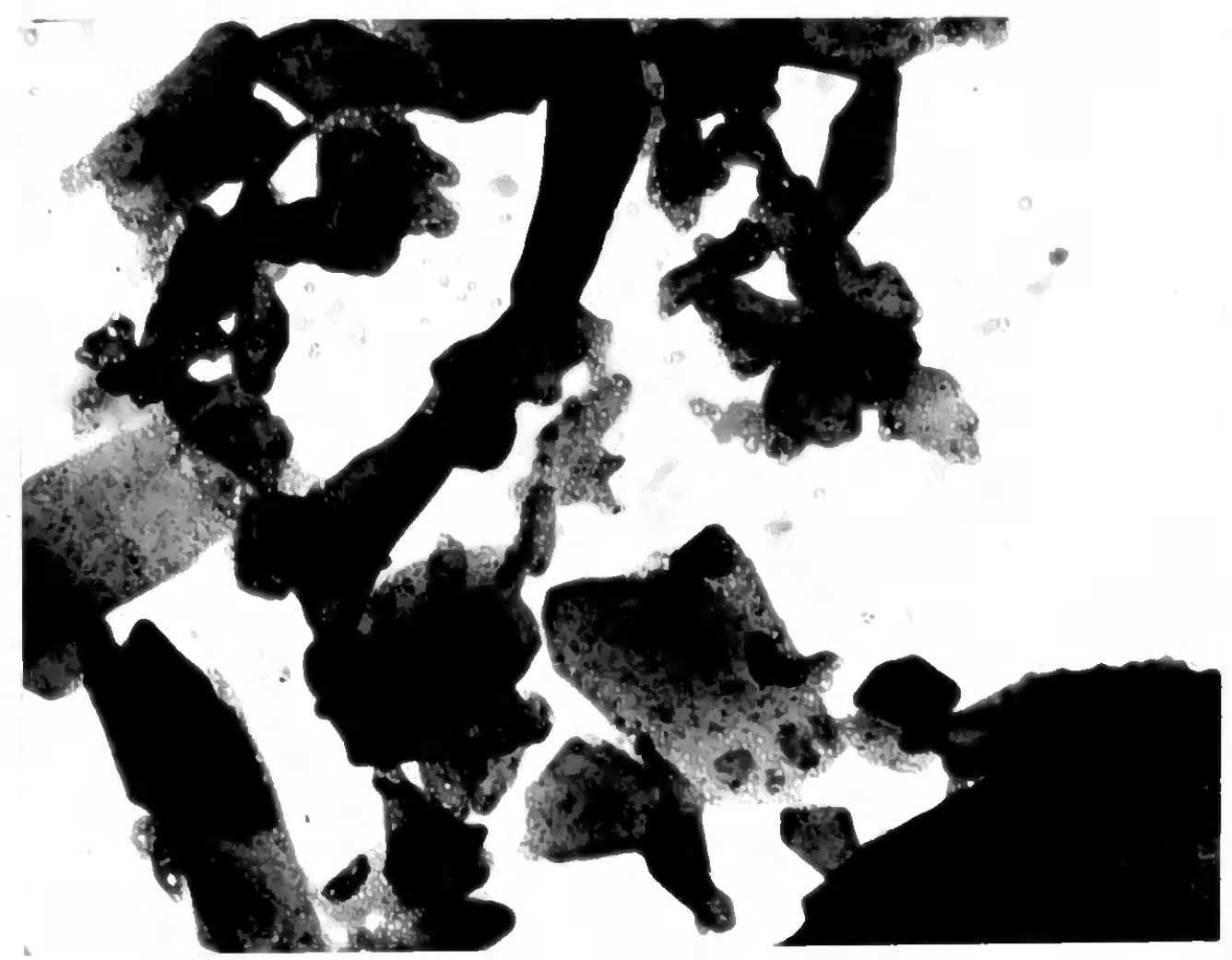

(b) At $363^{\circ} \mathrm{C}$ 


\section{Figure 4.2.11}

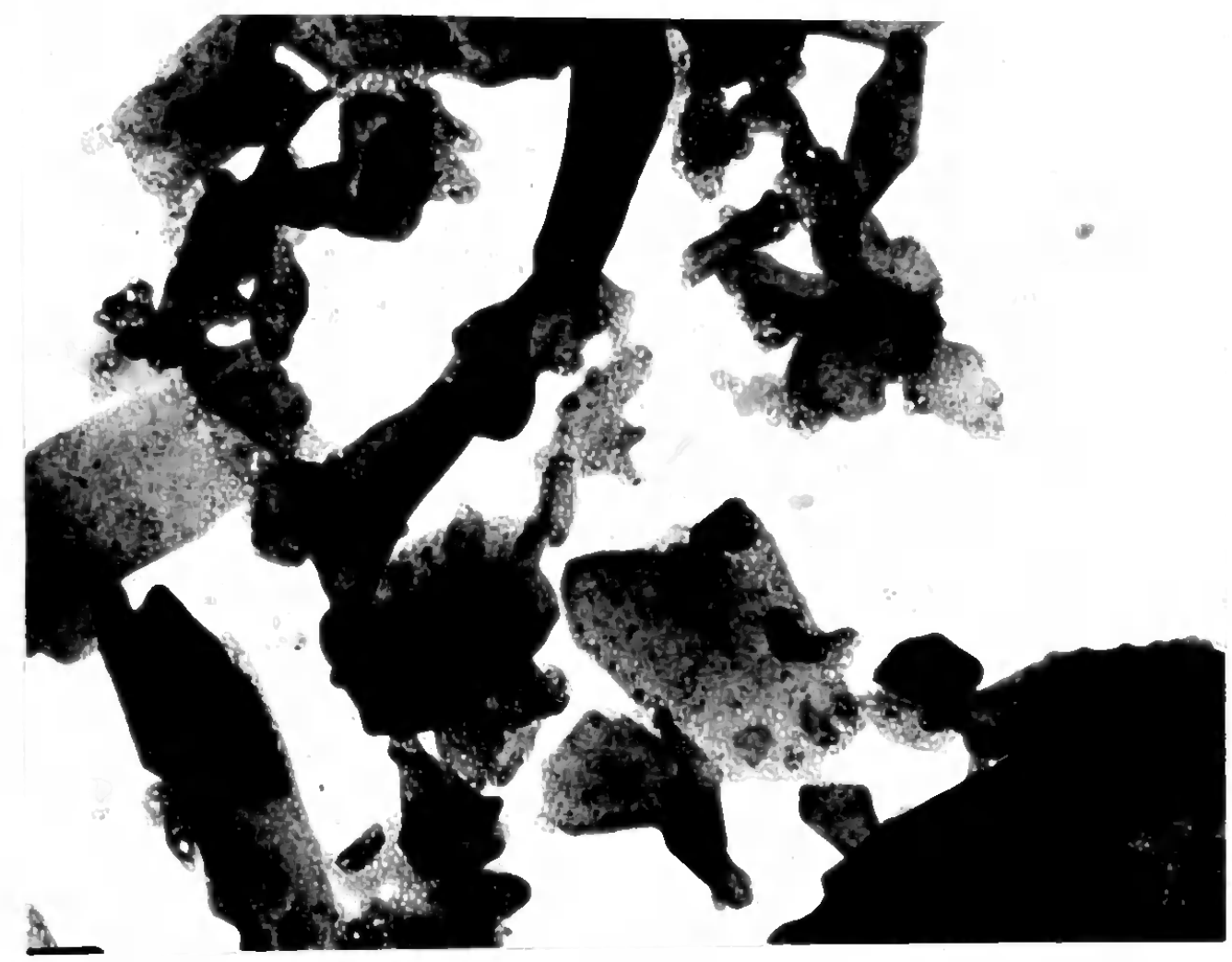

(c) At $393^{\circ} \mathrm{C}$

$\mu$

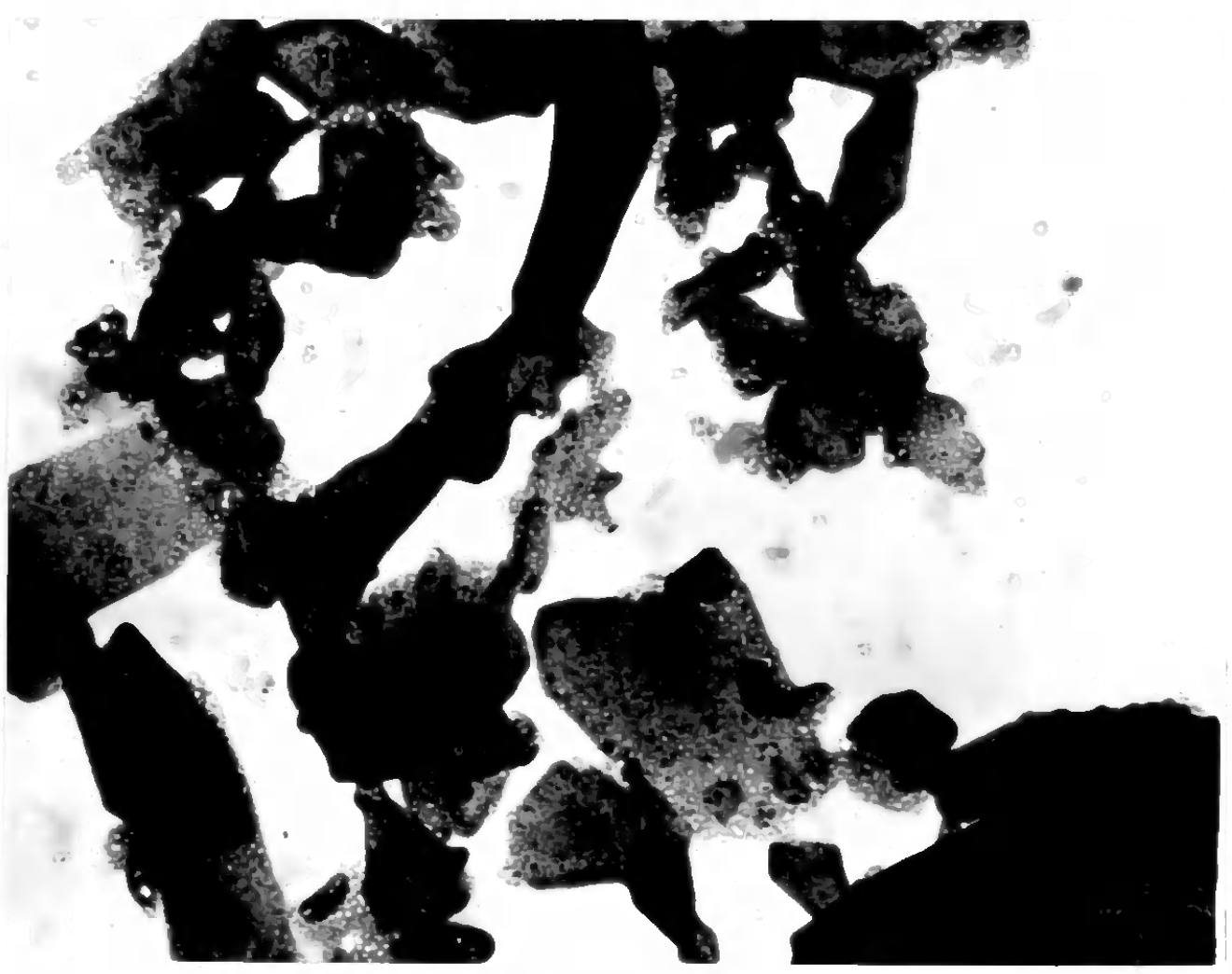

(d) At $393^{\circ} \mathrm{C}, 10$ minutes after (c)

' 
Figure 4.2.11
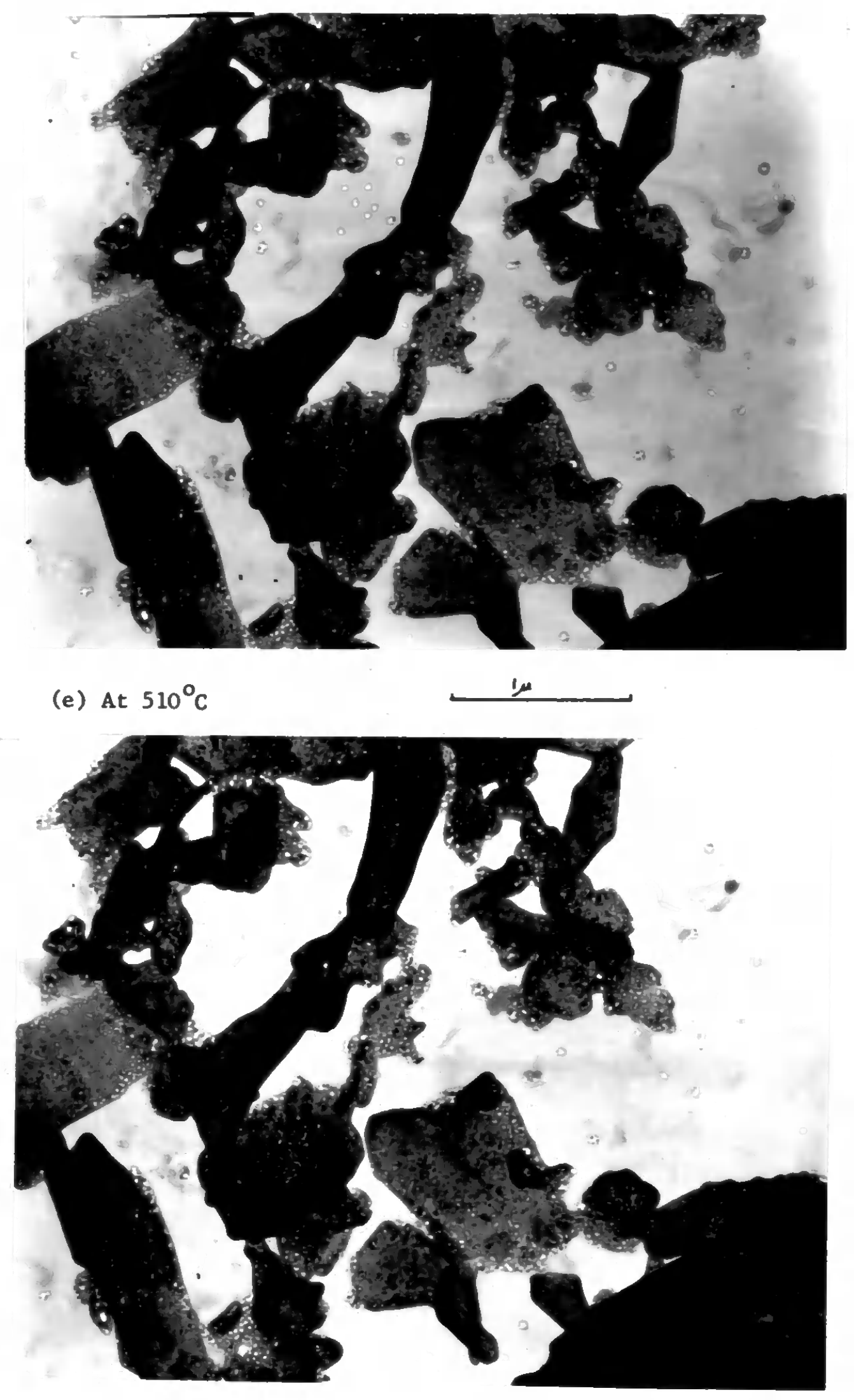

(f) At $510^{\circ} \mathrm{C}, 15$ minutes after (e) 


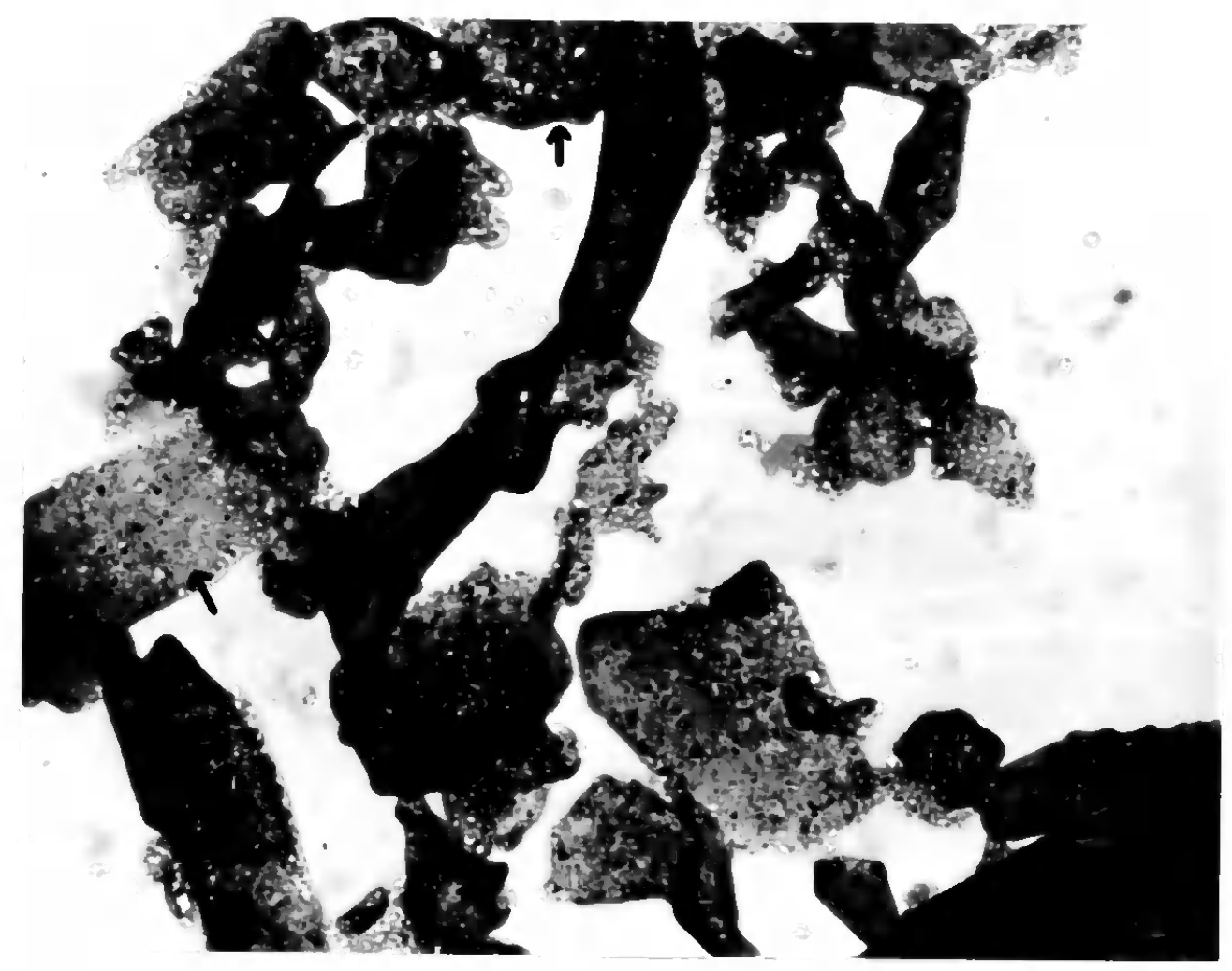

(g) At $701^{\circ} \mathrm{C}$

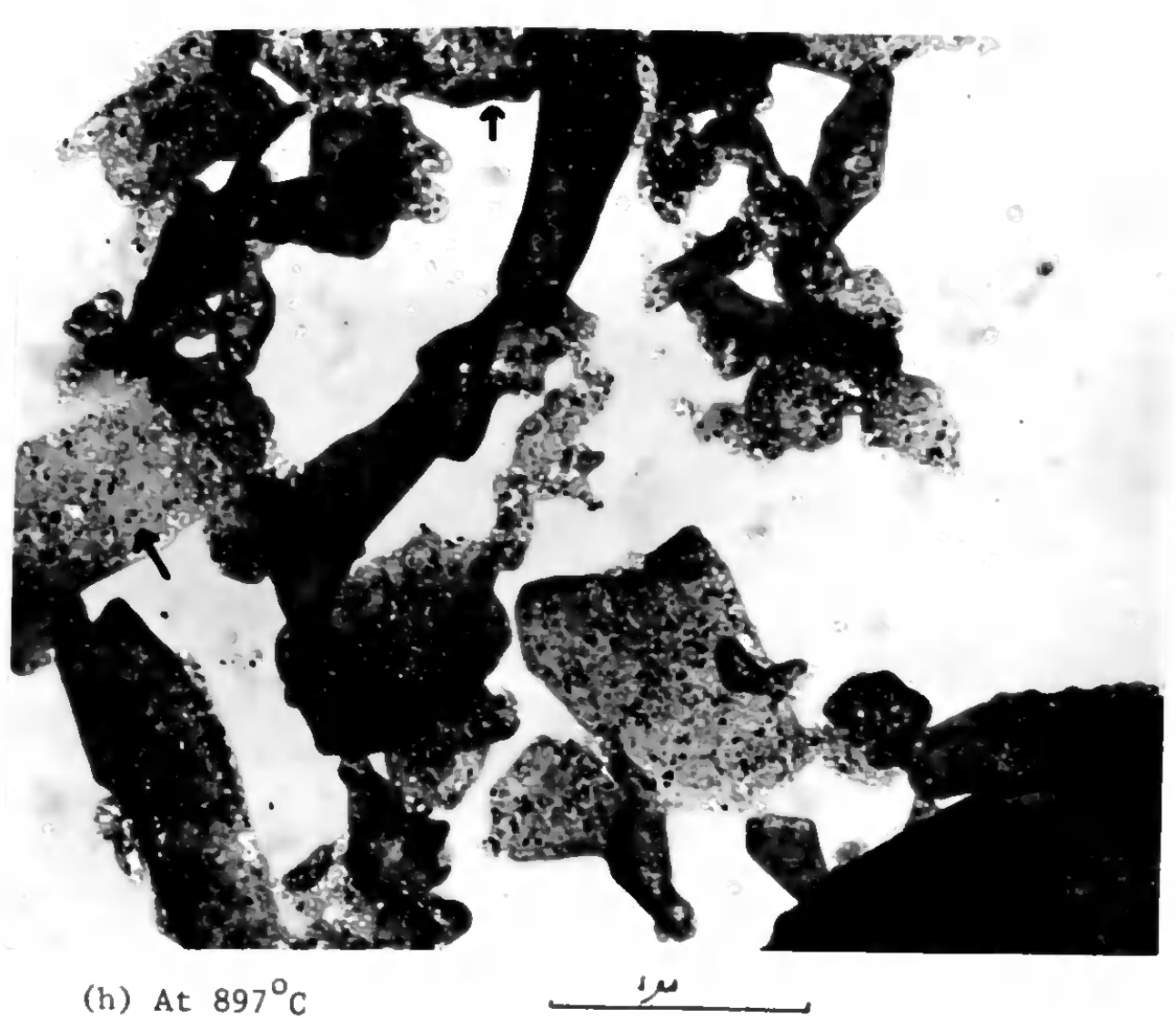


Figure 4.2.12 Effect of increasing electron-beam intensity

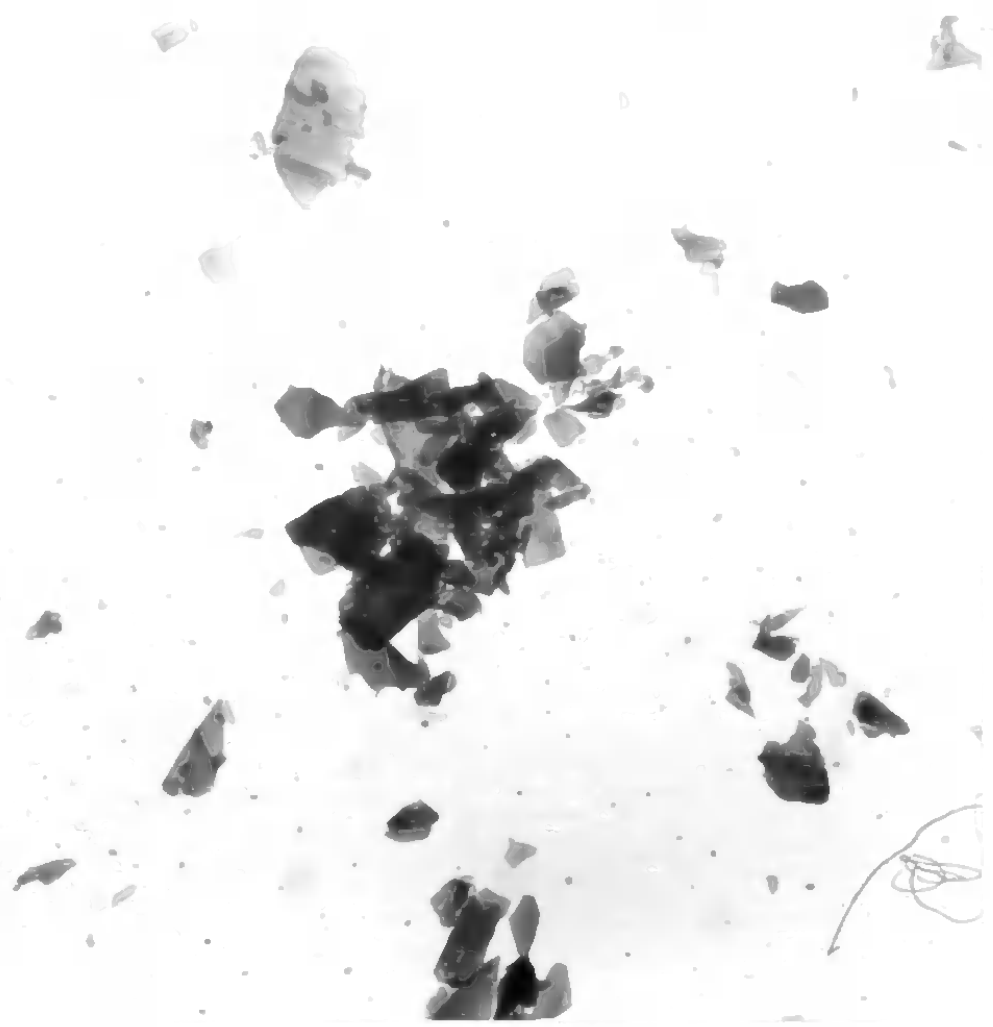

(a) $\mathrm{CaSO}_{3} \cdot 0 \cdot 5 \mathrm{H}_{2} \mathrm{O}$ at $25^{\circ} \mathrm{C}$; low magnification and intensity

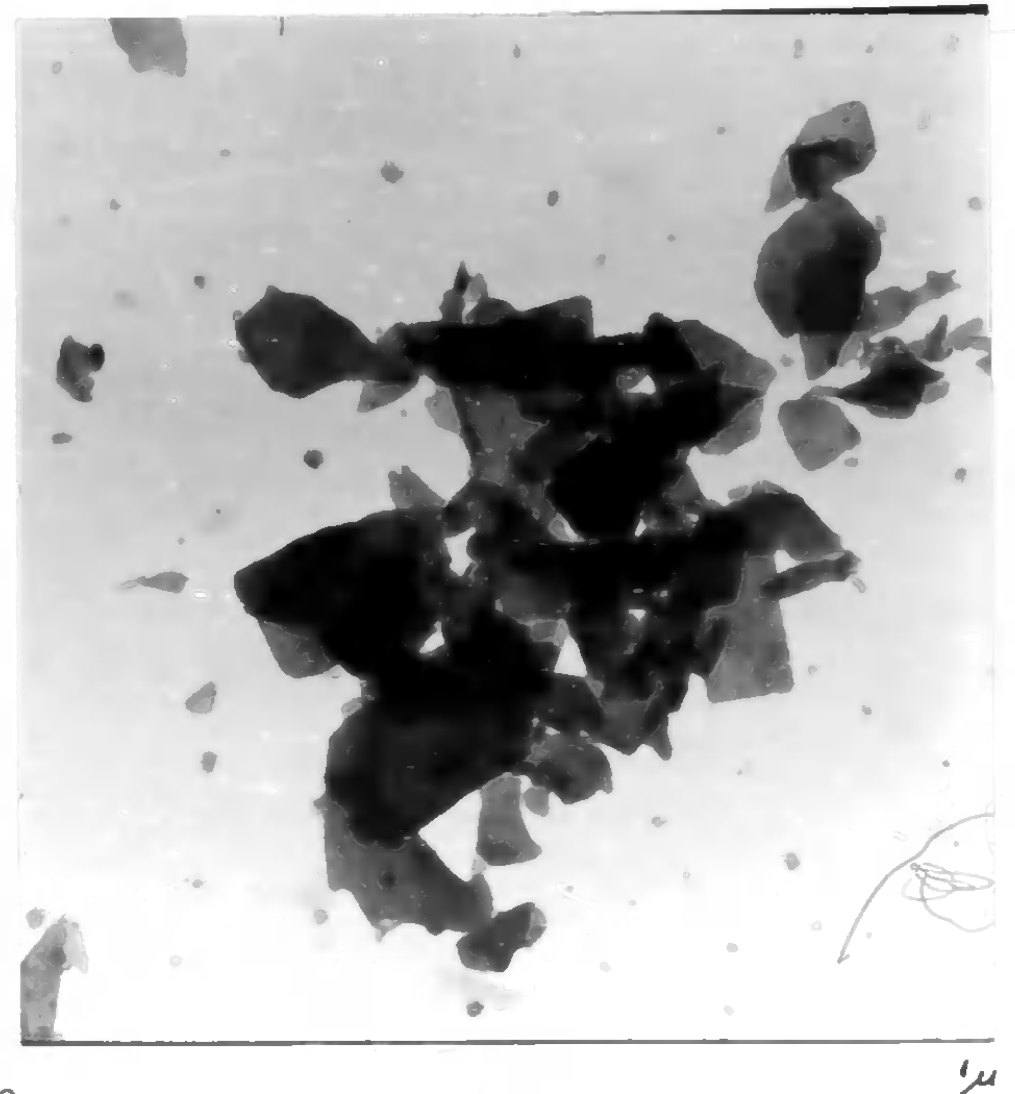

(b) At $25^{\circ} \mathrm{C}$; higher magnification and intensity

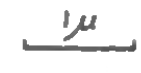


Figure 4.2.13 Comparison of specific surface changes found on heating $\mathrm{CaSO}_{3} \cdot 0.5 \mathrm{H}_{2} \mathrm{O}$ and $\mathrm{CaSO}_{4} \cdot 2 \mathrm{H}_{2} \mathrm{O}$ in vacuo

(a) $2 \mathrm{~h}$ calcination periods

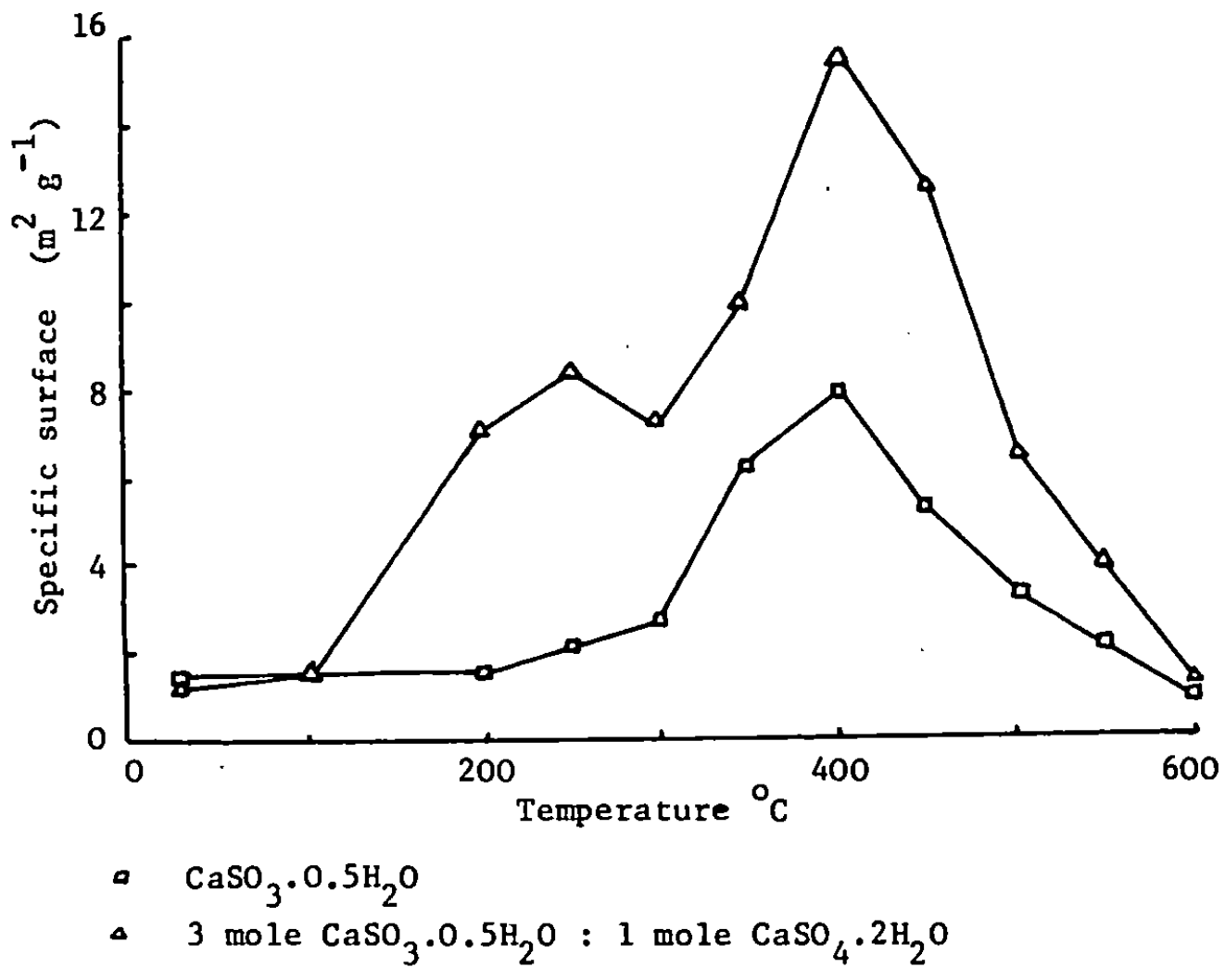

(b) Calcination of $\mathrm{CaSO}_{4} \cdot 2 \mathrm{H}_{2} \mathrm{O}$ for $5 \mathrm{~h}$ periods

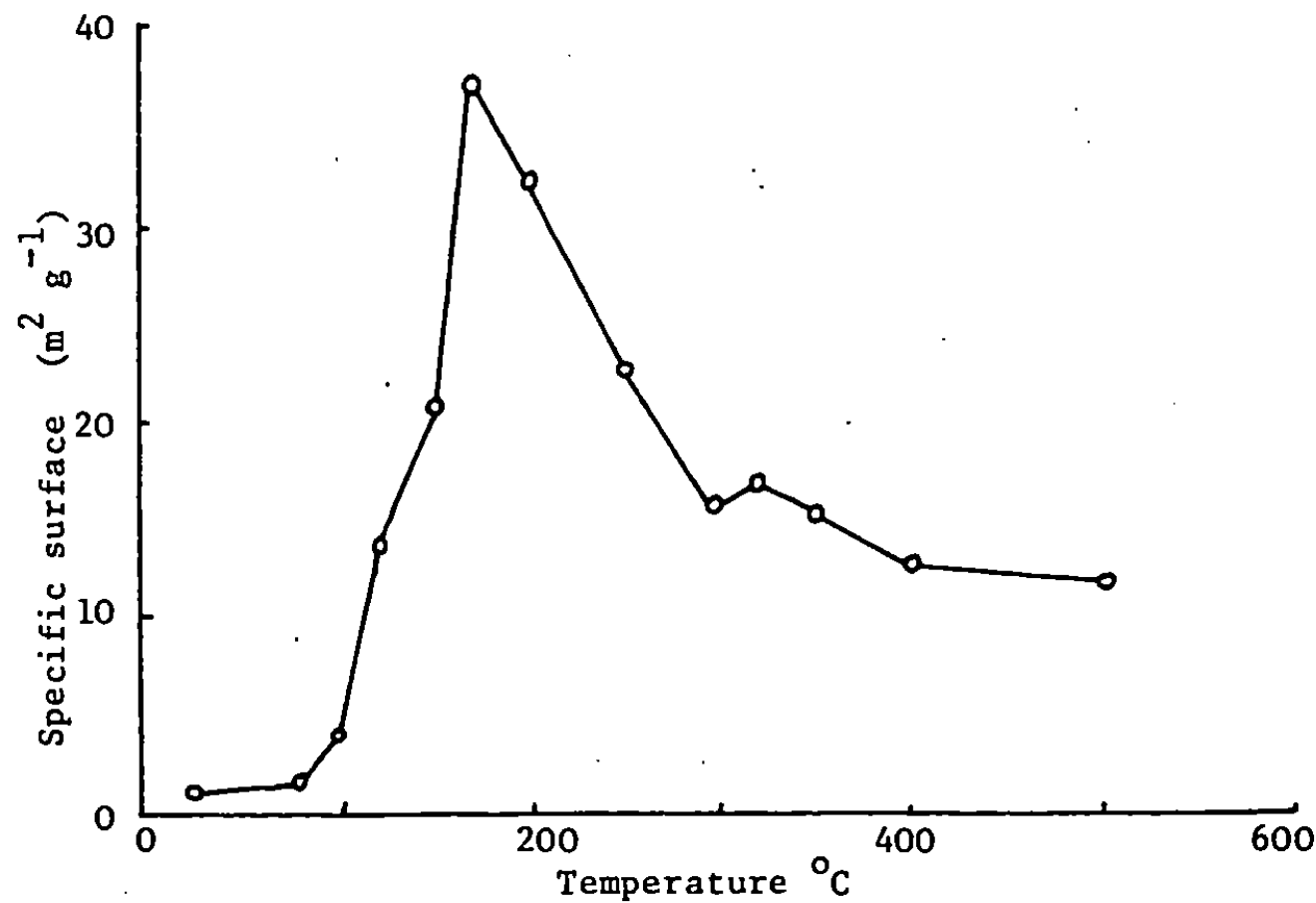


Figure 4.2.14 $\mathrm{CaSO}_{3} \cdot 0.5 \mathrm{H}_{2} \mathrm{O}$ calcined in air for $2 \mathrm{~h}$ periods
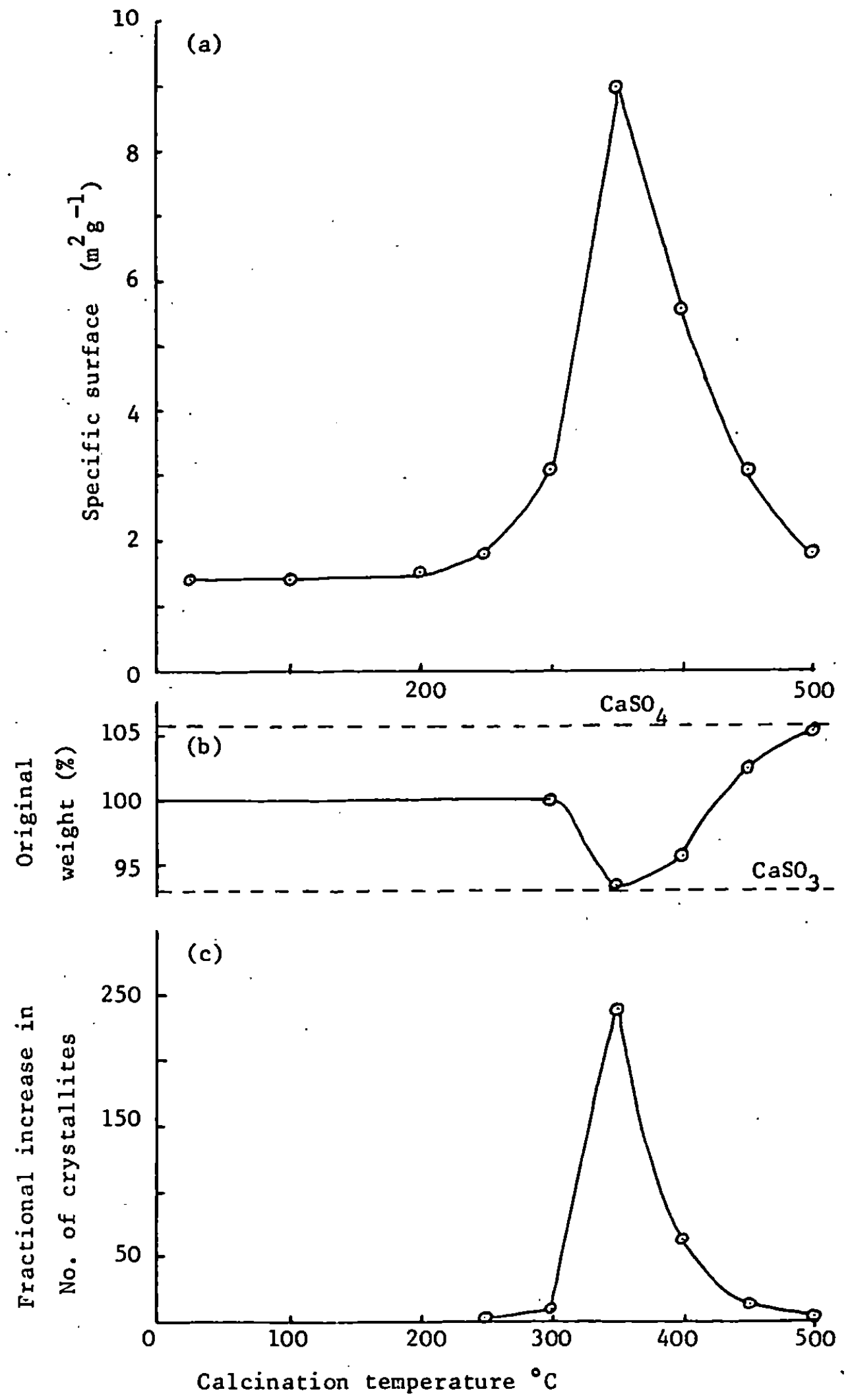


\subsection{Calcium Sulphite}

\subsubsection{Results}

Simultaneous dynamic thermogravimetry and differential thermal anaiysis on samples of calcium sulphite hemihydrate (at heating rates of $5^{\circ} \mathrm{C} \mathrm{min}^{-1}$ ) under different atmospheric conditions produced the results summarised in Figs 4.2 .1 to 4.2 .8 inclusive. As with magnesium sulphite hexahydrate, the first reaction in each case was dehydration, but complete conversion to the oxide was not attained always at the highest temperatures $\left(1100^{\circ} \mathrm{C}\right)$ reached.

(a) "In vacuo"

The TG curve, Fig 4.2.1, and the DTA curve, Fig. 4.2.2, show dehydration between $329^{\circ} \mathrm{C}$ and $393^{\circ} \mathrm{C}$, when the pressure was $1.3 \mathrm{~Pa}$, accompanied by an endotherm with a peak at $369^{\circ} \mathrm{C}$. The $0.3 \%$ water extra to that required by the stoichiometry of $\mathrm{CaSO}_{3} \cdot \frac{1}{2} \mathrm{H}_{2} \mathrm{O}$ was lost between $110^{\circ} \mathrm{C}$ and $250^{\circ} \mathrm{C}$. At $560^{\circ} \mathrm{C}$ the calcium sulphite began to decompose, releasing sulphur dioxide with a consequent weight loss.

$$
\begin{array}{ll}
\mathrm{CaSO}_{3} \longrightarrow \mathrm{CaO}+\mathrm{SO}_{2} & 4.11 \\
4 \mathrm{CaSO}_{3} \longrightarrow{ }_{3 \mathrm{CaSO}_{4}}+\mathrm{CaS} & 4.12
\end{array}
$$

However, the disproportionation reaction, 4.12, also occurred, and consequently the weight loss came to an end at $740^{\circ} \mathrm{C}$ when $72 \%$ of the calcium sulphite had been converted to calcium oxide. The remainder of the sample consisted of a mixture of calcium sulphate and calcium sulphide both of which had higher decomposition temperatures than calcium sulphite. The decomposition of calcium sulphite by reaction 4.11 was an endothermic change which gave the peak at $691^{\circ} \mathrm{C}$ on the DTA curve. This endotherm largely masked the exotherm which might have been expected from: the disproportionation reaction; 93 nevertheless, the endotherm may have what might be the tail of an exothermic peak following it. Another possible decomposition reaction 
would lead to the loss of sulphur.

$$
6 \mathrm{CaSO}_{3} \longrightarrow 4 \mathrm{CaSO}_{4}+2 \mathrm{CaO}+\mathrm{S}_{2}
$$

This reaction would be thermodynamically more favourable than 4.11, see Fig. 4.2.9, and would lead to an overall weight loss of $15.25 \%$ (based on loss of water and sulphur). The actual weight losses obtained were very much greater than $15.25 \%$, which would indicate that reaction 4.11 was the major pathway by which decomposition occurred.

Samples of calcium sulphite hemihydrate were heated for two hours in vacuo at a number of different temperatures and surface area measurements were made, by a gravimetric B.E.T. method with. nitrogen as the adsorbate, on the samples calcined at temperatures up to $600^{\circ} \mathrm{C}$. The variations in specific surface values obtained are illustrated in Fig. 4.2.10(a) and the weight losses from these isothermal reactions have been plotted on Fig. 4.2.1 for comparison with the dynamic thermogravimetric results and Fig. 4.2.10(b). Heating the samples isothermally for two-hour periods produced the equivalent degree of dehydration or decomposition at correspondingly lower temperatures than those required with a heating rate of $5^{\circ} \mathrm{C}$ per minute. The differences were of the order of $50^{\circ}-$ $100^{\circ} \mathrm{C}$ as illustrated in Table 4.2.1. 
Table 4.2.1 Temperatures required to produce given weight losses when heating $\mathrm{CaSO}_{3} \cdot \frac{1}{2} \mathrm{H}_{2} \mathrm{O}$ in vacuo

\begin{tabular}{|l|c|c|}
\hline \multirow{2}{*}{$\begin{array}{l}\text { Percentage } \\
\text { weight loss }\end{array}$} & \multicolumn{2}{|c|}{ Temperature in ${ }^{\mathrm{c}} \mathrm{C}$} \\
\cline { 2 - 3 } & Isothermal heating for 2 hours & Heating at $5^{\circ} \mathrm{C} \mathrm{min}^{-1}$ \\
\hline 0 & 200 & 340 \\
1.08 & 250 & 357 \\
2.86 & 300 & 365 \\
6.89 & 350 & 390 \\
7.12 & 400 & 500 \\
8.73 & 450 & 565 \\
11.93 & 500 & 575 \\
34.62 & 550 & 700 \\
45.53 & 600 & 930 \\
\hline
\end{tabular}

As would be expected, the longer period at an individual temperature in the isothermal experiments allowed the reactants and products to more nearly reach their thermodynamically stable equilibrium states for that temperature. In the dynamic heating experiments, the finite time required for a phase change meant that, at faster heating rates, the temperature would have risen appreciably before the phase change had been completed. When a reaction occurred rapidly above a particular initiation temperature, the differences in temperature between corresponding weight losses in the isothermal and dynamic experiments were reduced, as the results in Table 4.2.1 and Fig. 4.2.1 illustrated for the dehydration of calcium sulphite. hemihydrate.

The changes in surface area caused by the dehydration, sulphite decomposition and disproportionation processes reflected the thermal 
stabilities of the compounds. Thus the specific surface of the products, Fig. 4.2.10(a) reached a maximum at $400^{\circ} \mathrm{C}$ corresponding to complete dehydration. The average crystallite sizes (equivalent spherical diameters) of the products have been calculated from the specific surfaces and the $\mathrm{X}$-ray densities (which were determined to be $2.55 \mathrm{~g} \mathrm{~cm}$, $2.40 \mathrm{~g} \mathrm{~cm}^{-3}, 3.34 \mathrm{~g} \mathrm{~cm}^{-3}$ and $2.85 \mathrm{~g} \mathrm{~cm}^{-3}$ for $\mathrm{CaSO}_{3} \cdot \frac{1}{2} \mathrm{H}_{2} \mathrm{O}, \mathrm{CaSO}_{3}$, $\mathrm{CaO}$ and $3 \mathrm{CaSO}_{4} / \mathrm{CaS}$ respectively). The fractional increase in the numbers of crystallites was then deduced from the cube of the size ratio of the initial reactant and the product.

No. of crystallites per $\mathrm{cm}^{3}=\frac{10^{18} \mathrm{~m}^{3}}{\text { (equivalent spherical diameter, } \mu \mathrm{m}^{3} \text { ) }}$

Therefore, fractional increase $=\frac{\text { No. of crystallites per } \mathrm{cm}^{3} \text { in product }}{\text { No. of crystallites per } \mathrm{cm}^{3} \text { in initial }}$ reactant

(Equivalent spherical diameter initial $=$ reactant, $\mu \mathrm{m})^{3}$

(Equivalent spherical diameter product, $\mu \mathrm{m})^{3}$

The results have been presented in Table 4.2.2 and Fig. 4.2.10(c) which indicate that each initial crystal of $\mathrm{CaSO}_{3} \cdot \frac{1}{2} \mathrm{H}_{2} \mathrm{O}$ split into about 150 crystallites of $\mathrm{CaSO}_{3}$ on complete dehydration at $400^{\circ} \mathrm{C}$. This corresponded to a reduction in size from $1.7 \mu \mathrm{m}$ to $0.3 \mu \mathrm{m}$.

Decomposition of the anhydrous calcium sulphite did not produce a further increase in specific surface as occurred during the similar experiments with magnesium sulphite, Fig. 4.1.10. This was because the decomposition of the calcium sulphite was not so rapid, nor did it go to completion. Consequently, there was proportionately less disruption of the crystallites; also the higher temperatures for these reactions favoured the re-ordering of the new crystallites. 
Table 4.2.2 Crystallite size changes in $\mathrm{CaSO}_{3} \cdot \frac{1}{2} \mathrm{H}_{2} \mathrm{O}$ isothermally heated for $2 \mathrm{~h}$ in vacuo.

\begin{tabular}{|c|c|c|c|}
\hline $\begin{array}{c}\text { Temperature } \\
\text { oc }\end{array}$ & $\begin{array}{c}\text { Density } \\
\mathrm{g} \mathrm{cm}-3\end{array}$ & $\begin{array}{c}\text { Equivalent spherical } \\
\text { diameter, } \mu \mathrm{m}\end{array}$ & $\begin{array}{c}\text { Increase in no. } \\
\text { of crystallites }\end{array}$ \\
\hline Initial & 2.55 & 1.68 & - \\
200 & 2.57 & 1.46 & 1.5 \\
250 & 2.55 & 1.18 & 2.9 \\
300 & 2.50 & 0.857 & 7.6 \\
350 & 2.41 & 0.402 & 155 \\
400 & 2.41 & 0.313 & 46 \\
450 & 2.43 & 0.468 & 12 \\
500 & 2.46 & 0.739 & 4 \\
550 & 2.70 & 1.06 & 0.12 \\
600 & 2.92 & 3.42 & \\
\hline
\end{tabular}

The latter also occurred at the comparable. temperatures in the calcined magnesium sulphite samples. The formation of calcium sulphate and in particular the presence of lower-melting calcium sulphide, m.p. 1223K, would aid the sintering process. Temperatures above half the melting point, in degrees absolute, favour both surface and bulk diffusion ${ }^{88}$ wich would lead to adhesion of individual particles to each other and the removal of surface irregularities ${ }^{94}$. The photomicrographs, Fig, 4.2.11(a) - (h), of crystals of calcium sulphite hemihydrate heated to various temperatures, on the hot-stage in the electron microscope, illustrated the changes in crystal morphology during decomposition "in vacuo". In Fig. 4.2.11(a) the first signs of dehydration can be seen. Small light patches have. appeared in some of the smaller crystals, indicated by arrows. All 
the crystals showed dark patches and signs of formation of small crystallites, which were due to the effect of the electron beam. If the electron beam intensity was kept very low, the crystals were largely unaffected, Fig. 4.2.12(a), but as soon as the magnification, and hence the beam intensity, was increased the changes in structure were brought about, Fig. 4.2.12(b). The subsequent changes in the crystals on the hot-stage indicate that the rearrangement in the electron beam was not due to complete dehydration of the hemihydrate. At $363^{\circ} \mathrm{C}$, Fig. 4.2.11(b), the dehydration had produced very noticeable. effects with the thinner portions of the crystals having the appearance., at first sight, of having holes in them. With the temperature at $393^{\circ} \mathrm{C}, \mathrm{Fig} .4 .2 .11(\mathrm{c})$, the maximum disruption of the crystals, due to dehydration, seems to have been reached with. more. light patches than at $36.3^{\circ} \mathrm{C}$. Fig. 4.2.11(d), which was taken ten minutes after. (c), illustrated that rearrangement of the new structures had commenced as the number of light patches had decreased. The commencement of desulphurisation at $510^{\circ} \mathrm{C}$ was indicated by $\mathrm{Fig} .4 .2 .11(\mathrm{e})$ and $(\mathrm{f})$, with (f) having been taken fifteen minutes after (e). Comparison with. the photomicrographs (a) - (d) clearly showed that the thicker crystals, which had shown little change on dehydration, were beginning to "break up", being less electron dense and with grain boundaries being much more evident. The final two photomicrographs in the series, (g) at $701^{\circ} \mathrm{C}$ and (h) at $897^{\circ} \mathrm{C}$, showed the greatly reduced thickness of what were, by then, only calcium sulphite pseudomorphs due to conversion to calcium oxide. Comparison of (h) with (g). illustrated the growth in size of the calcium oxide crystallites, so that the pseudomorphs were composed of a smaller number of larger crystallites with more definite grain boundaries as the larger 
crystallites grew at the expense of the smaller ones. The arrows illustrate two regions where this grain growth was particularly clearly shown.

The types of changes in crystal size indicated by surface area measurements were shown by the crystals studied under the electron microscope, i.e. the large changes on formation of anhydrous calcium sulphite, and the effect of sintering as the temperature increased. The effect of the electron beam at low temperatures on the structure of the original crystals appeared to influence the subsequent changes which occurred. The introduction of defects into the crystal structure would tend to aid the loss of water and sulphur dioxide without causing a splitting apart of the original crystal form. The dehydration carried out on the hot-stage showed that an increase in surface area associated with this change was due to an increase in surface irregularity rather than the formation of isolated new crystallites. The sintering was clearly illustrated in the photomicrographs, where the corresponding reductions in specific surface were shown to be due to (a) growth of the anhydrous calcium sulphite, which remained undecomposed, (b) growth of the newly-formed calcium oxide. crystallites and (c). the concurrent reduction in surface irregularities. The effect of the presence of calcium sulphate and calcium sulphide could not be distinguished under the electron microscope. To ascertain the degree of sintering of the products, it would be necessary to determine the surface areas of samples which had been heated for various periods at each temperature.

A mixture of calcium sulphite hemihydrate and gypsum, with. the molecular ratio of $3 \mathrm{CaSO}_{3} \cdot \frac{1}{2} \mathrm{H}_{2} \mathrm{O}: 1 \mathrm{CaSO}_{4} \cdot 2 \mathrm{H}_{2} \mathrm{O}$, was also heated under similar conditions for two-hour periods, and specific surfaces were determined to give the results illustrated in Fig. 4.2.13. Comparison 
with those obtained previously from gypsum alune ${ }^{2}$, also given in Fig. 4.2.13, and with calcium sulphite hemihydrate alone, showed that the essential features of the three sets were similar, viz. increase. in surface area due to dehydration followed by reduction in surface area due to sintering. The increase in specific surface due to the conversion of $\gamma^{-}-\mathrm{CaSO}_{4}$ to $\mathrm{B}^{-\mathrm{CaSO}_{4}}$ (anhydrite). caused a second peak in the. pure gypsum curve and enhanced the second peak in the curve for the mixture of gypsum and calcium sulphite hemihydrate. However, the major factor in the increase in specific surface of this mixture at $400^{\circ} \mathrm{C}$ compared to pure calcium sulphite hemihydrate was the presence of the small crystallites of calcium sulphate. formed by the dehydration of gypsum.

The final desulphurisation reaction as shown by the TG and DTA curves took place between $915^{\circ}$ and $990^{\circ} \mathrm{C}$ to give calcium oxide. (b) In nitrogen

The first step in the decomposition of calcium sulphite hemihydrate when heated at $5^{\circ} \mathrm{Cmin}^{-1}$ in nitrogen, flowing at $11 \mathrm{~min}^{-1}$, was caused by dehydration between $345^{\circ} \mathrm{C}$ and $396^{\circ} \mathrm{C}, \mathrm{Fig}, 4.2 .3$, and there was a corresponding endothermic peak at $371^{\circ} \mathrm{C}$ in the DTA curve, Fig. 4.2.4. The anhydrous calcium.sulphite apparently then remained stable up to $682^{\circ} \mathrm{C}$, when a slow weight loss began which became more rapid as the temperature rose above $850^{\circ} \mathrm{C}$. The decomposition of calcium sulphite by either reaction 4.11 or 4.13 would be endothermic, but the DTA curve showed an exotherm commencing at $600^{\circ} \mathrm{C}$ and peaking at $718^{\circ} \mathrm{C}$, followed by an endotherm commencing at $920^{\circ} \mathrm{C}$ and peaking at $1033^{\circ} \mathrm{C}$. Chemical analysis, Table 4.2.3, and examination of X-ray diffraction patterns of samples confirmed that disproportionation, an exothermic reaction, had occurred before the desulphurisation reaction became dominant. The exotherm was therefore correlated with. the 
disproportionation reaction which occurred at the same time as the.

slower breakdown of calcium sulphite to liberate sulphur dioxide. The high-temperature endotherm was formed by the conversion of the calcium sulphate/calcium sulphide mixture to calcium oxide.

Table 4.2.3 Composition of samples of calcium sulphite hemihydrate. heated in $\mathrm{N}_{2}$ at $5^{\circ} \mathrm{C}_{\min ^{-1}}$

\begin{tabular}{|c|c|c|c|c|c|}
\hline \multirow{2}{*}{$\begin{array}{c}\text { Temperature } \\
{ }^{\circ} \mathrm{C}\end{array}$} & \multirow{2}{*}{$\begin{array}{c}\text { \% weight loss } \\
\text { less 6.98 }\end{array}$} & \multicolumn{3}{|c|}{ Percentage composition of calcined sample } \\
\cline { 3 - 6 } & 0 & $\mathrm{CaSO}_{3}$ & $\mathrm{CaSO}_{4}$ & $\mathrm{CaS}$ & $\mathrm{CaO}$ \\
\hline 620 & 0.6 & 99.6 & 0.2 & - & - \\
770 & 4.4 & 3.4 & 13.8 & 2.3 & 0.6 \\
897 & 42.9 & - & 23 & 13.8 & 4.4 \\
1074 & & & & & 74.9 \\
\hline
\end{tabular}

\section{(c) In air}

As in the cases above, the first reaction when calcium sulphite hemihydrate was heated in air, flow rate $11 \mathrm{~min}^{-1}$, at $5^{\circ} \mathrm{C}^{\circ} \mathrm{min}^{-1}$ was the loss of water, Fig. 4.2.5, accompanied by the absorption of energy, Fig. 4.2.6. However, this was almost immediately followed by an increase in weight as the anhydrous calcium sulphite was oxidised to calcium sulphate.

$$
2 \mathrm{CaSO}_{3}+\mathrm{O}_{2} \longrightarrow 2 \mathrm{CaSO}_{4} \quad 4.14
$$

The oxidation was rapid as the temperature rose to $520^{\circ} \mathrm{C}$, when $83.5 \%$ of the original sulphite had been oxidised. There was then only a small degree of further oxidation up to $998^{\circ} \mathrm{C}$. The coating of calcium sulphate formed reduced the rate of reaction with the. inner core of calcium sulphite. This core of caicium sulphite underwent disproportionation, to give a mixture of calcium sulphate and calcium sulphide, as well as a small degree of dissociation to calcium oxide. The slow increase in weight between $520^{\circ} \mathrm{C}$ and $998^{\circ} \mathrm{C}$ 
was due to oxidation of both calcium sulphite and calcium sulphide.

$$
\mathrm{CaS}+\mathrm{2O}_{2} \longrightarrow \mathrm{CaSO}_{4} \quad 4.15
$$

The oxidation commenced before the dehydration was completed, as shown by the maximum weight loss of $6.62 \%$ compared to the theoretical $6.98 \%$. A sample of calcium sulphite hemihydrate was heated to $390^{\circ} \mathrm{C}$ before the furnace was removed and the balance chamber evacuated, to prevent further oxidation; it was found finally to contain $2.8 \%$ calcium sulphate. The oxidation of the. calcium sulphite correlated with the large exotherm peaking at $467^{\circ} \mathrm{C}$.

A number of samples of calcium sulphite hemihydrate. were. isothermally heated in static air for two-hour periods at a series of temperatures. The specific surfaces of the products were determined gravimetrically, Fig. 4.2.14. Above $300^{\circ} \mathrm{C}$ dehydration occurred and oxidation had begun at $350^{\circ} \mathrm{C}$, Table 4.2.4. Oxidation became increasingly important, as the calcination temperatures increased, until there was $100 \%$ oxidation at $500^{\circ} \mathrm{C}$.

Table. 4.2.4 Composition of samples of calcium sulphite isothermally. heated for two hour periods in air.

\begin{tabular}{|c|c|c|c|}
\hline \multirow{2}{*}{$\begin{array}{l}\text { Temperature } \\
{ }^{\circ} \mathrm{C}\end{array}$} & \multicolumn{2}{|c|}{ Composition of product } & \multirow{2}{*}{$\begin{array}{c}\text { \%age conversion of } \mathrm{CaSO}_{3} \\
\text { to } \mathrm{CaSO}_{4}\end{array}$} \\
\hline & $\% \mathrm{CaSO}_{3}$ & $\% \mathrm{CaSO}_{4}$ & \\
\hline 350 & 96.2 & 3.8 & 3.4 \\
\hline 400 & 76.9 & 23.1 & 21 \\
\hline 450 & 19.0 & 81.0 & 79 \\
\hline 500 & 0 & 100 & 100 \\
\hline
\end{tabular}

The maximum in specific surface, Fig. 4.2.14(a), corresponded to the dehydration reaction and also the initial formation of calcium sulphate at the $\gamma-$ to $\mathrm{B}^{-\mathrm{CaSO}}{ }_{4}$ transition temperature. 
However, further oxidation to calcium sulphate, together with a greater degree of order in the anhydrous calcium sulphite, caused a reduction in surface area so that the maxima in air occurred at a lower temperature than "in vacuo", where there was no conversion to calcium sulphate in this temperature range.

The calcium sulphate began to decompose at $1064^{\circ} \mathrm{C}$ and there was a continuous weight loss as the temperature rose to $1096{ }^{\circ} \mathrm{C}$. (d) In sulphur dioxide and nitrogen

In order to compare the relative importance of the oxidation $\begin{array}{rl}\text { reactions } 2 \mathrm{CaSO}_{3}+\mathrm{O}_{2} \longrightarrow \mathrm{CaSO}_{4} & 4.14 \\ \text { and } 2 \mathrm{CaSO}_{3}+\mathrm{SO}_{2} \longrightarrow \mathrm{CaSO}_{4}+\mathrm{S} & 4.16\end{array}$ samples of calcium sulphite hemihydrate were heated in atmospheres of nitrogen and sulphur dioxide with the overall flow rate being 1 min $^{-1}$. The TG results are illustrated in Fig. 4.2 .7 and in Fig. 4.2.8 two of the DTA curves are reproduced. Comparison with results obtained by heating in air and in a mixture of air and nitrogen (shown by broken lines in Fig. 4.2.7) indicated that the reaction paths were similar for comparable concentrations of oxygen and sulphur dioxide respectively. The only differences were that, in the presence of oxygen, the rate of oxidation was greater, but slightly smaller amounts of sulphite were converted ultimately to sulphate, as shown in Table 4.2.5.

Table 4.2.5 Degree of oxidation of calcium sulphite in oxygen and in sulphur dioxide

\begin{tabular}{|c|c|c|}
\hline $\begin{array}{c}\text { Gas composition } \\
\text { in volume \% }\end{array}$ & $\begin{array}{c}\text { Temperature at } \\
\text { completion of main } \\
\text { oxidation reaction }\end{array}$ & $\begin{array}{c}\text { \%age conversion of } \\
\mathrm{CaSO}_{3} \text { at end of main } \\
\text { oxidation reaction }\end{array}$ \\
\hline $20.9 \mathrm{O}_{2} ; 79.1 \mathrm{~N}_{2}$ & $520^{\circ} \mathrm{C}$ & 83.5 \\
$20.2 \mathrm{SO}_{2} ; 79.8 \mathrm{~N}_{2}$ & $610^{\circ} \mathrm{C}$ & 87.3 \\
$4.2 \mathrm{O}_{2} ; 95.8 \mathrm{~N}_{2}$ & $680^{\circ} \mathrm{C}$ & 77.8 \\
$4.5 \mathrm{SO}_{2} ; 95.5 \mathrm{~N}_{2}$ & $790^{\circ} \mathrm{C}$ & 83.5 \\
\hline
\end{tabular}


Complete oxidation was prevented by the coating of calcium sulphate formed hindering access of the gaseous oxidant to the internal remnants of unreacted calcium sulphite. The formation of an unreacted core would appear to have been an unlikely event based on the original morphology of the calcium sulphite hemihydrate crystals, which, as the electron micrographs in Fig. 4.2.11 and 4.2.12 show, were tabular. The packing of the samples in the crucibles was also relatively open as indicated by the low sample weight loaded, in relation to the volume occupied and the density of the compound. However, on dehydration the samples in the crucibles showed a very large reduction in volume, approximately $70 \%$, with the sample having shrunk from the external walls and packed closely about the central dimple. As oxidation proceeded the sample became much harder, as neighbouring crystals were fused together and effectively reduced the access of the oxidant in the later stages of the reaction. The oxidation reaction involving sulphur dioxide resulted in a gaseous product, sulphur, and the evolution of this would tend to reduce the coherence of the sulphate coating, thus allowing rather greater access of the gaseous oxidant to the sample and hence a greater degree of conversion to calcium sulphate.

The reaction with 20.2 vol-\% sulphur dioxide came to an end at $620^{\circ} \mathrm{C}$ and was followed by disproportionation of the unreacted calcium sulphite, as indicated by the low, broad exotherm peaking at $710^{\circ} \mathrm{C}$, Fig. 4.2.8. In the presence of 20.9 vol-\% oxygen, the main oxidation reaction was completed by $520^{\circ} \mathrm{C}$ but a further slow steady oxidation continued until the temperature reached $1000^{\circ} \mathrm{C}$. There was also disproportionation, but the calcium sulphide formed was partially oxidised to calcium sulphate. The corresponding reaction with sulphur dioxide did not appear to occur though 
thermodynamically favourable at temperatures up to about $900^{\circ} \mathrm{C}^{95}$.

$$
\mathrm{CaS}+2 \mathrm{SO}_{2} \longrightarrow \mathrm{CaSO}_{4}+\mathrm{S}_{2} \quad 4.17
$$

The presence of sulphur dioxide in the atmosphere of the reaction chamber repressed the small amount of decomposition of calcium sulphite (to calcium oxide) which, in nitrogen alone, Fig. 4.2 .3 , occurred above $680^{\circ} \mathrm{C}$, and only traces of calcium oxide were found in samples heated to temperatures below $900^{\circ} \mathrm{C}$. The decomposition of calcium sulphate was also inhibited by the presence of sulphur dioxide. The stability range of calcium sulphate, compared to calcium sulphite, was extended at the lower temperature end as well. At $398^{\circ} \mathrm{C}$ a sample heated in 20.6 vol-\% $\mathrm{SO}_{2}$ contained $13.6 \%$ calcium sulphate, whereas a sample treated similarly in air contained $2.8 \%$ calcium sulphate.

\subsubsection{Discussion}

A comparison of the results presented in section 4.2.1 with a number of recently-published studies $86,93,96,97,98$ on aspects of the thermal stability of calcium sulphite indicates close agreement with the results obtained by Aoki et al ${ }^{96}$. They studied the thermal stability in air and in nitrogen, up to $1500^{\circ} \mathrm{C}$, of calcium sulphite hemihydrate samples, prepared by several different methods. Using micro-TG-DTA and X-ray powder diffraction methods, the rate of oxidation in air was found to correlate with the size of the original hemihydrate crystals, with the larger crystals having a lower rate of oxidation and allowing more disproportionation to occur. A comparison of the crystal sizes and shapes shown in the published electron micrographs with the specimens used in the present study indicated that comparable degrees of oxidation were obtained for similar samples. 
Lutz and E1 Suradi ${ }^{86}$ state that their DTA and TG studies were performed, in argon, up to $800^{\circ} \mathrm{C}$, but the curves shown only continue up to about $580^{\circ} \mathrm{C}$. Therefore, only the dehydration step is indicated with its associated endotherm.

Ingraham and Marier ${ }^{97}$ carried out DTA studies on $\mathrm{CaSO}_{3}$ in streams of nitrogen, oxygen and sulphur dioxide, up to temperatures of about $850^{\circ} \mathrm{C}$. The fact that they started with anhydrous calcium sulphite rather than the hemihydrate appears to be the major reason for the marked differences in DTA results compared to the curves reported in this thesis. In oxygen, they obtained an exothermic peak at $540^{\circ} \mathrm{C}$ due to the oxidation of calcium sulphite (cf $467^{\circ}$ in Fig. 4.2.6) followed by a second larger exotherm at $700^{\circ} \mathrm{C}$ due to disproportionation. It might be expected that there would be more extensive oxidation in oxygen than in air. However, the dehydration of $\mathrm{CaSO}_{3} \cdot 0.5 \mathrm{H}_{2} \mathrm{O}$ produces an increase in surface area and number of crystallites of anhydrous $\mathrm{CaSO}_{3}$ and this activated product begins to react rapidly, so that oxidation is almost complete by $520^{\circ} \mathrm{C}$. The smaller crystallites would not be deactivated so rapidly by a surface coating of sulphate, especially as the deactivation process apparently requires the aggregation of particles, which is favoured by higher temperatures. Ingraham and Marier did not state either how their calcium sulphite was prepared or what its size characteristics were. Similar differences are shown between their DTA curve in $\mathrm{SO}_{2}$ and Fig. 4.2.8. Again the activation caused by the dehydration reaction enhances the oxidation reaction, even though the concentration of oxidant is lower.

Cubicciotti et al ${ }^{98}$ measured the decomposition pressure of calcium sulphite over the temperature range $723-767 \mathrm{~K}$, by the torsion-effusion method, using mass spectrometric analysis of the 
effusing gases to identify them. In the temperature range used only reaction 4.11 was found, and the thermodynamically more favourable reaction, 4.13, did not commence until the temperature reached about $900 \mathrm{~K}$.

$$
\begin{aligned}
& \mathrm{CaSO}_{3} \longrightarrow \mathrm{CaO}+\mathrm{SO}_{2}\left(\Delta \mathrm{G}_{700}^{\circ}=98.5 \mathrm{~kJ} / \mathrm{mol}\right) \quad 4.11 \\
& 6 \mathrm{CaSO}_{3} \longrightarrow 4 \mathrm{CaSO}_{4}+2 \mathrm{CaO}+\mathrm{S}_{2}\left(\Delta \mathrm{G}_{700}^{\circ}=39.1 \mathrm{~kJ} / \mathrm{mole}\right) 4.13
\end{aligned}
$$

The higher activation energy for reaction 4.13 was explained by the need to rupture six S-O bonds compared to only one S-O bond in reaction 4.11 . 


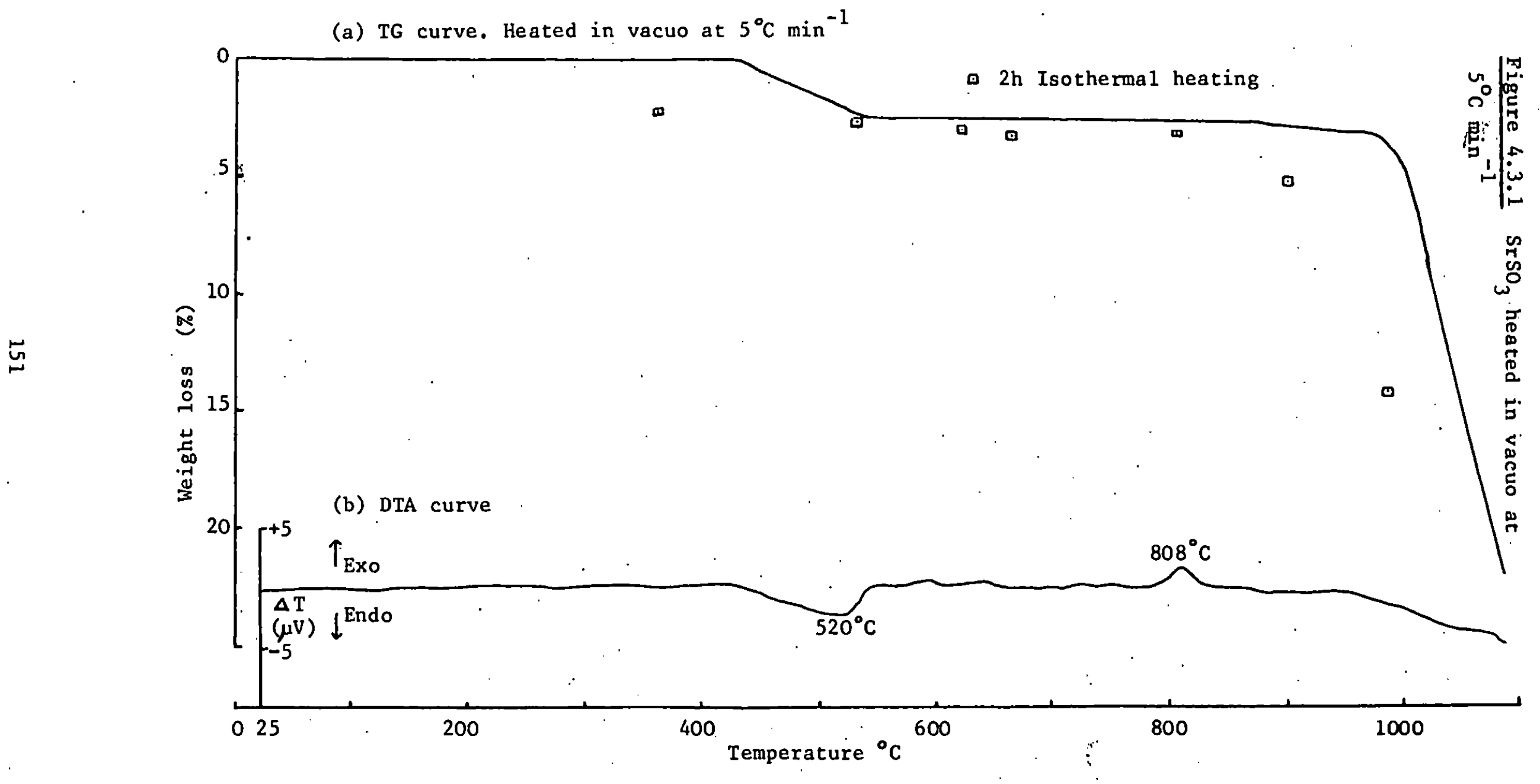



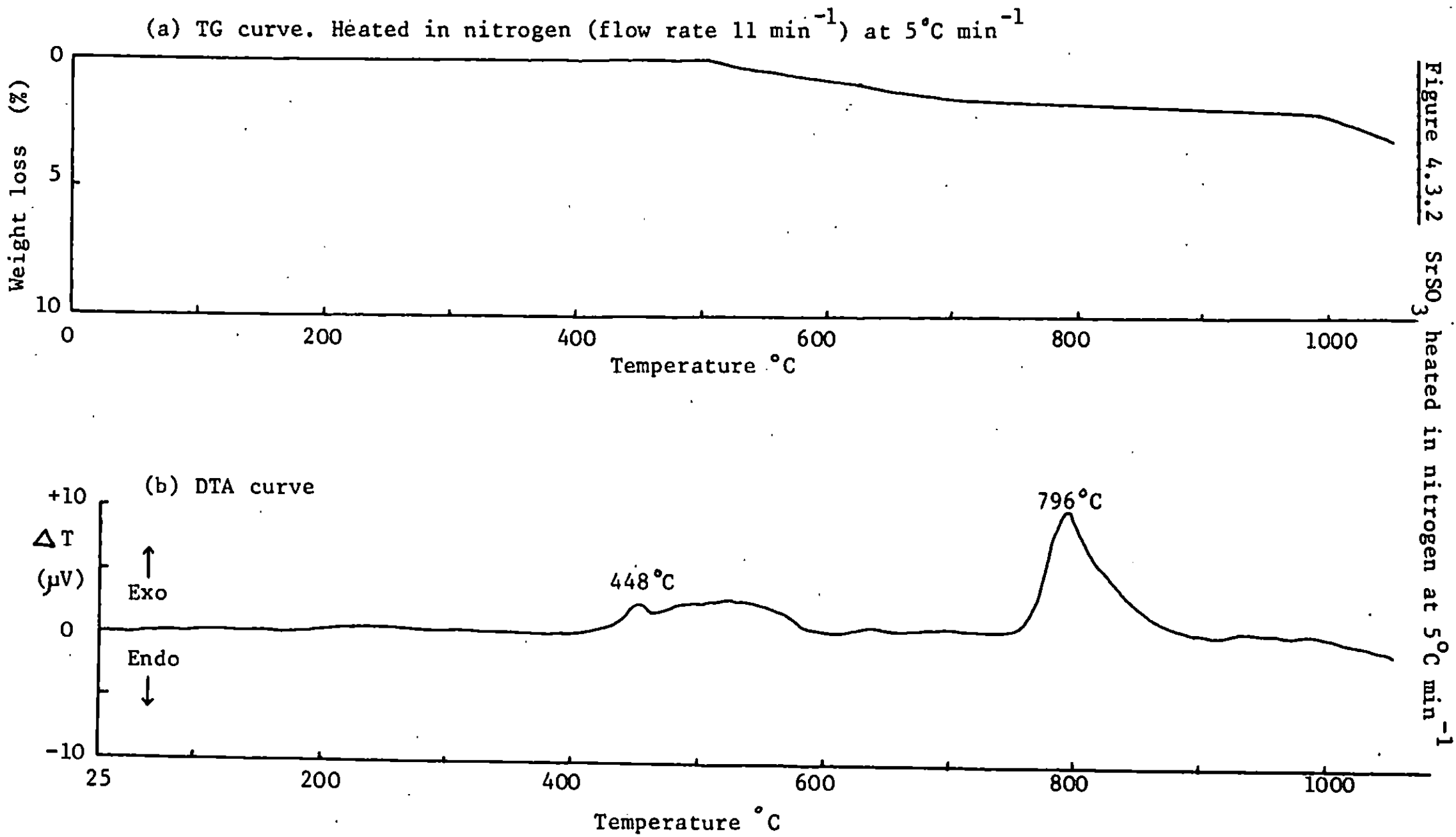

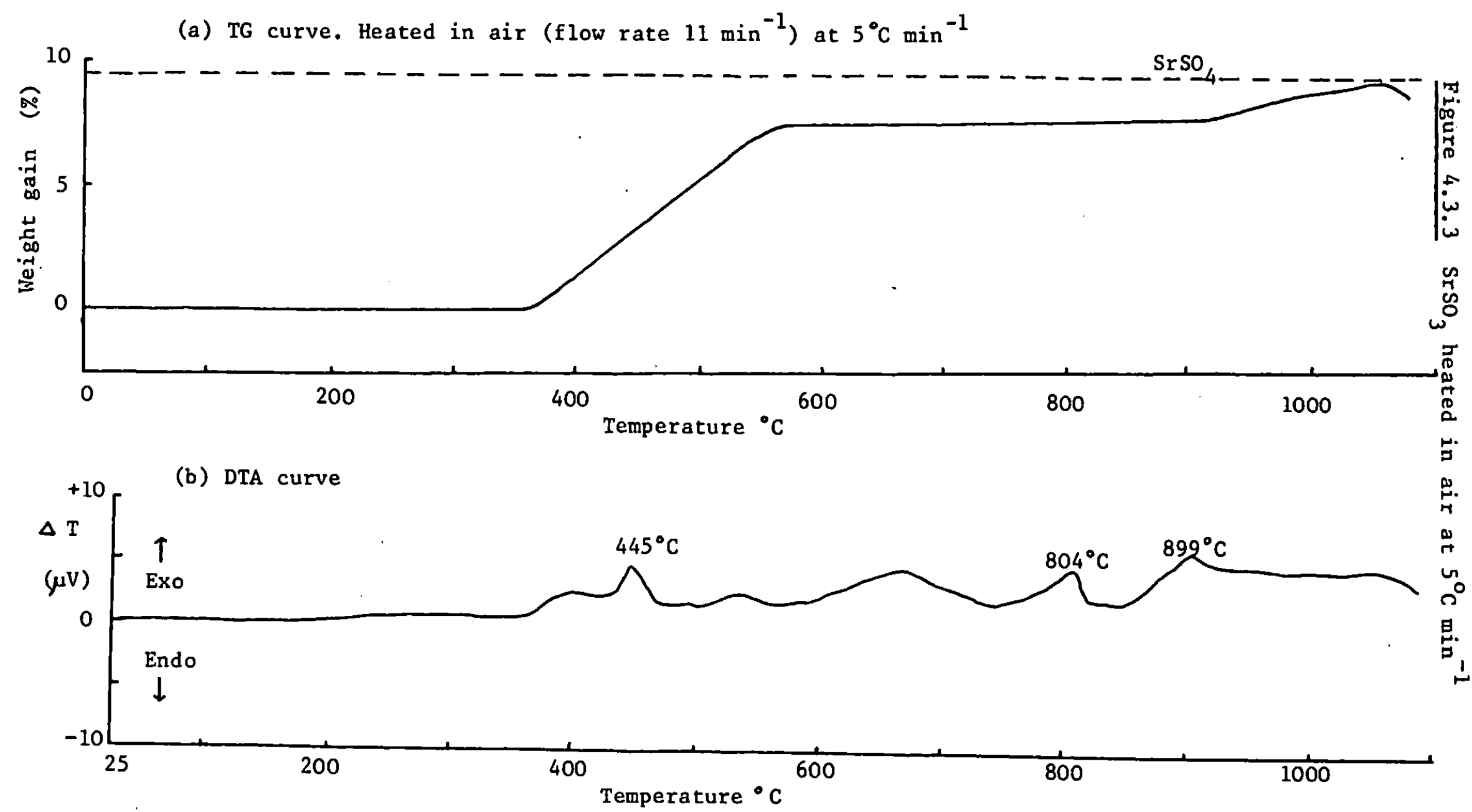

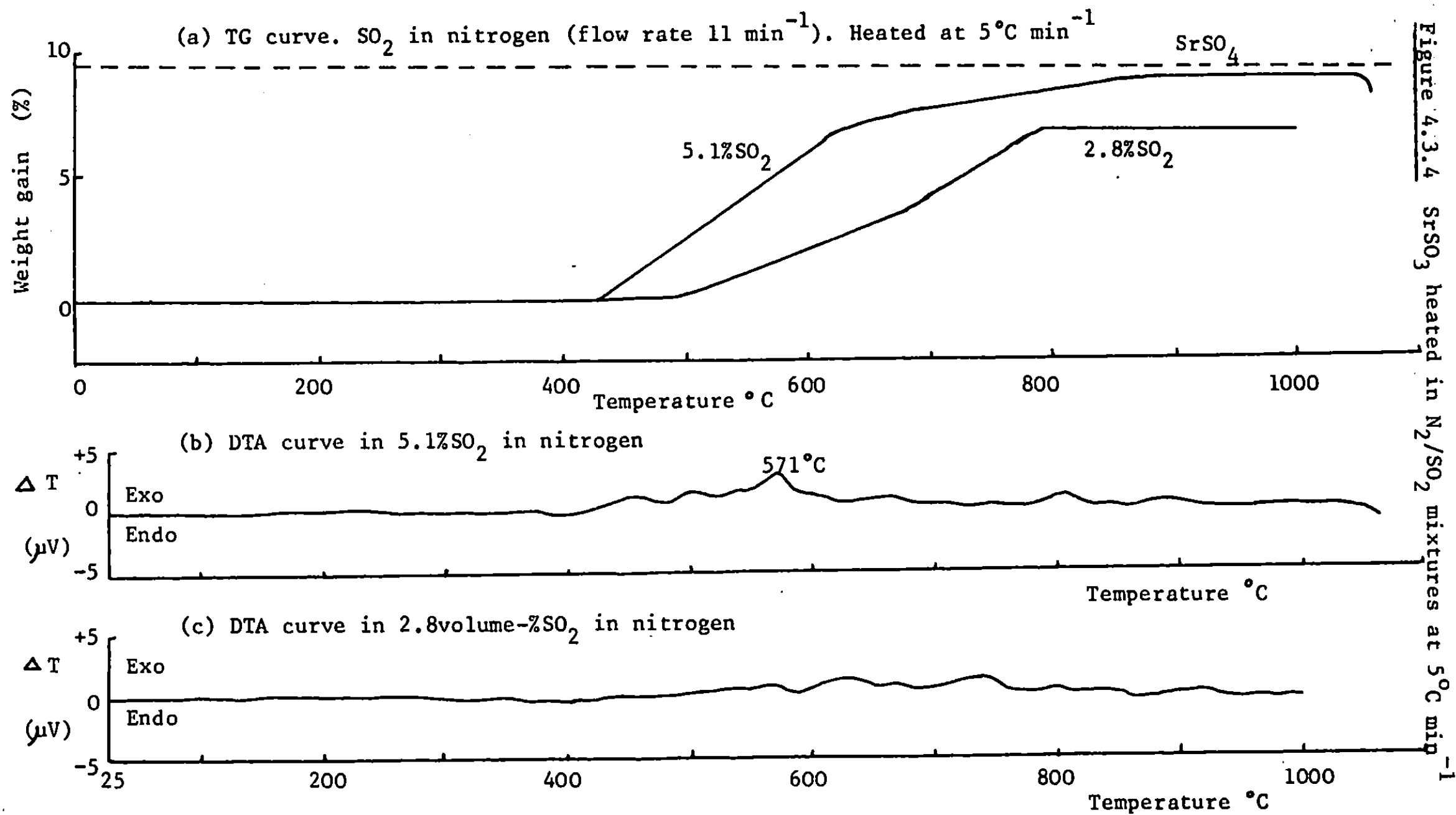
Figure 4.3.5 $\mathrm{SrSO}_{3}$ calcined in vacuo for $2 \mathrm{~h}$ periods

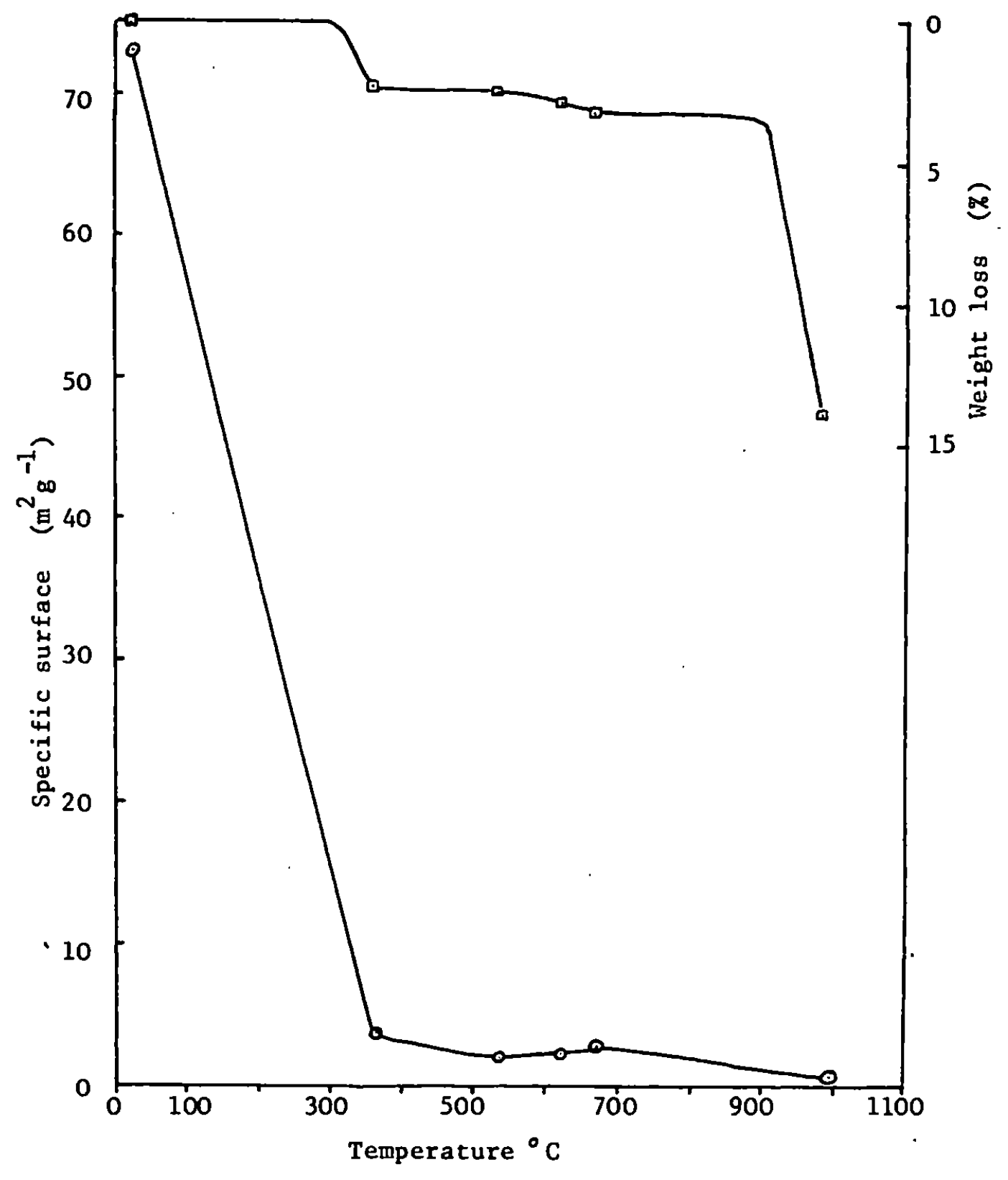


Figure 4.3.6 $\mathrm{SrSO}_{3}$ heated on electron microscope hot-stage

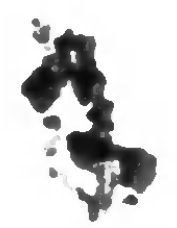

;:

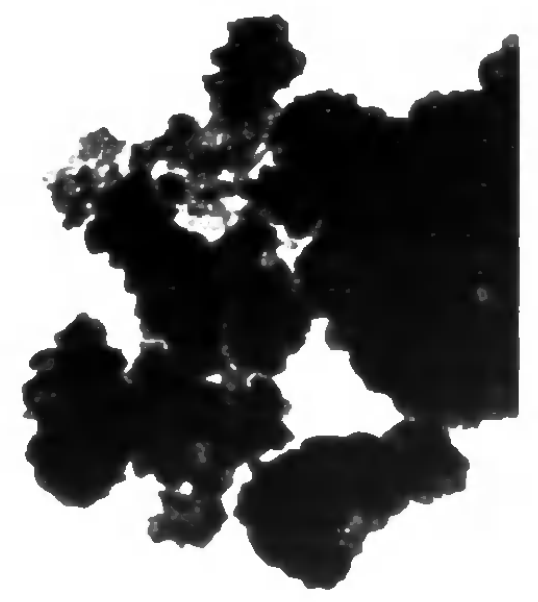

(a) At $26^{\circ} \mathrm{C}$
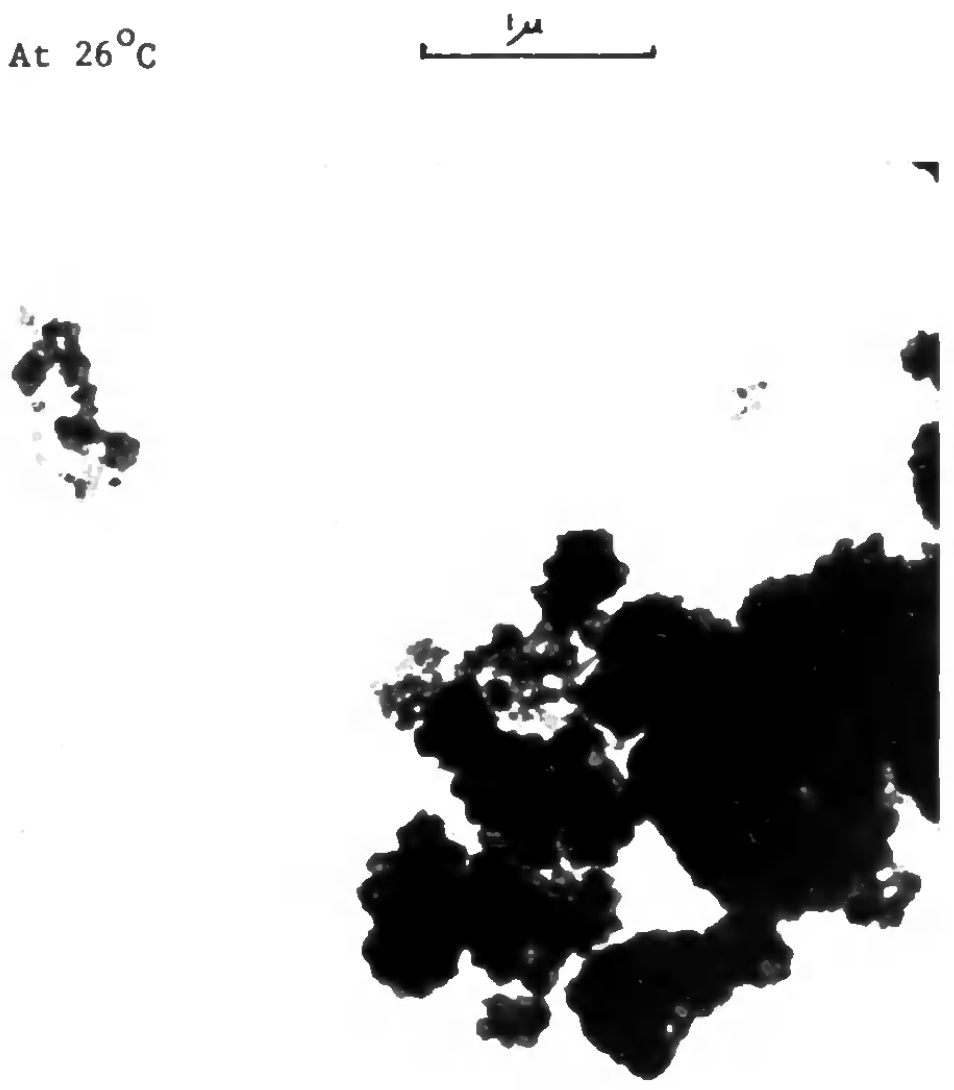

(b) At $335^{\circ} \mathrm{C}$

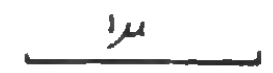


Figure 4.3.6
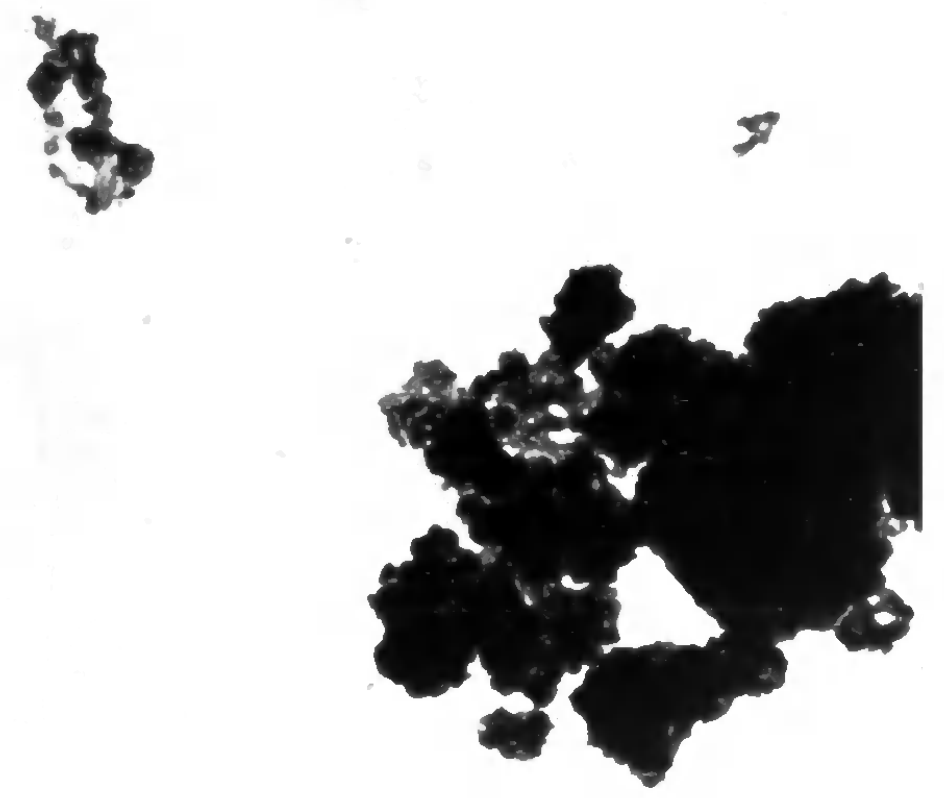

(c) At $616^{\circ} \mathrm{C}$
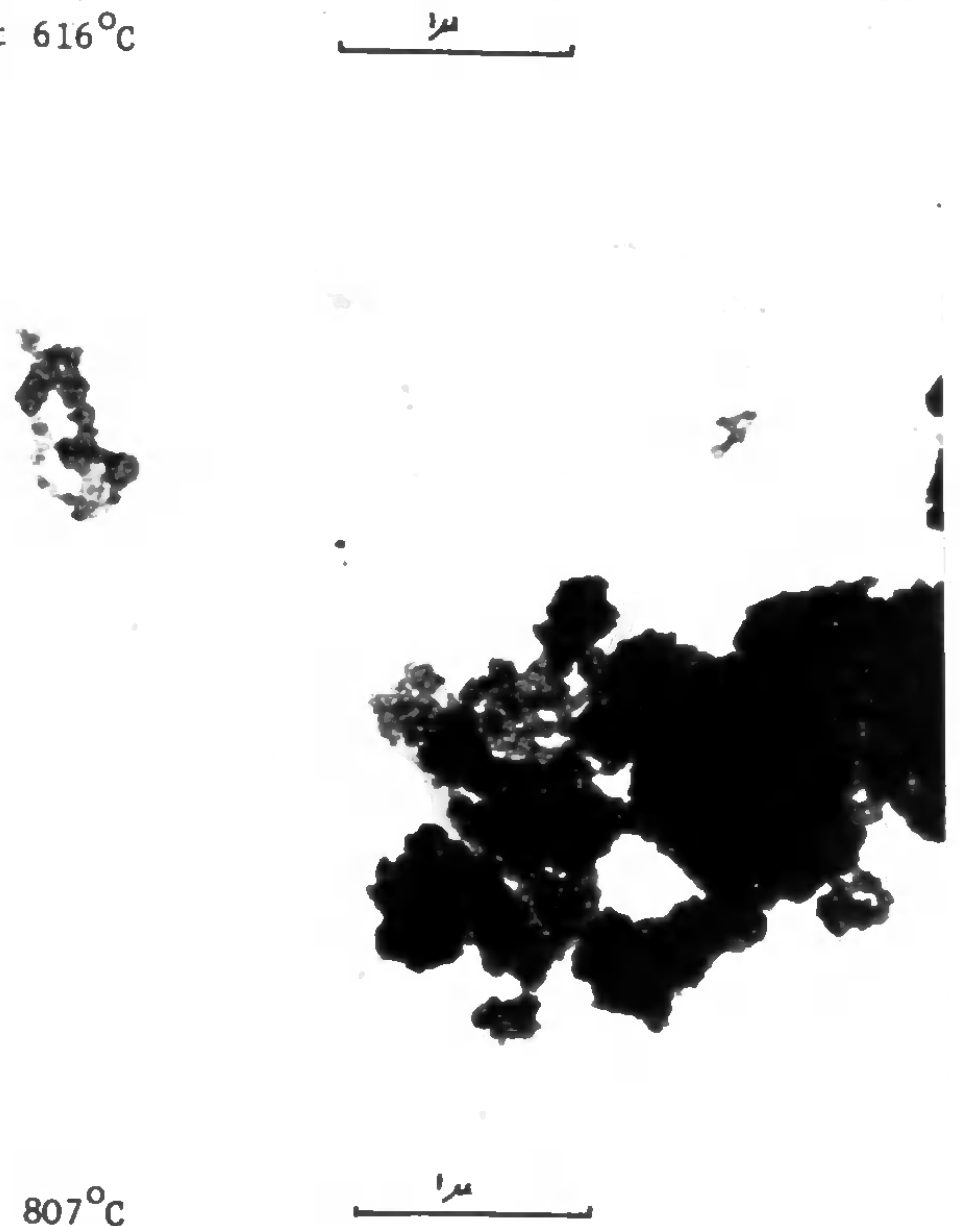

(d) At $807^{\circ} \mathrm{C}$ 
Figure 4.3.6
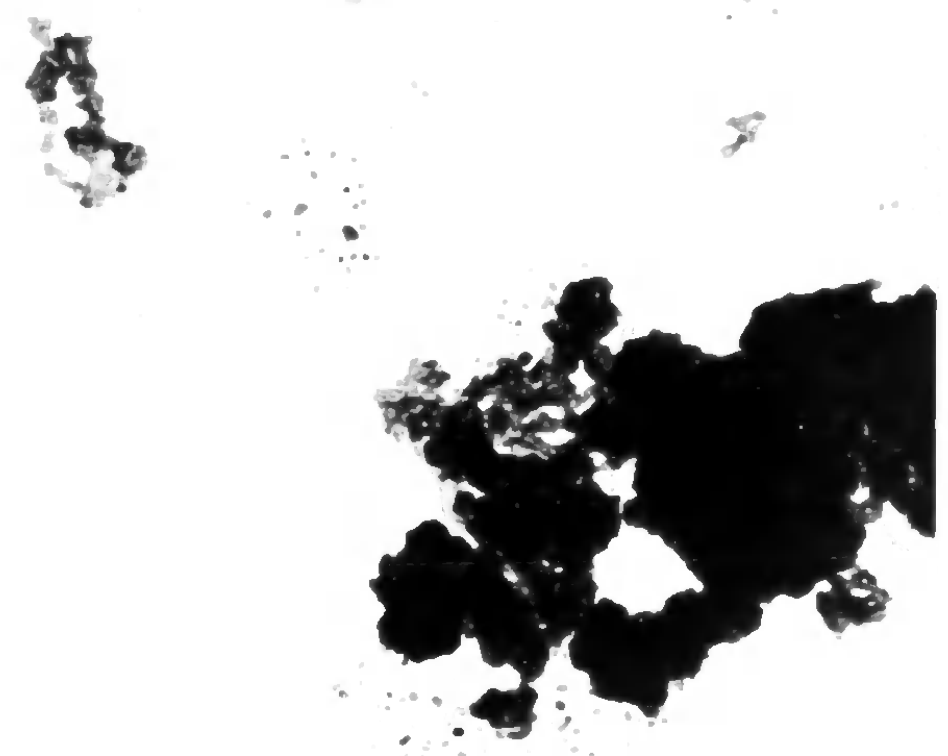

(e) At $945^{\circ} \mathrm{C}$
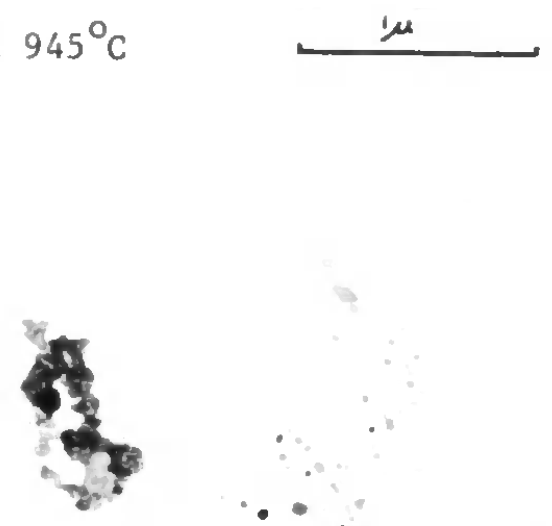

(f) At $949^{\circ} \mathrm{C}$

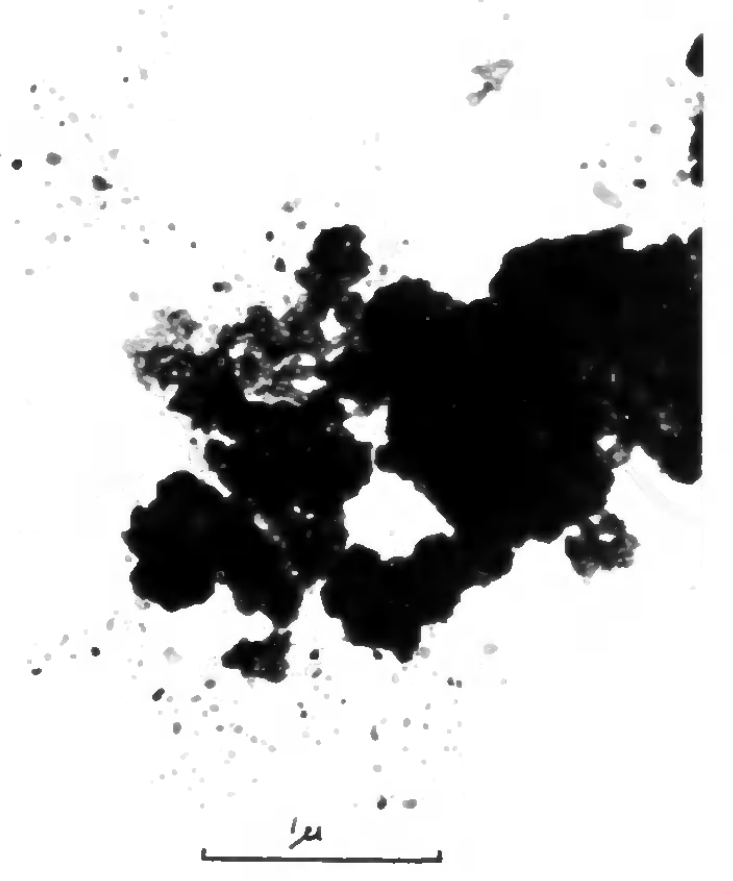


Figure 4.3.6

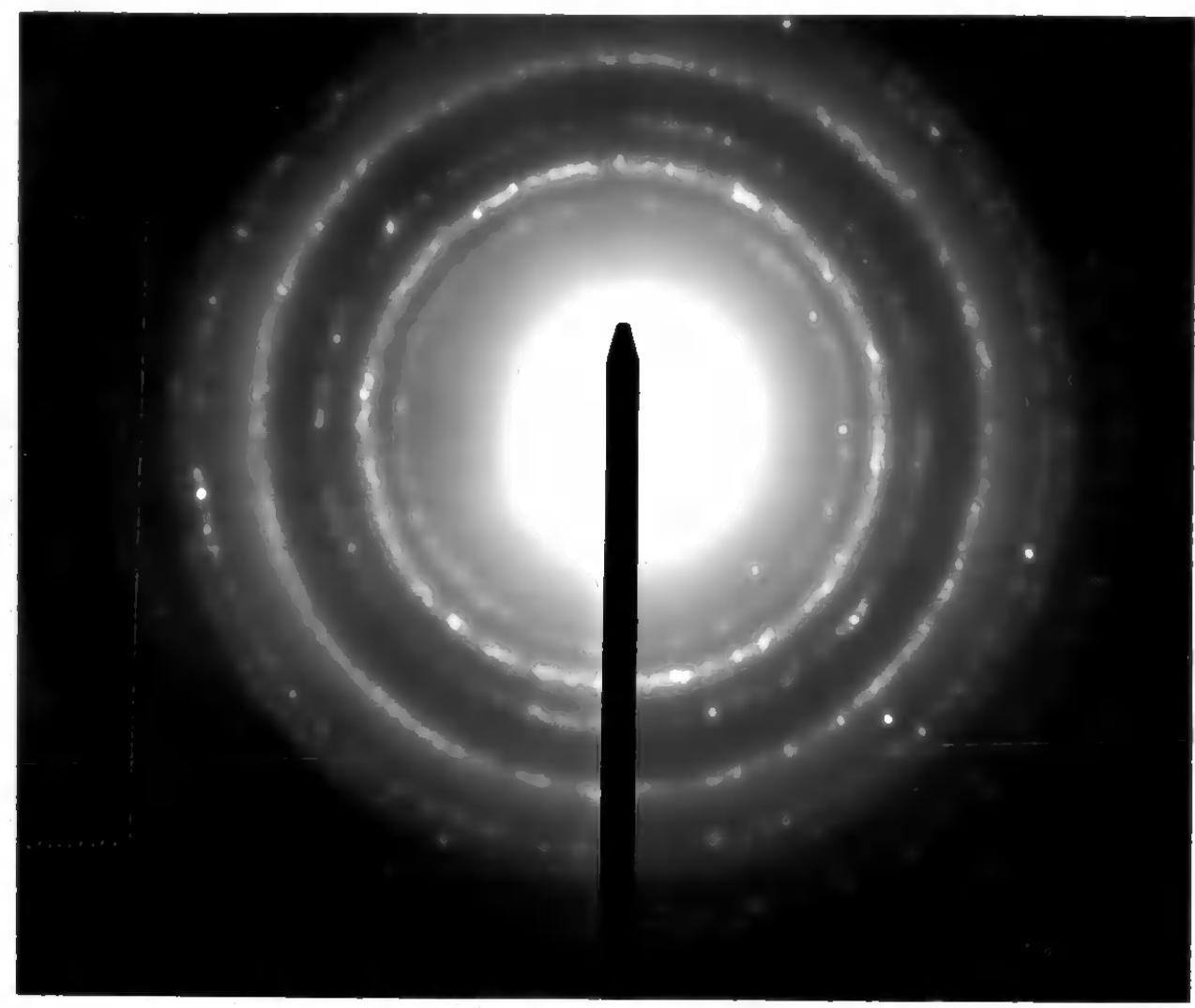

(g) Electron diffraction pattern at $741^{\circ} \mathrm{C}$

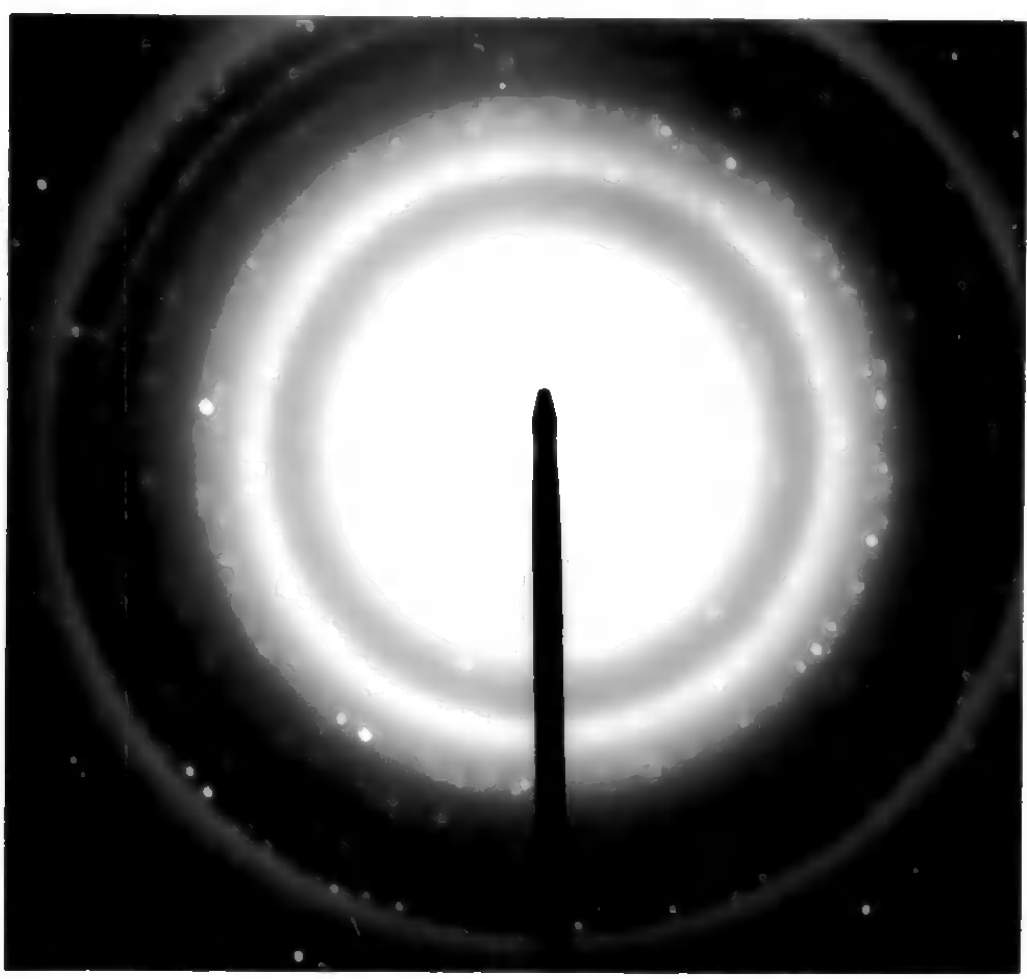

(h) Electron diffraction pattern at $945^{\circ} \mathrm{C}$ 


\subsection{Strontium Sulphite}

\subsubsection{Results}

Fig. 4.3.1 - 4.3.4 summarise the results obtained by the use of simultaneous dynamic thermogravimetry and differential thermal analysis, at heating rates of $5^{\circ} \mathrm{Cmin}^{-1}$, in various atmospheres. Strontium sulphite differed from magnesium and calcium sulphite in not forming an hydrated compound, thus, there could be no activation of the anhydrous sulphite caused by the break up of the hydrated structure.

\section{a) In vacuo}

Desulphurisation commenced at $415^{\circ} \mathrm{C}$, Fig. 4.3.1(a) and continued to $550^{\circ} \mathrm{C}$ with a weight $10 \mathrm{ss}$ of $2.6 \%$, which was equivalent to $6.8 \%$ of the strontium sulphite decomposing to form strontium oxide, (i), while the remainder disproportionated, (ii).
(i) $\mathrm{SrSO}_{3} \longrightarrow \mathrm{SrO}+\mathrm{SO}_{2}$
(ii) $4 \mathrm{SrSO}_{3}$
4.18

There was very little further weight loss until the temperature reached $870^{\circ} \mathrm{C}$ when slow decomposition occurred, becoming more rapid above $975^{\circ} \mathrm{C}$. Complete decomposition to strontium oxide was not achieved at the highest temperature reached, $1088^{\circ} \mathrm{C}$.

$$
3 \mathrm{SrSO}_{4}+\mathrm{SrS} \longrightarrow 4 \mathrm{SrO}+4 \mathrm{SO}_{2} \quad 4.19
$$

The DTA curve, Fig. 4.3.1(b), showed that the initial decomposition reaction was accompanied by a broad endothermic peak between $460^{\circ} \mathrm{C}$ and $540^{\circ} \mathrm{C}$. There was a small exothermic peak at $808^{\circ} \mathrm{C}$ which was not associated with any weight change, followed by an endothermic drift as the final decomposition reaction became dominant.

Samples of strontium sulphite heated isothermally for two-hour periods confirmed the concurrent nature of the desulphurisation and 
disproportionation reactions. The analyses of the products are given in Table 4.3.1 and the weight losses are shown in Fig. 4.3.1(a). The specific surfaces of these samples were also determined, Fig. 4.3.5. The high surface area of the original strontium sulphite, due to its rapid precipitation from solution, was in marked contrast to the low surface areas of the more slowly grown hydrated crystals of magnesium and calcium sulphite. The specific surface was rapidly reduced with increase in temperature, and the small degree of initial decomposition, to strontium oxide, was not sufficient to outweigh the sintering effects promoted by the crystal lattice rearrangements associated with disproportionation. Similarly at $984^{\circ} \mathrm{C}$ the freshly formed strontium oxide was quickly reduced in activity .

The specimens of strontium sulphite examined, using hot-stage electron microscopy, illustrated some of the changes discussed, Fig. 4.3.6(a) - (h). The crystals heated to $335^{\circ} \mathrm{C},(\mathrm{b})$, had undergone some changes which were marked by a tendency to occupy a smaller volume, thus producing larger gaps between aggregates and a "smoothing" of some of the edge features. With the temperature at $616^{\circ} \mathrm{C}$, (c), the thinning of many crystallites was noticeable as was the reduction in area of the aggregates. Photomicrograph (d), taken at $807^{\circ} \mathrm{C}$, showed strain lines on the carbon film consequent on the changes which had taken place causing a further reduction in the valume of the aggregates. The final two transmission electron photomicrographs (e) and (f), taken at $945^{\circ} \mathrm{C}$ and $949^{\circ} \mathrm{C}$ respectively with a time interval of 38 minutes, showed extensive "decrepitation" as well as sintering. The small particles on the carbon film were close to or at their melting point and in some cases could be seen 


\begin{tabular}{|c|c|c|c|c|c|c|c|}
\hline \multirow{2}{*}{$\begin{array}{c}\text { Temperature } \\
{ }^{\circ} \mathrm{C}\end{array}$} & \multirow{2}{*}{$\begin{array}{l}\text { Weight } \\
\text { loss, \% }\end{array}$} & \multicolumn{4}{|c|}{ Composition of product, $\%$} & \multirow{2}{*}{$\underset{\%}{\text { Desulphurisation }}$} & \multirow{2}{*}{$\begin{array}{c}\text { Disproport } \\
\text {-ionation } \\
\%\end{array}$} \\
\hline & & Sro & $\mathrm{SrSO}_{4}$ & SrS & $\mathrm{SrSO}_{3}$ & & \\
\hline 358 & 2.32 & 3.84 & - & - & 96.1 & 6.1 & - \\
\hline 530 & 2.60 & 4.3 & 35.3 & 7.7 & 52.7 & $\cdot 6.8$ & 41.9 \\
\hline 620 & 2.99 & 4.9 & 53.1 & 11.5 & 30.3 & 7.8 & 62.7 \\
\hline 663 & 3.30 & 5.5 & 64.9 & 14.1 & 14.8 & 8.6 & 76.4 \\
\hline 900 & 4.91 & 8.4 & 75.3 & 16.4 & - & 12.9 & 87.2 \\
\hline 984 & 13.9 & 26.1 & 61.5 & 13.4 & - & 36.4 & 64.4 \\
\hline
\end{tabular}


to move over the surface of the film. In the larger masses used for the thermogravimetric studies, these smaller particles, if formed, would be rapidly reincorporated in the larger aggregates thus reducing the specific surface. Changes in phase composition were confirmed by changes in the electron diffraction patterns obtained, Fig. $4.3 .6(\mathrm{~g})$ and $(\mathrm{h})$, taken at $741^{\circ} \mathrm{C}$ and $949^{\circ} \mathrm{C}$ respectively, which showed diffraction rings of different relative diameters for the same microscope settings. The "spottiness" of the rings indicated that the diffracting crystallites were relatively large, though in (h) the diffuseness of some of the rings showed that some of the newly-formed strontium oxide crystallites were very small.

\section{b) In nitrogen}

In the presence of nitrogen, Fig. 4.3.2, the decomposition of strontium sulphite to form strontium oxide commenced at a higher temperature, $507^{\circ} \mathrm{C}$, than "in vacuo", $415^{\circ} \mathrm{C}$, and also proceeded less rapidly. The decomposition had virtually ceased by $745^{\circ} \mathrm{C}$, but further reaction began above $1007^{\circ} \mathrm{C}$. The DTA curve differed from that obtained in vacuo, Fig. 4.3.1(b), by having a broad exotherm between $434^{\circ} \mathrm{C}$ and $585^{\circ}$, with a small initial peak at $448^{\circ} \mathrm{C}$, due to the disproportionation reaction. The second larger exotherm commencing at $755^{\circ} \mathrm{C}$, and peaking at $796^{\circ} \mathrm{C}$, must have been due to some phase change, because the exothermic disproportionation reaction was virtually completed at this temperature and therefore could not be responsible for such a relatively large peak.

\section{c) In air}

Strontium sulphite was oxidised to strontium sulphate when heated in air as shown by the increase in weight, Fig. 4.3.3(a), commencing at $351^{\circ} \mathrm{C}$ and continuing to $565^{\circ} \mathrm{C}$.

$$
2 \mathrm{SrSO}_{3}+\mathrm{O}_{2} \longrightarrow \mathrm{SrSO}_{4}
$$


The rate of weight increase became very slow until the temperature reached $895^{\circ} \mathrm{C}$ when a rather more rapid increase occurred as the strontium sulphide, formed by disproportionation, was oxidised.

$$
\begin{array}{lll}
\mathrm{SrS} & \longrightarrow \mathrm{O}_{2} \longrightarrow \mathrm{SrSO}_{4} & 4.21
\end{array}
$$

When the initial oxidation step was complete, $78.5 \%$ of the strontium sulphite had been oxidised with the remaining sulphite disproportionating to give a mixture of strontium sulphate and sulphide. Above $1060^{\circ} \mathrm{C}$ there was a small amount of dissociation of the sulphate

$$
\mathrm{SrSO}_{4} \longrightarrow \mathrm{SrO}+\mathrm{SO}_{3} \quad 4.22
$$

A sample of strontium sulphite heated in air at $5^{\circ} \mathrm{C} \mathrm{min}{ }^{-1}$, to $578^{\circ} \mathrm{C}$ (the system was then evacuated and cooled rapidly to prevent further oxidation) was found to have increased in weight by $7.51 \%$ and to contain $96.4 \% \mathrm{SrSO}_{4}$ and $3.5 \% \mathrm{SrS}$. This corresponded to $78.7 \%$ of the original strontium sulphite being oxidised and $21.3 \%$ disproportionating.

The DTA curve, Fig. 4.3.3(b), showed a series of rather low exothermic peaks between $361^{\circ} \mathrm{C}$ and $735^{\circ} \mathrm{C}$, though the peak at $445^{\circ} \mathrm{C}$ was somewhat sharper. These corresponded to the oxidation and disproportionation reactions. The oxidation of the strontium sulphide produced a small peak at $899^{\circ} \mathrm{C}$, and again there was the exotherm, peaking at $804^{\circ} \mathrm{C}$, shown "in vacuo" and in nitrogen.

(d) In sulphur dioxide and nitrogen

Strontium sulphite was oxidised by sulphur dioxide as well as by oxygen

$$
4 \mathrm{SrSO}_{3}+2 \mathrm{SO}_{2} \longrightarrow 4 \mathrm{SrSO}_{4}+\mathrm{S}_{2}
$$

There were, however, a number of differences in the extent of the reactions. 
With the concentrations of sulphur dioxide used, namely 5.1 vol $-\%$ and 2.8 vol $-\%$, the start of the oxidation reaction was at a higher temperature, Fig. 4.3.4(a), than in air, Fig. 4.3.3(a), but with the 5.1 vol-\% $\mathrm{SO}_{2}$ mixture the reaction proceeded more nearly to completion as the temperature rose to $876^{\circ} \mathrm{C}$. As in the equivalent reactions with calcium sulphite, the formation of sulphur as a gaseous product prevented the sulphate coating from becoming too coherent and so allowed the sulphur dioxide to penetrate the inner layers of the aggregates. The reaction between strontium sulphide was also favourable so the oxidation went almost to completion.

$$
\mathrm{SrS}+2 \mathrm{SO}_{2} \longrightarrow \mathrm{SrSO}_{4}+\mathrm{S}_{2} \quad 4.24
$$

These reactions produced corresponding low exotherms on the DTA curve, Fig. 4.3.4(b).

The rate of oxidation with the 2.8 vol-\% $\mathrm{SO}_{2}$ mixture was lower than with 5.1 vol-\% $\mathrm{SO}_{2}$ and the reaction almost ceased at $788^{\circ} \mathrm{C}$ when 73.8\% of the original strontium sulphite had been oxidised. The slower formation of sulphur had apparently allowed a more coherent sulphate coating to build up which prevented the weaker sulphur dioxide mixture from penetrating and reacting with the strontium sulphide formed by disproportionation.

\subsubsection{Discussion}

The disproportionation of strontium sulphite has been found to be more important than the dissociation reaction, as shown by the small quantities dissociating "in vacuo" and in nitrogen. Oxidation by oxygen and sulphur dioxide were both extensive reactions when the respective gases were present in sufficient concentrations.

The results obtained were in general agreement with the isothermal studies of Cola and Castellari $\mathrm{Bisi}^{44}$, i.e. disproportionation being 
the major reaction in nitrogen between $450^{\circ} \mathrm{C}$ and $800^{\circ} \mathrm{C}$. The degree of dissociation found in the present work was somewhat higher, maybe due to smaller samples being used. The only other experimental work which appears to have been recently published on the thermal stability of strontium sulphite is that of Lutz and El Suradi ${ }^{86}$, who used an argon atmosphere in their TG and DTA apparatus. They do not illustrate their results and only report a broad endotherm at $560^{\circ} \mathrm{C}$, which they equate to the disproportionation reaction. This result does not correspond to the findings reported in section 4.3.1, where the disproportionation reaction was shown to be exothermic. They report a similar result for barium sulphite which again is not in agreement with either the results reported in section 4.4 .1 or those obtained by other workers ${ }^{45}$. Decomposition of strontium sulphite, and of barium sulphite, to form the oxide is an endothermic reaction; however, Lutz and El Suradi do not report that any decomposition occurred. As discussed in Chapter 3, the $\mathrm{X}$-ray powder diffraction pattern of Lutz and El Suradi's strontium sulphite sample indicated that it contained an appreciable quantity of strontium sulphate. 


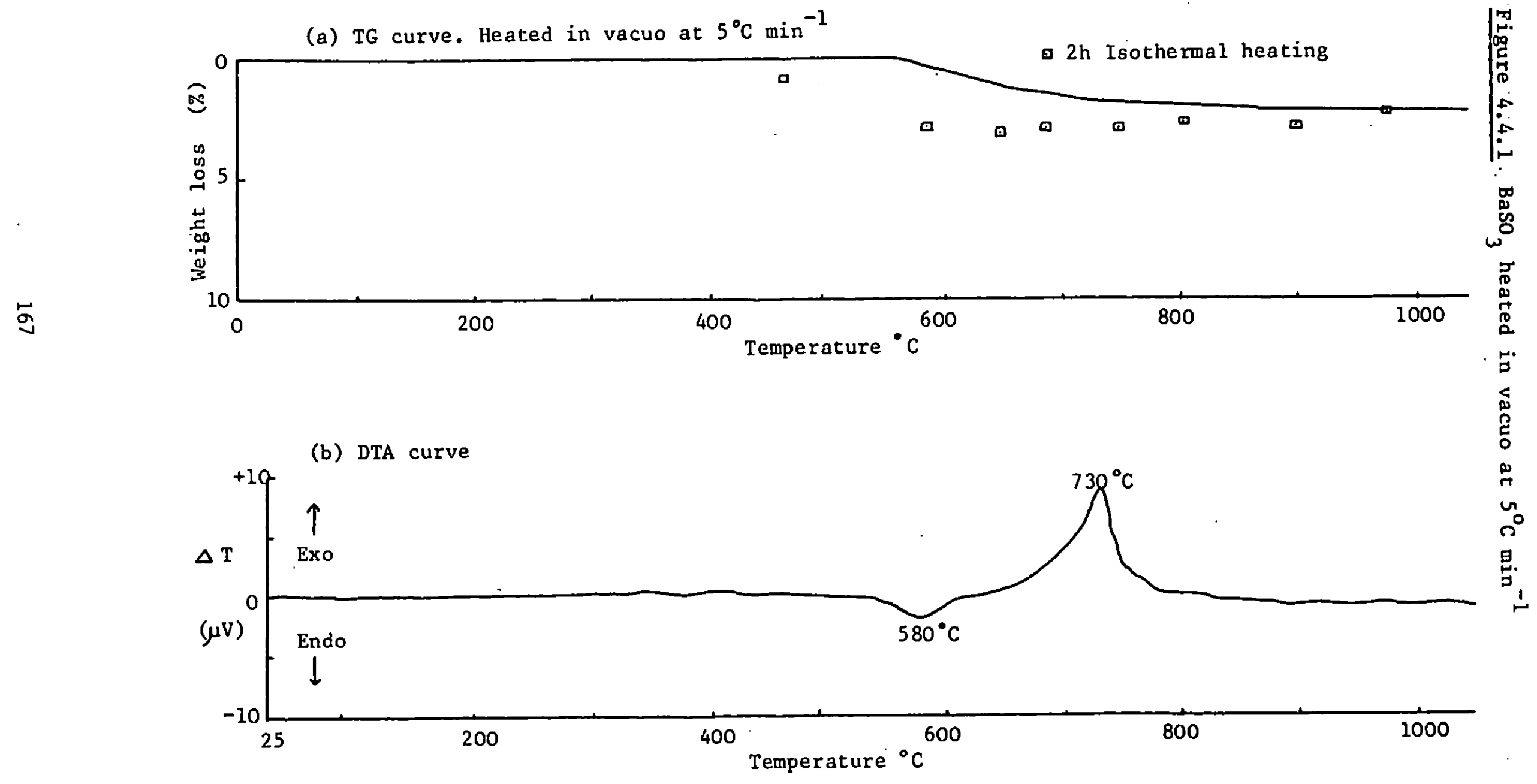


(a) TG curve. Heated in nitrogen ( $f$ low rate $18 \mathrm{~min}^{-1}$ ) at $5^{\circ} \mathrm{Cmin}^{-1}$

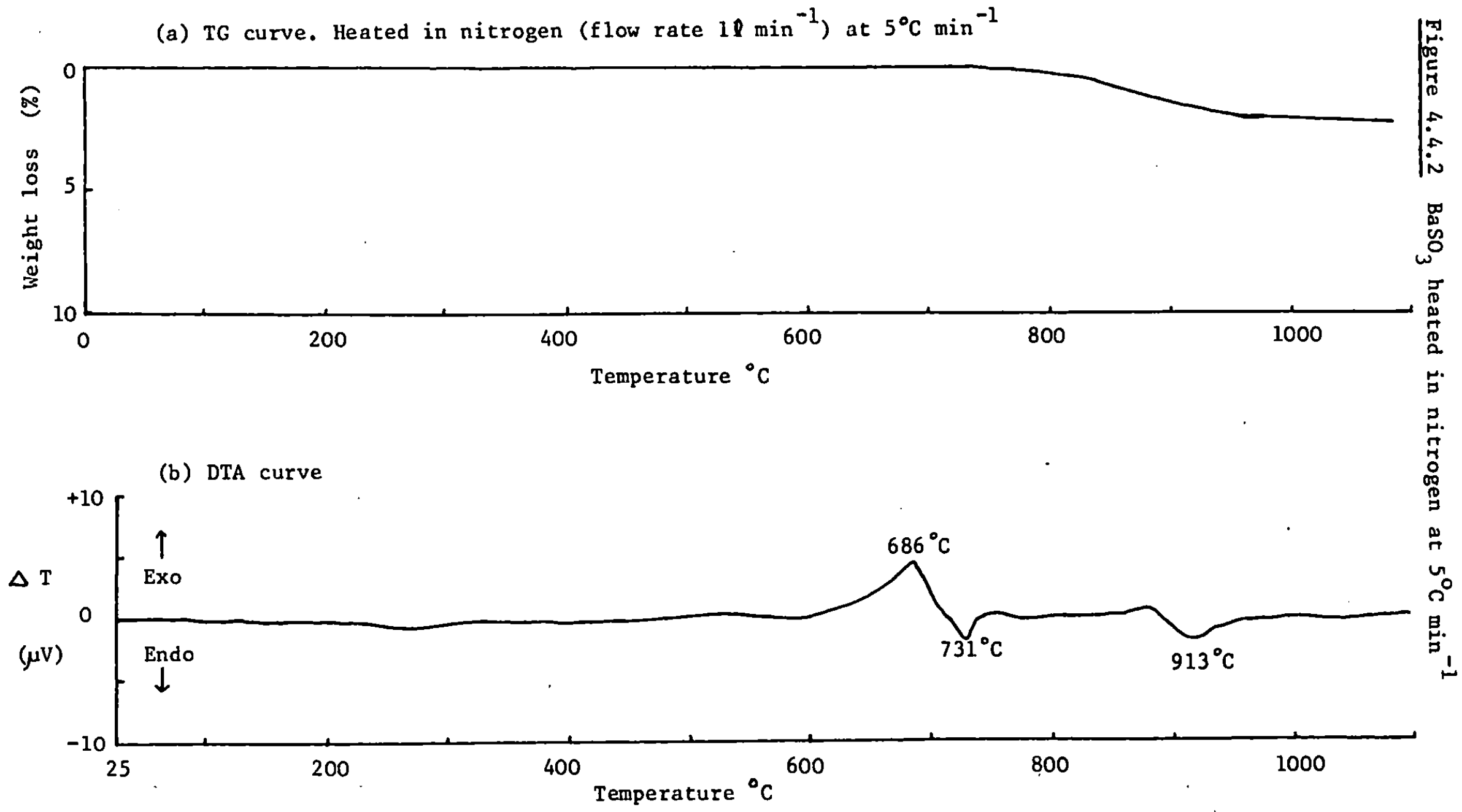




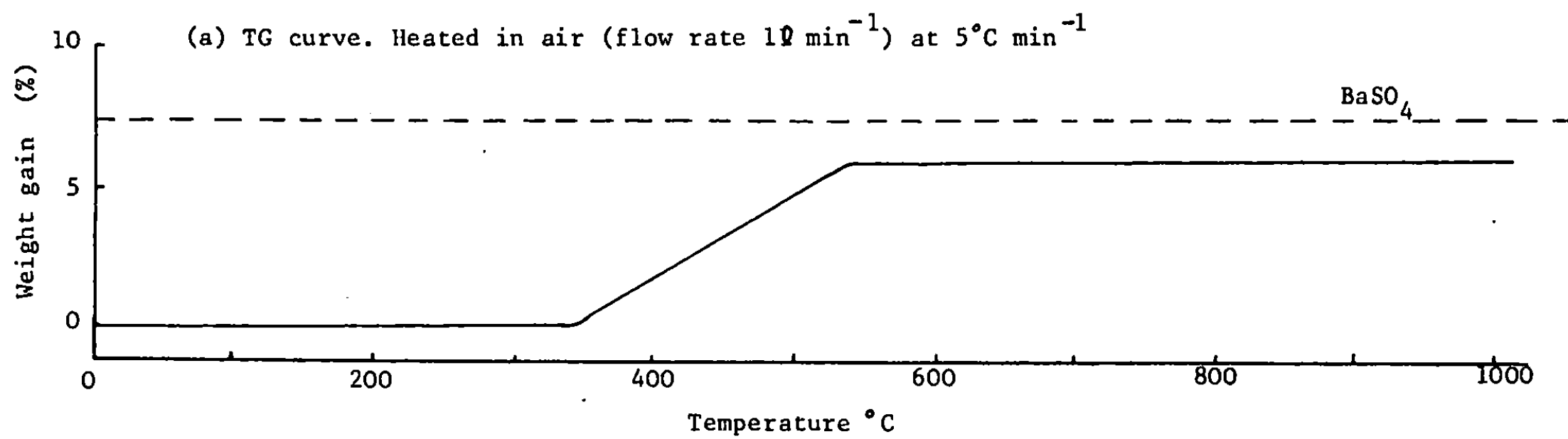

(b) DTA curve

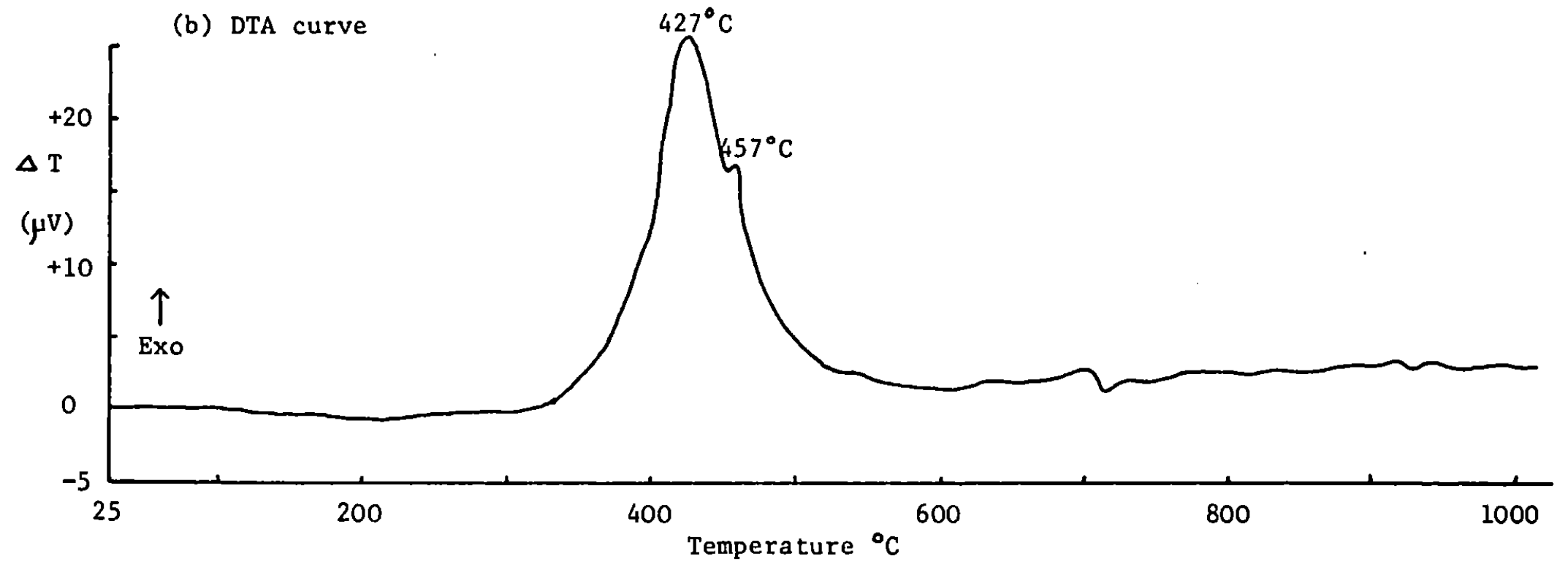




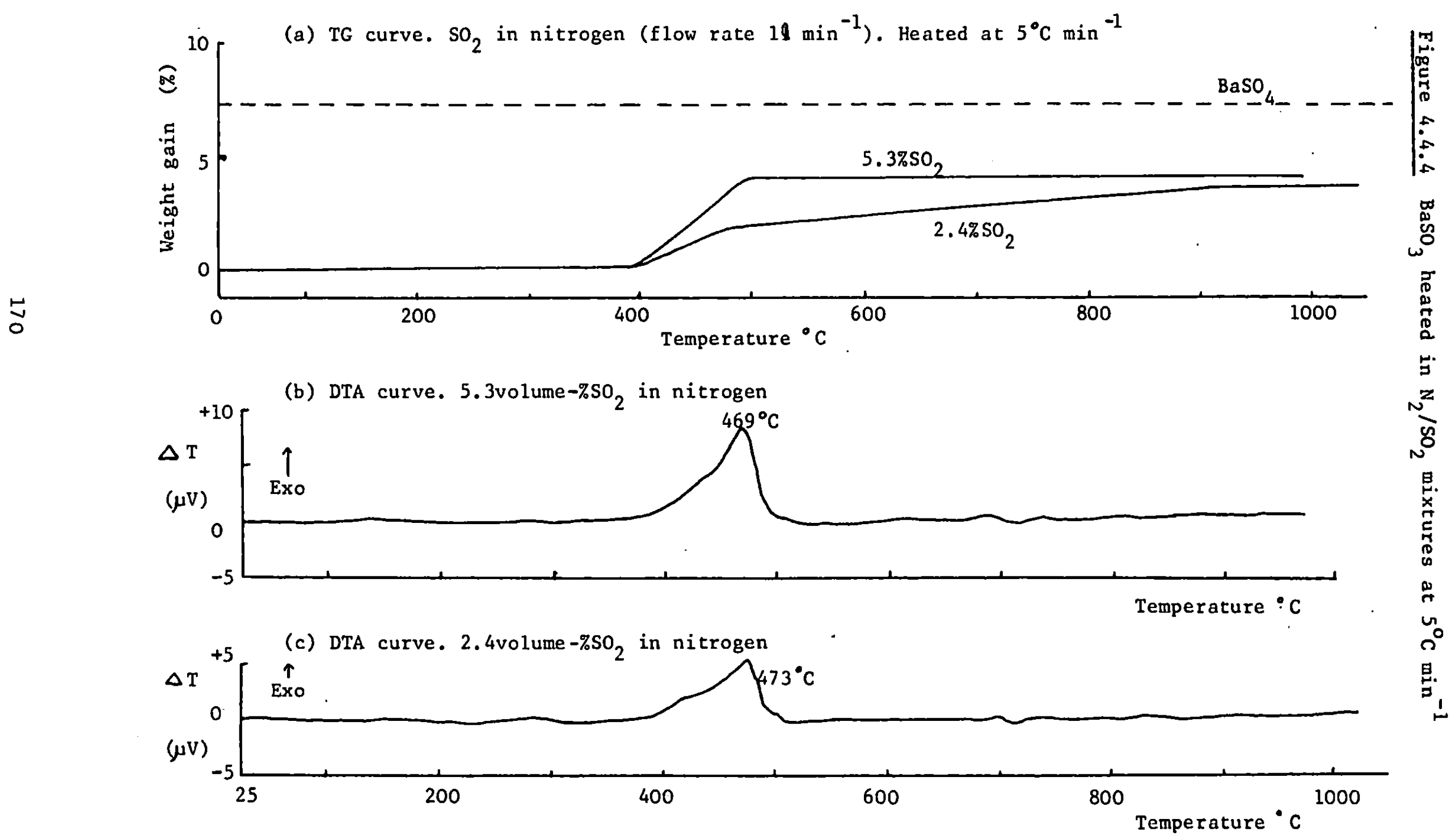


Figure 4.4.5 $\mathrm{BaSO}_{3}$ heated on electron microscope hot-stage

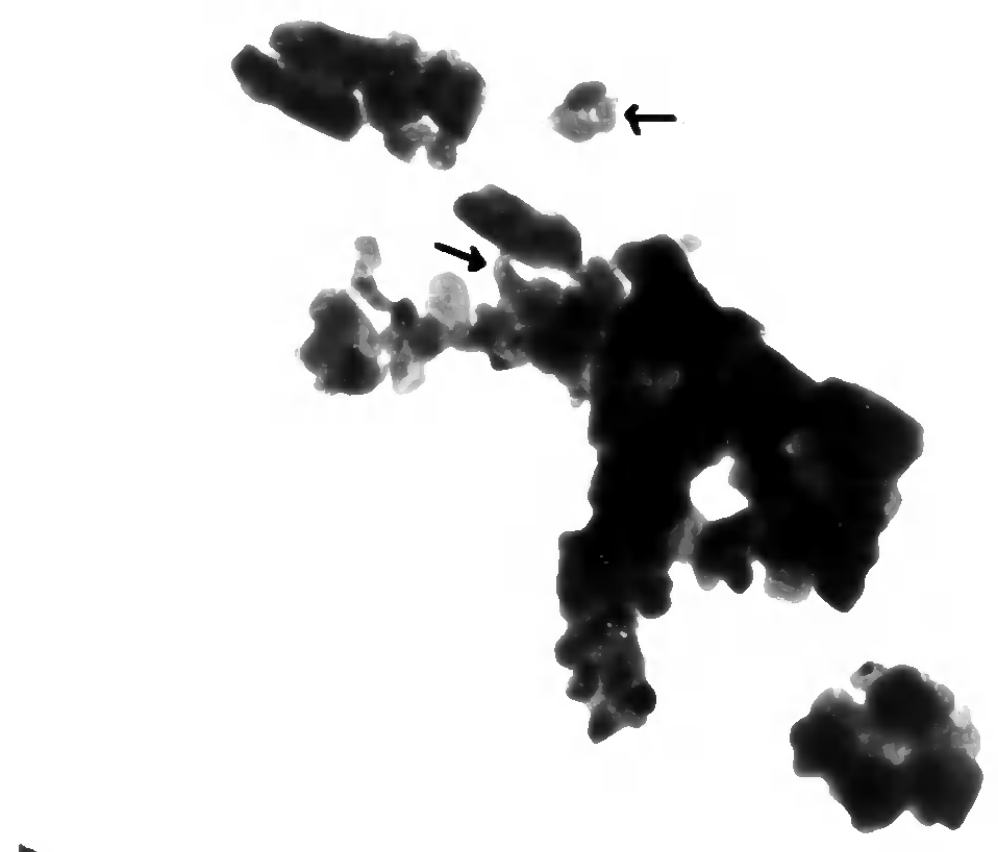

(a) At $25^{\circ} \mathrm{C}$

$1 \mu$

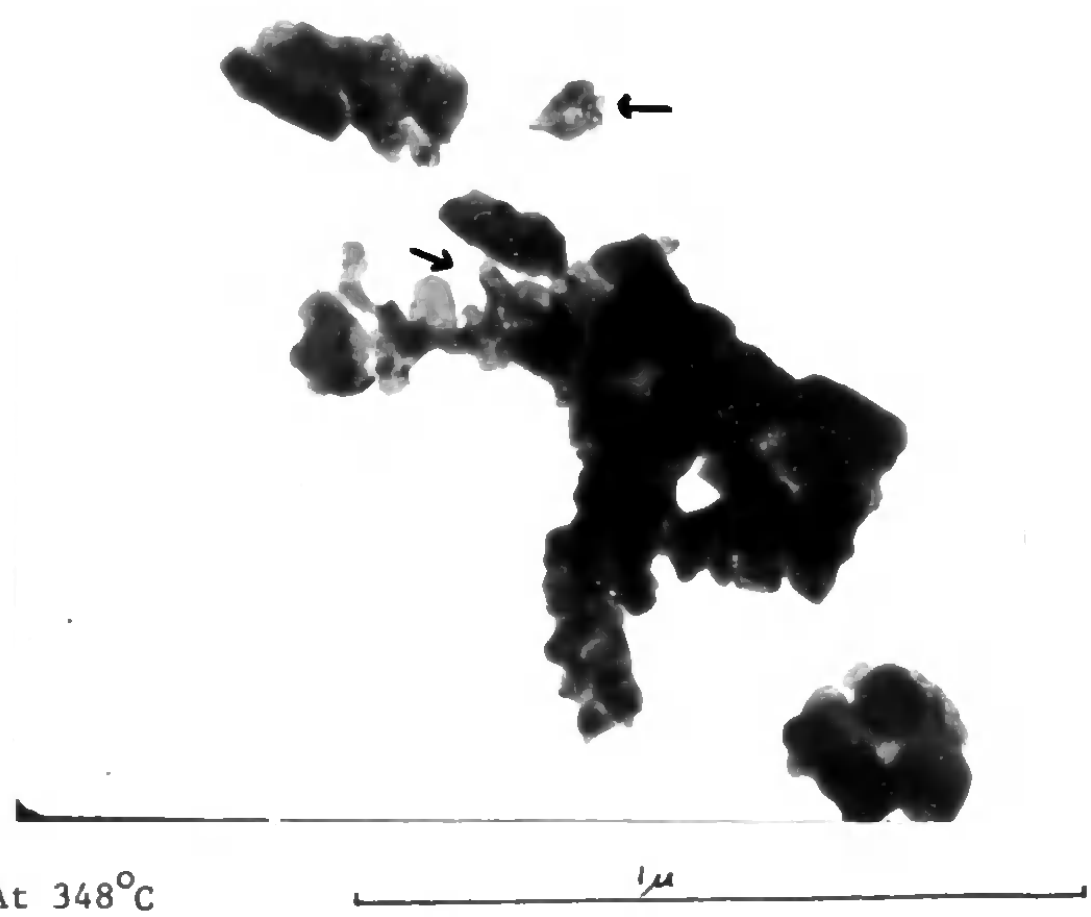

(b) At $348^{\circ} \mathrm{C}$ 
Figure 4.4.5

(c) At $383^{\circ} \mathrm{C}$
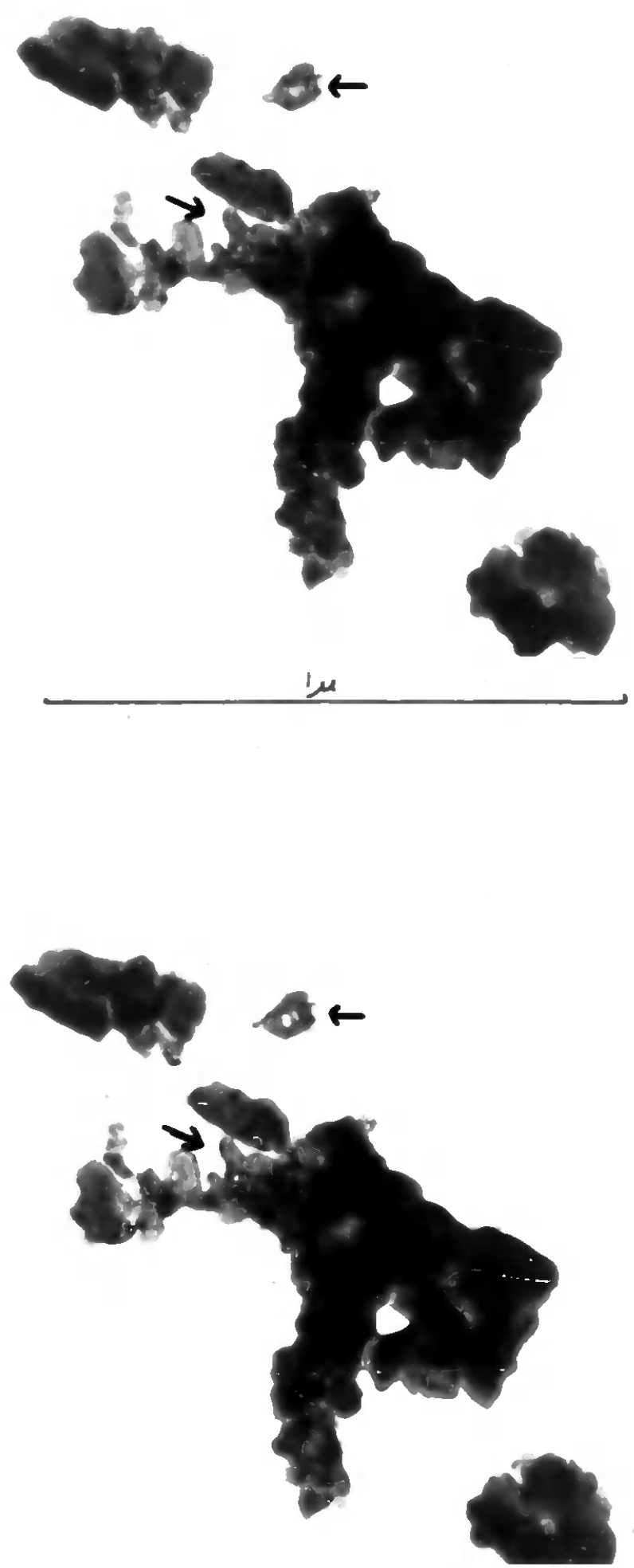

(d) At $519^{\circ} \mathrm{C}$ $1 \mu$ 
Figure 4.4.5
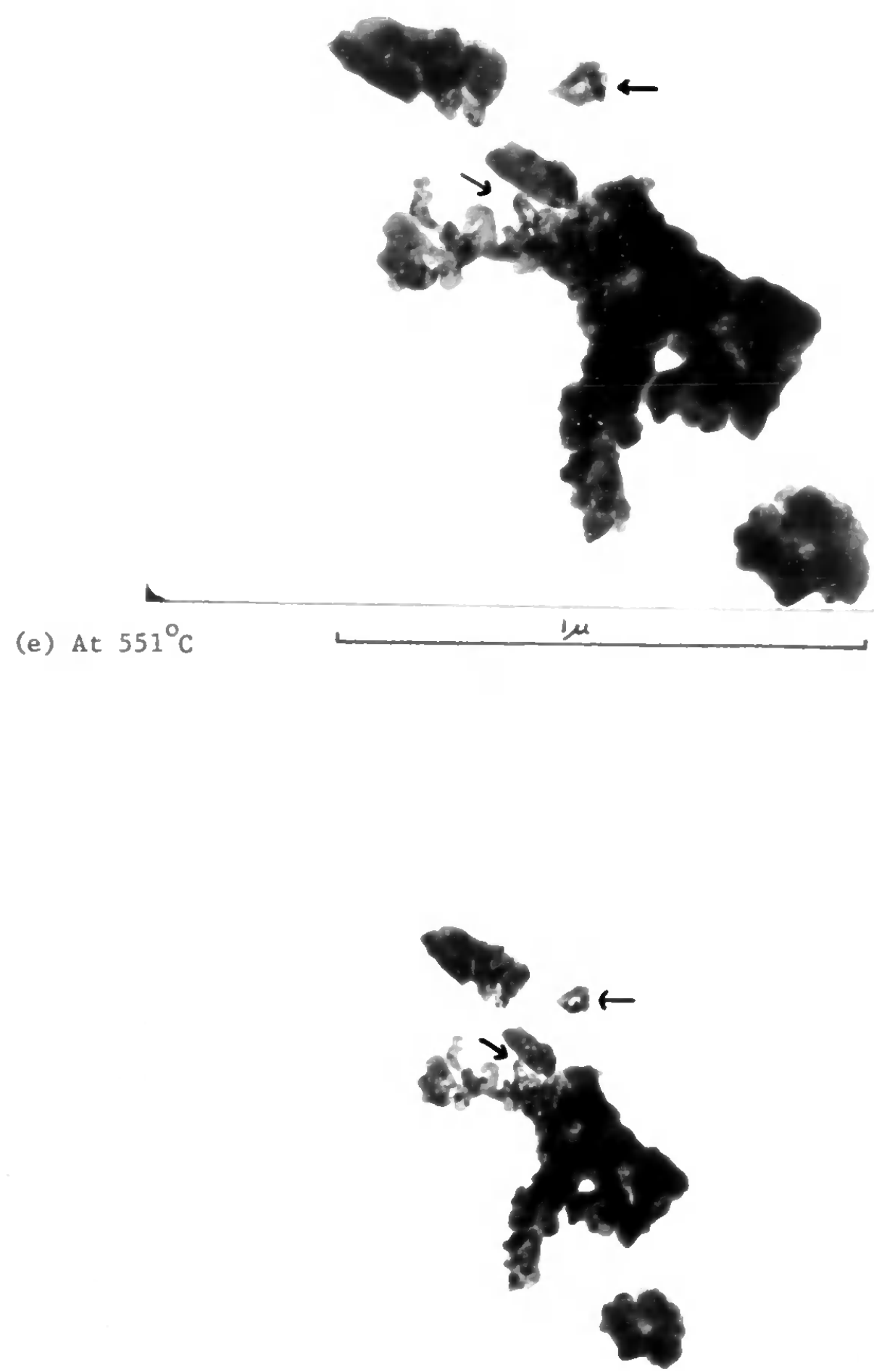

(f) At $620^{\circ} \mathrm{C}$

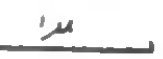


Figure 4.4 .5

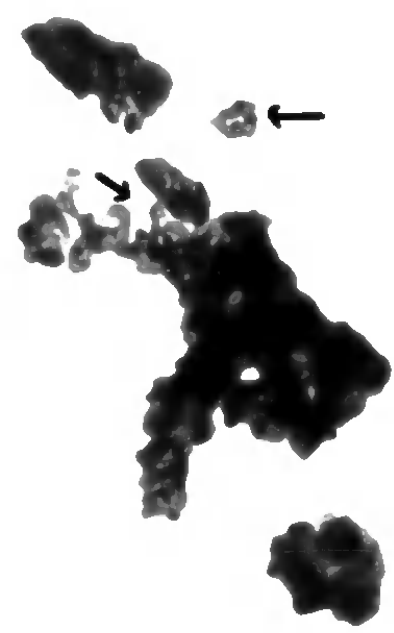

(g) At $719^{\circ} \mathrm{C}$
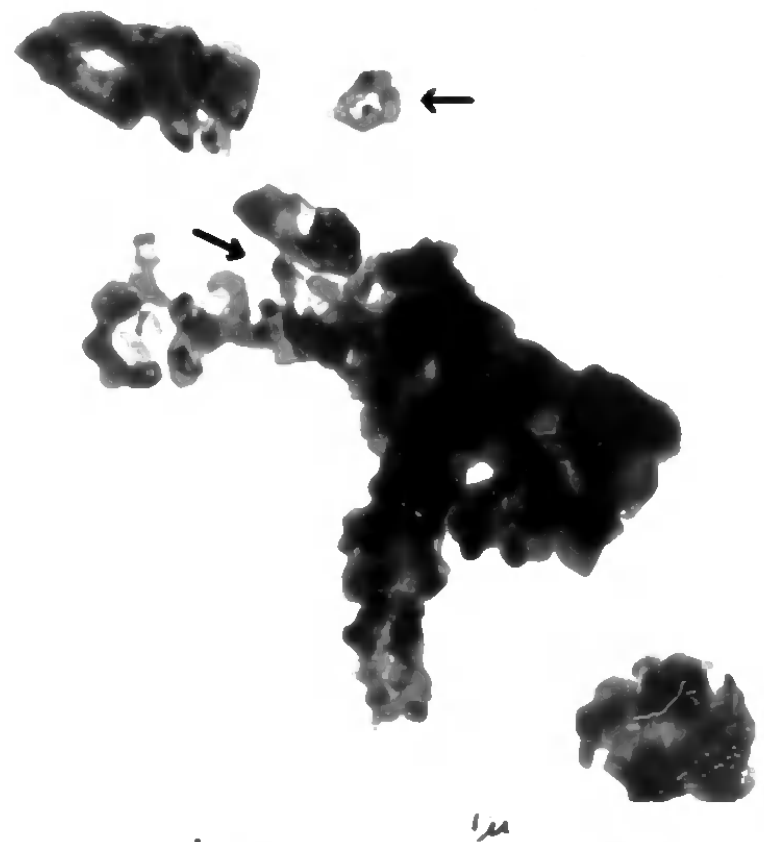

(h) At $777^{\circ} \mathrm{C}$ 


\subsection{Barium Sulphite \\ 4.4.1 Results}

Fig. 4.4.1 - 4.4.4 indicate the thermal stability of barium sulphite as determined by the use of simultaneous dynamic thermogravimetry and differential thermal analysis, at heating rates of $5^{\circ} \mathrm{Cmin}^{-1}$, in various atmospheres. Barium sulphite, like strontium sulphite, did not form an hydrated compound and the thermal stabilities of the two compounds were similar.

(a) "In vacuo"

Decomposition of barium sulphite to form barium oxide began at $549^{\circ} \mathrm{C}$, Fig. 4.4.1(a),

$$
\mathrm{BaSO}_{3} \longrightarrow \mathrm{BaO}+\mathrm{SO}_{2} \quad 4.25
$$

This decomposition reaction was not very rapid and became even slower above $725^{\circ} \mathrm{C}$. At that temperature $6.25 \%$ had dissociated and by $959^{\circ} \mathrm{C}$ the amount dissociated had on $1 y$ risen to $7.64 \%$. The DTA curve, Fig. 4.4.1(b), showed a small endotherm with a peak at $580^{\circ} \mathrm{C}$ associated with the onset of this dissociation reaction.

The small degree of desulphurisation was due to the competing disproportionation reaction which occurred over the same temperature range and gave an exothermic DTA peak at $730^{\circ} \mathrm{C}$.

$$
4 \mathrm{BaSO}_{3} \longrightarrow \mathrm{BaSO}_{4}+\mathrm{BaS} \quad 4.26
$$

Samples of barium sulphite were heated isothermally for two-hour periods at a number of temperatures, Fig. 4.4.1(a), and they too only showed a small degree of dissociation, Table 4.4.1.

They also gave indications that some of the barium sulphite was dissociating by a mechanism that produced free sulphur

$$
\begin{array}{rll}
\mathrm{BaSO}_{3} & \longrightarrow \mathrm{BaO}+\mathrm{SO}_{2} & 4.25 \\
4 \mathrm{BaSO}_{3}+2 \mathrm{SO}_{2} & \longrightarrow \mathrm{BaSO}_{4}+\mathrm{S}_{2} & 4.27 \\
(4.25+4.27) 6 \mathrm{BaSO}_{3} & \longrightarrow 4_{4 \mathrm{BaSO}_{4}+2 \mathrm{BaO}+\mathrm{S}_{2}} & 4.28
\end{array}
$$


Table 4.4.1 Composition of samples of $\mathrm{BaSO}_{3}$ isothermally heated for $2 \mathrm{~h}$ periods "in vacuo"

\begin{tabular}{|c|c|c|c|c|c|c|}
\hline \multirow{2}{*}{$\begin{array}{c}\text { Temperature } \\
\text { C }\end{array}$} & \multirow{2}{*}{$\begin{array}{c}\text { Weight } \\
\text { loss } \%\end{array}$} & \multicolumn{5}{|c|}{ Percentage composition } \\
\cline { 3 - 7 } & $\mathrm{BaSO}_{3}$ & $\mathrm{BaSO}_{4}$ & $\mathrm{BaS}$ & $\mathrm{BaO}$ & $\mathrm{S}^{\circ}$ \\
\hline 586 & 2.93 & 74.6 & 14.7 & 1.3 & 9.3 & 0.1 \\
687 & 2.93 & 26.2 & 54.0 & 10.8 & 8.8 & 0.2 \\
900 & 2.98 & 0 & 75.2 & 16.1 & 8.8 & - \\
\hline
\end{tabular}

* Determined by difference

The samples heated to $586^{\circ} \mathrm{C}, 649^{\circ} \mathrm{C}, 687^{\circ} \mathrm{C}$ and $749^{\circ} \mathrm{C}$, respectively, consisted of coarse grained, loosely fused pellets with a yellow or red-brown spotted appearance to the upper layers but with white interiors and bases. Portions of the coloured coating were scraped of $f$ and extracted with carbon disulphide. Evaporation of the solution on a microscope slide produced some pale yellow crystals which melted at $116^{\circ} \mathrm{C}$ on the hot stage of the optical microscope.

The smaller percentage of barium oxide in the product at $900^{\circ} \mathrm{C}$, compared to the lower-temperature samples, was due to the dissociation occurring mainly by loss of sulphur dioxide, reaction 4.25 , rather than by loss of sulphur, reaction 4.27 . The theoretical ratio of \%sulphate to \%sulphide due to disproportionation is $4.13: 1$ whereas the ratios found were $4.68: 1$ at $900^{\circ} \mathrm{C} ; 5.0: 1$ at $687^{\circ} \mathrm{C} ; 11.6: 1$ at $586^{\circ} \mathrm{C}$. The excess sulphate was due to decomposition by reaction 4.28 . The specific surfaces, Table 4.4.2, of these isothermally heated samples decreased very markedly with increase in temperature.

Crystals of barium sulphite were heated on the hot-stage in the electron microscope, Fig. 4.4.5(a) - (h). The changes in crystal form and electron opacity indicated that reactions were occurring steadily from $348^{\circ} \mathrm{C}$, (b), up to $777^{\circ} \mathrm{C}$, (h), with the arrowed crystals showing these changes particularly clearly. The reaction proceeded somewhat more rapidly at about $600^{\circ} \mathrm{C}$ (cf (e) and (f)). 
Table 4.4.2 Specific surfaces of samples of barium sulphite isothermally heated for $2 \mathrm{~h}$ periods "in vacuo".

\begin{tabular}{|c|c|}
\hline Temperature ${ }^{\circ} \mathrm{C}$ & Specific surface $\mathrm{m}^{2} \mathrm{~g}^{-1}$ \\
\hline Original sample & 43.2 \\
463 & 1.1 \\
586 & 1.0 \\
649 & 0.7 \\
687 & 0.5 \\
749 & 0.1 \\
900 & 0.3 \\
975 & 0.1 \\
\hline
\end{tabular}

No further reaction was noted above $777^{\circ} \mathrm{C}$. Photomicrograph (h) showed that decomposition and disproportionation had produced crystals of similar sizes to the original barium sulphite, (a), but thinner. The marked increase in the number of crystallites shown by magnesium and calcium sulphites was not found, indicating less disruptive lattice changes. The dispersal of the crystals on the carbon film prevented them fusing together to give the coarse aggregates found with the larger samples used in thermogravimetric studies.

(b) In nitrogen

The decomposition of barium sulphite, to form barium oxide, brought no measurable weight change until $727^{\circ} \mathrm{C}, \mathrm{Fig} \cdot 4.4 .2(\mathrm{a})$. The slow weight loss continued up to $970^{\circ} \mathrm{C}$, by which temperature it had reached $2.18 \%$, equivalent to the desulphurisation, as sulphur dioxide, of $7.4 \%$ of the original barium sulphite. However, 
samples removed at temperatures below $800^{\circ} \mathrm{C}$ contained traces of sulphur indicating that both desulphurisation mechanisms had been in operation. The DTA curve, Fig. 4.4.2(b) contained an exothermic peak at $686^{\circ} \mathrm{C}$, associated with the disproportionation reaction, followed by a small endotherm, peaking at $731^{\circ} \mathrm{C}$, associated with the onset of desulphurisation.

(c) In air

Oxidation of barium sulphite began at $342^{\circ} \mathrm{C}$, Fig. $4.4 .3(a)$, and continued to about $530^{\circ} \mathrm{C}$ when $79 \%$ of the original barium sulphite had reacted.

$$
2 \mathrm{BaSO}_{3}+\mathrm{O}_{2} \longrightarrow 2 \mathrm{BaSO}_{4}
$$

The oxidation reaction produced a coherent coating of barium sulphate which prevented access of the oxygen to the inner zone of the original barium sulphite crystals. The unoxidised barium sulphite disproportionated and the barium sulphide, so formed, was also protected from reaction with oxygen so that virtually no oxidation occurred as the temperature rose to over $1000^{\circ} \mathrm{C}$. The oxidation reaction produced a large exotherm between $320^{\circ} \mathrm{C}$ and $530^{\circ} \mathrm{C}$, peaking at $427^{\circ} \mathrm{C}$ with a shoulder at $457^{\circ} \mathrm{C}$, in the DTA curve, Fig. 4.4.3(b). The shoulder presumably indicated that the oxidation was occurring by more than a single-step process.

\section{(d) In sulphur dioxide and nitrogen}

The oxidation of barium sulphite by sulphur dioxide commenced at about $365^{\circ} \mathrm{C}$, Fig. 4.4.4(a).

$$
4 \mathrm{BaSO}_{3}+2 \mathrm{SO}_{2} \longrightarrow 4 \mathrm{BaSO}_{4}+\mathrm{S}_{2} \quad 4.30
$$

The reaction proceeded more rapidly in the higher concentration of sulphur dioxide (5.3 vol-\%) until $53 \%$ of the barium sulphite had reacted, at $470^{\circ} \mathrm{C}$, when the rate of oxidation became very much slower due to the build-up of sulphate coating. The oxidation finally 
ceased at about $755^{\circ} \mathrm{C}$, by which temperature the internal barium sulphite had largely disproportionated to a mixture of barium sulphate and sulphide. The great degree of sintering which these mixtures of barium compounds undergo was sufficient to prevent contact between the oxidising atmosphere and the barium sulphide.

The 2.4 vol-\% $\mathrm{SO}_{2}$ atmosphere initially produced less extensive oxidation, $23.4 \%$ barium sulphite at $457^{\circ} \mathrm{C}$, but the oxidation continued at a reduced rate up to $895^{\circ} \mathrm{C}$ with $48.0 \%$ of the barium sulphite oxidised; the sulphite coating had by then built up to a sufficient thickness to prevent further reaction.

Similar DTA curves, Fig. 4.4.4(b), were obtained with an exotherm corresponding to the oxidation reaction peaking at $473^{\circ} \mathrm{C}$, in $2.4 \mathrm{vol}-\% \mathrm{SO}_{2}$, and $469^{\circ} \mathrm{C}$, in $5.3 \mathrm{vol}^{-\% \mathrm{so}_{2}}$.

\subsubsection{Discussion}

As with strontium sulphite the disproportionation reaction of barium sulphite was more important than the desulphurisation reactions. The desulphurisation of barium sulphite took place by two mechanisms, reactions 4.25 and 4.28 , leading to the emission of noticeable quantities of sulphur as well as sulphur dioxide.

Mocek and Erdas ${ }^{80,99}$ have carried out extensive studies of the kinetics of disproportionation of barium sulphite at temperatures between $600^{\circ} \mathrm{C}$ and $700^{\circ} \mathrm{C}$, in nitrogen. They found that the rate was slow below $670^{\circ} \mathrm{C}$ and was increased by the presence of water vapour. A reaction mechanism proposed by "Nechkovskij" (Pechkovskii) and Ketov ${ }^{100}$ was mentioned, but not discussed in relation to their results. The reaction series was:

$$
\begin{array}{lll}
\mathrm{BaSO}_{3} \longrightarrow \mathrm{BaO}+\mathrm{SO}_{2} & 4.31 \\
2 \mathrm{BaSO}_{3}+\mathrm{SO}_{2} \longrightarrow 2 \mathrm{BaSO}_{4}+\frac{1}{2} \mathrm{~S}_{2} & 4.32 \\
2 \mathrm{BaO}+3 / 2 \mathrm{~S}_{2} \longrightarrow 2 \mathrm{BaS}+\mathrm{SO}_{2} & 4.33
\end{array}
$$


Though Mocek and Erdos stated "It is possible to explain the catalytic effects of the water vapour by that the water vapour acts as an oxygen carrier and thus supports the disproportionation." it is not clear to which step they are referring the need for an oxygen carrier. Further discussion of the mechanism will be made in section 4.5. The results obtained in the present work were similar to those obtained in the isothermal studies of Cola and Castellani Bisi ${ }^{44}$, carried out in nitrogen, and the DTA results, in argon, of Pechkovskii and Ketov ${ }^{45}$. As mentioned in section 4.3.2, the endotherm, stated by Lutz and El Suradi ${ }^{86}$ to be due to disproportionation, must have been caused by a dissociation reaction. Whether an endotherm or exotherm is obtained depends upon the relative rates of dissociation (endothermic) and disproportionation (exothermic). 


\subsection{General Discussion}

The results obtained from studies of the thermal stabilities of the alkaline earth metal sulphites are summarised in Tables $4.5 .1-4.5 .4$.

Considering firstly the reactions "in vacuo" and nitrogen, the extent by which the sulphites decompose by either loss of sulphur dioxide, equation 4.34 , or by disproportionation, equation 4.35, varies with the alkaline earth metal.

$$
\begin{array}{lll}
\mathrm{MSO}_{3} \longrightarrow \mathrm{MO}^{2}+\mathrm{SO}_{2} & 4.34 \\
4 \mathrm{MSO}_{3} \longrightarrow \mathrm{MSO}_{4}+\mathrm{MS} & 4.35
\end{array}
$$

The equation for the disproportionation reaction appears to be very unlikely to be an expression of how the reaction actually occurs. Equation 4.35 requires four solid-state species to interchange oxygen atoms and then migrate to form separate crystalline regions of sulphate and sulphide which are large enough to give clear X-ray diffraction powder patterns. If there was little or no migration the diffraction patterns would be either of an amorphous substance or show line broadening.

The same mechanism for the disproportionation reaction has been proposed by Pechkovskii and Ketov ${ }^{100}$, for barium sulphite (see section 4.4.2) and by Tarradellas and Bonnetain ${ }^{93}$, for calcium sulphite. The latter authors heated a sample of calcium sulphite, in helium, in a closed container, attached to an X-ray diffractometer, from $350^{\circ} \mathrm{C}$ to $950^{\circ} \mathrm{C}$. The $\mathrm{X}$-ray traces obtained indicated that calcium oxide was formed in increasing amounts up to about $650^{\circ} \mathrm{C}$ and the quantities present then decreased as the temperature rose further. At the same time there was a corresponding increase in the amounts of calcium sulphate and sulphide. As a result, they proposed that the following series of 
Table 4.5.1 Sumary of TG results obtained shen $\mathrm{MgSO}_{3} .6 \mathrm{~F}_{2} \mathrm{O}$ was heated at $5^{\circ} \mathrm{C}$ win in various atmospheres

\begin{tabular}{|c|c|c|c|c|c|c|c|c|}
\hline \multirow{4}{*}{ Atwosphere } & \multicolumn{8}{|c|}{ Temperature ${ }^{\circ} \mathrm{C}$} \\
\hline & \multicolumn{4}{|c|}{ Dehydration } & \multicolumn{2}{|c|}{ Sulphete forcuation } & \multicolumn{2}{|c|}{ Desulphurisation of } \\
\hline & \multicolumn{4}{|c|}{ No. of mols $\mathrm{H}_{2} \mathrm{O}$ remaining } & \multirow[t]{2}{*}{ Primary } & \multirow[t]{2}{*}{ Secondary } & \multirow{2}{*}{$\begin{array}{l}\text { Non-sulphate } \\
\text { compounds }\end{array}$} & \multirow[t]{2}{*}{$\mathrm{MgSO}_{4}$} \\
\hline & 6 & 3 & $<0.5$ & 0 & & & & \\
\hline "in vacuo" & 25 & & 198 & 230 & & & $\begin{array}{r}{[230]-387} \\
-531\end{array}$ & \\
\hline Nitrogen & 54 & 114 & 215 & 350 & & $300-576$ & $\begin{array}{r}{[350]-437} \\
-576\end{array}$ & $\begin{array}{l}819- \\
1002\end{array}$ \\
\hline Air & 57 & 115 & 220 & $(340)$ & $\begin{array}{r}(320)- \\
600\end{array}$ & $\begin{array}{l}(300)- \\
(600)\end{array}$ & $\begin{array}{l}(340)- \\
(600)\end{array}$ & $\begin{array}{l}883- \\
1022\end{array}$ \\
\hline $\begin{array}{l}2.8 \text { vols } \mathrm{SO}_{2} \\
\text { in } \mathrm{N}_{2}\end{array}$ & 59 & 114 & 213 & (350) & $\begin{array}{r}(320)- \\
615\end{array}$ & $\begin{array}{l}(300)- \\
(615)\end{array}$ & $\begin{array}{c}(350)- \\
615\end{array}$ & $\begin{array}{l}890- \\
1038\end{array}$ \\
\hline 20.9 volz $\mathrm{SO}_{2}$ & 59 & $\begin{array}{r}114- \\
157\end{array}$ & 222 & (350) & $\begin{array}{r}(320)- \\
590\end{array}$ & $\begin{array}{r}(300)- \\
(590)\end{array}$ & $\begin{array}{r}(350)- \\
590\end{array}$ & $\begin{array}{l}965- \\
(1100)\end{array}$ \\
\hline
\end{tabular}

Temperatures indicated: ( ) estimated

[ ] initial temperature, but only slight decomposition

Primary sulphate formation due to reactions with introduced atmosphere

(i) $2 \mathrm{MgSO}_{3}+\mathrm{O}_{2} \longrightarrow 2 \mathrm{MgSO}_{4}$

(ii) $2 \mathrm{MgSO}_{3}+\mathrm{SO}_{2} \longrightarrow 2 \mathrm{MgSO}_{4}+\mathrm{S}$

Secondary sulphoce formation due to reactions not directly dependent upon introduced atmosphere
(i) $\mathrm{MgSO}_{3} \longrightarrow \mathrm{MgO}+\mathrm{SO}_{2} \stackrel{2 \mathrm{MgSO}}{\longrightarrow} 2 \mathrm{MgSO}_{4}+\mathrm{s}$
(ii) $4 \mathrm{MgSO}_{3} \longrightarrow 3 \mathrm{MgSO}_{4}+\mathrm{MgS}$ 
Table 4.5.2 Sumary of the TG results obtained when $\mathrm{CaSO}_{3} \cdot 1 \mathrm{H}_{2} \mathrm{O}$ was heated at $5^{\circ} \mathrm{C}_{\text {ain }}{ }^{-1}$ in various atrospheres

\begin{tabular}{|c|c|c|c|c|c|c|}
\hline \multirow{3}{*}{ Atmosphere } & \multicolumn{6}{|c|}{ Temperature ${ }^{\circ} \mathrm{C}$} \\
\hline & \multicolumn{2}{|c|}{ Dehydration } & \multicolumn{2}{|c|}{ Sulphate formation } & \multicolumn{2}{|c|}{ Desulphurisation of } \\
\hline & Initial & Pinal & $\begin{array}{l}\text { Dispropor- } \\
\text { tionation }\end{array}$ & Oxidation & Sulphite & $\begin{array}{l}\text { Non-sulphite } \\
\text { compounds }\end{array}$ \\
\hline "in vacuo" & 329 & 393 & $(600)-740$ & & $540-740$ & $915-990$ \\
\hline Nicrogen & 345 & 396 & $(600)-900$ & & $\begin{array}{r}{[682]-850} \\
-(925)\end{array}$ & $(925)->1075$ \\
\hline Air & 343 & 395 & $\begin{array}{r}(600)- \\
(900)\end{array}$ & $\begin{array}{r}(385)-520 \\
-[998]\end{array}$ & $\begin{array}{l}([682])- \\
([900])\end{array}$ & $1064->1096$ \\
\hline $\begin{array}{l}2.8 \text { volt } \mathrm{SO}_{2} \\
\text { in } \mathrm{N}_{2}\end{array}$ & 343 & $399^{\circ}$ & $\begin{array}{r}(600)- \\
(900)\end{array}$ & $450-920$ & $\begin{array}{l}([700])- \\
([990])\end{array}$ & $940->1055$ \\
\hline $\begin{array}{l}4.5 \text { volz } \mathrm{SO}_{2} \\
\text { in } \mathrm{N}_{2}\end{array}$ & 343 & (399) & $\begin{array}{r}(600)- \\
(900)\end{array}$ & $(375)-790$ & $\begin{array}{l}([700])- \\
([800])\end{array}$ & $>1020$ \\
\hline $\begin{array}{l}20.2 \text { vol\% } \mathrm{SO}_{2} \\
\text { in } \mathrm{N}_{2}\end{array}$ & 344 & (399) & $\begin{array}{r}(600)- \\
(800)\end{array}$ & $(360)-610$ & $\begin{array}{l}([700])- \\
([800])\end{array}$ & $>1068$ \\
\hline
\end{tabular}
Temperatures indicated
( ) estimated
[ ] only slight reaction 
Table 4.5.3 Summary of the TG results obtained when $\mathrm{SrSO}_{3}$ was heated at $5^{\circ} \mathrm{C} \min ^{-1}$ in various atmospheres

\begin{tabular}{|c|c|c|c|c|}
\hline \multirow{3}{*}{ Atmosphere } & \multicolumn{4}{|c|}{ Temperature ${ }^{\circ} \mathrm{C}$} \\
\hline & \multicolumn{2}{|c|}{ Sulphate formation } & \multicolumn{2}{|c|}{ Desulphurisation of } \\
\hline & $\begin{array}{l}\text { Dispropor- } \\
\text { tionat ion }\end{array}$ & Oxidation & Sulphite & $\begin{array}{l}\text { Non-sulphite } \\
\text { compounds }\end{array}$ \\
\hline "in vacuo" & $(434)-(870)$ & & $\begin{array}{r}415-550 \\
-[870]\end{array}$ & $\begin{array}{r}{[870]-975} \\
->1088\end{array}$ \\
\hline Nitrogen & $434-(1007)$ & & $\begin{array}{c}507-745 \\
-([1007])\end{array}$ & $\begin{array}{l}{[1007]-} \\
>1050\end{array}$ \\
\hline Air & $(434)-(578)$ & $\begin{array}{l}351-565- \\
{[895]-1060}\end{array}$ & & $\begin{array}{l}1060- \\
>1082\end{array}$ \\
\hline $\begin{array}{l}2.8 \text { vol- } \% \mathrm{SO}_{2} \\
\text { in } \mathrm{N}_{2}\end{array}$ & $(434)-(600)$ & $392-788$ & . & \\
\hline $\begin{array}{l}5.1 \text { vol- } \% \mathrm{SO}_{2} \\
\text { in } \mathrm{N}_{2}\end{array}$ & $(434)-(578)$ & $390-876$ & & $\begin{array}{l}1050- \\
>1060\end{array}$ \\
\hline
\end{tabular}

Temperatures indicated ( ) estimated

[ ] only slight reaction 
Table 4.5.4 Summary of the TG results obtained when $\mathrm{BaSO}_{3}$ was heated at $5^{\circ} \mathrm{C} \min ^{-1}$ in various atmospheres

\begin{tabular}{|c|c|c|c|c|}
\hline \multirow{3}{*}{ Atmosphere } & \multicolumn{4}{|c|}{ Temperature ${ }^{\circ} \mathrm{C}$} \\
\hline & \multicolumn{2}{|c|}{ Sulphate formation } & \multicolumn{2}{|c|}{ Desulphurisation of } \\
\hline & $\begin{array}{l}\text { Dispropor- } \\
\text { tionat ion }\end{array}$ & Oxidation & Sulphite & $\begin{array}{l}\text { Other S } \\
\text { Compounds }\end{array}$ \\
\hline "in vacuo" & $(500)-959$ & & $\begin{array}{l}549-725 \\
-[959]\end{array}$ & \\
\hline Nitrogen & $(500)-970$ & & $727-970$ & \\
\hline Air & $(500)-(725)$ & $\begin{array}{l}342-530 \\
-[1001]\end{array}$ & & \\
\hline $\begin{array}{l}2.4 \text { vol-\% } \mathrm{SO}_{2} \\
\text { in } \mathrm{N}_{2} .\end{array}$ & $(500)-(800)$ & $\begin{array}{r}367-457 \\
-895 \\
\end{array}$ & & \\
\hline $\begin{array}{l}5.3 \text { vol\% } \mathrm{SO}_{2} \\
\text { in } \mathrm{N}_{2}\end{array}$ & $(500)-(755)$ & $\begin{array}{c}365-470 \\
-[755] \\
\end{array}$ & . & \\
\hline
\end{tabular}

Temperatures indicated ( ) estimated

[ ] only slight reaction 
reactions were occurring:

$$
\begin{array}{lll}
2 \mathrm{CaSO}_{3} \longrightarrow 2 \mathrm{CaO}+2 \mathrm{SO}_{2} & 4.36 \\
6 \mathrm{CaSO}_{3}+3 \mathrm{SO}_{2} \longrightarrow 6 \mathrm{CaSO}_{4}+3 / 2 \mathrm{~S}_{2} & 4.37 \\
2 \mathrm{CaO}+3 / 2 \mathrm{~S}_{2} \longrightarrow 2 \mathrm{CaS}+\mathrm{SO}_{2} & 4.38
\end{array}
$$

The attractive feature of this mechanism is that it contains gaseous molecules, sulphur dioxide and sulphur, which could diffuse rapidly through the solid lattice and so promote the transfer of material. However, these equations must only represent the overall reactions, with the actual individual steps involving fewer species.

The first step, 4.36, is identical with the dissociation reaction, 4.34, and involves the breaking of one $5-0$ bond to release the $\mathrm{SO}_{2}$ molecule and leave the remaining oxygen co-ordinated to the metal ion. A study of the structure of calcium sulphite hemihydrate shows that it contains "channels" perpendicular to the ac plane, Fig. 4.5.1, which seem suitable for the promotion of the reaction series proposed. It is assumed that the structure of anhydrous calcium sulphite is very similar to that of the hemihydrate, as the loss of water causes very little difference to the cell parameters as determined from the $\mathrm{X}$-ray powder patterns, and that the other sulphites also have similar structures (see Chapter 3 ). The "channels" are bounded by $\mathrm{six} \mathrm{Ca}^{2+}$ ions each connected to sulphite groups via oxygens. The breaking of one $\mathrm{s}-0$ bond would free a $\mathrm{SO}_{2}$ molecule and allow it to come in contact with other sulphite groups in the "channel". The arrangement of groups around the "channels" is such that the pyramidal $\mathrm{SO}_{3}{ }^{2-}$ species have their apical sulphur atoms directed towards the centre of the "channel" so that oxygen could be bonded to this sulphur to form the tetrahedral $\mathrm{SO}_{4}{ }^{2-}$ group, the oxygen being dominated by the $\mathrm{SO}_{2}$ molecule. The resulting so could react similarly 
Figure 4.5.1 Projection of unit cell of $\mathrm{CaSO}_{3} \cdot 0.5 \mathrm{H}_{2} \mathrm{O}$ after Schropper 81 .

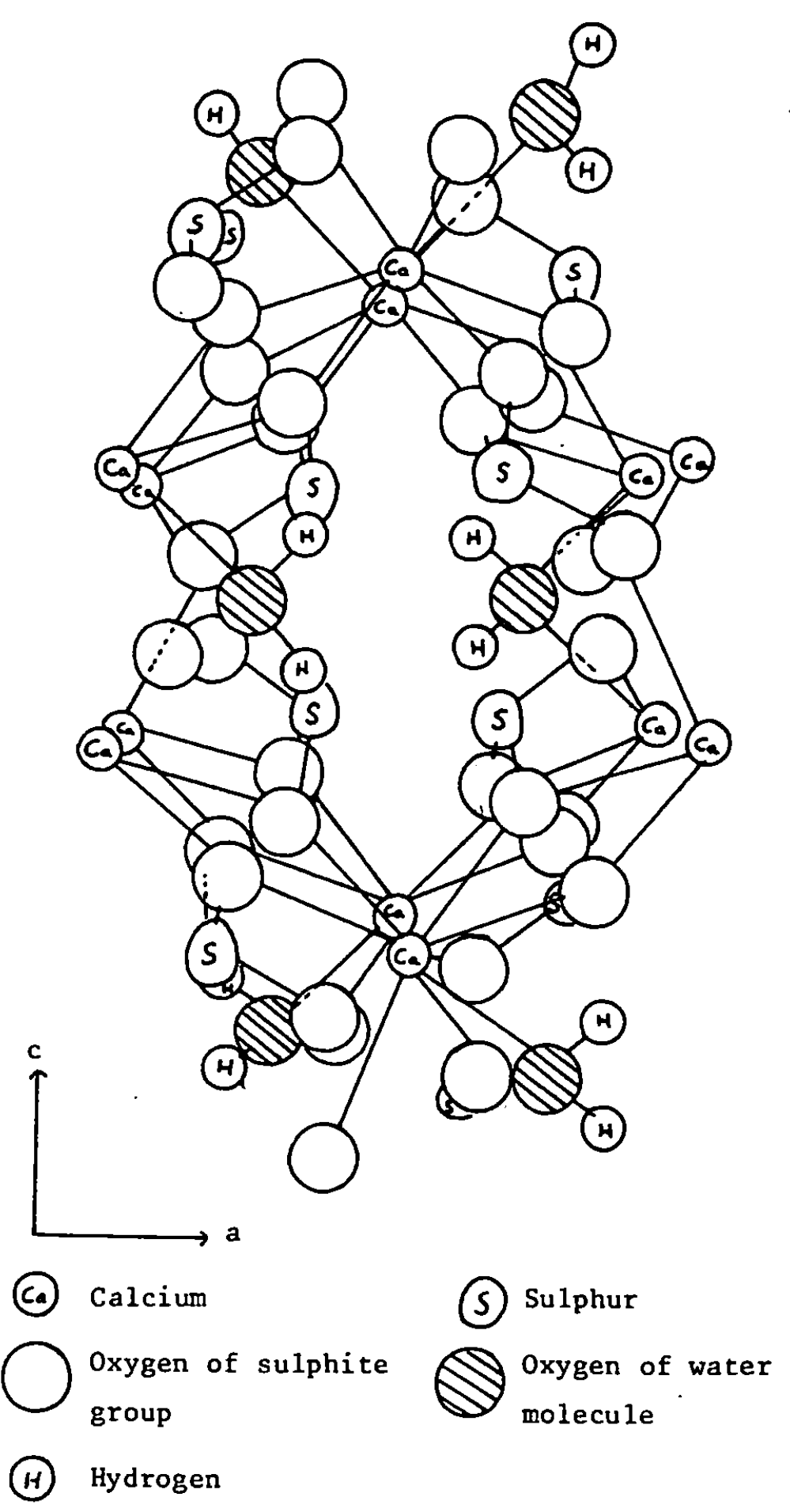


Figure 4.5.2 Possible reaction steps involved in the thermal decomposition of alkaline earth metal sulphites

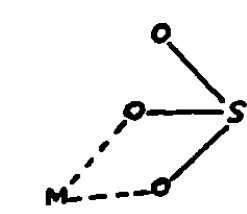

sulphite

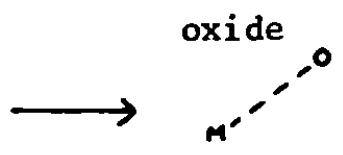

$\overbrace{0}^{5} \sum_{0}^{\infty}$<smiles>CCC</smiles>

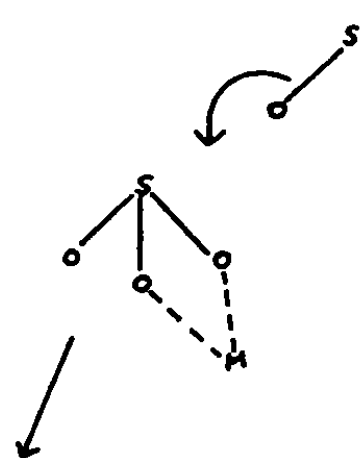<smiles>O=S1(=O)O[IH]O1</smiles>
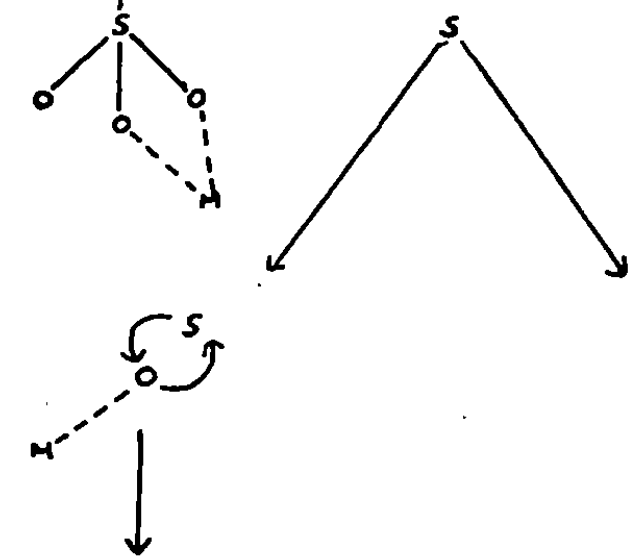

$s\urcorner$

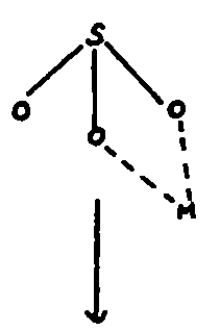

sulphide

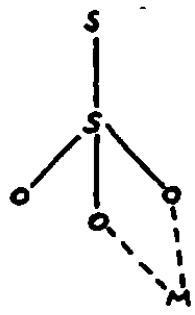

thiosulphate 
with another $\mathrm{SO}_{3}{ }^{2-}$ group forming sulphur. It is of interest to note that Papazion et al 101 have reported the presence of So, as well as $\mathrm{SO}_{2}$, in the effluent gas from the vacuum decomposition of calcium sulphite. The reacting sulphur could then (a) combine with another sulphur atom to form a diatomic molecule, which could escape from the structure; (b) exchange with an oxygen attached to the $\mathrm{Ca}^{2+}$ to form calcium sulphide; (c) react with exchanged oxygen to form sulphur dioxide (or monoxide); (d) bond to the sulphur of a $\mathrm{SO}_{3}{ }^{2-}$ group to form a tetrahedral thiosulphate, $\mathrm{S}_{2} \mathrm{O}_{3}{ }^{2-}$, group. This series of reaction steps would appear to be capable of producing a number of related mechanistic pathways by which the formation of all the phases found in the studies of the thermal stabilities of the alkaline earth metal sulphites in inert atmospheres can be explained. The following equations, and Fig. 4.5.2, summarise the proposed mechanisms:

$$
\begin{aligned}
& \mathrm{MOSO}_{2} \longrightarrow \mathrm{MO}+\mathrm{SO}_{2} \quad 4.39 \\
& 2 \mathrm{MO}_{3} \mathrm{~S}+\mathrm{SO}_{2} \longrightarrow 2 \mathrm{MO}_{3} \mathrm{SO}+\mathrm{S} \quad 4.40 \\
& \text { or } \mathrm{MO}_{3} \mathrm{~S}+\mathrm{SO}_{2} \longrightarrow \mathrm{MO}_{3} \mathrm{SO}+\mathrm{SO} 4.40 \mathrm{~A} \\
& \text { and } \mathrm{MO}_{3} \mathrm{~S}+\mathrm{SO} \longrightarrow \mathrm{MO}_{3} \mathrm{SO}+\mathrm{S} \text { 4.40B } \\
& \text { MO }+\mathrm{S} \longrightarrow \text { MS }+0 \quad 4.41 \\
& \mathrm{MO}_{3} \mathrm{~S}+\mathrm{S} \longrightarrow \mathrm{MO}_{3} \mathrm{SS} \quad 4.42 \\
& \mathrm{MO}_{3} \mathrm{~S}+\mathrm{O} \longrightarrow \mathrm{MO}_{3} \mathrm{SO} \quad 4.43 \\
& \mathrm{~s}+\mathrm{O} \stackrel{\mathrm{W}}{\longrightarrow} \mathrm{so} \stackrel{0}{\longrightarrow} \mathrm{SO}_{2} \quad 4.44 \\
& \mathrm{~S}+\mathrm{S} \longrightarrow \mathrm{S}_{2}
\end{aligned}
$$

Relating these reactions to the results obtained from each of the sulphites studied:

(i) Magnesium sulphite: "In vacuo" reaction 4.39 is dominant, but in nitrogen the slower loss of sulphur dioxide and the higher temperature required enables reactions $4.40,4.42$ and 4.45 to proceed and produce magnesium sulphate, magnesium thiosulphate and sulphur as well as the 
major products, magnesium oxide and sulphur dioxide. Reaction 4.41 only occurred to a very small extent presumably because it has a high activation energy and the temperature did not reach a high enough value before all the magnesium sulphite had decomposed. Schwitzgebel and Lowe $11^{90}$ point out that the free energy change for the overall disproportionation reaction is favourable for the reaction to occur, but that the rate is negligible below $600^{\circ} \mathrm{C}$. The free energy change for reaction $4.41^{8}$, at $480^{\circ} \mathrm{C}$, is about $+186 \mathrm{kJmole} \mathrm{e}^{-1}$ which is not very favourable, even making allowance for the fact that on the molecular scale the species involved are likely to be more reactive.

(ii) Calcium sulphite. The temperature required to initiate reaction 4.39 is higher and as a result the species involved in reactions 4.40 and 4.41 are more activated, resulting in disproportionation becoming the major reaction in nitrogen.

(iii) Strontium sulphite. The formation of sulphate and sulphide is even more favoured than with calcium sulphite, so that even "in vacuo" only about $10 \%$ of the sulphur dioxide is removed by reaction 4.39 . (iv) Barium sulphite. The replacement of oxygen by sulphur is not so favoured, as in the case of strontium, below $800^{\circ} \mathrm{C}$ and this results in the evolution of sulphur as well as sulphur dioxide.

In the presence of oxygen or sulphur dioxide, a second group of reactions, i.e. oxidation reactions, compete with the thermal decomposition reactions considered above. The extents of the oxidation reactions in the presence of either oxygen, 4.46, 4.47, or sulphur dioxide $4.48,4.49$ are very similar for corresponding concentrations of oxidant.

$$
\begin{array}{ll}
2 \mathrm{MSO}_{3}+\mathrm{O}_{2} \longrightarrow \mathrm{MSO}_{4} & 4.46 \\
\mathrm{MS}+2 \mathrm{O}_{2} \longrightarrow \mathrm{MSO}_{4} & 4.47 \\
4 \mathrm{MSO}_{3}+2 \mathrm{SO}_{2} \longrightarrow{ }_{4 \mathrm{MSO}_{4}+\mathrm{S}_{2}} \longrightarrow \mathrm{MSO}_{4}+\mathrm{S}_{2} & 4.48 \\
\mathrm{MS}+2 \mathrm{SO}_{2} \longrightarrow{ }^{2} & 4.49
\end{array}
$$


The degree to which oxidation occurs with the various alkaline earth metal sulphites is controlled by the extent of the decomposition reaction 4.34. The lower the temperature at which decomposition to oxide occurs the less sulphite, or sulphide, there is to be oxidised; therefore, the degree of oxidation is low for magnesium sulphite and high for strontium and barium sulphite.

Examination of the results of this study with a view to the possible utilisation of alkaline earth metal compounds in cyclic processes of flue gas desulphurisation (in which the oxide is converted to sulphite and then regenerated by thermal decomposition), indicates that magnesium sulphite is the only possibility using temperatures of about $1000^{\circ} \mathrm{C}$, or less. However, calcium sulphite would also decompose in this temperature range "in vacuo". The disproportionation and oxidation reactions, which would accompany sulphite formation and thermal decomposition reactions, produce sulphates and sulphides with greater thermal stabilities than the sulphites. The result is that the thermal decomposition of the sulphite, to form the oxide, is not an exclusive reaction and thermal decomposition alone, at temperatures below $1000^{\circ} \mathrm{C}$, cannot be used to regenerate an alkaline earth metal oxide absorbent. The commercial applicability of these reactions is discussed in Chapter 6. 


\section{CHAPTER FIVE}

REACT IVITY OF SOME ALKALINE EARTH METAL COMPOUNDS WITH SULPHUR DIOXIDE

\subsection{Dynamic Thermogravimetric Studies}

A number of solid reactants were heated in atmospheres containing sulphur dioxide in order to determine the changes in reactivity which occurred. The following solids were used:

(a) Calcium oxide - prepared by calcining BDH calcium carbonate, in air, at $925^{\circ} \mathrm{C}$ for three hours.

(b) ICI quicklime - a commercially produced quicklime.

(c) Calcium hydroxide, BDH.

(d) Limbux - an hydrated lime produced by ICI for industrial use.

(e) Calcium carbonate, BDH.

(f) Limestone - a Carboniferous limestone quarried by ICI from their Tunstead Quarry in Derbyshire.

(g) Magnesite.

(h) Dolomite - quarried by Steetley.

(i) Strontium carbonate, BDH.

(j) Barium carbonate, BDH.

The specific surfaces of the solids are given in Table 5.1.1.

The atmospheres under which the reactions were carried out, in the Mass-flow balance, were produced by mixing the required gases and controlling the flow-rates with valves and rotameters. The atmospheres used were (a) 2 volume-\% sulphur dioxide in nitrogen;

(b) 0.8 volume-\% sulphur dioxide in nitrogen; (c) 0.8 volume-\% sulphur dioxide, plus 8.2 volume-\% oxygen, in nitrogen; (d) nitrogen alone. Heating rates were $5^{\circ} \mathrm{Cmin}^{-1}$ and flow rates $1 \mathrm{~min}^{-1}$.

The majority of published TG studies (see for example Borgwardt ${ }^{30}$; Cout ant ${ }^{102}$; Chan ${ }^{11}$; Marrier ${ }^{103}$; James ${ }^{104}$ ) have employed isothermal 
Table 5.1.1 Specific surfaces of samples used in TG studies

\begin{tabular}{|l|c|}
\hline \multicolumn{1}{|c|}{ Sample } & Specific surface \\
\hline Calcium oxide & $\mathrm{m}^{2} \mathrm{~g}^{-1}$ \\
ICI quicklime & 5.0 \\
Calcium hydroxide & 0.8 \\
Limbux & 4.9 \\
Calcium carbonate & 14.2 \\
Limestone & 0.7 \\
Magnesium carbonate & 0.5 \\
Dolomite & 0.6 \\
Strontium carbonate & 0.4 \\
\hline
\end{tabular}


conditions and, usually, the materials have been pre-calcined, i.e. reactions between oxides and sulphur dioxide have been studied. As interest was directed towards determining the relative rates of reaction at temperatures lower than those found in the furnace, dynamic TG methods had the advantages that they would (i) allow a comparison of the relative rates of reaction at different temperatures to be conveniently made on the same sample; ( $i i)$ give an indication of the reactions which could occur during the period a cold particle was raised in temperature up to that of the hot gas into which it was injected.

It was found that simultaneous DTA and TG measurements did not provide much more useful information. The sulphur dioxide reaction rates were in many cases insufficient to give a marked temperature difference between the sample and reference material. Also, the type of sample container influenced the reaction rates. The comparatively narrow and deep crucibles (radius $2.75 \mathrm{~mm}$ ) necessary for DTA measurements, resulted in reduced reaction rates compared to those found with wider, shallower crucibles (radius $5.75 \mathrm{~mm}$ ) suitable for TG measurements. This effect is illustrated in Fig. 5.1.1 for the reaction between 2 volume-\% $\mathrm{SO}_{2}$ and Limbux. In (a) the actual measured percentage weight changes, have been plotted, and in (b) the weight changes have been adjusted to make allowance for the breakdown of calcium hydroxide to form calcium oxide, plus the decomposition of the small quantities of calcium carbonate also present. The wider container allowed the dehydration of the calcium hydroxide and the reaction with sulphur dioxide to proceed freely at the same time, whereas in the narrower DTA container the slower rate of sulphurisation was not sufficient to compensate for the loss in weight due to dehydration between $400^{\circ} \mathrm{C}$ and $500^{\circ} \mathrm{C}$. The overall result was 
Figure 5.1.1 Effect of crucible type on reaction of Limbux with 2volume-\% $\mathrm{SO}_{2}$, heating rate $5{ }^{\circ} \mathrm{C}$ min $^{-1}$

(a)

- Open crucible

$\triangle$ DTA crucible

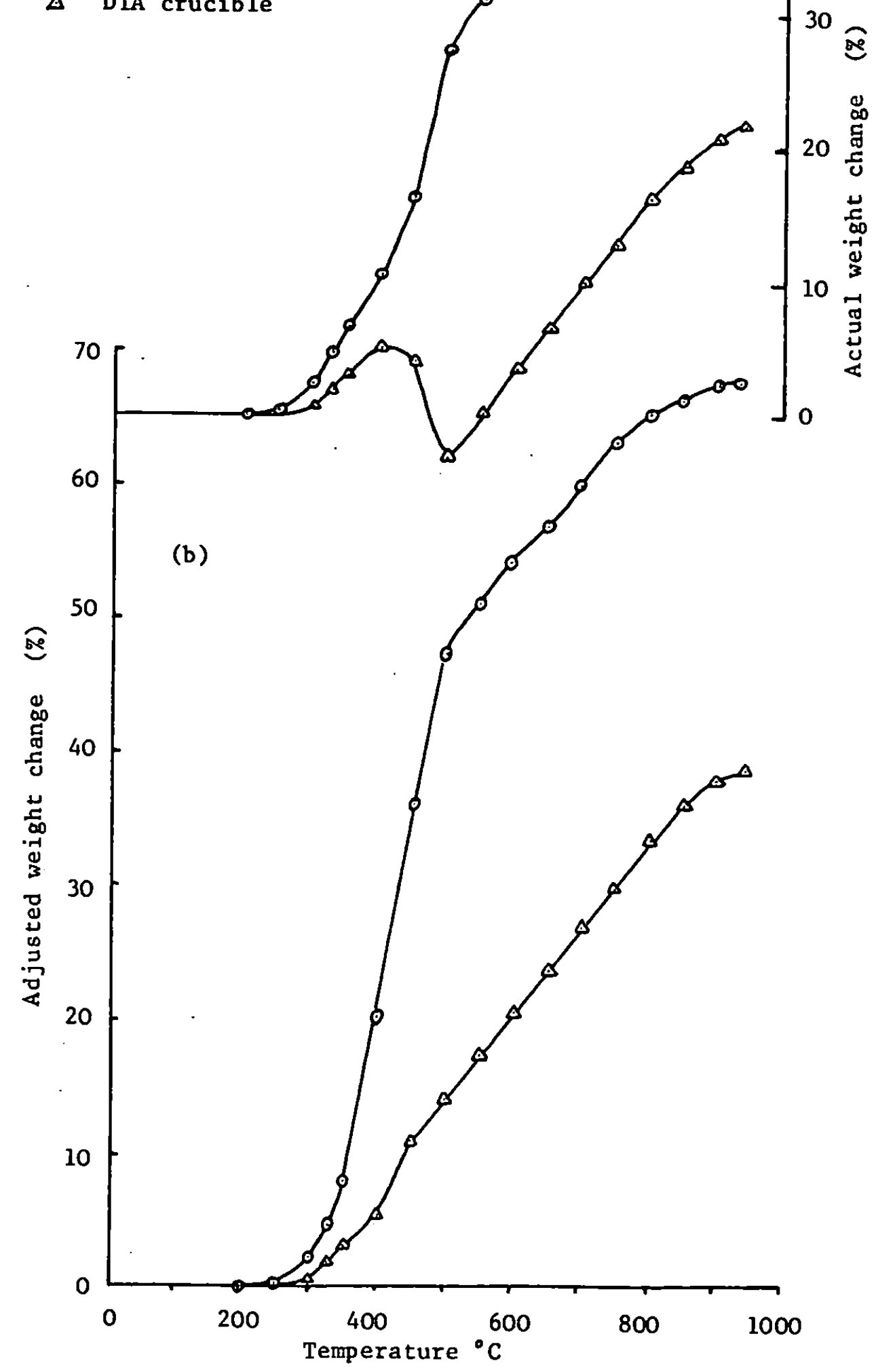


Figure 5.1.2 Reaction of $\mathrm{CaO}$ with $\mathrm{SO}_{2}$

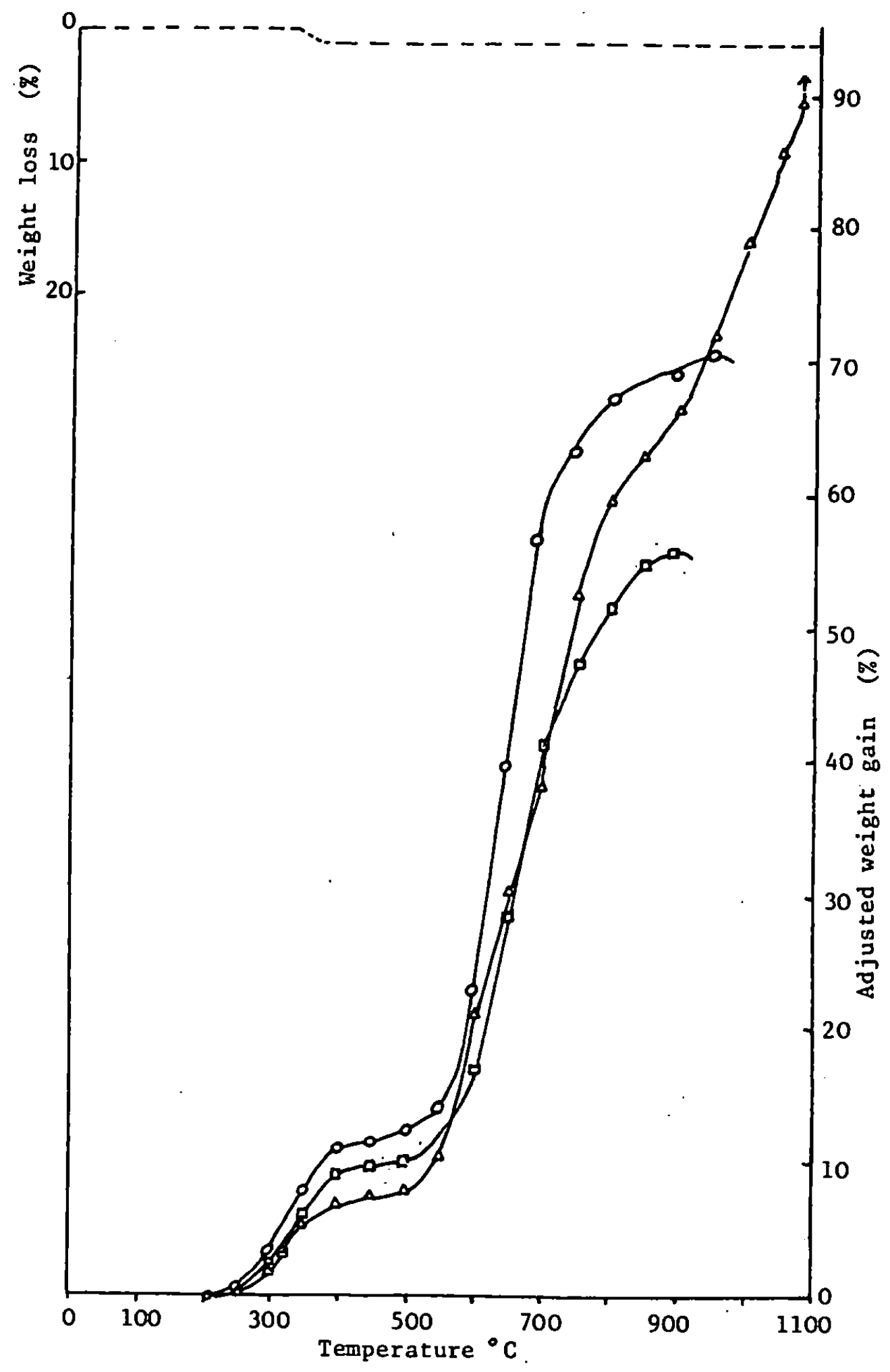

- $\mathrm{CaO}+2$ volume- $\% \mathrm{SO}_{2}$ in nitrogen

- $\mathrm{CaO}+0.8 \mathrm{volume}-\% \mathrm{SO}_{2}$ in nitrogen

$\Delta \quad \mathrm{CaO}+0.8$ volume $-\% \mathrm{SO}_{2}+8$ volume $-\%_{2}$ in nitrogen

--- $\mathrm{CaO}+$ nitrogen

Heated at $5^{\circ} \mathrm{Cmin}^{-1}$. Gas flow rate $10 \min ^{-1}$ 
Figure 5.1.3 Reaction of I.C.I. quick-lime with $\mathrm{SO}_{2}$

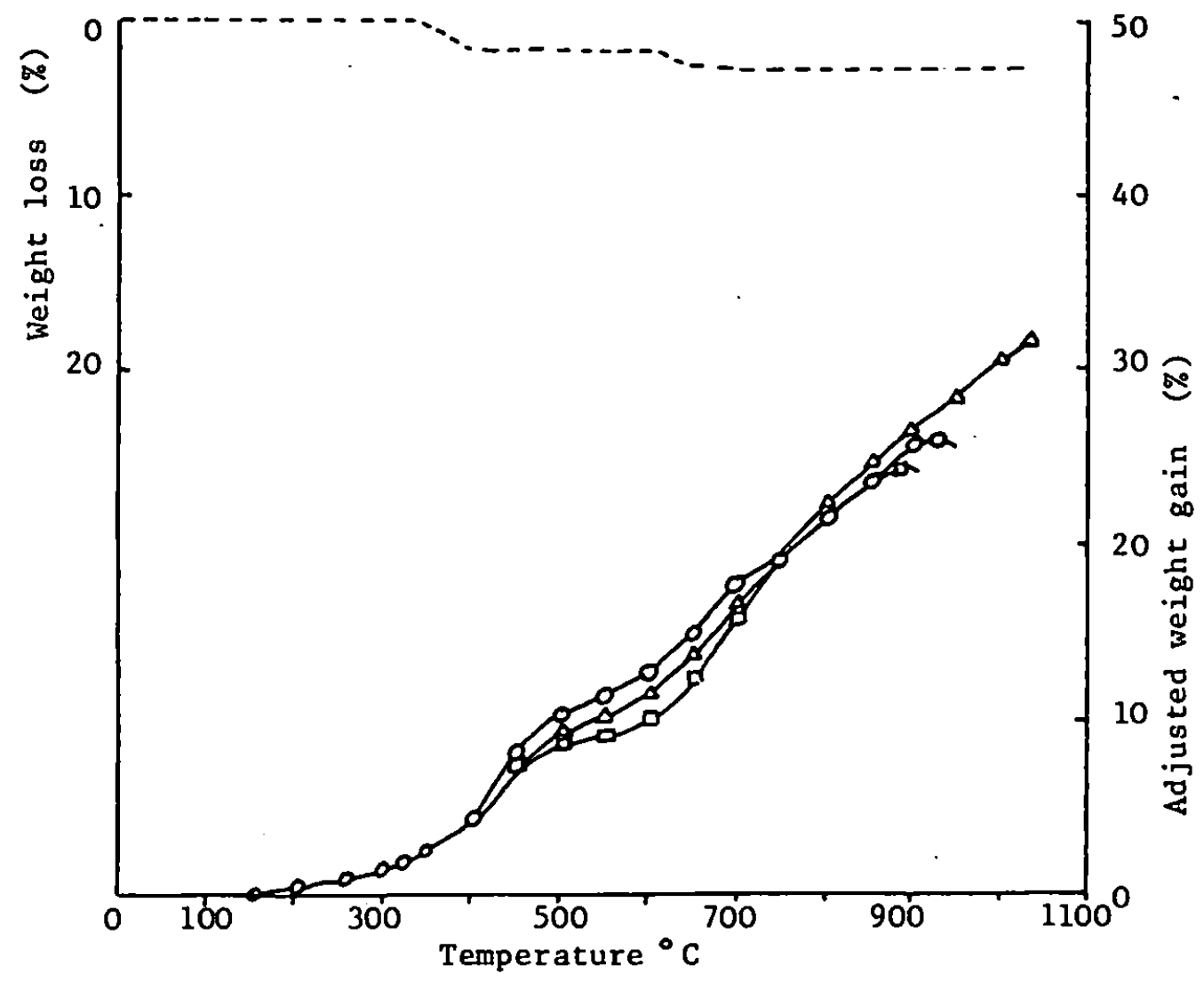

- I.C.I. $\mathrm{CaO}+2$ volume $-\% \mathrm{SO}_{2}$ in nitrogen

- I.C.I. $\mathrm{CaO}+0.8$ volume- $\% \mathrm{SO}_{2}$ in nitrogen

$\triangle \quad$ I.C.I. $\mathrm{CaO}+0.8 \mathrm{volume}-\% \mathrm{SO}_{2}+8$ volume $-\%_{2}$ in nitrogen

-... I.C.I. $\mathrm{CaO}+$ nitrogen Heated at $5^{\circ} \mathrm{Cmin}^{-1}$. Gas flow rate $10 \mathrm{~min}^{-1}$ 
Figure 5.1.4 Reaction of calcium hydroxide with $\mathrm{SO}_{2}$

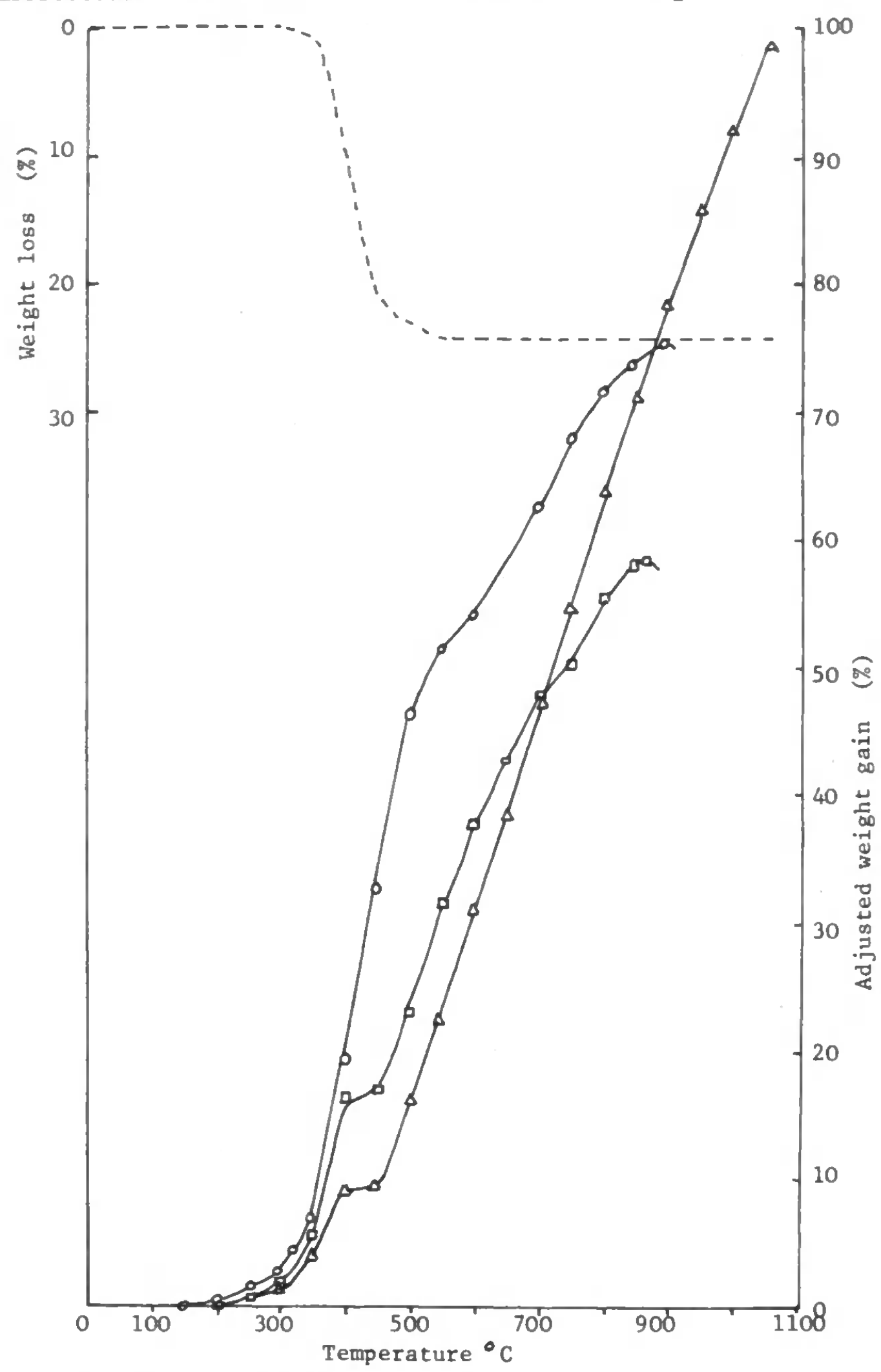

- $\mathrm{Ca}(\mathrm{OH})_{2}+2$ volume- $\% \mathrm{SO}_{2}$ in nitrogen

- $\mathrm{Ca}(\mathrm{OH})_{2}+0.8$ volume $-\% \mathrm{SO}_{2}$ in nitrogen

$\triangle \mathrm{Ca}(\mathrm{OH})_{2}+0.8$ volume $-\% \mathrm{SO}_{2}+8$ volume $-\% \mathrm{O}_{2}$ in nitrogen

-.- $\mathrm{Ca}(\mathrm{OH})_{2}+$ nitrogen

Heated at $5^{\circ} \mathrm{C}$ min $^{-1}$. Gas flow rate $10 \mathrm{~min}^{-1}$ 
Figure 5:1.5 Reaction of Limbux with $\mathrm{SO}_{2}$

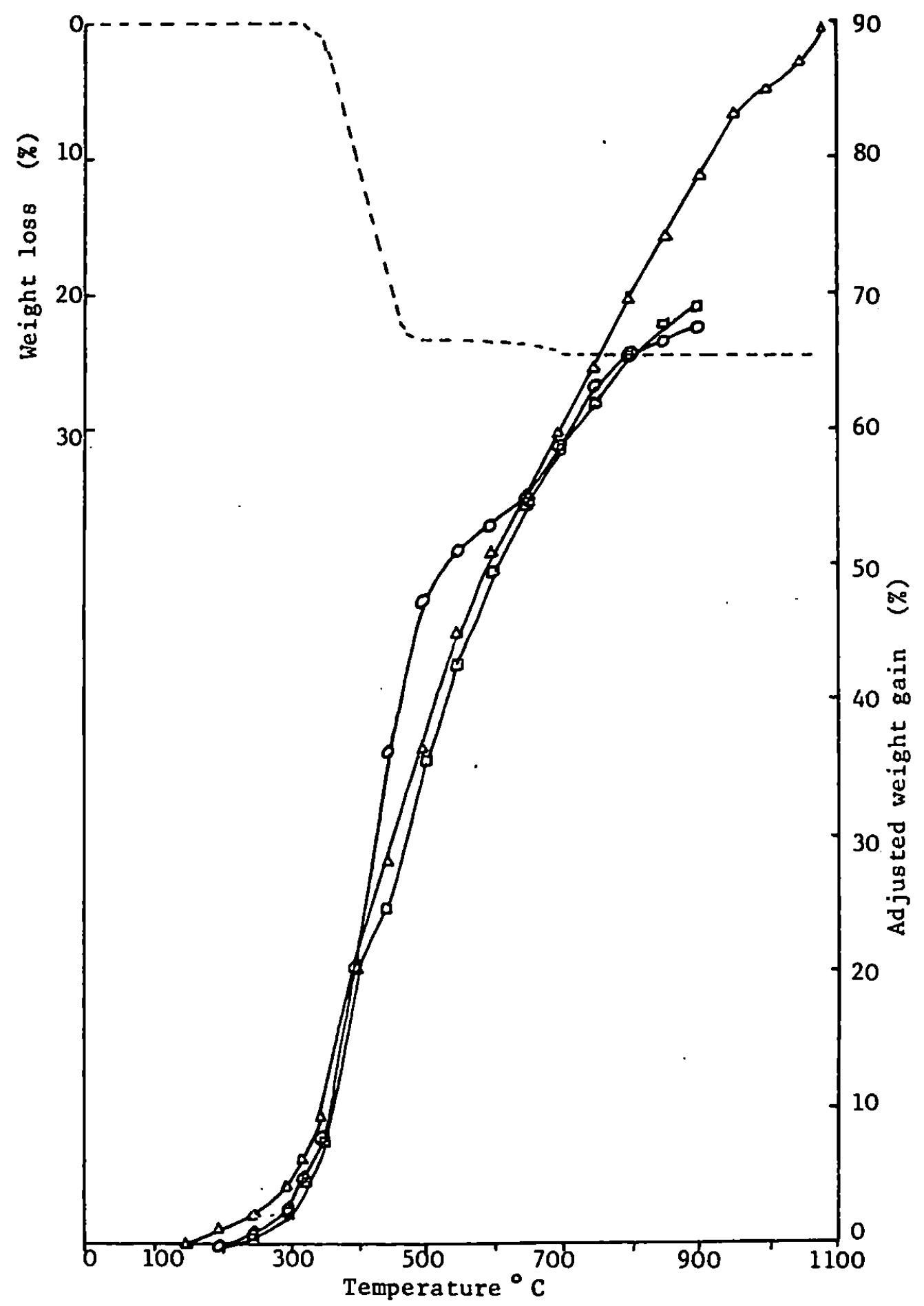

- Limbux +2 volume $-\% \mathrm{SO}_{2}$ in nitrogen

- Limbux +0.8 volume $-\% \mathrm{SO}_{2}$ in nitrogen

$\Delta \quad$ Limbux +0.8 volume $-\% \mathrm{SO}_{2}+8$ volume $-\% \mathrm{O}_{2}$ in nitrogen

- - - Limbux + nitrogen

Heated at $5^{\circ} \mathrm{C} \min ^{-1}$. Gas flow rate $10 \min ^{-1}$ 
Figure 5.1.6 Reaction of $\mathrm{CaCO}_{3}$ with $\mathrm{SO}_{2}$

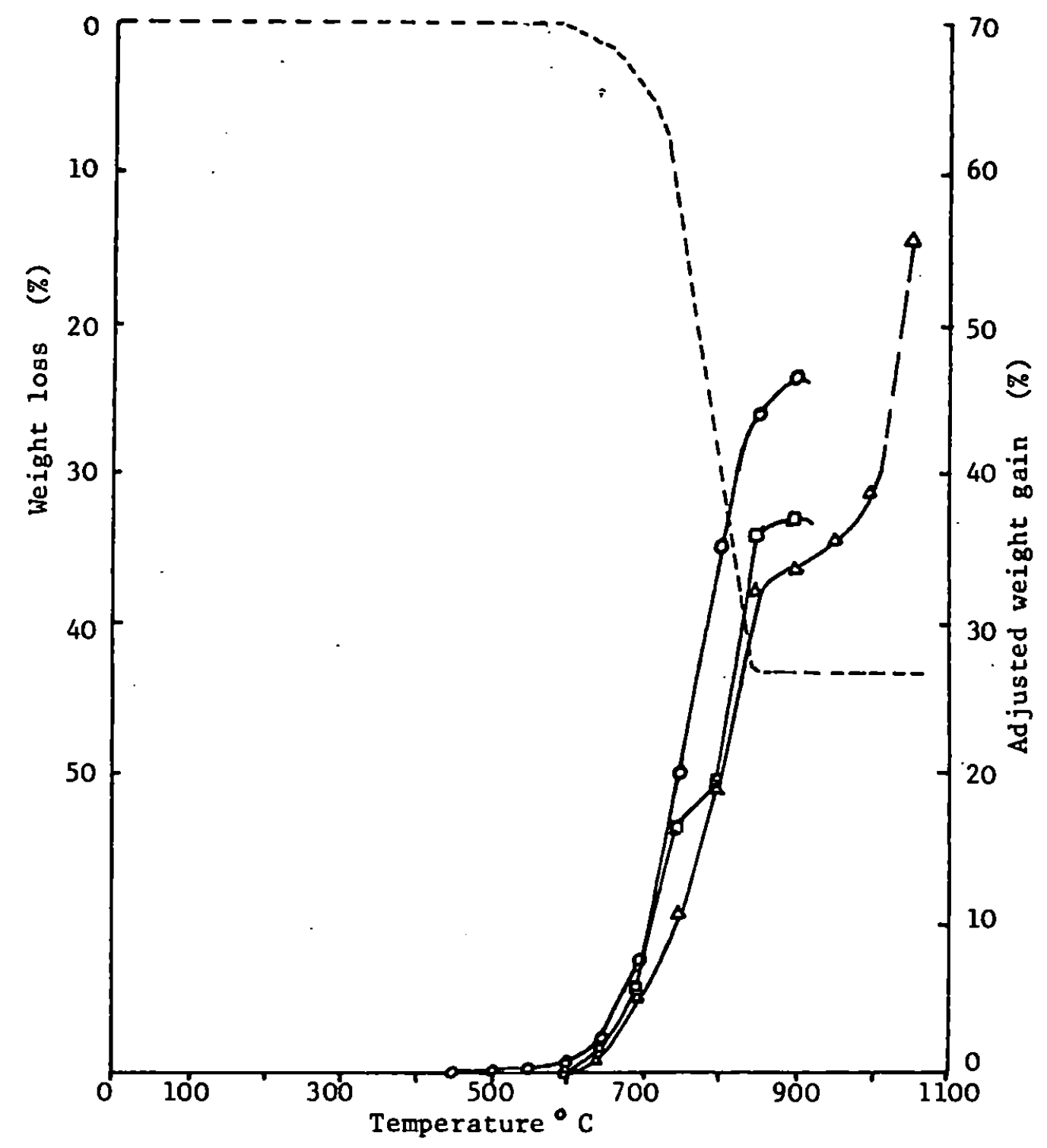

- $\mathrm{CaCO}_{3}+2$ volume-\% $\mathrm{SO}_{2}$ in nitrogen

- $\mathrm{CaCO}_{3}+0.8$ volume $-\% \mathrm{SO}_{2}$ in nitrogen

$\Delta \quad \mathrm{CaCO}_{3}+0.8$ volume- $\% \mathrm{SO}_{2}+8$ volume $-\% \mathrm{O}_{2}$ in nitrogen

$\mathrm{CaCO}_{3}+$ nitrogen

Heated at $5^{\circ} \mathrm{C} \min ^{-1}$. Gas flow rate $10 \mathrm{~min}^{-1}$ 
Figure 5.1.7 Reaction of limestone with $\mathrm{SO}_{2}$

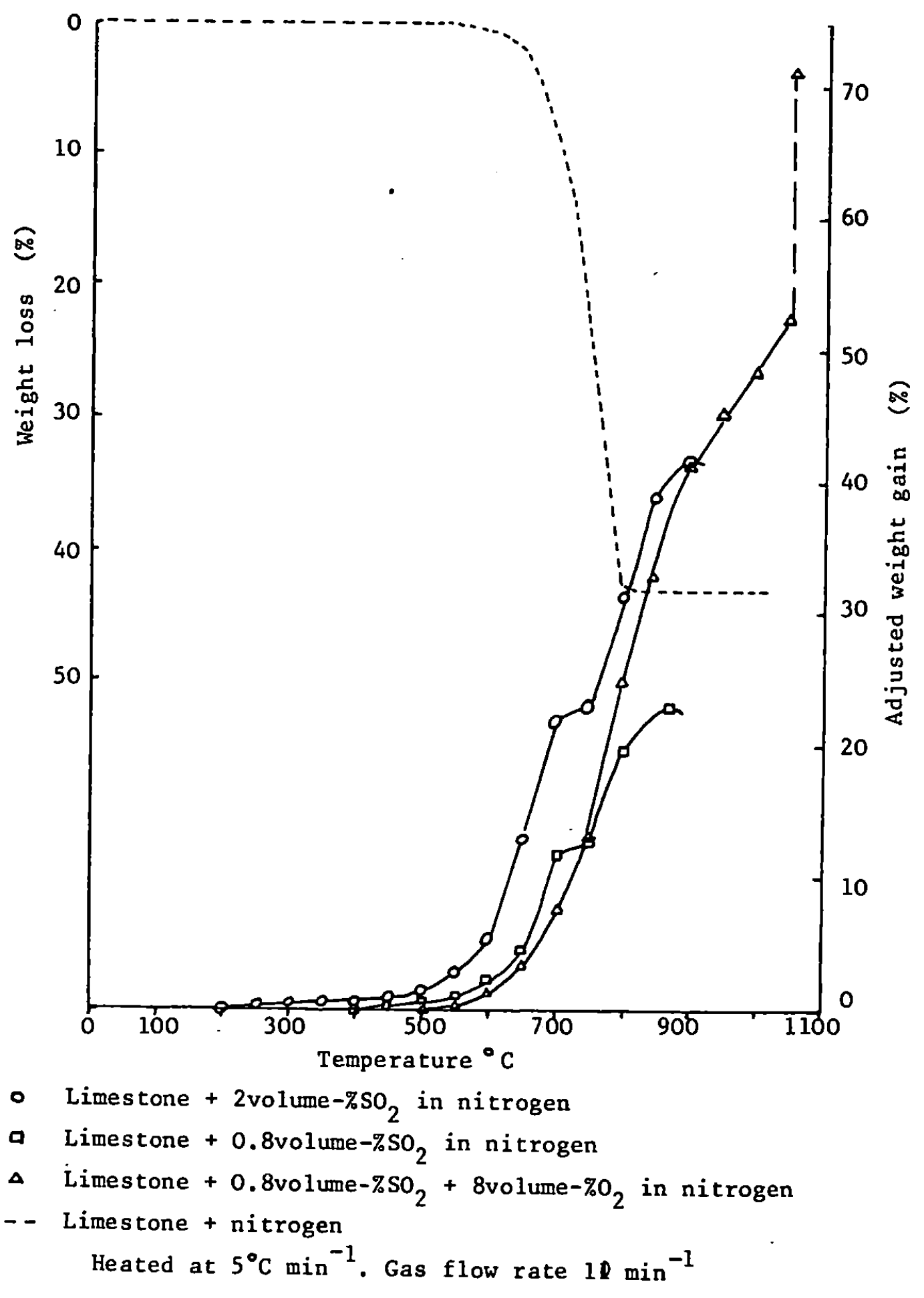


Figure 5.1.8 Reaction of magnesium carbonate with $\mathrm{SO}_{2}$

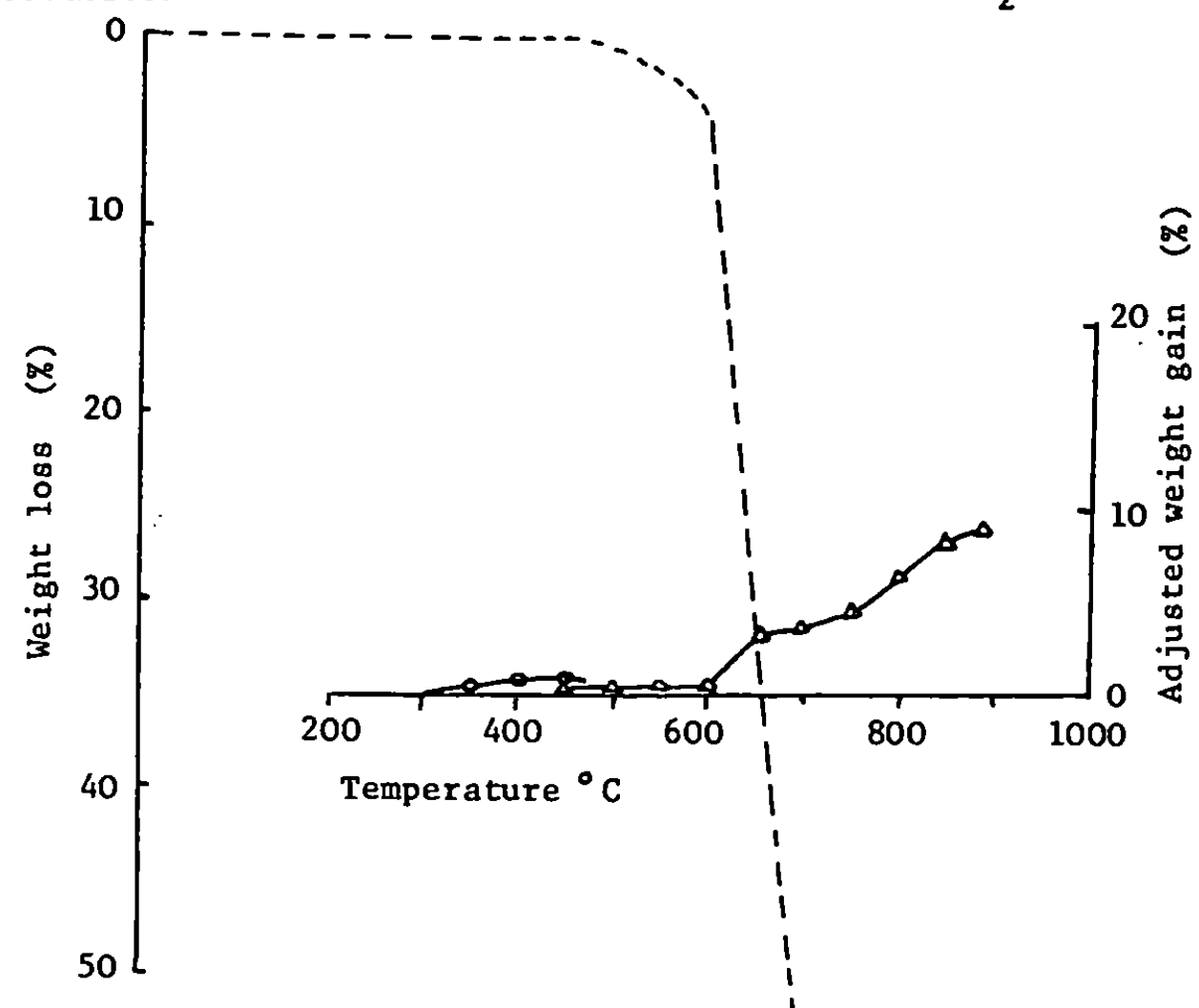

Figure 5.1.9 Reaction of dolomite with $\mathrm{SO}_{2}{ }^{\mathrm{L}}-\cdots----$

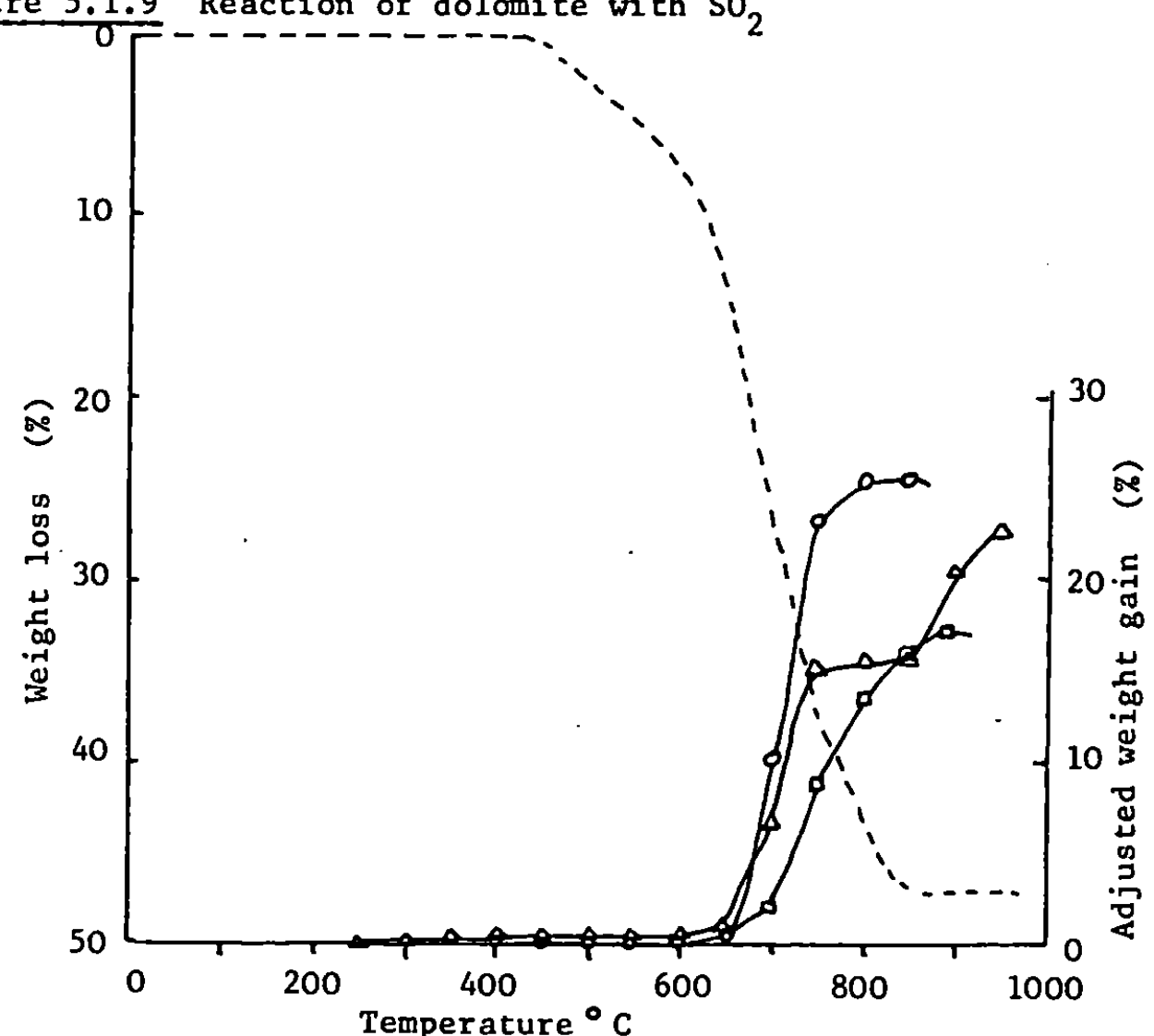

- In $2 \mathrm{vol}-\% \mathrm{SO}_{2}$ in $\mathrm{N}_{2}$ a In $0.8 \mathrm{vol}-\%_{2} \mathrm{SO}_{2}$ in $\mathrm{N}_{2} \ldots \ldots$ In $\mathrm{N}_{2}$. - In $0.8 \mathrm{vol}-\% \mathrm{SO}_{2}+8 \mathrm{vol}-\% \mathrm{O}_{2}$ in $\mathrm{N}_{2}$. Gas flow rate $18 \mathrm{~min}^{-1}$. 
Figure 5.1.10 Reaction of strontium carbonate with $\mathrm{SO}_{2}$

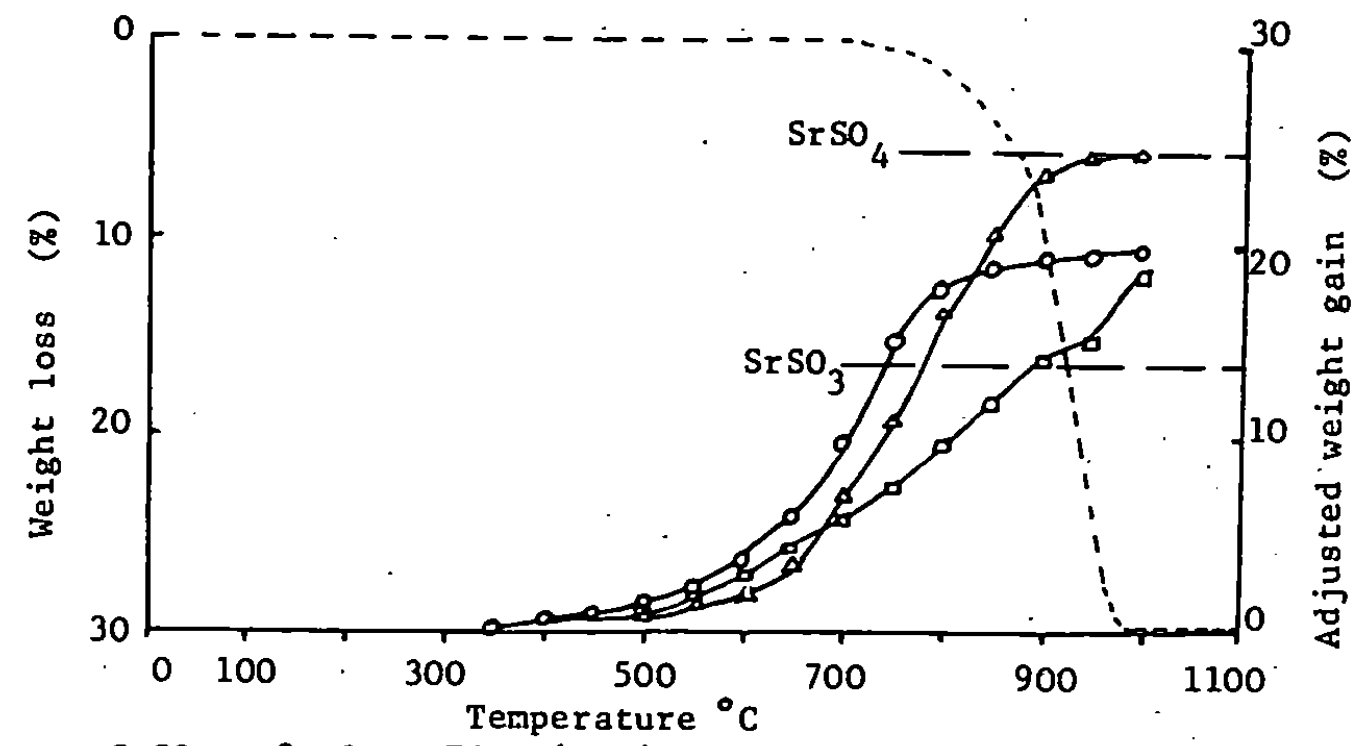

- $\mathrm{SrCO}_{3}+2$ volume $-\% \mathrm{SO}_{2}$ in nitrogen

- $\mathrm{SrCO}_{3}+0.8$ volume $-\% \mathrm{SO}_{2}$ in nitrogen

- $\mathrm{SrCO}_{3}+0.8$ volume $-\% \mathrm{SO}_{2}+8$ volume $-\%_{2}$ in nitrogen

- $\mathrm{SrCO}_{3}+$ nitrogen

Heated at $5^{\circ} \mathrm{Cmin}^{-1}$. Gas flow rate $10 \mathrm{~min}^{-1}$

Figure 5.1.11 Reaction of barium carbonate with $\mathrm{SO}_{2}$

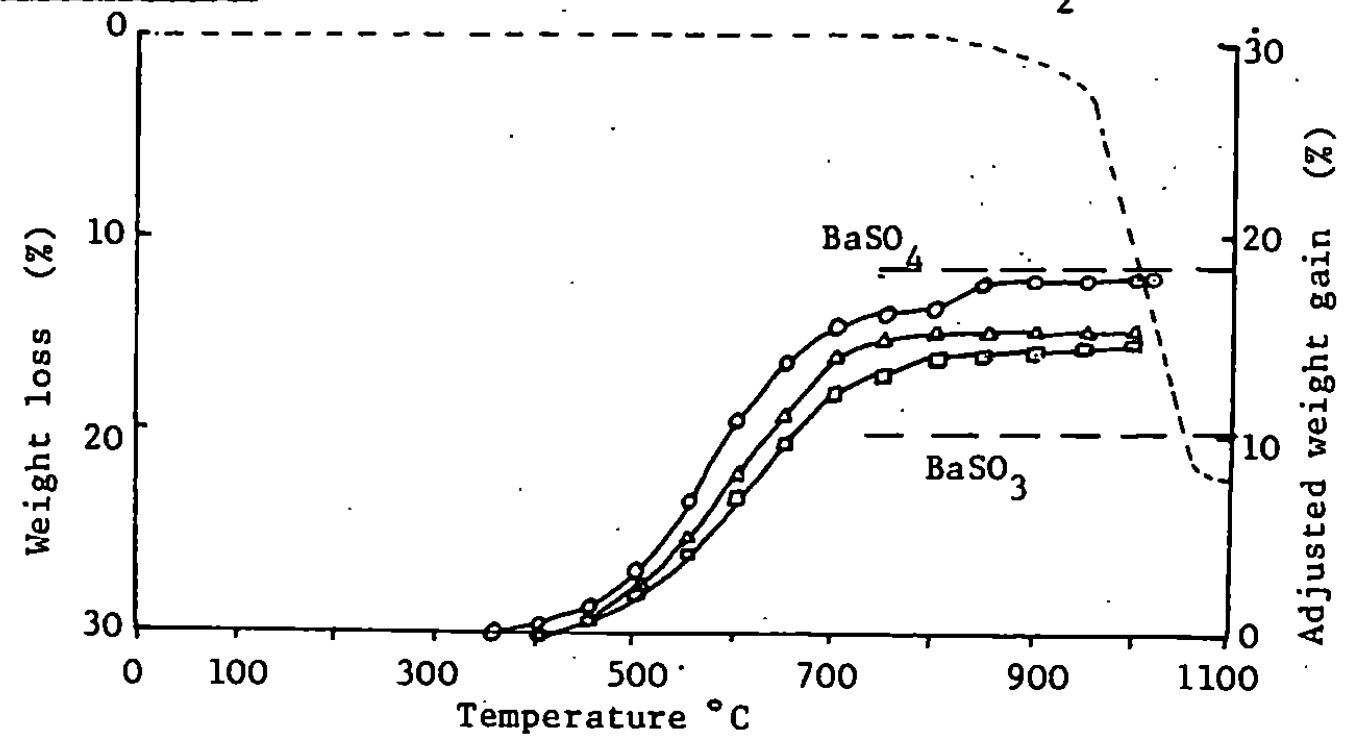

- $\mathrm{BaCO}_{3}+2$ volume- $\% \mathrm{SO}_{2}$ in nitrogen

- $\mathrm{BaCO}_{3}+0.8$ volume $-\% \mathrm{SO}_{2}$ in nitrogen

$\triangle \mathrm{BaCO}_{3}+0.8$ volume $-\% \mathrm{SO}_{2}+8$ volume $-\mathrm{FO}_{2}$ in nitrogen

$---\mathrm{BaCO}_{3}+$ nitrogen

Heated at $5^{\circ} \mathrm{Cmin}^{-1}$. Gas flow rate $10 \mathrm{~min}^{-1}$ 
Figure 5.1.12 Rates of uptake of $\mathrm{SO}_{2}$ by various alkaline earth metal compounds

- In 2volume- $\% \mathrm{SO}_{2}$ in nitrogen

- In 0.8 volume- $\% \mathrm{SO}_{2}$ in nitrogen

- In 0.8 volume $-\% \mathrm{SO}_{2}+8$ volume $-\% \mathrm{O}_{2}$ in nitrogen

...... In nitrogen

(a) I.C.I. Quick lime

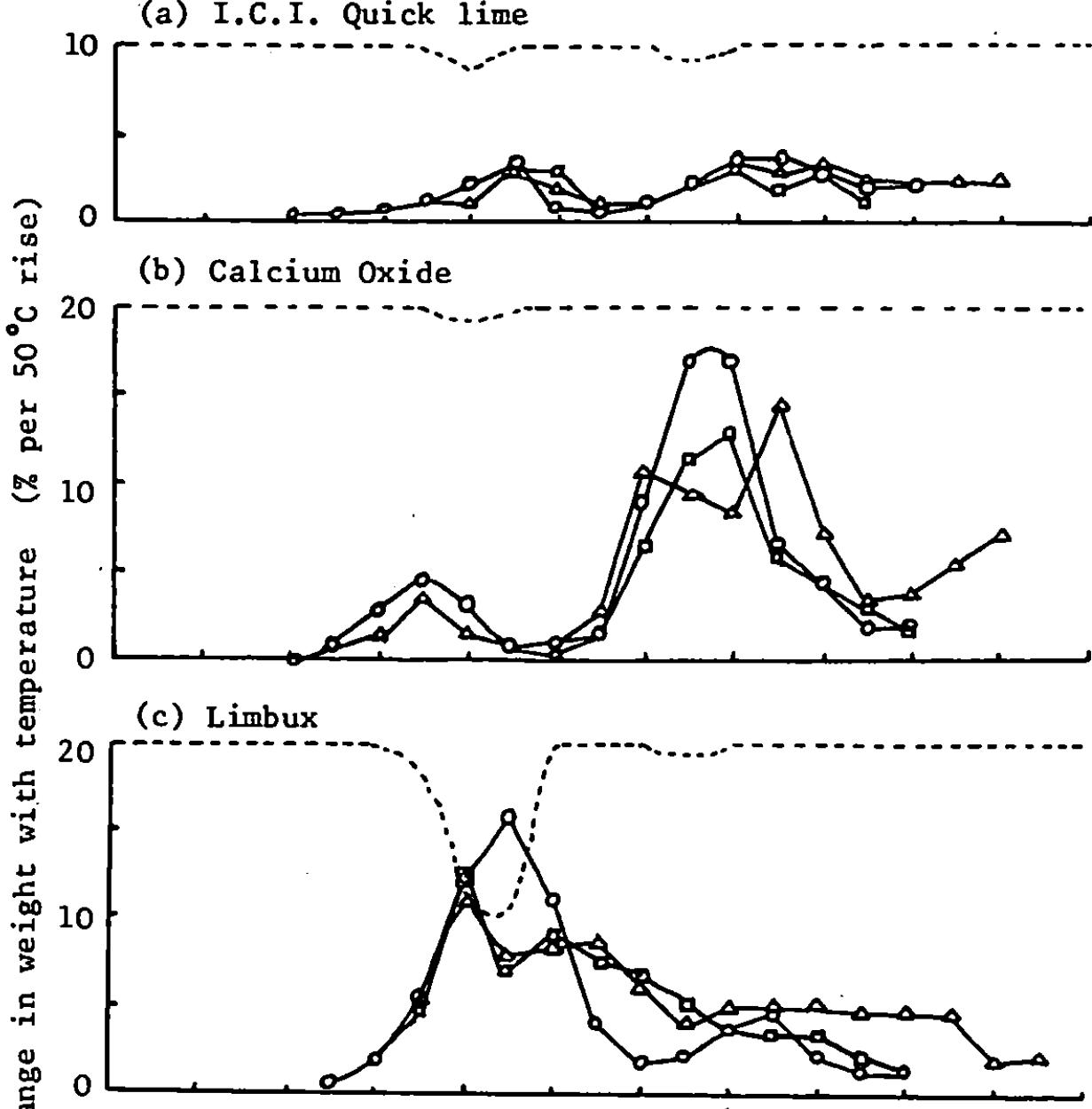

(d) Calcium Hydroxide

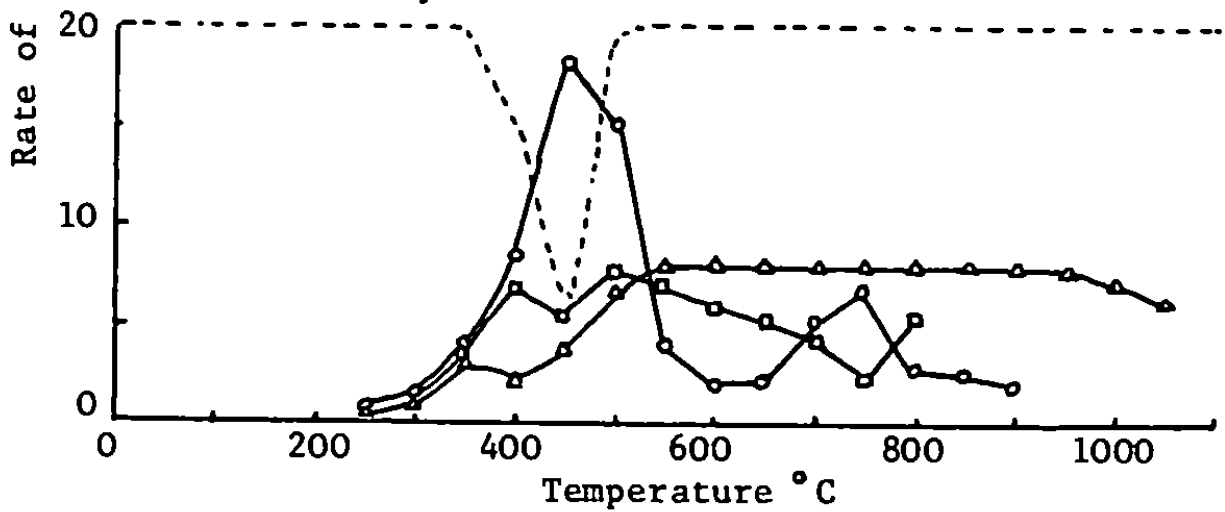


Figure $5.1: 12$
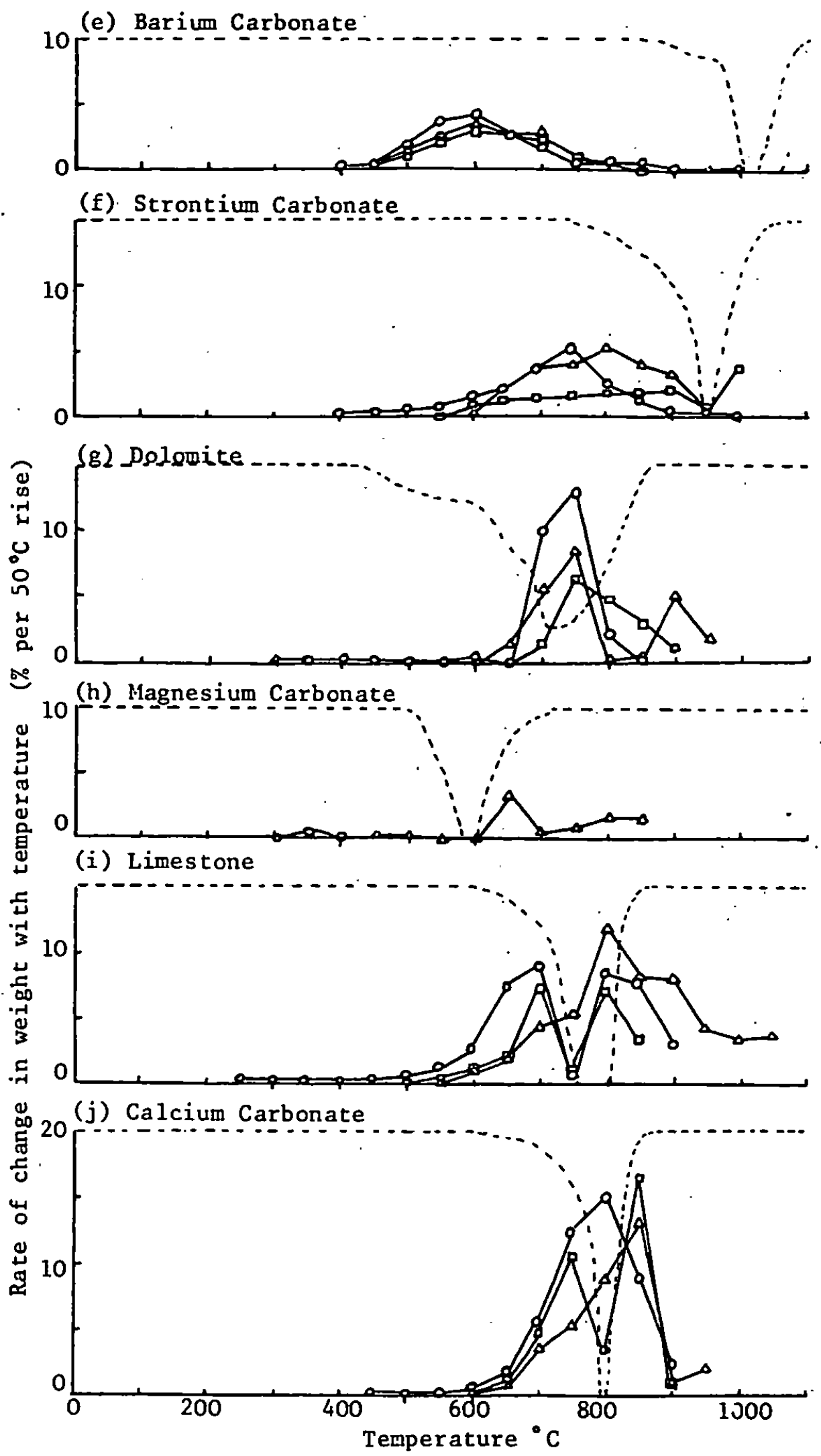

205 
Table 5.1.2 Maxima rates of weight increase show by samples heated in the presence of sulphur dioxide

\begin{tabular}{|c|c|c|c|c|c|c|c|c|c|c|c|c|}
\hline \multirow{3}{*}{$\begin{array}{l}\text { Solid } \\
\text { reactant }\end{array}$} & \multicolumn{12}{|c|}{ Gas mixtures } \\
\hline & \multicolumn{4}{|c|}{2 volz $\mathrm{SO}_{2}+\mathrm{N}_{2}$} & \multicolumn{4}{|c|}{0.8 volz so $2+\mathrm{N}_{2}$} & \multicolumn{4}{|c|}{$\begin{array}{l}0.8 \text { vold } \mathrm{SO}_{2}^{+} \\
8.2 \mathrm{volz} \mathrm{O}_{2}+\mathrm{N}_{2}\end{array}$} \\
\hline & $\begin{array}{l}\text { Temp. } \\
{ }^{\circ} \mathrm{C} \\
\end{array}$ & Rate* & $\begin{array}{c}\text { Temp. } \\
{ }^{\circ} \mathrm{C}\end{array}$ & Rote & $\begin{array}{c}\text { Tenp. } \\
{ }^{\circ} \mathrm{C}\end{array}$ & Rate $e^{\star}$ & $\begin{array}{c}\text { Temp. } \\
{ }^{\circ} \mathrm{C}\end{array}$ & Rate* & $\begin{array}{c}\text { Tepp. } \\
{ }^{\circ} \mathrm{C}\end{array}$ & Bate* & $\begin{array}{c}\text { Temp. } \\
{ }^{\circ} \mathrm{C}\end{array}$ & Rate* \\
\hline $\begin{array}{l}\text { Calcius } \\
\text { oxide }\end{array}$ & $\begin{array}{l}311 \\
-321\end{array}$ & 1.1 & $\mid \begin{array}{l}650 \\
-676\end{array}$ & 2.1 & $\begin{array}{l}315 \\
-325\end{array}$ & 0.57 & $\mid \begin{array}{l}594 \\
-689\end{array}$ & 1.3 & $\begin{array}{l}311 \\
-330\end{array}$ & 0.41 & $\begin{array}{l}714 \\
-747\end{array}$ & 1.4 \\
\hline $\begin{array}{l}\text { I. C.I. } \\
\text { Quicklime }\end{array}$ & $\begin{array}{l}415 \\
-429\end{array}$ & 0.44 & $\begin{array}{l}710 \\
-740\end{array}$ & 0.39 & $\begin{array}{l}436 \\
-457\end{array}$ & 0.39 & $\begin{array}{l}755 \\
-780\end{array}$ & 0.31 & $\begin{array}{c}412 \\
-433\end{array}$ & 0.41 & $\mid \begin{array}{l}678 \\
-708\end{array}$ & 0.32 \\
\hline $\begin{array}{l}\text { Calcium } \\
\text { bydroxide }\end{array}$ & $\begin{array}{l}311 \\
-326\end{array}$ & 0.59 & $\begin{array}{l}457 \\
-494\end{array}$ & 1.3 & $\begin{array}{l}301 \\
-331\end{array}$ & 0.41 & $\mid \begin{array}{l}467 \\
-549\end{array}$ & 0.76 & $\begin{array}{l}301 \\
-336\end{array}$ & 0.16 & $\begin{array}{l}464 \\
-831\end{array}$ & 0.65 \\
\hline Limbux & $\begin{array}{l}311 \\
-331\end{array}$ & 0.96 & $\mid \begin{array}{l}467 \\
-504\end{array}$ & 1.3 & $\begin{array}{l}309 \\
-321\end{array}$ & 0.77 & $\begin{array}{l}453 \\
-460\end{array}$ & 1.1 & $\begin{array}{l}306 \\
-331\end{array}$ & 0.63 & $\mid \begin{array}{l}476 \\
-549\end{array}$ & 1.0 \\
\hline $\begin{array}{l}\text { Calcium } \\
\text { carbonate }\end{array}$ & $\begin{array}{l}672 \\
-755\end{array}$ & 0.34 & $\left|\begin{array}{l}832 \\
-852\end{array}\right|$ & 0.69 & $\begin{array}{l}714 \\
-735\end{array}$ & 0.45 & $\left|\begin{array}{l}804 \\
-836\end{array}\right|$ & 1.0 & $\begin{array}{l}710 \\
-720\end{array}$ & 0.13 & $\mid \begin{array}{l}792 \\
-828\end{array}$ & 1.2 \\
\hline Limestone & $\begin{array}{l}646 \\
-697\end{array}$ & 0.17 & $\mid \begin{array}{l}771 \\
-832\end{array}$ & 0.69 & $\begin{array}{l}650 \\
-663\end{array}$ & 0.19 & $\left|\begin{array}{l}771 \\
-784\end{array}\right|$ & 0.57 & $\begin{array}{l}651 \\
-667\end{array}$ & 0.18 & $\mid \begin{array}{l}800 \\
-880\end{array}$ & $0.61^{\circ}$ \\
\hline Magnesite & $\begin{array}{l}330 \\
-351\end{array}$ & 0.02 & & & & & & & $\begin{array}{l}439 \\
-480\end{array}$ & 0.02 & \begin{tabular}{|l|}
745 \\
-828
\end{tabular} & 0.14 \\
\hline Dolonice & $\begin{array}{l}321 \\
-334\end{array}$ & 0.08 & $\begin{array}{l}697 \\
-752\end{array}$ & 1.3 & $\begin{array}{l}321 \\
-346\end{array}$ & 0.04 & $\begin{array}{l}765 \\
-787\end{array}$ & 0.45 & $\begin{array}{l}696 \\
-764\end{array}$ & 0.17 & $\begin{array}{l}842 \\
-863\end{array} \mid$ & 0.57 \\
\hline $\begin{array}{l}\text { Strontiug } \\
\text { carbonate }\end{array}$ & $\begin{array}{l}705 \\
-739\end{array}$ & 0.56 & & & $\begin{array}{l}667 \\
-864\end{array}$ & 0.22 & $\mid \begin{array}{l}966 \\
-999\end{array}$ & 0.34 & $\begin{array}{l}747 \\
-808\end{array}$ & 0.47 & & \\
\hline $\begin{array}{l}\text { Barium } \\
\text { carbonate }\end{array}$ & $\begin{array}{l}531 \\
-567\end{array}$ & 0.45 & & & $\begin{array}{l}659 \\
-697\end{array}$ & 0.32 & & & $\begin{array}{l}549 \\
-629\end{array}$ & 0.32 & & \\
\hline
\end{tabular}

*Rate expressed as weight increase per $100 \mathrm{mg}$ solid reactant per minute 
Table 5.1.3 Comparison of adjusted reight increases, utilisation factors and decomposition cenperatures of solid absorbents

\begin{tabular}{|c|c|c|c|c|c|c|c|c|c|}
\hline \multirow{3}{*}{$\begin{array}{c}\text { Solid } \\
\text { reactant }\end{array}$} & \multicolumn{9}{|c|}{ Gas mixtures } \\
\hline & \multicolumn{3}{|c|}{$2 \operatorname{volz~} \mathrm{SO}_{2}+\mathrm{N}_{2}$} & \multicolumn{3}{|c|}{$0.8 \operatorname{vol}=\mathrm{SO}_{2}+\mathrm{N}_{2}$} & \multicolumn{3}{|c|}{$\begin{array}{c}0.8 \text { vol- } \mathrm{SO}_{2}+ \\
8.2 \operatorname{vol} \mathrm{O}_{2}+\mathrm{N}_{2}\end{array}$} \\
\hline & $\begin{array}{l}\text { Max. } \\
\text { wt. } \\
\text { incr. }\end{array}$ & So $_{4}^{2-}$ & $\begin{array}{l}\text { Decomp. } \\
\text { temp. } \\
{ }^{\circ} \mathrm{C}\end{array}$ & $\begin{array}{l}\text { Max. A } \\
\text { wt. } \\
\text { inct. }\end{array}$ & $\begin{array}{c}\mathrm{So}_{4}^{2-} \\
\text { convers. }\end{array}$ & $\begin{array}{l}\text { Decomp. } \\
\text { temp. } \\
\text { oC }\end{array}$ & $\begin{array}{l}\text { Max. } \\
\text { ut. } \\
\text { incr. }\end{array}$ & \begin{tabular}{|c|}
$\mathrm{SO}_{4}^{2-}$ \\
convers.
\end{tabular} & $\begin{array}{c}\text { Decoop. } \\
\text { temp. } \\
\text { oC }\end{array}$ \\
\hline $\begin{array}{l}\text { Calcium } \\
\text { oxide }\end{array}$ & 70.6 & 49.5 & 895 & 55.9 & 39.2 & 888 & 103.7 & 72.7 & $>1086$ \\
\hline $\begin{array}{l}\text { T. C. I. } \\
\text { quickl ime }\end{array}$ & 25.7 & 24.3 & 923 & 24.5 & 23.1 & 890 & 31.6 & 29.8 & $>1031$ \\
\hline $\begin{array}{l}\text { Colcium } \\
\text { hydroxide }\end{array}$ & 75.4 & 69.7 & 895 & 58.6 & 54.2 & 862 & 99.5 & 92.1 & $>1059$ \\
\hline Limbux & 67.7 & 62.7 & 930 & 69.0 & 63.9 & 900 & 89.8 & 83.1 & $>1085$ \\
\hline $\begin{array}{l}\text { Calcium } \\
\text { carbonate }\end{array}$ & 46.8 & 58.5 & 916 & 37.2 & 46.5 & 907 & 56.0 & 70.0 & $>1045$ \\
\hline Lime st one & 41.7 & 52.1 & 907 & 23.4 & 29.3 & 868 & 71.3 & 89.1 & $>1059$ \\
\hline Magnesite & 0.5 & $2.1^{\mathrm{C}}$ & 476 & & & & 8.6 & 9.1 & 891 \\
\hline Dolomite & 25.8 & 29.7 & 882 & 17.3 & 19.9 & 884 & 22.8 & 26.3 & 992 \\
\hline $\begin{array}{l}\text { Strontium } \\
\text { carbonate }\end{array}$ & 19.4 & $79.4^{D}$ & $>1003$ & 18.2 & $74.6^{D}$ & $>1004$ & 24.4 & 100 & $>972$ \\
\hline $\begin{array}{l}\text { Barium } \\
\text { carbonate }\end{array}$ & 17.7 & $96.9^{D}$ & $>1014$ & 13.8 & $75.5^{D}$ & $>995$ & 15.1 & $82.6^{D}$ & $>999$ \\
\hline
\end{tabular}
A - Maximm percentage weight increase, adjusted for loss due to decomposition reactions where necessary.
B - Percentage conversion to sulphace based on $A$.
C - Percentage conversion to sulphite.
D - Actually 1007 utilisation in terms of sulphur to metal ratio. 
Table 5.1.4 Activation energy for the reaction between sulphur dioxide and calcium oxide

\begin{tabular}{|c|c|}
\hline $\begin{array}{c}\text { Activation energy } \\
\mathrm{kJ} \text { mole }\end{array}$ & Determined by \\
115 & Coutant et al ${ }^{-1}$ \\
$41-103$ & Ishihara ${ }^{106}$ \\
64 & Hatfield et al ${ }^{105}$ \\
$33-75$ & Borgwardt R. H. ${ }^{30}$ \\
128 & James \& Hughes 104 \\
\hline
\end{tabular}


that there was nearly twice as much reaction in the wider container as in the narrower container, between sulphur dioxide and limbux, before the decomposition temperature was reached. The detectable decomposition temperature was also influenced by the container. With the loss of decomposition products being hindered in the narrower crucible, the apparent decomposition temperature was raised from $930^{\circ} \mathrm{C}$ to $938^{\circ} \mathrm{C}$. The wide shallow type of alumina crucible with only a thin layer of solid reactant was used to minimise the various effects caused by the reactant gases having to diffuse through a bed of solid particles.

The results of a series of studies in which gas mixture composition, crucible type and bed depth were matched as closely as possible have been shown in Fig. 5.1.2 - 5.1.12 and in Tables 5.1.2 and 5.1.3. Because of the various competing reactions, see Table 1.1 (p.10), which could be occurring at the same time over a given temperature range (the actual simultaneous reactions would depend upon the solid reactants and gas composition) it was decided that attempts to extract precise quantitative values to describe the reaction kinetics would not yield much useful information. The range of published values for the activation energy of the reaction between sulphur dioxide and calcium oxide, Table 5.1.4, illustrates that even when results were analysed quantitatively, they were of little general applicability due to variations in study conditions and between samples.

Fig. 5.1.2 - 5.1.12 indicated the relative effectiveness of the various compounds in reacting with sulphur dioxide. Fig. 5.1.12 allowed a rapid comparison of the variation in reaction rates with temperature, gas composition and solid reactant to be made. Maximum rates of weight increase and the corresponding temperature ranges, as presented in Table' 5.1.2, define the conditions for maximum reactivity rather more closely than does Fig. 5.1.12. This assumed the 
weight increase was mainly related to sulphur uptake rather than to oxidation reactions.

\subsubsection{Efficiency of solid absorbents}

A major difficulty was found to be the presentation of a simple measure of how effective a particular solid reactant was in terms of what proportion of its possible sulphur absorbing capacity had actually been utilised. The problems may be illustrated by the reactions, with 0.8 volume-\% sulphur dioxide in nitrogen, of ICI quicklime, Fig. 5.1.3, and barium carbonate, Fig. 5.1.11. The quicklime increased in weight by $24.5 \%$, after making allowance for the $6.25 \% \mathrm{Ca}(\mathrm{OH})_{2}$ and $2.7 \% \mathrm{CaCO}_{3}$ also present, and the barium carbonate showed a $13.8 \%$ weight increase. If the maximum quantity of calcium sulphite had been formed, a weight increase of $105.8 \%$ should have been recorded, which indicated $23.2 \%$ utilisation of the lime. Similarly, the maximum conversion of barium carbonate to barium sulphite would have given a $10.2 \%$ weight increase and, thus, the apparent utilisation of the barium carbonate was $135.3 \%$. If the end products were assumed to be calcium sulphate and barium sulphate, these would give increases of $136.2 \%$, and $18.3 \%$ respectively and indicate corresponding utilisations of $18 \%$ and $75.4 \%$. Both the quicklime and barium carbonate samples, after reaction, were found to contain both sulphate and sulphide, which showed that some sulphite had been formed and this had subsequently disproportionated. In the presence of oxygen or sulphur dioxide, particularly at higher concentrations, any sulphite or sulphide formed could be oxidised to sulphate, as discussed in Chapter 4, but these reactions rarely go to completion due to the formation of protective layers of sulphate. Therefore, comparing the actual weight increase with the theoretical increase due to sulphite formation would be likely to give too high a value for the utilisation factor, due to the 
effects of oxidation, and a comparison with the theoretical increase due to sulphate formation would give too low a value for the utilisation factor, if all the sulphite and sulphide had not been oxidised. In Table 5.1 .3 comparison was made with the theoretical amount of sulphate which could be formed even though this would lead to apparently low utilisation factors, particularly for the reactions in 0.8 vol-\% sulphur dioxide in nitrogen, where the tendency for oxidation was least.

The results obtained were consistent with the view that the initial reaction with sulphur dioxide, at lower temperatures, led to the formation of sulphite, even in the presence of oxygen. The reactivity of the solids with the sulphur dioxide/oxygen mixtures was only slightly greater than that with gas mixtures containing the same quantity of sulphur dioxide, but no oxygen. The greater weight increases shown in the sulphur dioxide/oxygen mixtures were not as great as would have been expected if only sulphate was being formed. The larger total weight increases shown in the oxygen-containing gas mixtures were often due to the higher initial decomposition temperatures of the products which enabled the reactions to continue both to a higher temperature and for a longer period of time. This latter feature would also indicate that conversion of sulphur dioxide to sulphur trioxide was not a major factor in the increased uptake in the presence of oxygen. The proportion of sulphur trioxide in equilibrium with sulphur dioxide and oxygen decreases with rising temperature, though, of course, the rate of reaction would increase. This would agree with the findings of Coutant et al ${ }^{102}$, and Hatfield et $a 1^{105}$, that the presence of air had little effect on the rates of sulphur dioxide uptake by calcined limestones and dolomites.

The variations in reactivity shown by the carbonates studied could be explained in terms of the relative thermal stabilities of the 
unreacted carbonates and the sulphur containing products.

Magnesium carbonate, Fig. 5.1.8, only reacted slightly below its decomposition temperature and, as magnesium sulphite decomposed in the same temperature range, there was no possibility of reaction between the freshly formed magnesium oxide and sulphur dioxide to form magnesium sulphite. The free energy of formation of magnesium sulphite ${ }^{8}$, from magnesium carbonate and sulphur dioxide, is positive below $500^{\circ} \mathrm{C}$ whereas it is negative for reactions with sulphur trioxide and with sulphur dioxide plus oxygen; however, even with the latter mixture there was little reaction until the magnesium carbonate decomposed to magnesium oxide. The freshly produced magnesium oxide reacted with the $\mathrm{SO}_{2} / \mathrm{O}_{2}$ mixture to form magnesium sulphate, but only to a limited extent (less than $10 \%$ conversion to sulphate). Hatfield et al ${ }^{105}$ found that magnesium oxide, prepared by calcining magnesium hydroxide, did not react with a $\mathrm{SO}_{2} / \mathrm{O}_{2}$ mixture at $900^{\circ} \mathrm{C}$ in the absence of water vapour. In the present work, the magnesium sulphate formed began to decompose at $891^{\circ} \mathrm{C}$ and the majority of the reaction with the sulphur dioxide occurred with the more active magnesium oxide before it had had time to.sinter. These features would explain the lack of reaction at $900^{\circ} \mathrm{C}$.

Calcium carbonate, Fig. 5.1.6, limestone, Fig. 5.1 .7 and dolomite, Fig. 5.1.9, all behaved similarly. in that the major degree of reaction with sulphur dioxide occurred as the carbonates were decomposing to form active calcium oxide. The evolution of carbon dioxide reduced the rate of reaction in some cases, presumably by hindering the access of the sulphur dioxide to the decomposed particles. In the absence of oxygen the reaction products decomposed at about $900^{\circ} \mathrm{C}$, but the oxidation to sulphate, in the presence of oxygen, 
increased the stability of the products and thus the degree of utilisation was increased. Surprisingly, Hatfield et al ${ }^{105}$ could not detect a reaction between sulphur dioxide and limestone on their TG apparatus below the calcination temperature. This may have been due to lack of.

sensitivity in their apparatus or to the design of the sample holder, or they may have chosen a particularly unreactive limestone. Though the general features of the reaction sequence for the samples of calcium carbonate, limestone and dolomite studied were similar, the dolomite was much less reactive than the other two samples. As the highest rates of reaction in the dolomite corresponded with the calcination of the calcium carbonate rather than the magnesium carbonate component, it could be presumed that the magnesium carbonate in dolomite, like free magnesium carbonate, was relatively unreactive.

Strontium carbonate and barium carbonate were thermally more stable than the other alkaline earth metal carbonates and as a result the majority of the reaction with sulphur dioxide took place with the carbonate rather than the oxide. In the case of barium carbonate, there had been total replacement of carbonate before the decomposition temperature was reached. In 2 volume-\% sulphur dioxide the final product was $98.6 \% \mathrm{BaSO}_{4}$ and $1.4 \% \mathrm{BaS}$ whereas in 0.8 volume \% sulphur dioxide it was $89.2 \% \mathrm{BaSO}_{4}$ and $10.8 \% \mathrm{BaS}$. The presence of the sulphide indicated that barium sulphite had been present originally. This sulphite had then disproportionated to form a mixture of sulphate and sulphide, though some may have been oxidised directly to sulphate by either excess sulphur dioxide or oxygen, as described in Chapter 4: Complete oxidation of the sulphide had not taken place due to the formation of an impervious sulphate coating, which prevented the reaction between the gaseous oxidant and the unreacted sulphide at the centre of the sintered particle. 
The apparently greater reactivity, at lower temperatures of the barium carbonate compared to strontium carbonate may have been due to differences in specific surface between the two samples. Though the degree of sulphur dioxide uptake by strontium carbonate (as measured by the increase in weight) was less than for barium carbonate, the thickness of the reacted layer coating the strontium carbonate (as determined from the specific surface of the sample) was much greater than the coating on the barium carbonate at temperatures up to $500^{\circ} \mathrm{C}$, Table 5.1.5. The thicker coating would reduce the rate of reaction until this effect was outweighed by the increase in rate with temperature. The thickness of the sulphite coating, as presented in Table 5.1.5 and Table 5.1.6, was based on the average area occupied by the metal sulphite. This average area was estimated by taking the mean of the areas occupied by each side of the portion of the corresponding crystal unit cell occupied by one metal sulphite group. For example, the unit cell dimensions of barium sulphite (see Chapter 3 ) were $10.12 \AA \times 11.01 \AA \times 6.55 \AA$, with eight molecules per. unit cell. Therefore each $\mathrm{BaSO}_{3}$ was contained in a sub-cell of dimensions $5.06 \AA \times 5.50 \AA \times 3.27 \AA$ giving side areas of $27.83 \AA^{2}, 16.55 \AA^{2}$ and $17.99 \AA^{2}$, with a mean value of $20.79 \AA^{2}$. This assumed that each side was equally possible as a base, though a preferred orientation may have been dictated by the crystal lattice of the barium carbonate. However, as all samples would have been affected similarly and as only large general differences were of significance, : this orientation effect was discounted.

None of the carbonates reacted very rapidly below $500^{\circ} \mathrm{C}$, but the calcium hydroxide samples, Fig. 5.1.4 and 5.1.5, reached their maximum activity at, or below, this temperature, Table 5.1.2. The enhanced reactivity at these relatively low temperatures was related to the decomposition of calcium hydroxide to form calcium oxide, which 
Table 5.1.5 Relative thickness of sulphite coating formed on barium and strontium carbonate during reaction with sulphur dioxide.

\begin{tabular}{|c|c|c|c|c|}
\hline \multirow[b]{2}{*}{ Sample } & \multirow[b]{2}{*}{$\underset{{ }^{\circ} \mathrm{C}}{\text { Temp. }}$} & \multicolumn{3}{|c|}{ Number of layers* of sulphite formed in } \\
\hline & & $\begin{array}{l}2 \text { vol- } \% \mathrm{SO}_{2} \\
+\mathrm{N}_{2} \\
\end{array}$ & $\begin{array}{c}0.8 \text { vol- } \% \mathrm{SO}_{2} \\
+\mathrm{N}_{2} \\
\end{array}$ & $\begin{array}{r}0.8 \text { vol\% } \mathrm{SO}_{2}+ \\
8.2 \text { vol\% } \mathrm{O}_{2}+\mathrm{N}_{2} \\
\end{array}$ \\
\hline \multirow{2}{*}{$\begin{array}{l}\text { Strontium } \\
\text { carbonate }\end{array}$} & 400 & 34 & 22 & 20 \\
\hline & 500 & 91 & 98 & 54 \\
\hline \multirow{2}{*}{$\begin{array}{l}\text { Barium } \\
\text { carbonate }\end{array}$} & 400 & 6 & 2 & 2. \\
\hline & 500 & 37 & 26 & 25 \\
\hline
\end{tabular}

*Assuming average area occupied by $\mathrm{SrSO}_{3}$ group is $20.0 \AA^{2}$ and by $\mathrm{BaSO}_{3}$ group is $20.8 \AA^{2}$.

Table 5.1.6 Relative thickness of sulphite coating formed on calcium hydroxide and Limbux, at $300^{\circ} \mathrm{C}$ during reaction with sulphur dioxide.

\begin{tabular}{|c|c|c|}
\hline \multirow{2}{*}{ Gas composition } & \multicolumn{2}{|c|}{ No. of layers* of sulphite formed on } \\
\cline { 2 - 3 } 2 vol- $\mathrm{SO}_{2}+\mathrm{N}_{2}$ & 13 & Calcium hydroxide \\
\hline 0.8 vol- $\mathrm{SO}_{2}+\mathrm{N}_{2}$ & & 5 \\
\hline $0.8 \mathrm{vol}-\mathrm{SO}_{2}+8.2$ vol\% $\mathrm{O}_{2}+\mathrm{N}_{2}$ & 8 & 3 \\
\hline
\end{tabular}

*Assuming average area occupied by $\mathrm{CaSO}_{3}$ group is $19.5 \AA^{2}$. 
was completed by the time the temperature had risen to $500^{\circ} \mathrm{C}$. Even before the decomposition of calcium hydroxide was under way, the rate of reaction with sulphur dioxide was increasing rapidly, particularly in the case of Limbux which had the high initial specific surface of $14.2 \mathrm{~m}^{2} \mathrm{~g}^{-1}$, cf. $4.9 \mathrm{~m}^{2} \mathrm{~g}^{-1}$ for the $\mathrm{BDH}$ calcium hydroxide. However, the more rapid reaction between sulphur dioxide and Limbux was not in direct proportion to its greater specific surface and, as Table 5.1.6 illustrated, the relative degree of coverage of the Limbux was lower. Apart from the rather more rapid initial reaction there was little difference between these two types of calcium hydroxide. Limbux was rather more reactive at lower temperatures and had higher utilisation factors, except for the rather greater reactivity of the calcium hydroxide, in the presence of oxygen, above $600^{\circ} \mathrm{C}$. The reactivity of the prepared calcium oxide, Fig. 5.1.2, was similar to that of Limbux up to $350^{\circ} \mathrm{C}$, but the rate of reaction then decreased. Limbux began to dehydrate extensively above this temperature, thus providing new active lime to react with the sulphur dioxide and also disrupting the surface sulphite coating which had formed. This production of fresh surface and breaking-up of the surface coating was not as effective in the calcium oxide sample; therefore, the rate of reaction dropped until the temperature rose above $500^{\circ} \mathrm{C}$. Above this temperature, disproportionation and oxidation reactions became important and the volume changes caused by these reactions disrupted the surface coating of sulphite enough to allow access of the reacting gases and an increase in reaction rate. As the temperature continued to rise, the formation of calcium sulphite came to an end as its decomposition temperature was reached; further weight increases, in the absence of oxygen, were due to oxidation of sulphide and any undecomposed sulphite remaining. 
In the absence of oxygen, only about $50 \%$ of the calcium oxide had reacted before final decomposition of the products commenced at about $900^{\circ} \mathrm{C}$. In the presence of oxygen, a similar proportion of the calcium oxide had reacted at $900^{\circ} \mathrm{C}$, but because the product was essentially all sulphate, which was stable at this temperature, the reaction continued so that $73 \%$ of the calcium oxide had reacted at $1086^{\circ} \mathrm{C}$. ICI quicklime, Fig. 5.1.3, with a specific surface $0.77 \mathrm{~m}^{2} \mathrm{~g}^{-1}$, cf $4.99 \mathrm{~m}^{2} \mathrm{~g}^{-1}$ for calcium oxide, was less reactive, but showed a similar pattern of reactivity, with a maximum at $450-500^{\circ} \mathrm{C}$ followed by a reduction in rate and a second maximum at about $700^{\circ} \mathrm{C}$. Though the initial reactivity of the ICI quicklime was low, the quantity of sulphur dioxide absorbed by $500^{\circ} \mathrm{C}$ was about the same as that absorbed by the prepared calcium oxide. This somewhat later higher reactivity of the ICI quicklime may have been due to the dehydration of the $6 \%$ calcium hydroxide, which was present in the sample, providing active sites for the reaction with sulphur dioxide.

\section{1 .2 Industrial applicability}

A general comparison of the results obtained for the various solid absorbents indicated that only calcium oxide or calcium hydroxide could be reasonably considered as desulphurising agents for use below $500^{\circ} \mathrm{C}$. The same compounds would still have considerable activity just below $400^{\circ} \mathrm{C}$ - a temperature at which flue gases leave the economiser in electricity power plants ${ }^{47}$. However, in this temperature range, the reactivity of the commercially produced quicklime was not so great as that of the commercially produced calcium hydroxide. Therefore, on criteria of reactivity, the use of Limbux would be favoured.

The general trend with all samples was that the rate of reaction was dependent upon the concentration of sulphur dioxide, 
but the extent to which this influenced the rate varied between samples. Isothermal studies have shown that the uptake of sulphur dioxide by calcium oxide was first order with respect to the concentration of sulphur dioxide at $915^{\circ} \mathrm{C}^{28}$ and at $870^{\circ} \mathrm{C}^{30}$, but under non-isothermal conditions considerable scatter in the results was found ${ }^{22}$. The presence of oxygen increased the oxidation reaction at higher temperatures, as indicated by the rate curve for the oxygen-containing gas mixtures becoming markedly above that for the equivalent oxygenfree gas mixture. This greater conversion to sulphate also increased the stability of the solid product, so that measurable weight losses did not occur until a higher temperature had been reached.

For higher temperature desulphurisation reactions (above $700^{\circ} \mathrm{C}$ ), the calcium carbonate-based reactants would appear to be the most satisfactory, though strontium carbonate was also most reactive at about $800^{\circ} \mathrm{C}$. The high activity of the calcium carbonates was due to the decomposition of the carbonate to produce very active calcium oxide which could react rapidly with sulphur dioxide.

In general, the utilisation factors for the various absorbents were not high, with the notable exceptions (i) of strontium and barium carbonate, where there was effectively $100 \%$ utilisation based on metal to sulphur as opposed to metal to sulphate ratios, and (ii) in the presence of oxygen where the greater stability of the sulphate product allowed reactions to proceed to a higher temperature and for longer periods. One of the drawbacks of dry flue gas desulphurisation methods has been the relatively low degree of utilisation of the solid absorbent, as out lined in Chapter 1, related to the relatively low gas/solid contact times and the variations in rates of reaction with temperature. These features have been clearly illustrated in the present studies. 


\subsection{Porosity Changes in Calcined Limbux}

The greater reactivity of the calcium hydroxide samples at temperatures lower than those required for the other solid absorbents was related to the simultaneous formation of calcium oxide. Solid/gas reactions, of necessity, are influenced by the ability of the gas molecule to come in contact with reactive sites in the solid, and, as a layer of reaction product builds up on the surface of the solid, these reactive sites become more isolated from the gas unless channels of easy access are kept open. These channels are often provided by the pore structure of the solid. It was therefore decided to carry out an initial study of the porosity developed in freshly calcined Limbux and the changes which occurred in this structure on reaction with sulphur dioxide.

Samples of Limbux were heated in vacuo, at a heating rate of $8^{\circ} \mathrm{C} \min ^{-1}$, up to $510^{\circ} \mathrm{C}$ and held at this temperature. The total time between the commencement of heating and the end of the calcination period was two hours. Because of spurting problems it was not possible to use the TG balance to monitor the weight changes during this part of the process or subsequent treatments. Nitrogen was slowly admitted over a period of 10 minutes and the temperature of the sample was adjusted to the required value. The sulphur dioxide and/or nitrogen gas mixture was passed over the specimen for a fixed time. Then, the sample was cooled rapidly, in a nitrogen atmosphere, by removing the furnace. A weighed portion was transferred to the sorption balance and the nitrogen isotherms were determined gravimetrically. The sorption isotherms all had similar characteristics to that illustrated in Fig. 5.2.1.

The specific surfaces of the samples were calculated by the 
Figure 5.2.1 Isotherm of calcined Limbux $\left(500^{\circ} \mathrm{C}\right.$ in vacuo) after $5 \mathrm{~min}$. in nitrogen at $500^{\circ} \mathrm{C}$

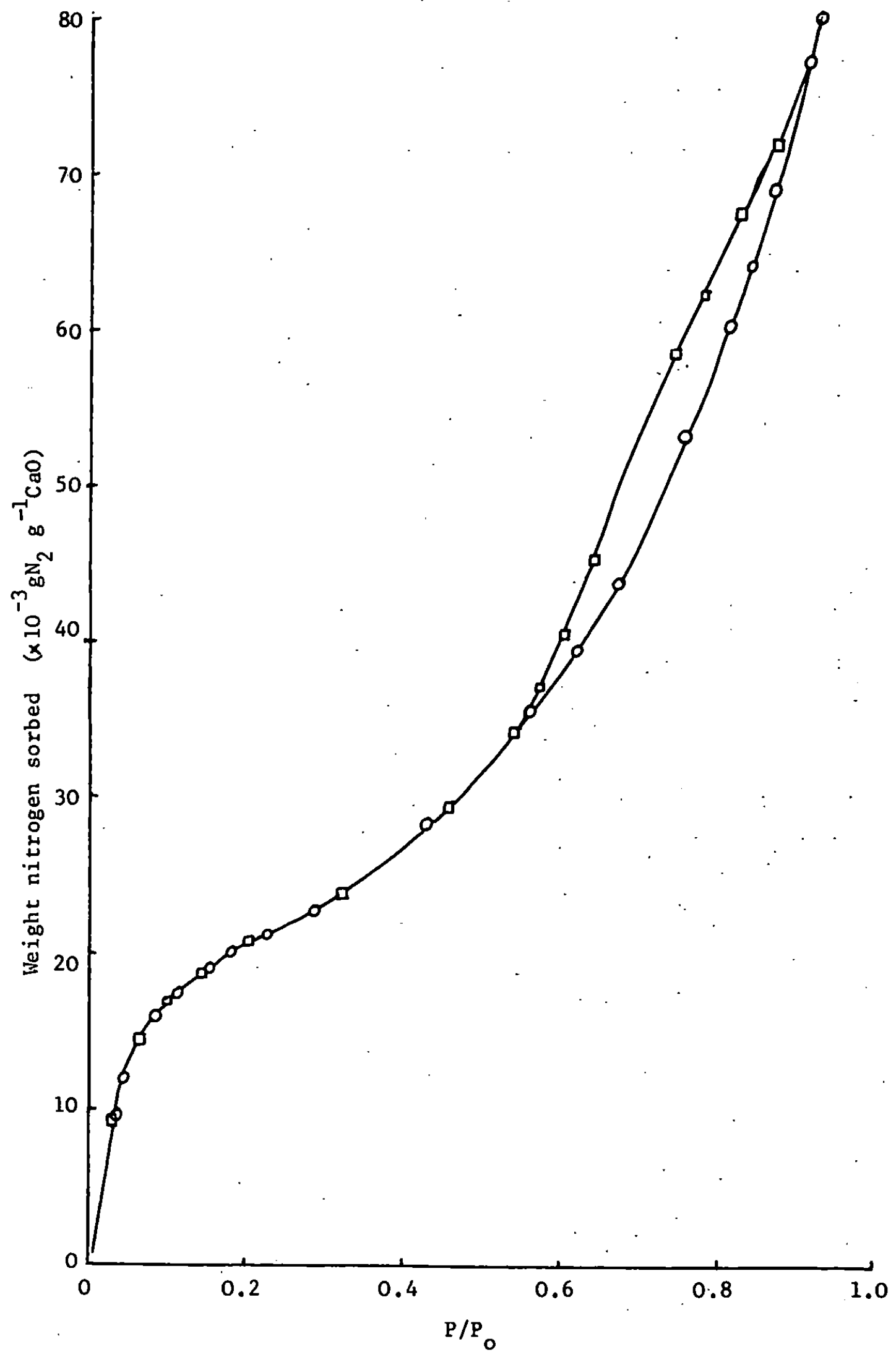

- Sorption

- Desorption 
Figure 5.2.2 Pore size distribution in calcined Limbux

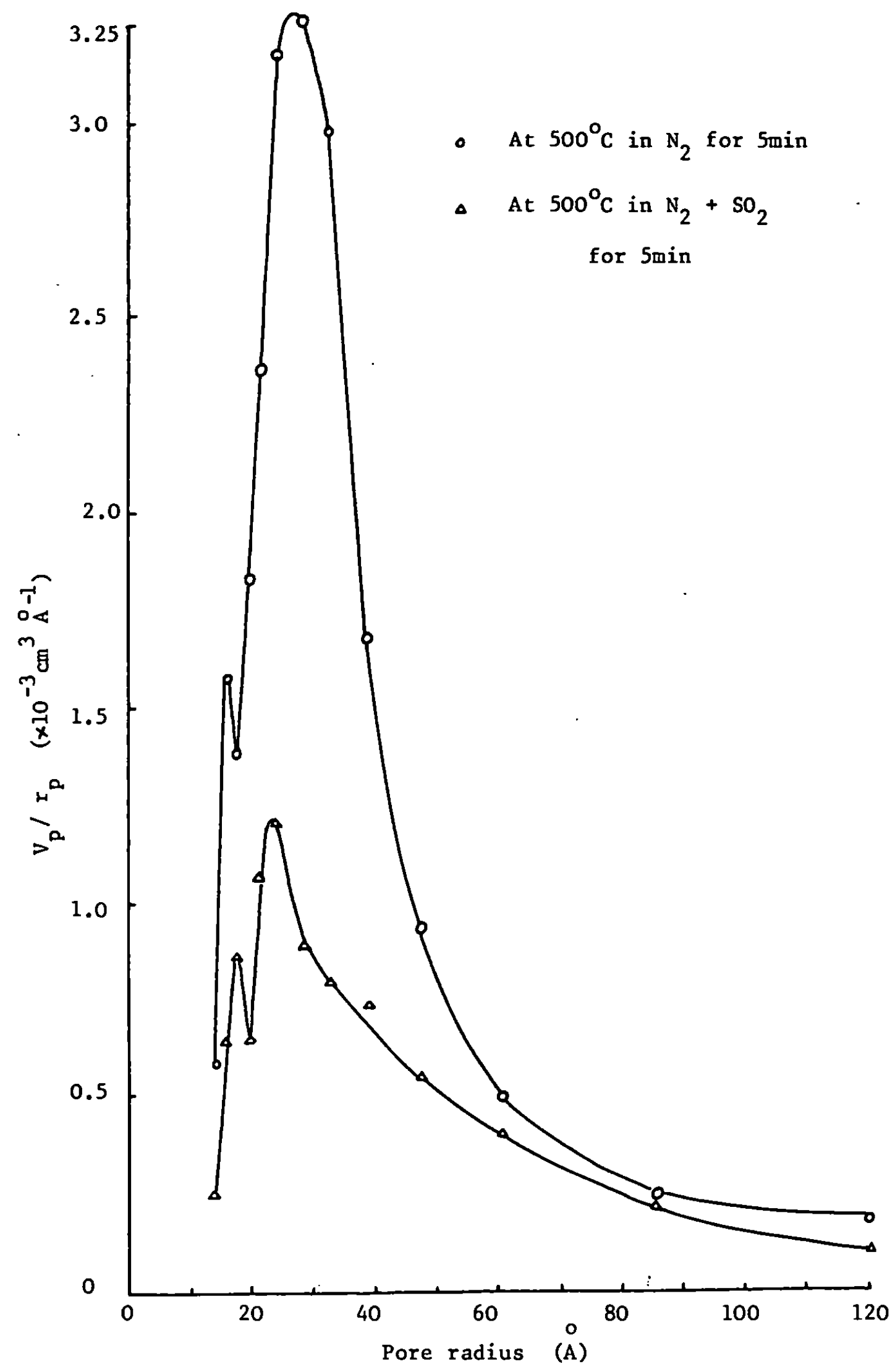


Figure 5.2.3 Pore size distribution in calcined Limbux

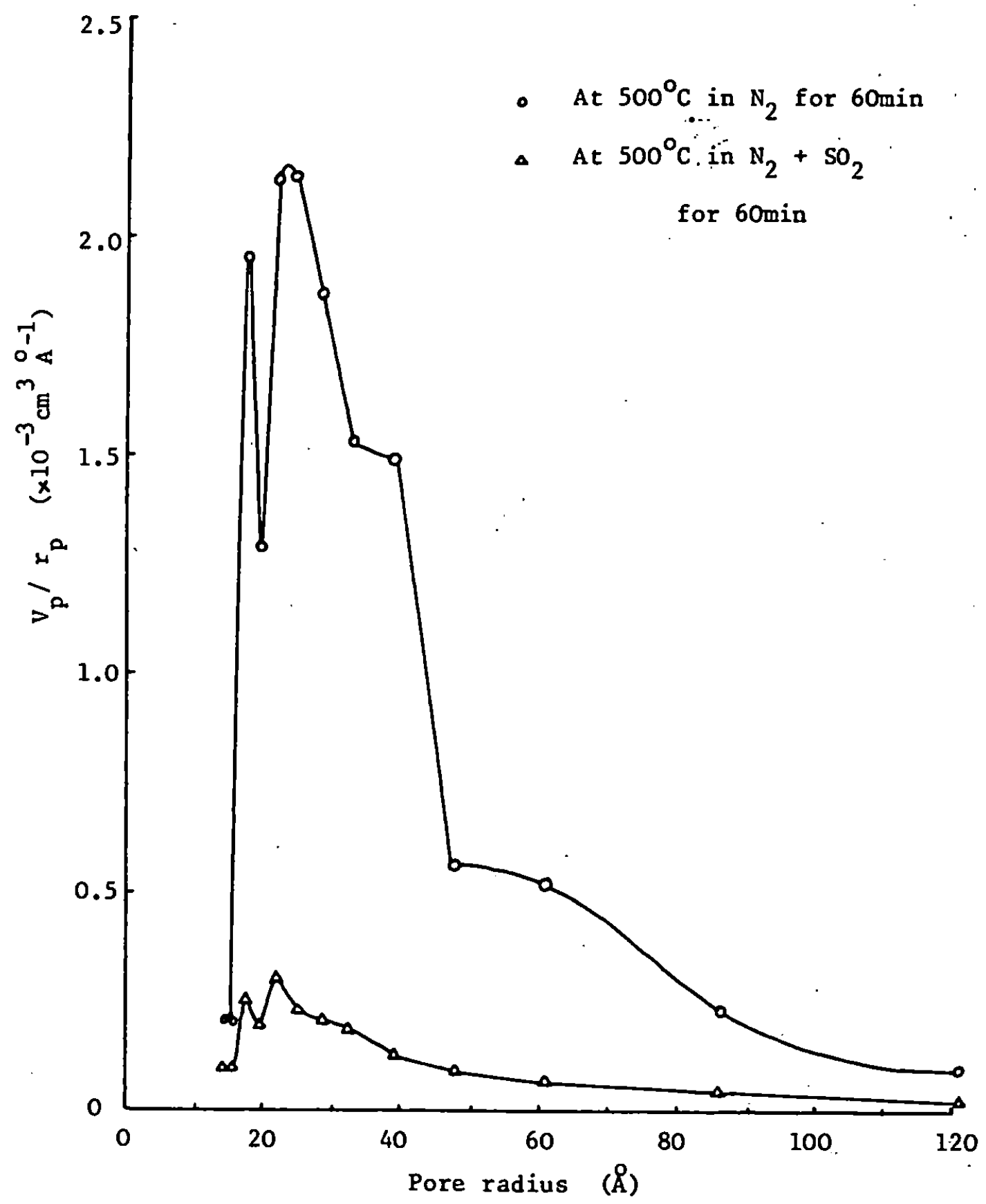


$\frac{\text { Figure 5.2.4 }}{3.5}$ Pore size distribution in calcined Limbux

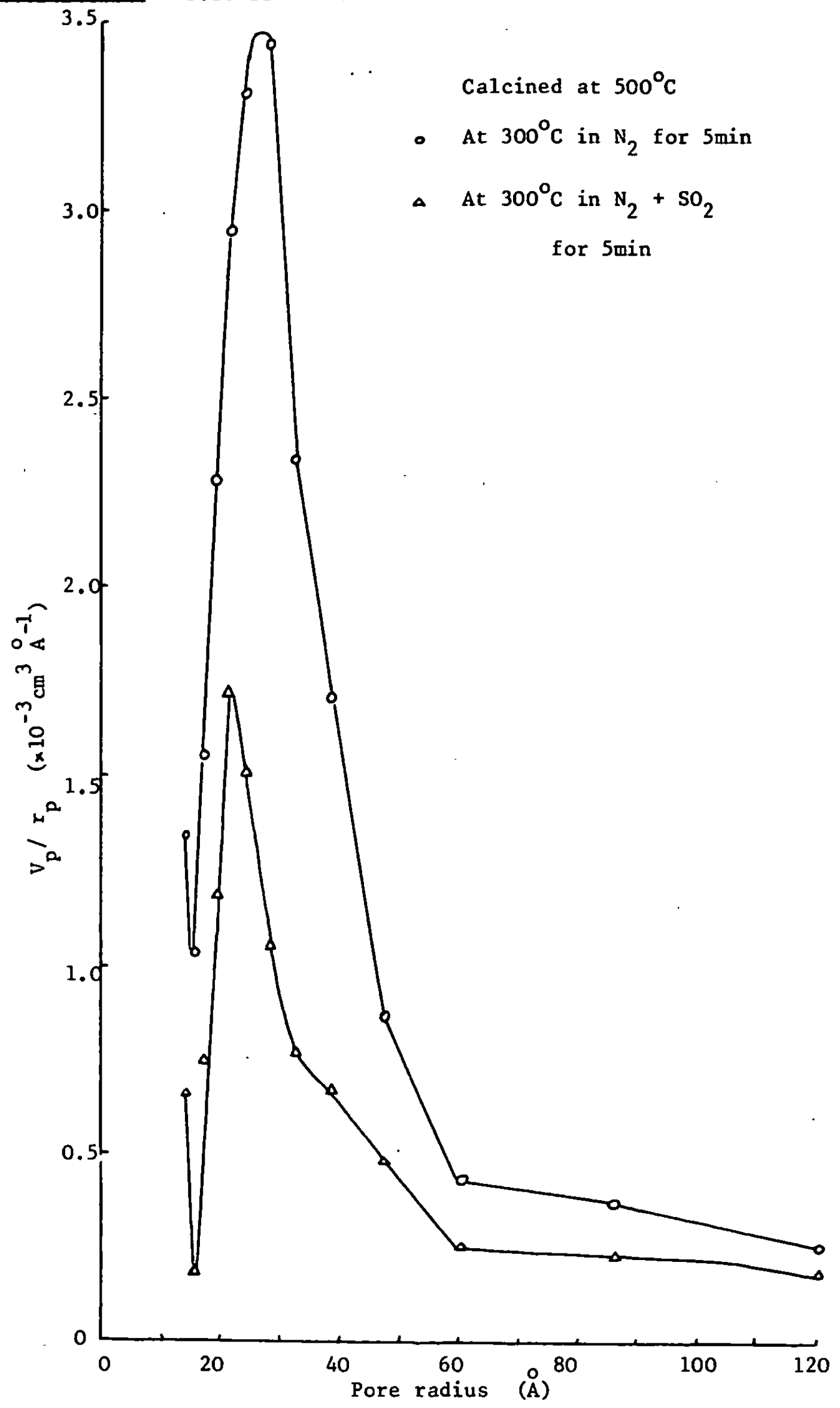




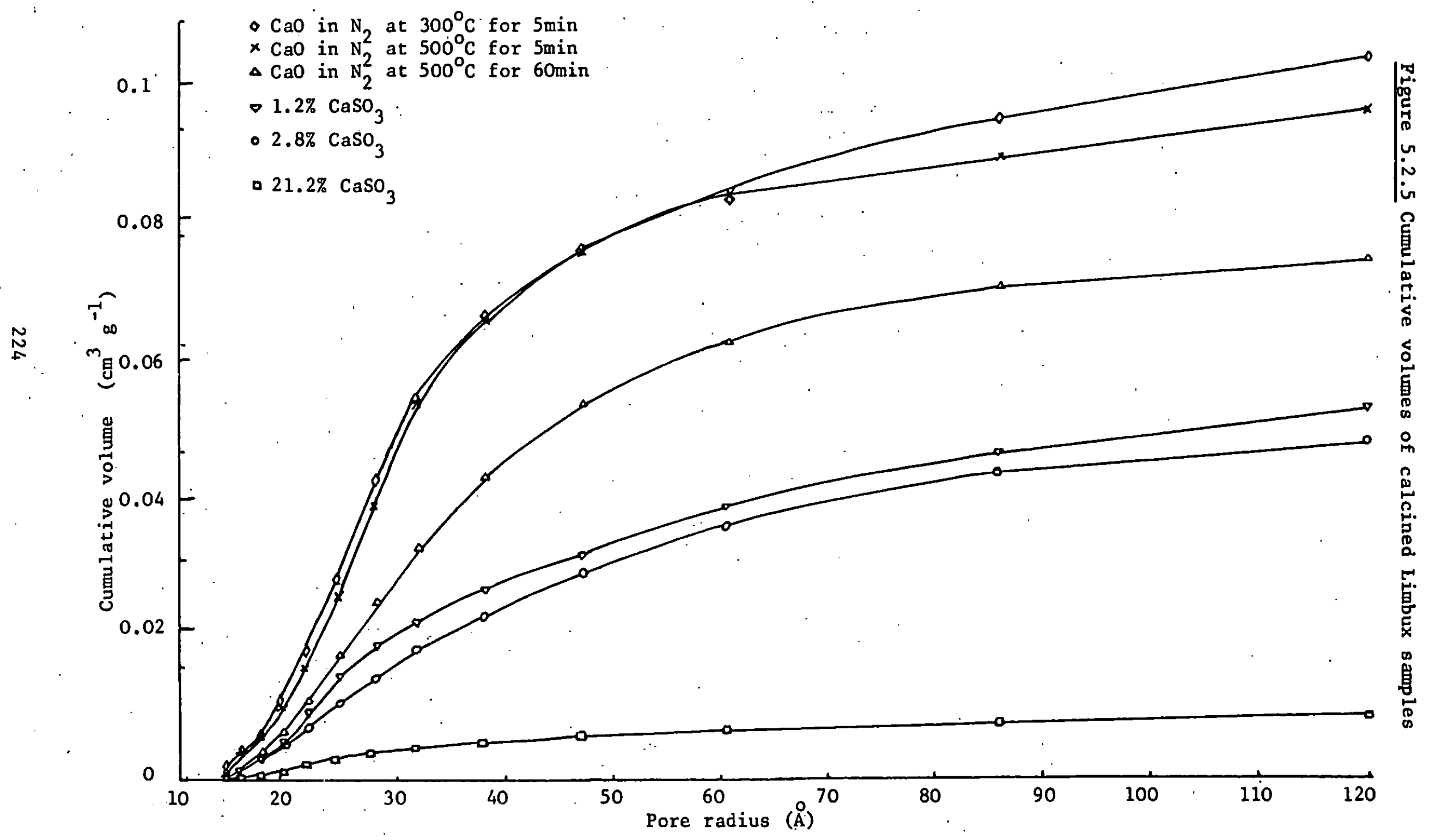


Table 5.2.1 Surface properties of samples of calcium oxide after heating in different atmospheres

\begin{tabular}{|c|c|c|c|c|c|}
\hline \multicolumn{3}{|c|}{ Heating conditions } & \multirow{2}{*}{$\begin{array}{c}\mathrm{CaSO}_{3} \\
\%\end{array}$} & \multirow{2}{*}{$\begin{array}{l}\text { Specific } \\
\text { surface } \\
m^{2} g^{-1}\end{array}$} & \multirow{2}{*}{$\begin{array}{c}\text { Cumulative } \\
\text { pore } \\
\text { volume } \\
\mathrm{cm}^{3} \mathrm{~g}^{-1}\end{array}$} \\
\hline $\begin{array}{c}\text { Gas } \\
\text { composition } \\
\text { volume }-\%\end{array}$ & $\underset{{ }^{\circ} \mathrm{C}}{\text { Temp. }}$ & $\begin{array}{l}\text { Time } \\
\text { minutes }\end{array}$ & & & \\
\hline $100 \mathrm{~N}_{2}$ & 500 & 5 & 0 & 62.2 & 0.096 \\
\hline $0.5 \mathrm{so}_{2}+99.5 \mathrm{~N}_{2}$ & 500 & 5 & 2.8 & 32.9 & 0.048 \\
\hline $100 \mathrm{~N}_{2}$ & 500 & 60 & 0 & 54.7 & 0.074 \\
\hline $0.5 \mathrm{so}_{2}+99.5 \mathrm{~N}_{2}$ & 500 & 60 & 21.2 & 9.4 & 0.009 \\
\hline $100 \mathrm{~N}_{2}$ & 300 & 5 & 0 & 64.5 & 0.104 \\
\hline $0.5 \mathrm{so}_{2}+99.5 \mathrm{~N}_{2}$ & 300 & 5 & 1.2 & 39.5 & 0.053 \\
\hline
\end{tabular}


Table 5.2.2 Distribution of pore volumes in samples of calcium oxide after heating in different atmospheres.

\begin{tabular}{|c|c|c|c|c|c|}
\hline \multicolumn{3}{|c|}{ Heating conditions } & \multirow{2}{*}{$\begin{array}{l}\text { Cumulative } \\
\text { pore volume } \\
\mathrm{cm}^{3} \mathrm{~g}^{-1}\end{array}$} & \multirow{2}{*}{$\begin{array}{l}\text { Percentage } \\
\text { of total } \\
\text { pore volume }\end{array}$} & \multirow{2}{*}{$\begin{array}{c}\text { Maximum } \\
\text { pore } \\
\text { radius } \\
\AA\end{array}$} \\
\hline $\begin{array}{c}\text { Gas } \\
\text { composition }\end{array}$ & $\begin{array}{l}\text { Temp. } \\
{ }^{\circ} \mathrm{C}\end{array}$ & $\begin{array}{l}\text { Time } \\
\text { minutes }\end{array}$ & & & \\
\hline $\begin{array}{c}\mathrm{N}_{2} \\
\mathrm{~N}_{2}+\mathrm{SO}_{2}\end{array}$ & 500 & 5 & $\begin{array}{l}0.083 \\
0.036\end{array}$ & $\begin{array}{l}87 \\
75\end{array}$ & \\
\hline $\begin{array}{c}\mathrm{N}_{2} \\
\mathrm{~N}_{2}+\mathrm{SO}_{2}\end{array}$ & 500 & 60 & $\begin{array}{l}0.063 \\
0.007\end{array}$ & $\begin{array}{l}85 \\
83\end{array}$ & 60.8 \\
\hline $\begin{array}{c}\mathrm{N}_{2} \\
\mathrm{~N}_{2}+\mathrm{SO}_{2}\end{array}$ & 300 & 5 & $\begin{array}{l}0.082 \\
0.039\end{array}$ & $\begin{array}{l}80 \\
70\end{array}$ & \\
\hline $\begin{array}{c}\mathrm{N}_{2} \\
\mathrm{~N}_{2}+\mathrm{SO}_{2}\end{array}$ & 500 & 5 & $\begin{array}{l}0.065 \\
0.023\end{array}$ & $\begin{array}{l}68 \\
49\end{array}$ & \\
\hline $\begin{array}{c}\mathrm{N}_{2} \\
\mathrm{~N}_{2}+\mathrm{SO}_{2}\end{array}$ & 500 & 60 & $\begin{array}{l}0.044 \\
0.005\end{array}$ & $\begin{array}{l}59 \\
60\end{array}$ & 38.7 \\
\hline $\begin{array}{c}\mathrm{N}_{2} \\
\mathrm{~N}_{2}+\mathrm{SO}_{2}\end{array}$ & 300 & 5 & $\begin{array}{l}0.066 \\
0.027\end{array}$ & $\begin{array}{l}64 \\
51\end{array}$ & \\
\hline $\begin{array}{c}\mathrm{N}_{2} \\
\mathrm{~N}_{2}+\mathrm{SO}_{2}\end{array}$ & 500 & 5 & $\begin{array}{l}0.026 \\
0.011\end{array}$ & $\begin{array}{l}27 \\
22\end{array}$ & \\
\hline $\begin{array}{c}\mathrm{N}_{2} \\
\mathrm{~N}_{2}+\mathrm{SO}_{2}\end{array}$ & 500 & 60 & $\begin{array}{l}0.018 \\
0.003\end{array}$ & $\begin{array}{l}25 \\
30\end{array}$ & 24.6 \\
\hline $\begin{array}{c}\mathrm{N}_{2} \\
\mathrm{~N}_{2}+\mathrm{SO}_{2}\end{array}$ & 300 & 5 & $\begin{array}{l}0.029 \\
0.014\end{array}$ & $\begin{array}{l}28 \\
27\end{array}$ & \\
\hline
\end{tabular}

(cont inued) 
Table 5.2.2

\begin{tabular}{|c|c|c|c|c|c|}
\hline \multicolumn{3}{|c|}{ Heating conditions } & \multirow{2}{*}{$\begin{array}{l}\text { Cumulative } \\
\text { pore volume } \\
\mathrm{cm}^{3} \mathrm{~g}^{-1}\end{array}$} & \multirow{2}{*}{$\begin{array}{l}\text { Percentage } \\
\text { of total } \\
\text { pore volume }\end{array}$} & \multirow{2}{*}{$\begin{array}{c}\text { Maximum } \\
\text { pore } \\
\text { radius } \\
\AA\end{array}$} \\
\hline $\begin{array}{c}\text { Gas } \\
\text { composition }\end{array}$ & $\begin{array}{l}\text { Temp. } \\
{ }^{\circ} \mathrm{C}\end{array}$ & $\begin{array}{l}\text { Time } \\
\text { minutes }\end{array}$ & & & \\
\hline $\begin{array}{c}\mathrm{N}_{2} \\
\mathrm{~N}_{2}+\mathrm{SO}_{2}\end{array}$ & 500 & 5 & $\begin{array}{l}0.010 \\
0.004\end{array}$ & $\begin{array}{r}10 \\
9\end{array}$ & \\
\hline $\begin{array}{c}\mathrm{N}_{2} \\
\mathrm{~N}_{2}+\mathrm{SO}_{2}\end{array}$ & 500 & 60 & $\begin{array}{l}0.006 \\
0.001\end{array}$ & $\begin{array}{r}9 \\
14\end{array}$ & 19.45 \\
\hline $\begin{array}{c}\mathrm{N}_{2} \\
\mathrm{~N}_{2}+\mathrm{SO}_{2}\end{array}$ & 300 & 5 & $\begin{array}{l}0.011 \\
0.005\end{array}$ & $\begin{array}{l}11 \\
10\end{array}$ & \\
\hline
\end{tabular}

Gas compositions: $\mathrm{N}_{2}$ contains $100 \% \mathrm{~N}_{2}$

$\mathrm{N}_{2}+\mathrm{SO}_{2}$ contains 99.5 vol\% $\mathrm{N}_{2}$ and 0.5 vol\% $\mathrm{SO}_{2}$ 
usual BET method 63 and the porosity characteristics determined by the method outlined in Gregg and Sing (p.162 - 172) ${ }^{64}$.

Pairs of samples were heated for similar durations at the same temperatures, with or without sulphur dioxide mixed with the nitrogen passing over them. They had the pore size distribution curves shown in Fig. 5.2.2 - 5.2.4. The cumulative volume curves for all the samples have been plotted in Fig. 5.2.5 and the specific surface, cumulative pore volumes and proportions of calcium sulphite have been listed in Table 5.2.1.

In each case, the reaction with sulphur dioxide caused a reduction in specific surface and cumulative pore volume. The pore volume distribution curves showed a marked reduction in the relative numbers of smaller pores; in Table 5.2.2, the relative proportions of pores in different size ranges have been presented. There were relatively more intermediate size pores $(20-60 \AA$ radius) in non-sulphited samples compared to the slightly sulphited samples. The more heavily sulphited sample had a small total pore volume cf. Table 5.2.1, which reflected the removal of most of the larger pores as well as the small pores.

The formation of calcium sulphite from calcium oxide would cause an increase in volume of $38.8 \%$ on a weight for weight basis and $197 \%$ on a molar volumie basis. Therefore, the formation of sulphite in the pores would produce a marked reduction in volume. The narrowest pores would soon be blocked and the intermediate pores reduced in radius. This would result in the type of changes in the distribution of pore volume actually found, i.e. an overall decrease in the number of intermediate pores. With a small amount of calcium sulphite formation, the relative effect on the large pores would be small, because the proportional reduction in radius would not be so great. Higher degrees of conversion would affect the large pores. The 
reaction of sulphur dioxide with calcium oxide would be likely to proceed more rapidly at the pore entrances, rather than inside the pore, as the sulphur dioxide would have easier access to the region closest to the pore entrance. This would result in a build-up of calcium sulphite with the narrower pore entrances becoming blocked, leading to more apparent reduction in pore volume, even though the whole pore was not filled.

The new pore volume, after the formation of a given quantity of calcium sulphite, can be calculated from the relative densities and the results for the samples studied have been given in Table 5.2.3. The actual measured pore volume was much smaller than the calculated pore volume, which would indicate that pore blocking must have taken place. The number of layers of calcium sulphite can be estimated from the specific surface of the non-sulphited sample, by the method outlined in section 5.1 assuming the average area occupied by each $\mathrm{CaSO}_{3}$ group was $19.5 \AA^{2}$. The apparent coverage, Table 5.2.4, for two of the samples was low yet the reduction in specific surface was very marked. Again, this would indicate a blocking of the pores rather than complete filling and a comparison of pore wall areas with total specific surfaces, Table 5.2.4, showed the same excessive reduction.

Though the changes in surface properties have been explained in terms of the blocking of pore entrances, the reduction in specific surfaces and pore volumes could also be influenced by increased sintering effects due to the presence of the calcium sulphite. The differences in specific surfaces and pore volumes shown by the samples heated in nitrogen alone were of the type expected from sintering. The larger changes, in the presence of sulphur dioxide, seemed more probably to have preferential pore blocking as their major cause 
Table 5.2.3 Comparison of actual and calculated pore volumes for calcium oxide heated in various atmospheres

\begin{tabular}{|c|c|c|c|c|c|}
\hline \multirow{2}{*}{$\begin{array}{l}\text { Temp. / Time } \\
\left({ }^{\circ} \mathrm{C}\right) \text { (min) }\end{array}$} & \multicolumn{2}{|c|}{ Measured volumes } & \multirow{2}{*}{$\begin{array}{l}\text { Calculated } \\
\text { volume } \\
\text { CS } \mathrm{cm}^{3} \mathrm{~g}^{-1}\end{array}$} & \multirow[b]{2}{*}{$\mathrm{MS} / \mathrm{MN}$} & \multirow[b]{2}{*}{$\mathrm{CS} / \mathrm{MN}$} \\
\hline & $\mathrm{cm}^{3} \mathrm{~g}^{-1}$ & $\mathrm{~cm}^{3} \mathrm{~g}^{-1}$ & & & \\
\hline $500 / 5$ & 0.096 & 0.048 & 0.093 & 0.50 & 0.97 \\
\hline $500 / 60$ & 0.074 & 0.009 & 0.050 & 0.12 & 0.67 \\
\hline $300 / 5$ & 0.104 & 0.053 & 0.095 & 0.51 & 0.91 \\
\hline
\end{tabular}

$\mathrm{MN}=$ measured cumulative volume for sample heated in $\mathrm{N}_{2}$

MS = measured cumulative volume for sample heated in 99.5 vol\% $\mathrm{N}_{2}$

$+0.5{\text { vol\% } \mathrm{SO}_{2}}$

CS = calculated cumulative volume for sample heated in 99.5 vol-\%

$$
\mathrm{N}_{2}+0.5 \text { vol\% } \mathrm{SO}_{2}
$$




\begin{tabular}{|c|c|c|c|c|c|c|}
\hline \multicolumn{3}{|c|}{ Gas treatment conditions } & \multirow{2}{*}{$\begin{array}{c}\text { Specific } \\
\text { surface } \\
m^{2} g^{-1}\end{array}$} & \multirow{2}{*}{$\begin{array}{l}\text { Pore wall } \\
\text { area } \\
\mathrm{m}^{2} \mathrm{~g}^{-1}\end{array}$} & \multirow{2}{*}{$\frac{\text { Pore wall area }}{\text { Specific surface }}$} & \multirow{2}{*}{$\begin{array}{c}\text { No. of } \\
\mathrm{CaSO}_{3} \text { layers }\end{array}$} \\
\hline $\begin{array}{l}\text { Temp. } \\
{ }^{\circ} \mathrm{C}\end{array}$ & $\begin{array}{l}\text { Time } \\
\text { min. }\end{array}$ & Composition & & & & \\
\hline 500 & 5 & $\mathrm{~N}_{2}$ & 62.2 & 58.6 & 0.94 & \\
\hline 500 & 5 & $\mathrm{~N}_{2}+\mathrm{SO}_{2}$ & 32.9 & 25.2 & 0.77 & 0.4 \\
\hline 500 & 60 & $\mathrm{~N}_{2}$ & 54.7 & 42.0 & 0.77 & \\
\hline 500 & 60 & $\mathrm{~N}_{2}+\mathrm{SO}_{2}$ & 9.4 & 5.3 & 0.67 & 3.8 \\
\hline 300 & 5 & $\mathrm{~N}_{2}$ & 64.5 & 61.9 & 0.96 & \\
\hline 300 & 5 & $\mathrm{~N}_{2}+\mathrm{SO}_{2}$ & 39.5 & 28.7 & 0.73 & 0.2 \\
\hline
\end{tabular}


rather than sintering, particularly as five minutes at $300^{\circ} \mathrm{C}$ or $500^{\circ} \mathrm{C}$ was a short time for extensive sintering to take place.

\subsection{Fluidised Bed Studies}

\subsubsection{Introduction}

A small number of experiments to investigate the feasibility of using a fluidised bed of absorbent to remove sulphur dioxide from a simulated flue gas were carried out.

The use of fluidised bed combustion units and the potential for combining desulphurisation with the combustion has been a subject of active study $34,109,110,111$. The method has given higher sulphur dioxide removal rates than the injection of the sorbent into a furnace. Stoichiometric quantities of lime, limestone, or dolomite have been reported $^{34}$ to remove $70-80 \%$ of the sulphur dioxide. However, the system requires the complete replacement of the conventional furnace and boiler assemblies and could on $1 \dot{y}$ be incorporated into new purposebuilt plants.

One of the reported ${ }^{102}$ problems with dry flue gas desulphurisation methods has been the poor utilisation of the sorbent due to the formation of a coating of sulphate which prevents further reaction between the sorbent particle and sulphur dioxide. A characteristic of fluidised-bed systems is that there is attrition of the particles 112 and often this is something to be avoided, i.e. materials must be chosen on the basis of their resistance to attrition. If the sulphate coating was preventing further reaction of the calcareous absorbent with sulphur dioxide, the attrition process might be useful in breaking up or removing the coating and increasing the degree of reaction. Fluidised beds should also have more controllable temperatures, which might allow desulphurising reactions to occur under optimum conditions. 


\subsubsection{Results and discussion}

Commercially available limestone from the I.C.I quarry at Tunstead, Derbyshire, was sieved to give sampies with relatively narrow particlesize ranges, as indicated in Table 5.3.1.

Table 5.3.1 Particle-size distribution of limestone samples

\begin{tabular}{|c|c|}
\hline $\begin{array}{c}\text { Particle-size range } \\
\mu \mathrm{m}\end{array}$ & $\begin{array}{c}\text { Percentage of original } \\
\text { limestone }\end{array}$ \\
\hline 1000 & 21 \\
$850-1000$ & 8 \\
$600-850$ & 14 \\
$105-600$ & 34 \\
$<105$ & 23 \\
\hline
\end{tabular}

It was necessary to have relatively narrow particle-size ranges to ensure that, when the gas flow was sufficient to fluidise the larger particles, there was not too great a loss of unreacted fines. It was found that the fraction greater than $1 \mathrm{~mm}$ in size could not be readily fluidised with the gas flows available. The "less than $105 \mu \mathrm{m}^{\prime \prime}$ fraction did not fluidise easily because of "channeling", i.e. the gas bubbles in the bed coalesced to allow the gas to stream through these open channels. This effect was enhanced by the tendency of the fine particles to form spherical aggregates, often $1 \mathrm{~mm}$ or more in diameter. It was thought that moisture sorbed on the surface of the fine particles may have been causing them to bind together, but the same phenomena occurred with samples heated to $300^{\circ} \mathrm{C}$ before fluidisation was attempted. The $105-600 \mu \mathrm{m}$ size fraction was used in subsequent runs in the presence of sulphur dioxide as it was likely to contain the most reactive, smallest particles, of the size ranges which were readily fluidisable. 
Runs were carried out at various temperatures between $210^{\circ} \mathrm{C}$ and $300^{\circ} \mathrm{C}$ with some gas mixtures containing water vapour and others without. The results, Table 5.3.2, were not very encouraging with only small degrees of sulphur dioxide uptake. Problems were encountered in keeping the temperature of the fluidised bed reasonably constant over a period of time. The monitoring of the variations in sulphur dioxide concentration in the exhaust gases was not very satisfactory. The gas analyser could only accept a proportion of the total gas flow and because of the necessity to regenerate the reagent, only intermittent gas flows could be passed through it. The consequent switching and proportioning of the gas streams made it difficult to measure the gas volumes actually passing through the analyser.

Since the initial results indicated that the method was not very promising and, because the facilities were not available to construct a more complex system (which would operate at higher temperatures and with more control of the variables), the planned work on this aspect of desulphurisation processes was abandoned.

other work ${ }^{113}$ which had been performed on similar systems suggested that particle sizes of less than $100 \mu$ were required to achieve desulphurisation. In general, the smaller the particle size the larger the fluidised bed has to be as gas velocities have to be reduced to prevent excessive elutrition ${ }^{114}$. The resulting calculations showed that for a.200 MW plant either one $54 \mathrm{~m}$ diameter fluidised bed or twenty $12 \mathrm{~m}$ diameter fluidised beds would be required (the largest operating fluidised bed was $17 \mathrm{~m}$ diameter). Installations of this order of size attached to furnaces or flue gas systems did not seem a practicable possibility. 
Table 5.3.2 Absorption of sulphur dioxide, from simulated flue gas, by limestone in a fluidised bed

\begin{tabular}{|c|c|c|c|}
\hline $\begin{array}{l}\text { Presence of } \\
\text { water vapour }\end{array}$ & $\begin{array}{c}\text { Temperature } \\
{ }^{\circ} \mathrm{C}\end{array}$ & $\begin{array}{c}\text { Time of reaction } \\
\text { minutes }\end{array}$ & $\begin{array}{c}\text { Percentage } \mathrm{SO}_{2} \\
\text { absorbed }\end{array}$ \\
\hline Present & 210 & 55 & 17.0 \\
Present & 230 & 27 & 5.4 \\
Absent & 230 & 60 & 3.6 \\
Present & 235 & 30 & 10.6 \\
Present & 245 & 85 & 8.2 \\
Present & 250 & 33 & 7.5 \\
Present & 260 & 50 & 8.7 \\
Present & 290 & 85 & 10.3 \\
Absent & 295 & 27 & 5.9 \\
\hline
\end{tabular}

Gas composition either (i) $83.2 \% \mathrm{~N}_{2} ; 9.1 \% \mathrm{O}_{2} ; 7.4 \% \mathrm{H}_{2} \mathrm{O} ; 0.30 \% \mathrm{SO}_{2}$

$$
\text { or (ii) } 89.7 \% \mathrm{~N}_{2} ; 10 \% \mathrm{O}_{2} ; 0.30 \% \mathrm{sO}_{2}
$$

(A11 volume-\%)

Temperature readings varied by $\pm 10^{\circ} \mathrm{C}$

Size range of limestone was $105-600 \mu \mathrm{m}$ 


\section{CHAPTER SIX}

THE USE OF ALKALINE EARTH. METAL COMPOUNDS FOR INDUSTRIAL FLUE GAS

\section{DESULPHURISATION PROCESSES}

\subsection{Recent Trends in Flue Gas Desulphurisation}

In the past seven years there has been a very rapid increase in the number and size of flue gas desulphurisation systems installed throughout the world. The expansion has been particularly marked in the U.S.A. and Japan, but more European countries are now investigating methods of reducing sulphur dioxide emissions. In Britain there appears to be little public pressure to change the present policy of using tall-stacks and implementing the $1956 \mathrm{Clean}$ Air Act in urban areas. The problems in Britain are somewhat less than in many industrial countries due to the combined effects of the relatively low sulphur content of the coal, usually less than $2 \%$ sulphur and often $1.5-1.6 \%$ sulphur (cf many American coals with over $4 \%$ sulphur) and the windy climate, which reduces the possibility of build-up of high concentrations of sulphur dioxide at ground level ${ }^{115}$. A review ${ }^{36}$ of flue gas desulphurisation methods published in 1969 stated that several methods were being tested in Japan and the largest unit had an equivalent capacity of $2 \mathrm{MW}$. (It is convenient to describe the capacity of flue gas systems in terms of the output from an electrical power station which would give the same volume of gas, i.e. $1 \mathrm{MW}$ is equivalent to approximately 3000 normal cubic metres flue gas per hour.) By $1971^{116}, 18$ plants had flue gas desulphurisation systems installed and a 1976 review $^{117}$ listed over three hundred installed systems with a total equivalent capacity of approximately 20,000 MW. About half this capacity was in electricity power stations and the remainder in industrial boilers or chemical works; 103 of the units used alkaline earth metal compounds and accounted for over $70 \%$ 
of the output capacity. It has been forecast ${ }^{118}$ that in the U.S.A. spending outside the electricity supply industry on flue gas desulphurisation methods will be $\$ 3 \times 10^{9}$ between 1976 and 1986 and that by $1980,30,000-40,000$ MW of electricity generation capacity will be using flue gas desulphurisation techniques and about $80 \%$ of these will be based on calcium or magnesium compounds.

\section{2 "Dry" Flue Gas Desulphurisation Systems}

The results in Chapter 5 showed that all the alkaline earth metal compounds were capable of reacting with sulphur dioxide, but none of them reacted very rapidly at any temperature below $1000^{\circ} \mathrm{C}$. Rapid reaction rates are important because the residence times of gases, and suspended solids, in industrial boiler systems are reported to be about three seconds. Improvements in rates of reaction could be achieved by (a) milling and/or (b) use of fluidised beds. As the surface areas of the samples used were as high, or probably higher, than those likely to be available in large-scale applications, improvement by increasing reactive surfaces by milling was unlikely to be made. Even though separated particles surrounded by the gas phase would react more readily than the static bed used in the TG experiments, it seems unlikely that the degree of reaction could be increased beyond that which has been found already in industrial conditions, unless the temperature of reaction could be controlled at that value where the rate was a maximum. For the calcium-based absorbents, this was the temperature at which the hydroxide or carbonate decomposed to form calcium oxide of high reactivity. The temperature of reaction could be controlled by the use of a fluidised bed introduced into the correct part of the system. This also would increase effectively the gas/solid contact time, but, as discussed in Chapter 5, the use of a fluidised bed did not seem to be a practicable solution. 
The low utilisation factors for dry flue gas desulphurisation methods have prevented their development beyond test-plants such as the one set up by the Tennessee Valley Authority and the Environmental Protection Agency in 1972 because "The main process question for power plants is whether to introduce the limestone into the boiler or into the scrubber". 119 The apparent advantage of using a lowcost absorbent which could be introduced into the furnace system with minimum of plant alteration was more than offset by the increased dust handing problems due to the inefficiency of the sulphur dioxide absorption process. The absorption of sulphur trioxide as well as sulphur dioxide meant that the surface conductivity of the dust was reduced $^{120}$ and therefore the electrostatic precipitators were not so efficient. Even if only stoichiometric quantities of limestone were injected, the precipitators had to be increased in size by factors of 2 to 3.5. Increasing the temperature at which the precipitators operated from $115^{\circ} \mathrm{C}$ to $315^{\circ} \mathrm{C}$ could reduce the size to that used before the sulphur trioxide was removed. The weight of fly ash, sulphated and unreacted sorbent to be disposed of would be about twice as great as the weight of fly ash alone. The actual ratio would depend on the proportion of absorbent injected, the degree of sulphation and the degree of subsequent hydration. As well as having to provide increased dust removal equipment, the inefficiency of the dry absorption process would entail increased transport facilities into the site. Using the example of a 2000 MW CEGB power station burning $1.9 \%$ sulphur coal, it has been estimated ${ }^{121}$ that 98 tons/hour of limestone would be required when the station was operating at full load. This would give a requirement of about 1650 tons/day of limestone for an average loading of $70 \%$, which would entail a fairly substantial increase in space for storage and delivery. As the coal requirement would be about 14,000 tons/day, it is surprising that this $12 \%$ increase was 
thought to produce so many problems of access to British sites ("The increase in rail traffic to the site would require additional sidings, the siting of which proved extremely difficult in all cases and technically impossible in several.") 121

\section{3 "Wet" Flue Gas Desulphurisation Systems}

"Wet" scrubbing methods based on lime and/or limestone slurries have become the dominant processes in use in both the U.S.A. and Japan, despite early doubts about these processes. The wet processes have much higher desulphurisation efficiencies and absorbent utilisations than the dry processes, due to faster and more complete absorption reactions in solution, and these have proved the critical factors in their acceptance. The Americans have disposed of the sulphated product as a wet sludge mixed with the fly ash whereas many of the Japanese processes are designed to produce gypsum, $\mathrm{CaSO}_{4} \cdot 2 \mathrm{H}_{2} \mathrm{O}$, as a saleable product.

The throwaway process requires less operational control, prescrubber clean-up and equipment than other desulphurisation processes, but produces very large quantities of waste. The area of 1 and for the storage of the waste produced over 20 years by a 1000 MW station has been estimated ${ }^{122}$ to be $1.3-1.7 \mathrm{mile}^{2}$, if a depth of ten feet of sludge is used. The dewatering of the sludge to levels below $50 \%$ has proven very difficult due to the thin plate-like crystals of calcium sulphite hemihydrate. Treatment of the sludge with $3 \%$ of lime causes it to set, as the water is taken up in crystal structures, due to (i) the reaction of calcium oxide with the soluble sulphate ions to form gypsum; (ii) the formation of insoluble sulphoaluminates, e.g. ettringite, $\mathrm{Al}_{2} \mathrm{O}_{3} \cdot 3 \mathrm{CaSO}_{4} \cdot 31 \mathrm{H}_{2} \mathrm{O}$, or sulphoferrites, by the reactions between calcium oxide, sulphate and fly ash; (iii) the formation of 
calcium silicates, e.g. tobermorite, by the reaction of calcium oxide with'silica in the fly ash. As well as providing a more satisfactory solid land-fill, the hardening of the sludge reduces the effects of water pollution due to escape of soluble ions from the storage ponds. The production of a saleable product such as gypsum overcomes the extra waste-disposal problem but increases the plant complexity and operating costs. In Japan, an increase of about $30 \%$ on capital costs has been found ${ }^{117}$. The size of the credit for sale of the product depends upon the market size and, again in Japan, the gypsum market has reached the limit of what can be sold without over-supplying the demand and causing a collapse in the price. The reclaiming of the sulphur and conversion into a useable product requires the producing company to enter the field of the chemical industry and develop specialised marketing knowledge, if maximum return on its investment is to be attained. The production of a saleable product still involves the supply of large quantities of sulphur dioxide absorbent, unless a process is developed in which the sulphur can be separated from the absorbent and this is then recycled.

The properties required for an absorbent suitable for recycling include: (i) ability to react rapidly with sulphur dioxide in the temperature range $150-1750^{\circ} \mathrm{C}$, but preferably between $150^{\circ} \mathrm{C}$ (flue gas temperature) and $400^{\circ} \mathrm{C}$ (upper temperature at which gas leaves economiser). The latter conditions would allow the sorption system to be incorporated with the minimum upset to the heat extraction system. If the sulphur trioxide was also removed the lower temperature could be reduced to $120^{\circ} \mathrm{C}$ as this would give sufficient buoyancy to the plume, and the lack of sulphur trioxide would remove acid deposition problems. (ii) The regeneration of the absorbent would take place at a temperature below about $800^{\circ} \mathrm{C}$, to keep costs of regenerator construction 
materials and energy input low. (iii) If the absorption of sulphur dioxide occurred below $400^{\circ} \mathrm{C}$, the ideal regeneration might be by thermal decomposition above $400^{\circ} \mathrm{C}$ or by the use of a cheap reducing agent.

Examination of the thermal stabilities of the alkali earth metal sulphites, as described in Chapter 3 , indicates that magnesium sulphite decomposes to magnesium oxide below $800^{\circ} \mathrm{C}$ in non-oxidising conditions, though some sulphate is formed also by disproportionation. However, as the results in Chapter 4 indicate, the reactivity of dry magnesium compounds for sulphur dioxide is not high and the reaction which does take place, in the presence of air, involves mainly sulphate formation. Magnesium oxide slurries have been used commercially 123,124 and they produce a mixture of magnesium sulphite hexahydrate and trihydrate together with some magnesium sulphate. These are thermally decomposed at $650^{\circ} \mathrm{C}$ in the presence of carbon which reduces the magnesium sulphate. The properties of calcium sulphite are such that it could be considered for a regenerative process. In the absence of air, calcium sulphite partially decomposes to calcium oxide above $700^{\circ} \mathrm{C}$, but most of the decomposition occurs above $900^{\circ} \mathrm{C}$ because some of the sulphite disproportionates to a more thermally stable mixture of sulphate and sulphide. The sulphate/sulphide mixture decomposes at a lower temperature than either calcium sulphate or calcium sulphide alone. The use of calcium hydroxide as a sulphur dioxide absorbent at about $400^{\circ} \mathrm{C}$ would give mainly a sulphite product, whereas the use of calcium compounds at higher temperatures would lead to sulphate formation due to oxidation of the initially formed sulphite. The presence of sulphate would require the use of a reducing agent in the regeneration process, but it has been suggested ${ }^{130}$ that partial reduction of sulphate to sulphide, to produce the 3 to 1 sulphate to sulphide ratio of a 
disproportionated calcium sulphite, would be sufficient. The sulphate/ sulphide mixture could then be thermally decomposed at about $950^{\circ} \mathrm{C}$ to yield calcium oxide. Wet scrubbing leads to extensive calcium sulphite hemihydrate formation, but the technical problem which is encountered is the separation of the fine crystals from the liquid. If the hemihydrate could be separated, the regeneration by mixed thermal and reducing decomposition might be practicable. Unlike magnesium sulphite hexahydrate, the relative amount of water to be driven off is not great, thus, even though the calcining temperature would be higher, the total energy output would not necessarily be higher. The thermal stabilities of strontium and barium sulphites do not appear favourable for decomposition reactions and their use would also entail health and cost problems.

The advantages of a desulphurising method incorporating the regeneration of the absorbent are that the material transport and disposal problems are very much reduced. The quantities of sulphur products available from large scale flue gas desulphurisation are such that they will have a major effect in the market price for whatever sulphur compound is being sold. It would appear, therefore, that in general the aim should be to produce elemental-sulphur, which can be used as a source of sulphur compounds, or can be conveniently stored, if it is not economical to sell it. In Britain, about 75,000 tons sulphur per year per $2000 \mathrm{MW}$ capacity are emitted ${ }^{47}$. For a $90 \%$ desulphurisation process, this would mean producing annually about 67,500 tons sulphur, or 210,000 cons $98 \%$ sulphuric acid, or at least 700,000 tons wet sludge. The storage requirements for the sulphur are only about one-tenth those for wet sludge. The weight of a dry throwaway absorbent will be similar to the product from the wet process 
because the lower efficiency of the dry process will require more absorbent to be used. The disadvantages of the recoverable absorbent processes are that technically they are much more complex, capital costs are higher, running costs are likely to be higher, particularly due to their increased energy demand. However, the throwaway processes have "hidden" energy costs in that the sorbent must be mined or manufactured and transported to the site, and the sludge must be transported away from the site and, possibly, subsequently treated.

A comparison of the advantages and disadvantages of the various desulphurisation processes discussed is given in Table 6.1.

\subsection{Economics of Flue Gas Desulphurisation Systems}

Comparison of the actual costs of flue gas desulphurisation processes with the estimated costs shows that the initial estimates were over-optimistic as the following examples illustrate. The $70 \mathrm{MW}$ Paddy's Run Plant, of Louisville Gas and Electric, was estimated ${ }^{125}$ in 1972 to cost $\$ 22 / \mathrm{kw}$ for a lime scrubber system. This estimate was later increased to $\$ 28.6 / \mathrm{kw}$ and when installation was completed, in 1973 , the actual cost was $\$ 57 / \mathrm{kw}^{126}$. Similarly, the $176 \mathrm{MW}$ Commonwealth Edison Will County No. 1 unit was estimated in 1972 to cost $\$ 49 / \mathrm{kw}^{126}$; this was later updated to $\$ 72 / \mathrm{kw}^{125}$, and the final cost when completed, in late 1972 , was $\$ 95 / \mathrm{kw}$ plus $\$ 13 / \mathrm{kw}$ for the sludge treatment system giving an overall cost of $\$ 108 / \mathrm{kw}^{126,127}$. The running costs of the plants were also higher than estimated. Using Will County No. 1, again, as an example, the running cost estimate was $0.27 \mathrm{cent} / \mathrm{kWh}$ (at the time of the $\$ 72 / \mathrm{kw}$ capital estimate), whereas, after two years of operation, the estimated cost for a $60 \% 10$ ad factor was 0.73 cent $/ \mathrm{kWh}$. In fact, the unit was only working intermittently during these first two years and the actual operating cost was 1.02 cent/kWh. Almost $30 \%$ of the operating costs were taken up by sludge disposal. 
Table 6.1 Comparison of "dry" and "wet" flue gas desulphurisation cethods

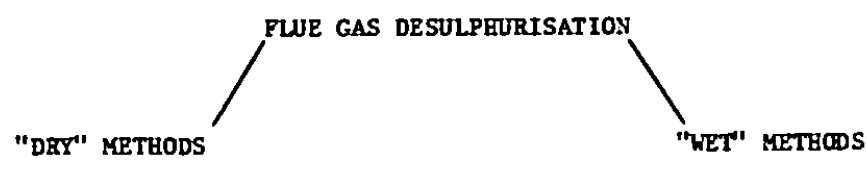

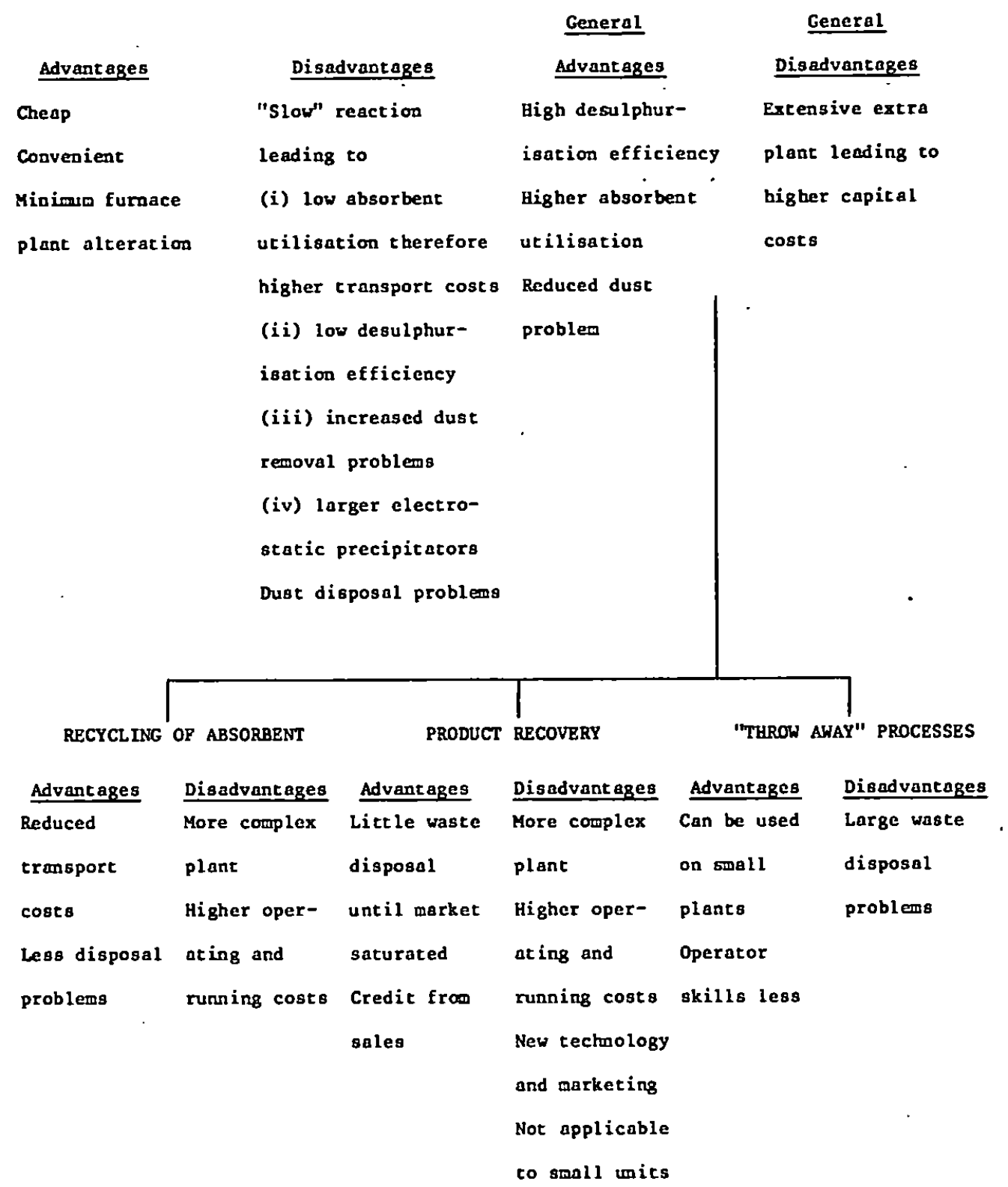


A survey ${ }^{118}$ published in 1977 of the actual installed costs of 45 flue gas desulphurisation systems in the U.S.A. shows a range from $\$ 24.4 / \mathrm{kw}$, for a limestone slurry scrubbing system which only treats half of the emitted flue gas, to $\$ 129 / \mathrm{kw}$ for a scrubbing system based on sodium sulphite. The average cost was $\$ 79 / \mathrm{kw}$. These costs did not always include further particulate control systems which could add $\$ 20$ million to the cost, i.e. $\$ 20 / \mathrm{kw}$ for a $1000 \mathrm{MW}$ plant. This latter figure corresponds with other estimates ${ }^{127}$ for electrostatic precipitators of $\$ 15-25 / \mathrm{kw}$.

The differences between early estimated costs, which were made before the problems of installation of full-scale plants were realised, and the actual installed costs reflect the size of the problems encountered. A number of authors ${ }^{126,127,128}$ have commented on the actual difficulties in commissioning plants in the U.S.A. and it has been reported 128 that at the end of 1975 only about $25 \%$ of the plants were operating satisfactorily: However, when the Japanese experience is examined, it is found that the majority of the plants installed, even though often technically more complex than those in the U.S.A., had fewer commissioning problems and most were operating satisfactorily ${ }^{117}$. As the same types of process, mainly based on wet lime/limestone scrubbing, were being used in both countries the differences are surprising, because the same chemical and technical principles must apply. The difference in the social and legal climate in the two countries is such that a company, in Japan, which does not comply with the sulphur dioxide limits can be closed down almost immediately, whereas, in the U.S.A., the Environmental Protection Agency has to show that its limits are achievable and the legal enforcement of the regulations may take several years, during which time the company can continue to operate. 
Because of the wide variation in capital costs, which depend upon both the process chosen and the site involved, average values for these costs are of little help in predicting what the costs at a particular site will be. In general, the cost of flue gas desulphurisation appears to add $20-30 \%$ to the cost of generating electricity whether a throw-away or saleable process is used 117,126 . It has been argued 129 that continuous reduction in sulphur dioxide emission levels is unnecessarily expensive as the ground levels only occasionally reach high values. The extent of sulphur dioxide removal facilities which needed to be added to a plant could be much reduced, if only partial removal was required as dictated by meteorological conditions. The U.S.A. costings quoted previously indicate the massive savings possible when only a portion of the flue gas is desulphurised - cost was only about a third of the average and a fifth of the most expensive system. The change to intermittent control would require the installation of a real-time sulphur dioxide and meteorological monitoring system, to provide the information for when desulphurisation should take place, and this would increase both the capital and running costs of the intermittent flue gas desulphurisation process.

As the prevention of sulphur dioxide entering the atmosphere means that sulphur compounds must be transferred to either the 1 and or water systems, all that may have been achieved is to convert one form of pollution into another form. The atmosphere has the advantage as a dispersal medium that it is usually capable of dispersing the sulphur dioxide widely thus keeping the levels low. The introduction of an intermittent desulphurisation system would continue to make use of the atmospheric dilution effect and reduce the concentrated land or water disposal problems. 


\section{CHAPTER SEVEN}

\section{CONCLUSIONS}

The investigations carried out have been presented in some detail in previous chapters of this thesis and the conclusions reached are brought together in the following pages.

The structures of calcium, strontium and barium sulphites appear to be similar, being orthorhombic and closely related to the structure of calcium sulphite hemihydrate. The changes in unit cell dimensions on passing from calcium sulphite to strontium sulphite to barium sulphite are of the order to be expected, based on the changes in octahedral ionic radii of the elements concerned.

The thermal stabilities of the alkaline earth metal sulphites were shown to vary with changes in the gaseous atmospheres surrounding the samples. The dehydration of the hydrated magnesium and calcium sulphites enhanced the reactivity of the resulting anhydrous sulphites. In non-oxidising atmospheres there was competition between (a) reactions leading to oxide formation and (b) disproportionation reactions, leading to the formation of a mixture of sulphate and sulphide. However, there were also a number of other side reactions occurring in some cases, e.g. formation of magnesium thiosulphate. The relative importance of the disproportionation reaction became greater as the atomic number of the cation increased. The temperature range over which disproportionation took place was similar for all the alkaline earth metal sulphites, but the thermal stability with respect to decomposition to oxide increased with atomic number; therefore; the relative position of the two reaction temperature ranges changed from (a) decomposition to oxide being below the disproportionation temperature range for magnesium sulphite to (b) the decomposition to 
oxide range being largely above the disproportionation range for barium sulphite. A mechanism, based on the arrangement of the species in the crystal lattices of the original sulphites, was proposed which suggested how the possible phases, found in the different reactions, could be formed.

In the presence of atmospheres containing oxidising agents (oxygen or sulphur dioxide) additional reactions were found. The sulphite could be oxidised to sulphate as could the sulphide formed by disproportionation. One result was to raise the temperature for the final decomposition to oxide, because of the greater thermal stability of the sulphate compared to either the sulphite or the sulphate and sulphide mixture formed by disproportionation.

The reactivity with sulphur dioxide was studied for a number of alkaline earth metal compounds, including naturally-occurring forms such as limestone and dolomite as well as large-scale manufactured industrial products such as Limbux and quicklime. All the substances used reacted to some extent with sulphur dioxide, but magnesium carbonate had a particularly low reactivity due to the low thermal stability of magnesium sulphite. None of the rates of reaction were high when consideration of the short residence times likely to be found in boiler systems is taken into account. The greatest reactivity amongst the calcium-based compounds was shown when the carbonate, or hydroxide, decomposed to form fresh, highly active calcium oxide. Reaction rates below $400^{\circ} \mathrm{C}$ were only appreciable with calcium hydroxide, and to a lesser extent calcium oxide. The presence of oxygen increased the degree of utilisation of the absorbent but did not appreciably affect the rate of sulphur dioxide uptake. This increase in utilisation arose from the oxidation of sulphite to produce the more thermally stable sulphate, which, 
because it decomposed at a higher temperature, allowed more time for: reaction to occur. Gas sorption measurements, made on freshly prepared calcium oxide samples, which had been reacted with sulphur dioxide, indicated that a surface layer of calcium sulphite was formed, which blocked the entrances to the narrower pores giving a rapid decrease in specific surface as the reaction proceeded.

The use of fluidised beds to.desulphurise flue gases did not seem to be a practicable proposition using alkaline earth metal compounds of greater than 100 micron particle size due to the poor reactivity of these compounds at low temperatures.

The development of a re-usable absorbent method for flue gas desulphurisation depends upon a reactive absorbent forming a product which is thermally unstable at not too high a temperature (approximately $1000^{\circ} \mathrm{C}$ ) either alone or in the presence of some relatively cheap chemical reactant. For dry desulphurisation methods only calcium compounds could possibly fit these requirements and a reductant such as hydrogen or carbon monoxide would be required for regeneration to the oxide, because any calcium sulphite formed at lower temperatures would be converted largely to calcium sulphate and sulphide at higher temperatures. If wet methods based on slurries of absorbent were used, magnesium compounds would appear to have better regeneration characteristics than calcium compounds as a greater proportion of the sulphite could be thermally decomposed without the use of a reducing agent.

The economics of the various desulphurisation processes are dominated by the balance between capital cost of the equipment installed and the cost of absorbent and disposal of the products of desulphurisation. Likely credits for resale of any product appear 
minimal, if large-scale desulphurisation is introduced, because of the limited market capacity for a saleable product. Simple throwaway processes have the lowest capital costs, but disposal costs may become high as may costs of buying large quantities of absorbent. Re-usable absorbent processes and saleable by-product processes have higher capital costs and running costs may be high, depending upon the process complexity. It appears that all full-scale desulphurisation processes are relatively costly, and all processes based on alkaline earth metal compounds are likely to lead to disposal of product problems of one type or another. 


\section{REFERENCES}

1. Glasson D.R., J. Appl. Chem. 1958, 8, 739, et seq.

2. Glasson D.R., O'Neil1 P., J. Appl. Chem. 1967, 17, 102.

3. O'Neill P., M.Sc. Thesis 1970 , University of Newcastle.

4. Reid W.T., J. Eng. Power 1970, $92(1), 11$.

5. McClellan G.H., Hunter S.R., Scheib R.M., "The Reaction Parameters of Lime", ASTM STP 472, 1970, 32.

6. de Groot J.H., Proc. Symp. Fluidisation, Ed. Drinkenburg A.A.H., $1967,348$.

7. Houmand S., Davidson J.F., Trans. Inst. Chem. Eng. 1968, 46(6), 190.

8. "Fundamental Study of Sulphur Fixation by Lime and Magnesia" Batelle Memorial Inst., Contract PH 86-66-108, 30th June 1966.

9. "JANAF Thermochemical Tables", Dow Chemical Co., Mich., 1965.

10. Landolt-Boernstein, Kalorische Zustandsgrossen 1961, 2(4).

11. Chan R.K., Murthi K.S., Harrison D., Can. J. Chem. 1970, 48, 2972.

12. J. Air Pollut. Contr. Assoc. 1977, $27(10), 948$.

13. U.S. National Clean Air Amendment 1970, (Washington).

14. Japan. Air Pollut. Prevent. Law 1969, (Tokyo).

15. Donath E., Oesterr. Chem. Ztg. 1915, 18, 103.

16. Dibbs H.P., Inform. Circ. (Can. Mines Bur.) NOIC-272, 1972.

17. Eschellman G. U.S. Patent 900,500, Oct. 61909.

18. Nonhebe1 G., Trans. Faraday Soc. 1936, 32, 1291.

19. Howard H., Stantial F.G., U.S. Patent 1,271,899, July 91918.

20. Young S.W., Met. Chem. Eng. 1917, 16, 309.

21. Wickert K., Mitt. V.G.B. 1963, 83, 74.

22. Coutant R.W., Barrett R.E., Lougher E.H., J. Eng. Power 1970, $92(4), 113$.

23. Quack I. R., Chem. Age India 1.969, 20(2), 137. 
24. Wiedersum G.C., J. Eng. Power 1970, $92(7), 349$.

25. Falkenberry H.L., Slack A.V., Chem. Eng. Prog. 1970, 65(12).

26. Reese J.T., Womble T.D., Greco J., Proc. Annu. Environ. Water Resource Eng. Conf. 1970, 9, 45.

27. Gartrell F.E., U.S. Nat. Tech. Inform. Serv. P.B. Rep. 1973 No. $228447 / 9 \mathrm{GA}$.

28. Harrington R.E., Borgwardt R.H., Potter A.E., Am. Ind. Hyg. Assoc. J. 1968, 29, 152.

29. Potter A.E., Amer. Ceram. Soc. Bull. 1969, 48(9), 855.

30. Borgwardt R. B., Environ. Sci. Techno1. 1970, 4(1), 59.

31. Borgwardt R.H., J. Eng. Power 1970, 92(4), 121.

32. Ketov A.N., Larikov V.V., Pechkovskii V.v., Shligerskii A.S., Zh. Prikl. Kh. 1968, 41(4), 725.

33. Everett D.H., "Introduction to the Study of Chemical Thermodynamics" 1959, Longmans (London).

34. Zielke C.W., Lebowitz H.E., Struck R.T., Gorin E., J. Air Pollut. Contr. Assoc. 1970, 20(3), 164.

35. "Kirk-Othmer Encyclopedia of Chemical Technology" vo1.'19, 2nd edn., 1969, Interscience (New York), p.386.

36. Zentgraf K.M., Combustion 1969, 11, 6 .

37. Jones J.W., Stern R.D., Proc. Flue Gas Desulph. Symp. 1973, Ed. Pyler E.L., Maxwe11 M.A., U.S. Nat. Tech. Inform. Serv. P.B: Rep. No. 230901.

38. Foerster F., Kubel K., Anorg. Allg. Chem. 1924, 139, 261.

39. Matthews F.W., McIntosh A.0., Can. J. Res. 1948, 26B, 747.

40. Mellor J.W. "A Comprehensive Treatise in Inorganic and Theoretical Chemistry", Vol. 10, 1930, Longmans and Green (London), p. 282.

41. Hodgeman C.D., "Handbook of chemistry and physics" 30th edn. 1968, Chemical Rubber Publ. Co. (Cleveland) p. 394. 
42. Bichowsky F.R., J. Amer. Chem. Soc. 1923, 45, 2225.

43. Okabe T., Hori S., Technol. Reps. Tohuku Univ, 1969, 23(2), 15.

44. Cola M., Castellani Bisi C., Guzz. Chim. Ital. 1961, 91, 173.

45. Pechkovskii v.v., Ketov A.N., Zh. Prikl: Khim. 1960, 33, 1719.

46. Tolley L.J., Proc. Int. Conf. Control Gas. Sulphur Cpd. Emissions, Vol. 1 1973, Salford Univ. (Salford).

47. Hart A.B., Lawn C.J., C.E.G.B. Research 1977, 5, 4.

48. Scriven R.A., Howel1s G., C.E.G.B. Research 1977, 5, 28.

49. Friend J.P., "Chemistry of the Lower Atmosphere", Ch. 4, Ed.

S. I. Rasool, 1973, Plenum Press (New York).

50. Robinson E., Robbins R.C., "Sources, Abundance and Fate of Gaseous Atmospheric Pollutants" 1968, Stanford Res. Inst. Final Rep. Proj. PR 6755. (Mendo Park, Calif.).

51. "An Economic and Technical Appraisal of Air Pollution in the U.K." 1972, Programe Analysis Unit, HMSO (London).

52. Braekke F.H. ed., "Impact of Acid Precipitation on Forests and Freshwater Ecosystems in Norway" 1976, SNSF Project FR 6/76.

53. "Effects of Airborne Sulphur Compounds on Forests and Freshwaters" 1976, D.o.E. Pollution Paper No. 7, HMSO (London).

54. Newill V.A., Proc. Flue Gas. Desulph. Symp. 1973, Ed. Pyler E.L., Maxwe11 M.A., U.S. Nat. Tech. Inform. Serv. P. B. Rep. No. 230901.

55. Menzel D.B., J. Occup. Med. 1976, 18(5), 337.

56. Wendlandt W.M., "Thermal Methods of Analysis" 2nd edn. 1974, Wiley (London).

57. Sestak J., Talanta 1966, 13, 567.

58. Glasstone S., Lewis D., "Elements of Physical Chemistry", 2nd edn., 1970, Macmillan..(London).

59. Doyle C.D., "Techniques and Methods of Polymer Evaluation", Ed. Slade P.E., Jenkins L.T., 1966, Marcel Dekker (New York). 
60. Sharp J.H., Wentworth S.A., Anal. Chem. 1969, 41, 2060.

61. Schwenker R.F., Whitwell J.C., "Analytical Calorimetry", vol. 1, Ed. Porter R.P., Johnson J.M., 1968, Plenum (New York).

62. Smyth H.T., J. Amer. Ceram. Soc. 1951, 34, 221.

63. Brunauer S., Emmett P. H., Teller E., J. Amer. Chem. Soc. 1938, $60,309$.

64. Gregg S.J., Sing K.S.W., "Adsorption, Surface Energy and Porosity", 1967, Academic Press (London).

65. Langmuir I., J. Amer. Chem. Soc. 1916, 38, 2221.

66. Brunauer S., Deming L.S., Deming W.E., Teller E., J. Amer. Chem. Soc. $1940,62,1723$.

67. Sing K.S.W., "Characterisation of Powder Surfaces", Ed. Parfitt G.D., Sing K.S.W., 1976, Academic Press (London).

68. Gregg S.J., M.T.P. Int. Rev. Sciences Physical Chem. Series One, Vo1. 7, Ed. Kerker M., 1972, Butterworths (London).

69. Glasson D.R., J. Chem. Soc. 1956, 1506.

70. IUPAC Manual of Symbols and Terminology, Appendix 2, Part 1, Colloid and Surface Chemistry, Pure Appl. Chem. 1972,. 31, 578.

71. Thomson W.T., Phil. Mag. $1871,42,448$.

72. de Boer J.H., Lippens B.C., Linson B.G., Brockhoff J.C.P., van der Hewel A., Osinga T.J., J. Colloid Interface Sci. 1966, 21,405 .

73. Lipson H., Steeple H., "Interpretation of X-ray Powder Diffraction Patterns", 1970, Macmillan (London).

74. Jones F.W., Proc. R. Soc. (A) 1938, 166, 16.

75. Stout G.H., Jensen H., "X-ray Structure Determination", 1.968, Macmillan (New York).

76. Bragg W.H., Bragg W.L., Proc. Royal Soc. 1913, 88, 428. 
77. "X-ray Powder Data File" sets 1 - 15, 1960-72, American Soc.

Test. Mat. (Philadelphia).

78. Kolthoff I.M., Belcher R., "Volumetric Analysis" Vo1. 3, 1957, Interscience (New York).

79. Jolly S.C., Ed. "Official, Standardised and Recommended Methods of Analysis", 1963, W. Heffer (Cambridge).

80. Mocek K., Erdos E., Collection Czech. Chem. Commun. 1971, 36, 494.

81. Schropper L., Z. Anorg. Alleg. Chemie, 1973, 401, 1.

82. F1ack H., Acta Cryst. 1973, B29, 656 .

83. Koehler G., Burns J.A., U.S. Nat. Tech. Inform. Serv. P. B. Rep. No. $247201,1975$.

84. Laing M.J., "X-ray programs for IBM 1130", 1970, Natal University (Durban).

85. Waerstod K.R., Scheib R.M., McClellan G.H., J. App1. Cryst. $1974,7(4), 447$.

86. Lutz H.D., E1 Suradi S., Z. Anorg. Alleg. Chem. 1976, 425, 133.

87. Pope M. I., Private Communication.

88. Huttig G.F., Kolloid Z.: 1942, 98, 263.

89. Lowell P.S., Corbett W.G., Brown G.D., Wilde K.A., E.P.A. Report No. 600/7 - 76 - 030, Oct. 1976.

90. Schwitzgebel K., Lowell P.S., Environ. Sci. Technol. 1973, $7(13), 1147$.

91. Mason B., "Principles of Geochemistry" Third edn., 1966, John Wiley and Sons, Inc. (New York).

92. Lutz H.D., E1 Suradi S.M., Engelen B., Z. Naturforsch. 1977, $32 \mathrm{~B}, 1230$.

93. Tarradellos J., Bonnetain L., Bul Soc. Chim. France 1973, No. 6, 1903. 
94. Glasson D.R., J. App1. Chem. 1967, 17, 91.

95. Dijksman D.J., Chem. Soc. Spec. Pub1. No. 12, 1958, 333.

96. Aoki S., Sawamura E., Arai Y., Gypsum and.1ime, 1976, 142, 3.

97. Ingraham T.R., Marier P., J. Air Pollut. Contr. Assoc. 1971, $21(6), 347$.

98. Cubicciotti D., Sanjurjo A., Hildenbrand D. L., J. Electrochem. Soc., $1977,124(6), 933$.

99. Mocek K., Erdos E., Collection Czech. Chem. Commun. 1972, 37, 3376.

100. Pechkovskii v.v., Ketov A.N., Chim, i Chim. Technol. 1959, 4, 667.

101. Papazian H.A., Pizzolato P.J., Peng J., Thermochim Acta 1972, $5(2), 147$.

102. Coutant R.W., McNulty J.S., Barrett R.E., Carson J.J., Fischer R., Lougher E.H., U.S. Nat. Tech. Inform. Serv. P. B. Rep. No. $180834,1968$.

103. Marrier P., Ingraham T.R., Canada. Metall. Quart. 1972, 11(4), 617.

104. James N.J., Hughes R., Proc. Sec. Int. Conf. Control Gas. Sulphur and Nitrogen Cpd. Emissions, Vol. 1, 1976, Salford Univ. (Salford).

105. Hatfield J.D., Rim Y.K., Mullins R.C., U.S. Nat. Tech. Inform. Serv. P. B. Rep. No. 202407, 1970.

106. Ishihara Y., Proc. 4th Dry Lst. Inject. Proc. Symp. 1970, (Gilbertsville, Kty).

107. Glasson D.R., Sheppard M. A., J. Appl. Chem. 1968, 18; 327.

108. Shannon R.D., Prewitt C.T., Acta Crystallogr. 1970, B26, 1076.

109. Moss G., Proc. Int. Conf. Fluid. Bed Combust. 1968, (Oxford, Ohio). 
110. Skopp A.P., Proc. Int. Conf. Fluid. Bed Combust. 1968 (Oxford, Ohio).

111. Williams D. R., Proc. Int. Conf. Fluid. Bed Combust. 1968 (Oxford, Ohio).

112. McCrea D.H., Myers J.G., Forney A.J., Proc. Sec. Int. Air Pollut. Conf. 1970 (Washington D.C.).

113. Bertrand R.R., Frost A.C., Skopp A., U.S. Nat. Tech. Inform. Serv. P.B. Rep. No. $186234,1968$.

114. Merrick D., Highley J., A. I.Ch.E. Symp. Series 1972, 70 (1.37), 366.

115. Bettelheim J., Private Communication.

116. Ando J., U.S. Nat. Tech. Inform. Serv. P. B. Rep. No. 208236, 1972.

117. Ando J., Isaacs G.A., U.S. Nat. Tech. Inform. Serv. P. B. Rep. No. $250585,1976$.

118. J. Air. Pollut. Contr. Assoc. 1977, $27(10), 1018$.

119. Slack A.V., Falkenberry H.L., Harrington R.E., J. Air Pollut. Contr. Assoc. 1972, 22(3), 159.

120. Walker A.B., Canada Min. Metal1. (C. I.M.) Bu11. Sept. 1971, 85.

121. Bettelheim J., Collins A. C., Chem. Ind. 1 Feb. 1975, 122.

122. Jones J.W., Stern R.D., Proc. Flue Gas Desulph. Symp. 1973, Ed. Pyler E. L., Maxwell M.A., U.S. Nat. Tech. Inform. Serv. P. B. Rep. No. 230901.

123. Houston P.S., Koehler G.R., Proc. Int. Conf. Contr. Gas Sulphur Cpd. Emission, Vol. 2, 1973, Salford Univ. (Salford).

124. Koehler G.R., Hess H.F., Englich J.E., Proc. Conf. Air Quality Manag. Elect. Power Ind. 1976 (Austin).

125. Hollinden G. A., Proc. Ann. Environ. Water Resource Engin. Conf. Vo1. $11,1972,183$. 
126. Dreifke G.E., McLaughlin J.F., Smith J.D., Environ. Letters $1975,9(4), 395$.

127. King T.A., Fox J.M., A. I. Ch. E. Symp. Ser. 1976, 72 (156), 1.

128. Bettelheim J., Billinge B.H.M., Proc. Sec. Int. Conf. Conorol

Gas. Sulphur and Nitrogen Cpd. Emissions, Vo1. 1, 1976, Salford Univ. (Salford).

129. Mahoney J.R., Gaut N.E., Newman E., A. I.Ch.E. Symp. Ser: 1974, $70(137), 167$.

130. Hubble B. R., Siegel S., Cunningham P.T., J. Air Pollut. Contr. Assoc. $1975,25(12), 1256$. 


\section{APPEINDIX DUE}

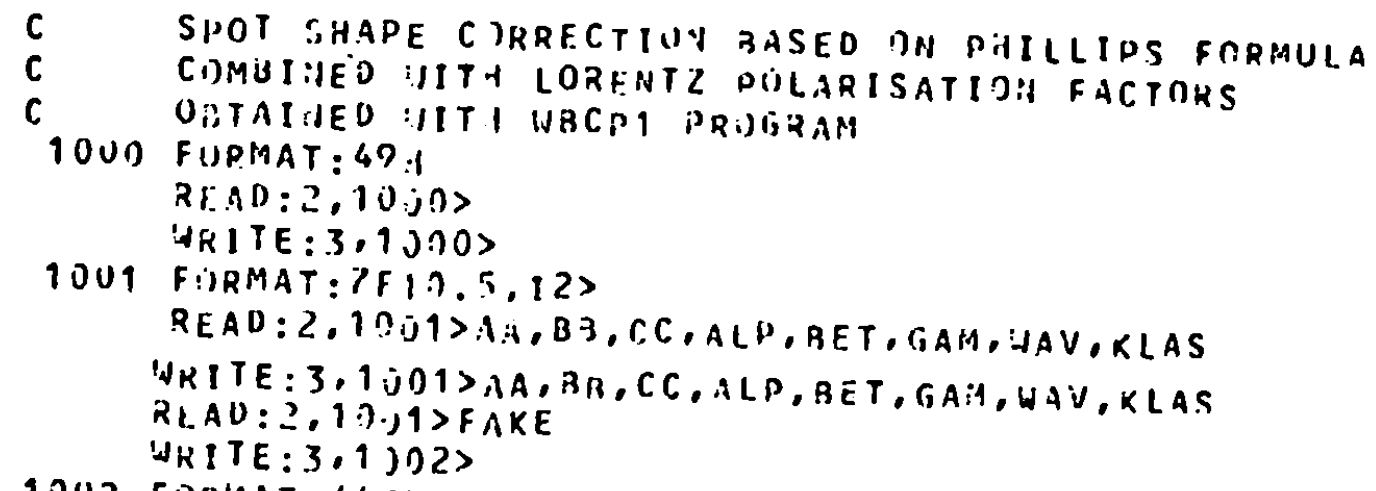

\section{FORHAT:/4;:1}

I, J3HSPSHC LPTS
Ji) 1

$1 J K) 0$

?. $J(L) 0$

If: $J: 4>3,3,6$

3 I $F: J K>4,4,6$

1. IF:JL>5.5,

$5 J() 1$

h $F(1), 1 H$

(x) $d x$

$\bar{F} L) J L$

IF:O. $-F K>13,13,20$

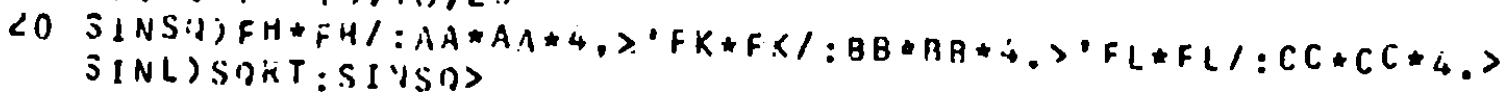

SINTO)WAV IJAVESINSU

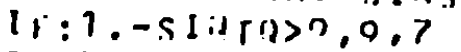

7 SINT)SIRT:SI.1TOS

GISIT)SIHTH*:

FLP) SURT: :USS $[: 1>/: 1,-2, * C n S I V\rangle$

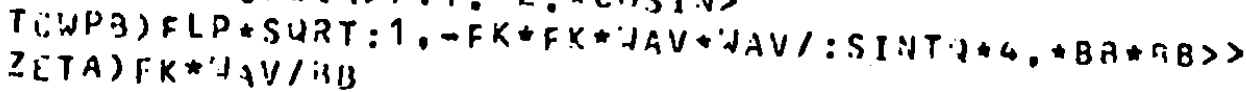

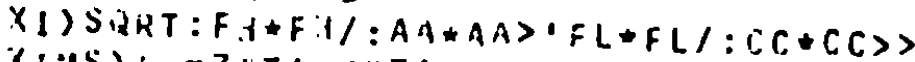

XIISS $\therefore .-Z Z T A=\angle E T A$

PHILA)SQ?T:XI:IS/:XI*XI>-1,>

PAILB) 180 . ZETA*PHILA

गHILCSSURT: 1.-0.25* LETA*ZETAD

3 AILD) $28.7 / P$ ILC. 75 .

DIILE) $12 ., 366$ i *PHILI)

SPSHC) 1.0 PHILU/PHILE

R.PTSB)TCIPB SPSHC

Ji) $F$ i

$J(K) F K$

$J(L) F L$

WRITE:3,1 JO3 JH,JK,JL, JINT, FLP,TCUPH, SOSHC OPPTSY

1003 FUIPMAT: $3 X, 13,1 X, 13,1 \times, 13,1 X, 5 F R, 4>$

:j.) TO 8

$8 J L) J L \cdot 1$

(j) $\mathrm{TO} 6$

Q IF:I-JL>1, I, 11,11

Iก JU)Jir'?

Gi) TO 2

11 If $: 1-J H>1 ?, 1 \geq, 13$

$12 J K) J K \cdot 1$

(i) TO 1

13 CUNTIHUE

18 CALL EXIT 
LIST UF F( TSSERVEO) ANQ F(CALCJLATED) FIR CALCIIIM SULPHITE HE'IIHYDRATE

\begin{tabular}{|c|c|c|c|c|}
\hline 4 & $k$ & $\mathbf{L}$ & $\left.F_{1}\right) B S$ & FCALC \\
\hline 2 & 1) & 0 & 5.) .4 & $6 u$. \\
\hline & $i$ & 0 & 6 , & \\
\hline & j & 0 & $11 i .2$ & 102 \\
\hline & i) & 0 & 14.3 & \\
\hline ? & 3 & 2 & 5 & $3 c$ \\
\hline & $i$ & 4 & $9 ?$ & 92 \\
\hline & i & 6 & 77 & 82 \\
\hline & $\therefore$ & 8 & 74 & 78 \\
\hline & $1)$ & 10 & 50 & 35 \\
\hline & i) & 12 & 50 & 51 \\
\hline & ;) & 1 & ن & 61 \\
\hline & $i$ & 3 & $4 ?$ & \\
\hline 1 & $\dot{y}$ & 5 & & \\
\hline 1 & 0 & 7 & $6 j$ & \\
\hline 1 & .) & $?$ & $5 \%$ & \\
\hline 1 & 4 & 11 & 30 & \\
\hline 1 & i) & 13 & 4.1 & \\
\hline ? & $\therefore$ & 2 & & 20 \\
\hline 2 & .) & 4 & 9190.3 & 107 \\
\hline 2 & $\therefore$ & 6 & $40^{\circ}$ & 20 \\
\hline 2 & $\dot{j}$ & .8 & & \\
\hline 2 & $\therefore$ & 10 & 6? & क4 \\
\hline 2 & n & 12 & 24 & 18 \\
\hline 3 & $\dot{i}$ & 1 & $90-$ & $1 n$ \\
\hline 3 & 0 & 3 & 19) & 18. \\
\hline 3 & i) & 5 & 1 & 10 \\
\hline 3 & $\hat{0}$ & 7 & 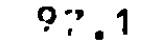 & 85 \\
\hline 3 & ) & () & 27 & \\
\hline 3 & 11 & 11 & ó & 64 \\
\hline 4 & ؛) & 2 & 3.7 & \\
\hline 4 & ) & 4 & 2.4 & \\
\hline 4 & i) & 6 & o? & \\
\hline 4 & ii & X & 20 & \\
\hline 4 & $\overline{0}$ & $1 n$ & 27 & \\
\hline 5 & i) & 1 & & \\
\hline 5 & $\dot{\theta}$ &.$j$ & 29 & \\
\hline 5 & $\because$ & 5 & 13 & \\
\hline 5 & . & 7 & 4.5 & \\
\hline$S$ & $i$ & () & & \\
\hline 6 & $\therefore$ & ? & & \\
\hline h & $j$ & 4 & 3 & \\
\hline 6 & j & 6 & & 17 \\
\hline 6 & $\therefore$ & 8 & & \\
\hline 7 & $\therefore$ & 1 & & \\
\hline 7 & $\therefore$ & 3 & & \\
\hline$?$ & i) & 5 & $1 / 4$ & \\
\hline 7 & $\therefore$ & 7 & 11. & 12 \\
\hline a & $\therefore$ & 2 & $\because .2$ & 1. \\
\hline 2 & 1 & 0 & & \\
\hline & 1 & $n$ & & \\
\hline n & 1 & 0 & & \\
\hline
\end{tabular}

\begin{tabular}{|c|c|c|c|c|}
\hline 4 & $k$ & L & FunS & $F C A L C$ \\
\hline 8 & i & 0 & 24.3 & $3 \cdot 1$ \\
\hline & 1 & 1 & 44.0 & 21 \\
\hline & $i$ & 1 & 62.1 & \\
\hline & 1 & 9 & & \\
\hline 4 & 1 & 1 & 7 & 68 \\
\hline 5 & 1 & 1 & 52.5 & iO \\
\hline 6 & i & 1 & 0 & .3 \\
\hline 7 & 1 & 1 & 8 & 13 \\
\hline R & 1 & 1 & 0.0 & \\
\hline 1 & 1 & 2 & $1: 6.17$ & 119 \\
\hline 2 & 1 & $?$ & $5 \% .4$ & 44 \\
\hline 3 & 1 & 2 & 33 & $1: 3$ \\
\hline 4 & $\hat{\imath}$ & 2 & 23.1 & 19 \\
\hline 5 & 1 & 2 & .32 .7 & 27 \\
\hline & $i$ & 2 & $?$ & 12 \\
\hline$?$ & 1 & 2 & 41.1 & 4.3 \\
\hline 1 & 1 & 3 & 30.1 & 100 \\
\hline 2 & 1 & 3 & 20.0 & 20 \\
\hline 3 & 1 & 3 & 33 & 68 \\
\hline 4 & : & 3 & 11.5 & 12 \\
\hline 5 & 1 & 3 & 3.0. & 15 \\
\hline 6 & i & 3 & & 1 \\
\hline 7 & : & 3 & & \\
\hline 1 & $i$ & 4 & 12.2 & 13. \\
\hline 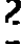 & i & 4 & 6 & 52. \\
\hline 3 & i & 4 & 12 & \\
\hline 4 & 1 & 4 & 14.2 & 12 \\
\hline 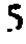 & 1 & 4 & 0 & $y$ \\
\hline 6 & $\mathbf{i}$ & 4 & $1 \% .2$ & 15 \\
\hline 7 & $i$ & $\dot{q}$ & $1 \pi$ & 14 \\
\hline 1 & $\hat{\imath}$ & 5 & $1: 3.0$ & 31 \\
\hline ? & $\mathrm{i}$ & 5 & 42.5 & 37 \\
\hline 3 & 1 & 5 & 0 & 12 \\
\hline 4 & $i$ & 5 & $i_{.+.} .4$ & 41 \\
\hline 5 & $i$ & 5 & 15 & 0 \\
\hline & $i$ & 5 & 25.5 & 23.3 \\
\hline & 1 & 3 & 0.0 & 0.4 \\
\hline 1 & $i$ & 6 & .0 & 4. \\
\hline C & I & 6 & 17.2 & 10. \\
\hline 3 & 1 & 6 & 0.8 & 4. \\
\hline 4 & $i$ & 0 & 7. & 7. \\
\hline 5 & $i$ & 6 & $i .0$ & 9. \\
\hline & $i$ & 3 & 3.0 & \\
\hline 7 & $i$ & $h$ & $2 \% .0$ & $? 9.2$ \\
\hline & $i$ & 7 & 10.1 & 27.8 \\
\hline & i & 7 & $3 i_{4} 00$ & 33. \\
\hline & $!$ & 7 & $\bar{u} .0$ & 9. \\
\hline & 1 & 7 & 2.). 5 & 2.0 \\
\hline & 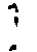 & 7 & $3 r .6$ & 4.3. \\
\hline & $i$ & 7 & j. & 3 \\
\hline & & $r$ & & \\
\hline
\end{tabular}




\begin{tabular}{|c|c|c|c|c|c|c|c|c|c|c|}
\hline H & r. & L & FOBS & $F C A L C$ & & 4 & $k$ & $\mathbf{L}$ & $\left.F_{i}\right)$ BS & FCALC \\
\hline 1 & 1 & 3 & $\overline{0} .0$ & 3.8 & & 6 & 2 & ? & 0.0 & 6 \\
\hline 2 & 1 & గ & 32.3 & 36.9 & & 7 & 2 & 2 & 53 & 44 \\
\hline ) & 1 & 3 & 15.9 & 14.5 & & 8 & 2 & 2 & 0 & 5 \\
\hline 4 & $i$ & $a$ & 13.0 & 13.6 & & 1 & 2 & 3 & ?in & 24 \\
\hline 5 & i & 8 & 0.0 & 11.2 & & 2 & $?$ & 3 & $? 5.2$ & 72 \\
\hline 6 & 1 & 8 & 0.0 & 2.7 & & 3 & 2 & 3 & $1 \bar{v} .7$ & 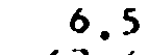 \\
\hline 1 & $i$ & 9 & $1 \geq .1$ & 5.9 & & 4 & $\therefore$ & 3 & 67.9 & 6.2 \\
\hline 2 & 1 & n & 12.3 & 6.9 & & 5 & 2 & 3 & u. in & 4 \\
\hline 4 & i & $n$ & i. & 6.1 & & 6 & $\leq$ & 3 & 17.2 & 16 \\
\hline 4 & 1 & 9 & 2.5. 1 & 26.3 & & 7 & $i^{2}$ & 3 & 12.2 & 11 \\
\hline 6 & $i$ & $?$ & j. 0 & 11.4 & & 8 & 2 & 3 & $? 6$ & $2 !$ \\
\hline 1 & $i$ & $?$ & 3. 3 & 11.9 & & 1 & 2 & 4 & $7 \%$ & 71 \\
\hline 2 & 1 & 10 & 41). 3 & 36.9 & & $?$ & $\therefore$ & 4 & 28 & 45 \\
\hline $\begin{array}{l}2 \\
3\end{array}$ & 1 & 17 & i). & 1 . & & 3 & 2 & 4 & 24.3 & \\
\hline 4 & $i$ & 78 & $j$ & 0.9 & & 5 & $\therefore$ & 4 & $\begin{array}{l}11 \\
3 \cdot\end{array}$ & \\
\hline $\begin{array}{l}4 \\
5\end{array}$ & 1 & 10 & 11. & 16.0 & & 6 & 2 & 4 & נ3 & \\
\hline 1 & 1 & 10 & 17. & 1 & & $r$ & 5 & 5 & 11 & \\
\hline 1 & 1 & 17 & 2 & $\begin{array}{l}31 \\
20\end{array}$ & & $?$ & $\therefore$ & 5 & $1 n 3$ & $10<$ \\
\hline 3 & i & 11 & $\because \because$ & 155 & & 3 & 3 & 5 & & \\
\hline 4 & 1 & 19 & 10.3 & 108 & & 4 & $\ddot{a}$ & 5 & $7 i .3$ & 62 \\
\hline 1 & $\mathrm{i}$ & 92 & 14.6 & 12.1 & & 5 & 2 & s & $\therefore 0$ & \\
\hline$?$ & 1 & 12 & 10.1 & 22.3 & & $h$ & 2 & 5 & 10.2 & 13 \\
\hline 3 & $\hat{\mathfrak{i}}$ & 12 & $\therefore .2$ & צ. 1 & & 7 & 2 & 5 & 0.1 & 6 \\
\hline 1 & $\hat{\imath}$ & 13 & 13.1 & 24.5 & & 1 & 2 & 6 & 10.6 & 107 \\
\hline 2 & 1 & 13 & 3.7 & 14.0 & & $?$ & $?$ & $h$ & $11) .7$ & \\
\hline 2 & 2 & 0 & $2 j .1$ & 34.4 & . & 3 & $\ddot{c}$ & 6 & ز & \\
\hline 2 & 4 & 0 & 69.3 & 57.6 & & 4 & $?$ & 6 & 12 & \\
\hline$?$ & 0 & $n$ & 28.3 & 24.7 & & 5 & ?. & "s & 50.4 & \\
\hline ? & 3 & 0 & 10.9 & 11.6 & & 6 & $?$ & 6 & j. 0 & \\
\hline 0 & $\therefore$ & 1 & 10.4 & 5.6 & & 7 & $\therefore$ & 6 & 9 & \\
\hline 1) & ? & 2 & 1.3 .6 & 30 & & 1 & $?$ & 8 & 50.7 & \\
\hline$n$ & $\therefore$ & 3 & 57.3 & 51) & & $?$ & 2 & 8 & 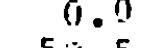 & \\
\hline$n$ & $\therefore$ & 4 & 17.3 & $3 i$ & & 3 & 2 & त & 5 & \\
\hline$n$ & $\therefore$ & 5 & 30 & 64 & & $=$ & 2 & 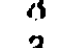 & c & \\
\hline n & $?$ & 6 & 23.5 & 42.2 & & 5 & 2 & 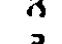 & 53. & 36 \\
\hline n & $\therefore$ & 7 & 39.1 & 2.0 .7 & & 6 & 2 & 3 & 1). 0 & \\
\hline n & ? & 8 & 1). 0 & 17.9 & & 1 & $?$ & 9 & 0 & \\
\hline 0 & 2 & $?$ & 17.4 & 16 & & $?$ & $\therefore$ & 0 & 74.2 & \\
\hline 11 & ? & 10 & 10.0 & 14.1 & . & 3 & $?$ & 9 & $\dot{0}$ & \\
\hline n & ?. & 11 & 4.3 .2 & 45 & & 4 & $?$ & ") & 56 & \\
\hline n & 2 & 12 & $\because$ & 14.0 & & 5 & ? & 3 & 1) & \\
\hline$n$ & $\therefore$ & 13 & .3 & 5.9 & & 1 & $a$ & 10 & 35 & \\
\hline 1 & 2 & 1 & ) & 1.3 & & $?$ & 2 & 10 & $1 i$ & \\
\hline ? & 2 & 1 & 132.5 & 124.4 & & 3 & $?$ & 10 & 27 & 2 \\
\hline 3 & 2. & 1 & $1+.7$ & 10.5 & & 4 & $?$ & 10 & & .4 \\
\hline 4 & 2 & 1 & $33 . ?$ & 82.7 & & 5 & $\because$ & 10 & 2.1 .5 & 31 \\
\hline 5 & 2 & 1 & ن. 0 & 5.1 & & 1 & $?$ & 11 & & \\
\hline$h$ & 2 & 1 & 3.5 & 2.9 & & $?$ & $?$ & 11 & 22.2 & 11.3 \\
\hline 7 & ?. & 1 & .7 .0 & 4.2 & & 3 & $?$ & 19 & 9.0 & 9 \\
\hline 8 & 2 & 1 & 35.0 & 35.7 & & 4 & ?. & 11 & 18.9 & 14 \\
\hline 1 & $\therefore$ & 2 & l'i & 144.1 & & 1 & $?$ & 12 & 30.9 & 41.6 \\
\hline$?$ & $\therefore$ & 2. & $2 \because .2$ & 34.4 & & 2 & $?$ & 12 & i). 0 & 3.9 \\
\hline 3 & ?. & 2 & 35.3 & & & 3 & 2 & 12 & 30.3 & 37.1 \\
\hline 4 & 2 & 2 & 0.0 & 15 & & 1 & 2 & 1.3 & 0.0 & 3. \\
\hline 5 & ? & 2 & $79 . ?$ & 89.8 & & 2 & 2 & 13 & 21.2 & 41 \\
\hline
\end{tabular}




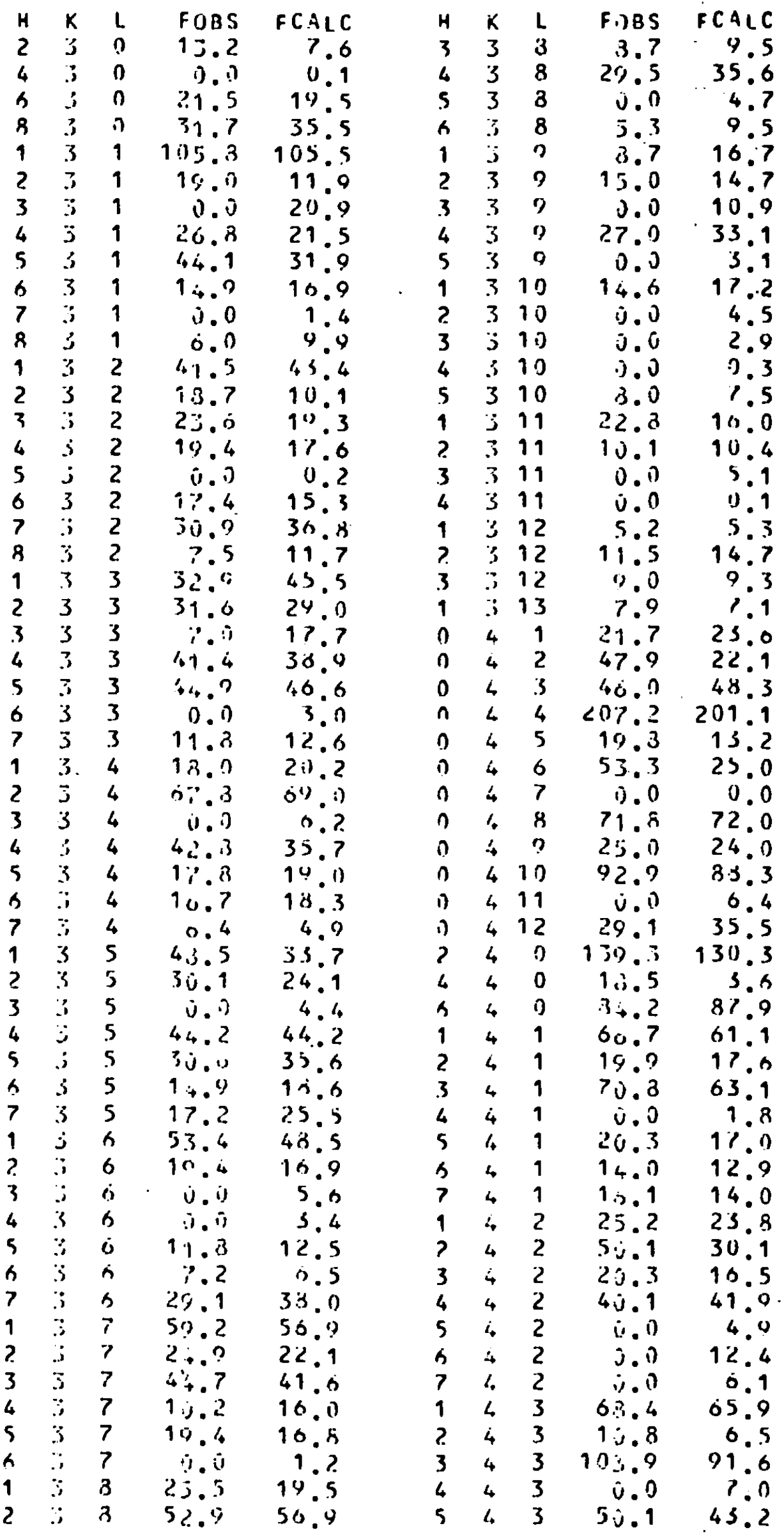




\begin{tabular}{|c|c|c|c|c|c|c|c|c|c|}
\hline H & K & L & $F$ ') BS & $F C A L C$ & H & $k$ & $L$ & FO3S & $F C$ \\
\hline 6 & 4 & 3 & 13.6 & 13.7 & 7 & 5 & 1 & 0.0 & 9.8 \\
\hline 7 & 4 & 3 & 14.8 & 13.3 & 1 & 5 & 2 & 43.6 & 53 \\
\hline 1 & 4 & 4 & 3.0 & 0.3 & 2 & 5 & 2 & 6.4 & 7 \\
\hline 2 & 4 & 4 & $\therefore 0$ & $5 . ?$ & 3 & 5 & 2 & .1 & 17 \\
\hline 3 & 4 & 4 & 14.9 & 12.5 & 4 & 5 & 2 & 17.4 & \\
\hline 4 & 4 & 4 & 55.0 & 48.9 & 5 & 5 & 2 & 31.4 & 2 \\
\hline 5 & 4 & 4 & 13 & 11.5 & 6 & 5 & 2 & 3.6 & 2 \\
\hline 6 & 4 & 4 & 35 & 69.2 & 7 & 5 & 2 & $3 j .4$ & 34 \\
\hline 1 & 4 & 5 & $3 \div .1$ & 21.8 & 1 & 5 & 3 & 13.0 & 26 \\
\hline 2 & 4 & 5 & 0.0 & 10.6 & 2 & j & 3 & $3 j .0$ & \\
\hline 3 & 4 & 5 & 31.2 & 70 & 4 & 5 & 3 & 0 & \\
\hline 4 & 4 & 5 & 17.2 & 17.1 & 5 & 5 & 3 & 51.4 & \\
\hline 5 & 4 & 5 & 23.4 & 28.7 & 6 & 5 & 3 & $4 \div .1$ & \\
\hline 6 & 4 & 5 & 12.3 & 12.1 & 1 & .5 & 4 & 311.2 & \\
\hline 1 & 4 & 6 & 11.7 & 0.1 & ? & 3 & 4 & 37.9 & 30 \\
\hline 2 & 4 & 6 & 5.3 .5 & 62.2 & 3 & 5 & 4 & .0 & \\
\hline 3 & 4 & 6 & 41.0 & 34.5 & 4 & $j$ & 4 & $1 \therefore .4$ & \\
\hline 4 & 4 & 6 & 33.0 & 22.4 & 5 & 3 & 4 & 17.8 & 19 \\
\hline 5 & 4 & 6 & 13.1 & 0.1 & 6 & 5 & 4 & 21.8 & 22 \\
\hline 6 & 4 & 6 & 39 & 34.7 & 7 & 5 & 4 & 0.3 & \\
\hline 1 & 4 & 7 & 33 & 27.0 & 1 & 5 & 5 & 20.1 & \\
\hline 2 & 4 & 7 & 0 & 4.9 & 2 & 5 & 5 & $5 \% .0$ & 49 \\
\hline 3 & 4 & 7 & 123.3 & 119.3 & 3 & 5 & 5 & 0 & \\
\hline 4 & 4 & 7 & 0 & $2 . ?$ & 4 & j & 5 & $5_{2}^{2}$ & 46 \\
\hline 5 & 4 & 7 & 15.3 & :1.0 & 5 & 5 & 5 & $1 i_{\phi}$ & 22 \\
\hline h & $\dot{4}$ & 7 & 10.0 & .5. & 6 & 5 & 5 & 1 & 14 \\
\hline 1 & 4 & 8 & 11.7 & 10.8 & 1 & 5 & 6 & 4. & 52 \\
\hline 2 & 4 & 3 & 0.0 & $12: 0$ & 2 & 5 & 6 & 1. & \\
\hline 3 & 4 & 8 & 9 & 10.3 & 3 & 5 & 6 & 12.5 & \\
\hline 4 & 4 & 8 & $\dot{u} .0$ & 5.3 & 4 & 5 & 6 & 5.0 & (9). \\
\hline 5 & 4 & 8 & & 2.7 & 5 & 5 & 6 & 15.8 & 13.6 \\
\hline 6 & 4 & 8 & 45 & 58.4 & 6 & .5 & 6 & $1: .4$ & 12.9 \\
\hline 1 & 1. & 9 & 35 & 28.9 & 1 & 5 & 7 & 33 & 3 \\
\hline$?$ & 4 & 9 & $\bar{u}$. & 3.3 & $?$ & 5 & 7 & 3 & 3 \\
\hline 3 & 4 & $?$ & 0.0 & 4.0 & 3 & 5 & 7 & 3 & \\
\hline 4 & 4 & 9 & 0.17 & 3.1 & 4 & .5 & $?$ & $2:$ & \\
\hline 5 & 4 & $?$ & 11.2 & 11.2 & 5 & 5 & 7 & 17.9 & 18 \\
\hline 1 & 4 & 10 & 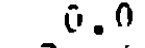 & 1.0 & 6 & 5 & 7 & ? & \\
\hline 2 & 4 & 10 & 21. & 17.1 & 1 & .5 & 8 & 31.4 & 24.7 \\
\hline 3 & 4 & 10 & & 10.9 & $?$ & 5 & 8 & 30.2 & 26. \\
\hline 4 & 4 & 30 & 3 & 37.2 & 3 & 5 & 8 & 0. & 4. \\
\hline 1 & 4 & 11 & 29 & 23.4 & 4 & 5 & 8 & 13.0 & 93. \\
\hline 2 & 4 & 11 & G & 4.3 & 5 & 5 & 8 & 7.2 & ?. 8 \\
\hline 3 & 4 & 11 & 51.1 & $53 . n$ & 1 & 5 & 9 & 12.2 & 23.6 \\
\hline 1 & 4 & 12 & 9.1 & 10.2 & 2 & 5 & り & 29 & 1 \\
\hline$?$ & 4 & 12 & 11.0 & 10.6 & 3 & 5 & 9 & 0 & .1 \\
\hline$?$ & 5 & 0 & 37.2 & 35.1 & 4 & 5 & 0 & 33.9 & 3 \\
\hline 4 & 5 & 0 & 17.1 & 6.4 & 1 & 5 & 10 & 10 & .4 \\
\hline 6 & 5 & 0 & 17.0 & 15.2 & 2 & 5 & 10 & 12.6 & 12.5 \\
\hline$\lambda$ & 5 & 0 & 32 & & 3 & 5 & 10 & 0.0 & 1.1 \\
\hline 1 & 5 & 1 & 20 & 38.9 & 1 & 5 & 11 & i). i) & ) .9 \\
\hline 2 & 5 & 1 & . & 4.7 & 2 & 5 & 19 & 15.1 & 14.9 \\
\hline 3 & 5 & 1 & 24.6 & 31.6 & 1 & .5 & 12 & is. 0 & 3 \\
\hline 4 & 5 & 1 & $2 i, .4$ & 10.8 & $?$ & 5 & 12 & 7.6 & 11. \\
\hline 5 & $\overline{2}$ & 1 & $? .1 .7$ & 12.7 & 0 & 0 & 1 & 23.5 & 11. \\
\hline 6 & 5 & 1 & 20.5 & 10.7 & $n$ & 0 & 2 & 35 & \\
\hline
\end{tabular}




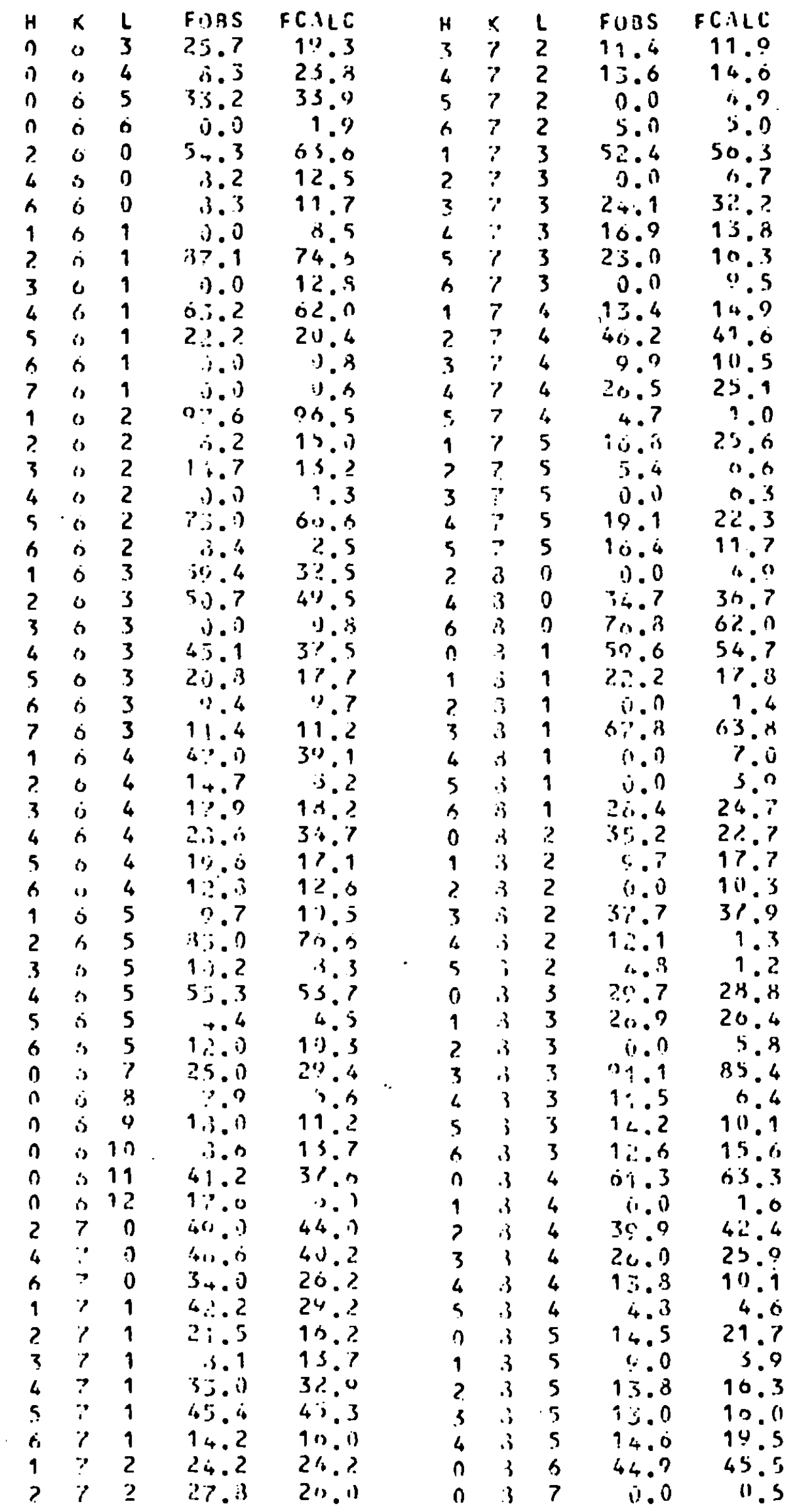




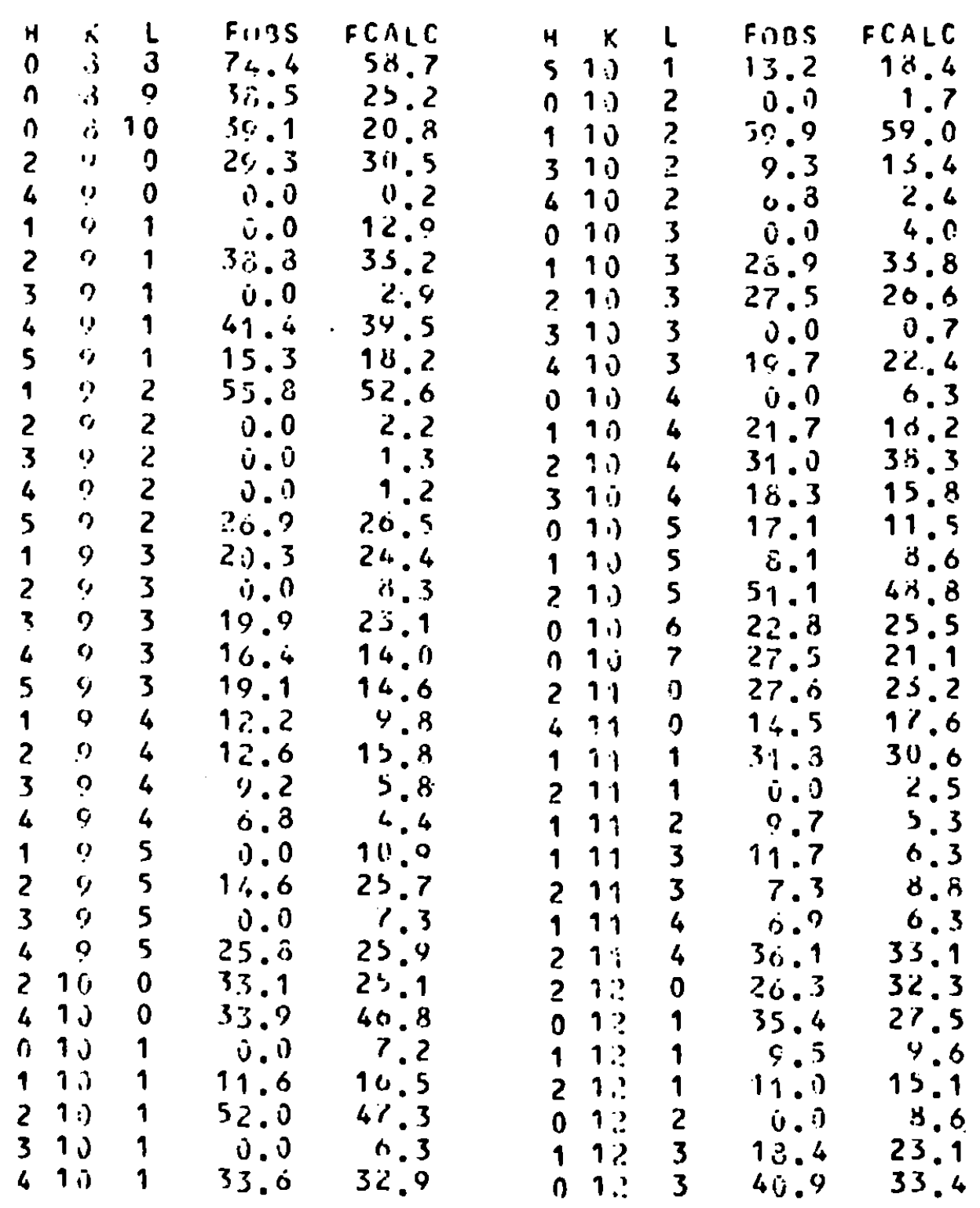




\section{APPEHDIX THREE}

X-RAY PIWDER UIFFRACTIUH DATA FOR STROITIUM HYDROXIDE AS DETERHTINED AY D.R. GLASSOJ

\begin{tabular}{|c|c|c|c|c|c|c|c|c|c|}
\hline I & $\theta\left({ }^{0}\right)$ & & & $\left.{ }_{1}^{\mathrm{OH}}\right)_{2}$ & $\mathrm{~d}(\stackrel{\circ}{A})$ & & $\mathrm{rCC}$ & & (i) \\
\hline s & 9.90 & 2 & $1)$ & i) & 4.49 & & & & $d(A)$ \\
\hline$M$ & 12.37 & ) & $n$ & $\therefore$ & 3.60 & 1 & 1 & 1 & 3.55 \\
\hline$S$ & $1 \therefore$ 8n & $?$ & 1 & ! & 3.48 & 0 & 2 & 1 & 3.48 \\
\hline in & $1 \% .10$ & 1 & $?$ & 1 & 3.40 & & & & \\
\hline$M$ & 1.3 .45 & 2 & 1 & $?$ & 3.32 & & & & \\
\hline$\therefore$ & $1 \% .47$ & 2 & 2 & 1 & 3.10 & & & & \\
\hline 3 & 15.80 & & & & 2.83 & $:)$ & 3 & 1 & 2.83 \\
\hline s & 15.45 & $?$ & $n$ & $?$ & 2.81 & & & & \\
\hline$s$ & $1 \therefore .55$ & 3 & $?$ & $n$ & 2.45 & 3 & $\begin{array}{l}2 \\
1\end{array}$ & $\begin{array}{l}2 \\
?\end{array}$ & $\begin{array}{l}2.46 \\
2.45\end{array}$ \\
\hline s & 10.30 & 2 & 3 & 1 & $\therefore$ 233 & $?$ & $i$ & $i$ & 2.27 \\
\hline S & $? 0.40$ & $j$ & 1 & 2 & $2 . ? 1$ & & & & \\
\hline$w$ & $\because 1.0 .5$ & 7 & 2 & 3 & 2.04 & & & & \\
\hline & & 1 & 4 & 1 & 2.09 & & & & \\
\hline$w$ & $2 ? .00$ & & & & 2.00 & $?$ & $?$ & 1 & 2.76 \\
\hline i1 & $? 2.2 .7$ & 1 & 2 & $i$ & 2.04 & & & & \\
\hline if & 23.711 & & & & 1.271 & 1 & 4 & $n$ & 1.07 .1 \\
\hline$w$ & n & 2 & 4 & 1 & 1.9 .34 & & & & \\
\hline in & 24.00 & $?$ & $?$ & 3 & $1.89{ }^{\circ}$ & $\begin{array}{l}? \\
?\end{array}$ & $\begin{array}{l}1 \\
3\end{array}$ & $\begin{array}{l}2 \\
0\end{array}$ & $\begin{array}{l}1.39 ; \\
1.90 .1\end{array}$ \\
\hline$\because$ & ) & 3 & 1 & 3 & 1.327 & 1 & 1 & 3 & $1.82 i$ \\
\hline 58 & $\therefore \div<0$ & & & & 1.811 & :) & 2 & 3 & 1.815 \\
\hline$\|$ & ; 55 & 1 & , & 2 & $18 \times 1$ & 2 & 3 & 1 & $1.31 ?$ \\
\hline$w$ & $25.4 n$ & $: 1$ & $\vec{n}$ & $\ddot{4}$ & 1.74 .4 & & & & \\
\hline & & 1 & 3 & $?$ & 1.793 & & & & \\
\hline ' & $2 ; .45$ & 4 & 3 & $?$ & $1.70 ?$ & & & & \\
\hline & & 1 & $n$ & 4 & 1.702 & & & & \\
\hline$w$ & 27.01 & 2 & $n$ & $\dot{4}$ & 1.065 & & & & \\
\hline $1+3$ & $2 \because .15$ & $?$ & $?$ & 14 & 1.657 & & & & \\
\hline 18 & $2,3.32$ & & & & $9.61 i$ & $\begin{array}{l}1 \\
3\end{array}$ & $\begin{array}{l}5 \\
1\end{array}$ & ?) & $\begin{array}{l}1.51 j \\
1.611\end{array}$ \\
\hline$M$ & $\therefore .90$ & 0 & 4 & $i$ & 1.546 & & & & \\
\hline 4 & 29.55 & 1 & 4 & $?$ & 1.513 & & & & \\
\hline$w$ & 29.35 & ; & 4 & $?$ & 1.505 & & & & \\
\hline$w$ & 24.05 & 4 & $l$. & 1 & 1.547 & & & & \\
\hline$w$ & sit. 00 & 3 & $n$ & 4 & $1.54 ?$ & & & & \\
\hline-1 & sii. & a) & 3 & 4 & 1.52 .1 & & & & \\
\hline$w$ & $3(1.0)$. & 4 & 4 & $?$ & $1.51 \%$ & & & & \\
\hline
\end{tabular}


APPENDIX FOUR 
FPRST EUROPEAN SMMPOSTUR ON THERLIAL ANALYSTS

The Chemical Society

Salford, 20-24th September, 1976.

THETHOGRAVDMETRIC SIUDIES OF ALKAIMINE

EAPTY NETAL SULPHTTES

by

D. R. Glasson and P. O'Neill

John Graymore Chemistry Laboratories,

Plymouth Polytechnic, Plymonth PL4 8AA, England. 


\title{
THERMOGRAVIMETRIC STUDIES OF ALKALINE
}

\section{EARTH MF.TAL SULPHITES}

\author{
By D. R. Glasson and P. O'Neill \\ John Graymore Chemistry Laboratories, \\ Plymouth Polytechnic, Plymouth PL4 8AA, \\ England.
}

Formation, thermal stability and oxidation of magnesium, calcium, strontium and barium sulphites have been investigated and compared with other metal sulphites.

The alkaline earth metal sulphites are produced either by precipitation frcm solution (by double decomposition of the metal salt with sodium sulphite) or by reaction of the metai oxide, hydroxide or carbonate with sulphur dioxide, as in the industrial removal of sulphur dioxide from filue gases. The hydrated forms are dehydrated completely in air or in vacuo at temperatures below $400^{\circ} \mathrm{C}$. At higher temperatures, atmospheric oxidation to sulphate becomes appreciable; stability to oxidation becomes greater with increasing atomic weight of the metal. In vacuo above $500^{8} \mathrm{C}$, there is some disproportionation to sulphate and sulphide, e.g., $4 \mathrm{CaSO}_{3}=3 \mathrm{CaSO}_{4} \neq \mathrm{CaS}$, and some decomposition to oxide occurs with stability again increasing with the atomic veight of the metal. Thus, $\mathrm{SrSO}_{3}$ only decomposes to oxide appreciably at temperatures above $900^{\circ} \mathrm{C}$ in vacuo and $11.00^{\circ} \mathrm{C}$ in nitrogen, while $\mathrm{BaSO}_{3}$ is stable up to $1000^{\circ} \mathrm{C}$ in this respect, but it disproportionates. This behaviour. of decomposition andior disproportionation is similar to that of the heavy metal sulphites such as those of $z$ inc and lead.

Typical thermograms are shown in Fig. 1 and 2. Thus, the TG curve in Fig. 1 for $\mathrm{CaSO}_{3}, \frac{1}{2} \mathrm{H}_{2} \mathrm{O}$ indicates that dehydration occurs in vacuo mainly between $200^{\circ}$ and $400^{\circ} \mathrm{C}$, while most of the CaSO decomposes to lime between $550^{\circ}$ and $750^{\circ} \mathrm{C}$, being accompanied by some disproportionation. There is greater stability in nitrogen atmospheres, most of the decomposition of the $\mathrm{CaSO}_{3}$ taking place at temperatures between $880^{\circ}$ and $1070^{\circ} \mathrm{C}$. Similarly, the DTA curves in Fig. 2 show endothermic peaks corresponding to these dehydrations and losses of $\mathrm{SO}_{2}$. In air, dehydration is followed immediately by oxidation which gives an exothermic peak at $460^{\circ} \mathrm{C}$. Decomposition of the sulphate begins at about $930^{\circ} \mathrm{C}$.

The thermal stability of the $\mathrm{CaSO}_{3}, \frac{1}{2} \mathrm{H}_{2} \mathrm{O}$ is reflected in the changes in surface area, caused by the dehydration, decomposition and disproportionation processes. .In Fig. 3, specific surfaces, $\underline{S}$, of the 

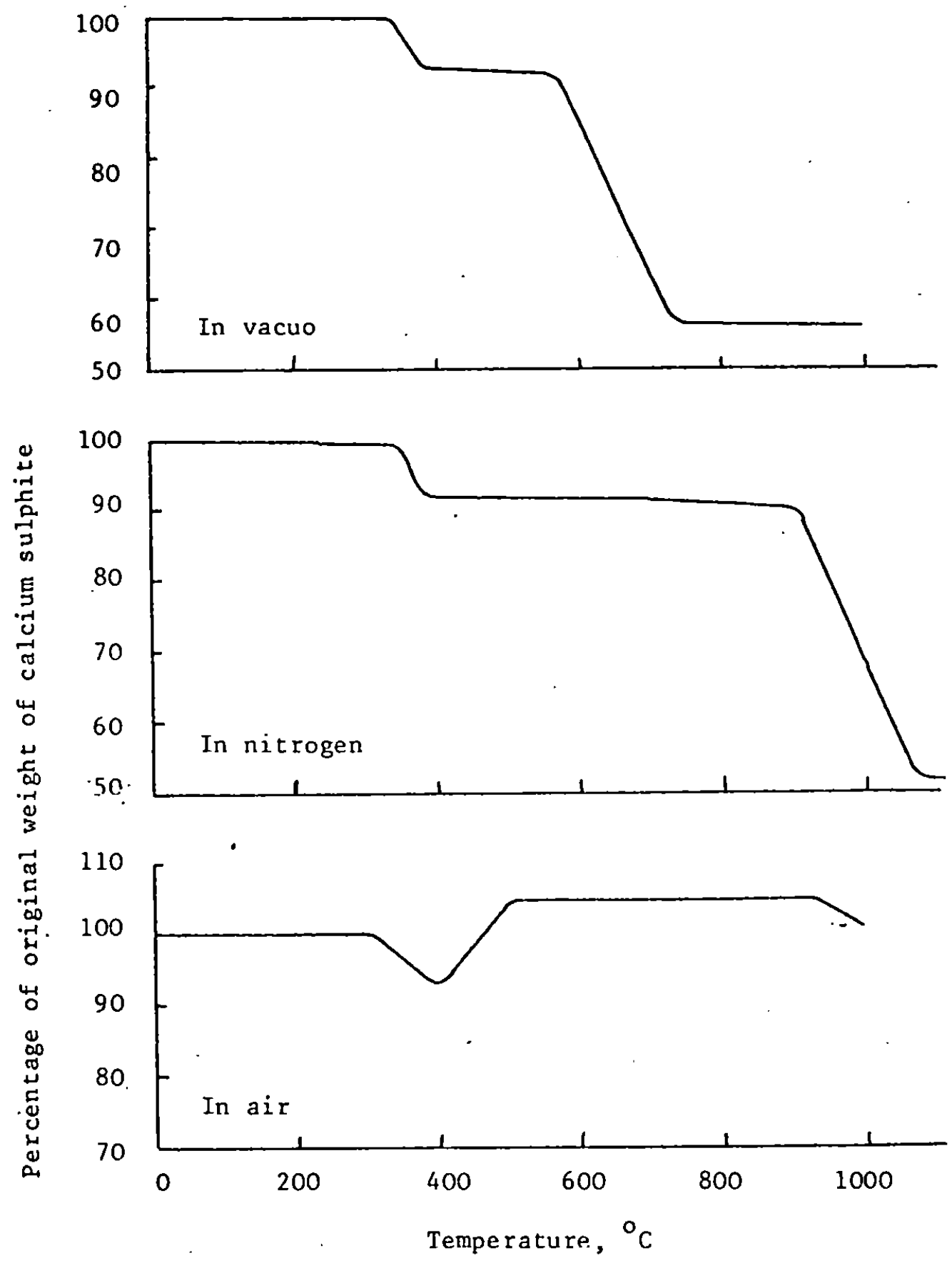

Fig. 1. Weight changes on heating $\mathrm{CaSO}_{3} \frac{1}{2} \mathrm{H}_{2} \mathrm{O}$ at $6^{\circ} \mathrm{Cmin}^{-1}$. 

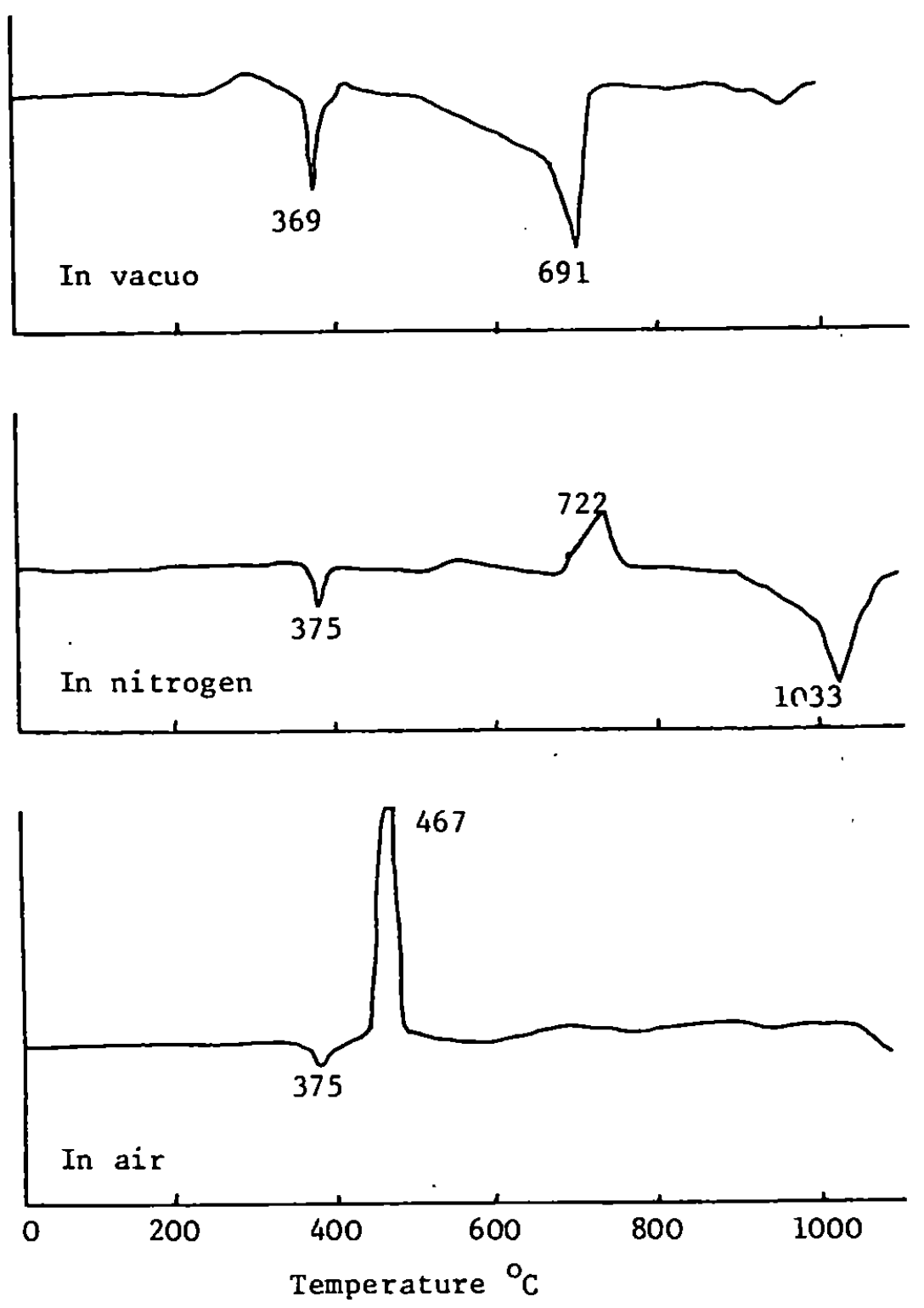

Fig. 2;- DTA curves for $\mathrm{CaSO}_{3} \cdot \frac{1}{2} \mathrm{H}_{2} \mathrm{O}$

(heating rate $6^{\circ} \mathrm{C} \min ^{-1}$ ) 


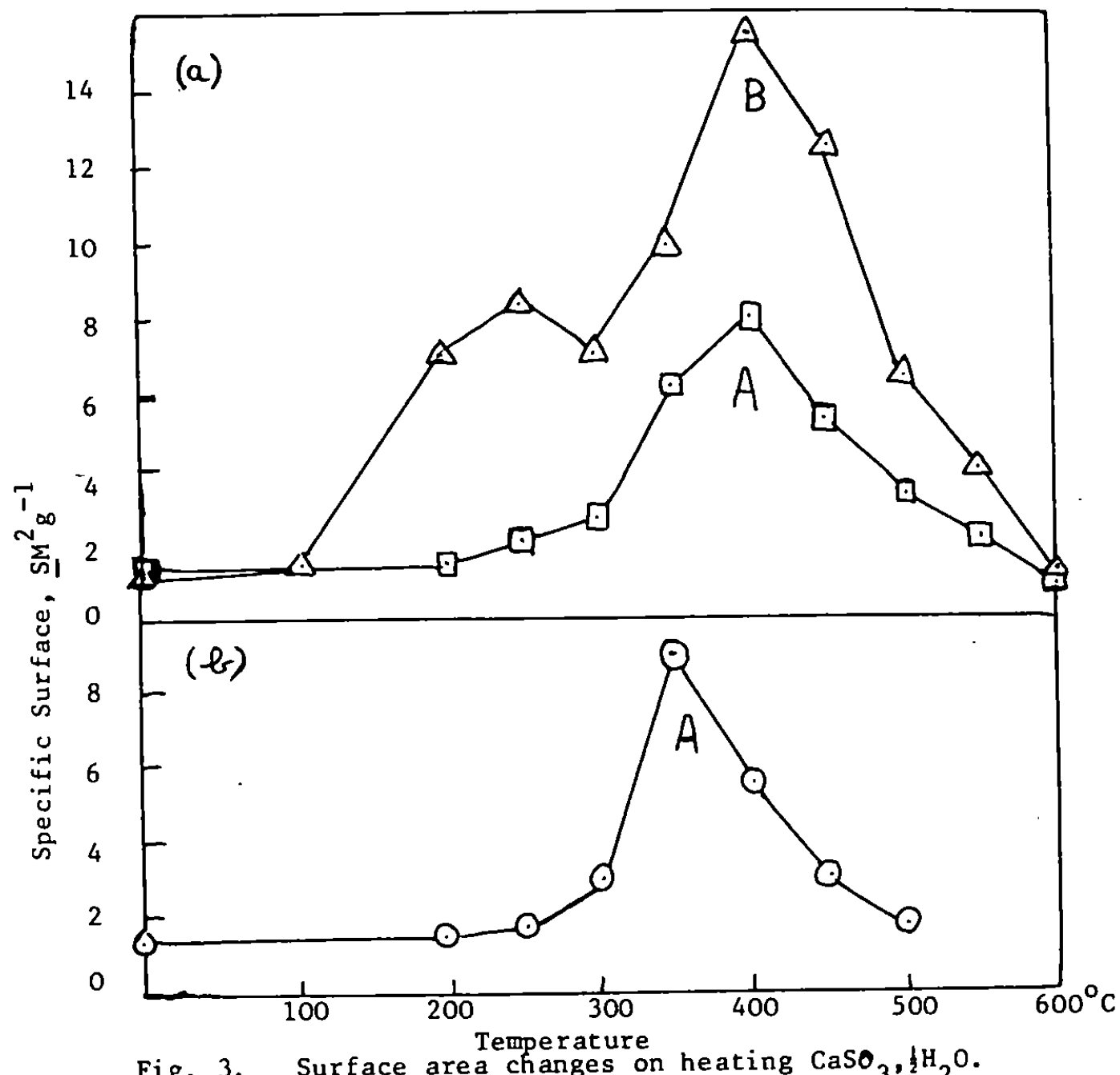

Fig. 3. Surface area changes on heating $\mathrm{CaSO}_{3}, \frac{1}{2} \mathrm{H}_{2} \mathrm{O}$.

products are shown for separate samples calcined for $2 \mathrm{~h}$. isothermally at a series of temperatures in vacuo (a) and in air (b). The maxima in at $400^{\circ} \mathrm{C}$ in the curves for the calcinations in vacuo corresponds to the complete dehydration of the samples from batches A and B. Batch A contains only $\mathrm{CaSO}_{3}, \frac{1}{2} \mathrm{H}_{2} \mathrm{O}$, but $B$ contains a molecular ratio of $3 \mathrm{CaSO}_{3}, \frac{1}{2} \mathrm{H}_{2} \mathrm{O}$ : $1 \mathrm{CaSO}_{4}, 2 \mathrm{H}_{2} \mathrm{O}$ and thus gives an additional peak at $250^{\circ} \mathrm{C}$, for the dehydration of the sulphate. The maximum for batch $B$ is increased considerably at $400^{\circ} \mathrm{C}$ compared with batch $\mathrm{A}$ by the crystal transformation $\gamma \rightarrow \mathrm{B}^{-\mathrm{CaSO}_{4}}$ (anhydrite), known to increase $\mathrm{S}$ from our previous research at temperatures about $350-400^{\circ} \mathrm{C}$. Hence, the dehydration of $\mathrm{CaSO}_{3}, \frac{1}{2} \mathrm{H}_{2} \mathrm{O}$ (batch $\mathrm{A}$ ) in air gives a maximum at $350^{\circ} \mathrm{C}$, with $S$ being increased somewhat by the onset of oxidation of the $\mathrm{CaSO}_{3}$ to $\mathrm{CaS} \mathrm{S}_{4}$ at the $\mathrm{\gamma} \rightarrow \mathrm{B}-\mathrm{CaSO}_{4}$ transition temperature. Direct oxidation to anhydrite is more extensive at the higher temperatures, when there is less of surface caused by sintering. There is also extensive sintering in vacuo at the higher temperatures $\left(600^{\circ} \mathrm{C}\right)$ when much of the $\mathrm{CaSO}_{3}$ decomposes to lime; the sintering is accelerated probably by the small amounts of lower-melting CaS formed in the disproportionation of some of the sulphite. 


\author{
SYMPOSIUM ON THERMAL ANALYSIS AND CALORIIIETRY \\ JOURNEES DE CALORIMETRIE ET D'ANALYSE THERMIQUE \\ The Chemical Society \\ Association Francaise de Calorimétrie et d'Analyse \\ Thermique \\ P1ymouth, Fngland, 19th-21st September 1977.
}

HOT-STAGE MICROSCOPY OF ALKALINE EARTU METAL SULPHITES

By P. O'Neill

John Graymore Cheñistry Laboratories, Plymouth Polytechnic, Plymouth PLA 8AA, U.K. 


\section{EARTH METAL SULPHITES}

By P. O'Neill

\section{John Graymore Chemistry Laboratories,}

Plymouth Polytechnic, Plymouth PL4 8AA,

England

Further investigations have been made of the thermal stability of magnesium, calcium, strontium and barium sulphites using hot-stage microscopy to identify the temperatures for the decomposition and disproportionation reactions, and to observe the formation of the products, especially nucleation and the changes in crystal morphology and size.

Thermograms previously presented for $\mathrm{CaSO}_{3}, \frac{1}{2} \mathrm{H}_{2} \mathrm{O}$ (1) indicated that dehydration in vacuo xccurred nainly between $200^{\circ}$ and $400^{\circ} \mathrm{C}$, while most of the $\mathrm{CaSO}_{3}$ decomposed to 1 ine between $550^{\circ}-750^{\circ} \mathrm{C}$, being accompanied by some disproportionation. This is further illustrated by comparing the weight losses for separate samples calcined for $2 \mathrm{~h}$ isothermally at a series of temperatures, cf. Fig. $1(a)$ and (c). The thermal stabilicy is reflected also in the changes in surface area caused by the dehydration, sulphite decomposition and disproportionation

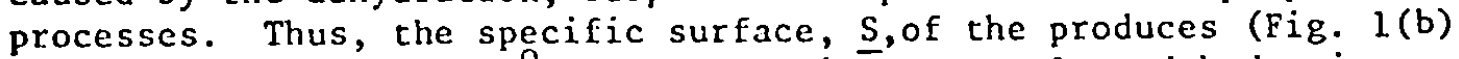
reaches a maximum at $400^{\circ} \mathrm{C}$, corresponding to complete dehydration. . The average crystallite sizes (equivalent spherical dismeters) of the products have been calculated from $S$ and the $X$-ray densitics (determined as $2.55,2.40$ and 3.34 for $\mathrm{CaSO}_{3}, \frac{1}{2} \mathrm{H}_{2} \mathrm{O}, \mathrm{CaSO}_{3}$ and $\mathrm{CaO}$ respectively), and the fractional increases in the numbers of crystallites have been deduced (cube of the size ratio of the initial reactant and the product) (2); these are compared in Fig. 1(d), where each initial crystal of $\mathrm{CaSO}_{3}, \frac{1}{2} \mathrm{H}_{2} \mathrm{O}$ splits into about 1150 crystallites of $\mathrm{CaSO}_{3}$ on complete dehydration in vacuo at $400^{\circ} \mathrm{C}$. This corresponds to a reduction in size from about $1.7 \mu \mathrm{m}$ to $0.3 \mu \mathrm{m}$. Decomposition and disproportionation of the $\mathrm{CaSO}_{3}$, viz. (i) $\mathrm{CaSO}_{3}=\mathrm{CaO}+\mathrm{SO}_{2}$ and (ii) $4 \mathrm{CaSO}_{3}=3 \mathrm{CaSO}_{4}+\mathrm{CaS}$, is accompanied by sintering, probably caused by small amounts of the lower-melting CaS acting as a mineraliser. Therefore, the produce at $600^{\circ} \mathrm{C}$ (mainly 1 ime) has an average crystallite size of as much as $3.4 \mu \mathrm{m}$. These changes are confirmed by electron-microscopy, using a Philips EM 300 microscope with hot-stage attachment with a temperature range of up to $1000^{\circ} \mathrm{C}$

Similar studies have been made of the thermal behaviour of magnesium, strontium and barium sulphites.

Acknowledgements

The author thanks Dr. D.R. Glasson and Mr. L.C. Anderson for their interest and encouragement in this work; also Imperial Chemical

Industries Ltd. and the Science Research Council, U.K. for sponsorship. 

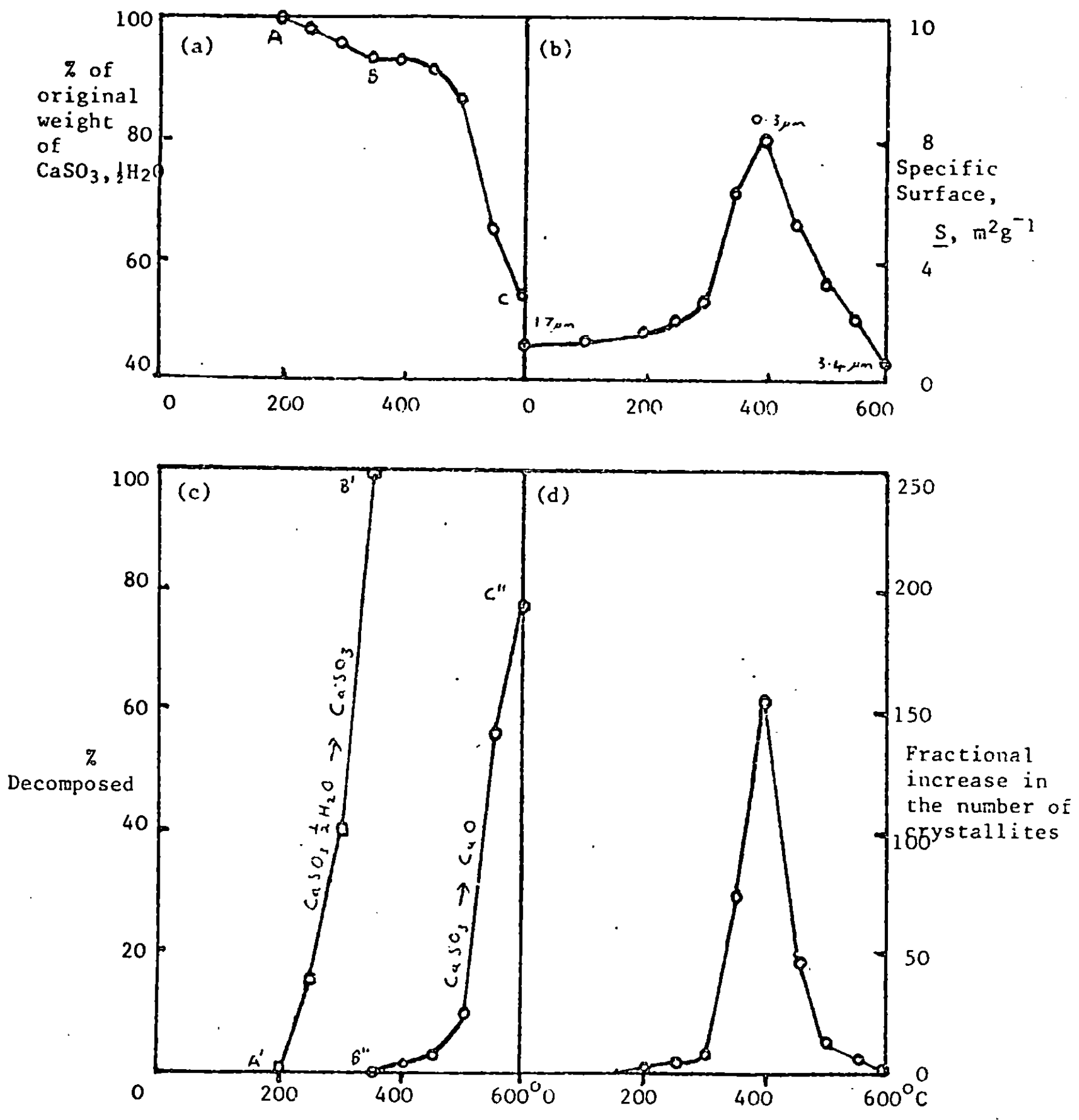

Calcination temperature

Fig. 1. Thermal decomposition of $\mathrm{CaSO}_{3}, \frac{1}{2} \mathrm{H}_{2} \mathrm{O}$ in vacuo: 2h-calcinations at fixed temperatures. 


\section{References}

1. D.R. Glasson and P. O'Neill, Proc. First European Symposium Thermai Analysis, Salford, England, 1976, pp. 283-86 (London: Heycen)

2. D.R. Glasson, J. appl. Chem., Jond., 1958, 8, 798-803 
SYMPOSIUM ON THE CHARACTERISATION OF POROUS SOLIDS Neuchâtel 9-13th July

POROSITY OF ABSORBENTS FOR DESULPHURISATION OF INDUSTRIAL FLUE GASES

\section{by}

Douglas R. Glasson and Peter $0^{\prime}$ Neill

John Graymore Chemistry Laboratories,

Plymouth Polytecinic, P1ymouth, PL4 8AA, England. 
POROSITY OF ASSORBENTS FOR DESULPHURISATION OF INDUSTRIAL FLUE GASES

by

Douglas R. Glasson and Feter O'Neill,

John Graymore Chemistry Laboratories,

Plymouth Polytechnic, Plymouth PL4 8AA, England

\begin{abstract}
The reactivity of calcareous materials used as absorbents for desulphurising industrial flue gases depends mainly on their alkaliniiy and surface activity. Dynamic thermogravimetric studies indicate that only quicklime or hydrated $i$ ivie can be considered reasonably as industrial desulphurising agents for use below $500^{\circ} \mathrm{C}$, such as required in electricity power plants where the flue gases leave the economisers at just below $400^{\circ} \mathrm{C}$. For higher-temperature desulphurisation, above $700^{\circ} \mathrm{C}$, calcium-carbonate based reactants appear to be the most satisfactory.

In practice, reaction temperatures need to be such that the maximum rate of sulphur dioxide absorption by both hydrated and carbonated limes occurs as they decompose to quicklimes. This minimises blockage of pores in the absorbents caused by sintering and reaction with sulphur dioxide to form calcium sulphite.
\end{abstract}

Gas sorption studies provide quantitative information regarding variations in surface area and porosity of the absorbents during desulphurisation processes. 


\section{Introduction}

The reactivity of sulphur dioxide absorbents, such as 1 ime and related materials, depends mainly on their alkalinity and surface activity. Commercially-available milled limestone and dolomite are generally above micron crystallite size (i.e., specific surface below $2 \mathrm{~m}^{2} \mathrm{~g}^{-1}$ ), and can be reduced to $0.1 \mathrm{~mm}$ size (ca. $20 \mathrm{~m}^{2} \mathrm{~g}^{-1}$ ) crily by specialised milling (1). More expensive precipitated calcium carbonate is available down to $0.1 \mu \mathrm{m}$ size as is comnercial hydrated lime (Limbux) at more reasonable cost.

The porosity of lime obtained on decomposition of limestone $\left(900-1000^{\circ} \mathrm{C}\right)$ has been investigated by Anderson and Vernon (2). Since very little change occurs in external dimension, the lime produced is highly porous and has an apparent density of $1.5-1.6 \mathrm{gcm}^{-3}$ compared with $3.3 \mathrm{gcm}^{-3}$ when it is completely fused and $2.7 \mathrm{gcm}^{-3}$ for the original limestone. A lime like this with low density has a comparatively high specific surface, a sponge-like structure (as shown by scanning-electron micrographs comparing limes of densities 1.7 and $2.4 \mathrm{gcm}^{-3}$ ).

The uptake of sulphur dioxide by lime gencrally produces $\mathrm{CaSO}_{3}$ at lower temperatures (below $300^{\circ} \mathrm{C}$ ) and $\mathrm{CaSO}_{4}$ at higher temperatures $\left(300-1000^{\circ} \mathrm{C}\right.$ ). The voidage in lime of apparent density 1.52 is about $55 \%$ of the total volume. The $\mathrm{X}$-ray densities of $\mathrm{CaSO}_{3}$ and $\mathrm{CaSO}_{4}$ are 2.41 (present work) and 2.96 (A.S.T.M. value), so that voidage is only sufficient to accommodate $\mathrm{SO}_{2}$ uptakes of $61 \%$ and $69 \%$ of theoretical respectively, without external expansion being required; thus considerable loss of porosity is expected in practice. The uptake of $\mathrm{SO}_{2}$ by hydrated lime gives volume increases of $50 \%$ and $39 \%$ in forming $\mathrm{CaSO}_{3}$ and $\mathrm{CaSO}_{4}$ respectively. For limestone, corresponding increases of $35 \%$ and $25 \%$ are given.

In milled limestone, the closest possible packing of particles (assumed approx. spherical) within the aggregates would still only leave a total voidage just sufficient to accommodate complete conversion to $\mathrm{CaSO}_{3}$. The particles of milled $\mathrm{CaCO}_{3}$ have comparatively little porosity, but after intensive milling porosity can be developed by uptake of water vapour (3). Precipitated calcium carbonates ( $\underline{s}=1$ to $20 \mathrm{~m}^{2} \mathrm{~g}^{-1}$ ) vary in features from highly-crystalline with open surfaces to almost exclusively microporous structures $(3-6)$.

In the present work, variations in surface area and porosity of calcareous absorbents during desulphurisation of gases have been compared. 


\section{Materials}

For absorbents, initially hydrated lime, "Limbux", specific surface, $\underline{S}=14.2 \mathrm{~m}^{2} \mathrm{~g}^{-1}$, was obtained from I.C.I. and carbonated lime, precipitated calcium carbonate, "Calofort $U^{\prime}, \underline{S}=18.9 \mathrm{~m}^{2} \mathrm{~g}^{-1}$, was obtained from Sturges. As a standard for X-ray identification purposes and volume or density determinations, calcium sulphite hemihydrate was prepared by precipitation from solutions of ${\mathrm{M}-\mathrm{CaCl}_{2}}_{2}$ and $\mathrm{M}-\mathrm{Na}_{2} \mathrm{SO}_{3}$. The crystais of $\mathrm{CaSO}_{3}, \frac{1}{2} \mathrm{H}_{2} \mathrm{O}$ had lattice constants of $\underline{a}=6.45 \mathrm{~A}, \underline{b}=9.78 \mathrm{~A}, \underline{c}=10.66 \mathrm{~A}$, giving an $\mathrm{X}-\mathrm{ray}$ density, $D_{x}=2.55$ (powder data) in good agreement with single crystal data $\underline{a}=6.49 \mathrm{~A}, \underline{b}=9.81 \mathrm{~A}, \underline{c}=10.66 \mathrm{~A}$. The hemihydrate was dehydrated $\underline{\text { in }}$ vacuo at $400^{\circ} \mathrm{C}$ for $2 \mathrm{~h}$ giving $\mathrm{CaSO}_{3}$ with $\underline{a}=6.45 \mathrm{~A}, \underline{b}=9.42 \mathrm{~A}$, $\underline{c}=10.60 \mathrm{~A}, \mathrm{D}_{\mathrm{x}}=2.41$ (powder data).

For dynamic thermogravimetric studies, the following absorbents were used (Table I).

\section{Table I}

Absorbents used in dynamic thermogravimetric studies

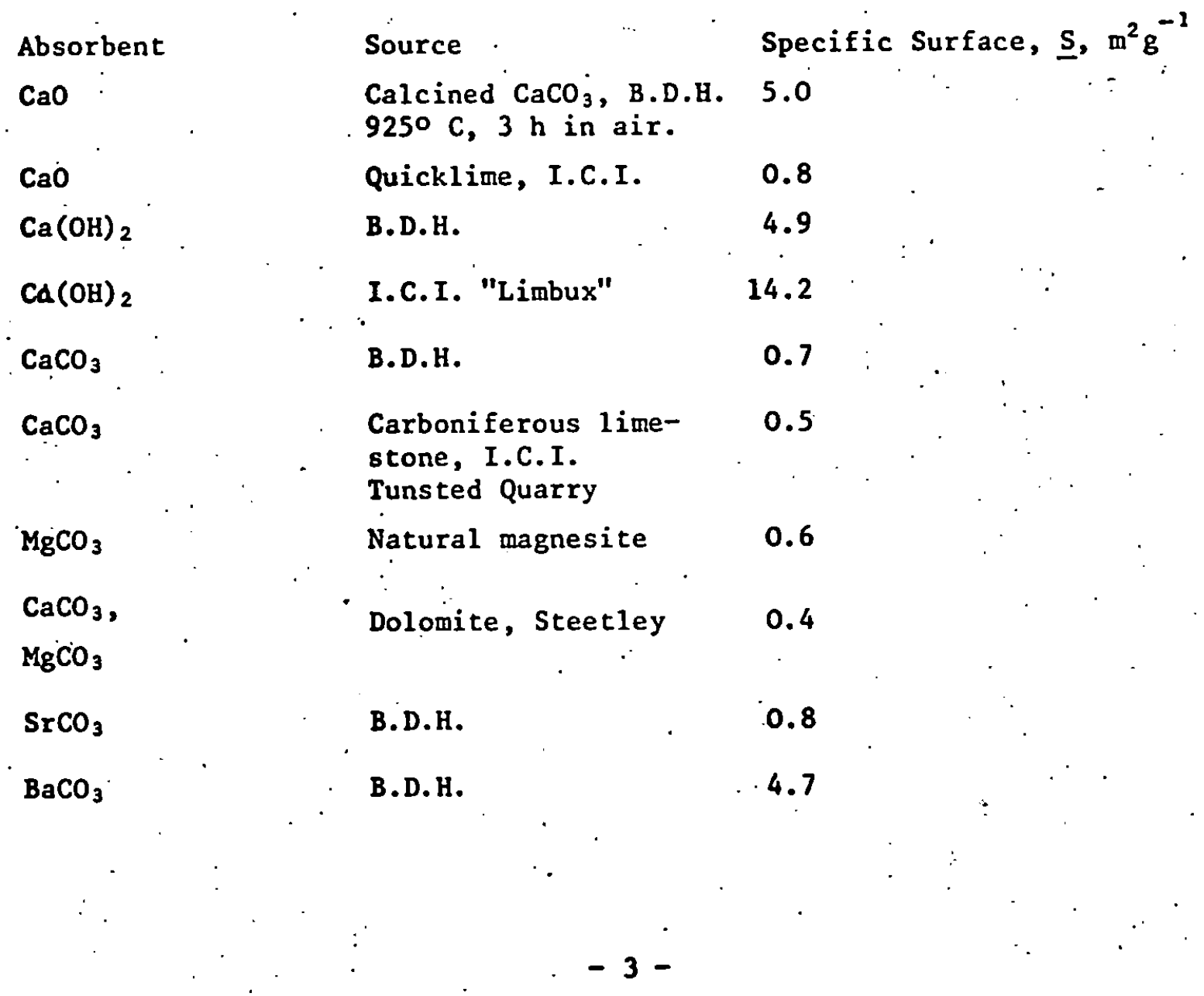




\section{Procedure}

$5 \mathrm{~g}$-samples of hydrated lime ("Limbux", specific surface $\underline{S}=14.2 \mathrm{~m}^{2} \mathrm{~g}^{-1}$ ) and carbonated lime ("Calofort $U ", S=18.9 \mathrm{~m}^{2} \mathrm{~g}^{-1}$ ) were reacted with sulphur dioxide for $2 \mathrm{~h}$ in combustion tubes at a series of fixed temperatures from $200-1100^{\circ} \mathrm{C}$. The gas was passed through at constant streaming rates $\left(5 \mathrm{~h} \mathrm{~h}^{-1}\right)$ and was moistened beforehand by passing it through wate ${ }_{2} \mathrm{fSO}_{2} \mathrm{SO}_{2}$ on wet charges industrially. Blank experiments were performed using nitrogen in place of sulphur dioxide.

The specific surfaces of the cooled samples were determined gravimetrically by the B.E.T. method (7) from nitrogen sorption isotherms at $-183^{\circ} \mathrm{C}$ recorded on an electrical sorption balance ( 8$)$, (9). The average crystallite sizes (equivalent spherical diameters) were deduced from the specific surfaces and $x$-ray densities. The initial samples and the products were $x$-rayed for phase identification and analysed thermally and volumetrically for water content, alkalinity and sulphur compounds.

In the dynamic thermogravimetric studies, DTG, using a mass-flow balance, the atmospheres were (a) 2 vol-? $\mathrm{SO}_{2}$ in $\mathrm{N}_{2}$, (b) 0.8 vol-\% $\mathrm{SO}_{2}$ in $\mathrm{N}_{2}$, (c) 0.8 vol-\% SO $2+8.2$ vol $-\% \mathrm{O}_{2}$ in $\mathrm{N}_{2}$ and (d) $\mathrm{N}_{2}$ alone, with heating rates of $5^{\circ} \mathrm{Cmin}^{-1}$ and flow rates of $11 \mathrm{~min}^{-1}$. These methods give (i) a comparison. of the relative reaction rates at different temperatures on the same sample and (ii) indication of the reactions during the period in which a cold particle was raised in temperature to that of the hot gas into which it was injected, as in an industrial dry flue gas desulphurisation. Simultaneous DTA and TG measurements did not provide much more useful information, since the sulphur dioxide reaction rates were often insufficient to give a marked temperature difference between the sample and reference material. The relative effectiveness of the above absorbents in reacting with sulphur dioxide could be rapidly seen by comparing the variation in reaction rates with temperature and gas composition for each solid reactant. This indicated that only calcium oxide or calcium hydroxide could be reasonably considered as industrial desulphurising agents for use below $500^{\circ} \mathrm{C}$.

The greater reactivity of the calcium hydroxide samples at temperatures lower than those required for the other absorbents was related to the simultaneous formation of activated calcium oxide, especially at temperatures above about $400^{\circ} \mathrm{C}$, cf. also Fig. 2 and earlier research (9). Accordingly, further 
samples of the same batch of Limbux were decomposed to quicklime by calcining in vacuo at $500^{\circ} \mathrm{C}$ (heating rate $8^{\circ} \mathrm{C} \mathrm{min}^{-1}$, before holding at this tenperature for a total time of $2 \mathrm{~h}$ ). Then the products were heated in streams of nitrogen, with or without sulphur dioxide, at fixed temperatures for different lengths of time. After cooling in nitroger, surface areas and changes in porosity characteristics caused by sintering and reaction with sulphur dioxide were determined from nitrogen sorption isotherms at $-196^{\circ} \mathrm{C}$ recorded $g=a v i-$ metrically.

\section{Results}

Variations in specific surface when samples of Calofort $U$ and Limbux react with wet sulphur dioxide at different temperatures are presented in Fig. 1 and 2 where they are compared with the calcinations in wet nitrogen.

Decompositions of $\mathrm{Ca}(\mathrm{OH})_{2}$ and $\mathrm{CaCO}_{3}$ were practically complete within $2 \mathrm{~h}$ in wet nitrogen at tempteratures above $500^{\circ}$ and $700^{\circ} \mathrm{C}$ respectively. The specific surfaces of the quicklimes produced from the hydroxide were generally similar to those obtained in air, but the limes from the $\mathrm{CaCO}_{3}$ had much lower specific surfaces than those producei by calcination of either precipitated calcium carbonate or calcium oxalate in air (10). Although the $\mathrm{CaCO}_{3}$ does not thermally decompose below $500^{\circ} \mathrm{C}$, nevertheless it reacts with the $\mathrm{SO}_{2}$, giving products of composition shown in Table II.

Table II

Reactivity of $\mathrm{CaCO}_{3}$ (Calofort $U$ ) with $\mathrm{SO}_{2}$

Temperature

$200^{\circ} \mathrm{C}$
$300^{\circ}$
$400^{\circ}$
$500^{\circ}$

Products

$91.0 \% \mathrm{CaCO}_{3}, 9.0 \% \mathrm{CaSO}_{3}, \frac{1}{2} \mathrm{H}_{2} \mathrm{O}$

$86.4 \% \mathrm{CaCO}_{3}, 13.6 \% \mathrm{CaSO}_{3}, \frac{1}{2} \mathrm{H}_{2} \mathrm{O}$

$81.2 \% \mathrm{CaCO}_{3}, 18.8 \% \mathrm{CaSO}_{3}$

$47.5 \% \mathrm{CaCO}_{3}, 52.5 \% \mathrm{CaSO}_{3}$ *

* tending to disproportionate to $\mathrm{CaSO}_{4}$ and $\mathrm{CaS}$

Fig. 3-7 show a typical sorption isotherm and changes in pore volume distribution and cumularive pore volume for samples of Limbux, $\mathrm{Ca}(\mathrm{OH})_{2}$, calcined at $500^{\circ} \mathrm{C}$ in vacuo and then treated with $\mathrm{SO}_{2}$ at $300^{\circ}$ and $500^{\circ} \mathrm{C}$.

\section{Discussion}

Desulphurisation of wet flue gases

The reaction between $\mathrm{CaCO}_{3}$ and $\mathrm{SO}_{2}$ (Fig. 1 and Table II) at lower temperatures, 
up to about $500^{\circ} \mathrm{C}$, is $\mathrm{CaCO}_{3}+\mathrm{SO}_{2}=\mathrm{CaSO}_{3}+\mathrm{CO}_{2}$, i.e., of type Solid $\mathrm{A}+$ Gas I = Solid B + Gas II. The products tend to split away from the remining $\mathrm{CaCO}_{3}$, so that high surface areas are maintained. However, at higher temperatures where $\mathrm{CaCO}_{3}$ can decompose to $\mathrm{CaO}$, there is considerable loss of surface, probably caused by extensive sintering of the products with ultimate loss of porosity. Reaction of $\mathrm{SO}_{2}$ with the hydrated lime caused loss of surfaces at all temperatures (Fig. 2) with considerable agglomeration ("caking") of the samples above $500^{\circ} \mathrm{C}$, when much of the $\mathrm{CaSO}_{3}$ disproportionated to $\mathrm{CaSO}_{4}$ and $\mathrm{CaS}$. If accessible, the latter could regenerate-CaO by hydrolysis (with the moisture present), so that ultimately all of the CaO should convert to $\mathrm{CaSO}_{4}$. In practice, reaction temperatures are such that the maximum rate of $\mathrm{SO}_{2}$ absorption by both carbonated and hydrated limes occurs as they decompose to quicklimes.

Desulphurisation of dry flue gases

Changes in porosity (11) during uptake of $\mathrm{SO}_{2}$ are illustrated in more detail in Fig. $3-7$. Fig. 3 is a typical nitrogen sorption isotherm, showing hysteresis at relative pressures above about 0.5 . Fig. $4-7$ show the changes in pore volume distribution and cumulative pore volume for samples of Limbux, $\mathrm{Ca}(\mathrm{OH})_{2}$, calcined at $500^{\circ} \mathrm{C}$ in vacuo and then treated with sulphur dioxide at $300^{\circ} \mathrm{C}$ or $500^{\circ} \mathrm{C}$. As is clearly seen, the conversion to $\mathrm{CaSO}_{3}$ caused a marked decrease in the smaller pores. The proportion of surface area due to pores also decreases as the amount of $\mathrm{SO}_{2}$ uptake increases; a feature which would follow from the preferential filling of the smaller pores, cf. Table III, for samples reacted with $\mathrm{SO}_{2}$ at $500^{\circ} \mathrm{C}$. 
Table III. Changes in surface areas of samples of calcium oxide after heating in various atmospheres.

\begin{tabular}{|c|c|c|c|c|c|c|c|}
\hline \multirow{2}{*}{$\begin{array}{l}\text { Sample } \\
\text { Compo- } \\
\text { sition }\end{array}$} & \multicolumn{3}{|c|}{ Heating conditions } & \multirow{2}{*}{$\begin{array}{l}\text { Specific } \\
\text { surface } \\
\mathrm{m}^{2} \mathrm{~g}^{-1}\end{array}$} & \multirow{2}{*}{$\begin{array}{l}\text { Pore Wall } \\
\text { area } \\
\mathrm{m}^{2} \mathrm{~g}^{-1}\end{array}$} & \multirow{2}{*}{$\begin{array}{l}\text { Pore area } \\
\begin{array}{l}\text { Specific } \\
\text { surface }\end{array}\end{array}$} & \multirow{2}{*}{$\begin{array}{l}\text { No. of } \\
\text { sulphite } \\
\text { layers }\end{array}$} \\
\hline & $\begin{array}{l}\text { Gas } \\
\text { composition }\end{array}$ & $\begin{array}{l}\text { Temperature } \\
{ }^{\circ} \mathrm{C} \text {. }\end{array}$ & $\begin{array}{l}\text { Time } \\
\text { minutes }\end{array}$ & & & & \\
\hline $\begin{array}{l}\mathrm{CaO} \\
\mathrm{CaO}+ \\
2.8 \% \\
\mathrm{CaSO}_{3} .\end{array}$ & $\mathrm{N}_{2}$ & $500^{\circ}$ & 5 & $\begin{array}{l}62.2 \\
32.9\end{array}$ & $\begin{array}{r}58.6 \\
25.2\end{array}$ & $\begin{array}{c}0.94 \\
\vdots \\
0.77\end{array}$ & 0.4 \\
\hline $\begin{array}{l}\mathrm{CaO} \\
\mathrm{CaO}+ \\
21.2 \% \\
\mathrm{CaSO}_{3}\end{array}$ & $\begin{array}{l}\mathrm{N}_{2} \\
\mathrm{~N}_{2}+\mathrm{SO}_{2}\end{array}$ & 500 & 60 & $\begin{array}{r}54.7 \\
9.4\end{array}$ & 5.3 & $\begin{array}{l}0.77 \\
0.67\end{array}$ & 3.8 \\
\hline $\begin{array}{l}\mathrm{CaO} \\
\\
\mathrm{CaO}+ \\
1.4 \% \\
\mathrm{CaSO}_{3}\end{array}$ & $\begin{array}{c}\mathrm{N}_{2} \\
\mathrm{~N}_{2}+\mathrm{SO}_{2}\end{array}$ & . & 5 & $\begin{array}{l}64.5 \\
39.5\end{array}$ & 28.7 & $\begin{array}{l}0.96 \\
0.73\end{array}$ & 0.2 \\
\hline
\end{tabular}

Gas compositions:- $\mathrm{N}_{2} \quad$ contains only nitrogen.

$\mathrm{N}_{2}+\mathrm{SO}_{2}$ contains 99.5 vol. $\% \mathrm{~N}_{2}+0.5$ vol. $\% \mathrm{SO}_{2}$ 
This is confirmed by calculating the percentage change in volume on conversion to $\mathrm{CaSO}_{3}$ and comparing this with the actual decrease in porosity. It is found that the measured porosity is less than the calculated porosity for the samples; Pable.IV, which indicates that, pores are being blocked. The number. of layers of $\mathrm{CaSO}_{3}$ was estinated from the specific surface of the non-sulphited sample, assuming that. the average area occupied by each $\mathrm{CaSO}_{3}$ group was $19.5 \mathrm{~A}^{2}$. This gave apparent coverages of $0.2,0.4$ and 3.8 sulphite layers for the 3 sample in Table III and Fig. 4-7. The low coverages of 0.2 and 0.4 in Table III are accompanied; however, by marked reductions in specific surface indicating blocking of the pores rather than complete filling; a comparison of pore wall area with total specific surface also shows excessive reduction. At these temperatures, reduction in specific surface and pore volumes due to sintering are comparatively small, as exemplified by "blank" experiments in which the quicklime is heated in nitrogen alone for similar lengths of time, cf. CaO samples in Table III. This pore blocking is analogous to that found earlier in the recasbonation of calcined limestone, where not more than $80 \%$ of the carbon dioxide initially evolved can be replaced in the quicklime (12).

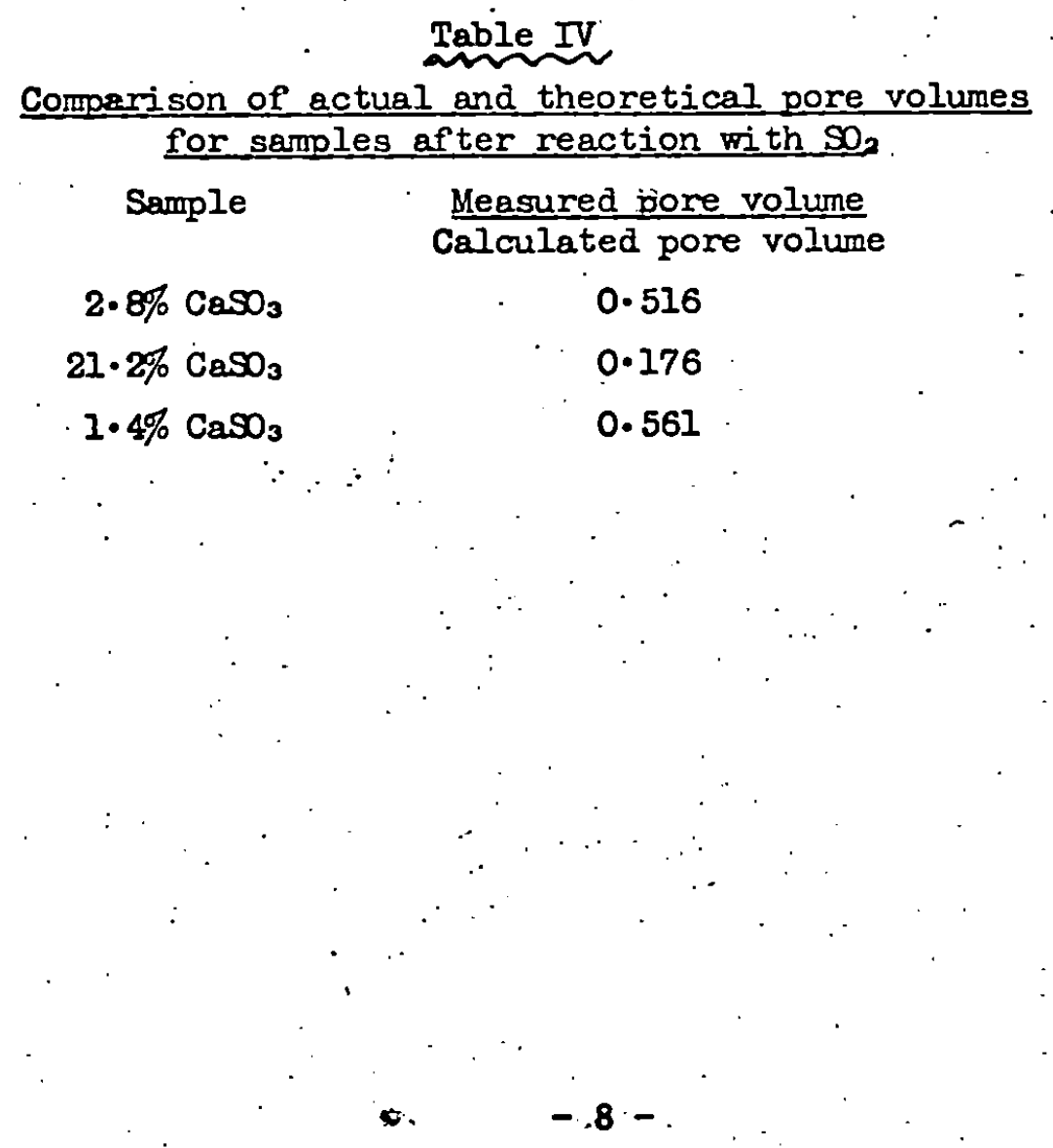




\section{Acknowledgments}

The authors thank Mr. L.C. Anderson for his interest and encouragement in this research; also Imperial Chemical Industries Ltd. (Mond Division) and the Science Research Council, U.K., for sponsorship.

\section{References}

1. R.B. Gammage, D.R. Glasson and R. Srodzinski, 2nd Anglo-French Symposium on Thermal Analysis (Chem. Soc. - A.F.C.A.T.), Plymouth, September 1977, Proceedings, pp. 97-100.

2. L.C. Anderson and J. Vernon, J. Iron St. Inst., 1970, 208, (4), 329-35.

3. R.B. Gamnage, H.F. Holmes, E.L. Fuller Jr., and D.R. Glasson, J. Colloid Interface Sci., 1974, 47, (2), 350-64.

4. R.B. Gammage and D.R. Glasson, J. Colloid Interface Sci., 1976, 55, (2), 396-401; idem., "Colloid and Interface Science". Vol. V, pp. 437-52 (Londor: Academic Press, 1976).

5. F. Stoeckli, H. Sophal and A. Perret, Helv. Chim. Acta, 1976, 59, 2653-6.

6. F. Stoeckli and J.P. Dubois, Bull. Soc. fr. Min. Crist., 1977, $100,104-5$.

7. S. Brunauer, P.H. Emmett and E. Teller, J. Amer. chem. Soc., $1938,60,309$.

8. S.J. Gregg, J. chem. Soc., 1946, pp. 561-3.

9. D.R. Glasson, J. chem. Soc., 1956, pp. 1506-10.

10. D.R. Glasson, J. app1. Chem., London, 1958, 8, 793-7.

11. S.J. Gregg and K.S.W. Sing, "Adsorption, Surface Area and Porosity", (London: Academic Press, 1967).

12. D.R. Glasson, J. appl. Chem., London, 1960, 10, 42-8. 


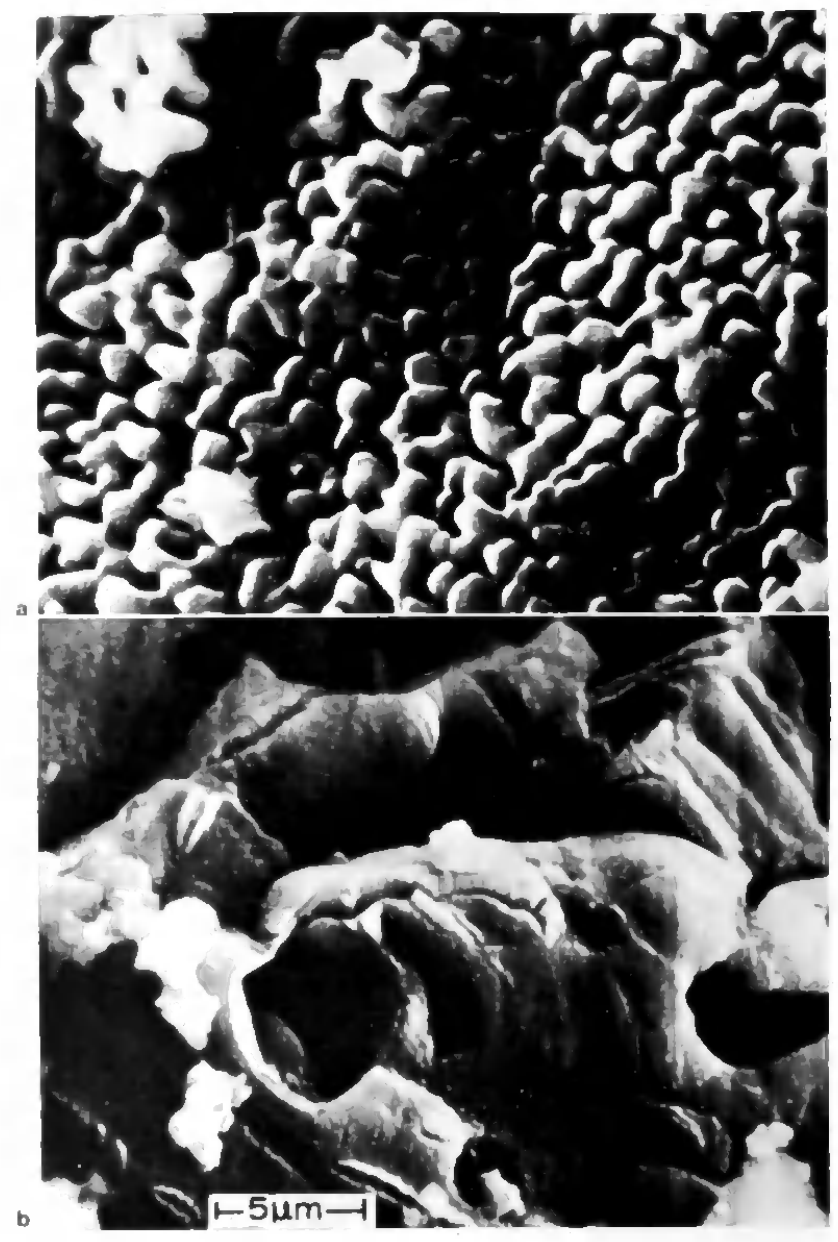

a lime density $1.7 \mathrm{~g}^{-\mathrm{cm}^{3}:}, b$ lime density $2.4 \mathrm{~g} / \mathrm{cm}^{3}$

igtereoscan micrographs of internal surfaces of lime 
Variations in surface area of absorbents during desulphurisation of: gases

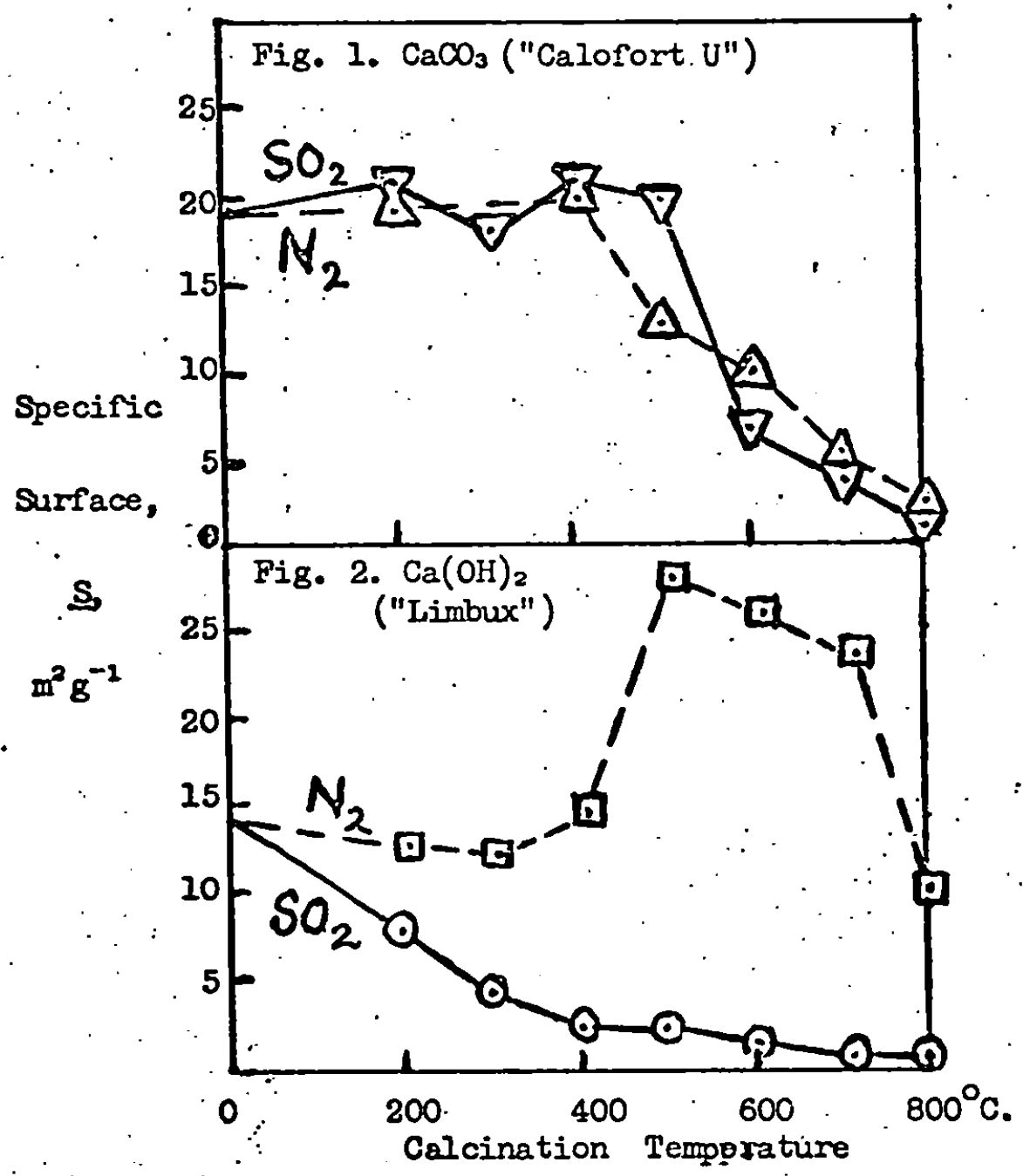


Fig 3. Typical sorption isotherm of a calcareous absorbent

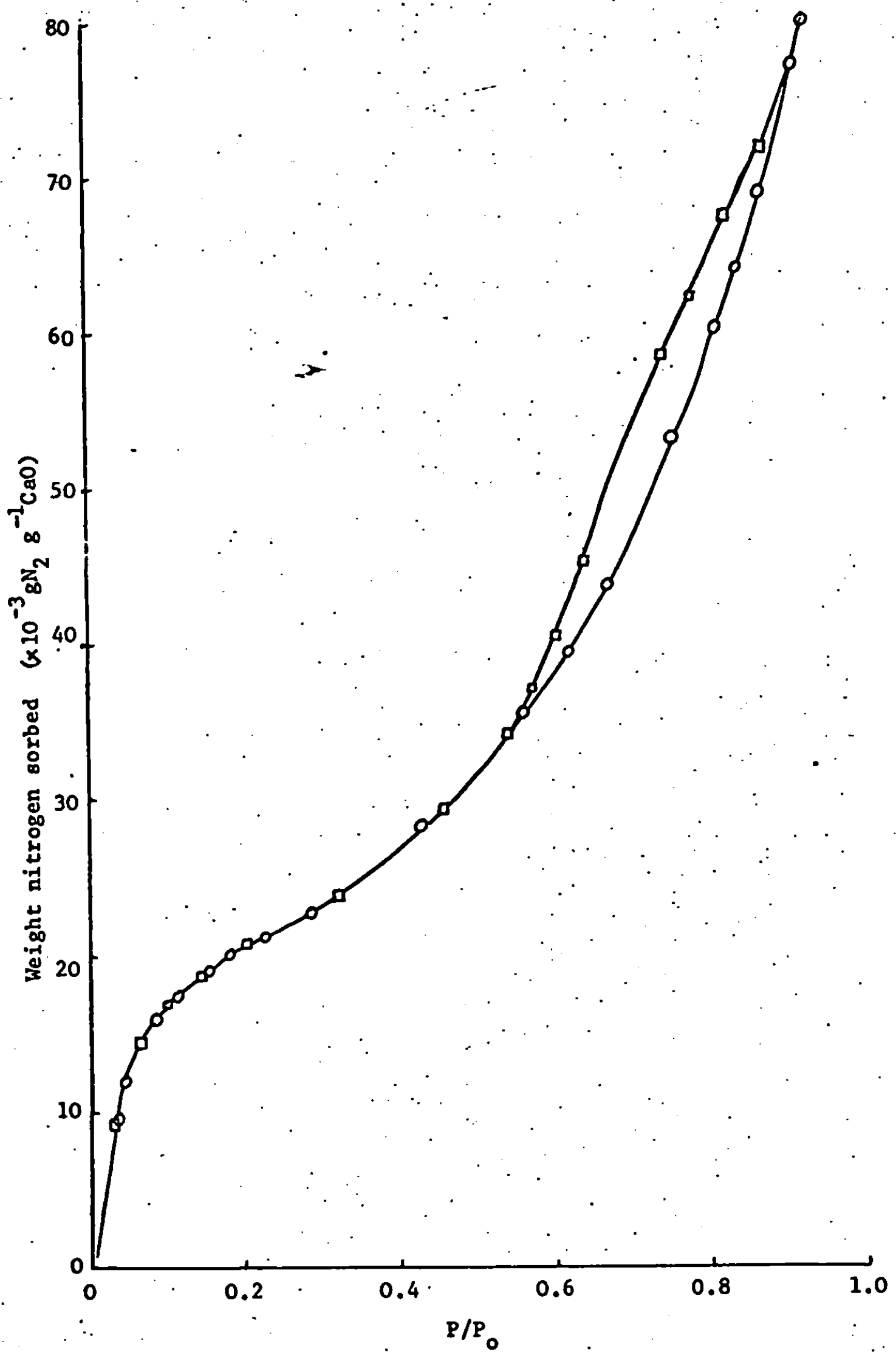

- Sorption .

- Desorption 
Flg. 4. Pore size distribution in calcined Limbux

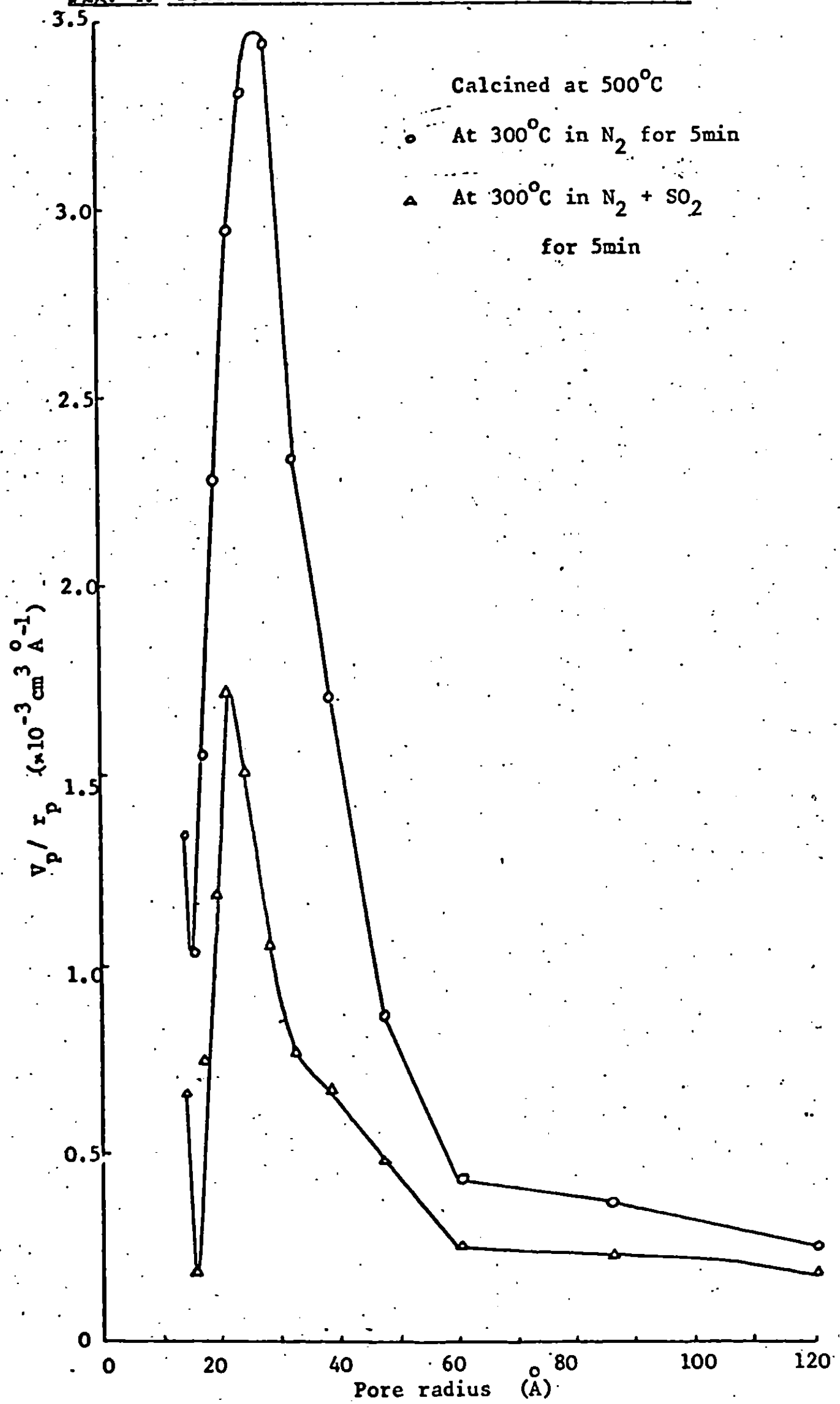


Fig. 5. Pore size distribution in calcined simbux

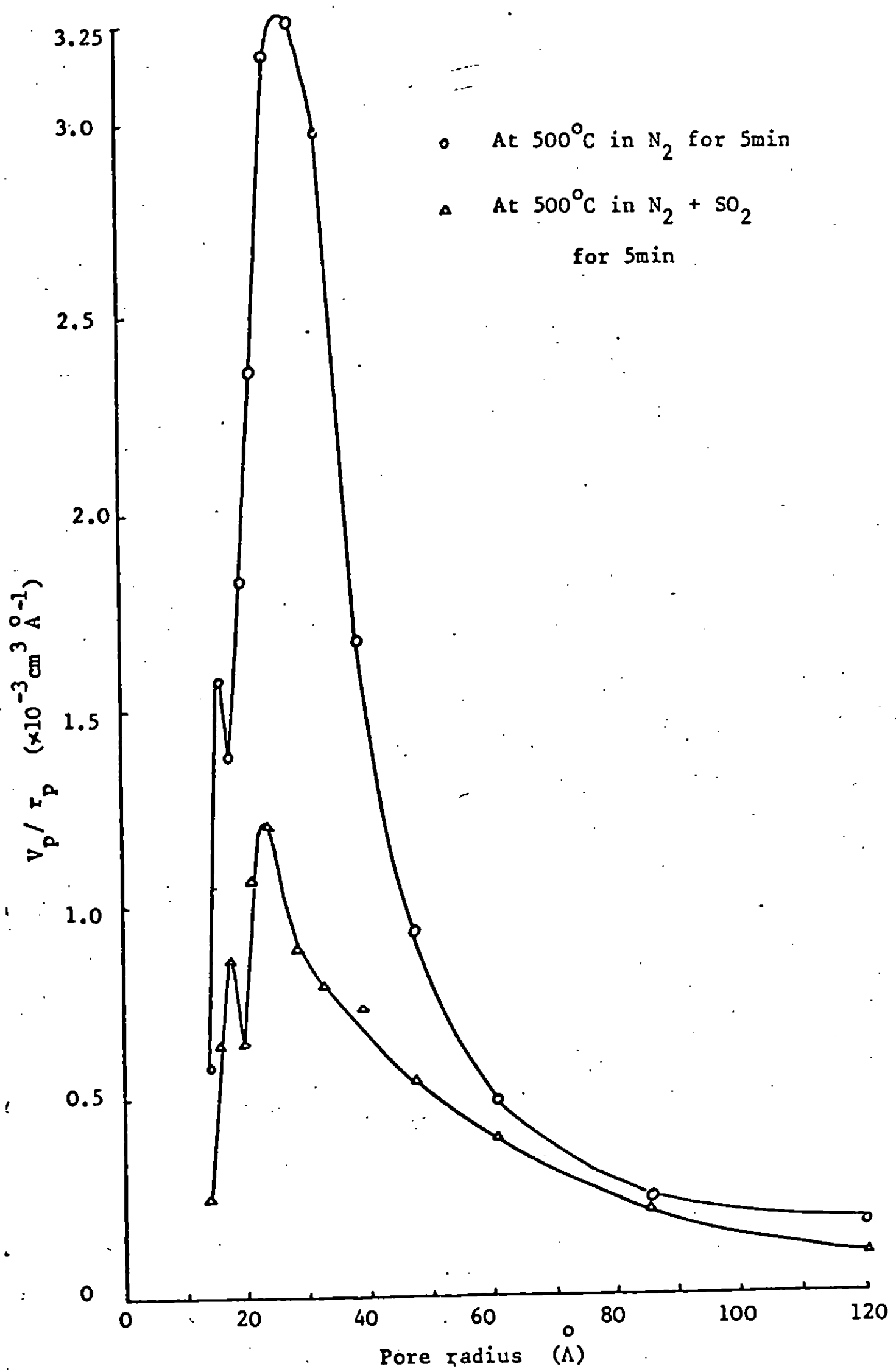




\section{Big. 6. Pore size distribution in calcined Limbux}

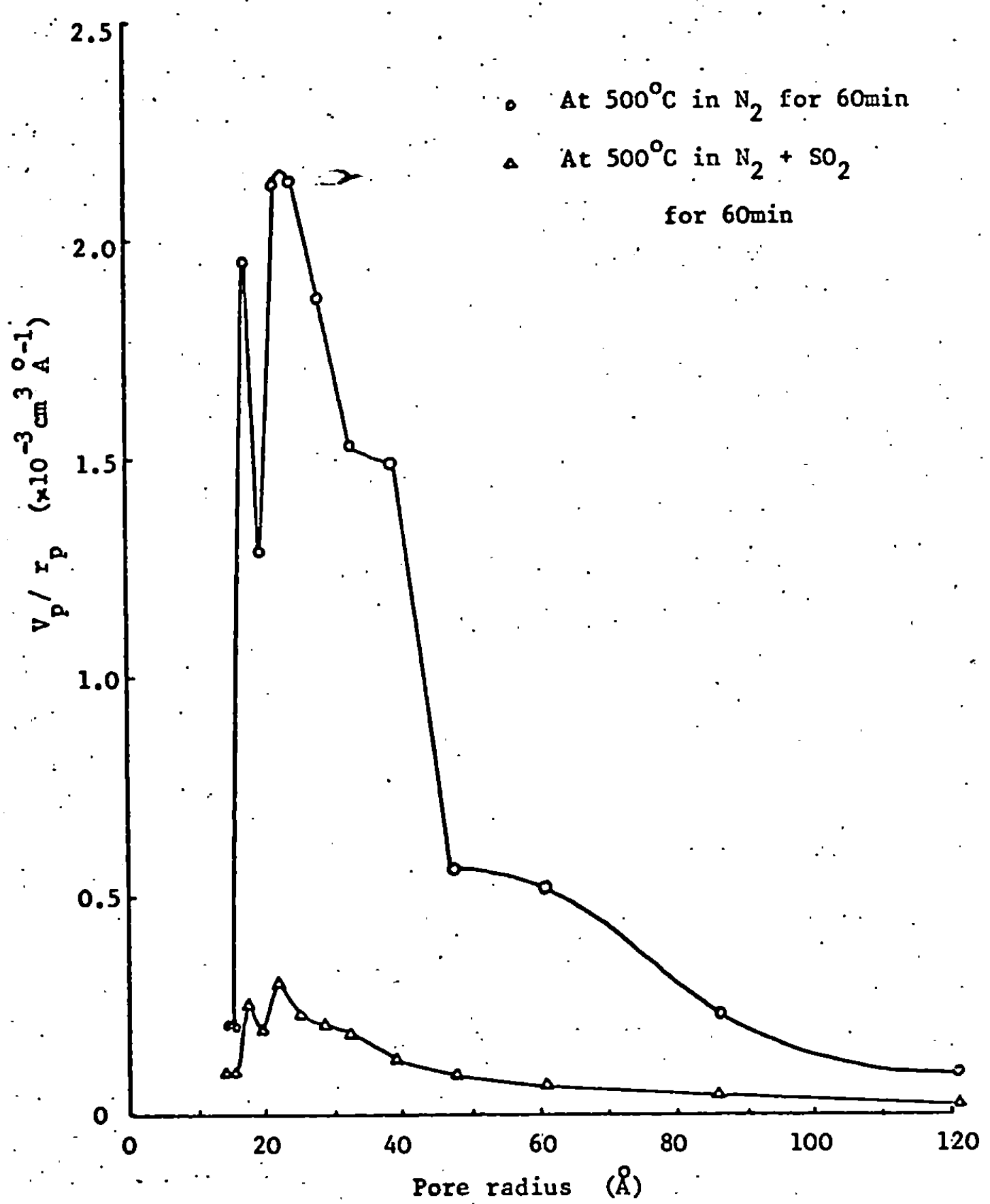


Fig. 7. Cumulative volumes and pore radil of quicklime absorbents

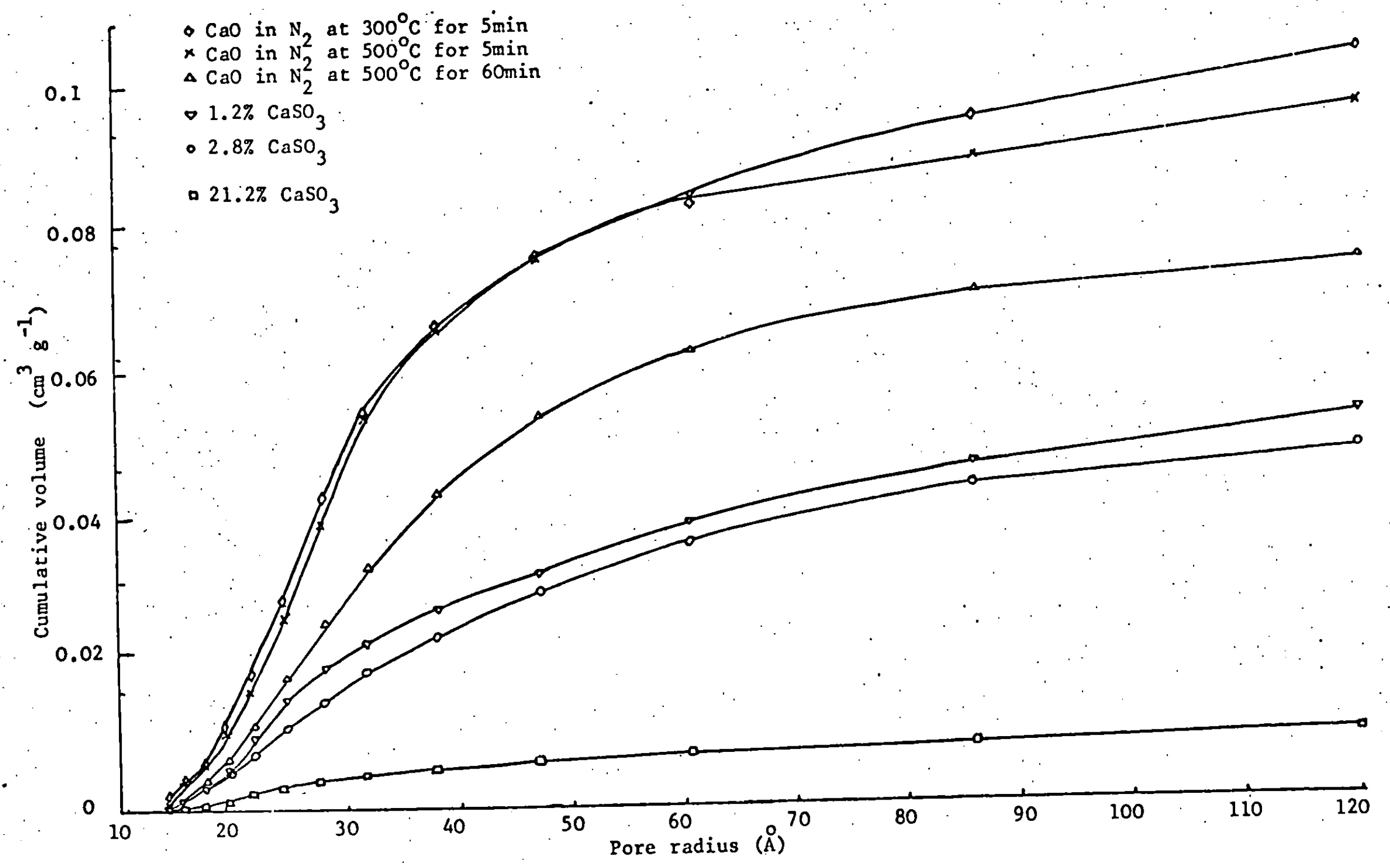


APPENDIX FIVE 


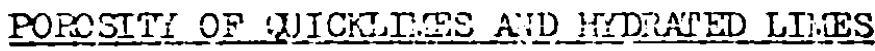

Bý L.C. Anderson and D. R. Glasson

\section{(1) 2uicklimes}

On decomposition, iimestone loses more than $40 \%$ of its weight as carbon dioxide. Since very little change occurs in extemal dimension, the lime produced is highly porous and has an apparent density of 1.5 $1.6 \mathrm{gcm}^{-3}$ compared vith $3.3 \mathrm{gcm}^{-3}$ when it is completely fused and 297 $\mathrm{gcm}^{-3}$ for the original limesione. A lime with this low density has a high specific surface, a sponge-like structure and reacts alnost explosively with vater. Continued heating of the lime after formation leads to sintering and ageregation of the crystais comprising the lime lump. In consequence the limp shrinks, becoming profressively denser or hardburned, less porolis and less reactive to water. Inis effect is illustrated by comparing the scanning-electror-microscope pictures of the surfaces of two samples of line, one pith a density of $1.7 \mathrm{gcm}^{-3}$ and the other $2.4 \mathrm{gcm}^{-3}$ (Fig. l(a) and (b)). The arnount of sintering of line writch occurs is a function of both time and termerature of heating after formation, with the latter parameter predoninating. Some sintering of the outer lime layer may occur even vinile a linestone lump is decomposing, since the suriace of the lump may be at a high temperature and consequently there is an apparent density gradient vithin a freshl.j-decomposed lump of lime fron the outside inwards. A schematic illustrotion of the changes in apparent density duriag the decomposition of a limestone lunp and during subseguent heating of the lime is shom in Fig. 2. The rgte of sintering of line $i s$ dependent also or the presence of irpurities such as iron, alumia and silica, wich promote liquid formation at the surfaces of the calcium oxide crystals during the lime-burning process. ${ }^{2}$

Because its intcinal surfaces are large in relation to its external surface, reactive low-density commercial. lime may have a spesific surface as high as $2 \mathrm{~m}^{2} \mathrm{~g}^{-1}$, compared vrith $0.5 \mathrm{~m}^{2} \mathrm{~g}^{-1}$ for inactive lime of higher density. However, the porosity of these limes is almost entirely due to macroporcs, $i . c_{0}$ above $100 \mathrm{~A}$, since oxygen adsorption isotherms show little or no hysteresis over relative pressure ranges corresponding to meso- or micro-porosity ${ }^{3}$, i.e. about 10-100 $\mathrm{A}$ and below about $10 \mathrm{~A}$ pore radius respectivaly, cf. ilis. 3 for quicklime of sp. surface, $S=2.0 \mathrm{~m}^{2} \mathrm{~g}^{-1}$ equivalent to an arerage crystallite size of about 1 pm.

viore reactive limes specially prepared at lower temperatures (rrom $\left.\mathrm{Ca}(\mathrm{OH})_{2}\right)^{4}$ are much less sintered and have sp. surfaces of up to about $100 \mathrm{~m}^{3} \mathrm{~g}^{-1}$, as show in Table 1 . 


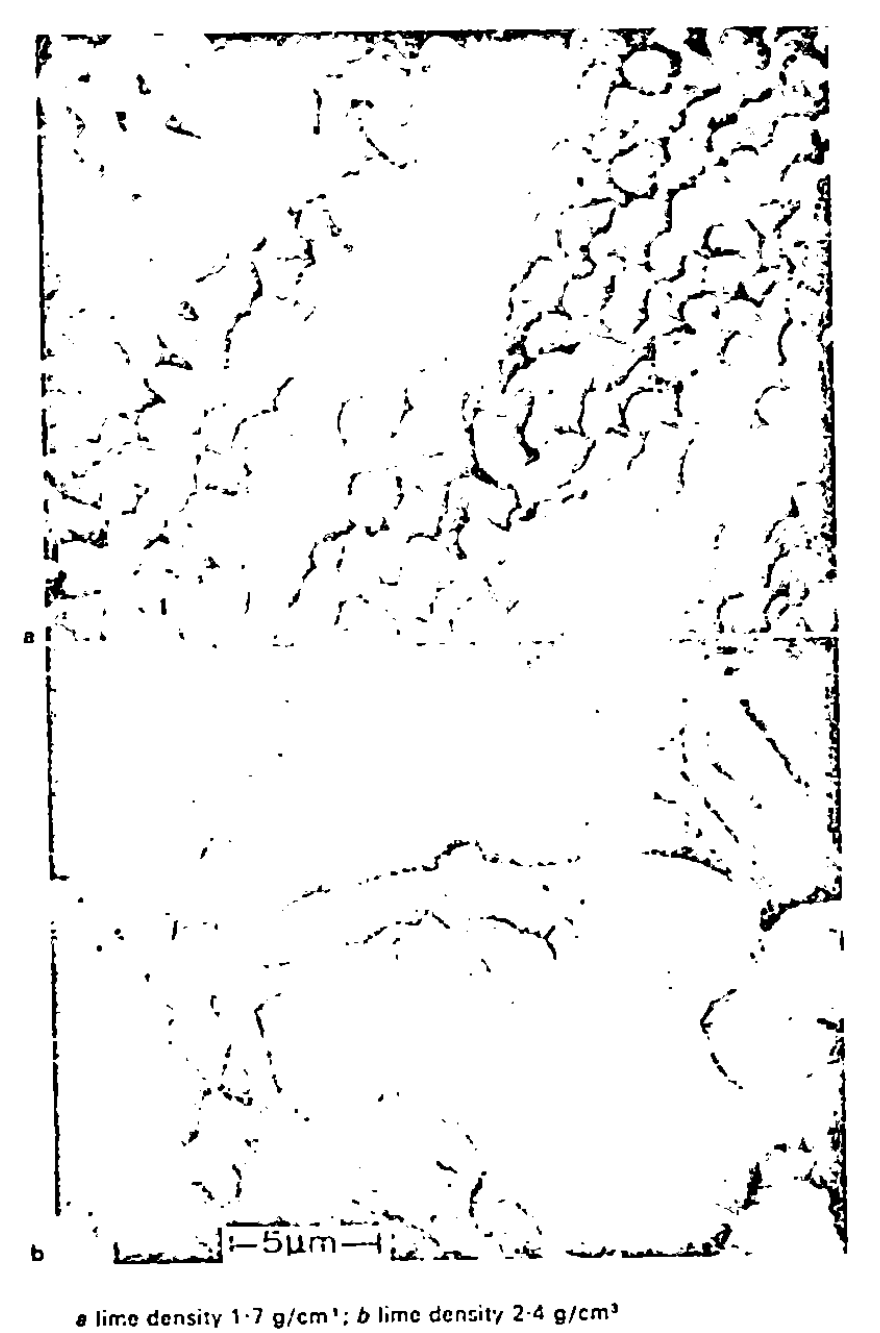

Fig. I. Stereoscan micrographs of internal surfaces of lime

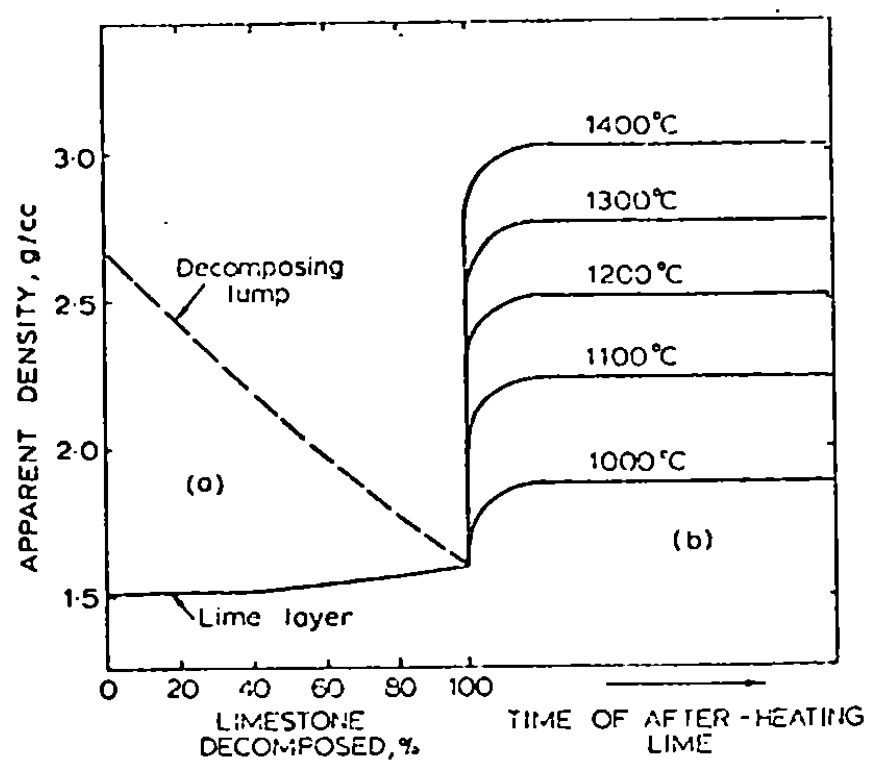

Fig.2. Clanges in apparent dentity: a during liprertone descomposition: $b$ during after-hesting of line 
Fig. 3and 4. Adsorption of $\mathrm{O}_{2}$ at $-183^{\circ} \mathrm{C}$ on $\mathrm{CaO}$ calcined at $900^{\circ} \mathrm{C} / 500^{\circ}$ and $700^{\circ} \mathrm{C}$

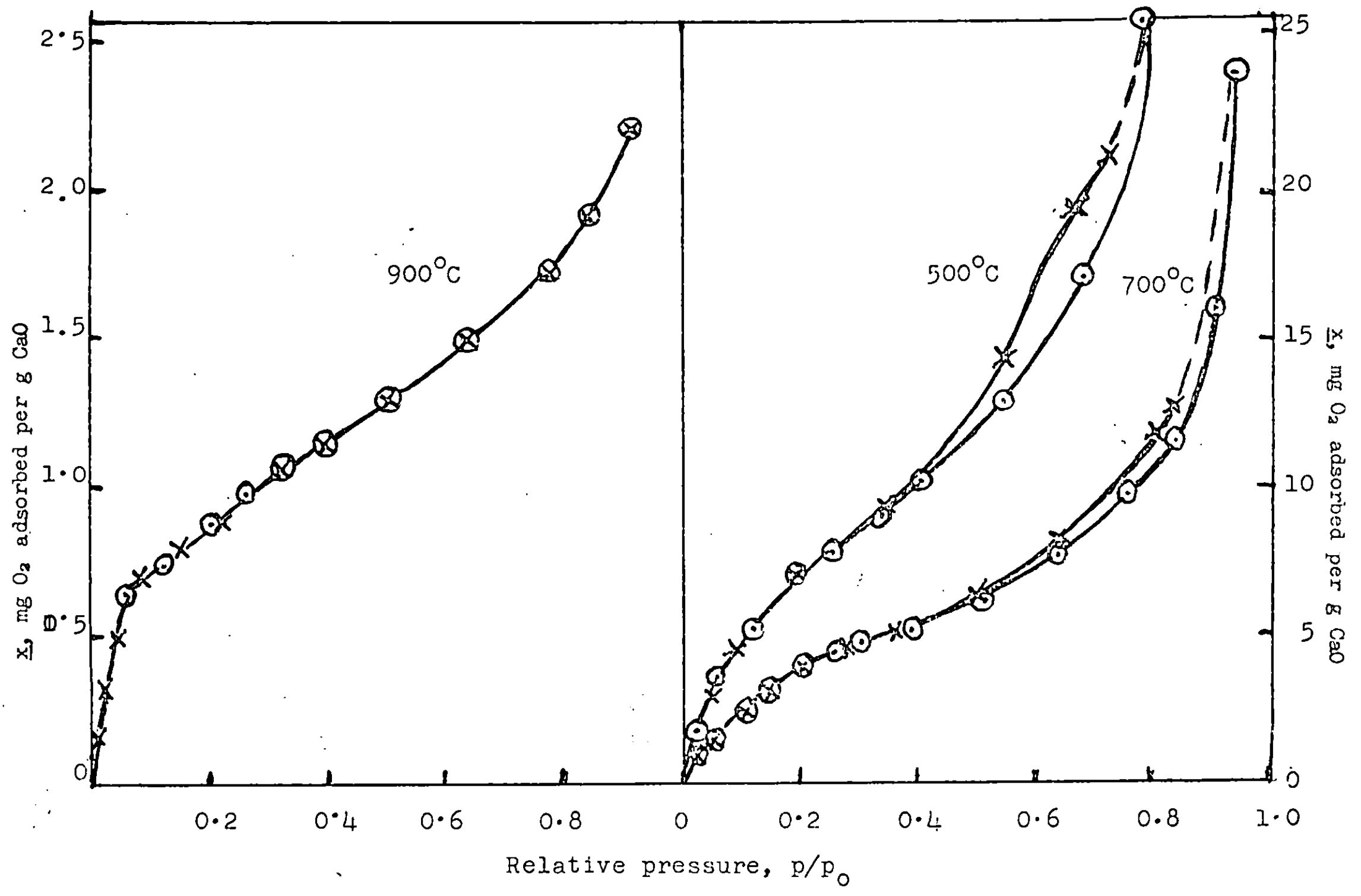


Fig. 5. Adsorotion cf $\mathrm{O}_{2}$ at $-183^{\circ} \mathrm{C}$ on $\mathrm{CaO}$ calcined at $400^{\circ} \mathrm{C}$ in vacuo

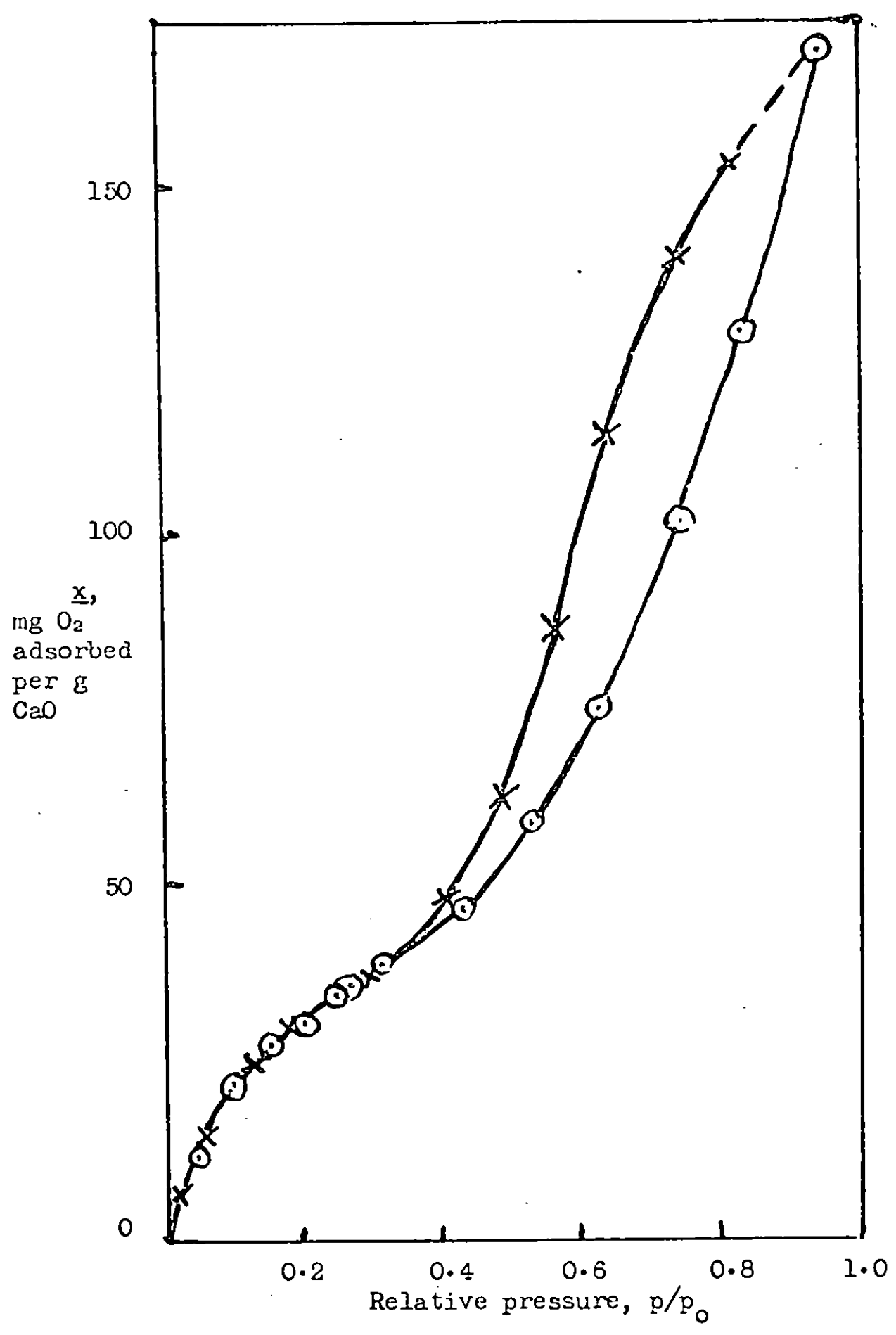


Table 1.

Surface arcas of quicklimes and h:drated limes

(from nitrogen and oxygen acisorytion isotherms at $-183^{\circ} \mathrm{C}$ )

Calcination

temperature $\left({ }^{\circ} \mathrm{C}\right)$

$350^{\circ}$ in vacuo

$400^{\circ}$, ,

$450^{\circ} \quad$, ,

$450^{\circ}$ in air

$500^{\circ}$, ,

$550^{\circ}$, ,

$600^{\circ}$, ,

$700^{\circ} \quad$,

$800^{\circ}$,

$900^{\circ}$

* $900^{\circ}$
$\mathrm{Sp}$. surface of $\mathrm{CaO}$

$\mathrm{S}_{2}$
101.4

$85 \cdot 5$

$71 \cdot 1$

$28 \cdot 0$

$18 \cdot 6$

$15 \cdot 8$

13.7

主主. 4

5.8

$1 \cdot 9$

$1 \cdot 3$
$\mathrm{S}_{\mathrm{d}}$

$87 \cdot 3$

$72 \cdot 7$

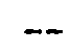

$18 \cdot 8$

$16 \cdot 0$

$14 \cdot 3$

$11 \cdot 8$

$6 \cdot 3$

$2 \cdot 0$

1.5 $\left(\mathrm{m}^{2} \mathrm{~g}^{-1}\right) \mathrm{Sp}$. surface of $\mathrm{Ca}(\mathrm{OH})_{2}\left(\mathrm{~m}^{2} \mathrm{~g}^{-1}\right)$

$\mathrm{S}_{\mathrm{d}}$ $\mathrm{S}_{2}$

23.3

$24 \cdot 2$

$20 \cdot 5 \quad 21 \cdot 2$

$18 \cdot 4 \quad 18.8$

$15 \cdot 9 \quad 16 \cdot 1$

$9.0 \quad 8.8$

$* 6.6$

5.3

5.3

Calcination tines $5 \mathrm{~h}$, except ai $350^{\circ}$ in vacuo where $15 \mathrm{~h}$ ras required for almost complete decomposition of $\mathrm{Ca}(\mathrm{OH})_{2}$ to $\mathrm{CaO}$.

\section{Fig. 6.}

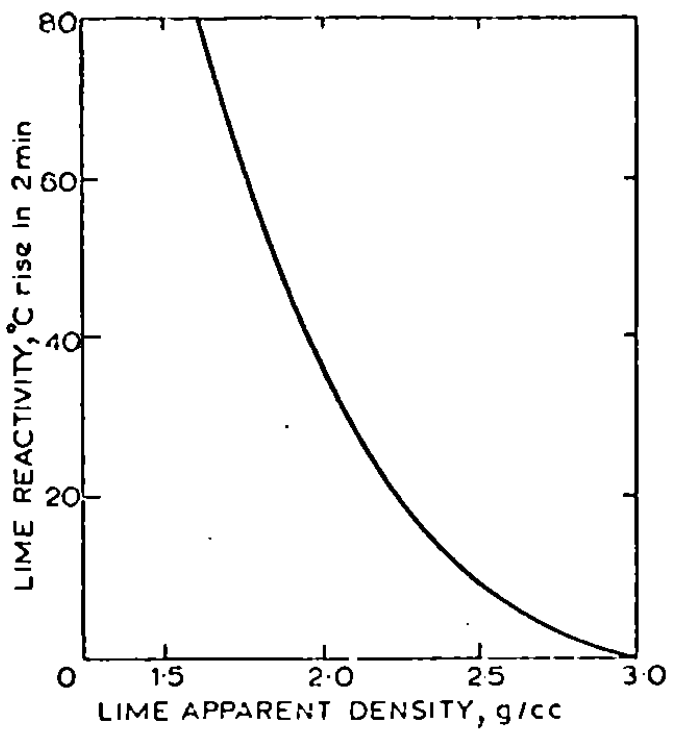

Relationship between line reactivity (ICl test) and apparent density 
I'hese more reactive limes give oxyen adsorption isotherns showing progressively greater hystcresis with lower calcination temperature and larger surface area, cf. Fig. 4 and 5. Since the hysteresis loops practically close at the relative pressures of about $0.3-0 \cdot 4$, there is development of meso-porosity (pores $10-100 \mathrm{~A}$ radius), but very litile micro-porosity (pores below 10 A radius)。

\section{(2) Hydrated Iigies}

The rate of reaction of lime with water depends among other factors on the area of calciurn oxide surface available to water molecules. In the case of a highly-porcus, lovi-density line, not only the external surface area of the lump but also the internal surfaces are reajily accessible to water rolecules. The rate of reaciion is then a function of the total specific surface of the line. Figure of illusirates the relati_onship hetween lime apparent density a.s determined hy mercury displúcenent and l.ine reactivity to water measured by our test. Ithis involves the sluking of $255 \mathrm{~g}$ of l.ime with $700 \mathrm{~cm}^{3}$ of rater at $20^{\circ} \mathrm{C}$ and reporting the temperature rise after 2 min. The rate of reaction of a given lime rith water ic often accepeci as a :aeasure of the ability of the lime to forn an early basic slag in the basic oxygen steclmaking process. "We are currently supplying lime for this use to a reacivivity specification in terms of the I.C.I.test requiring a minimum temperature rise in $2 \mathrm{~min}$ of $40^{\circ} \mathrm{C}$ at the tine of despatch from the I.C.I. works.'

When hydrated with liquid water, the nost active lires ( $\underline{S}=\mathrm{ca}$. $\left.100 \mathrm{~m}^{2} \mathrm{~g}^{-1}\right)$ decrease considerably in surface erea, e.g., 93 to $40 \mathrm{~m}^{2} \mathrm{~g}^{-1}$, in $1 / 4 \mathrm{~h}$ during nydration, before losing more surface on ageing. ${ }^{6}$ In contrast, those lines of lower activity ( $\underline{\mathrm{S}}$ below about $10 \mathrm{~m}^{2} \mathrm{~g}^{-1}$ ) increase their surface areas on "wet" hydration, $e_{0} \tilde{s}_{\circ}, 5.9$ to $26.4 \mathrm{~m}^{2} \mathrm{~g}^{-1}$ in $\frac{1}{2} \mathrm{~h}$ during hydration. Limes of intermediate activity shor cormparatively little change in surface area on "wet" hydration. Thus, the lime calcined at $600^{\circ} \mathrm{C}$ (Table 1) vith $\underline{S}=13.7 \mathrm{~m}^{2} \mathrm{~g}^{-1}$ forms $\mathrm{Ca}(\mathrm{OH})_{3}$ with $\underline{S}=14.4 \mathrm{~m}^{2} \mathrm{~g}^{-1}$ after being in contact with liquid water at room temperature for $18 \mathrm{~h}$.

Similar behaviour is shom on "dry" hydration vith mater vapour:, 6 Thus, highly-active lime, $\underline{S}=93 \mathrm{~m}^{2} \mathrm{~g}^{-1}$ decreases in surface area to about 40, 33 and $28 \mathrm{~m}^{2} \mathrm{~g}^{-1}$ during hydration with water vapour at relative pressures of $0.25,0.50$ and 0.95 . Less active limes, with $\underline{S}$ below about $20 \mathrm{~m}^{2} \mathrm{~g}^{-1}$, show increases in surface on hydration with water vapour near s.v.p. (relative pressure, 0.95), of. Table 1. 'ihe least active of the hydrated products ( S about $5 \mathrm{~m}^{2} \mathrm{~g}^{-1}$ ) show no appreciable meso- or micro-porosity, but the more active $\mathrm{Ca}(\mathrm{OH})_{2}$ samples ( $\mathrm{S}$ above about $10 \mathrm{~m}^{2} \mathrm{~g}^{-1}$ ) show some porosity; oxygen adsorption isotherms indicate mainly meso-porosity, 


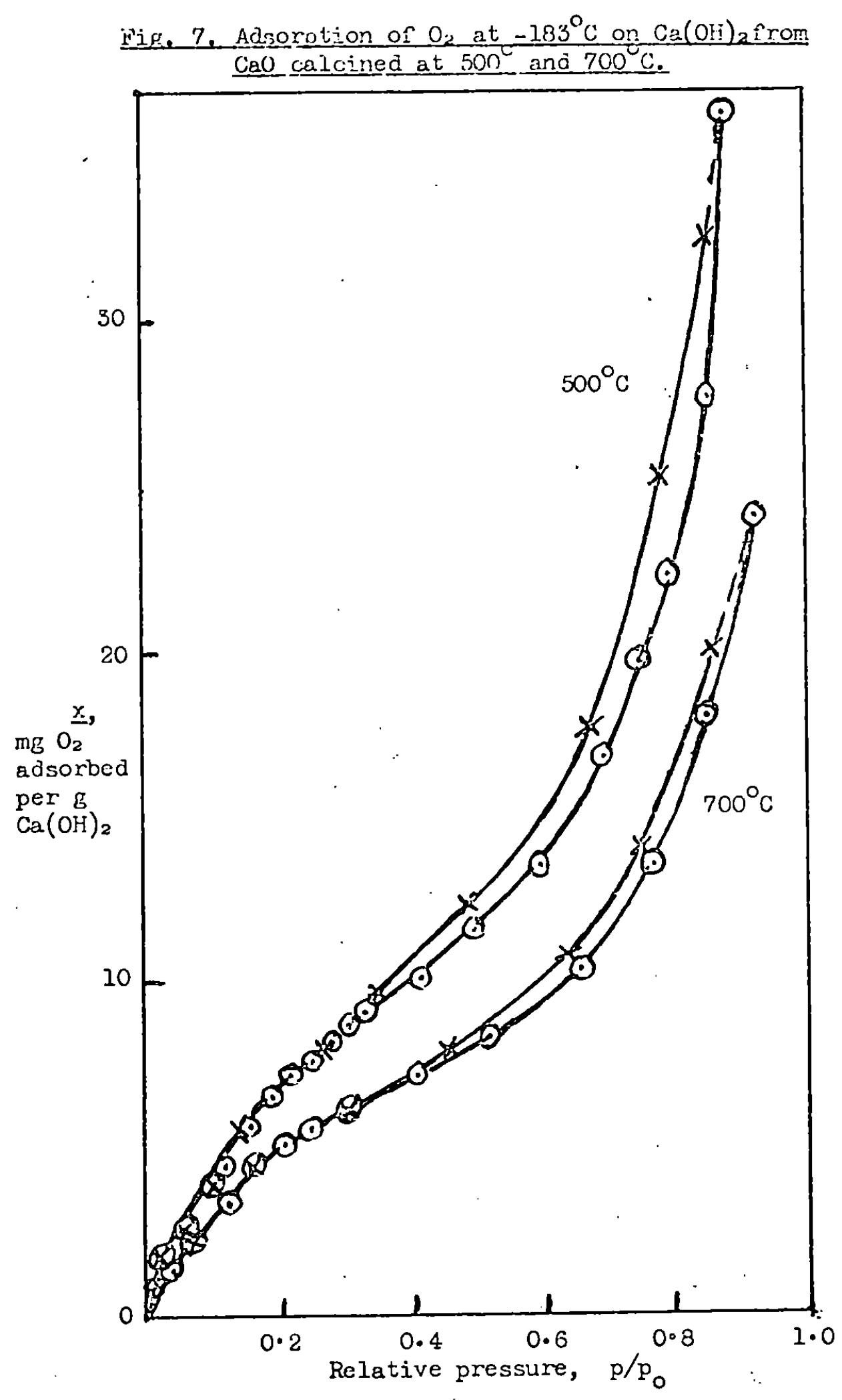




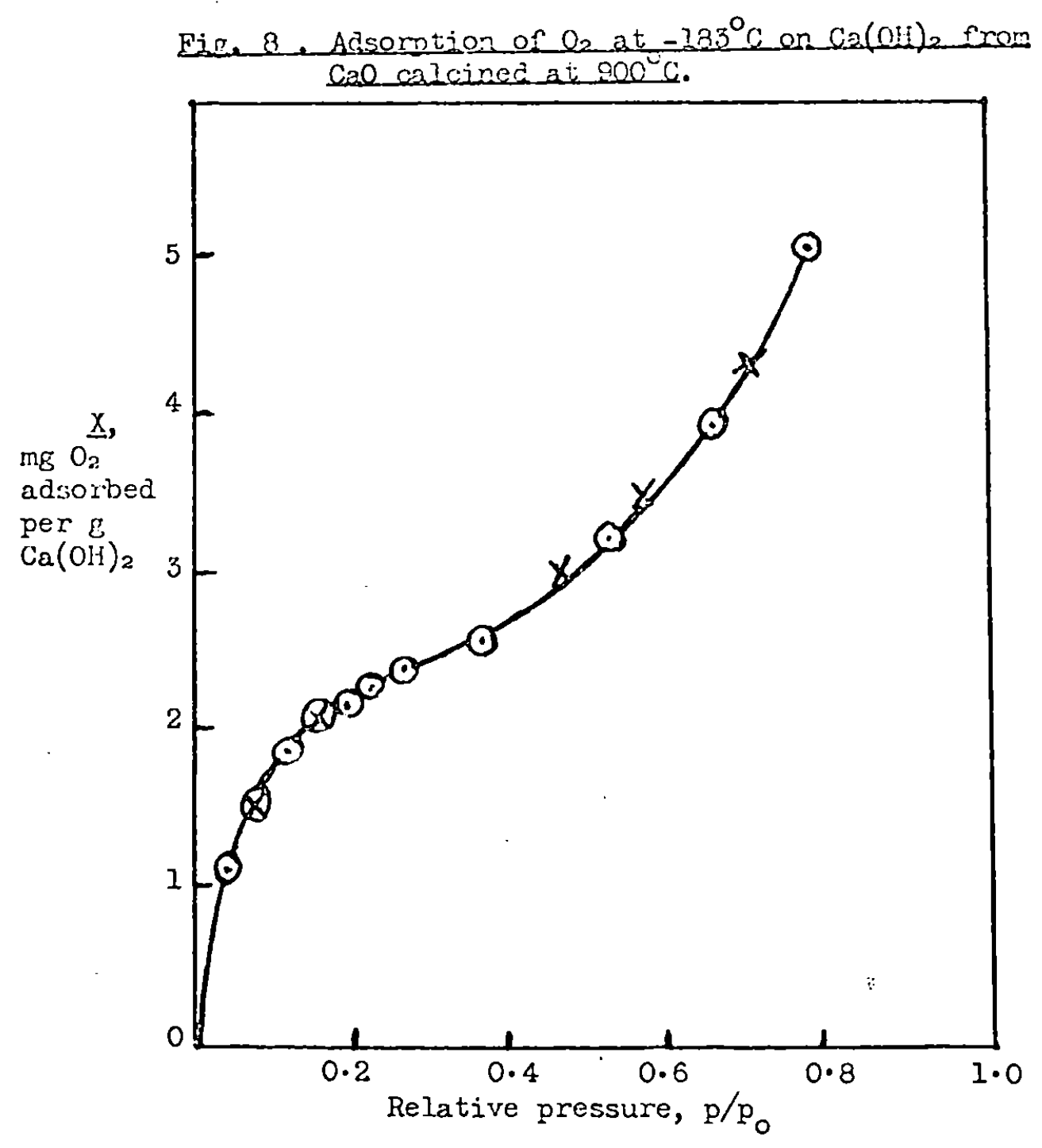


Fig. 9. Adsorotion of $\mathrm{O}_{2}$ at $-183^{\circ} \mathrm{C}$. on Limbux.

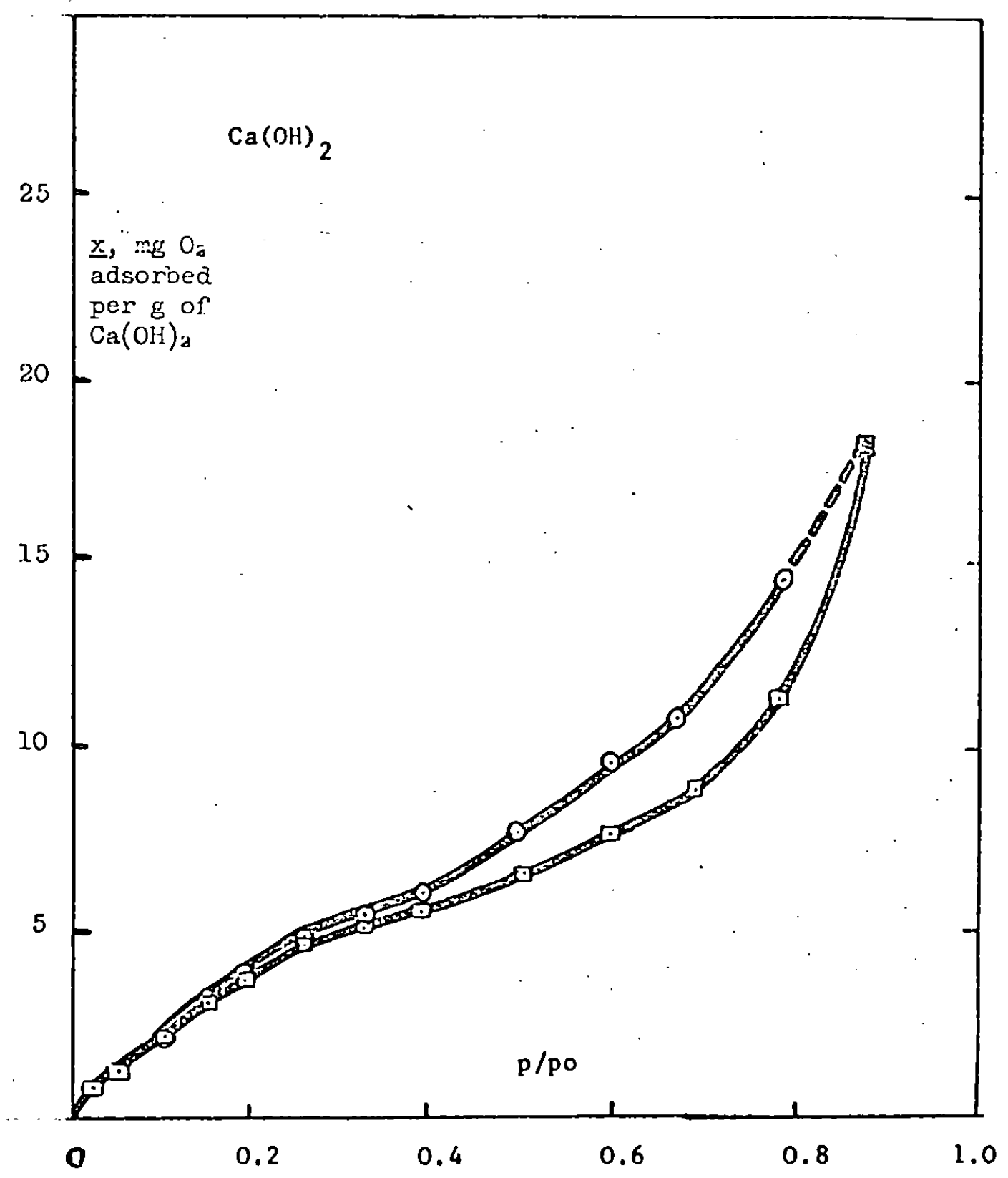


cf. Fig. 7 and 8. By comparison, similar type or porosity is shown by comnercia]. hydrated lime, Limbux, (Fig. 9), where $\underline{S}=14.2$ and $14.4 \mathrm{~m}^{2} E^{-1}$ from isotherns of nitrogen and of oxygen respectively. The most active of. the hydrated productis ( $\underline{S}$ about $40 \mathrm{~m}^{2} \mathrm{~g}^{-1}$ ) still has practically no micro-porosity.

\section{References}

1 L. C. Anderson and J. Vernon, J. Imor St.Inst., 1970, 200, (4), 329-35.

a D. R. Glasson, I. appl. Che lo. Lonāo, 1967, 17, 91-96.

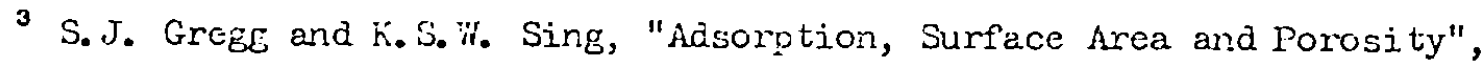
(London: Acaderiic Press, 1967).

4 D. R. Glasson, i. chem. Soc., 1956, pp. I506-10; J.appI. Chenes Lond., $1958, \underline{8}, 793-96$.

5 D. R. Glasson, J. appl. Chemes Iond., 1953, ㅇ, 797-803; ibid., 1960, 10, 38-42; ibid., 196́l, 11] 24-27.

- D.E. Glasson and Diana F. E. Linttead-Snith, "Progress in Vacuun lijicrobalance i'echniques", Vol. 2, Fp. 209-1.3 (Iondon: Fieyden, 1973)。 